Florida International University FIU Digital Commons

6-29-2011

\title{
The Ineffectiveness of a Multinational Sanctions Regime Under Globalization: The Case of Iraq
}

Manuel De Leon

Florida International University, rivero1@hotmail.com

DOI: $10.25148 /$ etd.FI1 1081006

Follow this and additional works at: https://digitalcommons.fiu.edu/etd

\section{Recommended Citation}

De Leon, Manuel, "The Ineffectiveness of a Multinational Sanctions Regime Under Globalization: The Case of Iraq" (2011). FIU Electronic Theses and Dissertations. 463.

https://digitalcommons.fiu.edu/etd/463 


\section{FLORIDA INTERNATIONAL UNIVERSITY}

Miami, Florida

THE INEFFECTIVENESS OF MULTILATERAL

SANCTIONS REGIMES UNDER GLOBALIZATION:

THE CASE OF IRAQ

A dissertation submitted in partial fulfillment of the

requirements for the degree of

DOCTOR OF PHILOSOPHY

in

POLITICAL SCIENCE

by

Manuel De Leon

2011 
To: Dean Kenneth Furton

College of Arts and Sciences

This dissertation, written by Manuel De Leon, and entitled The Ineffectiveness of Multilateral Sanctions Regimes Under Globalization: The Case of Iraq, having been approved in respect to style and intellectual content, is referred to you for judgment.

We have read this dissertation and recommend that it be approved.

Mohiaddin Mesbahi

Dario Moreno

Astrid Arraras

Ronald W. Cox, Major Professor

Date of Defense: June 29, 2011

The dissertation of Manuel De Leon is approved.

Dean Kenneth Furton College of Arts and Sciences

Dean Lakshmi N. Reddi

University Graduate School

Florida International University, 2011 


\section{DEDICATION}

I dedicate this dissertation to my grandmother because ella quería que yo fuera alguien en la vida; and to Joaquín Arguelles because he taught me how to read and lent me his books. 


\section{ACKNOWLEGMENTS}

I wish to thank first Doctor Ronald Cox for his support, guidance, patience and, above all, giving me the academic freedom to approach this dissertation according to my own method, thinking, and viewpoints.

I wish to acknowledge Doctor Astrid Arraras for her support and understanding. I also want to thank Doctor Dario Moreno and Doctor Mohiaddim Mesbahi for their time and commitment to this project, the most important in my life.

I thank all my professors in the Department of Political Science and International Relations, in particular those with whom I took courses. They all, in one way or the other, contributed to my academic endeavors, and of course to this dissertation.

I thank Florida International University for providing me with all the tools and materials necessary to complete my dissertation. I want to thank the good people at the library, the cafeteria, and even the Wellness Center for their prompt and efficient work. 


\author{
ABSTRACT OF THE DISSERTATION \\ THE INEFFECTIVENESS OF MULTILATERAL \\ SANCTIONS REGIMES UNDER GLOBALIZATION: \\ THE CASE OF IRAQ \\ by
}

Manuel De Leon

Florida International University, 2011

Miami, Florida

Professor Ronald Cox, Chair

This dissertation examines the effectiveness and limits of multilateral sanctions regimes as instruments of foreign policy, particularly when trying to prevent the acquisition, development and proliferation of weapons of mass destructions. I hypothesize that globalization undermines the overall effectiveness of sanctions regimes. I analyze the agents and means of globalization. Agents are nation-states, corporations, non-state actors and organizations, and individuals. Means are the global import-export industry, global banking and investment, global corporate models, and global manufacturing industries. They all have contributed to vast increases in transnational economic activity and, furthermore, to more political tensions between nation-states, all of which jeopardize the implementation and enforcement of multilateral sanctions regimes.

To test this thesis, I examine how those factors impacted the multilateral sanctions regime imposed against Iraq from 1991 to 2002. This multilateral sanctions regime was conceived, approved and enforced by most nations in the United Nations. 
Indeed, evidence collected for this dissertation suggests that Iraq did manage to consistently circumvent the UN sanctions regime, and that it did it by astutely utilizing the agents and means of globalization. Evidence also indicates that Iraq managed to rebuild parts of its military infrastructure, and that Iraq was on its way to rebuild its missile capability, for which it purchased large quantities of parts, components, technologies and manpower in the global market. 


\section{TABLE OF CONTENTS}

CHAPTER

PAGE

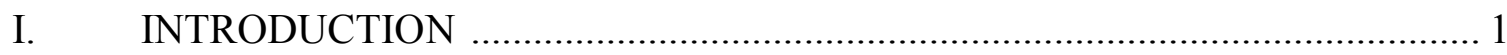

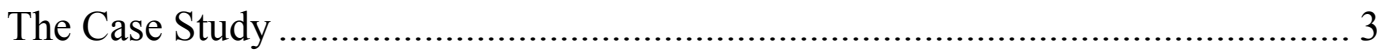

Theoretical Framework ................................................................................... 7

Liberal Institutionalism, Realism, and Historical Structuralism........................... 7

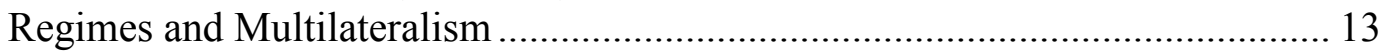

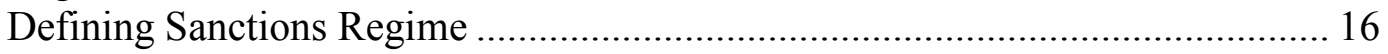

Globalization and the Circumvention of Sanctions Regimes ............................... 17

Testing the Hypothesis................................................................................... 19

The Research Methodology ........................................................................... 23

II. AGENTS AND MEANS OF GLOBALIZATION: NATIONS, NATIONAL SECURITY, GLOBAL DEMAND OF RAW MATERIALS AND

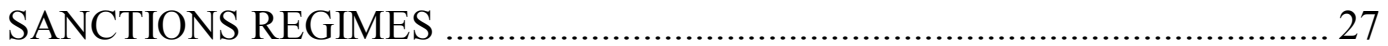

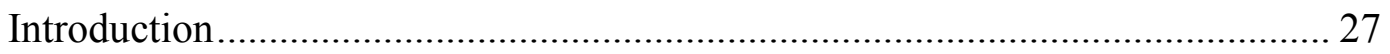

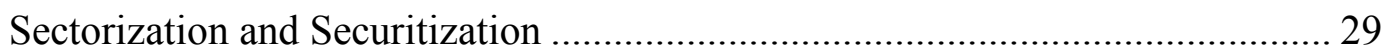

Sectorization of the Oil Industry and Securitization of Access to Oil Wells........ 34

France, Russia and China............................................................................. 46

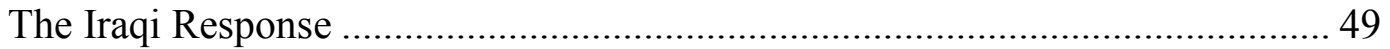

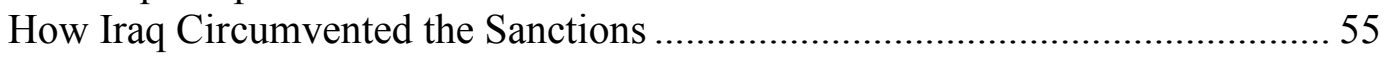

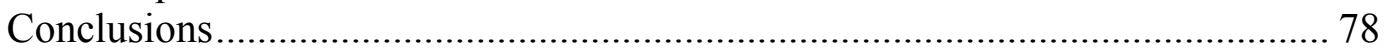

III. AGENTS AND MEANS OF GLOBALIZATION: NATION-STATES, GLOBAL TRADE AND THEIR EFFECTS ON MULTILATERAL

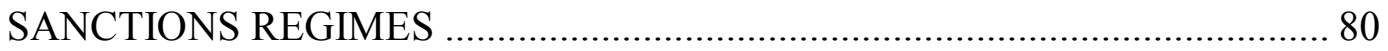

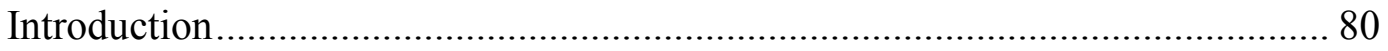

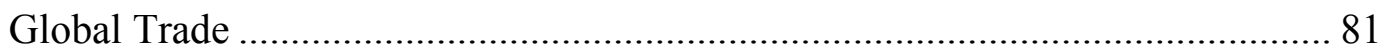

The Lessons of Interdependency Theory ............................................................... 84

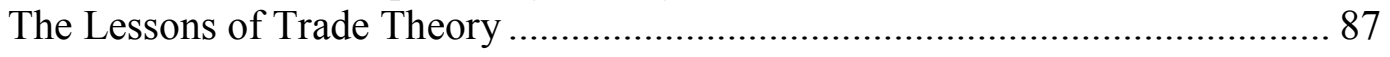

The Politics of Bilateral Trade ............................................................................... 97

Global Trade with Iraq during the Sanctions Regime ........................................ 100

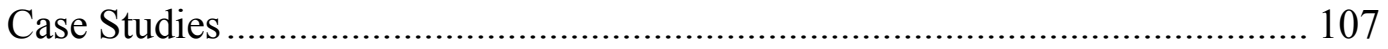

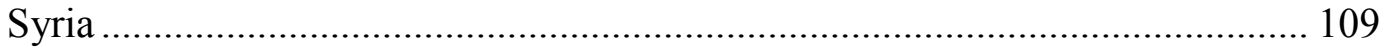

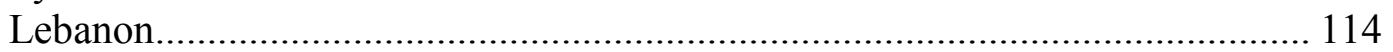

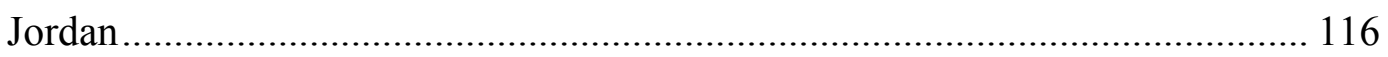

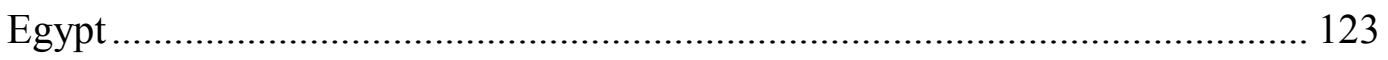

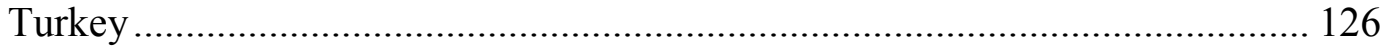

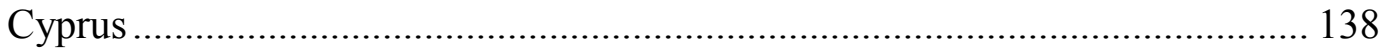

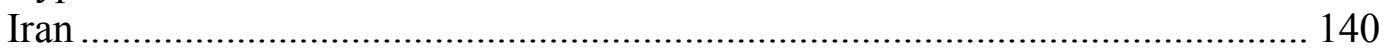

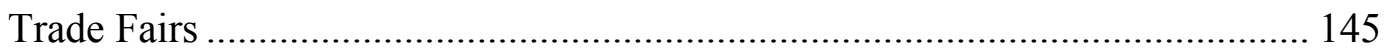

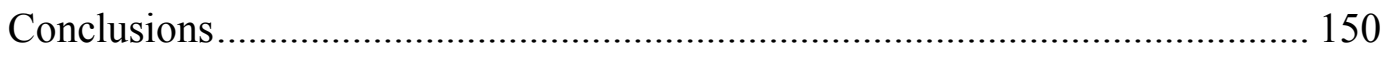


IV. AGENTS AND MEANS OF GLOBALIZATION: GLOBAL CIVIL SOCIETY AND NON-STATE ACTORS ................................................... 153

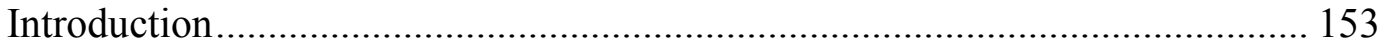

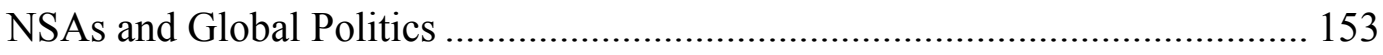

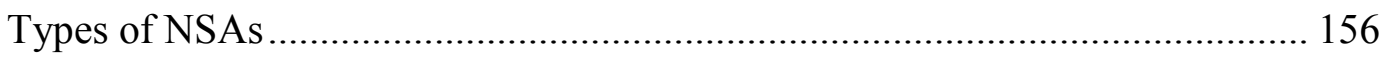

Overview of NSA Activities during the UN Sanctions Regime...................... 167

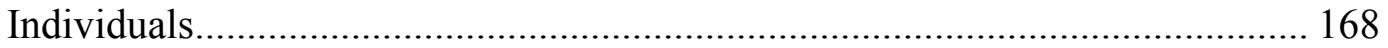

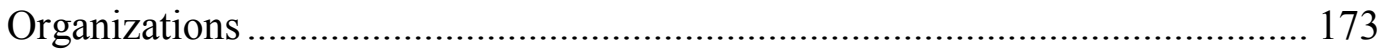

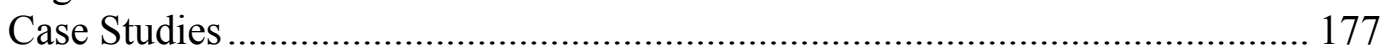

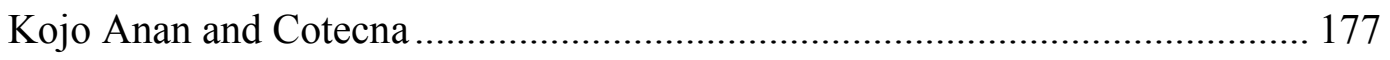

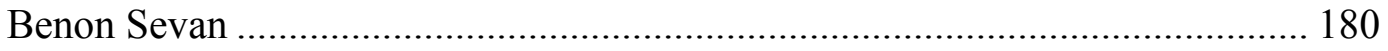

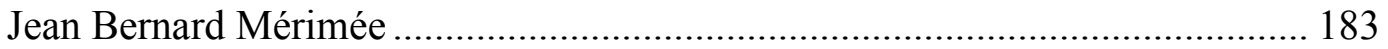

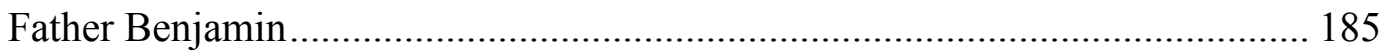

George Galloway .................................................................................. 186

Vladimir Zhirinovsky and the Liberal Democratic Party ................................ 189

Communist Party of the Russian Federation ................................................... 192

The ANC, the South Africa-Iraq Friendship, and the Non-Aligned Movement 195

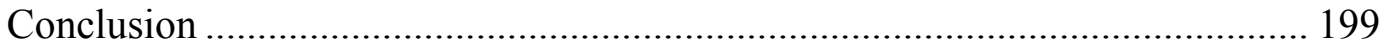

V. AGENTS AND MEANS OF GLOBALIZATION: THE GLOBAL BANKING SYSTEM, BANKS, INVESTORS AND SPECULATORS ............................ 202

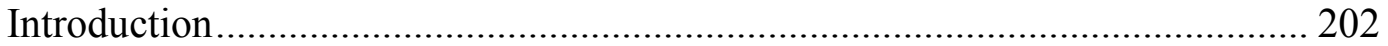

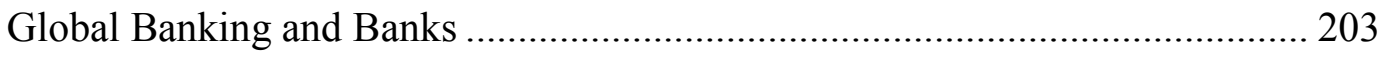

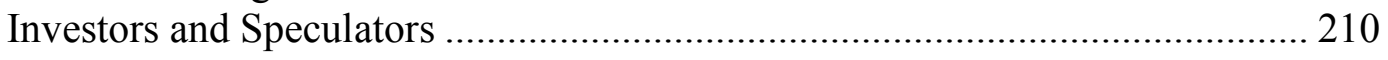

Global Banking and Iraq .......................................................................... 212

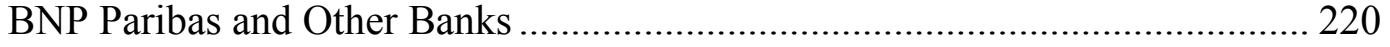

Investors and Speculators ........................................................................ 228

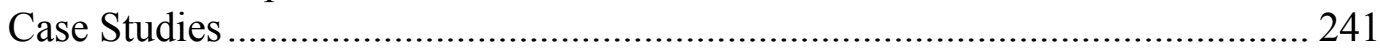

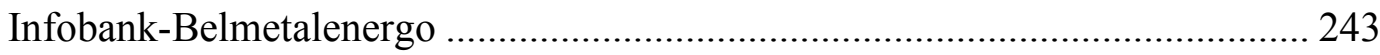

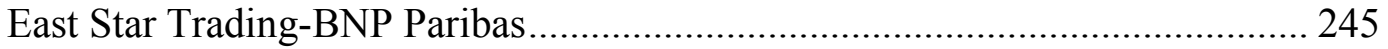

David Chalmers and Bayoil ............................................................................ 249

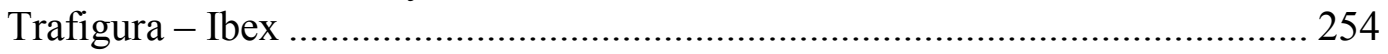

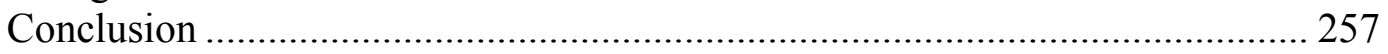

VI. AGENTS AND MEANS OF GLOBALIZATION: CORPORATIONS AND

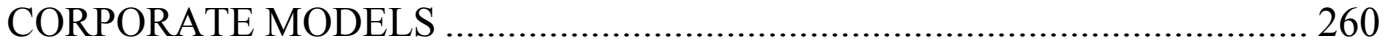

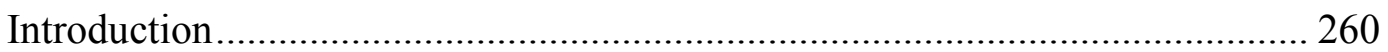

The Corporation: A Global Agent and Globalizing Force............................... 260

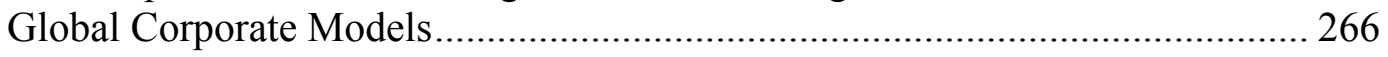

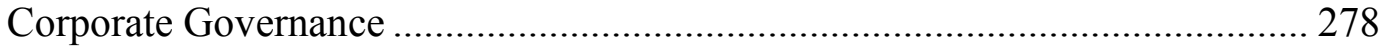

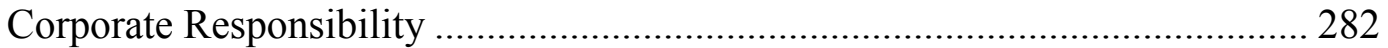

Corporate Models and the Evasion of the Sanctions Regime in Iraq ................ 291

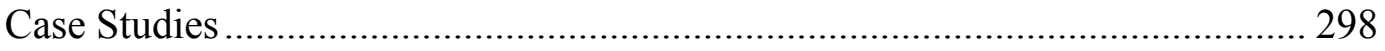

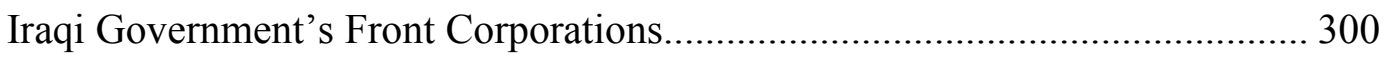

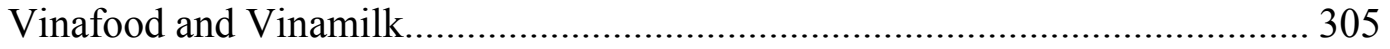




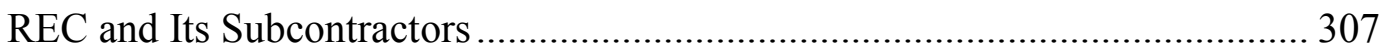

El Paso Corporation, Coastal Petroleum Company and Mr. Oscar Wyatt ......... 310

Vitol Group and Vitol France ...................................................................... 312

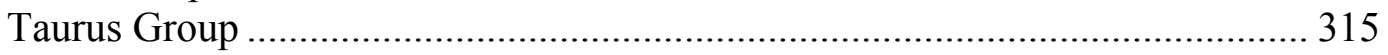

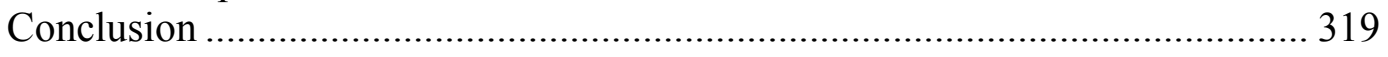

VII. AGENTS AND MEANS OF GLOBALIZATION: THE GLOBAL ASSEMBLY LINE, CONTRACT MANUFACTURERS AND VALUE

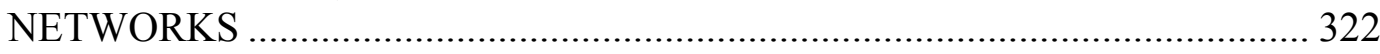

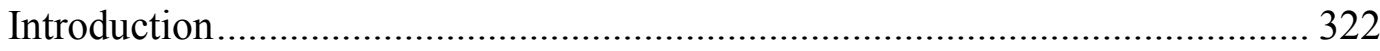

From International to Transnational Production.............................................. 322

Transnational Production and Regulatory Regimes ........................................ 338

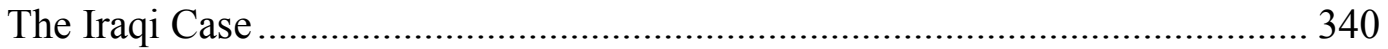

Iraq's Procurement Effort ........................................................................... 341

Two Case Studies on Iraq's Rearmament: Missile and Chemical Programs...... 349

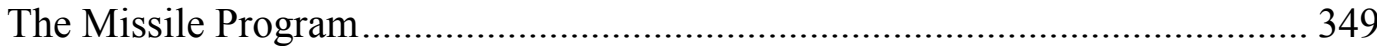

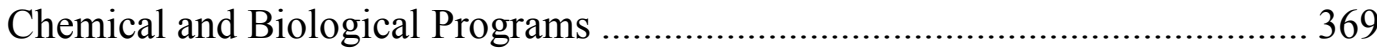

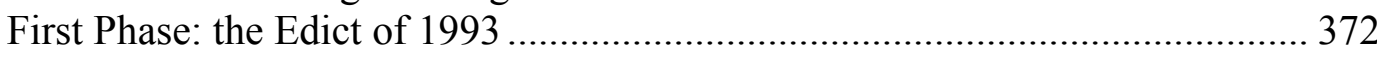

Second Phase: the Edict of 1997................................................................ 374

Third Phase: Procurement Program .......................................................... 378

Combustible Materials for Missiles .............................................................. 380

The Unmanned Aerial Vehicle Project and WMDs ....................................... 385

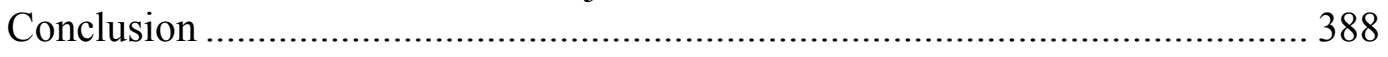

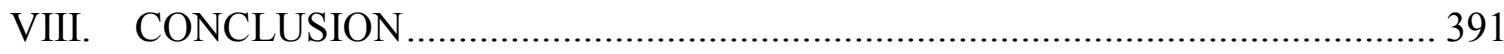

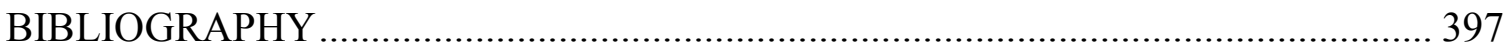

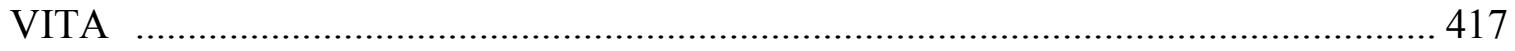




\section{LIST OF TABLES}

TABLE

PAGE

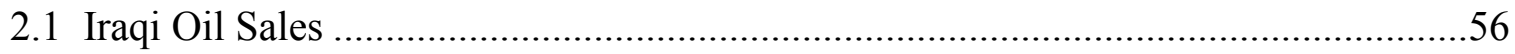

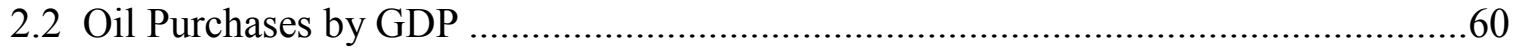

2.3 Nations that Lifted Over a Billion Dollars Barrels of Oil...........................................62

2.4 Fifteen Largest Oil Purchasers and Fifteen Highest GDPs........................................63

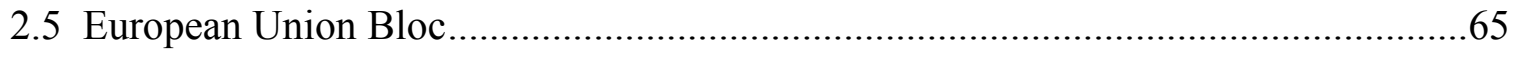

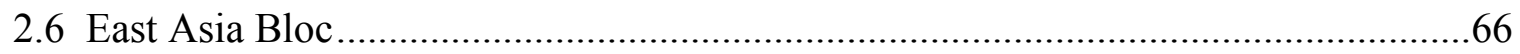

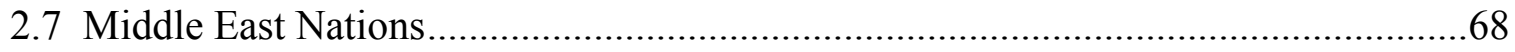

2.8 Iraqi Profits from Smuggling with Middle East Nations ............................................69

2.9 Permanent Members of UN Security Council …………………….........................71

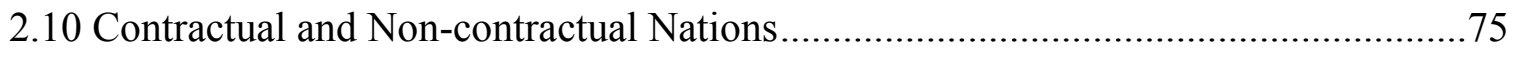

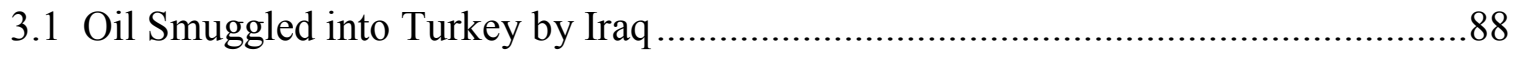

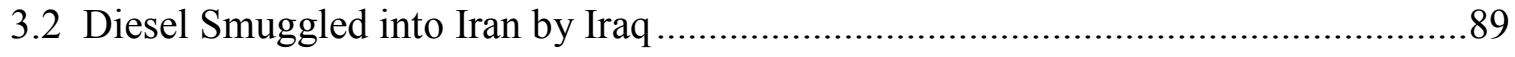

3.3 Trade Contracts under the UN Sanctions Regime …………………......................91

3.4 Trade Performance of Middle East Nations under UN Sanctions Regime..................93

3.5 Muslim and Arab Nations that Signed Trade Agreements with Iraq........................105

3.6 Trade Volume between Iraq, Syria and Lebanon from 1999 to 2002 .....................115

3.7 Trade Volume between Iraq and Jordan ..............................................................121

3.8 Kurds' Profits for Moving Oil and Diesel ............................................................133

3.9 Iraqi Revenues Drawn from Iraq-Turkey Protocol..................................................137

3.10 Estimates of Iraq-Iran Oil Trade under Udai's Command.......................................143

4.1 Individuals-Violators of UN Sanctions Regime ...................................................169 
4.2 Organizations-Violators of the UN Sanctions Regime

4.3 George Galloway's Visits to Iraq during the UN Sanctions Regime ………….......187

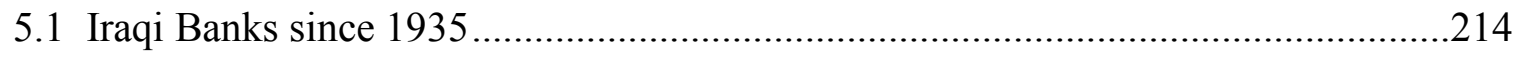

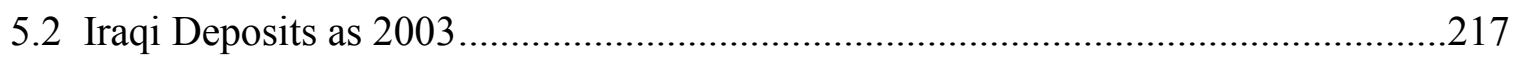

5.3 Distribution of Letters of Credit through BNP ....................................................221

5.4 Most Used Banking Centers under the UN Sanctions Regime................................225

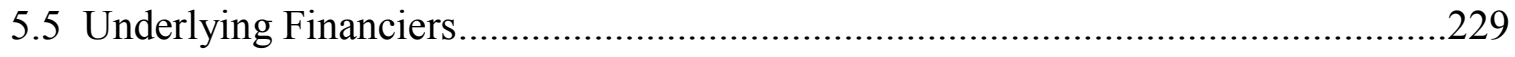

5.6 American Investors Financing Non-American Firms...........................................231

5.7 American Investors Financing Firms from Belarus, Russian and Ukraine ……......234

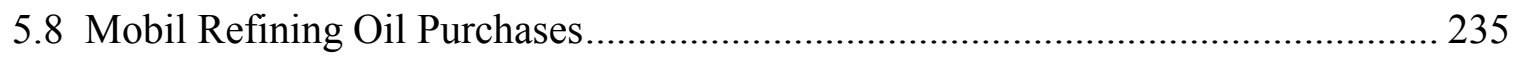

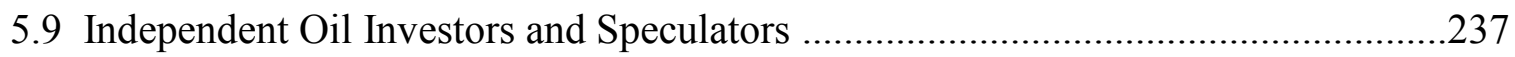

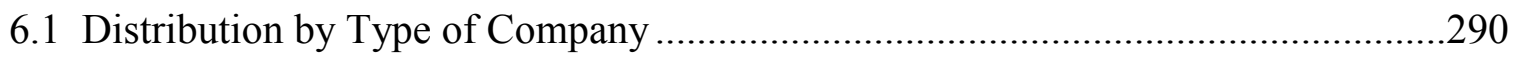

6.2 American Companies Trading with Iraq from France ...........................................292

6.3 Top Ten Nations Sponsoring Front Corporations.......................................................224

6.4 Iraqi Front Firms in Partnership with Private Firms from the Middle East..............295

6.5 Top Ten Corporate Paradises ............................................................................296

7.1 Some of the Most Important CMs in the Global Assembly Line ...............................329

7.2 The Largest CMs of Hard and Software in Global PC Industry .................................331

7.3 Most Important Military Companies in Iraq ...........................................................343

7.4 Organizational Assembly Lines of a Al Samud II Missile ………………................352

7.5 Dual Use Machines and Technologies...................................................................361

7.6 Parts of Iraqi Missiles Accounted by ISG, CIA, and IIC ...........................................366

7.7 Iraqi Missiles Accounted as Operational by IIS, CIA and Michigan Project............367 


\section{LIST OF CHARTS}

CHART

PAGE

2.1 Largest Oil Reserves per Nation Relative to World's Oil Reserves .........................39

2.2 American Currency held by nations of East Asia Bloc .........................................45

2.3 Iraqi Oil Sales under the UN Sanctions Regime................................................. 74

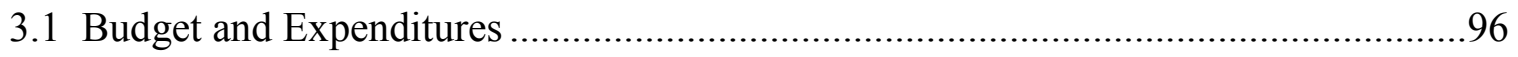

3.2 Main Sources of Income for Iraq under the UN Sanctions Regime .......................103

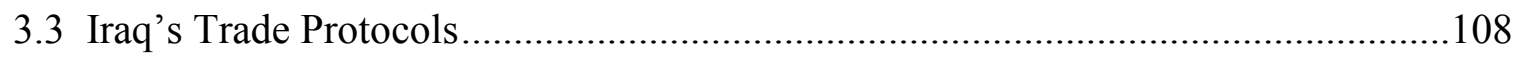

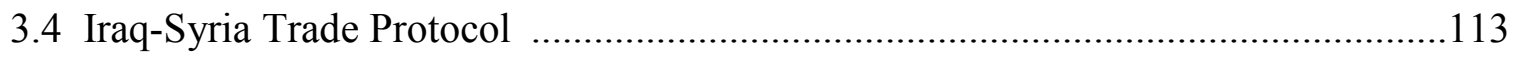

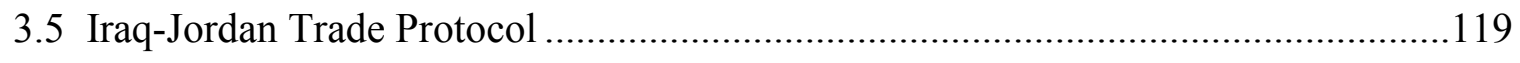

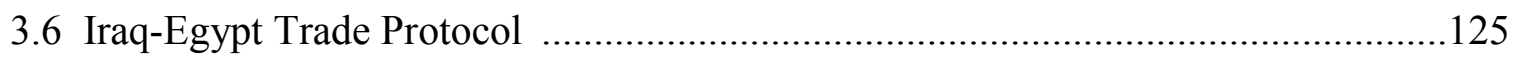

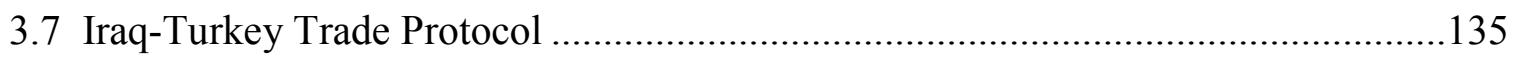

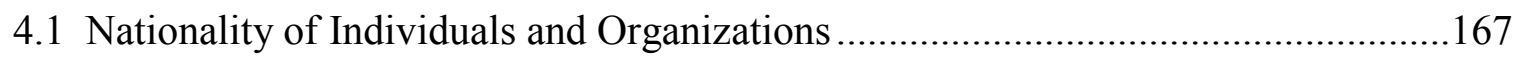

4.2 Benon Sevan's Personal Bank Account during the UN Sanctions Regime..............182

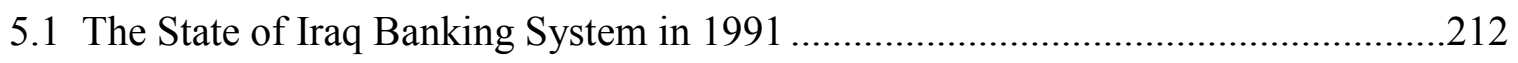

5.2 BNP Earnings under the UN Sanctions Regime................................................223 


\section{LIST OF FIGURES}

FIGURE

PAGE

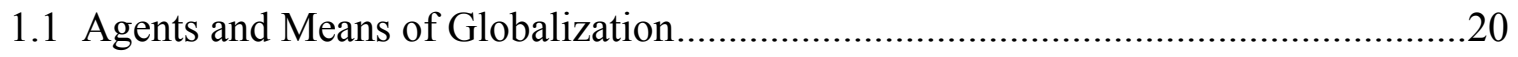

1.2 Circumvention of a Multilateral Sanctions Regime under Globalization..................23

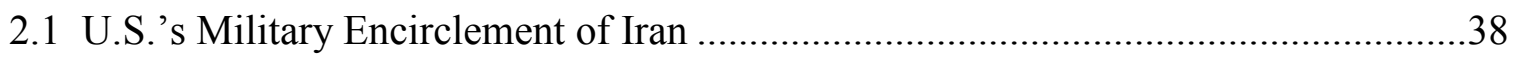

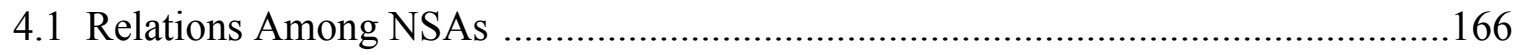

5.1 Most Common Financing Scheme under the UN Sanctions Regime .....................241

6.1 Transnational "XYZ Inc" Operating under the Multinational Model .....................261

6.2 Transnational "XYZ Inc” Operating under Uniform Transnational Markets..........263

6.3 Structure of Transnational "XYZ Inc" under Globalization .................................273

6.4 Iraq's Corporate Modeling to Circumvent the UN Sanctions Regime....................298

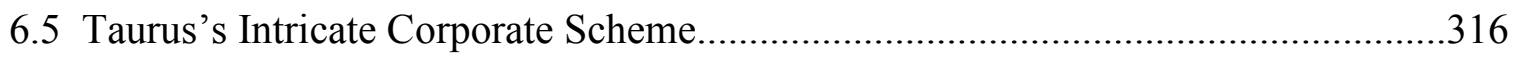

7.1 Market Shares of CMs per Nation across Regions ..........................................335

7.2 Iraqi Plants and Labs for Liquid Propellant..................................................380 


\section{ACRONYMS}

\begin{tabular}{|c|c|}
\hline $\mathrm{ANC}$ & African National Congress \\
\hline ARADET & Arab Company for Detergent Chemicals \\
\hline $\mathrm{ACT}$ & Arm Control Today \\
\hline ASEA & Association of Southeast Asian Nations \\
\hline $\mathrm{BNP}$ & Bank Nationale Paris \\
\hline CAMECON & Council for Mutual Economic Assistance \\
\hline CBI & Central Bank of Iraq \\
\hline $\mathrm{CEO}$ & Chief Executive Operation \\
\hline CIA & Central Intelligence Agency \\
\hline $\mathrm{CM}$ & Contract Manufacturer \\
\hline CFIJ & Coalition for International Justice \\
\hline $\mathrm{CW}$ & Chemical Weapons \\
\hline GAO & General Accountability Office \\
\hline GDP & Gross Domestic Product \\
\hline EU & European Union \\
\hline HSBC & Hong Kong and Shanghai Banking Corporation \\
\hline GATT & General Agreement on Tariffs and Trade \\
\hline GPS & Geographical Positioning System \\
\hline GRL & Goods Review List \\
\hline IIC & Independent Inquiry Committee \\
\hline IIS & Iraqi Intelligent Services \\
\hline
\end{tabular}




\begin{tabular}{|c|c|}
\hline IMF & International Monetary Fund \\
\hline INVO & Iraq Nuclear Verification Office \\
\hline ISG & Iraqi Survey Group \\
\hline ISS & Iraqi Security Services \\
\hline KPRF & Communist Party of the Russian Federation \\
\hline MERCOSUR & Mercado Común del Sur \\
\hline MIC & Military Industrial Commission \\
\hline MIMI & Ministry of Industry and Military Industrialization \\
\hline MIO & Military Industrialization Organization \\
\hline NAFTA & North America Free Trade Agreement \\
\hline NAM & Non-Aligned Movement \\
\hline NATO & North Atlantic Treaty Organization \\
\hline NCS & Non-cooperative Country Status \\
\hline NGO & Nongovernmental organizations \\
\hline NSA & Non-State Actors \\
\hline OFAC & Office of Foreign Assets Control \\
\hline OIP & Office of Iraq Program \\
\hline $\mathrm{PC}$ & Personal Computer \\
\hline SABCETT & South African Business Council for Economic Transformation \\
\hline SAIFA & South Africa-Iraq Friendship Association \\
\hline SDN & Specially Designated National \\
\hline SIPRI & Stockholm International Peace Research \\
\hline SOMO & State Oil Marketing Organization \\
\hline
\end{tabular}




$\begin{array}{ll}\text { SOTI } & \text { State Organization for Technical Industries } \\ \text { TIPC } & \text { Turkish Petroleum International Company } \\ \text { UAV } & \text { Unmanned Aerial Vehicle } \\ \text { UEA } & \text { United Emirates Arabic } \\ \text { UN } & \text { United Nations } \\ \text { UN OFF } & \text { United Nations Oil for Food Program } \\ \text { UNSCOM } & \text { United Nations Special Commission } \\ \text { UNMOVIC } & \text { United Nations Monitoring Verification and Inspection } \\ & \text { Commission } \\ \text { UAE } & \text { United Arab Emirates } \\ \text { UK } & \text { United Kingdom } \\ \text { US } & \text { United States } \\ \text { WB } & \text { World Bank } \\ \text { WMD } & \text { Weapons of Mass Destruction } \\ \text { WTO } & \text { Word Trade Organization }\end{array}$




\section{INTRODUCTION}

In this dissertation, I will study the limits of multilateral sanctions regimes as instruments of foreign policy. I argue that the political economy of contemporary globalization jeopardizes the overall effectiveness of multilateral sanctions regimes in two important ways. The first is the competing global agendas of states and non-state actors with respect to sanctions regimes. The second is growing transnational economic, political and civic activities linked to the process of globalization. To test this thesis, I will examine how those two factors impacted the UN sanctions regime against Iraq.

The UN sanctions regime makes an excellent case study. First, the UN General Assemble approved it, meaning that a majority of nation-states voted for it. Second, a vast majority of nations stopped trading with Iraq. Third, UN inspectors monitored it while the American and British armies enforced it. Finally, the sanctions included: trade and military blockages, military occupation of northern and southern Iraq, autonomy for the Kurdistan, enforcement of two no-fly zones, random inspections of military and civilian facilities, random bombings and raids. The sanctions lasted for almost 12 years, isolating the Iraqi government and causing hundreds of thousands of deaths among the Iraqi people. Sanctions were so intense that at some point the Iraqi regime almost collapsed. But it did not. Iraq suddenly began to evade the sanctions, and the Iraqi economy began to grow. It required another American led invasion to bring down the Iraqi regime.

In the Iraqi case, I hypothesize that there were several important contradictions between the strategic and economic objectives of the five permanent members of UN 
Security Council and the implementation and enforcement of the sanctions. For instance, the American unilateralism toward Iraq clashed with the mandates of the UN and with the strategic objectives of European states. The U.S. switched its goals from finding and dismantling weapons of mass destruction to regime change, undermining the overall legitimacy of the sanctions regime. Besides, American, Chinese, French and Russian corporations kept selling military technologies and hardware to Iraq and neighboring states. They at times did it with the consent of their governments.

Second, I will study the relationship between globalization and efforts in UN to establish viable and enforceable sanctions against Iraq. I will explore two issues. The first concerns non-state actors like transnational corporations, financiers, and speculators competing for Iraqi oil during the 1990s, a process that states, mainly industrial nations, encouraged in their quest for global access to oil. Competition for global access to oil intensified in the 1990s when oil became a national security concern for most nations, thereby jeopardizing UN sanctions against Iraq. The second issue concerns the power of states and international institutions relative to those of non-state actors. The core premise is that states and international institutions have been losing power and influence to nonstate actors, a process that globalization accelerated during the 1990s. Drastic changes in global trade and politics have led to a more profound trans-nationalization of economic and political activities in detriment of national interests. As William I. Robinson states, "Globalization represents a new transnational phase in the development of the world capitalist system" (Robinson, 2004, p. 9), often in frank contradiction with states' political and military goals, including the enforcement of a sanctions regime.

In all, I argue that due to the factors mentioned above, sanctions regimes have 
become inefficient instruments of foreign policy. This was apparent in the case of Iraq, where the UN conceived and enforced a sanctions regime to prevent the acquisition, development and proliferation of weapons of mass destruction (WMD). In order to test my hypothesis, I will study four main points.

The first is the central question of whether or not Iraq violated the sanctions regime. It is important to go beyond whether or not Iraq circumvented the sanctions for economic survival in favor of examining whether or not Iraq acquired and developed weapons of mass destruction despite the UN sanctions regime. The second issue is about how Iraq circumvented the sanctions regime. I aim at identifying what I call the agents and means of globalization that Iraq employed to evade UN sanctions. For instance, I want to detect trade relations established for the sole purpose of acquiring goods, services and technologies prohibited by the sanctions regime. I also want to find linkages among corporations, banks, and other non-state actors with specific economic interests in Iraq and the Middle East. A third issue to study is, in comparative terms, the state of the Iraqi economy and trade relations with the rest of the world before and after the imposition of UN sanctions. The goal is to determine how much of the economic decline was due to the sanctions and not to factors such as world market conditions, economic policies, climatic changes, etc, inherent or intrinsic to the Iraqi economic and political systems.

\section{The Case Study}

This dissertation tackles the following questions: Did the sanctions regime imposed against Iraq reflect the development of thriving international cooperation among states, global institutions and corporations? Or did the sanctions regime break apart due 
to conflicts among nation-states and/or the deepening of globalization? Why choosing Iraq instead of other nation-states like North Korea, Libya or Iran, which were subjected to sanctions during the 1990s?

Three main points qualify Iraq as a sound case study. First, the sanctions regime imposed upon Iraq constitutes the most extensive and intensive effort among nationstates and international institutions to cooperate for the enforcement of a sanctions regime. For the strength of the sanctions, for the commitment that the United Nations, United States and other nations showed when enforcing the regime, and for the consistency with which the international media, NGOs and international organizations scrutinized it, the UN sanctions regime against Iraq has no parallel in the history of international politics. This has important theoretical implications because if I find enough evidence to confirm the central argument of this dissertation, then my thesis may have validity against other cases not so rigorous as the case of Iraq.

Second, Iraq is a case worth studying because there seems to be an important contradiction between the central question of this dissertation -to what extent multilateral economic sanctions prevented Iraq from acquiring and/or developing weapons of mass destruction- and the argument made to justify the latest American invasion of Iraq: the illegal acquisition and/or development of weapons of mass destruction by Iraq. This contradiction suggests that, despite the sanctions regime and despite the support expressed by the international community of nations and institutions with respect to the sanctions, some credible sources affirmed that Iraq acquired and/or developed WMDs. If this was correct, then I must conclude two things: first, that Iraq somehow managed to evade UN sanctions and, second, as the thesis of this dissertation suggests, sanctions 
regimes are not effective means of foreign policy in the global economy.

The third aspect to consider is that this dissertation is time sensitive, meaning that it only focuses on the 1991-2002 period. This is not arbitrary. First, it was during the 1990s that the world consolidated itself as unipolar and the United States secured its position as the sole world superpower. This new structural configuration and the resulting balance of power had significant implications for world politics. Some scholars soon began to argue that the United States alone could not guarantee peace and stability in the world, and that a unipolar world was more unstable than a bipolar one (Waltz, 1993.)

Next, with the disappearance of the Soviet Union, the second world nuclear superpower, the problem of proliferation of weapons of mass destruction occupied most of the agenda of the United States, its allies and international institutions such as UN, NATO and the EU. Also, it was during the 1990s that proliferation of weapons of mass destruction suddenly became a serious concern as nations like Pakistan, India, and North Korea resumed building nuclear weapons or, at least, increased their nuclear capabilities. In fact, all throughout the 1990s, economic, political, and diplomatic sanctions of all sorts were imposed upon North Korea, Libya, Pakistan, India and other nations for attempting to acquire and/or develop nuclear capabilities and WMD.

Finally, it was also during the 1990s that globalization gained momentum in academic circles as a phenomenon worth observing for its influence in culture, religion, economics and, more broadly, world politics. Although there seems to be no consensus on a definition of globalization, I can summarize it according to three main schools. For instance, some scholars describe globalization as a socio-cultural phenomenon defined by Tomlinson (1999) as complex connectivity. This school argues that even though 
globalization has been around for many years, it became more evident during the 1990s thanks to new technological trends such as computerization, communication and transportation. But scholars like Gowan (1999) and Negri and Hardt (2000) see globalization as a political process related to power and world domination through militarization, institutionalization and trans-nationalization of international relations. In that respect, Huntington (1990) argues that globalization will bring about confrontations among civilizations, and that the next wars will be fought along religious lines.

Still, for Fukuyama (1992) globalization marks the beginning of an era in which the principles of liberalism and capitalism dominate world politics. Robinson (2004) agrees, but he predicts more conflicts among social classes while Fukuyama sees a great opportunity for cooperation. For Robinson, globalization represents an epochal shift in world politics and economics. It is a transition toward a more severe systemic economic interdependency. This transition entails three aspects: fragmentation of production, the ascendance and dominance of transnational capital, and the consolidation of global circuits of accumulation (Robinson, 2004, p. 9). The result is the substitution of national markets for a global one that integrates the flow of capital, goods and services. It means that a nation under a sanctions regime still have access to some alternative niches where it can allocate its exports. It allows nations to import goods and services, technologies and materials needed to stabilize their economy, sustain their military apparatus, and safeguard their territorial integrity.

Based on those points, I define globalization as political and economic, highly interconnected and interdependent relations between the agents and means of globalization. I will elaborate more on such a definition, but first I like to examine the 
theoretical approach for this dissertation.

Theoretical Framework

Liberal Institutionalism, Realism, and Historical Structuralism

Three important theoretical approaches to international relations frame the central question of this investigation: liberal institutionalism, realism and historical structuralism

First, I pay special attention to liberal institutionalism for one main reason: this dissertation examines a sanctions regime promoted, enacted and enforced under the auspices of the United Nations, arguably the most important international political institution in the world.

Even though a final definition of institution is still in debate, most institutionalists focus on the whole range of societal, state, and institutional settings that shape how political actors define and protect their interests with respect to institutions. Liberal institutionalism favors institutions as a forum for political debate, negotiation and, conflict resolution. Institutionalism focuses on institutional structures that frame selfinterests, behaviors and outcomes. Included in the framework are: institutional rules, procedures, conflicts among institutional actors, and relations of power between bureaucracies and between them and non-institutional actors.

Most institutionalists are interested in what Peter Hall (1986) defines as the relational character of institutions, meaning how a given institutional configuration shapes political interaction not only with other institutions but also with respect to individuals, businesses, and group interests. For example, Hall defines institutions in terms of "Formal rules, compliance procedures and standard operating practices that structure relationships between individuals in various units of the polity and economy" 
(Hall, 1986, p. 14). Most of all, Hall is concerned with how institutional structures offer a comparative advantage to a particular nation. This approach has implications for: 1) how institutions fit in the analysis of policymaking; 2) how institutional advantages affect worldwide treaties and trade accords; 3) how corporations set macroeconomic strategies with respect to international institutions in the context of the world economy.

For his part, Ikemberry $(1988,2000)$ concedes that institutions do matter in international politics when trying to prevent conflicts, bring about peace, and promote multilateralism among nations. Ikemberry breaks down institutions in "Three distinct levels that range from specific characteristics of government institutions to the more overarching structures of the state, to the nation's normative social order" (Ikemberry, 2000 , p. 27). His goal is to study intermediate institutional levels and compare them across nation-states. He assesses how state-level institutions and assessments of states' interests contribute to the creation of lasting and effective international institutions. In line with Ikemberry, scholars like Katzenstein (1985) study structures and organizations of key economic actors. Skocpol (1979) and Axelrod (1981) focus on public policy and interest-group behavior.

Liberal institutionalists are prompt to question the overall effectiveness of a sanctions regime under globalization. For example, they inquire about whether the sanctions regime imposed against Iraq effectively grappled with the geopolitical realities of the 1990s, mainly the emergence of a unipolar world and the subsequent consolidation of liberalism and capitalism across nations. They ask whether institutional frameworks conceived to facilitate international cooperation kept pace with new global economic and political trends. They also refer to the increasing participation of global non-state actors 
and global civic societies in global institutions and politics. Consequently, based on those assumptions, in the case of the UN sanctions regime upon Iraq, I can argue that if the sanctions were effective, I should find enough evidence of institutional coherence that would indicate some success related to the primary goals of the sanctions. Specifically, I would be able to illustrate that the regime succeeded in its two most basic tasks: 1) the prevention of weapons flowing into Iraq; 2) the prevention of exports to Iraq that would have allowed the country to rebuild its WMD program.

Realism is the second theoretical approach to the central question of this investigation. Realists are particularly skeptical about the overall effectiveness of international institutions in world politics. For example, in the case of Iraq, realists would argue that the UN sanctions regime was doomed to fail for two main reasons. First, because it was promoted, enforced and monitored by international institutions that lacked any independent legal authority and enforcement mechanism. Second, the conflicting interests among great powers did not allow an institution like the UN to define a common policy toward Iraq.

For realists, the problem of international politics rests with the true nature of nation-states themselves. Realists consider nation-states as the single biggest obstacle to the efficacy of institutions, multilateralism and a sanctions regime. Nation-states are unitary actors, always concerned with their physical survival in an anarchic world (Morgenthau, 1948; Viotti \& Kauppi, 1999). In fact, it is national security and the security dilemma that set the political agenda of nation-states at domestic and international levels. Not surprisingly, nation-states spend many resources on the military, the use of force, how to attain and maintain peace, and the prevention of violations of 
territorial integrity.

The concept of power is central to Realism, but there is no consensus among realists on how to define it. As a whole, they agree that power is an attribute of states, and that it is the sum of all the military and strategic capabilities of a state with respect to other states. Realists define military capabilities as a strategic issue of high politics, whereas economic and social issues are considered low politics. The terms are not arbitrary for they are directly related to the concept of power and what it means to Realism and the hierarchy of its geopolitical agenda. Finally, realists define nation-states as rational self-interested actors, focused on their own political and economic wellbeing. It means that I should expect from nation-states a rational foreign policy derived from a unitary decision-making process which includes clear objectives, consideration of alternatives, discussion of vulnerabilities vs. capabilities, and cost-benefit analysis. However, some realists acknowledge some inconsistencies when defining nation-states as rational actors. Gilpin (1981), for example, finds a contradiction between cost-benefit analysis and the quality and quantity of information that governments utilize to engage in decision-making. Jervis (1976), for his part, affirms that information is not always accurate enough, that it may lead to faulty policy formulation and even misperceptions about key issues in international politics. Faulty information can take nations to war and, in some cases, to a military defeat.

Overall, the effectiveness of institutions depends on the extent to which the interests of nation-states enforcing those institutional norms, rules and regulations are consistent. But realists believe that they are not consistent. If realists are correct, I should expect that strategic and economic interests of states would affect the level of cooperation 
and conflict in the development, oversight and implementation of the sanctions regime that UN implemented against Iraq. Especially, I should expect national security issues, not economic ones, to dominate the political agenda of nations in the UN. Also, I should expect a high degree of skepticism by great powers in regard to the efficacy of international institutions in world politics.

Finally, historical structuralism is the third theoretical approach to the central argument of this dissertation. Three major assumptions are central to this framework. First, the level of analysis in international relations is the global context within which nation-states, businesses, and international institutions behave and interact. The rationale here is that domestic politics is not the only factor shaping nation-states' behavior. It is rather the overall configuration of international politics and the international economic system which determines political behavior.

The second assumption is that international politics must be seen from both historical and economic standpoints. That is, history and economics are linked, so that in order to understand the current configuration of world politics, I must look at the historical evolution of the world economy. Here, historical structuralists, Marxists and non-Marxists alike, affirm that capitalism is the defining historical feature of international economic and political systems. Historical patterns of global capitalist production and development frame the modern global political economy. In particular, historical structuralists analyze a sanctions regime within a larger context of global capitalism and the structural problems sustained and exacerbated by it. The analysis includes unequal development and distribution of wealth, widespread poverty fierce competition for market shares, cheap labor, and scarce natural resources. According to historical 
structuralists, those are the true causes of international tensions, conflicts and wars. If that is correct, then I should examine how globalization affects international institutions and multilateral regimes created to develop and enforce sanctions.

The last assumption is that, like liberal institutionalists, historical structuralists acknowledge the roles that states and global non-state actors play in world politics. Yet, they above all pay attention to how a minority of nation-states, businesses and elites concentrate economic and political power and benefit from the preservation of the status quo. Structuralists want to know how such a concentration of power came about. They study the structural nature of relationships among states which they see as hierarchical, based on economic exploitation and domination. For historical structuralism, dependency is the most common relationship among nation-states, especially between developed, developing, and underdeveloped nations. In fact, dependency is for historical structuralism what interdependence is to liberal institutionalism and what balance of power is to realism.

With respect to the Iraqi case, historical structuralists would argue that the emergence of a global economy and transnational capitalism made it extremely difficult for nation-states and international institutions to enforce a sanctions regime. Sanctions regimes and global capitalism are incompatible. They cannot coexist. Sanctions regimes alter the natural course of capitalism, which is toward expansion and dominance of global markets. Sanctions regimes are irreconcilable with five fundamental features of global capitalism: open markets, free trade, competition, free flow of capital, and profits. Also, historical structuralists see sanctions regimes as a significant source of conflict within nation-states and between transnational firms and nation-state actors. They argue that 
business interests are in frank contradiction with political ones; therefore, transnational firms and state actors would disagree in their orientation to sanctions regimes. In fact, historical structuralists tend to be skeptical about the ability of nation-states to enforce a sanctions regime under globalization. They consider that sanctions regimes are unenforceable not so much for the lack of commitment from nation-states but due to the powers that non-state actors have gained with respect to state actors. In the era of globalization, non-state actors such as banks, corporations and NGOs are more visible and influential than ever. They seem more resolute than ever to seize power from state actors. They have developed legal, financial and political powers to do so.

\section{$\underline{\text { Regimes and Multilateralism }}$}

I utilize the term sanctions regime when referring to multilateral economic, political, and diplomatic measures imposed against Iraq by the international community of nation-states under the auspices of the UN from 1991 to 2002. The objectives then were to isolate Iraq, weaken it economically and politically, and prevent it from acquiring hardware and technologies that would allow it to develop weapons capabilities. Why do I use the term regime and not simply economic sanctions, or embargoes?

Two key concepts are central to this argument: regime and multilateralism. First, the term regime derives from domestic politics where it refers to an existing governmental order, meaning monarchical, democratic, authoritarian or totalitarian in a particular nation. A regime is a specific set of rules, laws, procedures and institutions conceived and established to govern unilateral and multilateral relations among individuals, groups, businesses and even social classes within a particular nation-state. 
Laws, procedures and institutions usually constitute the rules of the game, and in time they become intrinsic features of the cultural and social configuration of a people. Stephen Krasner (1983) too defines regime as a set of rules, but one conceived to regulate multilateral relationships between nation-states, international institutions and nongovernmental organizations. Nation-states recognize and promote rules voluntarily to create some sense of order and certainty in global relations, which is very important given the absence of a supranational authority in world politics.

The term regime also refers to "implicit or explicit principles, conventions, and decision-making procedures around which actors' expectations converge in a given area of international relations" (Krasner, 1983, p. 49). A regime may be associated with international and nongovernmental organizations, but an international regime is not the same as, or does not refer to, an international organization. Three schools of thought address this issue. The first is power-based realism, with its emphasis on the role of anarchy and relative distribution of capabilities in international politics. Within this school, the theory of hegemonic stability argues that a regime is established and preserved when a state dominates in terms of power. As power declines, so would do the state and the regime it established. The second is the interest-based school. It focuses on the role that international regimes play when states try to realize common interests. Neoliberal institutionalism is a common approach in this school, which sees state and non-state actors as key players in international politics (Keohane, 1984). The third is knowledge based cognitive school. This school argues that actors of diverse backgrounds, not states, create states' interests. In order to understand politics, it is necessary to examine preferences of actors and those who participate in the decision-making process. 
In sum, states can redefine their interests without altering the overall balance of power. They can do it through regimes, institutions, and multilateralism.

Next, some scholars associate regimes with specific issue areas such as the environment, genocide, economic development, nuclear proliferation as well as proliferation of WMD and others. In recent years, the concept of regime has been stretched out to move from the mere notion of international cooperation to multilateralism, which is a much broader, more inclusive framework. But for Ernst B. Haas (1990), multilateralism is an agent of change, a process tied to power, interests, knowledge and access to information, decision making, and structures of international organizations. Yet, voluntarism is the basis of multilateralism because, in the end, it is up to the sovereign nation-state to engage in multilateral relations. And as for Ruggie (1993), he defines multilateralism not as a theory of international politics in itself but as concept, an organizing principle, an institution arranged in a multilateral form to coordinate multilateral relations among nation-states on the basis of generalized behavioral principles, always conditional to an already existing institutionalized relationship. The main characteristics of multilateral relations are indivisibility, nondiscrimination of issues, and dispersed reciprocity.

In all, multilateralism should be seen as a tool for compromising and/or accommodating potential conflicting differences. It aims at finding common interests through institutions and organizations acting as intermediaries or trustees. With the end of the Cold War and the advent of a unipolar world, this yearning for finding common interests through international norms and institutions became, more than a necessity, a strategic maneuvering of second class world powers as they sought to counterbalance the 
might of the US, by then the world's sole superpower. For example, Ruggie (1993) argues that it was a common interest among nation-states, arguably a common fear toward international political destabilization with the consequent smuggling and proliferation of nuclear weapons that ultimately brought nations together to help stabilize international politics after the collapse of the Soviet empire. A common interest brought nation-states together to conceive, establish and enforce economic, political and military sanctions against Iraq for most of a decade.

\section{Defining Sanctions Regime}

Generally speaking, sanctions regimes establish four forms of sanctions (Carter, Chaves, Damrosch, and Lori, 1997). The first form is purposeful sanctions. They intend to inflict economic hardship in order to force the targeted nation to change its overall behavior with respect to another nation. A second form is palliative sanctions. These are mild sanctions, imposed to publicly articulate the disapproval of the international community, or supranational actors, for the reckless behavior of a nation. A third type of sanctions is punitive, and they aim at inflicting actual economic damages upon the sanctioned nation. The objective here is to retaliate against a specific action of the targeted nation or reaffirm the status quo. Lastly, partisan sanctions target a specific region or community of a nation. They are mainly employed in ethnic and religious conflicts, and their attempt to affect specific commercial activities in a particular community, religious group or entity. What about the specifics of those sanctions?

A first set of sanctions could suspend, limit, condition, terminate and/or prohibit foreign assistance to a nation. A second round of sanctions might end all non-profit and 
NGOs programs as well as terminate all financial support to private organizations operating within the sanctioned nation. A third level of sanctions could target both public and private institutions by cutting off access to profits, trade, financing and even assets deposited in foreign banks and investments firms. A more drastic round of sanctions would restrict imports and exports of some or all goods, commodities and technologies by revoking licenses, strengthening shipping stipulations and related commercial terms. On top of all that, sanctions could terminate all governmental contracts and trade agreements as well as restrict or deny access to international air and maritime corridors. It could later become an air and naval blockade of low, moderate or high intensity. Other mechanisms may include: deny visas to travel to sanctioned nations; increase fines and years of imprisonment to individuals who violate the sanctions; prosecute corporations suspected of breaking the sanctions regime; and arrest and prosecute political and businessmen from sanctioned nations in international courts. Finally, it is worth noting that economic sanctions do not necessarily include suspensions of diplomatic contacts and relations, cut off of diplomatic and military attachés, and closing of embassies. Also, direct military actions are not considered part of economic sanctions although enforcing them may require some military involvement such as espionage, surveillance, patrolling, and other low-intensity military means.

In all, I can affirm that the multilateral mobilization against Iraq included all the features described above. It certainly included military occupations, raids and bombings.

\section{Globalization and the Circumvention of Sanctions Regimes}

Nation-states have historically circumvented sanctions regimes by establishing 
new chains of supplies and alternative markets, including the black-market. That is easier under globalization because the global economy opens up domestic markets and facilitates the flow of goods, services and capital. Likewise, globalization accelerates economic competition, which in turn creates an excess of failing corporations seeking for alternative ways of survival. In that respect, Wallenstein $(1974,1981)$ would recommend examining the role played by corporations located in the semi-periphery and periphery. They usually pick up economic opportunities left behind by more prosperous corporations or winners of global capitalism.

There are specific features of globalization that facilitate the evasion of sanctions regimes. The first is the nature of the global banking system and the widespread use of offshore accounts, electronic money, transnational capital and indirect investments. The second is the fragmentation and globalization of production, which stimulates the proliferation of subsidiaries, parent companies and intermediaries with multiple layers of management and administrative bodies with no recognizable legal relations and obligations. In general, the nature of the global banking system and global business structures facilitate illegal operations and the emergence of black-markets, making it easier for a sanctioned nation-state to break a sanctions regime.

The high cost of enforcement versus the problem of funding also helps nations to evade sanctions regimes. Two different trends conflict here: while nations promoting a sanctions regime are not always willing to commit enough funds to enforce sanctions, nations under a sanctions regime tend to commit themselves to economic survival at any cost. Monitoring and enforcing sanctions regimes depend on the funds that nations commit for the task. Not to mention that sanctions regimes also affect finances and 
economies of nations promoting the sanctions, mainly those already affected by global competition and other features of globalization. As result, it is not unusual to see nations and corporations resenting sanctions regimes, against which they lobby governments and international institutions with all kind of arguments, from environmental to humanitarian. On the other hand, sanctions regimes actually benefit some nations and corporations, which find it advantageous to maintain economic contacts with the sanctioned nation. This became a serious issue in the case of Iraq as Russia, France, Germany and other nations were frequently accused of having business interests there.

Finally, the size of the market also affects monitoring and enforcement of a sanctions regime. Flow of money, goods and services occur more frequently in larger markets than in smaller ones. Hence, I would argue that the larger the market, the harder it is to monitor and enforce a sanctions regime. Also, monitoring and enforcing sanctions regimes become sensitive in nations such as North Korea, Libya and Iraq due to their centralized political and economic systems, and closed societies.

\section{Testing the Hypothesis}

A key aspect of this dissertation is how to test the hypothesis, namely how to establish that globalization allowed Iraq to circumvent the UN sanctions and rebuild its economy and military infrastructures.

First, I define globalization as high, intense interrelations and interdependencies among agents and means of globalization. Agents of globalizations are nation-states and non-state actors. Whereas nation-states' actors include governments, states' agencies and states' officials, non-state actors refer to corporations, financiers, interest-groups, NGOs, 
empowered individuals and others. For their part, the means of globalization are: global access to raw materials, global trade (the import-export industry), the global banking system, corporate models, the global manufacturing system and/or global assembly line. Figure 1.1 illustrates the two groups.

Figure 1.1 - Agents and Means of Globalization

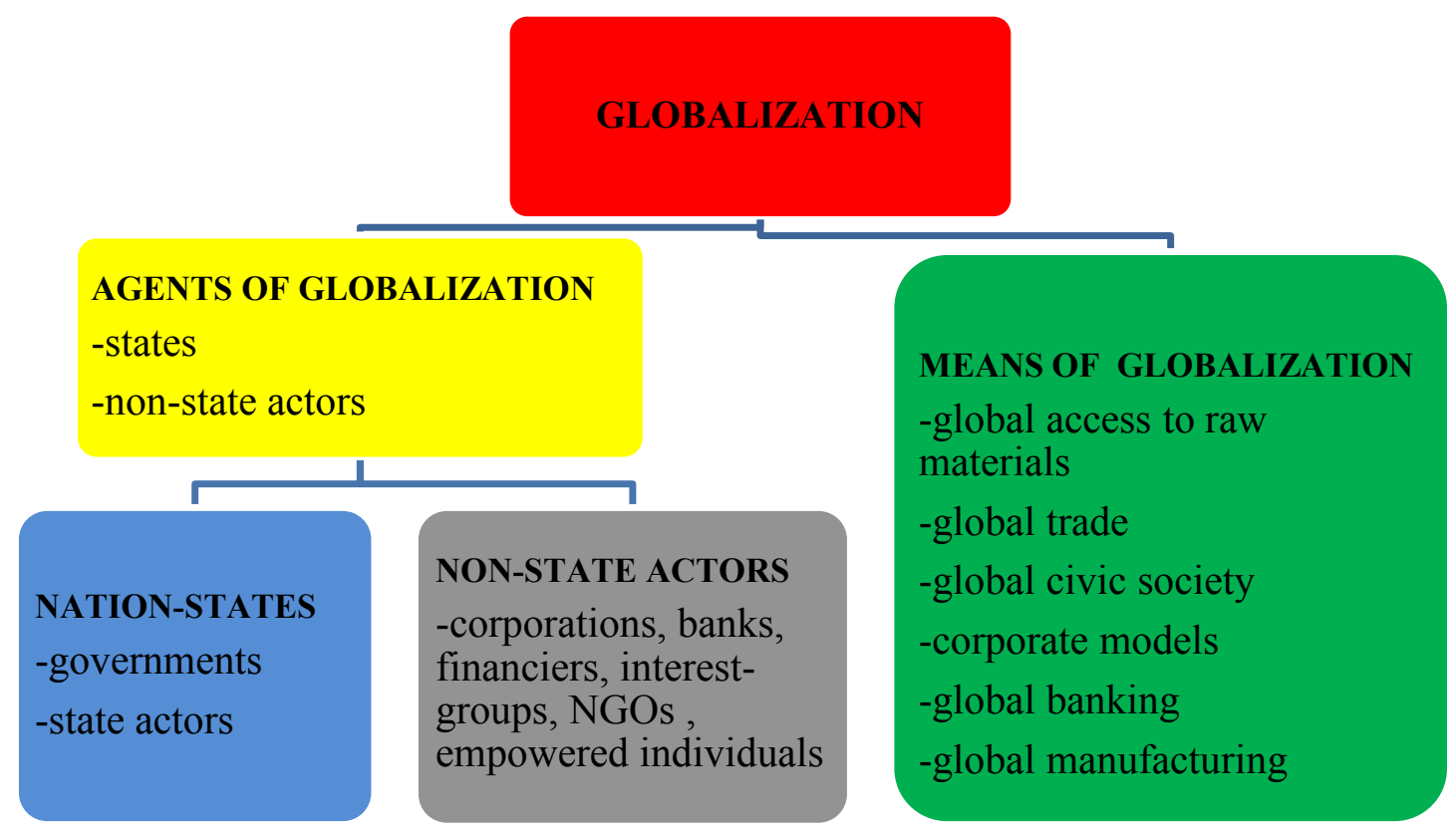

Second, I find that six key features of globalization jeopardize the efficacy of sanctions regimes as instruments of foreign policy. They are: 1) intense global competition among nation-states for strategic raw materials; 2) the nature of global trade, or the import-export industry, fragmented by regional and bilateral trade blocs and/or agreements; 3) the emergence of a global civic society and proliferation of global non- 
state actors such as NGOs, religious denominations, interest-groups, and empowered individuals equipped with -and interrelated through- global means of communication, mass media, and transportation; 4) the nature of the global banking system built on transnational capital and credit, electronic money, offshore accounts, and other financial instruments conceived to move capital at high speed throughout global markets; 5) proliferation of global corporate models such as joint ventures, subsidiaries, dormant, shell, and parent companies; 6) the global production process, reconfigured around a global assembly line linked to contract manufactures (CMs) and regional manufacturing centers.

Those six features of globalization create a high level of interrelation and interdependency among nation-states and their actors, and between them and non-state actors. Thus, I study each one of them but separately, in six chapters structured as follow.

In chapters II and III, I focus on nation-states. In Chapter II, I explain how global demand for oil affects national security. This is not arbitrary. Oil is a key commodity for world superpowers, to the point that they have defined it as a national security issue. But Iraq holds one the largest oil reserves in the world. It has so much oil that it built its national security on it. Still, the UN sanctions regime specifically targeted Iraqi oil, creating a conflict of interest among the world superpowers and triggering competition for access to Iraqi oil. I explain in Chapter II that both securitization and competition for oil allowed Iraq to circumvent the UN sanctions regime. Then, in Chapter III, I analyze nation-states within the context of global, regional and bilateral trade. I argue that global trade is in fact fragmented into multiple regional trade zones and bilateral trade agreements. This fragmentation allowed Iraq to access global markets where it purchased 
not only goods and services for civilian ends but also components, equipment and technologies to rebuild its military infrastructure, including its WMD Program.

After that, I move away from nation-states to focus on global non-state actors, on how they interact in a global civic society and affect global politics. Thus, in Chapter IV, I analyze NGOs, interest-groups, religious organizations, exiled communities, political parties and empowered individuals. I study how they facilitated circumvention of the UN sanctions regime. In Chapter V, I focus on financiers, speculators, banks and global banking. Here, the underlying assumption is that whereas global banks and financiers finance global trade, the global banking industry guarantees the rapid circulation of money in a secured and efficient manner throughout global markets. I argue that Iraq utilized regional banking to access global banking and conceal it from the UN. Afterwards, in Chapter VI, I examine yet another non-state actor and a means of globalization. I analyze the corporation and corporate models. Corporations design corporate models to go global, evade states' laws, avoid accountability and maximize profits. I discuss how nation-states, non-state actors and Saddam Hussein employed corporations and global corporate models to circumvent the UN sanctions regime.

Lastly, in Chapter VII, I study another feature of globalization: global productions for local assembly lines. I recreate the strategy Saddam Hussein employed to rebuild its military apparatus and WMD Programs. I show how Saddam went around the world purchasing technologies and components of all sorts to assembly them in Iraqi and nonIraqi military plants. Saddam's strategy was so novel that the UN had to conceive and enforce a second sanctions regime, known as the embargo on goods of dual use, meaning goods designed for one purpose but that could be used for other ends, in the Iraqi case for 
military weapons.

In all, my findings should explain the hypothesis of this dissertation: that agents and means of globalization undermine a multilateral sanctions regime. How they do it is represented in Figure 1.2.

Figure 1.2 - Circumvention of a Multilateral Sanctions Regime under Globalization

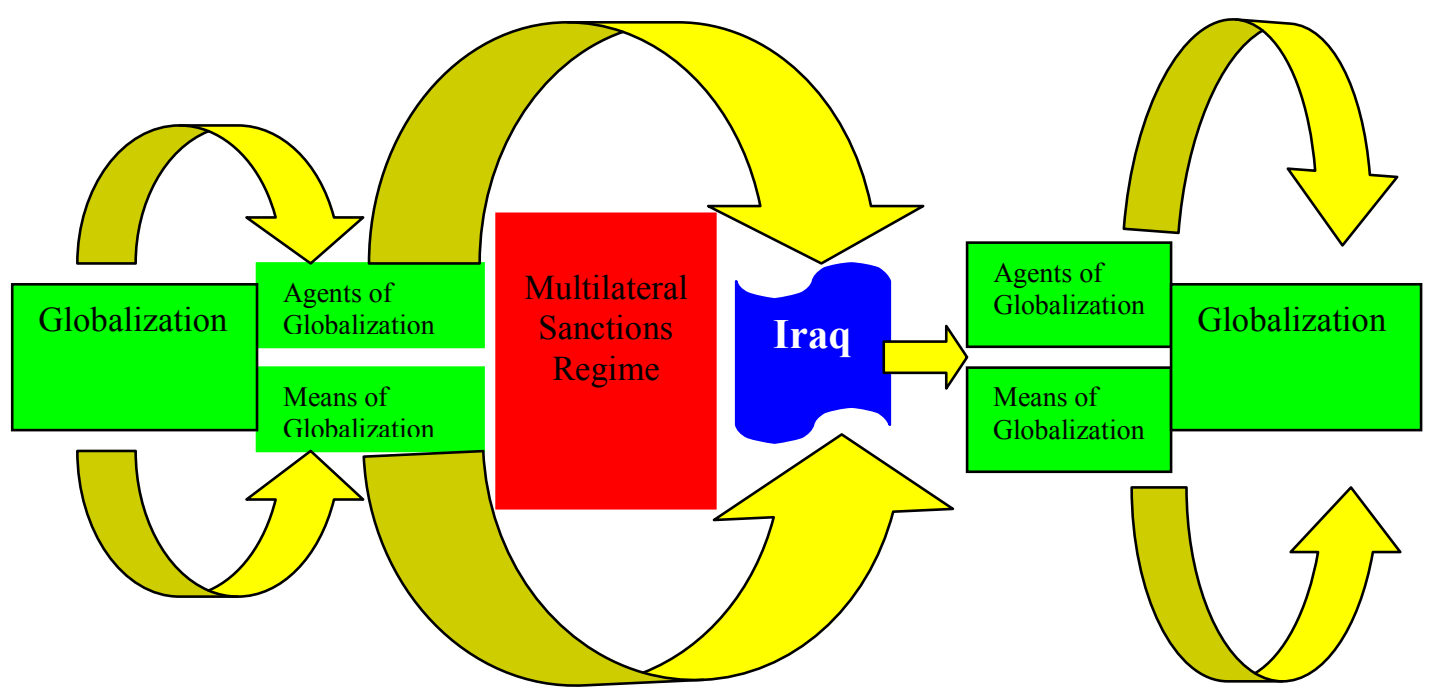

The Research Methodology

Another important aspect in this dissertation is the research methodology. I employ two methods: the follow the money approach and the comparative approach.

In the follow the money approach, I research three bodies of sources: the UN, the US, and independent sources. I examine the entire sanctions regime, but I pay special attention to the so called "UN Oil-For-Food Program." Several credible sources found 
that some states, non-state actors and even Saddam Hussein utilized "the Programme" to circumvent the UN sanctions regime, profiting hundreds of billions of dollars. Following this money is essential to determine how it was done, where the money originated and where it ended up. Thus, I follow transactions and wire transfers. I review bank accounts, statements, and ledgers. In addition, I employ the comparative method to compare data and sources. I utilize two main sources of data. One source is the Volcker Report, prepared by the IIC. The other is the Duelfer Report, prepared by the CIA. The goal here is threefold: analyze the organizational coherence of UN sanctions, examine mechanisms for enforcing them, and detect potential contradictions between both the Volcker and the Duelfer Reports.

The Volcker Report owes its name to Mr. Paul Volker, Chairman of the IIC. The U.S. Congress mandated and sponsored the IIC, but independent institutions collaborated, including the Anglo-American Security Policy, the Institute for International Peace Studies, University of Notre Dame, and the Middle East Research Institute. The objective of the IIC was to investigate violations of the UN sanctions regime. Alternatively, the Duelfer Report compares the Iraqi economy before and during the UN sanctions regime as well as the structures of the Iraqi government and its multiple agencies. The Duelfer Report also analyzes how Iraq purchased components and technologies to rebuild its weaponry, including its WMD Program. The Report discusses cases of money laundering in Iraq by banks, corporations, and other non-state actors.

Next, I use several independent sources as part of the comparative research. For instance, the Stanley Foundation financed various research projects on sanctions regimes as instruments of foreign policy. It held two conferences that explicitly discussed the 
Iraqi case and how American corporations and banks at times jeopardize American economic sanctions against targeted nations. Panels included representatives from Microsoft Corp., Caterpillar Corp., Chase Manhattan Bank, Bank One, Conoco Inc, Exxon-Mobil, and others. Also, I include investigations from the British and Australian Parliaments, the Heritage Foundation, the Michigan Project, and the Iraq Watch Project.

Finally, it is imperative to assess and compare Iraq's weapon arsenals before and after the U.S. led invasion of Iraq in 2003. The goal is to survey Iraq's military hardware and weaponry, as well as goods with weapons-related utility that Iraq acquired during the sanctions regime. I want to trace their manufacturing origins, determine how they were obtained and smuggled into Iraq. For that end, the U.N. and its several agencies are important sources. Among them are the International Atomic Energy Agency Iraq Action Teams, also known as Iraq Nuclear Verification Office (INVO), the UN Special Commission (UNSCOM), which consists of multinational teams responsible for inspecting chemical, biological, and nuclear arsenals in Iraq, and the UN Monitoring, Verification and Inspection Commission (UNMOVIC). Also, taking into account that the state of Israel is a key ally of the U.S. and arguably the most threatened of all Saddam Hussein's enemies, it will be potentially informative to study what Israeli's intelligence agencies have to say about Iraq's attempts to circumvent the sanctions regime in order to acquire and/or develop nuclear capabilities and WMDs. The rationale is that Israel's intelligence services are among the most effective and credible in the world, so their findings could be a reference to compare with findings form UNMOVIC and intelligence service agencies of other nations.

One important aspect to observe is that, in the years to come, I should expect 
more independent investigations on the topic being conducted by universities, academic institutions and even journalists from different parts of the world. The fact that there were so many violations of the UN sanctions against Iraq and that no weapon of mass destruction were there makes this kind of research an attractive one, appealing to scholars of all schools and tendencies. Moreover, "the problem of Iraq" is being replicated in the case of Iran as I speak, presenting a new challenge to the UN in terms of how to inspect Iran's arsenals, how to prevent Iran from obtaining nuclear materials and technologies from other nations, and whether or not a UN's embargo will be enough to deter Iran from acquiring and/or developing nuclear capabilities. Again, these kinds of questions will probably trigger an array of research and analysis about the topic in the years to come.

In conclusion, in this dissertation I examine the overall effectiveness of sanctions regimes in today's global economy. I analyze whether or not sanctions regimes are enforceable and how efficient they are as instruments of foreign policy, chiefly when trying to prevent the acquisition, development and proliferation of nuclear weapons and WMDs. I study national and transnational interests and how they affect, and are affected by, non-state actors, institutions and multilateralism. This is of great relevance for international relations since, as I speak, the UN, the U.S. and other world powers attempt to cope with Iran's ambitions for nuclear technologies. Some policymakers are already proposing a sanctions regime against Iran led by the UN. Some scholars see sanctions regimes as the main mechanism to prevent Iran from acquiring and developing nuclear technologies. Others consider that globalization is an obstacle. The debate will remain open for years to come, and this dissertation could shed some light on it. 


\section{AGENTS AND MEANS OF GLOBALIZATION: NATIONS, NATIONAL SECURITY, GLOBAL DEMAND OF RAW MATERIALS AND SANCTIONS $\underline{\text { REGIMES }}$}

"The real culprit in the Oil-for-Food scandal is not the UN but members of the Security Council such as the United States, United Kingdom, France, China and Russia... Most of the oil smuggling was condoned by the United States and other Security Council members".

Mr. Mark M. Brown, Kofi Annan's Chief of Staff

"At a minimum, Saddam wanted to divide the five permanent members and foment international public support of Iraq at the UN and throughout the world by a savvy public relations campaign and an extensive diplomatic effort".

The Duelfer Report

"...the billions which went missing were because of that kind of realpolitik calculation by governments".

The Volcker Report

"In theory, any public issue can be located on the spectrum ranging from nonpoliticized trough politicized to securitized, meaning that the issue is presented as an existential threat, requiring emergency measures".

Buzan, Waever and Wilde

\section{$\underline{\text { Introduction }}$}

In this chapter, I examine a key agent and an important means of globalization: nation-states and their quest for global access to raw materials under globalization. I argue that there is a fundamental contradiction between globalization and the security interests of nation-states imbedded in the concept of securitization. This contradiction too often leads to geopolitical tensions when states attempt to come together to enforce multilateral foreign policies such as a multilateral sanctions regime. This is particularly problematic when it comes to natural resources like oil. Oil is so important for national economies that most nations have defined it as a national security issue. If globalization triggers global demand for oil, national security interests restrict access to it. In this chapter, we will see that such a contradiction allowed Iraq to circumvent the UN sanctions and allocate large quantities of oil in regional and global markets. 
The problem is that Iraq possessed so much oil that the Iraqi regime built its national infrastructure on revenues obtained from the sale of oil. Then, there were the world superpowers, five of which sit permanently at the UN Security Council. They had securitized, or defined, global access to oil as a national security issue due to two main factors: 1) their high imbalances between oil consumption, production, and reserves; 2) the importance of oil for their economies and defenses. For its part, the UN conceived the sanctions regime against Iraq around restricting Iraq's oil sales, hoping that it would prevent Iraq from rearming and resuming its WMD program. But such a rationale failed. Instead, it created a conflict of interests among the five nations sitting at the UN Security Council and between them, Iraq and UN itself.

To illustrate my argument, I divide this chapter into two parts. In the first section, I discuss the concepts of sectorization and securitization. I discuss how nation-states attach issues such as demand for oil to national security. The discussion has two perspectives: one is from the world superpowers' perspectives; the other is Iraq's perspective. In the second section, I explain how nation-states performed under the UN sanctions regime against Iraq in terms of oil purchases. I explore how macroeconomic features such as GDP and oil consumption influenced oil purchases from Iraq. I also examine how non-macroeconomic features such as geopolitics, regional trade, and traditional trade relations affected the overall efficacy of the sanctions regime. Chiefly, I explore how the American unilateral political position with respect to Iraq clashed with the economic interests of world powers such as France, Russia, Germany, and China. For the discussion, I rely on the IIC, GAO and Duelfer Reports.

\section{$\underline{\text { Sectorization and Securitization }}$}


The concept of national security is not rigid but flexible. As Katzenstein argues, "The domain of national security issues is variable" (Katzenstein, 2006, p.10) and policymakers often redefine it according to the interests of the state and the always changing demands of global politics. Still, I would argue that, in general, there are two main approaches to national security: one is narrow, and the other is broad.

Realists and Liberals have a narrow definition of national security (Buzan, Waver \& Wilde, 1998, p. 2). Realists like Gilpin (1981) focus on material capabilities, what some scholars call hard power or tangible resources such as the military and the economy. Liberals too toy with the Hobbesian Doctrine, the base of security studies. They do not ignore material capabilities since, according to Grotius' approach to it, "Material power matters, but only within a framework of normative expectations embedded in public and customary international law" (Japperson, Wendt \& Katzenstein, 2006, p. 44). Both Realists and Liberals, some more than others, look at institutions, cooperation, international law, and diplomacy as collateral to military power. Conversely, a broad definition of national security would include culture, norms, religion, language and national identity among others in the national security agenda. According to this broad definition, the concept of statehood implies a notion of national identity, a people united within a territory by a common history, language, culture and norms. It is a concept born out of the Westphalia statehood system and reinforced under the post-Cold War globalization process. This approach measures power in terms of intangible resources such as culture, ideology, identity and others. Either way, narrow or broad, the definition of national security is directly related to two concepts: securitization and sectorization. 
For Realists and Neorealists, security is inherently related to the nature of global politics. They measure security in terms of power, meaning vulnerabilities vs. capabilities (Buzan, 1991, p. 19-20; Weaver, 1993, p. 21; Katzenstein, 1996, p. 2-6; Huntington, 1991, p. 7; Wendt, 1996, p. 31-36.) Liberals, Structuralists and Constructivists take a broader notion to include systems, structures, religion, norms, culture, identity, language, and other unconventional factors (Buzan, 1991, p. 19-20; Weaver, 1993, p. 21; Huntington, 1991, p. 7; Wendt, 1996, p. 31. But they all accept that security is about surviving and existing despite manifested existential threats, vulnerabilities, uneven capabilities and unbalanced power in an unstable world (Buzan, Waver \& Wilde, p. 27). Security concerns arise when a threat is directed to the very existence of the state, to society in general and to a government explicitly. Security threats justify the use of special security measures, which include -but are not limited to- the use of force. Security measures focus on preparing for war, the very first step to deterring one. In fact, deterrence begins with sectorization and securitization.

Sectorization is, more than a method, a practical approach to analysis. It aims at simplicity through disaggregation of a system from the top to the bottom. The core assumption is that we can dismember the whole into pieces, the system into subsystems, units into sub-units, and so on. The idea is to "Confine the scope of inquiry to more manageable proportions by reducing the number of variables in play" (Buzan, Waver \& Wilde, 1998, p. 8). Sectorization looks for patterns, differentiations, similarities and relations. Yes, there is a bit of Waltz's systemic theory and structuralism in this concept, but the focus is on sectors because "Sectors are views of the international system through 
a lens that highlights one particular aspect of the relationship and interaction among all its constituent units" (Buzan, Jones \& Little, 1993, p. 31).

There are five main sectors according to Buzan, Waver and Wilde (1998). The first is the military. It deals with national security and the ability to defend the nationstate in case of aggression. The second is the political sector. It focuses on issues related to sovereignty. It deals with existential questions like survival, legitimacy, recognition, and authority. The third sector is the economy. Here, it is important to say that economic and political sectors often converge because the economy is politically strategic when it comes to national security. For instance, the defense industry is politically important for national defense. Whereas a strong defense industry is central for deterrence, dependency on foreign oil makes nations vulnerable to global political instability. The fourth sector is the environmental. Its advocates claim that a healthy natural environment is vital for the existence of any state. Pollution, exhaustion of natural resources, poor quality of water, worn-out land and other environmental issues could eventually lead to health crisis, political instability and mass migration. It can affect, at the long run, not only national security but the very existence of the state.

Finally, there is the societal sector, which deals with questions of national identity, of what constitutes a nation-state. It includes religion, race, culture, history and even language. Indeed, Hitler's Germany defined the German state in terms of common blood and language. Israel calls itself the Jewish state while Iran is the Islamic state. Both Israel and Iran define religion as a raison d'eta. In Germany, Israel and Iran national identity led to strong states, but in Spain religion, language and culture have fragmented the state into various autonomous regions, each having its own government and even 
national flag. Presumably, national identities are vulnerable to external influences, chiefly to new religious and cultural trends. Still, a "well managed" national identity can unite a people in case of a foreign aggression. It is a very good reason for securitizing national identity.

Sectorization assumes, first, that each sector has distinctive characteristics and values, so we should not treat them equally. Second, each sector is vulnerable to specific threats, so survival must be approached differently across sectors. Securitization is a further measure. It is a complement, an escalation of sectorization (Buzan, Waver \& Wilde, 1998). Securitization is the process by which governments declare an issue a concern of national security. Securitization means that an "Issue is presented as an existential threat, requiring emergency measures and justifying actions outside the normal bounds of political procedure" (Buzan, Waver \& Wilde, 1998, p. 23-24.) For Katzenstein (2006), securitization aims at maximizing capabilities and minimizing vulnerabilities. The process can be ad hoc or institutionalized, depending on the severity and urgency of the threat relative to national security. Some threats come and go. In those cases, security measures can be temporary. But some threats are recurrent, and in time they become permanent. Those are institutionalized. They have priority in the national security agenda. They absorb large portions of the military and economic sectors.

The concept of securitization can be manipulated to respond to prefabricated ideological, economic and political interests. Securitization is "A self-referential practice in which the issue becomes a security issue not necessarily because a real existential threat exits but because the issue is presented as such a threat" (Buzan, Waver \& Wilde, 1998, p. 24). In that sense, securitization is basically " $A$ more extreme version of 
politicization" (Buzan, Waver \& Wilde, 1998, p. 25). As Buzan, Waver and Wilde put it: it is "Either as a special kind of politics or as above politics" (Buzan, Waver \& Wilde, 1998 , p. 24). It means that once an issue belongs to the realm of national security, it is not political anymore but a security issue. It is a raison d' eta. Based on this rationale, Realists and Neorealists emphasize the securitization of the economy and the military. They do it to fortify the physical integrity of the state.

For their part, Liberals and Constructivists securitize issues that may weaken the physical integrity of the state, including social unity, religion, ethnicity, culture, tradition and even language. For instance, minority groups keep challenging traditional national identities in Great Britain, France, the Netherlands and other European nations. As result, national identity has been moved to the national security agenda in those nations. In Spain, separatism constitutes a direct threat to the Spanish state and Kingdom. Lacking a cohesive national identity, Spain has moved national unity to the top of the list of the national security agenda.

The problem is that "Securitization creates a scale of chain reactions" (Buzan, Waver \& Wilde, 1998, p. 25), meaning that securitizing an issue often leads to the securitization of other issues. It could mean the securitization of issues across sectors and/or an entire one. The classic case is the securitization of oil by world superpowers early in the $20^{\text {th }}$ century. It drove world superpowers to securitize access to oil far beyond their natural borders. It triggered competition for oil wells across the world, a new wave of Western expansionism, an armaments race, political polarization of entire regions, and interventionism. 
In the end, it all has made oil not only the most expensive but also the riskiest commodity politically speaking. For example, Mexicans related oil to American interventionism, so they nationalized oil and declared it a national security issue, defined as such in the Mexican Constitution. Mexico expelled all foreign oil companies, especially Americans, from its territory. In Iran, oil was the reason for deposing the proAmerican regime of the Shah, expelling American oil corporations from Iranian territories, and declaring oil a national security issue. In Iraq too, oil was used as the reason for expelling American and British oil firms from Iraqi territories. Oil was nationalized and securitized. We will see in coming sections of this chapter that the Iraqi regime used oil to circumvent the UN sanctions regime, and as a means of survival.

In sum, securitization and sectorization link national security to "Intersubjective threats with a saliency sufficient to have substantial political effects" (Buzan, Weaver \& Wilde, 1998, p. 25). In this dissertation, I relate it to global trade, global civic society, global banking industry, transnationals, and the global production line. In this chapter, I argue that sectorization of oil and securitization of global access to it created political disagreements among nation-states, mainly between world powers, affecting the efficacy of the UN sanctions regime upon Iraq. In the next section, I discuss how the oil industry became a strategic sector, how access to global oil wells became a national security issue, and how it all affected the UN sanctions regime upon Iraq.

\section{$\underline{\text { Sectorization of the Oil Industry and Securitization of Access to Oil Wells }}$}

The turning point in the geopolitics in the Middle East was the discovery of oil around 1908 in Persia, specifically in the territories of what is Iran and Iraq today (Klare, 
2004). By then, oil was already a solid, profitable industry in the West, crucial for Western economies and armies. In fact, the sectorization of oil had began in the early 1900s when the armies of the world superpowers -U.K., France, and Germany in particular- started to use it as energy to move their tanks, planes, and warships (Klare, 2004). Securing access to oil became a national security issue, the foremost reason for further Western intervention in the Middle East.

The British and French governments conceived the Sykes-Picot Agreement to basically partition and control the Middle East. In an act legitimized by the League of Nations, France took control over Syria and its coastal lands, known as Lebanon, and the U.K. took over Iraq and Palestine. The U.K. kept a stronghold on most of the Arabian Peninsula, leading to the creation of Saudi Arabia and what are today the states of Persian Gulf. Soon, oil was found there too, mobilizing even more Western attention toward the region. By the end of WWII, the U.S. too had made access to global oil wells an issue of national security and declared the Middle East a strategic region. According to Klare (2004), it was the rationale for the meeting between President Roosevelt and Ibn Saud, King of Saudi Arabia, in 1945. There, President Roosevelt stamped what became the Roosevelt Doctrine, the core of the American foreign policy post-WW II toward Saudi Arabia and the entire Middle East.

The end of WWII brought a new structure to global politics. On one hand, there were the U.S. and the Soviet Union, the two new world superpowers immersed in a cold war. On the other hand, there was the end of Colonialism, through which colonies became sovereign nations-states. The new nation-states rapidly allied to either the Soviet Union or the U.S., engaging in proxy politics and wars (Ray \& Kaarbo, 2005, p. 72). The 
Soviets attempted to influence nations around the Caspian Sea and the Mediterranean basin, mainly Turkey, Greece and Iran where they had historic and strategic interests. Wary about the Soviets' intentions, the U.S. legitimized Roosevelt's policy toward the Middle East with a series of presidential doctrines.

President Truman issued the first Doctrine. For Klare (2004), it was twofold; 1) in tune with Kennan's doctrine of Containment, the U.S. must support political regimes in Greece, Turkey and Iran to contain Soviet expansionism in the region; 2) the U.S. must provide military assistance to Saudi Arabia, so it could defend itself from foreign and domestic threats.

Next, President Eisenhower's Doctrine went a step further. It authorized American Presidents to use military force to protect American interests, namely access to oil, in the Middle East. The American Senate and House of Representatives approved it in a joint resolution. Under the Doctrine, President Eisenhower sent American troops to Lebanon. Later, the Nixon Doctrine constituted a shift in American policy toward the Middle East by authorizing a greater flow of military aid to American allies in the region, so they could protect the flow of oil to the U.S. and Europe. The U.S. was committed, more than ever, to the Middle East. After all, the U.S. was by then importing more oil than what it produced. It had become dependent on Middle East's oil. Yet, the U.S. restrained itself from directly engaging in armed conflicts in the region.

The West learned the hard way about its dependency on foreign oil. First, oil producers in the Middle East united themselves under OPEC and boycotted production and deliveries; then, the Shah of Iran fell and Iranians assaulted the American embassy in Tehran; next, oil prices became volatile and Western economies fell into hyperinflation, 
stagnation and political instability. In sum, those events showed the inadequacy of the Nixon Doctrine, so President Carter expanded the number of American military bases in the Middle East and increased military aid to "friendly" regimes there. More notably, he recommitted American combat forces to conflicts in the Middle East. President Reagan ratified the Carter Doctrine and pledged to protect not only Saudi Arabia but the Saudi Royal family too. Lastly, President George H. Bush claimed all those Doctrines, from Roosevelt's to Reagan's, to legitimize the American led invasion of Iraq in 1990.

The unexpected collapse of the Soviet empire in 1991 created a new world order based on two new features: unipolarism and globalization. In geopolitical terms, the world became unipolar; in economic terms, capitalism consolidated itself as global capitalism, or globalization. In both, the U.S. was hegemonic. Most of the Soviets' political "satellites" were up for grab and the U.S. seized the occasion to shape the new world order according to its geopolitical interests, oil included.

The invasion of Iraq in 1991 was an advance of what came thereafter: the consolidation of American military presence in Kuwait, Saudi Arabia, Qatar, Bahrain, United Arab Emirates and Oman; the expansion of NATO toward Russian frontiers; the establishment of long-term American military bases in Bosnia, Rumania, and Kosovo; and American military expansion to Central Asia, mostly Uzbekistan and Kyrgyzstan. By 2003, the U.S. had almost completed its military expansion toward the Caspian Sea, dominating the Russian-European and the Russian-Central Asian borders and completing what Klare calls the "encirclement" of Iran, a key oil producer in the Middle East from where, as I stated, American and European oil firms were expelled. Figure 2.1 illustrates the American military presence in the Middle East and encirclement of Iran. 
Figure 2.1 - U.S.'s Military Encirclement of Iran

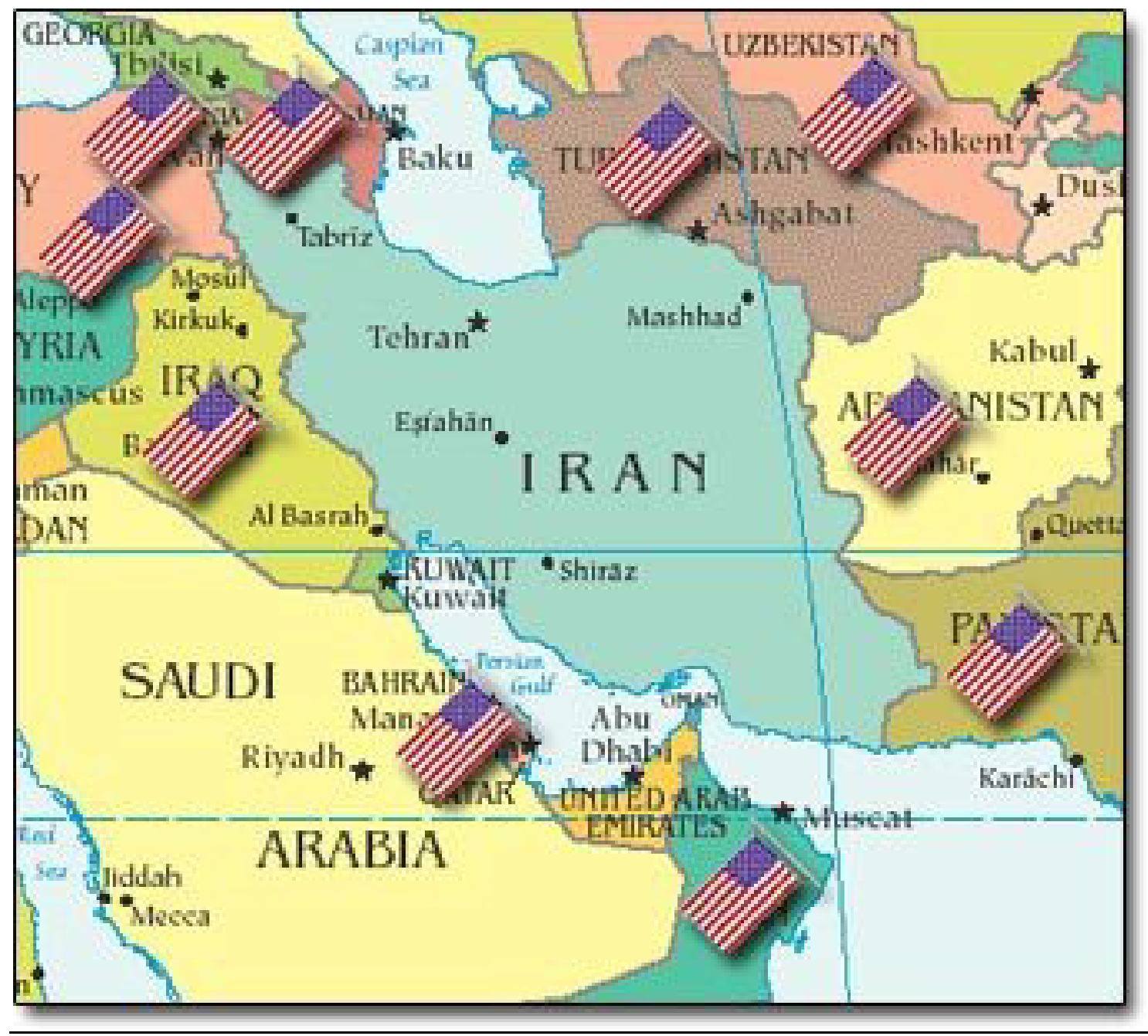

Source: Centre for Global Research on Globalization

Note that the U.S. has flanked Iran with military bases in Afghanistan and Pakistan from the west, Turkey, the Kurdistan and Iraq from the East, Kuwait, Qatar and the Arabic Peninsula from the south, and Georgia, Turkmenistan and Uzbekistan from the north. The Map also indicates that the distribution of American military bases in and around the Middle East coincides with the distribution of oil reserves in the region, as 
shown in Chart 2.1.

\section{Chart 2.1 - Largest Oil Reserves per Nation Relative to World's Oil Reserves}

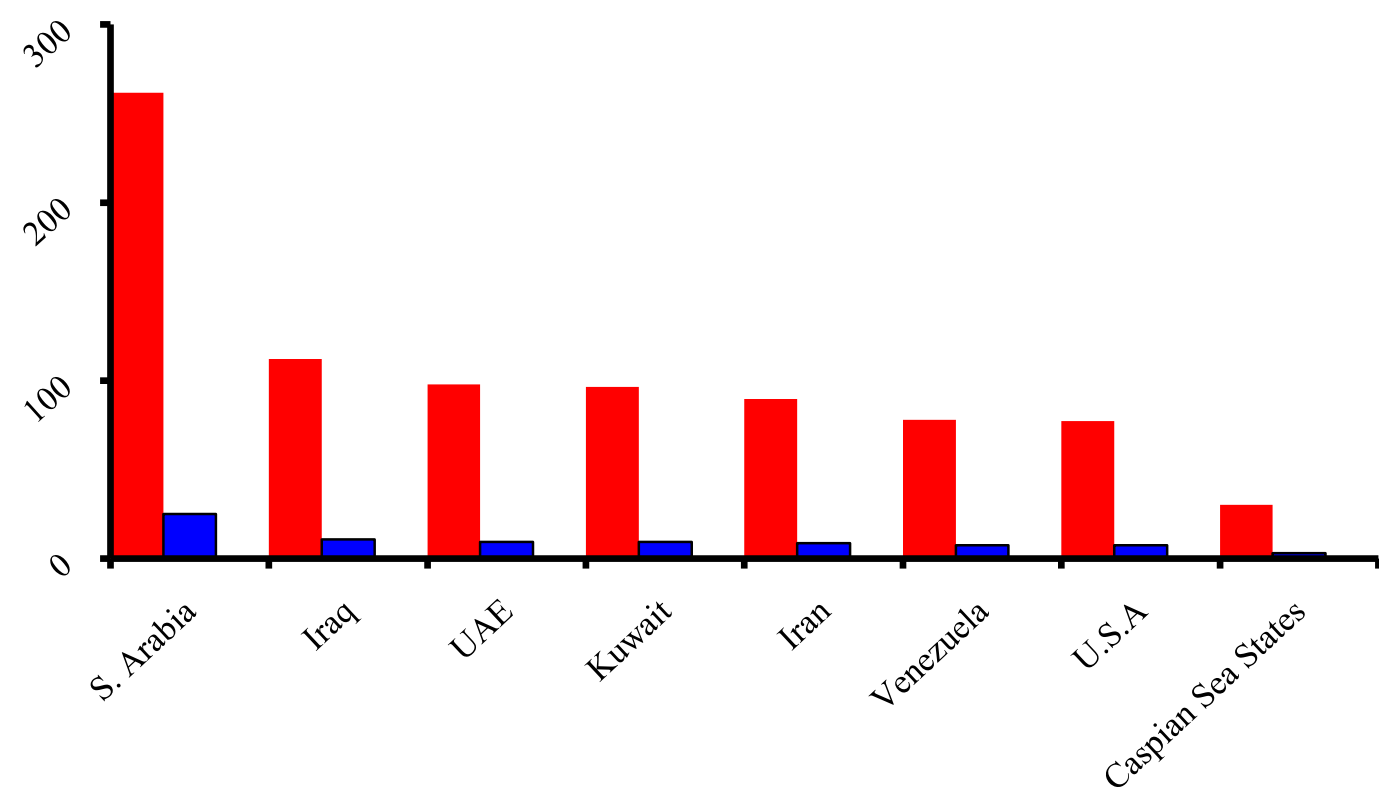

Source: "Blood and Oil" by Michael T. Klare

Chart 2.1 shows nations that hold the largest oil reserves in the world. The red bars indicate their proven oil reserves. The blue bars indicate the percentage of oil reserves they hold with respect to world total oil reserves. Red and blue bars use barrels of oil as their measure.

Chart 2.1 reveals that five Middle Eastern nations hold the largest oil reserves in the world, including Iraq and Iran. The U.S. ranks seventh and the Caspian Sea states ranks eighth. These states include Azerbaijan and Turkmenistan, which are chiefly 
important because: 1) they have borders with Iraq and Iran; 2) they have historically fell under the geopolitical interests of Russia, but the U.S. has manifested strategic interests in the region since the collapse of the Soviet Union; 3) the U.S. has established several military bases in Azerbaijan and Turkmenistan. Yet, the main observation here is the following: overall distribution of American military bases in the Middle East coincides with distribution of oil reserves in the region. The U.S. has military bases in the oil rich nations of South Arabia, the EAU, Kuwait, Iraq, and some of the Caspian Sea States. Not to mention that it is in the Gulf state of Bahrain where the U.S. houses its Fifth Fleet. The U.S. had accomplished two strategic goals by establishing military bases in the Middle East during the 1990s: a) it controls access to oil wells in the Middle East; 2) it had encircled Iran and Iraq.

Some scholars see the so called encirclement of Iran from two angles. One group argues that the American presence in the Middle East is to contain Iran. Another group speculates that the U.S. needs to control oil reserves in the region not for its own consumption but to beef up its hegemonic status.

Henry Kissinger, a balance of power Realist, leads the first approach. He proposes "A more plausible alternative explanation which would assign greater significance to the regional context and American actions in the Middle East" (Kissinger, p. 1). Kissinger refers to Iran and three events that lessened American influence in the region: the fall of the Shah, the invasion of the American Embassy in Iran in 1979, and Iran's nuclear ambitions. Yet, the U.S. led invasion of 1991 and the UN sanctions regime left Iraq too weak to counterbalance Iran. Kissinger implies that deposing Saddam Hussein was a geopolitical error because Iraq was the one nation in the region strong enough to deter 
Iran. Kenneth Pollack agrees with Kissinger when suggesting that once Saddam was removed, the balance of power shifted toward Iran and "Security problems in the Persian Gulf are likely to get more challenging instead of less" (Pollack, 2003, p. 27). Kissinger and Pollack argue that Iran's nuclear ambitions and continued threats to Israel legitimize the long term American presence in region. They see the U.S. as the balancing power in the region.

The second approach comes from the hegemony school. It states that the American attempts to control oil riches in the Middle East is not for the American own consumption but to beef up its power. There are three points here. First, the U.S. utilizes oil as a geopolitical tool in world politics. Second, the U.S. must secure the flow of oil for its allies in Europe and East Asia. Third, the U.S. must restrict Chinese and Russian access to Middle Eastern oil.

For instance, Joseph Gerson sees that "The American presence in the region has military and geostrategic objectives; the motive of oil is not meant for the U.S. market but rather as an instrument of power and control" (Gerson, 2007, p. 4). Klare adds that "By remaining the dominant power in these areas, the United States can achieve more than just the safety of its future oil supply; it can also exercise a degree of control over the energy supply of other oil-importing countries" (Klare, 2004, p. 150). For their part, Chalmers Johnson (2003) and Ikemberry (2006) support such a hegemony-based rationale as an analytic outline, only that they define it in malign-benign terms.

For Johnson, the U.S. is a malign empire still fighting the Cold War. He says that "What the U.S. wanted in Iraq was the deployment of some more permanent military bases there to prevent Russia from establishing a stronghold in the region. The fall of the 
Soviet Union did not mean the end of Russia as a world superpower. Russia's economic and political crisis of the 1990's was temporary; Russia would eventually rebound as a key geopolitical player" (Johnson, 2003, p. 24). Johnson, as well as Klare (2004) and Grossman (2002), points to the fact that by 1998 Russia was already rebuilding its military in the Caspian basin and Central Asia. In contrast to Johnson, Klare and Grossman, Ikemberry sees American hegemony as "Benevolent, institutionalized and infused with reciprocal processes of political interactions, quail-rule-based and open" (Ikemberry, 2006, p. 145). Europe and East Asia were "Attached to the exercise of American power in the 1940s when the U.S. sought to build an order that would avoid the return to the antagonist regional blocs of the 1930s" (Ikemberry, 2006, p. 152). Controlling those two blocs "Required the building of an elaborate system of forward bases in Asia and Europe" (Ikemberry, 2006, p. 152). It became part of the containment policy, which, as Robert Gilpin argues, was built on two pillars: "The American military and the American dollar" (Gilpin, 1981, p. 32). The U.S. provided security to Western Europe and East Asia and allowed them to prosper at the expense of huge trade and fiscal deficits.

Noam Chomsky sees it in a curious way. He states that "Since the 1940s we know that one of the best ways to control your enemies is by controlling their access to oil. The main enemies of the United States are in Western Europe and East Asia, the two world regions that could move toward economic and political independence; one of the best ways to prevent it is by controlling oil wells around the world" (Chomsky, 2005, p. 14).

Indeed, the European Union and East Asia are highly dependent on oil. To explain it, Nile Gardiner led a congressional commission sponsored by U.S. Congress 
and the Heritage Foundation in 2004. The study found, first, that the European Union was gravely reliant on foreign oil, especially from Russia. In fact, the EU is the world largest importer of oil and gas. It imports $82 \%$ of oil and $57 \%$ of gas and expects to increase them in $93 \%$ and $84 \%$ respectively in the next 25 years (Gardiner Commission, 2004, p. 61). The EU imports $25 \%$ of oil and $25 \%$ of gas from Russia (Gardiner Commission, 2004, p. 61). In contrast, Russia holds $27 \%$ of the world's oil and gas reserves. Gazprom, a Russian state owned-company, owns $25 \%$ of the world's gas reserves and produces $16 \%$ of the global output, just behind Saudi Arabia and Iran, and ahead of Iraq and Kuwait; Gazprom produces $94 \%$ of Russia's gas and $60 \%$ of Russia's oil. Russia exports 7 million barrels daily, of which $85 \%$ goes to the EU through Ukraine and Belarus' pipelines (Gardiner Commission, 2004, p. 63).

This dependency on Russian oil goes back to the 1980s when, at the peak of the Cold War, Europe and the former Soviet Union saw in oil and gas supplies a means to cooperation and constructive politics. Western Europe financed and provided the technology to build the pipes while the Soviet Union carried on the construction and guaranteed steady supplies. Cooperation continued and consolidated during the 1990s, and by 2003 Europe found itself highly dependent on Russian's oil and gas supplies. During the Ukraine-Russian political crisis of the 2005, Russia threatened the EU with cutting off oil and gas supplies if it sided with Ukraine. Russian oil and gas pipes cross through Ukraine toward Europe, and Russia could either raise the price of deliveries of just cut them off completely. After it, as the price of energy rose, President Putin began to use oil and gas as a political instrument against the EU, just what the U.S. had been trying to prevent. 
East Asia presents serious issues as well. First, there are unsettled disputes in the region. There are disputes between North and South Korea, China and Taiwan, China and Vietnam, China and Japan, Japan, South and North Korea, and between Japan and Russia, just to mention a few. Also, we should not ignore the unsolved nuclear issue between the U.S. and North Korea, which threatens American allies and makes the entire region more volatile. Second, East Asia has a population of 1.5 billion. It is $40 \%$ of the Asian population and a quarter of the world (Gardiner Commission, 2004, p. 127). In terms of economics, East Asia constitutes the fastest growing economy in the world. In 2006 , it had a combined GDP of $\$ 8,433,888$ million dollars, the third largest in the world just after the EU and U.S. (Gardiner Commission, 2004, p. 127). East Asia has a cheap well-trained labor force and a high-tech approach to productivity, making it a very attractive market for the European and American firms. Third, East Asia confronts a major energy dilemma: it depends on foreign oil for $90 \%$ of its energy needs. China and Japan are now the second and third largest oil importers in the world, but the economies of South Korea, Taiwan, Hong Kong and Singapore rank 12th, 22nd, 36th and $44^{\text {th }}$, which, along with the economies of Indonesia and Thailand, are among the strongest in the world (Gardiner Commission, 2004, p. 134). They all have taken regional oil demands to new historic highs. This is essential since East Asia has two main sources of oil: Russia and the Middle East. According to Ji Guoxing, of the Shanghai Institute of International Strategy Studies, "The Asia-Pacific region's dependency on Middle Eastern oil may exceed $90 \%$ by 2010, and while oil fields in Russian Siberia and Central Asia do offer some short-term energy relief, the lack of existing infrastructure to facilitate the 
transport of this oil poses costly political and economic challenges" (Guoxing, 2005, p.4).

The issue is that American control over Middle East's oil makes the East Asian Bloc dependent not only on foreign oil but also on American dollar. Five nations form this bloc: Japan, South Korea, Taiwan, Singapore and Hong Kong. The bloc has close economic, military and geopolitical relations with the U.S. It, along with China, pays for their oil imports with American dollars and Treasury securities, de facto financing the American federal deficit. It is more problematic as the value of the Nikkei and other East Asian currencies increase while the American dollar weakens. Chart 2.2 shows the amount of American currencies held by East Asia Bloc.

\section{Chart 2.2 - American Currency Held by Nations of East Asia Bloc}

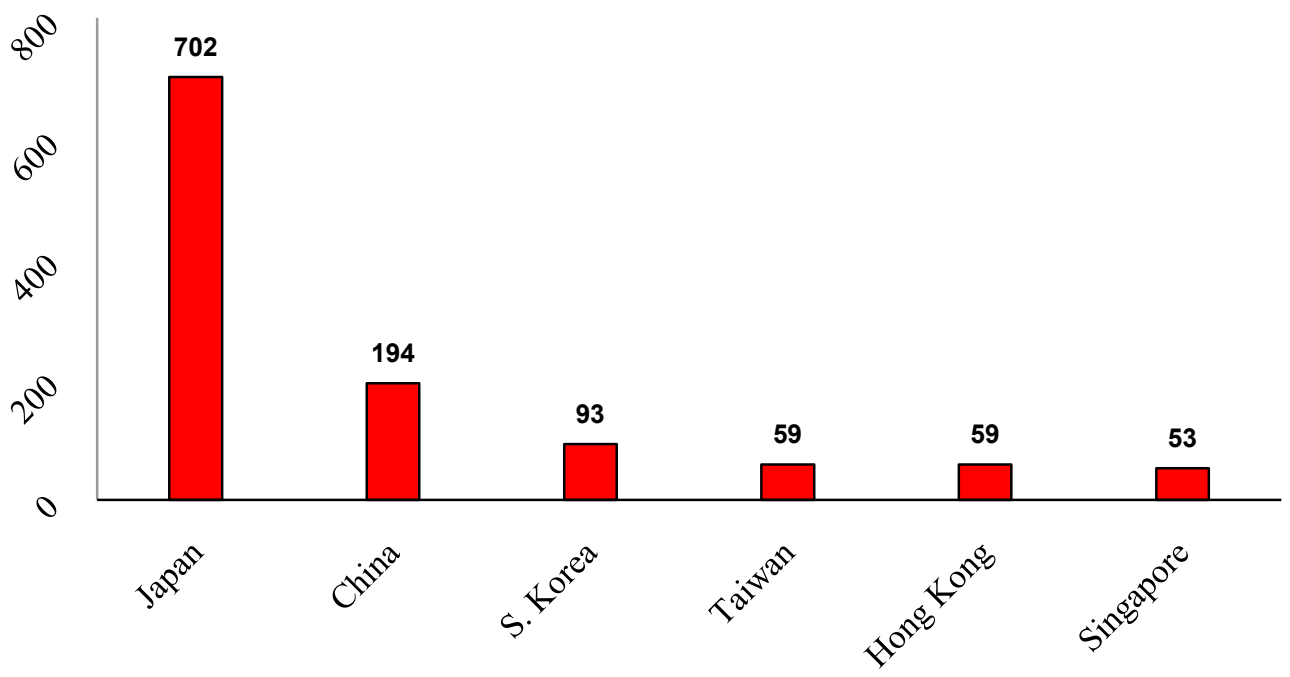

Source: U.S. Department of Treasury, 2003

According to the Chart, in 2003 those six nations alone held \$1,163 billion dollars in American securities. Japan led the group, but China had already surpassed South 
Korea and Taiwan, two key American allies. On the other hand, the rest of the world held $\$ 1,960$ billion. Comparatively, it held less than the East Asia Bloc, revealing the influence that the East Asia Bloc has for the American economy. The East Asia bloc must prevent the U.S. from defaulting. Otherwise, it will collapse, jeopardizing the political stability of the region. In fact, it is in that sense that we should interpret China's approach to its currency and investments in oil fields around the world, in Africa in particular (Klare, 2004, p. 161-169). Oil has become a matter of national security for China, which must secure the flow of it into its voracious economy. China must secure access to global oil wells if it is to become independent in terms of oil consumption. It must secure access to global oil wells if it is to challenge American hegemony over Asia's economy and politics.

\section{France, Russia and China}

The fall of the Soviet Union meant the end of the bipolar world and the beginning of American hegemony over world politics. The two events raised key questions related to global politics. For example, how do other world powers counterbalance American hegemony? Could France, Russia and China challenge it in the Middle East? In Iraq, why did the U.K. side with the U.S. while France, Russia and China did not?

Klare explains it through the context of oil. He argues that "The United States, France, Russia China are competing for the energy riches of these areas" (Klare, 2004, p. 147). Some events on the ground seem to confirm it. For example, in September 2007, France announced the opening of a branch of its Saint Cyr Military Academy to train Qatari army officers (The New York Times, March $6^{\text {th }}$, 2006). In March, 2008, France 
declared that it was establishing a permanent military base in UAE with about 500 military troops stationed there permanently (New York Times, March $\left.6^{\text {th }}, 2008\right)$. It was the first Western, non-American military base established in the region since the British gave up its military presence there in 1971. France has also been conducting military exercises in the Persian Gulf since 1995 when it signed a defense agreement with UAE. Among other things, the agreement called for conducting 25 simulated maneuvers per year and engaging in at least one actual military maneuver every two years. Actual maneuverings were conducted in $1996,2000,2005$, and 2008. They have consistently been expanded to the point that in 2008, 4000 French troops took part and Qatari soldiers were invited (New York Times, March $\left.6^{\text {th }}, 2008\right)$. The maneuvers always take place at UAE's western region, near the Saudi border and the Persian Gulf where $40 \%$ of the world's oil is shipped (New York Times, March, $\left.6^{\text {th }}, 2008\right)$. Also, France is a leading military supplier to the UAE, Qatar, Arab Saudi and other nations in the region. France's arm sales to Middle East nations amount to $\$ 20$ billion dollars annually (New York Times, March, $\left.6^{\text {th }}, 2008\right)$. France also signed a deal to develop peaceful nuclear energy with UAE, Qatar and other Arab nations. With respect to Iraq, France challenged the U.S. by pulling out from the enforcement of the two-no fly-zones over Iraq, opposing "smart sanctions" in the UN, and opposing the invasion to Iraq in 2003. Even under the UN sanctions regime, France negotiated oil deals with Iraq such as the Majnoon and Nahr Umar oil field projects. The fields hold $25 \%$ of Iraqi oil reserves, nearly 26 billion barrels and $\$ 650$ billion dollars in revenues to France (New York Times, March $6^{\text {th }}, 2008$ ).

Like France, Russia had challenged the sanctions regime that the U.S. proposed against Iraq in the UN. Despite the sanctions regime, Russia signed a 23-year contract in 
1997 to revitalize the 15 billion barrel oil field of West Quarna (www.iraqiwatch.com). This oil field holds the comparable of all proven oil reserves of Exxon-Mobil, the largest oil company in the world. In 1997 too, Gazprom, a state-owned Russian conglomerate, signed a contract for $\$ 18$ million dollars to repair gas stations in Iraq. In 1998 , the Russian-Belarus conglomerate Salvneft negotiated a \$52 million dollar contract to drill at Tuba oil field in Southern Iraq (www.iraqiwatch.com). In 2000, Russian companies Zaruezhneft and Tatneft obtained contracts to drill Saddam, Kirkuk and Bai Hassan oil fields. The deal was for $\$ 13.2$ million, not much, but it had a collateral contract for $\$ 900$ million to explore for new oil wells in Iraq (www.iraqiwatch.com). If oil was found, the two companies would exercise full ownership for 10 years. The contract included: 1) 67 new oil-related projects in southern Iraq and its Western Desert, including Suba, Luhais, West Qurna, and Rumaila; 2) reconstruction of the pipeline that runs from southern to northern Iraq; 3) drilling gas wells throughout Iraq. Curiously, the U.S. cancelled all those contracts in June 2007, alleging that they violated the UN sanctions regime against Iraq (New York Times, April $8^{\text {th }}$, 2007).

China is, as Klare $(2004,2006)$ states, already a rising world superpower and a new actor in the Middle East. Its voracious demand for oil has pushed it into world economics and politics with resources committed to it only comparable to the American's. China has successfully invested in nations such as Kuwait, Egypt, Yemen and Saudi Arabia, not to mention Latin America, traditional "partners" of the U.S. In keeping with its increasing involvement in "conflict zones" for oil, China ranked second in oil purchases and exports to Iraq under the UN sanctions regime. In terms of arms sales, China has consistently increased its exports to the region. According to IraqiWatch, 
from 1995 to 2002, China sold \$1.6 billion in arms, and by 2006, China had sold \$27 billion, including war planes and missile technologies. Some of them had American technologies (www.iraqiwatch.com).

In contrast, the American and British's oil shares in Iraq were not as solid as France, Russia and China's. American and British oil companies dominated three-quarter of the Iraqi oil production until 1972, when Iraq nationalized its oil industry. But the U.S and U.K. were forced out while the French and Russians managed to stay in. American companies did not sign any oil contract with Iraq until 2003, and Iraq was only the sixth largest oil provider to the U.S. from 1980 to 1990 (www.iraqiwatch.com). Likewise, the U.K. did not sign any oil contract with Iraq from 1972 on, but it did obtain Iraqi oil through investments made in oil traders or subcontractors which, from 1972 to 1991 , represented $7.4 \%$ British oil purchases. U.K.'s commitment to have a presence in the Middle East sharply increased during the 1990s (www.iraqiwatch.com).

In all, the historical evidence suggests that there is a contradiction between globalization and demand for access to oil, securitization of oil by world superpowers, and enforcement of the UN sanctions against Iraq. The contradiction led to geopolitical conflicts among world powers. It led them to intervene in oil rich nations, in the Middle East in particular. Their acts still resonate in world politics. The UN sanctions regime upon Iraq illustrates it.

\section{The Iraqi Response}

Securitization almost always has political consequences across regional and global levels. When a nation-state securitizes an issue, it is basically sending a message to 
neighboring nations. Securitization constitutes a shift in terms of policy for it alters the balance of power among neighboring nation-states (Buzan, Waver \& Wilded, 1998, p. 27). For Realists like Carr (1939) and Kissinger (1957), it is the typical security dilemma, in which security actions in one nation constitute existential threats to others. Hence, we can argue that the securitization of the oil industry in oil rich nations created security concern in nations of high oil consumption, which in turn securitized access to oil and their relations with oil rich nations.

The sectorization and securitization of Iraqi oil began in 1970 when Iraq nationalized its oil industry. This was done in the name of Iraq's sovereignty, its right to self-determination, and its will to control its national resources. It was a bold move to end almost 60 years of Western control over Iraqi oil, which often translated into corruption, abuses, and political control over Iraqi political institutions and processes. Iraq expelled all foreign companies from Iraqi soil. It then established criteria to grant oil contracts based on Iraq's priorities, arguably its national interests. Under the new regime, Iraq granted most contracts to Soviet and French companies since the Soviet Union and France were the main economic partners to Iraq at the time. Conversely, Iraq denied any participation to American and British oil Firms. There were some contacts between Iraq's Oil Ministry and American companies at some point during the Iraq-Iran War, but for the most part American and British companies were forced out of Iraq's oil riches.

Sectorization and securitization of Iraqi oil took a new meaning with the UN sanctions regime for it presented a direct threat to Iraq's national security. Saddam argued that "The UN sanctions regime undermined the sovereignty and security of Iraq" (Meyer \& Califano, 2006, p. VIII). The CIA agreed by stating that "UN sanctions hindered his 
ability to rule Iraq with complete authority and autonomy. In the long run, the UN sanctions also interfered with his efforts to establish a historic legacy. According to Saddam and his senior advisors, the UN, at the behest of the US, placed an economic strangle hold on Iraq. The UN controlled Saddam's main source of revenue (oil exports) and determined what Iraq could import" (Dulfer Report, Regime \& Finance, p. 3).

In turn, the Heritage Foundation affirmed that "Saddam considered UN sanctions as a form of economic war and the UN's OFF program and Northern and Southern Watch Operations as campaigns of that larger economic war orchestrated by the US and UK” (Heritage Foundation, Report On Iraq, 2005, p. 61). In fact, we should not ignore that UN sanctions included: a) occupation of northern and southern Iraq by American and British armed forces; b) autonomy for Kurds, de facto fragmenting and debilitating Iraq's territorial integrity; c) two no-fly-zones over Iraqi skies; d) the presence of UN's inspectors on Iraqi soil; e) control over Iraqi ports, roads and borders to inspect the Iraqi import-exports operations. I must add a dozen military bases that the U.S. had around Iraq, which made of Iraq a besieged nation. All those measures constituted direct security concerns to Iraq. They all threatened Iraq as a nation-state.

Still, Iraq did not limit its security concerns to the UN sanctions regime and "Western threats." Iraq feared others. And I am not talking about Israel, which for many Muslims and Arabs it is just another American military base in the region. Rather, I am talking about Iran, Iraq's strong neighbor to the East and archenemy. In that regard, the CIA found that "Saddam aspired to develop a nuclear capability —in an incremental fashion, irrespective of international pressure and the resulting economic risks-but he intended to focus on ballistic missile and tactical chemical warfare (CW) capabilities. 
Iran was the pre-eminent motivator of this policy. All senior level Iraqi officials considered Iran to be Iraq's principal enemy in the region. The wish to balance Israel and acquire status and influence in the Arab world were also in considerations, but secondary” (Dulfer Report, Regime Strategic Intent, p. 1). The FBI confirmed Saddam's concerns about Iran in a report published in The New York Times. The FBI reported that "In a series of interrogations before his execution, Saddam Hussein told a F.B.I agent that, on the eve of the 2003 American invasion, Iraq was trapped between United Nations' orders to demonstrate that it had disarmed and a fear that appearing too weak would invite attacks from its powerful neighbor and foe, Iran" (New York Times, July $3^{\text {rd }}$, 2009). Saddam went on to reveal that "He was more concerned about Iran discovering Iraq's weaknesses and vulnerabilities than the repercussions in the United States for his refusal to allow UN inspectors back into Iraq" (New York Times, July $3^{\text {rd }}$, 2009). Saddam thought that "UN inspectors would have directly identified to the Iranians where to inflict maximum damage to Iraq" (New York Times, July $3^{\text {rd }}$, 2009).

For those reasons, the UN sanctions regime posited a security concern to Iraq, a threat that required urgent security measures. Iraq's response was the securitization of oil to new levels. Oil was Iraq's main commodity for "Oil accounted for more than $60 \%$ of the country's GDP and 95\% of foreign currency earnings" (Dulfer Report, Regime \& Finance Procurement, Sources of Revenues, Annex D, p. 3). Given the high global demand for oil, it became Iraq's main weapon. Oil became a means to circumvent the UN sanctions regime. Oil and evading the UN sanctions regime became a national security measure of high priority for the Iraqi state. 
Indeed, the CIA, the IIC and the Michigan Project found that Iraq securitized the sanctions regime. The CIA stated that "Saddam's primary goal from 1991 to 2003 was to have UN sanctions lifted while maintaining the security of the Regime. He sought to balance the need to cooperate with UN inspections - to gain support for lifting sanctions" (Dulfer Report, Regime Strategic Intent, p. 1). For its part, the IIC confirmed that "Throughout the Sanctions, Saddam continually directed his advisors to formulate and implement strategies, policies, and methods to terminate the UN's sanctions regime established by UNSCR 661. The Regime devised an effective diplomatic and economic strategy of generating revenues and procuring illicit goods utilizing the Iraqi intelligence, banking, industrial, and military apparatus that eroded United Nations' member states and other international players' resolve to enforce compliance, while capitalizing politically on its humanitarian crisis" (IIC, p. 227). And the Michigan Project noted that "Saddam's security measures included unhinging the UN's sanctions against Iraq, centered on Saddam's efforts to influence certain UN permanent member of SC such as Russia, France, and China and some nonpermanent (Syria, Ukraine) members to end UN sanctions. Under Saddam's orders, the Ministry of Foreign Affairs (MFA) formulated and implemented a strategy aimed at these UNSC members and public opinion with the purpose of ending UN sanctions and undermining its subsequent OFF program by diplomatic and economic means" (www.iraqiwatch.com).

Those findings corroborate my argument here, that Iraq sectorized and securitized its oil industry as a reaction to the UN sanctions regime to strengthen its national security and to guarantee the survival of the Iraqi state. Nonetheless, several events gave Iraq some comparative advantage in that sense: Iraq had enough oil reserves to meet global 
demand for oil. First, there was an intense, growing global demand for oil during the 1990s as result of intense global economic growth. On one hand, Western industrial economies, the U.S. in particular, demanded more oil to satisfy their high oil consumption and dependency on foreign oil. On the other hand, there was China, India, South Africa and other "emergent" nations, which demanded more oil to sustain their intense economic activities. Most of them turned to the Middle East as a potential supplier of oil. The second event was the collapse of the oil industry in former Soviet Republics, on which European economies depended for oil and gas. Declining oil exports from ex Soviet Republics meant that European nations had to seek new suppliers. They too turned to the Middle East, intensifying competition in the region, and competition among nation-states usually carries a great deal of political confrontation. But what is relevant here is that those events increased the demand of oil across the world, especially from the Middle East. It guaranteed some sound business opportunities for Iraq.

In all, new trends in global supply-demand for oil represented a sound source of revenues for Iraq and its regime. The globalization process of the 1990s constituted, among other things, intensification of global trade resulting from rapid economic growth in numerous nations. Oil was a key commodity, and access to oil supplies a prerequisite for economic growth and political instability. Therefore, global demand for oil opened the doors for the Iraqi oil industry. It allowed Iraq to sustain its economic, military and political infrastructures to acceptable levels. And here "acceptable" refers to Iraq's image as a sovereign, independent, strong, aggressive nation-state, a leader in the Arab world. It was the image that Saddam Hussein wanted to expose to the rest of the world in order to straighten Iraq's national security. As Buzan states, "We should not ignore that, when it 
comes to securitization, image is crucial" (Buzan, Waver, and Wilded, 1998, p. 32). It is vital how nation-states see a particular nation in terms of vulnerabilities and capabilities. The CIA argued that "Throughout the 1990s and up to March 2003, Saddam focused on one set of objectives: the survival of himself, his Regime, and his legacy. To secure those objectives, Saddam needed to exploit Iraqi oil assets, to portray a strong military capability to deter internal and external threats, and to foster his image as an Arab leader" (Duelfer Report, Regime Finance and Procurement, p. 3).

It is worth noting that image is limited by reality and perception by facts. For despite all Iraqi oil, Iraq suffered the crushing impact of the UN sanctions, to the point that it almost collapsed, mainly during the first 3 years of the sanctions. Yes, oil allowed Iraq to boost its image as Iran's strong counterbalance and America's challenger. Both oil and image allowed Saddam to prolong his regime for a few more years. The U.S. led invasion proved that Iraq was a weak nation, and its regime was in decay.

\section{$\underline{\text { How Iraq Circumvented Sanctions }}$}

In this section, I present evidences of how both global demands for oil and securitization of global access to oil were important factors that motivated the circumvention of the UN sanctions regime by Iraq. Explicitly, I explore how nations reached Iraqi oil wells and how Iraq reached global markets. I also study economic factors such as GDP relative to oil purchases and oil consumption per nation. I discuss traditional trade relations, geopolitics, and how politics among the members of the UN Security Council affected the sanctions. But first I present Table 2.1, which summarizes Iraq's total oil sales under UN sanctions. The Table has three blocks, each with three 
columns. In Block I, column I shows nation-states that purchased oil from Iraq under the UN sanctions. Column II contains the number of contracts that those nations received from Iraq. Column III includes percentages of number of contracts received. Block I is sorted by number of contracts. In Block II, Column I includes nation-states that purchased oil from Iraq under the sanctions regime. Column II represents the number of oil barrels those nations actually lifted, and Column III shows the percentages of oil barrels lifted per nations with respect to total oil sales per nation as well. Block II is sorted by number of barrels of oil lifted. For its part, Block III reproduces the total value of contracts that nation-states received from Iraq. The contracts are represented in US dollars. Column I tally all nation-states that obtained contracts from the Iraq. Column II shows the value of all contracts obtained. Column III accounts for percentages of oil sales per nation with respect to total Iraq's oil sale.

$\underline{\text { Table } 2.1 \text { - Iraqi Oil Sales }}$

\begin{tabular}{|c|c|c|c|c|c|c|c|c|}
\hline & Block I & & & Block II & & & Block III & \\
\hline \multirow[t]{2}{*}{ Countries } & \# of & $\%$ of & Countries & barrels & $\%$ of barrels & countries & Barrels & $\%$ barrels \\
\hline & Contracts & contracts & & lifted & lifted & & lifted & lifted \\
\hline Russia & 244 & 21.57 & Russia & $1,011,356,506$ & 29.70 & Russia & $19,300,618,432$ & 30.70 \\
\hline France & 69 & 6.10 & France & $252,001,935$ & 7.40 & France & $4,248,213,159$ & 6.62 \\
\hline Switzerland & 62 & 5.48 & Turkey & $182,814,102$ & 5.37 & Switzerland & $3,434,083,024$ & 5.35 \\
\hline Italy & 58 & 5.13 & UK & $170,559,574$ & 5.01 & UK & $3,350,739,850$ & 5.22 \\
\hline Turkey & 55 & 4.86 & Switzerland & $165,115,918$ & 4.85 & Turkey & $3,343,252,936$ & 5.21 \\
\hline UEA & 40 & 3.54 & Italy & $143,777,071$ & 4.22 & Italy & $2,718,083,135$ & 4.23 \\
\hline Spain & 38 & 3.36 & China & $127,991,479$ & 3.76 & China & $2,624,806,812$ & 4.09 \\
\hline UK & 38 & 3.60 & Liechtenstein & $120,025,880$ & 3.32 & Liechtenstein & $2,467,770,768$ & 3.84 \\
\hline China & 35 & 9.00 & Spain & $87,723,077$ & 2.58 & Spain & $1,643,749,098$ & 2.56 \\
\hline Syria & 32 & 2.83 & Malaysia & $73,558,738$ & 2.16 & Malaysia & $1,485,199,149$ & 2.31 \\
\hline Jordan & 28 & 2.48 & UEA & $71,215,261$ & 2.09 & Vietnam & $1,405,961,742$ & 2.19 \\
\hline Pakistan & 22 & 1.95 & Vietnam & $68,901,134$ & 2.02 & UEA & $1,371,407,184$ & 2.14 \\
\hline Ukraine & 22 & 1.95 & Argelia & $62,155,862$ & 1.83 & Syria & $1,134,317,406$ & 1.77 \\
\hline Liechtenstein & 20 & 1.77 & Monaco & $54,734,724$ & 1.61 & Argelia & $1,109,337,575$ & 1.73 \\
\hline
\end{tabular}




\begin{tabular}{|c|c|c|c|c|c|c|c|c|}
\hline Panama & 20 & 1.77 & Syria & $52,981,902$ & 1.56 & Cyprus & $1,048,437,558$ & 1.63 \\
\hline Cyprus & 19 & 1.68 & Cyprus & $50,959,316$ & 1.50 & India & $872,678,344$ & 1.36 \\
\hline Malaysia & 18 & 1.59 & Aruba & $47,888,047$ & 1.41 & Morocco & $742,838,933$ & 1.16 \\
\hline Vietnam & 18 & 1.59 & India & $45,415,198$ & 1.33 & Jordan & $735,728,580$ & 1.15 \\
\hline United States & 15 & 1.33 & Morocco & $42,392,022$ & 1.24 & Aruba & $713,492,385$ & 1.11 \\
\hline Belarus & 14 & 1.24 & Jordan & $35,351,738$ & 1.04 & Panama & $703,170,873$ & 1.10 \\
\hline South Africa & 14 & 1.24 & Netherlands & $34,180,002$ & 1.00 & Belarus & $613,877,735$ & 0.96 \\
\hline Argelia & 12 & 1.06 & Panama & $32,424,699$ & 0.95 & Ukraine & $538,411,832$ & 0.84 \\
\hline Austria & 12 & 1.06 & United States & $29,675,585$ & 0.87 & Netherlands & $532,184,460$ & 0.83 \\
\hline Egypt & 12 & 1.06 & Bulgaria & $29,178,829$ & 0.86 & Egypt & $506,657,165$ & 0.79 \\
\hline India & 12 & 1.06 & Belarus & $28,289,438$ & 0.83 & Pakistan & $490,181,751$ & 0.76 \\
\hline Indonesia & 12 & 1.06 & Ukraine & $26,264,430$ & 0.77 & United States & $482,825,657$ & 0.75 \\
\hline Morocco & 12 & 1.06 & Egypt & $24,189,974$ & 0.71 & South Africa & $397,692,624$ & 0.62 \\
\hline Lebanon & 11 & 0.97 & Pakistan & $23,503,987$ & 0.69 & British Islands & $394,853,212$ & 0.62 \\
\hline Yemen & 11 & 0.97 & British Islands & $22,284,374$ & 0.65 & Greece & $347,836,069$ & 0.54 \\
\hline Greece & 10 & 0.88 & Hong Kong & $21,513,207$ & 0.63 & Bulgaria & $333,739,464$ & 0.52 \\
\hline Nigeria & 10 & 0.88 & South Africa & $17,569,792$ & 0.52 & Thailand & $330,192,170$ & 0.51 \\
\hline Qatar & 10 & 0.88 & Austria & $16,840,773$ & 0.49 & Belgium & $301,953,188$ & 0.47 \\
\hline Thailand & 10 & 0.88 & Greece & $16,161,428$ & 0.47 & Austria & $262,883,339$ & 0.41 \\
\hline Tunisia & 10 & 0.88 & Belgium & $15,713,607$ & 0.46 & Singapore & $262,123,492$ & 0.41 \\
\hline Aruba & 8 & 0.71 & Singapore & $13,548,632$ & 0.40 & Indonesia & $255,138,745$ & 0.40 \\
\hline Netherlands & 8 & 0.71 & Thailand & $13,319,531$ & 0.39 & Yemen & $251,116,047$ & 0.39 \\
\hline Bulgaria & 7 & 0.62 & Indonesia & $13,266,555$ & 0.39 & Bermuda & $247,261,893$ & 0.39 \\
\hline Kenya & 7 & 0.62 & Yemen & $11,917,999$ & 0.35 & Lebanon & $241,763,377$ & 0.38 \\
\hline Other nations & 7 & 0.62 & Other nations & $11,830,982$ & 0.35 & Hong Kong & $227,838,241$ & 0.35 \\
\hline Belgium & 6 & 0.53 & Lebanon & $10,752,535$ & 0.32 & Cayman Island & $207,859,782$ & 0.32 \\
\hline Canada & 6 & 0.53 & Bermuda & $10,218,507$ & 0.30 & Other nations & $197,127,047$ & 0.31 \\
\hline Hong Kong & 6 & 0.53 & Qatar & $8,390,797$ & 0.25 & Tunisia & $180,361,361$ & 0.28 \\
\hline Oman & 6 & 0.53 & Cayman Island & $8,104,258$ & 0.24 & Nigeria & $179,040,409$ & 0.28 \\
\hline Namibia & 4 & 0.35 & Kenya & $8,016,945$ & 0.24 & Sudan & $173,784,987$ & 0.27 \\
\hline Singapore & 4 & 0.35 & Namibia & $7,975,587$ & 0.23 & Qatar & $161,646,541$ & 0.25 \\
\hline Ireland & 3 & 0.27 & Sudan & $7,812,818$ & 0.23 & Oman & $149,377,008$ & 0.23 \\
\hline Japan & 3 & 0.27 & Nigeria & $7,394,498$ & 0.22 & Romania & $138,376,912$ & 0.22 \\
\hline Romania & 3 & 0.27 & Tunisia & $7,170,739$ & 0.21 & Brazil & $137,860,626$ & 0.21 \\
\hline Sudan & 3 & 0.27 & Canada & $6,589,991$ & 0.19 & Namibia & $132,363,487$ & 0.21 \\
\hline Bahamas & 2 & 0.18 & Oman & $6,104,617$ & 0.18 & Kenya & $123,891,238$ & 0.19 \\
\hline Bermuda & 2 & 0.18 & Romania & $6,023,119$ & 0.18 & Finland & $107,331,748$ & 0.17 \\
\hline Cayman Islan & 2 & 0.18 & Bahamas & $5,673,263$ & 0.17 & Japan & $105,587,299$ & 0.16 \\
\hline Finland & 2 & 0.18 & Japan & $5,518,277$ & 0.16 & Venezuela & $103,313,147$ & 0.16 \\
\hline Germany & 2 & 0.18 & Ireland & $4,925,580$ & 0.14 & Bahamas & $102,326,624$ & 0.16 \\
\hline Portugal & 2 & 0.18 & Finland & $4,426,915$ & 0.13 & Ireland & $92,406,127$ & 0.14 \\
\hline Slovakia & 2 & 0.18 & Venezuela & $4,005,435$ & 0.12 & Canada & $78,252,230$ & 0.12 \\
\hline Venezuela & 2 & 0.18 & Gambia & $3,967,591$ & 0.12 & Gambia & $72,112,479$ & 0.11 \\
\hline Yugoslavia & 2 & 0.18 & Slovakia & $2,832,863$ & 0.08 & Monaco & $54,734,724$ & 0.09 \\
\hline Brazil & 1 & 0.09 & Portugal & $2,815,877$ & 0.08 & Denmark & $52,933,910$ & 0.08 \\
\hline British Islands & 1 & 0.09 & Denmark & $2,257,853$ & 0.07 & Portugal & $34,118,051$ & 0.05 \\
\hline Denmark & 1 & 0.09 & Germany & $1,890,657$ & 0.06 & Germany & $33,288,119$ & 0.05 \\
\hline Gambia & 1 & 0.09 & Hungary & 999,529 & 0.03 & Slovakia & $30,544,942$ & 0.05 \\
\hline Hungary & 1 & 0.09 & Yugoslavia & 990,745 & 0.03 & Philippines & $27,858,288$ & 0.04 \\
\hline Monaco & 1 & 0.09 & Philippines & 982,692 & 0.03 & Hungary & $17,476,765$ & 0.03 \\
\hline Philippines & 1 & 0.09 & Brazil & 717,374 & 0.02 & Yugoslavia & $17,102,041$ & 0.03 \\
\hline Total & 1,131 & 100.00 & Total & $3,405,152,370$ & 100.00 & Total & $64,183,493,296$ & 100.00 \\
\hline
\end{tabular}

\section{Source: IIC and FMI}


I draw several conclusions from Table 2.1. First, 64 nations purchased Iraqi oil under the UN sanctions regime. If we consider that they were rich and poor nations, oil exporters and importers, of large and small populations, and of all sorts of political and economic systems, then we can say that UN sanctions had a global, multilateral character. But the UN has 192 members, so 64 accounts for just $33.3 \%$ of UN's membership (www.un.org). It is way below 50\%. Thus, I argue that the sanctions regime was not so multinational in terms of participation by nation. Second, Bloc I shows the number of contracts obtained per nation. Iraq granted a total of 1,131 oil contracts under the UN sanctions regime. By comparing Blocs I and II, we see that large numbers of oil contracts did not always translate into large numbers of oil barrels lifted. It was so because oil contracts varied in terms of amounts of oil barrels. So in Bloc I, Switzerland ranked third in terms of number of contracts obtained, above Turkey and U.K., but in Bloc II Switzerland ranked fifth, right behind Turkey and U.K. Although Switzerland obtained more contracts than Turkey and U.K., it actually lifted less oil barrels than the other two nations. The same discrepancies arise in Bloc III. In Bloc II, the UEA obtained more oil barrels than Vietnam, but in Bloc III Vietnam surpassed the UEA, profiting more from the total value of its contracts. The same occurred with Switzerland, Turkey and other nations. In Bloc II, Switzerland obtained fewer contracts than Turkey, but in Bloc III it outperformed Turkey for its contracts had more value in terms of US dollars.

Also, demand for oil per nation did not justify their oil purchases. If not, then how to explain that, as Bloc I shows, rich industrial nations, highly dependent on oil imports, purchased less oil than nonindustrial, smaller nations? Bloc I shows that the U.S., Japan and Germany, the most industrialized nations in the world, purchased less oil than Syria, 
Jordan, Panama, and Cyprus. And in Bloc II nonindustrial nations like Liechtenstein, Panama, Cyprus, Monaco and Aruba lifted more oil barrels than the U.S., Germany, and Japan! Similarly, in Bloc III, Russia, France and Switzerland ranked first, second and third respectively while the U.S. fell to the $19^{\text {th }}$ position, far behind Syria, Algeria, Vietnam and Morocco. The case of Russia is notable. Russia ranked first in all Blocs; yet, its GDP is smaller than the GDP of the U.S., UK, and France. Russia is the $7^{\text {th }}$ largest oil producer in the world. Russia holds $7.4 \%$ of the world's oil reserves, which means that it does not need to import oil, not the quantities it imported under the UN sanctions regime. Besides, Russia was under an economic crisis during the period I analyze, so its oil consumption dropped to a 0.84 GDP-oil consumption rate. That is, Russia required 0.84 barrel of oil to produce $\$ 1000$ dollars of its GDP while the U.S. and UK produced $\$ 1000$ with 1.65 and 3.75 barrels of oil daily during the same period (www.energy.gov).

Why using GDP as a comparative measure? There are two main ways to measure oil consumption per nation: population and GDP. The measure by population assumes that large populations consume more energy than smaller ones, but this assumption is not always true for it does not account for macroeconomic factors. GDP is more reliable in that regard. GDP is one of the most researched macroeconomic indicators. GDP refers to the total output of goods and services in a nation. GDP accounts for macroeconomic data like efficiency, industrial and agricultural outputs, employment and investment among others. Most economists agree that economies of larger GDPs require more oil to output more goods and services. Since the economies of the U.S., UK, France, Germany, Japan and China are dependent on oil imports, I expect them to have purchased large volumes of oil under the sanctions regime. I test that assumption in Table 2.2. 
Table 2.2 - Oil Purchases by GDP

\begin{tabular}{|c|c|c|c|c|c|c|}
\hline \multicolumn{3}{|c|}{ Bloc I } & \multicolumn{3}{|c|}{ Bloc II } & \\
\hline Countries & $\begin{array}{c}\text { Average GDP } \\
1992-2003\end{array}$ & Barrels lifted & Countries & $\begin{array}{c}\text { Average GDP } \\
1992-2003\end{array}$ & Barrels lifted & $\begin{array}{l}0 \text { barrels } \\
\text { lifted }\end{array}$ \\
\hline USA & $5,776,984,615,385$ & $482,825,657$ & Russia & $200,521,192,308$ & $19,300,618,432$ & 30.46 \\
\hline Japan & $2,609,043,615,385$ & $105,587,299$ & France & $911,806,923,077$ & $4,248,213,159$ & 6.70 \\
\hline Germany & $1,321,445,846,154$ & $33,288,119$ & Switzerland & $168,780,315,385$ & $3,434,083,024$ & 5.42 \\
\hline France & $911,806,923,077$ & $4,248,213,159$ & UK & $897,155,538,462$ & $3,350,739,850$ & 5.29 \\
\hline UK & $897,155,538,462$ & $3,350,739,850$ & Turkey & $117,111,376,923$ & $3,343,252,936$ & 5.28 \\
\hline Italy & $754,663,692,308$ & $2,718,083,135$ & Italy & $754,663,692,308$ & $2,718,083,135$ & 4.29 \\
\hline China & $733,042,869,231$ & $2,624,806,812$ & China & $733,042,869,231$ & $2,624,806,812$ & 4.14 \\
\hline Canada & $422,199,107,692$ & $78,252,230$ & Liechtenstein & $1,780,000,000$ & $2,467,770,768$ & 3.89 \\
\hline Spain & $397,681,161,538$ & $1,643,749,098$ & Spain & $397,681,161,538$ & $1,643,749,098$ & 2.59 \\
\hline Brazil & $383,365,623,077$ & $137,860,626$ & Malaysia & $56,140,118,462$ & $1,485,199,149$ & 2.34 \\
\hline India & $285,186,946,154$ & $872,678,344$ & Vietnam & $18,921,695,385$ & $1,405,961,742$ & 2.22 \\
\hline Netherlands & $262,389,930,769$ & $532,184,460$ & UEA & $38,904,620,000$ & $1,371,407,184$ & 2.16 \\
\hline Russia & $200,521,192,308$ & $19,300,618,432$ & Syria & $10,865,513,846$ & $1,134,317,406$ & 1.79 \\
\hline Switzerland & $168,780,315,385$ & $3,434,083,024$ & Argelia & $32,845,419,231$ & $1,109,337,575$ & 1.75 \\
\hline Belgium & $158,395,000,000$ & $301,953,188$ & Cyprus & $6,056,231,385$ & $1,048,437,558$ & 1.65 \\
\hline Austria & $132,536,369,231$ & $262,883,339$ & India & $285,186,946,154$ & $872,678,344$ & 1.38 \\
\hline Turkey & $117,111,376,923$ & $3,343,252,936$ & Morocco & $22,173,945,385$ & $742,838,933$ & 1.17 \\
\hline Indonesia & $111,173,834,615$ & $255,138,745$ & Jordan & $5,188,421,231$ & $735,728,580$ & 1.16 \\
\hline Denmark & $108,524,361,538$ & $52,933,910$ & Aruba & $2,250,000,000$ & $713,492,385$ & 1.13 \\
\hline Hong Kong & $101,042,161,538$ & $227,838,241$ & Panama & $6,956,038,462$ & $703,170,873$ & 1.11 \\
\hline South Africa & $83,725,600,000$ & $397,692,624$ & Belarus & $8,749,721,538$ & $613,877,735$ & 0.97 \\
\hline Thailand & $82,679,707,692$ & $330,192,170$ & Ukraine & $25,382,237,692$ & $538,411,832$ & 0.85 \\
\hline Finland & $80,705,923,077$ & $107,331,748$ & Netherlands & $262,389,930,769$ & $532,184,460$ & 0.84 \\
\hline Greece & $80,214,423,077$ & $347,836,069$ & Egypt & $53,065,439,231$ & $506,657,165$ & 0.80 \\
\hline Portugal & $75,439,438,462$ & $34,118,051$ & Pakistan & $42,274,733,846$ & $490,181,751$ & 0.77 \\
\hline Ireland & $63,148,556,923$ & $92,406,127$ & USA & $5,776,984,615,385$ & $482,825,657$ & 0.76 \\
\hline Venezuela & $58,452,143,846$ & $103,313,147$ & South Africa & $83,725,600,000$ & $397,692,624$ & 0.63 \\
\hline Malaysia & $56,140,118,462$ & $1,485,199,149$ & Virgin Islands & $1,570,000,000$ & $394,853,212$ & 0.62 \\
\hline Singapore & $54,842,733,846$ & $262,123,492$ & Greece & $80,214,423,077$ & $347,836,069$ & 0.55 \\
\hline Egypt & $53,065,439,231$ & $506,657,165$ & Bulgaria & $8,281,049,308$ & $333,739,464$ & 0.53 \\
\hline Philippines & $47,343,123,846$ & $27,858,288$ & Thailand & $82,679,707,692$ & $330,192,170$ & 0.52 \\
\hline Pakistan & $42,274,733,846$ & $490,181,751$ & Belgium & $158,395,000,000$ & $301,953,188$ & 0.48 \\
\hline UEA & $38,904,620,000$ & $1,371,407,184$ & Austria & $132,536,369,231$ & $262,883,339$ & 0.41 \\
\hline Hungary & $33,390,502,308$ & $17,476,765$ & Singapore & $54,842,733,846$ & $262,123,492$ & 0.41 \\
\hline Argelia & $32,845,419,231$ & $1,109,337,575$ & Indonesia & $111,173,834,615$ & $255,138,745$ & 0.40 \\
\hline Nigeria & $25,956,688,462$ & $179,040,409$ & Yemen & $5,102,082,308$ & $251,116,047$ & 0.40 \\
\hline Romania & $25,453,282,308$ & $138,376,912$ & Bermuda & $4,500,000,000$ & $247,261,893$ & 0.39 \\
\hline Ukraine & $25,382,237,692$ & $538,411,832$ & Lebanon & $10,442,206,923$ & $241,763,377$ & 0.38 \\
\hline Morocco & $22,173,945,385$ & $742,838,933$ & Hong Kong & $101,042,161,538$ & $227,838,241$ & 0.36 \\
\hline Vietnam & $18,921,695,385$ & $1,405,961,742$ & Cayman Island & $1,93,000,000$ & $207,859,782$ & 0.33 \\
\hline Slovakia & $14,045,603,846$ & $30,544,942$ & Other nations & & $197,127,047$ & 0.31 \\
\hline Tunisia & $12,659,013,846$ & $180,361,361$ & Tunisia & $12,659,013,846$ & $180,361,361$ & 0.28 \\
\hline Oman & $10,971,586,923$ & $149,377,008$ & Nigeria & $25,956,688,462$ & $179,040,409$ & 0.28 \\
\hline Syria & $10,865,513,846$ & $1,134,317,406$ & Sudan & $7,751,802,615$ & $173,784,987$ & 0.27 \\
\hline Lebanon & $10,442,206,923$ & $241,763,377$ & Qatar & $9,323,203,846$ & $161,646,541$ & 0.26 \\
\hline Qatar & $9,323,203,846$ & $161,646,541$ & Oman & $10,971,586,923$ & $149,377,008$ & 0.24 \\
\hline Belarus & $8,749,721,538$ & $613,877,735$ & Romania & $25,453,282,308$ & $138,376,912$ & 0.22 \\
\hline Bulgaria & $8,281,049,308$ & $333,739,464$ & Brazil & $383,365,623,077$ & $137,860,626$ & 0.22 \\
\hline Kenya & $8,107,111,538$ & $123,891,238$ & Namibia & $2,164,295,077$ & $132,363,487$ & 0.21 \\
\hline Sudan & $7,751,802,615$ & $173,784,987$ & Kenya & $8,107,111,538$ & $123,891,238$ & 0.20 \\
\hline Panama & $6,956,038,462$ & $703,170,873$ & Finland & $80,705,923,077$ & $107,331,748$ & 0.17 \\
\hline
\end{tabular}




\begin{tabular}{|l|r|r|l|r|r|r|}
\hline Cyprus & $6,056,231,385$ & $1,048,437,558$ & Japan & $2,609,043,615,385$ & $105,587,299$ & 0.17 \\
\hline Jordan & $5,188,421,231$ & $735,728,580$ & Venezuela & $58,452,143,846$ & $103,313,147$ & 0.16 \\
\hline Yemen & $5,102,082,308$ & $251,116,047$ & Bahamas & $2,883,384,615$ & $102,326,624$ & 0.16 \\
\hline Bermuda & $4,500,000,000$ & $247,261,893$ & Ireland & $63,148,556,923$ & $92,406,127$ & 0.14 \\
\hline Bahamas & $2,883,384,615$ & $102,326,624$ & Canada & $422,199,107,692$ & $78,252,230$ & 0.12 \\
\hline Aruba & $2,250,000,000$ & $713,492,385$ & Gambia & $536,513,985$ & $72,112,479$ & 0.11 \\
\hline Namibia & $2,164,295,077$ & $132,363,487$ & Monaco & $986,000,000$ & $54,734,724$ & 0.09 \\
\hline Cayman Island & $1,930,000,000$ & $207,859,782$ & Denmark & $108,524,361,538$ & $52,933,910$ & 0.08 \\
\hline Liechtenstein & $1,780,000,000$ & $2,467,770,768$ & Portugal & $75,439,438,462$ & $34,118,051$ & 0.05 \\
\hline Virgin Islands & $1,570,000,000$ & $394,853,212$ & Germany & $1,321,445,846,154$ & $33,288,119$ & 0.05 \\
\hline Monaco & $986,000,000$ & $54,734,724$ & Slovakia & $14,045,603,846$ & $30,544,942$ & 0.05 \\
\hline Gambia & $536,513,985$ & $72,112,479$ & Philippines & $47,343,123,846$ & $27,858,288$ & 0.04 \\
\hline Other nations & & $197,127,047$ & Hungary & $33,390,502,308$ & $17,476,765$ & 0.03 \\
\hline Yugoslavia & & $17,102,041$ & Yugoslavia & & $17,102,041$ & 0.03 \\
\hline Total & $16,997,210,595,141$ & $64,183,493,296$ & Total & $16,995,280,595,141$ & $64,183,493,296$ & 100.00 \\
\hline
\end{tabular}

Source: the IIC and FMI

Table 2.2 contains two blocs. Bloc I has two columns and Bloc II has three. In Bloc I, column I records nations that purchased oil under the sanctions regime. Column II reports average GDP per nation from 1992, when the sanctions regime began, to 2003 when it ended. Column III accounts for oil barrels lifted under the sanctions regime. Bloc I was sorted by GDP. Bloc II contains the same columns and data as Bloc I, with the exception of column IV, which shows the percentage of oil barrels lifted per nation with respect to Column III, number of barrels lifted in USD. Bloc II was sorted by Column III.

Table 2.2 shows mixed results. First, the size of a GDP did not really influence oil purchases under UN sanctions. For instance, In Bloc I, U.S., Japan, and Germany have the largest GDPs; yet, Bloc II shows that the U.S. ranked $26^{\text {th }}$, Japan $52^{\text {nd }}$, and Germany $61^{\text {st }}$ in oil purchases. Russia, France and Switzerland ranked $13^{\text {th }}, 4^{\text {th }}$, and $14^{\text {th }}$ respectively in terms of GDP, but they led oil purchases in Bloc II. Here too the case of Russia is notable. It purchased $30.7 \%$ of the oil Iraq sold, ranking $13^{\text {th }}$ in GDP. The case 
of Switzerland is interesting too for it ranks $14^{\text {th }}$ in GDP and still surpassed Japan, Germany, UK and Italy despite their higher GDP. The same occurred with Malaysia, Vietnam, UEA, Syria, and Cyprus. They outperformed the U.S., Japan and Germany, the three leading industrial and oil consumers in the world. The most striking case is Lichtenstein, a non-industrial nation with an average GDP of just $\$ 1.78$ billion. This tiny nation surpassed the U.S., Japan and Germany by purchasing 3.84\% from Iraq. The next Table shows the same discrepancies but from a different angle. It lists nations that lifted over \$1 billion worth of oil under the UN sanctions and their respective GDPs.

Table 2.3 - Nations That Lifted Over Billion Dollars Barrels of Oil

\begin{tabular}{|l|r|r|l|r|r|r|}
\hline \multicolumn{3}{|c|}{ Block I } & \multicolumn{3}{c|}{ Block II } \\
\hline Countries & $\begin{array}{c}\text { Ave. GDP 1992-2003 } \\
\text { in USD billions }\end{array}$ & Barrels lifted & Countries & $\begin{array}{c}\text { Ave. GDP 1992-2003 } \\
\text { in USD billions }\end{array}$ & Barrels lifted & $\begin{array}{r}\% \text { lifted } \\
\text { in USD }\end{array}$ \\
\hline France & $911,806,923,077$ & $4,248,213,159$ & Russia & $200,521,192,308$ & $19,300,618,432$ & 38.08 \\
UK & $897,155,538,462$ & $3,350,739,850$ & France & $91,806,923,077$ & $4,248,213,159$ & 8.38 \\
Italy & $754,663,692,308$ & $2,718,083,135$ & Switzerland & $168,780,315,385$ & $3,434,083,024$ & 6.78 \\
China & $733,042,869,231$ & $2,624,806,812$ & UK & $897,155,538,462$ & $3,350,739,850$ & 6.61 \\
Spain & $397,681,161,538$ & $1,643,749,098$ & Turkey & $117,111,376,923$ & $3,343,252,936$ & 6.60 \\
Russia & $200,521,192,308$ & $19,300,618,432$ & Italy & $754,663,692,308$ & $2,718,083,135$ & 5.36 \\
Switzerland & $168,780,315,385$ & $3,434,083,024$ & China & $733,042,869,231$ & $2,624,806,812$ & 5.18 \\
Turkey & $11,111,376,923$ & $3,343,252,936$ & Liechtenstein & $134,000,000$ & $2,467,770,768$ & 4.87 \\
Malaysia & $56,140,118,462$ & $1,485,199,149$ & Spain & $397,681,161,538$ & $1,643,749,098$ & 3.24 \\
UAE & $38,904,620,000$ & $1,371,407,184$ & Malaysia & $56,140,118,462$ & $1,485,199,149$ & 2.93 \\
Argelia & $32,845,419,231$ & $1,109,337,575$ & Vietnam & $18,921,695,385$ & $1,405,961,742$ & 2.77 \\
Vietnam & $18,921,695,385$ & $1,405,961,742$ & UAE & $38,904,620,000$ & $1,371,407,184$ & 2.71 \\
Syria & $10,865,513,846$ & $1,134,317,406$ & Syria & $10,865,513,846$ & $1,134,317,406$ & 2.24 \\
Cyprus & $6,056,231,385$ & $1,048,437,558$ & Argelia & $32,845,419,231$ & $1,109,337,575$ & 2.19 \\
Liechtenstein & $134,000,000$ & $2,467,770,768$ & Cyprus & $6,056,231,385$ & $1,048,437,558$ & 2.07 \\
\hline Total & $4,344,630,667,541$ & $50,685,977,828$ & Total & $4,344,630,667,541$ & $50,685,977,828$ & 100.00 \\
\hline
\end{tabular}

Source: The IIC Report and FMI

Two Blocs form Table 2.3. They contain a list of fifteen nations, their average GDP from 1992 to 2003, and the amount of barrels they purchased from Iraq. Bloc I was sorted by average GDP. Bloc II was sorted by barrels lifted. Note that 15 nations lifted 
over \$1 billion worth of oil, but the U.S., Japan and Germany are not among them despite their larger GDPs. Those 15 nations obtained 758 contracts, $67 \%$ of all contracts Iraq granted under the UN sanctions regime. They lifted $\$ 50,393,714,531$ billion, $78.89 \%$ of the total oil Iraq sold. Note in Bloc I that GDP varies sharply with respect to oil barrels lifted. France, U.K., Italy, China, Spain, Russia, Switzerland and Turkey are among the 15 highest GDPs. They, with the exception of Spain, are also in Bloc II, as the 15 largest oil purchasers. In those cases, GDPs correlated with oil purchases, but we cannot say the same of Liechtenstein, Cyprus, Syria, Vietnam, Algeria and Malaysia. They lifted over 1 billion worth of oil although their GDPs were much smaller. Once again, Russia led oil purchases with $30.07 \%$ and a GDP rather small. Here, demand for oil did not justify oil purchases. But let us see from a different perspective.

Table 2.4 - Fifteen Largest Oil Purchasers and Fifteen Highest GDPs

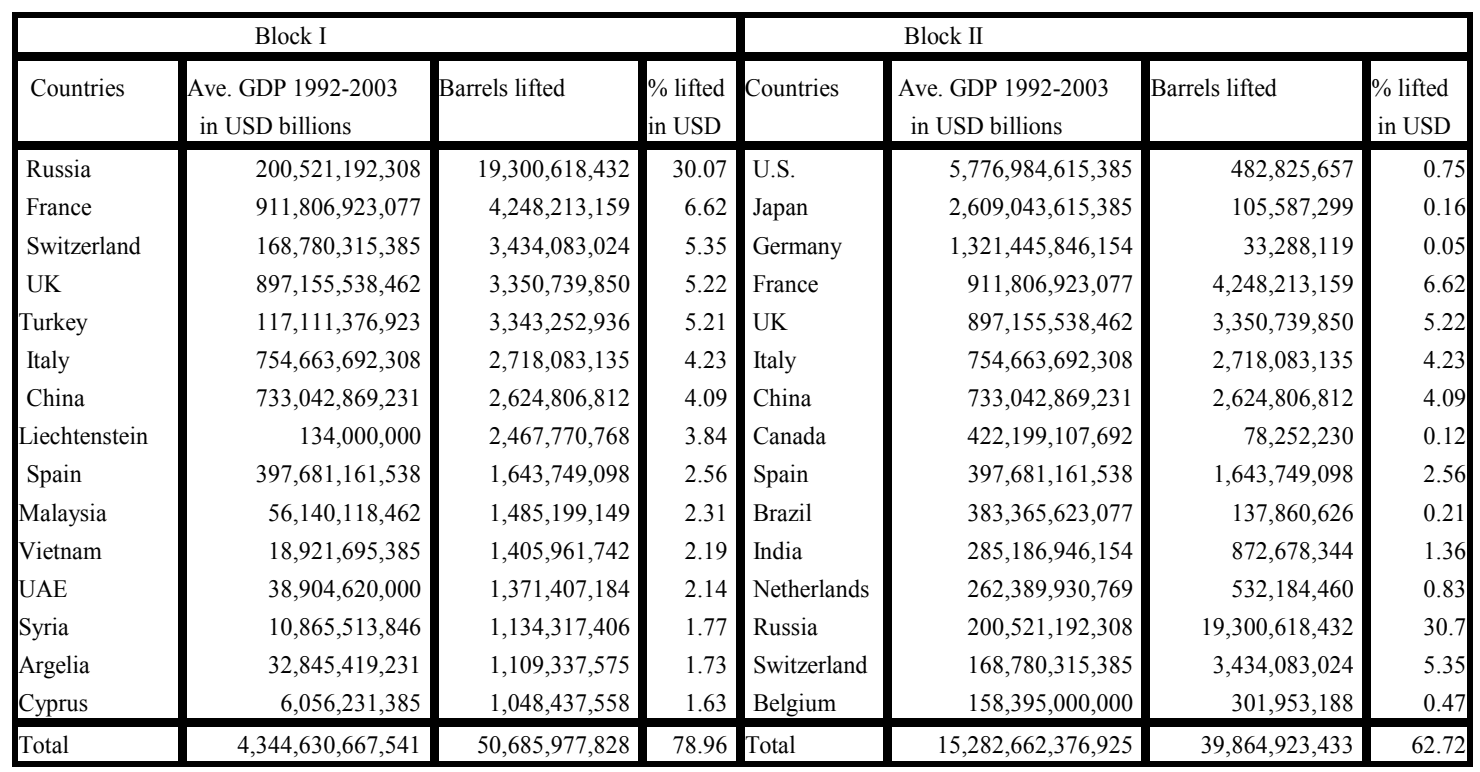

Source: the IIC Report and FMI 
Table 2.4 compares the 15 largest oil purchasers with the 15 highest GDPs in the world. Two Blocs form Table 2.4. Bloc I shows a list of 15 nations that purchased over \$1 billion dollars worth of oil from Iraq. It also shows their average GDP from 1995 to 2003, the amount of barrels lifted expressed in USD billions, and the percentage of barrels they purchased with respect to the total Iraq sold. Bloc I is sorted by Column III. On the other side, Bloc II shows the 15 highest GDPs in the world, the amount of oil barrels they lifted, and the percentage they represented with respect to all oil purchases under the Program. Bloc II is sorted by Column average GDP.

Now, observe in Block I that that only seven nations that purchased over $\$ 1$ billion of oil barrels made it to Bloc II as nations with largest GDPs. They were Russia, France, Switzerland, U.K., Italy, China, and Spain. But Liechtenstein, Cyprus, Syria, Vietnam, Algeria and Malaysia spent over $\$ 1$ billion in oil despite their smaller GDPs. It would be worth finding what Liechtenstein did with so much oil because Liechtenstein is a nation with a population of just 35,322 , with a service oriented economy, no heavy industry and no even intense agriculture. Why would it need so much oil? Conversely, the U.S., Japan and Germany did not make it to Bloc I although they led Bloc II with the highest average GDPs. Why did they not purchase much more oil from Iraq under the UN sanctions regime?

Whatever the reasons, it seems that GDP did not drive oil purchases under the UN sanctions regime against Iraq, and that further testing from different perspectives is essential. For instance, Table 2.5 shows members of the European Union, the second largest economic bloc in the world but highly dependent on oil imports, mainly from Russia, the leading oil purchasers under the UN sanctions regime. 
Table 2.5 - European Union Bloc

\begin{tabular}{|c|c|c|c|c|c|c|}
\hline \multicolumn{3}{|c|}{ Bloc I } & \multicolumn{3}{|c|}{ Bloc II } & \\
\hline Countries & $\begin{array}{l}\text { Ave. GDP 1992-2003 } \\
\text { USD millions }\end{array}$ & barrels lifted & Countries & $\begin{array}{l}\text { Ave. GDP 1992-2003 } \\
\text { USD millions }\end{array}$ & barrels lifted & $\begin{array}{l}\% \text { of } \\
\text { barrels }\end{array}$ \\
\hline Germany & $1,321,445,846,154$ & $33,288,119$ & France & $911,806,923,077$ & $4,248,213,159$ & 27.78 \\
\hline France & $911,806,923,077$ & $4,248,213,159$ & UK & $897,155,538,462$ & $3,350,739,850$ & 21.91 \\
\hline UK & $897,155,538,462$ & $3,350,739,850$ & Italy & $754,663,692,308$ & $2,718,083,135$ & 17.77 \\
\hline Italy & $754,663,692,308$ & $2,718,083,135$ & Spain & $397,681,161,538$ & $1,643,749,098$ & 10.75 \\
\hline Spain & $397,681,161,538$ & $1,643,749,098$ & Cyprus & $6,056,231,385$ & $1,048,437,558$ & 6.86 \\
\hline Netherlands & $262,389,930,769$ & $532,184,460$ & Netherlands & $262,389,930,769$ & $532,184,460$ & 3.48 \\
\hline Belgium & $158,395,000,000$ & $301,953,188$ & Greece & $80,214,423,077$ & $347,836,069$ & 2.27 \\
\hline Austria & $132,536,369,231$ & $262,883,339$ & Bulgaria & $8,281,049,308$ & $333,739,464$ & 2.18 \\
\hline Denmark & $108,524,361,538$ & $52,933,910$ & Belgium & $158,395,000,000$ & $301,953,188$ & 1.97 \\
\hline Finland & $80,705,923,077$ & $107,331,748$ & Austria & $132,536,369,231$ & $262,883,339$ & 1.72 \\
\hline Greece & $80,214,423,077$ & $347,836,069$ & Romania & $25,453,282,308$ & $138,376,912$ & 0.90 \\
\hline Portugal & $75,439,438,462$ & $34,118,051$ & Finland & $80,705,923,077$ & $107,331,748$ & 0.70 \\
\hline Ireland & $63,148,556,923$ & $92,406,127$ & Ireland & $63,148,556,923$ & $92,406,127$ & 0.60 \\
\hline Hungary & $33,390,502,308$ & $17,476,765$ & Denmark & $108,524,361,538$ & $52,933,910$ & 0.35 \\
\hline Romania & $25,453,282,308$ & $138,376,912$ & Portugal & $75,439,438,462$ & $34,118,051$ & 0.22 \\
\hline Slovakia & $14,045,603,846$ & $30,544,942$ & Germany & $1,321,445,846,154$ & $33,288,119$ & 0.22 \\
\hline Bulgaria & $8,281,049,308$ & $333,739,464$ & Slovakia & $14,045,603,846$ & $30,544,942$ & 0.20 \\
\hline Cyprus & $6,056,231,385$ & $1,048,437,558$ & Hungary & $33,390,502,308$ & $17,476,765$ & 0.11 \\
\hline Czech Rep. & - & - & Czech Rep. & - & - & \\
\hline Estonia & - & - & Estonia & - & - & \\
\hline Latvia & - & - & Latvia & - & - & \\
\hline Lithuania & - & - & Lithuania & - & - & \\
\hline Luxembourg & - & - & Luxembourg & - & - & \\
\hline Malta & - & - & Malta & - & - & \\
\hline Poland & - & - & Poland & - & - & \\
\hline Slovenia & - & - & Slovenia & - & - & \\
\hline Sweden & - & - & Sweden & - & - & \\
\hline Total & $5,331,333,833,771$ & $15,294,295,894$ & Total & $5,331,333,833,771$ & $15,294,295,894$ & 100.00 \\
\hline
\end{tabular}

Sources: the IIC Report and FMI

The Table has two blocs. Bloc I accounts for members of EU, average GDP from 1992 to 2003, and their oil purchases. Bloc I is sorted by average GDP. Then, Bloc II shows the same data only that it has a fourth column to reflect percentages of barrels lifted with respect to the total of oil sold under the sanctions regime. Bloc II is sorted by \# of barrels purchased. 
Table 2.5 indicates that France, U.K., Italy and Spain have the four largest GDPs in the EU, and they ranked first, second, third and fourth in oil purchases under the sanctions regime. The Netherlands ranked $6^{\text {th }}$ in oil purchases, but it then fell behind Cyprus, a nation of much smaller GDP. Belgium, Austria and Denmark have large GDPs; however, they purchased less oil than Cyprus, Greece and Bulgaria. Germany, the leading GDP in the E.U, ranked $16^{\text {th }}$. Germany purchased less oil than nations of much smaller GDPs such as Cyprus, Greece, Bulgaria and Rumania, which are the poorest nations in the E.U. Consequently, in Table 2.5, GDP did not predict oil purchases under the UN sanctions regime. Let us then test the third largest economic bloc in the world, the East Asia Bloc.

Table 2.6 - East Asia Bloc

\begin{tabular}{|l|r|r|r|r|r|r|}
\hline \multicolumn{2}{|c|}{ Bloc I } & \multicolumn{3}{c|}{ Bloc I } \\
\hline Countries & Av. GDP 1992-2003 & \# barrels lifted & Countries & Av. GDP 1992-2003 & \# barrels lifted & \% Barrels \\
& In USD millions & in USD millions & & In USD millions & in USD millions & lifted \\
\hline Japan & $2,609,043,615,385$ & $105,587,299$ & China & $733,042,869,231$ & $2,624,806,812$ & 49.35 \\
China & $733,042,869,231$ & $2,624,806,812$ & Malaysia & $56,140,118,462$ & $1,485,199,149$ & 27.92 \\
Indonesia & $111,173,834,615$ & $255,138,745$ & Thailand & $82,679,707,692$ & $330,192,170$ & 6.21 \\
Hong Kong & $101,042,161,538$ & $227,838,241$ & Singapore & $54,842,733,846$ & $262,123,492$ & 4.93 \\
Thailand & $82,679,707,692$ & $330,192,170$ & Indonesia & $111,173,834,615$ & $255,138,745$ & 4.80 \\
Malaysia & $56,140,118,462$ & $1,485,199,149$ & Hong Kong & $101,042,161,538$ & $227,838,241$ & 4.28 \\
Singapore & $54,842,733,846$ & $262,123,492$ & Japan & $2,609,043,615,385$ & $105,587,299$ & 1.99 \\
Philippines & $47,343,123,846$ & $27,858,288$ & Philippines & $47,343,123,846$ & $27,858,288$ & 0.52 \\
S. Korea & & & S. Korea & & 0 & 0 \\
Taiwan & & & Taiwan & & 0 & 0 \\
\hline Total & $3,795,308,164,615$ & $5,318,744,196$ & Total & $3,795,308,164,615$ & $5,318,744,196$ & 100.00 \\
\hline
\end{tabular}

Source: the IIC Report and FMI

Table 2.6 is divided into two blocs. In Bloc I, Column I accounts for nations from 
South East Asia. Column II shows their GDPs, and Column III accounts for their oil purchases under the UN sanctions regime expressed in USD. Bloc I is sorted by average GDP from 1992-2003. For its part, Bloc II has the same columns as Bloc I, but I added Column IV to reflect percentages of oil purchases. Bloc II is sorted by number of barrels lifted expressed in American dollars.

In the Table, we can see that nation-states in East Asia have a total GDP of $\$ 3,795,308,164,165$, second only to the European Union. Yet, they imported just $\$ 5,318,744,196$ million worth of Iraqi oil. A large percentage of it went to China, which led purchases with $\$ 2,624,806,812$ million. Malaysia outperformed Japan, Indonesia and Hong Kong. Japan performed poorly in terms of oil purchases, behind Hong Kong and only better than the Philippines. However, Japan invested $\$ 660$ million dollars in oil infrastructures in Iraq from 1996 to 2000, and it signed several "protocols of intention" for further investments in the Iraqi oil industry. Japan also had investment interests in three oilfields: the East Baghdad camps, which are said to hold reserves of 18 billion barrels; and Gharraf and Tuba, both located in southern Iraq. They have oil reserves for 2.6 billion barrels. So in terms of oil investments, Japan outperformed all other East Asia nations, including China. Taiwan and South Korea did not purchase oil from Iraq.

Consequently, Table 2.6, like previous Tables presented here, shows that GDP did not justify oil purchases under the UN sanctions regime. Perhaps non-macroeconomic factors like religion, ethnicity, family and tribal relations, illegal trade and geopolitics played a more important role. Examining performance of Middle East nations may lead to new findings. 
Table 2.7 - Middle East Nations

\begin{tabular}{|l|r|r|l|r|r|r|}
\hline & \multicolumn{1}{|c|}{ Bloc I } & & & \multicolumn{1}{c|}{ Block II } & & \\
\hline Countries & GDP1992-2003 & Barrels & Countries & $\begin{array}{l}\text { GDP 1992-2003 } \\
\text { in USD millions }\end{array}$ & $\begin{array}{l}\text { Barrels } \\
\text { lifted }\end{array}$ & $\begin{array}{l}\text { \% barrels } \\
\text { lifted }\end{array}$ \\
\hline Turkey & 342.0 & $3,343,253$ & Turkey & 342.0 & $3,343,253$ & 45.25 \\
Saudi Arabia & 289.0 & - & UAE. & 112.0 & $1,371,407$ & 18.56 \\
UAE & 112.0 & $1,371,407$ & Syria & 26.4 & $1,134,317$ & 15.35 \\
Syria & 26.4 & $1,134,317$ & Jordan & 13.5 & 735,729 & 9.96 \\
Oman & 23.0 & 149,377 & Yemen & 12.7 & 251,116 & 3.40 \\
Lebanon & 22.1 & 241,763 & Lebanon & 22.1 & 241,763 & 3.27 \\
Qatar & 15.0 & 161,647 & Qatar & 15.0 & 161,647 & 2.19 \\
Jordan & 13.5 & 735,729 & Oman & 23.0 & 149,377 & 2.02 \\
Yemen & 12.7 & 251,116 & Saudi Arabia & 289.0 & - & - \\
\hline Total & 855.7 & $7,388,609$ & Total & 855.7 & $7,388,609$ & 100.00 \\
\hline
\end{tabular}

Source: IIC Report and FMI

Nine nations in the Middle East purchased oil from Iraq despite UN sanctions. In five cases -Turkey, UAE, Syria, Jordan, and Yemen-, GDP correlated with oil barrels lifted. Lebanon, Qatar, Oman and Saudi Arabia did not perform according to their GDP. Turkey led GDP and oil purchases. Turkey itself is not rich in oil, which may explain its performance here. Turkey houses most of the pipelines that pump oil from the Middle East to Europe. Turkey has borders with the Kurdistan, the richest oil region in Iraq. So it may be that Turkey purchased the Iraqi oil not for itself but to resell it in European markets. Lastly, Saudi Arabia did not purchase oil at all despite its high GDP. Saudi Arabia is one of the largest oil producers in the world, for which it does not need to purchase any. Syria ranked $3^{\text {rd }}$ in oil purchases and $4^{\text {th }}$ in GDP. On the contrary, the case of Jordan is interesting because, having the $2^{\text {nd }}$ smaller GDP in the region, it ranked $4^{\text {th }}$ in oil purchases. Why? The reasons may be found in the CFIJ and IIC Reports. First, the CFIJ stated that "Iraq evaded UN sanctions by means of "Protocols" or government-to- 
government economic trade agreements. Protocols allowed Saddam to generate a large amount of revenues outside the purview of the UN; protocols or government to government agreements generated over $\$ 7.5$ billion for Saddam” (CFIJ, p. 54). Here, the CFIJ refers to the trade protocols Iraq signed with Jordan, Turkey, Egypt, Lebanon and Syria, and the IIC accused those same nations of: 1) hiring front companies and intermediaries to trade with Iraq; 2) allow their banks to conceal and laundry Iraqi profits; 3) smuggle oil out of Iraq and into the global market. The IIC found that "Saddam made about $\$ 990$ million from oil cash sales or smuggling” (IIC, p. 17). I discuss the protocols in the next Chapter, but for now, let us study the data in the next table.

Table 2.8 - Iraqi Profits from Smuggling with Middle East Nations

\begin{tabular}{|c|c|c|c|c|c|}
\hline \multirow[t]{2}{*}{ Nations } & \multicolumn{2}{|c|}{$\begin{array}{c}\text { Coallition for } \\
\text { International Justice }\end{array}$} & \multicolumn{2}{|c|}{$\begin{array}{l}\text { ISG } \\
\text { Report }\end{array}$} & $\begin{array}{l}\text { U.S. Senate } \\
\text { PIC }\end{array}$ \\
\hline & \multicolumn{2}{|c|}{$1992-1996$} & \multicolumn{3}{|c|}{ 1992-1996 } \\
\hline Jordan & $\$$ & 699 & $\$$ & 2,220 & $\mathrm{n} / \mathrm{a}$ \\
\hline Turkey & $\$$ & 99 & $\$$ & & $\mathrm{n} / \mathrm{a}$ \\
\hline Iran & $\$$ & 117 & $\$$ & - & $\mathrm{n} / \mathrm{a}$ \\
\hline Private Sales & $\$$ & 70 & $\$$ & 180 & \\
\hline Total & $\$$ & 985 & $\$$ & 2,400 & $\mathrm{n} / \mathrm{a}$ \\
\hline & & 002 & & $7-2003$ & 1997-2002 \\
\hline Jordan & $\$$ & 1,654 & $\$$ & 2,226 & \\
\hline Turkey & $\$$ & 2,126 & $\$$ & 710 & \\
\hline Syria & $\$$ & 2,234 & $\$$ & 2,814 & \\
\hline Egypt & $\$$ & - & $\$$ & 33 & \\
\hline Iran & $\$$ & 1,714 & $\$$ & - & \\
\hline Kurdistand & $\$$ & - & $\$$ & - & 45 \\
\hline Private Sales & $\$$ & 595 & $\$$ & 1,022 & \\
\hline Total & $\$$ & 8,323 & $\$$ & 6,805 & 45 \\
\hline
\end{tabular}

Source: IIC, CFIJ, ISG Report, and U.S. Senate

The Table shows profits Iraq made from oil smuggling through nations in the 
Middle East. I collected the data from the IIC by the CFIJ, the ISG, and the U.S Senate, its Permanent Subcommittee on Investigations-Committee on Governmental Affairs. The data show that Iraq engaged in oil smuggling through Jordan, Turkey and Iran from 1992 to 1996. The CFIJ reported $\$ 985$ million of dollars while ISG reported $\$ 2,400$ million. From 1997 to 2003, smuggling expanded to Syria, Egypt and Kurdistan, increasing to $\$ 6,805$ million dollars. It is true that the data vary from source to source, but the most relevant finding is not the volume of oil smuggled but rather the participation of Middle Eastern nations in the smuggling, which raises very important questions. For example, why would those nations allow smuggling from and to Iraq, a nation embargoed by the international community, a nation that threatened its neighbors, those very same nations?

To respond the question, perhaps I should analyze non-macroeconomic factors such as traditional trade, ethnic, religious and even family relations, which, according to Fukuyama (2006), are the base of good business and trade relations. Iraq and its neighbors have traded for centuries. The region was united under an empire for hundreds of years, enough to forge long-lasting trade relations and customs. So it is understandable that those relations remained strong even under a sanctions regime. After all, sanctions regimes affect embargoed and not embargoed nations. Sanctions regimes are prompt to cut off trade relations among nations, but they are slow in finding new sources of commerce for the nations affected, mainly for nations of limited resources and incomes, like Iraq, Syria, Jordan, and Lebanon. Still, I should further ask, how did geopolitics among world superpowers affect the sanctions regime? Specifically, how did the Permanent members of UN Security Council performed under the UN sanctions regime against Iraq? 
Table 2.9 - Permanent Members of UN Security Council

\begin{tabular}{|c|c|c|c|c|c|c|}
\hline \multirow{3}{*}{ Country } & \multirow{2}{*}{$\frac{\text { Bloc I }}{\text { GDP 1992-2003 }}$} & \multirow[b]{2}{*}{ Total Imports } & \multirow[b]{2}{*}{ Country } & \multicolumn{2}{|c|}{ Bloc II } & \multirow[b]{2}{*}{$\%$} \\
\hline & & & & GDP 1992-2003 & Total Imports & \\
\hline & in USD millions & in USD millions & & in USD millions & in USD millions & \\
\hline U.S. & $5,776,984,615,385$ & $482,825,657$ & Russia & $200,521,192,308$ & $19,300,618,432$ & 64.32 \\
\hline France & $911,806,923,077$ & $4,248,213,159$ & France & $911,806,923,077$ & $4,248,213,159$ & 14.16 \\
\hline Uk & $897,155,538,462$ & $3,350,739,850$ & Uk & $897,155,538,462$ & $3,350,739,850$ & 11.17 \\
\hline China & $733,042,869,231$ & $2,624,806,812$ & China & $733,042,869,231$ & $2,624,806,812$ & 8.75 \\
\hline Russia & $200,521,192,308$ & $19,300,618,432$ & U.S. & $5,776,984,615,385$ & $482,825,657$ & 1.61 \\
\hline Total & $8,519,511,138,463$ & $30,007,203,910$ & Total & $8,519,511,138,463$ & $30,007,203,910$ & 100.00 \\
\hline
\end{tabular}

Source: IIC Report and FMI

See in Table 2.9 the performance of permanent members of UN Security Council in the UN sanctions regime. Here too, GDP did not correlate with oil purchases. Russia and France lifted more oil than the U.S. and UK. The U.S. led GDP, but it ranked last in oil purchases. In contrast, Russia ranked last in GDP, but it led oil purchases. The case of UK is interesting for it ranked fourth in barrels lifted, in tune with its GDP but not with its overall political attitude toward Iraq and the sanctions regime. That is, the UK, along with the U.S., led the fight against Saddam in the UN Security Council. The UK cosponsored the two no-fly-zones over Iraq and the American led invasions of Iraq in 1991 and 2003. For their part, France and China had a balanced attitude France ranked second in both GDP and oil purchases. China ranked fourth in oil purchases, consequent with its political opposition to the UN sanctions and the invasion of Iraq in 2003. In all, as Meyer and Califano argue, "Iraq steered nearly half of its oil sales to companies from three permanent members of the UN Security Council-Russia, China, and France- that it 
believed were most sympathetic to lifting the sanctions against it" (Meyer and Califano, 2006, p. 145). Moreover, the CIA argued that "Iraq's "sticks" included not only redirecting those contracts to other more "pro-Iraqi" companies, but held the threat of forfeiture of foreign debts - totaling between approximately \$116-250 billion; Saddam expressed confidence that France, Russia and China would support Iraq's efforts to further erode the UN sanctions regime" (Dulfer Report, Saddam Strategic Intent, p. 12).

There is yet another way of testing performance under the UN sanctions regime. The IIC stated that "Iraq preferred to sell its oil to companies and individuals from countries that were as friendly to Iraq, and in particular, if they were permanent members of the Security Council in a position potentially to ease the restrictions of sanctions" (IIC, Manipulation of OFFP, p. 2). The quote implies that political interests in UN Security Council, not GDP, explain the overall performance of members of UN Security Council in regard to the UN sanctions since Saddam obtained two key concessions from the UN Security Council: 1) he was allowed to choose companies that he wanted to trade with; 2) he was allowed to negotiate prices and contracts. As Meyer and Califano put it, "The ill-fated decision to allow Saddam to choose his contracting partners unwittingly empowered him with political and economic leverage to advance his broader agenda; Saddam used this leverage to build and maintain political support for his efforts to overturn the sanctions regime and to circumvent the sanctions" (Meyer and Califano, 2006, p. 18).

Indeed, Saddam lobbied the Security Council, which then eased their tough stand toward Iraq and the sanctions. The IIC stated that "Saddam Hussein, in exercising his ability to designate both buyers and sellers, did favor companies registered with those 
permanent members of the Security Council most reluctant to maintain strong sanctions, specifically Russia, France and China; conversely, there was strong bias against potential U.S. or U.K. contractors" (Meyer and Califano, 2006, p. 19).

France, Russia and China opposed the UN sanctions regime in various ways. First, they used their veto power to propose UN resolutions to: 1) reschedule debates for renewal of the sanctions from one every six month to once a year; 2) expand the scope of the sanctions or the list of goods and services allowed into Iraq; 3) oppose smart sanctions; 4) oppose British and American resolutions to block humanitarian contracts; 5) end the sanctions regime; 6) oppose the American led invasion of Iraq in 2003. Second, they lobbied the Iraqi regime to sign long-term contracts to explore new oil reserves and drill untapped oil wells. For instance, prior to the regime change in April 2003, French and Russian oil firms signed long-term oil contracts with Iraq that covered roughly $40 \%$ of Iraq's wealth (New York Times, March $6^{\text {th }}$, 2008). France negotiated with Iraq oil deals such as the Majnoon and Nahr Umar oil field projects. Located in southern Iraq, the fields hold $25 \%$ of Iraqi oil reserves, approximately 26 billion barrels, representing about $\$ 650$ billion in revenues for France (New York Times, March $\left.6^{\text {th }}, 2008\right)$. Russia signed a 23-year contract with Iraq to revitalize the West Quarna oil field and drill in Saddam, Kirkuk and Bai Hassan oil fields. Russian companies also signed contracts for 67 new oil-related projects in Suba, Luhais, West Qurna, and Rumaila (The New York Times, March $6^{\text {th }}$, 2008). Lastly, China did not sign any oil deal with Saddam Hussein, but as we will see in coming chapters, Chinese firms were very active trading with Iraq.

On the other hand, the U.S. and U.K. collaborated to enforce two non-fly-zones and the UN sanctions regime upon Iraq. The price tag was $\$ 921$ and $\$ 270$ billion dollars 
respectively (IIC, Summary, p. 9), which included the creation of "smart sanctions," the blocking of humanitarian contracts, and the blocking of delivery of goods of 'dual use'. Nevertheless, British and American tough stand against Iraq did not prevent American and British firms from accessing Iraqi oil wells. The hitch is that governments and firms had different goals. In other words, while British and American governments promoted and enforced the sanctions, American and British firms evaded and profited from them. Chart 2.3 illustrates Iraqi oil sales to firms from around the world under the UN sanction.

\section{$\underline{\text { Chart 2.3 - Iraqi Oil Sales under the UN Sanctions Regime }}$}

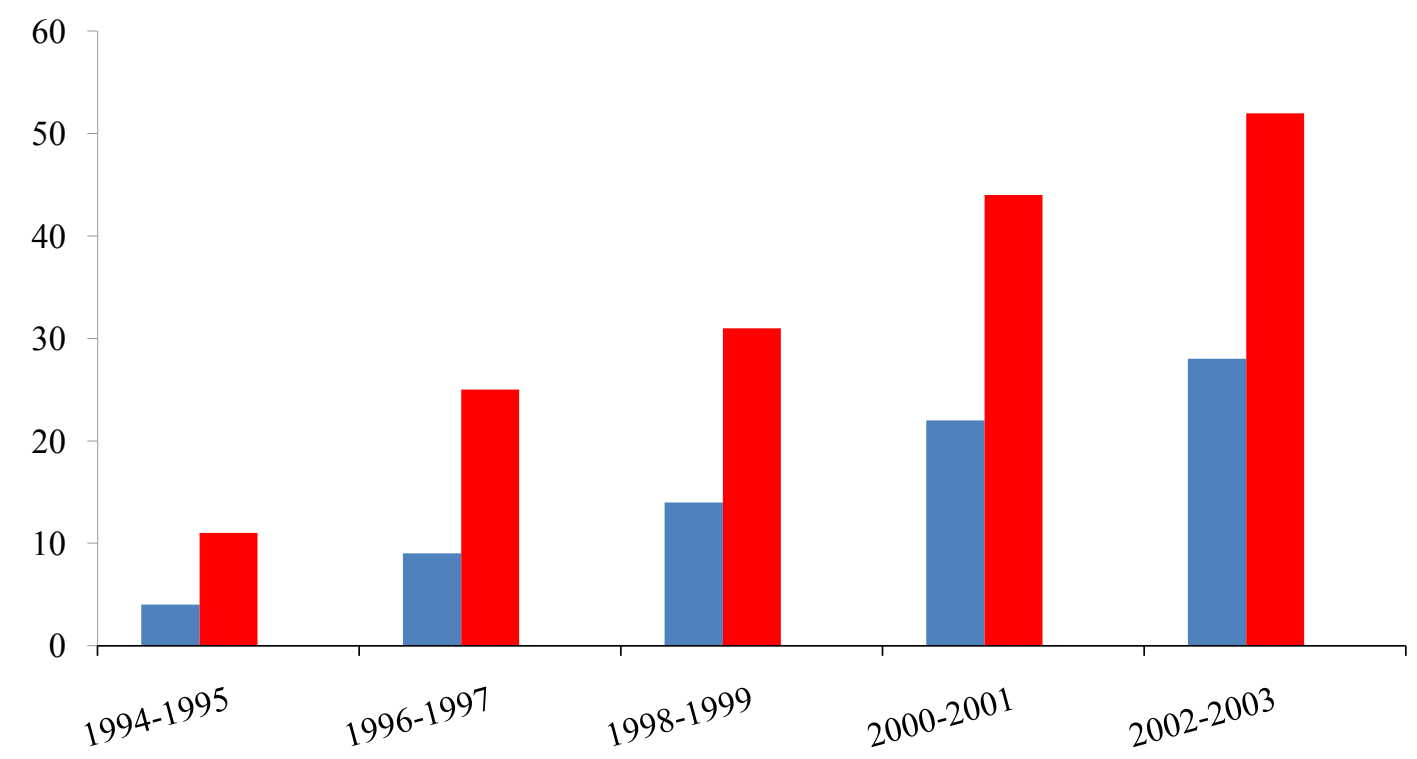

Source: The Duelfer Report (CIA)

The Chart shows Iraqi legal and illegal oil sales to two main groups of firms. The first group includes American and British oil firms, in red bars. The second group 
consists in firms from 37 "other nations," represented by the blue bars. The data cover from the year 1994 to 2003 . The quantity of oil is expressed in USD million of barrels.

At first glance, it seems that American and British corporations purchased less oil than corporations from all other nations. However, that is not accurate if we take into consideration that American and British corporations were competing against firms from 37 nations. Above all, I find that American and British corporations did benefit from the sanctions regime that the UN imposed against Iraq, and that they did not follow the policies that the American and British governments had enacted toward the Iraqi regime. Specifically, I found that firms usually sold their contracts to other companies regardless of their nation of origin, and that this practice allowed American corporations to acquire oil contracts without declaring their nations of origin to Iraqi authorities and UN. Table 2.10 shows a relation of two groups of nations: contractual and non-contractual nations.

Table 2.10 - Contractual and Non-contractual Nations

\begin{tabular}{|c|c|c|c|c|c|c|c|c|}
\hline & Bloc I & & & Bloc II & & & Bloc III & \\
\hline Contractual & Noncontrac & Barrels & Contractual & Noncontrac & Barrels & Contractual & Nonctractual & Barrels \\
\hline Nations & Nations & transferred & Nations & Nations & transferred & Nations & Nations & transferred \\
\hline Algeria & Switzerland & $2,041,000$ & Lebanon & Austria & $2,006,000$ & France & Switzerland & $36,975,000$ \\
\hline Austria & UAE & $1,023,000$ & Libya & Austria & $5,407,000$ & Jordan & Switzerland & $28,381,000$ \\
\hline Bangladesh & Russia & $22,285,000$ & Lebanon & Cyprus & $3,049,000$ & Iran & UK & $27,983,000$ \\
\hline Bangladesh & Jordan & $8,613,000$ & Libya & Cyprus & $4,927,000$ & USA & Cyprus & $26,257,000$ \\
\hline Belarus & Russia & $3,435,000$ & USA & Cyprus & $26,257,000$ & Bangladesh & Russia & $22,285,000$ \\
\hline Brazil & Lebanon & 500,000 & Various natio & Cyprus & $1,002,000$ & Jordan & Spain & $14,105,000$ \\
\hline Brazil & Italy & $1,481,000$ & Russia & Denmark & $2,258,000$ & France & Netherlands & $13,201,000$ \\
\hline Cyprus & Panama & $7,291,000$ & Qatar & Egypt & $2,927,000$ & India & Liechtenstei & $11,732,000$ \\
\hline Chad & UAE & $1,047,000$ & Syria & Egypt & 997,000 & France & Switzerland & $10,751,000$ \\
\hline Egypt & Jordan & $1,995,000$ & Syria & Finland & 492,000 & Yugoslavia & UK & $10,219,000$ \\
\hline Egypt & Switzerland & $7,625,000$ & Jordan & France & $5,278,000$ & Palestine & Syria & $10,126,000$ \\
\hline Egypt & Pakistan & $2,078,000$ & Lebanon & France & $4,549,000$ & Bangladesh & Jordan & $8,613,000$ \\
\hline
\end{tabular}




\begin{tabular}{|c|c|c|c|c|c|c|c|c|}
\hline Egypt & Jordan & $1,000,000$ & Spain & France & $1,351,000$ & Egypt & Switzerland & $7,625,000$ \\
\hline France & Switzerland & $36,975,000$ & UK & France & $4,450,000$ & Cyprus & Panama & $7,291,000$ \\
\hline France & Jordan & $3,360,000$ & Brazil & Italy & $1,481,000$ & India & Switzerland & $6,985,000$ \\
\hline France & Netherlands & $13,201,000$ & Lebanon & Italy & $1,764,000$ & UK & Jordan & $6,681,000$ \\
\hline France & Lichtenstein & $2,027,000$ & Portugal & Italy & $2,568,000$ & Jordan & Panama & $6,035,000$ \\
\hline France & Switzerland & $10,751,000$ & Yugoslavia & Italy & $3,164,000$ & Qatar & UAE & $5,954,000$ \\
\hline Hungary & Rumania & $1,101,000$ & Bangladesh & Jordan & $8,613,000$ & Libya & Austria & $5,407,000$ \\
\hline India & Liechtenstein & $11,732,000$ & Egypt & Jordan & $1,995,000$ & Ukraine & Russia & $5,318,000$ \\
\hline India & Switzerland & $6,985,000$ & Egypt & Jordan & $1,000,000$ & Jordan & France & $5,278,000$ \\
\hline Iran & UK & $27,983,000$ & France & Jordan & $3,360,000$ & Palestine & Jordan & $5,188,000$ \\
\hline Italy & Switzerland & $2,055,000$ & Palestine & Jordan & $5,188,000$ & Libya & Cyprus & $4,927,000$ \\
\hline Italy & UAE & $2,049,000$ & Portugal & Jordan & $1,578,000$ & Yemen & Panama & $4,713,000$ \\
\hline Jordan & Pakistan & $2,826,000$ & UK & Jordan & $6,681,000$ & Lebanon & Switzerland & $4,594,000$ \\
\hline Jordan & France & $5,278,000$ & Brazil & Lebanon & 500,000 & Lebanon & France & $4,549,000$ \\
\hline Jordan & Turkey & $2,002,000$ & France & Lichtenstein & $2,027,000$ & UK & France & $4,450,000$ \\
\hline Jordan & South Africa & $1,047,000$ & India & Liechtenstein & $11,732,000$ & Syria & Panama & $4,430,000$ \\
\hline Jordan & UAE & $1,902,000$ & Spain & Liechtenstein & $2,076,000$ & Syria & UAE & $4,112,000$ \\
\hline Jordan & Spain & $14,105,000$ & UAE & Liechtenstein & $1,955,000$ & Palestine & Qatar & $4,080,000$ \\
\hline Jordan & Switzerland & $28,381,000$ & Various nations & Malaysia & $1,949,000$ & Russia & Switzerland & $3,988,000$ \\
\hline Jordan & Panama & $6,035,000$ & Portugal & Monaco & $1,996,000$ & Belarus & Russia & $3,435,000$ \\
\hline Lebanon & Italy & $1,764,000$ & France & Netherlands & $13,201,000$ & France & Jordan & $3,360,000$ \\
\hline Lebanon & Spain & 995,000 & Egypt & Pakistan & $2,078,000$ & Yugoslavia & Italy & $3,164,000$ \\
\hline Lebanon & Switzerland & $4,594,000$ & Jordan & Pakistan & $2,826,000$ & Lebanon & Cyprus & $3,049,000$ \\
\hline Lebanon & France & $4,549,000$ & Morocco & Pakistan & 797,000 & Qatar & Egypt & $2,927,000$ \\
\hline Lebanon & Cyprus & $3,049,000$ & Palestine & Pakistan & $2,016,000$ & Jordan & Pakistan & $2,826,000$ \\
\hline Lebanon & Austria & $2,006,000$ & Cyprus & Panama & $7,291,000$ & Syria & Switzerland & $2,824,000$ \\
\hline Libya & Austria & $5,407,000$ & Jordan & Panama & $6,035,000$ & Morocco & Switzerland & $2,574,000$ \\
\hline Libya & Cyprus & $4,927,000$ & Pakistan & Panama & $1,022,000$ & Portugal & Italy & $2,568,000$ \\
\hline Morocco & Switzerland & $2,574,000$ & Palestine & Panama & 966,000 & Romania & UAE & $2,560,000$ \\
\hline Morocco & Pakistan & 797,000 & Syria & Panama & $4,430,000$ & Slovakia & Russia & $2,520,000$ \\
\hline Pakistan & Panama & $1,022,000$ & Syria & Panama & $2,049,000$ & Russia & Denmark & $2,258,000$ \\
\hline Palestine & Spain & $1,200,000$ & Turkey & Panama & 892,000 & Egypt & Pakistan & $2,078,000$ \\
\hline Palestine & Syria & $10,126,000$ & Yemen & Panama & $4,713,000$ & Spain & Liechtenstein & $2,076,000$ \\
\hline Palestine & Jordan & $5,188,000$ & Palestine & Qatar & $4,080,000$ & Italy & Switzerland & $2,055,000$ \\
\hline Palestine & Qatar & $4,080,000$ & Romania & Qatar & 753,000 & Italy & UAE & $2,049,000$ \\
\hline Palestine & Panama & 966,000 & Hungary & Rumania & $1,101,000$ & Syria & Panama & $2,049,000$ \\
\hline Palestine & Pakistan & $2,016,000$ & Bangladesh & Russia & $22,285,000$ & Algeria & Switzerland & $2,041,000$ \\
\hline Palestine & Russia & $1,550,000$ & Belarus & Russia & $3,435,000$ & France & Lichtenstein & $2,027,000$ \\
\hline Portugal & Jordan & $1,578,000$ & Palestine & Russia & $1,550,000$ & Palestine & Pakistan & $2,016,000$ \\
\hline Portugal & Italy & $2,568,000$ & Slovakia & Russia & $2,520,000$ & Lebanon & Austria & $2,006,000$ \\
\hline Portugal & Monaco & $1,996,000$ & Ukraine & Russia & $5,318,000$ & Jordan & Turkey & $2,002,000$ \\
\hline Qatar & UAE & $5,954,000$ & Jordan & South Africa & $1,047,000$ & Portugal & Monaco & $1,996,000$ \\
\hline Qatar & Egypt & $2,927,000$ & Jordan & Spain & $14,105,000$ & Egypt & Jordan & $1,995,000$ \\
\hline Romania & UAE & $2,560,000$ & Lebanon & Spain & 995,000 & Ukraine & Switzerland & $1,983,000$ \\
\hline Romania & Qatar & 753,000 & Palestine & Spain & $1,200,000$ & UAE & Liechtenstein & $1,955,000$ \\
\hline Russia & Denmark & $2,258,000$ & Algeria & Switzerland & $2,041,000$ & Various nation & Malaysia & $1,949,000$ \\
\hline Russia & Ukraine & $1,940,000$ & Egypt & Switzerland & $7,625,000$ & Russia & Ukraine & $1,940,000$ \\
\hline Russia & Switzerland & $3,988,000$ & France & Switzerland & $36,975,000$ & Jordan & UAE & $1,902,000$ \\
\hline Slovakia & Russia & $2,520,000$ & France & Switzerland & $10,751,000$ & Yugoslavia & UAE & $1,840,000$ \\
\hline Total & & $418,110,000$ & & & $418,110,000$ & & & $418,110,000$ \\
\hline
\end{tabular}

Source: IIC 
Basically, Table 2.10 illustrates the nations that in the end executed the oil contracts obtained from the Iraqi regime. The Table has three blocks. Each has three columns. In all Blocks, Column "contractual nations" means nations that obtained oil contracts from Iraq. Column "non-contractual nations" means nations that ultimately executed the contracts. Column "barrels transferred" means the amount of barrels that contractual nations transferred to non-contractual nations. Bloc I is sorted by "contractual nations. Bloc II is sorted by "no contractual nations". Bloc III is sorted by "barrels transferred".

The data show one important finding: most contractual nations transferred their oil contracts to "non-contractual nations", which then executed the contracts and sold the oil in the global market. That is, in Bloc I, we see that Algeria transferred $\$ 2,041,000$ million worth of oil to Switzerland. Bangladesh transferred $\$ 22,285,000$ million to Russia and $\$ 8,613,000$ to Jordan. Jordan and Syria led Bloc I as they transferred eight contracts respectively, only that Jordan's contracts were worth $\$ 61,576,000$ million while Syria's were worth $\$ 13,855,000$ million. The case of Palestine is interesting because it received seven contracts worth $\$ 25,126$ million dollars, but it transferred them to no contractual nations. This is rational considering that Palestine does not even have oil refineries to refine crude oil. Palestine actually satisfies its energy needs by importing energy from Israel.

In Bloc II, Austria received \$2,006,000 million dollars worth of oil from Lebanon and $\$ 5,407,000$ million from Libya. Cyprus obtained $\$ 3,049,000$ from Lebanon, $\$ 4,927,000$ million from Libya, $\$ 1,002,000$ from various, not identified nations, and $\$ 26,257,000$ million from the U.S. This last transfer is meaningful because the U.S. does 
not export oil; instead, it depends on foreign oil for economic growth. In fact, bloc II shows that the U.S. did not receive any transfer. But why would the U.S. transfer oil contracts to a small nation like Cyprus? Lastly, France led bloc III with the largest transfer, worth $\$ 36,975,000$ million dollars. Jordan followed through with $\$ 28,381,000$ million. In turn, Switzerland received both transfers to actually lead with 13, worth $\$ 112,571,000$ million dollars, as shown in bloc II, "no contractual nations".

\section{$\underline{\text { Conclusion }}$}

From the analysis, first I infer that despite its macroeconomic importance, GDP was not the leading motive for oil purchases under the UN sanctions regime. Instead, non-macroeconomic factors such as regional and illegal trade may have influenced oil purchases among nations in the Middle East. Second, geopolitics among permanent members of the UN Security Council influenced the effectiveness of the UN sanctions regime. The UN Security Council was divided into two blocs: the U.S. and U.K. on one side, and France, Russia and China on the other. This division affected the scope of the Program, assignment of contracts and oil purchases, as well as overall enforcement of the sanctions regime. Third, corporate practices such as speculation, third party intermediation and transfer of contracts may have also played relevant roles in terms of financing oil purchases and oil flows.

One important finding is that nations and oil firms approached the UN sanctions regime in different and opposite ways. That is, even though the U.S.'s oil purchases were low, American companies were among the leading beneficiaries under the Program. For its part, Iraq utilized disagreements in the UN Security Council to circumvent the UN 
sanctions regime. Iraq managed to sell $\$ 64,183,493,296$ million dollars in oil, plus another \$26 billion that the IIC affirmed Iraq bartered or exchanged for goods and services. The CIA calculated that "Iraq earned an additional \$12 billion from kickbacks and surcharges associated with the UN OFF program, \$19 billion from oil "cash sales" or smuggling, and another \$230 million from other surcharge impositions" (Duelfer Report, p.217). The entire operation amounted to about 100 billion dollars in ten years. It would be fair to ask: What did Iraq do with so much money? After all, Iraq was an embargoed nation, supposedly with no access to global markets, financing and investments. In the next chapter we will see that Iraq utilized revenues from its oil sales in two ways. First, Iraq utilized portions of its revenues to purchase goods and services around the world so it could feed its people and sustain its political regime. Second, Iraq utilized another portion of its revenues to revitalize its economy and its military apparatus so it could defend itself. How did Iraq do it? Did Iraq access global markets? 


\section{AGENTS AND MEANS OF GLOBALIZATION: NATION-STATES, GLOBAL TRADE AND THEIR EFFECTS ON MULTILATERAL SANCTIONS REGIMES}

"The question is whether regional trade blocs are building blocs or stumbling blocs to the global trade system".

J. Bhagwati

"The highest levels of the government, including the President and the Presidential Secretary, used trade Protocols and other cooperative agreements after 1991 as vehicles to circumvent UN sanctions and to facilitate the economic recovery of Iraq".

Coalition for International Justice

"Iraq's bilateral trade Protocols with neighboring states provided Saddam with his largest source of illicit income during UN sanctions. Just the protocol with Jordan ensured the Regime's financial survival".

The Duelfer Report

"France questions bilateral trade unions that the US engaged in the region. We mean to say Egypt, Turkey and Jordan; for they were Saddam's trade darlings during this period. Even the Office of the US Trade Representatives acknowledges that American exports to Jordan grew 90\% between 1999- 2003 alone".

Statement by the French Ministry of Foreign Affair, Paris, July 22, 2003

$\underline{\text { Introduction }}$

The critical question in this dissertation is whether globalization helps circumvent sanctions regimes. The key question for Iraq was how to get around the UN sanctions regime and access the global market to engage in trade relations with nations and corporations. I argue that the nature of the global trade system helps circumvent sanctions regimes. Global trade is so competitive, antagonistic and unmanageable that it creates what Bhagwati calls "The building and stumbling blocs of the multilateral trading system" (Bhagwati, 1993, p. 32). Global trade is not monolithic. Global trade is rather fragmented, built on numerous regional and bilateral trade blocs that can either straighten or weaken its foundations.

In this chapter I present evidences indicating that Iraq circumvented UN sanctions 
regimes through regional and bilateral trade blocs. Iraq accessed global trade through bilateral trade agreements that it signed with numerous nations, but mainly with its neighbors Jordan, Egypt, Lebanon, Turkey and Syria. Those nations opened up their markets to Iraq, and almost instantly numerous nations from around the globe followed through. It was a two-way trade route: Iraq exported oil to global markets through Jordan, Egypt, Turkey and Syria. In turn, Iraq purchased goods and services from all around the world by using those nations as its trade headquarters. In part, it explains why Jordan, Egypt, Turkey, Syria attracted so much trade during the 1990s. Above all, it calls our attention the fact that the U.S. also signed bilateral trade agreements with Egypt in 1999, Turkey in 2000, and Jordan in 2001, while the UN sanctions regime was still being enforced. It prompted the French Minister of Foreign Affair to emphasize in July 23, 2003, what the Office of the U.S. Trade Representative (www.ustr.gov) had reported: American exports to Jordan grew by $90 \%$ between 1999 and 2003; the year that the U.S. led military coalition ousted Saddam Hussein.

Consequently, as in chapter II, I use nations-states as the level of analysis, only that I focus on trade, one of the main means of globalization. First, I analyze how nationstates approached global trade with Iraq under the UN sanctions regime. Second, I examine how the nature of global trade allowed Iraq to circumvent the UN sanctions regime. For that purpose, I rely on data collected from the IIC, CFIJ, GAO, and the Duelfer Reports.

\section{Global Trade}

Global trade has historically been the cause of geopolitical conflicts among 
nation-states. David S. Landes explains in "The Wealth and Poverty of Nations" that the quest for dominance over global trade led to the emergence of the Spanish, French, and British empires and the creation of the colonial system (Landes, 1999). Most colonial wars of the 1700 s and 1800 s aimed at securing the seas for commercial navigation and new markets. In "Imperialism, the Last Stage of Capitalism", Lenin argues that disputes over trade cause wars (Lenin, 1996). He saw competition over trade as an intrinsic trait of global capitalism, which would in time produce an all-out war among world powers. President Wilson too saw in unfair trade one of the causes of wars. He argued that protectionism (closed markets, export quotas, and high tariffs among others) were among the causes of WWI. He thought that freedom of the seas and freedom from trade barriers were the basis for a lasting peace among nations, so he included them both in his Fourteen Points Plan for Peace. But protectionism prevailed and, for many, led to the collapse of global banking in 1929 and the economic depression that followed afterwards.

In fact, the Bretton Woods Accords enacted during the last years of WWII tried to correct the malpractices incurred in global trade during the 1920s and 1930s. Ikemberry (2006) argues that free global trade was what American officials had in mind when they conceived the European and Asian blocs after WWII. He quotes American officials as saying that "Long-term American prosperity required open markets, unhindered access to raw materials, and the rehabilitation of much - if not all- of Eurasia along liberalcapitalist lines” (Ikemberry, 2006, p. 151).

For his part, J. Bhagwati (1999) states that right after the Cold War the tendency was to build global trade on bilateral and regional trade blocs. Examples are regional trade blocs such NAFTA, Mercosur, EU and hundreds of bilateral trade agreements that, 
according to the WTO, have been signed by nations during the last 20 years, a trend that remains to this day.

In effect, Ikemberry points out that the current global trade system "Is really an American order built on four pillars: open markets, social bargains, intergovernmental institutions and cooperative security" (Ikemberry, 2006, p. 145). Global trade "Is organized around American-led regional security, alliances in Europe and Asia, open and multilateral economic relations, several layers of regional and global multilateral institutions built around American power" (Ikemberry, 2006, p. 145).

The two quotes imply that: a) global trade can be unstable and create global conflicts; b) cooperation and regionalization by trade blocs can lead to common security. The quest for free trade is so challenging that nation-states often link it to domestic political stability. Some nations even link it to national security and survival, as it was the case of Iraq. Iraq engaged in bilateral trade with its neighbors as a means to engage in regional trade, reach global markets and secure its survival as a nation. Thus, trade and security complement each other. By the same token, integration vis-à-vis cooperation aims at both trade and national security. That is, bilateral and regional integration beefs up national security vis-à-vis cooperation in issues such as bilateral and regional trade.

The rationale is that bilateral and regional trade has domino effects: they change trade patterns, which then lead to integration of production and labor across borders, which ultimately lead to negotiated trade policies. It all leads to a common market in which common security is the guarantor of stable trade.

Two theories are vital to explicate the sudden collaboration among Iraq and its neighbors, mainly Jordan, Syria, Turkey, Egypt and Iran under the UN sanction regime. 
The two theories are interdependency theory and trade theory.

\section{The Lessons of Interdependency Theory}

Interdependency theory states that nations are interconnected through multiple and complex linkages, which include political, economic, technological, legal, religious, ideological, ecological and others (Keohane \& Nye, 2001). Nations are so interconnected that policies enacted in one nation could cross boundaries and trigger social, economic, and political reactions in other nations. Second, interdependence theory relies on two basic points. For one, states are not the sole unit of analysis. Various non-state-actors (NSAs) shape global agendas, among which are corporations, NGOs, and international institutions such as the UN and WTO. Actors behave according to their interests. They make decisions based on cost-benefit analysis aimed at securing the best outcomes for themselves. But there are multiple channels of relations among actors. Keohane and Nye (2001) call them interstate, transgovernmental, and transnational channels of relations. Since there are also NSAs, we must pay attention to non-state channels as well. Another mark of interdependency is the lack of hierarchy in a global agenda (Keohane \& Nye, 2001). Global politics implies diversity of issues, from security and trade to governance, finance, drug trafficking, the environment, and many others. Yet, their priority in the global agenda depends on factors such as severity of the issue, media attention, coalitions forming, negotiation capabilities, and other variables. In an interdependent world, nonstate and state actors clash over agenda setting. An issue in a particular nation may lead to a regional and even global crisis, redefining regional and global political agendas. Lastly, interdependence theory does not assign much weight to the role of the military, mainly when dealing with trade (Keohane \& Nye, 2001). Military confrontation does not 
fix the problems of bilateral, regional and global trade. In the case of Iraq, enforcement of the UN sanctions regime was a priority for both the U.S. and U.K., so they assigned it to their armies. The U.S. and U.K. had military control over Northern and Southern Iraqis territories, enforced by a naval blockade and two no-fly zones. Yet, Iraq kept trading with its neighbors. Iraq managed to rebuild its economy and resist 13 years of sanctions.

Two examples illustrate how interdependency among the U.S. and nations in the Middle East undermined the UN sanctions against Iraq. They are Turkey and Lebanon.

First, the UN sanctions created a political dilemma for the U.S. and Turkey. Turkey is a member of NATO. As such, the U.S. used its territories to invade Iraq in 1991. Now the U.S. was using Turkish military bases to enforce the no-fly zone in Northern Iraq. Even so, for its geographic position, Turkey had for centuries been a vital trade route between Europe and the Middle East. The UN sanctions cut off the route and halted trade along the Iraqi-Turkey border, affecting the economies of Turkey, Kurdistan, Jordan and Lebanon, three American allies in the region. The economic crisis led to the rise of a huge black market along the Turkish-Iraqi border. Trade along the Turkish-Iraqi border was so good that even the PKK benefited from it. The U.S. and U.K. tried to look the other way, but Turkey did not allow it. The CFIJ summed it up by stating that "Turkey claims that the impoverished and rebel-ridden southeast is enjoying a boost from the $\$ 300$ million diesel trade. The trade has been tolerated by the U.S. and UK in part for this reason, in part because it has been brokered by and has handsomely benefited the Iraqi Kurds, but it is benefiting Kurd rebels as well who use the money to launch a guerrilla type offensive against Turkey" (CFIJ, 2002, p. 28). 
The CFIJ was referring to the Iraqi-Kurds and Turkish-Kurds. Turkey had no problem with Iraqi-Kurds, but it did have serious issues with Turkish-Kurds organized around the PKK. Turkey views the PKK as a terrorist group. The PKK claimed a piece of Turkish territory for itself, so Turkey treated it as threat to its national security. It became a political dilemma for the U.S. Therefore, the U.S. had to offer a solution to Turkey without affecting Iraqi-Kurds and without benefiting the Turkish Kurds. The solution was: 1) allow Turkey to go after the PKK without crossing the Iraq border; 2) allow trade, namely smuggling, of oil and other goods along the Turkish-Iraqi border for it benefitted a key protégés of the U.S. in the zone: the Iraqi Kurds and their KDP; 3) allow Turkey to open a free trade zone along its border with Iraq. In all, the American plan had mixed results. The plan mostly legalized contraband along the Turkish-Iraqi borders. The CFIJ argued that "The Iraq-Turkey trade agreement was a rationalization and expansion of preexisting private-sector contracts along the Turkish-Iraqi border" (CFIJ, 2002, p. 32). The Plan did alleviate the economic conditions of Iraqi-Kurds and increased Turkish trade opportunities in the region to make up for losses of revenues to truckers and smugglers. However, Saddam Hussein took advantage of it and began to pay Turkish and Iraqi-Kurds for smuggling. The CIA estimated that smuggling represented about $\$ 1$ billion yearly for Iraq (Duelfer Report, Saddam Strategic Intent, p. 12).

Second, the case of Lebanon is as telling. Lebanon benefitted from the UN sanctions regime against Iraq vis-à-vis Syria, a political enemy of both the U.S. and Iraq. But Syria allied to Iraq to upset the U.S., which in turn needed Syria to: a) cooperate with the Israel-Palestinian peace negotiations; b) keep under control Hezbollah and other guerrilla groups in southern Lebanon but without upsetting Lebanon's political stability. 
To return the favor to Syria, the U.S. allowed illicit trade along the Syrian-Iraqi border. The CFIJ noted that "The US recognized that cooperation is critical to succeed in negotiating peace for the Middle East, including stability in Lebanon, and has therefore been reluctant to demand that President Bashar Assad make good on his year old promise that he would crack down on his country's illicit trade with Baghdad... these included moving Iraqi oil to Lebanon and, in return, facilitating the transshipment though Syria of Lebanese goods" (CFIJ, 2002, p. 32). Such political maneuverings shows the level of interconnection between geopolitics and economics, and among nations.

\section{The Lessons of Trade Theory}

Like interdependency, trade theory explains unexpected cooperation of Middle Eastern nations with Iraq under the UN sanctions regime. Trade theory in fact explains the level of economic interconnections among nations in the Middle East, mainly among political archenemies like Iraq and Iran, all which jeopardized the UN sanctions regime.

Krugman, (1979), Lancaster (1980) and Helpman (1981) introduce trade theory to explain global trade after World War II. Explicitly, they look at three features of global trade: a) trade among industrialized nations; b) trade among non-industrialized nations; c) the ratio of trade relative to GDP. Trade theory builds on David Ricardo's comparative advantage theory, which states that nations maximize trade when they produce goods with resources available to them. But Ricardo's theory led some scholars to assume that nations without natural resources are naturally unfitted for global trade. Scholars like Ohlin and Samuelson think differently. They argue that factors of proportions like labor, capital, industrial capacity and the size of a market can lead to a comparative advantage. 
Then, Krugman elaborates on Ohlin-Samuelson's model to include "unconventional" factors such as geography, namely the distance from production to consumption markets. For Krugman, geography is essential for decreasing the cost of trade. First, geographical proximity between production and consumption markets decreases transportation costs, mainly between nations of common borders. Geographical proximity is also central for factors such as movement of capital and people. Krugman argues that "When people and capital can move, however, factor proportions are themselves something to be explained" (Krugman, 1991, p. 491).

Free movement of capital and people within a specific geography or region brings down the cost of transportation and labor. In fact, cheap transportation and labor helped Iraq engage in smuggling with Jordan, Syria, Lebanon, Turkey and Iran. Transportation and labor were so cheap that although Iraq imposed all sorts of taxes and fees, smuggling was among the main sources of revenue for Iraq, and trucking became one of the most lucrative industries under the UN sanctions regime. Trucking brought about $\$ 600$ million dollars every year into the Kurdish economy only. I present two examples, one is Turkey and the second is Iran.

Table 3.1 - Oil Smuggled into Turkey by Iraq

\begin{tabular}{|r|r|r|r|r|r|}
\hline $\begin{array}{l}\text { \# of oil } \\
\text { Barrels per } \\
\text { Day }\end{array}$ & $\begin{array}{l}\text { Iraq's Sales } \\
\text { Price in USD }\end{array}$ & $\begin{array}{l}\text { Transportation } \\
\text { Fees in USD }\end{array}$ & $\begin{array}{l}\text { Iraq's Final } \\
\text { Sales in USD }\end{array}$ & $\begin{array}{l}\text { Price at Global } \\
\text { Markets in }\end{array}$ & $\begin{array}{l}\text { Global } \\
\text { Uarket's Final } \\
\text { Sales }\end{array}$ \\
\hline 100,000 & 21 & 3 & $2,400,000$ & 25 & $2,500,000$ \\
\hline $\mathbf{1 1 0 , 0 0 0}$ & 21 & 3 & $2,640,000$ & 25 & $2,750,000$ \\
\hline 110,000 & 22 & 3 & $2,750,000$ & 25 & $2,750,000$ \\
\hline 110,000 & 22 & 4 & $2,860,000$ & 26 & $2,860,000$ \\
110,000 & 22 & 5 & $2,970,000$ & 27 & $2,970,000$ \\
\hline
\end{tabular}




\section{Sources: IIC, CFIJ and Duelfer Reports}

In Table 3.1, I explain the price of Iraqi oil smuggled into Turkey by Iraq. Note that Iraq had ample room for maneuvering. Iraq could manipulate: a) production of oil per day (Column I); b) sell price (in Column II); c) transportation fees (in Column III). I bold Iraq's tree choices for better understanding. Now, note that Iraq can keep its sell price (in Column II) below the price in the global market (Column V) by a $\$ 3$ or $\$ 4$ dollars. It would not affect Iraq's revenues. Iraq can even charge $\$ 3$ to $\$ 4$ dollars more to make up for transportation costs since its final sales (in Column IV) do not go over sales in the global market (Column VI). Iraq can do so due to three comparative advantages: 1) Iraq has plenty of oil, but Turkey does not; 2) Iraq has a border with Turkey, securing low transportation costs; 3) Kurds transported Iraq's oil to Turkey, and the Kurdish economy relied on Iraq's trade with Turkey. Iraq in fact controlled Kurdish labor costs. Yet, Iraq has two other advantages: a) Turkey's excellent infrastructures to refine Iraqi crude oil; b) Turkey's geographical position with respect to Europe, the second largest oil consumer of imported oil. As I explained in Chapter II, most of the oil Iraq smuggled ended up in European markets. Still, the next example is more telling for it involves Iran, Iraq's political archenemy.

Table 3.2 - Diesel Smuggled into Iran by Iraq 


\begin{tabular}{|r|r|r|r|r|r|}
\hline $\begin{array}{l}\text { \# of Oil } \\
\text { Barrels per } \\
\text { Day }\end{array}$ & $\begin{array}{l}\text { Iraq's Sell } \\
\text { Price in } \\
\text { USD }\end{array}$ & $\begin{array}{l}\text { Price at } \\
\text { Transportation } \\
\text { Fees in USD }\end{array}$ & $\begin{array}{l}\text { Iraq's Final } \\
\text { Sales in USD } \\
\text { Markets in } \\
\text { USD }\end{array}$ & $\begin{array}{l}\text { Global } \\
\text { Market's } \\
\text { Final Sales }\end{array}$ \\
\hline 100,000 & 11 & 3 & $1,400,000$ & 16 & $1,600,000$ \\
\hline $\mathbf{1 1 0 , 0 0 0}$ & 12 & 3 & $1,650,000$ & 17 & $1,870,000$ \\
\hline 110,000 & 13 & 3 & $1,760,000$ & 18 & $1,980,000$ \\
\hline 110,000 & 14 & 4 & $1,980,000$ & 19 & $2,090,000$ \\
\hline 110,000 & 15 & 5 & $2,200,000$ & 20 & $2,200,000$ \\
\hline
\end{tabular}

\section{Sources: IIC, CFIJ}

Like in the previous example, here Iraq had three choices. Iraq can increase: a) oil production per day (Column I); b) sale price (Column II); c) transportation fees (in Column III). In all, the increases never lead to final sales (Column IV) higher than final sales at global markets (Column VI). But this case is relevant for four main reasons. First, Iraq and Iran are oil rich nations, but they do not have infrastructures to convert it into gasoline; second, Iraq and Iran have common borders; thirdly, Iraq and Iran have a common enemy: the U.S. On the other hand, Iraq has a comparative advantage over Iran. Iraq has borders with Turkey, and Turkey does have industrial capacity to refine crude oil. Note that at the time, Iran could not get gasoline from Saudi Arabia and Kuwait, both Iran's neighbors and the two largest gasoline producers in the region. Iran, a political enemy of the U.S., does not have good political relations with Saudi Arabia and Kuwait, two key American political allies in the region. Iran, to this date, does not have refinery capacity. It subsidizes and rations its gasoline.

Accordingly, Iraq and Iran have good reasons to work together to circumvent the UN sanctions against Iraq. Cooperation here consists in Iraq using Iraqi-Kurds to ship its oil to Turkey, which then converts it into gasoline. Iraqi-Kurds smuggled the gasoline into Iran via Iraq with the consent of the Iraqi regime. Here, low transportation and labor 
costs guarantee low gasoline prices for Iran. Iraq itself makes a profit by taxing truckers for crossing Iraqi territories, not to mention the hundreds of thousands of dollars that Kurd truckers spend in Iraqi goods and services while crossing Iraqi territories. In total, the gains illustrate how geographic proximity between production and consumption centers can decrease transportation and labor costs, which in turn lead to a comparative advantage as explained by trade theory.

All those factors can certainly contribute to the "natural" emergence of a regional trade blocs. In fact, it is Krugman who coins the notion of natural trade blocs, which he ironically defines in terms of a governmental policy. Krugman states that "The low cost of transportation at regional levels makes regional trade blocs a natural and beneficial policy" (Krugman, 1991, p. 485). That is, policy makers can build bilateral and regional trade blocs by using factors of proportions such as geography, culture, language and others as means to comparative advantages. It helps explain trade relations between Iraq, Jordan, Syria, Turkey and Egypt under the sanctions regime. Table 3.3 illustrates how those relations weakened the UN sanction against Iraq.

$\underline{\text { Table } 3.3 \text { - Trade Contracts under the UN Sanctions Regime }}$ 


\begin{tabular}{|l|r|r|r|r|l|r|r|r|}
\hline \multicolumn{2}{|c|}{ Block I } & & & \multicolumn{2}{|c|}{ Block II } & \\
\hline Nations & Contracts & Percent & \multicolumn{1}{|l|}{ Exports in } & Percent & Nations & Contract & Percent & Exports in \\
\hline Jordan & 2515 & 13.78 & $2,548,005,219$ & 7.2800 & Russia & 1205 & 6.60 & $3,669,047,718$ \\
\hline France & 2149 & 11.78 & $3,132,610,302$ & 8.9500 & France & 2149 & 11.78 & $3,132,610,302$ \\
\hline Turkey & 1280 & 7.01 & $1,649,514,851$ & 4.710 & Egypt & 847 & 4.64 & $2,962,660,858$ \\
\hline Italy & 1249 & 6.84 & $1,091,074,655$ & 3.110 & Jordan & 2515 & 13.78 & $2,548,005,219$ \\
\hline Russia & 1205 & 6.60 & $3,669,047,718$ & 10.480 & Australia & 68 & 0.37 & $2,336,339,178$ \\
\hline UAE & 1070 & 5.86 & $1,944,219,047$ & 5.550 & Vietnam & 205 & 1.12 & $1,951,470,213$ \\
\hline Egypt & 847 & 4.64 & $2,962,660,858$ & 8.460 & UAE & 1070 & 5.86 & $1,944,219,047$ \\
\hline India & 847 & 4.64 & $1,176,830,860$ & 3.360 & China & 810 & 4.44 & $1,839,790,132$ \\
\hline China & 810 & 4.44 & $1,839,790,132$ & 5.250 & Turkey & 1280 & 7.01 & $1,649,514,851$ \\
\hline Syria & 648 & 3.55 & $1,544,681,993$ & 4.410 & Syria & 648 & 3.55 & $1,544,681,993$ \\
\hline Lebanon & 550 & 3.01 & $770,030,253$ & 2.200 & India & 847 & 4.64 & $1,176,830,860$ \\
\hline Germany & 516 & 2.83 & $535,821,022$ & 1.530 & Italy & 1249 & 6.84 & $1,091,074,655$ \\
\hline Belgium & 422 & 2.31 & $269,062,223$ & 0.760 & Tunisia & 329 & 1.80 & $1,056,700,795$ \\
\hline Switzerland & 331 & 1.81 & $660,038,383$ & 1.8800 & Lebanon & 550 & 3.01 & $770,030,253$ \\
\hline Tunisia & 329 & 1.80 & $1,056,700,795$ & 3.0100 & Thailand & 59 & 0.32 & $717,959,615$ \\
\hline Spain & 287 & 1.57 & $280,446,290$ & 0.8000 & Switzerland & 331 & 1.81 & $660,038,383$ \\
\hline Malaysia & 242 & 1.33 & $581,161,511$ & 1.6600 & Saudi Arabia & 165 & 0.90 & $654,764,093$ \\
\hline \hline
\end{tabular}




\begin{tabular}{|c|c|c|c|c|c|c|c|c|c|}
\hline Indonesia & 232 & 1.27 & $230,831,644$ & 0.6596 & Malaysia & 242 & 6.19 & $581,161,511$ & 10.9942 \\
\hline Austria & 226 & 1.24 & $327,446,260$ & 0.9357 & Germany & 516 & 13.20 & $535,821,022$ & 10.1365 \\
\hline UK & 223 & 1.22 & $153,819,313$ & 0.4395 & Algeria & 154 & 3.94 & $442,324,147$ & 8.3678 \\
\hline Vietnam & 205 & 1.12 & $1,951,470,213$ & 5.5762 & Austria & 226 & 5.78 & $327,446,260$ & 6.1945 \\
\hline Saudi Arabia & 165 & 0.90 & $654,764,093$ & 1.8709 & Spain & 287 & 7.34 & $280,446,290$ & 5.3054 \\
\hline Algeria & 154 & 0.84 & $442,324,147$ & 1.2639 & Belgium & 422 & 10.79 & $269,062,223$ & 5.0900 \\
\hline Sri Lanka & 152 & 0.83 & $84,078,140$ & 0.2402 & Morocco & 80 & 2.05 & $262,928,365$ & 4.9740 \\
\hline Cyprus & 147 & 0.81 & $87,946,799$ & 0.2513 & Belarus & 76 & 1.94 & $251,127,327$ & 4.7508 \\
\hline Denmark & 134 & 0.73 & $150,734,159$ & 0.4307 & Netherlands & 78 & 1.99 & $235,312,350$ & 4.4516 \\
\hline Oman & 134 & 0.73 & $160,733,569$ & 0.4593 & US & 41 & 1.05 & $234,105,616$ & 4.4287 \\
\hline Sweden & 110 & 0.60 & $186,404,505$ & 0.5326 & Indonesia & 232 & 5.93 & $230,831,644$ & 4.3668 \\
\hline Morocco & 80 & 0.44 & $262,928,365$ & 0.7513 & Sweden & 110 & 2.81 & $186,404,505$ & 3.5263 \\
\hline Yemen & 80 & 0.44 & $101,257,783$ & 0.2893 & Oman & 134 & 3.43 & $160,733,569$ & 3.0407 \\
\hline Netherlands & 78 & 0.43 & $235,312,350$ & 0.6724 & UK & 223 & 5.70 & $153,819,313$ & 2.9099 \\
\hline Belarus & 76 & 0.42 & $251,127,327$ & 0.7176 & Denmark & 134 & 3.43 & $150,734,159$ & 2.8515 \\
\hline Australia & 68 & 0.37 & $2,336,339,178$ & 6.6759 & Pakistan & 66 & 1.69 & $102,606,433$ & 1.9411 \\
\hline Pakistan & 66 & 0.36 & $102,606,433$ & 0.2932 & Yemen & 80 & 2.05 & $101,257,783$ & 1.9156 \\
\hline South Korea & 63 & 0.35 & $49,304,315$ & 0.1409 & Japan & 43 & 1.10 & $98,080,939$ & 1.8555 \\
\hline Thailand & 59 & 0.32 & $717,959,615$ & 2.0515 & Cyprus & 147 & 3.76 & $87,946,799$ & 1.6638 \\
\hline Greece & 47 & 0.26 & $41,920,115$ & 0.1198 & Sri Lanka & 152 & 3.89 & $84,078,140$ & 1.5906 \\
\hline Japan & 43 & 0.24 & $98,080,939$ & 0.2803 & South Africa & 27 & 0.69 & $59,742,802$ & 1.1302 \\
\hline US & 41 & 0.22 & $234,105,616$ & 0.6689 & Brazil & 21 & 0.54 & $51,367,238$ & 0.9718 \\
\hline Finland & 33 & 0.18 & $6,686,514$ & 0.0191 & South Korea & 63 & 1.61 & $49,304,315$ & 0.9327 \\
\hline Canada & 28 & 0.15 & $33,798,631$ & 0.0966 & Greece & 47 & 1.20 & $41,920,115$ & 0.7930 \\
\hline Romania & 28 & 0.15 & $37,879,449$ & 0.1082 & Sudan & 13 & 0.33 & $39,404,573$ & 0.7454 \\
\hline South Africa & 27 & 0.15 & $59,742,802$ & 0.1707 & Romania & 28 & 0.72 & $37,879,449$ & 0.7166 \\
\hline Ireland & 25 & 0.14 & $14,596,678$ & 0.0417 & Yugoslavia & 19 & 0.49 & $34,901,480$ & 0.6603 \\
\hline Bahrain & 21 & 0.12 & $10,080,214$ & 0.0288 & Canada & 28 & 0.72 & $33,798,631$ & 0.6394 \\
\hline Brazil & 21 & 0.12 & $51,367,238$ & 0.1468 & Qatar & 8 & 0.20 & $19,847,964$ & 0.3755 \\
\hline Bulgaria & 19 & 0.10 & $13,354,097$ & 0.0382 & Ireland & 25 & 0.64 & $14,596,678$ & 0.2761 \\
\hline Ukraine & 19 & 0.10 & $10,740,679$ & 0.0307 & Libya & 6 & 0.15 & $13,846,445$ & 0.2619 \\
\hline Yugoslavia & 19 & 0.10 & $34,901,480$ & 0.0997 & Bulgaria & 19 & 0.49 & $13,354,097$ & 0.2526 \\
\hline Liechtenstein & 14 & 0.08 & $8,865,457$ & 0.0253 & Ukraine & 19 & 0.49 & $10,740,679$ & 0.2032 \\
\hline Hungary & 13 & 0.07 & $8,691,371$ & 0.0248 & Bahrain & 21 & 0.54 & $10,080,214$ & 0.1907 \\
\hline Slovenia & 13 & 0.07 & $3,757,494$ & 0.0107 & Myamar & 4 & 0.10 & $9,915,821$ & 0.1876 \\
\hline Sudan & 13 & 0.07 & $39,404,573$ & 0.1126 & Liechtenstein & 14 & 0.36 & $8,865,457$ & 0.1677 \\
\hline Cuba & 12 & 0.07 & $2,598,541$ & 0.0074 & Hungary & 13 & 0.33 & $8,691,371$ & 0.1644 \\
\hline Croacia & 8 & 0.04 & $1,424,021$ & 0.0041 & Finland & 33 & 0.84 & $6,686,514$ & 0.1265 \\
\hline Iran & 8 & 0.04 & $6,317,729$ & 0.0181 & Singapore & 7 & 0.18 & $6,331,519$ & 0.1198 \\
\hline Qatar & 8 & 0.04 & $19,847,964$ & 0.0567 & Iran & 8 & 0.20 & $6,317,729$ & 0.1195 \\
\hline Singapore & 7 & 0.04 & $6,331,519$ & 0.0181 & Macedonia & 1 & 0.03 & $6,196,213$ & 0.1172 \\
\hline Libya & 6 & 0.03 & $13,846,445$ & 0.0396 & Luxembourg & 2 & 0.05 & $5,692,990$ & 0.1077 \\
\hline Poland & 5 & 0.03 & $4,229,195$ & 0.0121 & Poland & 5 & 0.13 & $4,229,195$ & 0.0800 \\
\hline Myamar & 4 & 0.02 & $9,915,821$ & 0.0283 & Kenya & 1 & 0.03 & $3,908,984$ & 0.0739 \\
\hline New Zealand & 3 & 0.02 & 744,366 & 0.0021 & Slovenia & 13 & 0.33 & $3,757,494$ & 0.0711 \\
\hline Argentina & 2 & 0.01 & 119,185 & 0.0003 & Cuba & 12 & 0.31 & $2,598,541$ & 0.0492 \\
\hline Luxembourg & 2 & 0.01 & $5,692,990$ & 0.0163 & Bangladesh & 1 & 0.03 & $2,426,485$ & 0.0459 \\
\hline Portugal & 2 & 0.01 & 613,791 & 0.0018 & Monaco & 1 & 0.03 & $1,995,014$ & 0.0377 \\
\hline Slovakia & 2 & 0.01 & $1,401,378$ & 0.0040 & Croacia & 8 & 0.20 & $1,424,021$ & 0.0269 \\
\hline
\end{tabular}

Source: IIC 
Table 3.3 shows the largest nation-exporters to Iraq. The Table has two blocs divided into five columns, which are nations, contracts and percentage of contracts per nation, exports in USD million, and percentages of total exports per nation. In the Table, first note that the number of contracts does not always render large volumes of exports. Jordan, Turkey and Italy rank first, third, and fourth respectively in Bloc I, but they rank fourth, ninth and twelfth respectively in Bloc II. Russia and Egypt rank fifth and seventh in Bloc I. Russia accounts for $10.6 \%$ of all contracts, leading exports under the UN sanction regime. Egypt jumps from seventh to third with contracts worth nearly \$3 billion, $8.7 \%$ of all exports. The case of Vietnam is as notable for it goes from twenty first in Bloc I to sixth in Bloc II. Yet, the main finding is that Jordan, Turkey, Egypt and Syria are among the top ten in both blocs. They are Iraqi neighbors, and they have historically had good trade relations with Iraq. I argue that their common trade relations and geography facilitated the signing of bilateral trade agreements, which d' facto created a regional trade bloc. To illustrate it, I present Table 3.4.

Table 3.4 - Trade Performance of Middle East Nations under UN Sanctions Regime

\begin{tabular}{|c|c|c|c|c|c|}
\hline \multicolumn{2}{|r|}{ Bloc I } & & \multicolumn{2}{|r|}{ Bloc II } & \\
\hline Countries & $\begin{array}{c}\text { Ave. GDP } \\
1992-2003 \text { in USD }\end{array}$ & $\begin{array}{l}\text { Exports in } \\
\text { USD }\end{array}$ & Countries & $\begin{array}{c}\text { Ave. GDP } \\
1992-2003 \text { in USD }\end{array}$ & $\begin{array}{l}\text { Exports in } \\
\text { USD }\end{array}$ \\
\hline S. Arabia & $154,469,346,725$ & $654,764,093$ & Egypt & $53,065,439,231$ & $2,962,660,858$ \\
\hline Turkey & $117,111,376,923$ & $1,649,514,851$ & Jordan & $5,188,421,231$ & $2,548,005,219$ \\
\hline Egypt & $53,065,439,231$ & $2,962,660,858$ & UEA & $38,904,620,000$ & $1,944,219,047$ \\
\hline UEA & $38,904,620,000$ & $1,944,219,047$ & Turkey & $117,111,376,923$ & $1,649,514,851$ \\
\hline Syria & $10,865,513,846$ & $1,544,681,993$ & Syria & $10,865,513,846$ & $1,544,681,993$ \\
\hline Lebanon & $10,442,206,923$ & $770,030,253$ & Lebanon & $10,442,206,923$ & $770,030,253$ \\
\hline Qatar & $9,323,203,846$ & $19,847,964$ & S. Arabia & $154,469,346,725$ & $654,764,093$ \\
\hline Jordan & $5,188,421,231$ & $2,548,005,219$ & Qatar & $9,323,203,846$ & $19,847,964$ \\
\hline Total & $399,370,128,725$ & $12,093,724,278$ & & $399,370,128,725$ & $12,093,724,278$ \\
\hline
\end{tabular}

Source: IIC Report 
Table 3.4 summarizes exports of Middle East nations to Iraq under the UN sanctions. The Table has two blocs. Bloc I has two columns. One is for GDP. The other is for exports. Whereas Bloc I is sorted by GDP, Bloc II is sorted by export volumes. Note that I include Turkey and Egypt in this table although one is located in Europe and the other in North Africa, but not far from Iraq. Egypt is a Muslin nation. Its trade relations with Iraq are as old as their culture and religions. When the sanction regime was enacted in 1991, Egypt was Iraq's main trade partner after Russia and France. For their part, Turkey and Iraq have common borders. They are both Muslim nations with a large population of Kurds. Their trade relations date back to ancient times, long before they were part of the Persian and Ottoman Empires. Still, Table 3.4 also shows that, in most cases, nations with borders with Iraq scored higher exports. Note that GDP does not correlate with exports. Egypt has the third largest GDP in the region and leads in exports per nation. The UAE has the fourth largest GDP and ranks third in exports. Syria and Lebanon occupy the same positions in terms of GDP and exports. However, Saudi Arabia has the largest GDP but ranks sixth in exports. Jordan has the smallest GDP, but it exports more than Saudi Arabia. Turkey has the second largest GDP but ranks fourth in exports. Lastly, consider that nations from the EU exported about $\$ 8$ billion to Iraq, $\$ 4$ billion less than what all nations in Table 3.4 exported even though they have smaller GDPs. Middle Eastern nations outdid the members of the UN Security Council by nearly $\$ 3$ billion. In all, based on Tables 3.3 and 3.4, I argue that, as the CIA put it, "Geographic proximity, cultural affinity, and historical economic relationship explain why Turkey, Jordan, and Syria reached formal trade Protocols with Iraq in contravention of UN resolutions" (Duelfer Report, Saddam Strategic Intent, p. 9). 
Krugman $(1979,1991)$ and Samuelson $(1949,1983)$ explain it better than the CIA. Krugman treats geography, culture, and ethnicity not as mere factors but as determinants in regional trade. He incorporates what he calls determinants in his intercontinental trading costs versus regional trading costs model, from which he infers that nations of common determinants form a natural regional bloc (Krugman, 1991, p.490). Krugman would argue, I think, that such was the case of Iraq, Jordan, Syria, Turkey, Iran, and even Lebanon and Egypt under the UN sanctions regime against Iraq. For his part, Samuelson would argue that trade among Iraq, Jordan, Turkey and Syria was endogenous, that it consolidated after hundreds of years of economic interactions due to common borders, cultures, customs, language and other historic patterns. Samuelson adds that, "When patters are endogenous, small initial differences can make big effects in terms of costs and profits" (Samuelson, 1983, p. 57). I think that it is in that sense that Jordan, Syria, Turkey, Iran and Iraq constitutes one common market, and as Samuelson states, "Trade costs shape the pattern of trade..., and costs are well explained by geography and a set for regional trade patterns" (Samuelson, 1983, p. 74).

Of course, the Middle East was not the only regional trade block that Iraq utilized to circumvent the UN sanctions and reach global markets. Iraq also used the former Communist Bloc, in particular the bloc of nations that formed former Soviet Union. Here I define the Communist Bloc not only for its political and social configuration but also in terms of an economic system highly independent from the rest of the global market. The former Soviet Union brought Eastern European communist nations into the Soviet economy and a trade treaty known as the CAMECON. The problem is that those nations developed close trade relations with Iraq during the 1970s and 80s. The Soviet Union 
invested heavily in Iraq's oil, construction and military industries. As I showed in Chapter II, the Soviet Union alone was the second most important trade partner to Iraq before Gulf War of 1991. When the Soviet Union fell and Russia, Ukraine, Belarus, and Byelorussia emerged as independent republics, they did not break trade relations with Iraq. They were under such an economic crisis that they needed as many trade partners as possible. Russia, Ukraine, Belarus, and Byelorussia took over the trade relations and contracts that the Soviet Union had with Iraq. For Iraq, it was a fortunate confluence of historic circumstances. Iraq could not afford to lose one trade partner under the UN sanctions. Certainly, it did not lose Russia, Ukraine, Belarus and other ex Soviet republics. In this Dissertation, Chapters V and VI in particular, we will see that ex Soviet republics continued to trade with Iraq until the final fall of Saddam's regime in 2003.

All in all, regional economies make up the global economic system. They are the base of the global economy and the strongest link to global trade. Both global and regional trade is built on interconnected, interdependent transnational and corporate relations. They aim at opening markets, tearing down trade barriers, and enacting fairer trade policies at regional levels. Some scholars see regional trade as a desertion from global trade. But for Krugman, global and regional trade can function in harmony. He sees regional trade as "Improving in nature and likely to have a positive impact on the global trade system" (Krugman and Obstfel, 2003, p .77). The question is, as Bhagwati summarizes it, "Whether regional trade blocs are building blocks or stumbling blocks to the global trade system" (Bhagwati, 1993, p. 42). For Iraq, regional trade under the UN sanctions regime was a building block aimed at circumventing the UN sanctions regime 
and reaching global markets. For Iraq's regional trade partners too, regional trade was a building block to counterbalance the effects of UN sanctions on their economies.

\section{The Politics of Bilateral Trade}

The UN sanctions against Iraq had a malign and benign domino effect in the Middle East. It had malign effects because Iraq's neighboring economies suffered as much as Iraq's. It had benign effects because as Iraq's economy improved, Iraq's neighboring economies resurged and the entire region enjoyed a relative economic boom. The Iraqi economy became more interconnected to its neighbors through a series of trade protocols which in turn led to more solid political interconnectness. The result was a new political map for the Middle East in detriment to the UN sanctions regime, the UN, and the U.S. and its allies.

Bilateral trade protocols are a means to more bilateral trade. Bilateral trade protocols are biding contracts between two nations of common commercial interests. The two nations agree to discuss and implement a set of common goals related to bilateral trade (Bhagwati, Krishna \& Panagariya, 1999, p. 64). The goal is to promote bilateral trade by minimizing undesirable bilateral competition between each other while maximizing comparative advantages. Each nation agrees to give each other some sort of special treatment in terms of tariffs, export-imports quotas and discounts among other benefits. For example, in the bilateral trade protocols that Iraq signed with Syria and Egypt, Iraq agreed to increase crude oil supplies to Syria and Egypt only after those two nations accepted a drastic decrease in taxes to agricultural and construction products that Iraq purchased from them (CFIJ, p. 55). Iraq agreed to sign a bilateral trade protocol with 
Turkey only after Turkey agreed to meet one key Iraqi demand: lift the embargo on jewelry and other high ticket items that the Iraqi regime needed, so it could reward its most loyal servicemen (CFIJ, p. 55).

In general, bilateral trade protocols do not cover all economic sectors, goods and services, which are limited to the rules and items of the protocols. Also, bilateral trade protocols are limited by time, meaning that they are valid for one, two or three years, after which the two parties can either renegotiate the terms of the Protocol or just opt out of it. For instance, Iraq signed its first trade protocol with Jordan in 1983 (CFIJ, p. 57). It was the largest trade protocol Iraq ever signed although it was limited to the trade of Iraqi oil for Jordanian grains. It contained a clause to allow both parties to amend it, include more goods and increase trade quotas (CFIJ, p. 57). The Protocol became inactive in 1991, but in 1992 Iraq and Jordan renegotiated it based on that Clause. By 2003, it became a full Trade Agreement valid for 10 years and renegotiable every 2 years. The Agreement accounted for 94 Jordanian goods and 27 Iraqi products, of which 21 were oil derivatives (CFIJ, p. 57). The new Iraqi government has not ratified the Agreement.

Note that bilateral trade can have positive effects on political relations between bilateral trading partners. Bilateral trade usually translates into political cooperation on wider range of issues. For example, by 1998, the good trade relations between Iraq and Jordan began to translate into good political relations. Relations improved so much that Iraq invited Jordanian Prime Minister Ali Abdul Ragheb to visit Iraq, the first visit to Iraq of any Arab Prime Minister since the enactment of the UN sanctions regime (CFIJ, p. 58; Duelfer Report, p. 88). 
In November 2000, the Prime Minister landed in Bagdad. He carried a message from the King of Jordan that read: "Jordan would no longer comply with UN Resolution 867" (CFIJ, p. 58). To confirm it, he publicly declared that “Jordan's expansion of trade with Iraq was the government's prime objective" (CFIJ, p. 58), and for that purpose "A Jordan-Iraqi company examines expanding land transport fleet, and that the General Assemble of Iraqi-Jordanian land Transport Company would meet in Bagdad" (CFIJ, p. 58). In February 16, 2001, Iraq News Agency and the Jordan Times reported in headlines: "King, Crown Prince meets with Iraqi transport minister." Two weeks later, Jordan expelled Lloyd's Register, the company that UN had designated to monitor and audit the enforcement of the UN sanctions against Iraq (CFIJ, p. 59). On the other hand, to show that Jordan was still a moderate nation, King Abdullah travelled to Kuwait where he made a conciliatory speech. The King also sent a note to Israel and Saudi Arabia, two key Jordan trade partners but Iraqi rivals. He declared to the Jerusalem Post that "Iraqi exports to Israel are not out of the question." He was responding to rumors that "Israel had made a tentative agreement to import oil from Iraq via Jordan (CFIJ, p. 59). In the case of Saudi Arabia, he offered subsidized oil for Jordan. But oil was not a concern to Jordan; after all, it was getting cheap oil from Iraq. Jordan's real concern was its agricultural and agro-industrial exports to Iraq, which accounted for near $34 \%$ of Jordan GDP (CFIJ, p. 59).

The U.S. did not like what Jordan was doing, so it accused Jordan of violating the UN sanction regime against Iraq and took over enforcement of the sanctions in Jordan territories. The U.S. and UK began to patrol and inspect Jordan ports, prompting a Jordanian official to declare that: "What we are experiencing is a blockade against a 
non-sanctioned nation" (CFIJ, p. 58). U.S. Secretary of State Warren Christopher travelled to Amman on two occasions to demand "Effective enforcing of the sanctions, only them the US would recall its patrols from Jordan ports" (CFIJ, p. 58). Yet, Jordan resisted the pressure and joined the large group of nations that by the year 2000 were openly opposing the UN sanctions against Iraq. High level Jordanian officials voiced Jordan's position, and some of them travelled to Bagdad to show public support for Iraq.

\section{Global Trade with Iraq during the Sanctions Regime}

Global trade is about trade as much as it is about politics. It is so because there are many parties involved. Nations, corporations, states' agencies, civic organizations and individuals, they all have some interests vested in trade. So they all, one way or the other, participate in trade politics. That is why trade politics is not monolithic but fragmented according to trade interests. For its part, global trade is divided into regions, sub-regions, blocs and sectors, resembling the world's political map. If 20 years ago there were a first, second, and third world, today there are developing and developed nations. If 20 years ago there were a couple of trading blocs, namely nations allied to the U.S. and nations allied to the former Soviet Union, today there is about a dozen of them. Trade blocs act and interact under the umbrella of globalization. They are interconnected and interdependent. Despite all the grouping and subgrouping, there is just one global economic system, namely the capitalist system. It all undermines a sanctions regime, even if it is multilateral, enforced by the UN with the support of the U.S., namely the most powerful nation in the world.

Indeed, in chapter II, I explained how Iraq obtained about $\$ 75$ billion from oil 
sales. Evidences suggest that those revenues allowed Iraq to: 1) access and engage in trade relations in the global economy; 2) increase purchases in global markets; 3) reactivate its economy; 4) increase its expenditures. Chart 3.1 shows Iraq's budgetary and expenditures under the UN sanctions regime.

\section{Chart 3.1 - Budget and Expenditure}

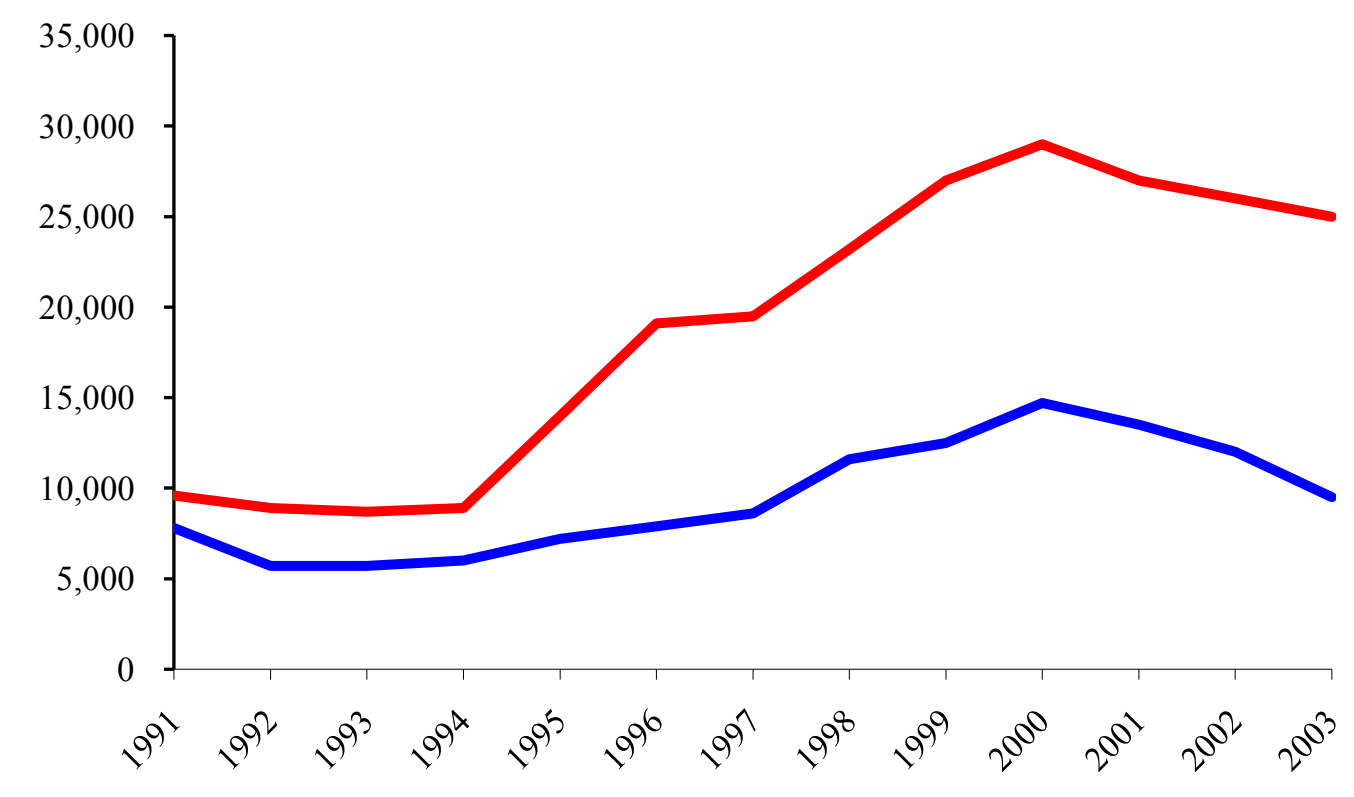

Source: the Duelfer Report

The Chart is a representation of Iraq's budget and expenditures from 1991 to 2003, the timeframe of the UN sanctions against Ira. The blue line represents Iraq's budget while the red represents Iraq's expenditures. Notice that Iraq's budget fell sharply from 1991 to 1992, right after the Gulf War, and that it stagnated between 1993 and 1994. The GDP per capita fell from $\$ 2,304$ to $\$ 495$ dollars. The dramatic decline was due 
to two main factors: 1) UN sanctions were in fact effective; 2) Saddam Hussein was still preparing a plan to evade the sanctions. But observe in the Chart how the budget began to pick up by the end of 1994 and grew steadily until 2000 when the Iraqi economy slowed down and its budget shrunk once again, losing nearly $\$ 4,000$ million by 2003 . It was in 1994 when Iraq finally adopted a plan to circumvent the UN sanctions regime.

In contrast, the red line shows that Iraq's expenditures grew noticeably. Note that the Iraqi budged stayed below the $\$ 10,000$ million from 1991 to 1998 , but Iraq spent roughly \$20,000 million during the fiscal year 1997-1998, twice its budget. This trend continued until 2003 although the Iraqi budget began to shrink once again in 2000. This relation between budget and expenditure suggests three points. First, Iraq was making enough money as to afford sharp budgetary increases during the UN sanctions regime. Second, Iraq showed no intention to slow down expenditures, living beyond its means for most of the UN sanctions regime. Third, it shows the intensity of Iraq's trade. During the Gulf War, Iraq's infrastructures were basically destroyed, its industries paralyzed, its agriculture unproductive. Iraq needed to import all kind of goods and services, from food, cloth and medicines to industrial parts, hardware and machineries. Iraq's lucrative oil sales allowed it to afford those purchases. But the question remained: How did Iraq circumvent the sanctions? For Iraq, the answer was twofold. Iraq would focus on regional markets as a means to reach global trade, and regional trade to engage in global trade. Second, in order to ensure regional trade, Iraq sought trade agreements with its neighbors. After all, Iraq knew its neighbors very well. It had been trading with them for centuries. Evidences suggest that Iraq used geography as a comparative advantage. Iraq utilized regional and bilateral trade to evade UN sanctions and reach global markets. Iraqi 
commerce rested on several bilateral trade protocols that Iraq signed with about 30 nations, including North Korea, Russia, Belarus, Ukraine, Bulgaria, Romania, China, South Africa, Thailand, Vietnam, and Taiwan. Yet, the bulk of Iraqi trade fell on a dozen nations in the Middle East, mainly on Jordan, Syria, Turkey, Egypt, and Lebanon. The Chart below shows the main sources of income for Iraq under the UN sanctions regime.

\section{Chart 3.2 - Main Sources of Income for Iraq under UN Sanctions Regime}

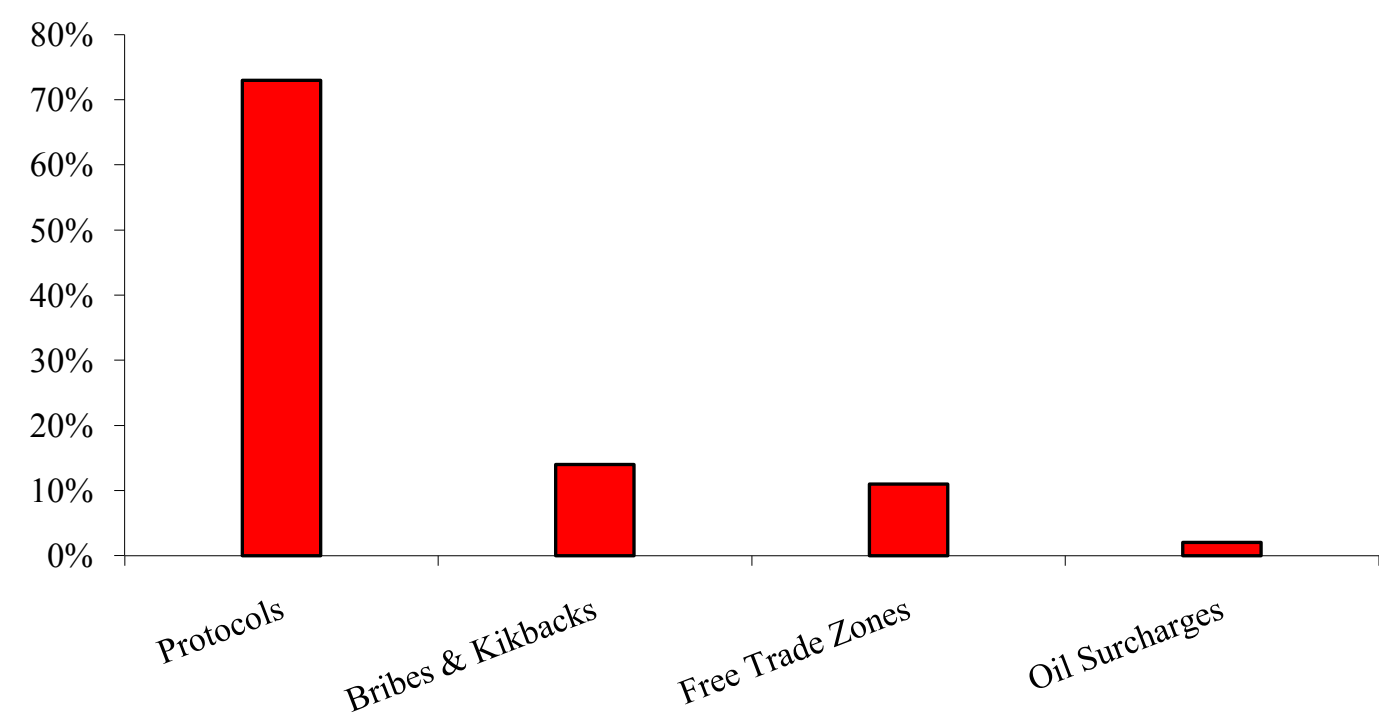

Sources: CFIP, the Duelfer Report

The Chart shows that trade agreements rounded $70 \%$ of all Iraqi revenues under the UN sanctions regime. It was well ahead of bribes and kick-backs, which Iraq utilized, along with the protocols, for political and economic purposes.

In terms of politics, Iraq first used trade agreements to gather support against the UN sanctions. Iraq did an excellent job showing the world the wrongs that the sanctions caused on Iraqi people. In the age of global media, pictures and videos of Iraqi children 
and women dying due to hunger and malnutrition circulated around the world, causing great sympathy toward the Iraqi people. As years passed, support for the sanctions regime eroded, and it became more difficult for UN and the U.S. to prevent nations from trading with Iraq. Second, UN and American officials did not take into account advices from economists like Bhagwati who argue that bilateral and regional trade constituted the foundation of the global economy, so Iraq could well utilize bilateral and regional trade to reach the global market. Third, the sanctions had a domino effect in the entire region. For example, Jordan and Syria fell into a deep recession right after UN began to enforce the sanctions because they could not export their agricultural products to Iraq, and Iraq could not sell its oil and derivatives to them. Turkey lost a vital source of income: charging the E.U. and Iraq for using Turkish transcontinental oil pipes to move Iraqi crude oil from Northern Iraq to European markets. And Egypt and Lebanon had to buy oil from Libya and Saudi Arabia at a higher price.

Lastly, Iraq used trade as means to political integration via trade integration with the Middle East. The CFIJ quoted the Iraqi Minister of Foreign Affair as saying that "The free market agreements are steps on the road of Arab economic integration and unity. This is Iraq's principled stand. Unlike some of the industrialists, we do not view every stage and every step that we take in this regard from the angle of loss on profit. This is a huge strategic action. Any pan-Arab step has gains and may have losses although we do not considerer them as losses from our principled and pan-Arab perspective” (CFIJ, p. 74). The CIA was well aware of the political implications of the protocols for the region. In a Memo dated May 1998, the CIA stated: "Iraq stands to gain from these agreements on several fronts. First, it gets the immediate political benefit of publicizing agreements 
that can demonstrate domestically and internationally the ongoing erosion of sanctions. Second, the agreements enable Iraq to increase its presence in the Arab world, which has ongoing trade negotiation both among Arab nations and with other key partners, particularly under the EU-Mediterranean free trade pact. Iraq's apparent objective here would be to solidify its standing with regard to a future Arab Common Market. Third, these agreements, once ratified, and so far, only the UAE and Tunisia have done so - will guarantee Iraq preferential trading access as soon as sanctions are lifted" (Duelfer Report, p. 264). The CIA got it right because, by 2003, 14 Muslim and Arab nations had openly signed trade agreements with Iraq. Table 3.5 lists them.

Table 3.5-Muslim and Arab Nations that Signed Trade Agreements with Iraq

\begin{tabular}{|l|l|}
\hline Egypt & $1997,1999,2001$ \\
Syria & $1997,1999,2000$ \\
Tunisia & February-01 \\
Yemen & August-01 \\
Algeria & October-01 \\
UAE & November-01 \\
Sudan & March-01 \\
Bharain & March-01 \\
Oman & April-01 \\
Lebanon & $1999,2001,2002$ \\
Qatar & June-02 \\
Jordan & $1998,1999,2002$ \\
Saudi Arabia & 1999,2002 \\
Morroco & June-01 \\
\hline
\end{tabular}

Sources: CFIJ, the Duelfer Report

First, observe in the Table that Egypt and Syria signed protocols with Iraq as early as 1997. In the case of Jordan, although it signed its first Protocol in 1998, it had been 
negotiating it since 1995. Second, note that some nations signed Agreements in several years. The parties meet to renegotiate terms of contracts, expand lists of products or just adapt trade relations to realities on the ground. This was chiefly true of Iraq, which varied its business dealings according to the political demands of the U.S. and UN, not to mention that Iraq kept testing American influence in the UN with respect to the sanctions regime. Such was the case, just to mention one, of the Jordan-Iraqi Special Protocol to allow Muslim pilgrims to visit Iraq's most revered shrines. Jordan was to manage the Protocol, but Iraq not only wanted to charge $\$ 2,000$ per pilgrim, it also demanded that the money be deposited at the Iraqi Central Bank (CFIJ, p. 57). The U.S. and UK opposed it. France, Russia and China went for it. Then, Iraq asked for more. It asked to raise the number of pilgrims from 10,000 to 30,000 per year. The CIA calculated that so many pilgrims would bring to Iraq about $\$ 100$ million dollars. So the U.S. fiercely lobbied France, Russia and China, which this time voted against Iraq's request (CFIJ, p. 57).

The most relevant here is that the Agreements became the most important source of revenues for the Iraqi regime. The CIA stated that 'The protocols allowed Saddam to generate large amounts of revenues outside the purview of the UN" (Duelfer Report, $\mathrm{p}$. 29). The Heritage Foundation found that "Iraq's bilateral trade Protocols with neighboring states provided Saddam with his largest source of illicit income during UN sanctions. Jordan, Egypt and Turkey welcomed it but OPEC hated Saddam" (Heritage Foundation, p. 15). And the IIC concluded that "Trade protocols earned Saddam over $\$ 800$ billions of revenues that he did not have to account for to UN. His trade partners knew it all along" (IIC, Illicit Trade, p. 8). It led Mr. Volcker, Chairman of the IIC, to declare to Congress, in frustration, that "It is particularly important to state for the 
records, Mr. Chairman, that this is more than six times as much as he was able to skim off the Oil for-Food Program. This is massive trade, Mr. Chairman; tremendous amount of trade to the gates of Europe, Asia and North America and we didn't see it Mr. Chairman, we didn't" (Hearing before the Subcommittee on Energy and Air Quality, House of Representatives, 108th Congress).

Indeed, Iraq's trade relations with its neighbors were the gates to global markets. Yet, Mr. Volker failed to note some key facts. First, nations like Yugoslavia, Bulgaria, Ukraine, Belarus, Russia, France and even the U.S. were at the other end of Saddam's scheme, for they all had some kind of trade agreements with Jordan, Syria, Egypt, and Turkey. Therefore, purposely or not, they all engaged in trade with Iraq. Second, the U.S. and UN actually endorsed and promoted some of those trade agreements to amend "unexpected" side-effects of UN sanctions against Iraq. As I stated earlier, the Iraqi economy was so interconnected to its neighbors that UN sanctions almost bankrupted the economies of Jordan, Turkey, and the Kurdistan, which happened to be political allies of the U.S. On the other hand, the sanctions were benefiting US enemies like Iran. I next present four case studies to explain how Iraq utilized bilateral trade agreements with its neighbors to evade the UN sanctions regime and reach the global market.

\section{$\underline{\text { Case Studies }}$}

In this section we present four cases of trade agreements that were instrumental in the circumvention of UN sanctions. They are: Jordan, Syria, Egypt and Turkey. We selected those cases based on the following rationale. First, they all are Middle Eastern nations, and three of them have borders with Iraq. This is very important because 
geographical proximity between trade partners seems to have helped Iraq tremendously in reducing transportation costs, time and resources. Also, knowing the terrain was crucial for smuggling, and we will see here that smuggling was a key means to evade UN inspectors and US military patrols, not to mention that it was also one of the most essential sources of revenue for Iraq. Second, the cases of Syria, Jordan and Turkey had several secondary effects. They ended up benefiting third parties such as Lebanon, Iran, Cyprus and the Kurds. The trade agreements between Iraq, Syria, Jordan and Turkey are, indeed, illustrative of the multiplicative effects that bilateral trade can have on regional and global trade. Lastly, the trade protocols were the most lucrative for Iraq. Chart 3.3 shows estimates of revenues through the protocols with Jordan, Syria, Turkey, and Egypt.

\section{Chart 3.3 - Iraq's Trade Protocols}

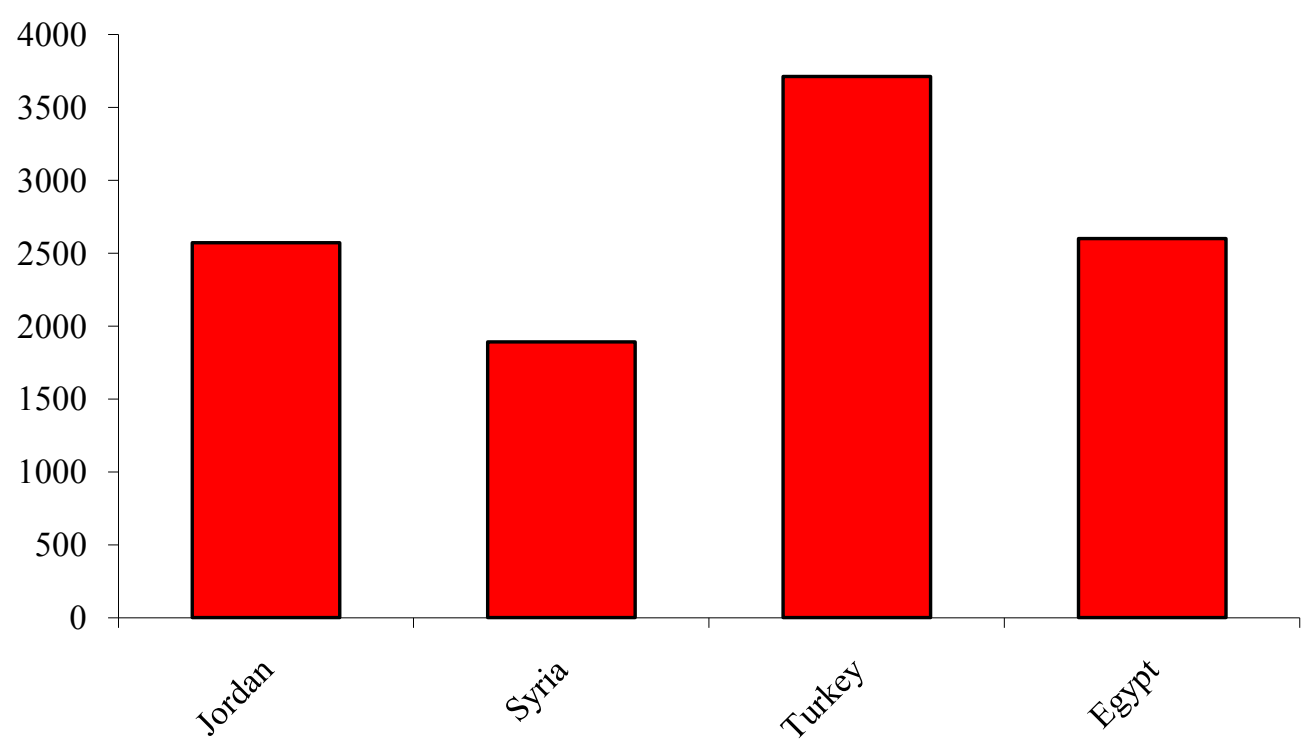

Source: Duelfer Report, IIC, CFIJ, Michigan Project 
I obtained the data from four main sources. Although they did not coincide $100 \%$ in their findings, the numbers were close enough. I added them up and determined an average, so I can utilize just one measure to simplify the comparative analysis. I sorted the cases according to revenues. In other words, I discuss first Syria because it had the lowest revenues. And I end with Turkey for it had the highest revenues.

$\underline{\text { Syria }}$

Syria-Iraqi trade was not as profitable as others. Yet, I discuss it here because it brought Syria and Iraq together, two nations that had had serious political disagreements since their foundations. Syria-Iraq trade also had key implications for Jordan and, mainly, Lebanon, a nation within the sphere of influence of Syria.

Syria and Iraq always had good trade relations. They are natural markets. They share borders, culture, language, religion, tribal and family relations, and even the same food diet. As I stated in Chapter II, the entire territory once constituted just one people. It was partitioned by the British first and later by the UN. In 1991, Syria dominated $21 \%$ of the Iraqi market, but the trade was rather informal due to the shaky political relations the two nations have had since their foundation (Duelfer Report, Syria-Iraq Protocol, p.12). Political tension escalated when Syria sided with Iran during the Iraq-Iran war and with Kuwait during the Iraqi invasion of that nation. Syria thought that one day Saddam would invade it. Still, in 1994, the two nations began to talk about 'a new era' and, particularly, about 'reviewing' their trade relations. In 1995, they agreed to reopen an oil pipeline that had been shot down in 1980 (CCFIJ, p. 41). In 1995 too, they established border posts to allow commercial trucks to move freely between the two nations. The trucks belonged to 
Syrian and Iraqi smugglers hand-picked by their respective governments to do the smuggling, and the so called border posts were in fact military patrols purposely created to protect smugglers and their cargoes from UN inspectors (CFIJ, p.41). Then, in 1996, Syria and Iraq created several free trade zones along the Syria-Iraq border. They were opened not only for smugglers but also for Syrian and Iraqi merchants. According to the CFIJ, "It all occurred so fast that Iraqi and Syrian merchants thought that it was one of Saddam's political moves to crack down on his political enemies" (CFIJ, p. 42).

Indeed, commerce picked up, and in 1997 the two nations began to announce a series of trade protocols which the media from the two nations celebrated with fanfare and headlines. For example, Iraq News Agency announced in July $10^{\text {th }}$, 1997 that "Iraq and Syria sign joint cooperation minute", and the Syria Live commented that "Syria and Iraq sign transport agreement" (CFIJ, p. 39). But perhaps the most important agreement, at least for Iraq, was the Memorandum of Understanding that was signed to reopen the oil pipeline that had been closed in 1980. This time, the Syria Live headlined the event with some exaggeration for it affirmed, on February 23, 1997, that "The new Syrian-Iraqi oil pipeline will carry 1.4 million barrels per day" (CFIJ, p. 39). According to most experts on the field, the pipeline could not handle such an amount of barrels per day, but work to repair the pipeline still began almost immediately. By July 1998, Syria had repaired its portion of the pipe although it was having technical issues with some pumping posts. Syria called French engineers for help. The French not only repaired the pumps but also redesigned a 12 mile expansion of pipe. Oil began to flow from Iraq to Syria in 2001.

Reopening of the pipeline was a great momentum for the trade relations between the two nations. The British newspaper The Guardian highlighted its importance in 
March 26th $\mathrm{th}^{\mathrm{st}}, 2001$ by stating that "Syrian economic rehabilitating is in the pipeline". The Iraqi Press celebrated it by stating on July $20^{\text {th }}$ that “Iraq's trade with Syria booms despite UN embargo". The CFIJ noted that "The oil flow accelerated the thaw in bilateral relations for it led to a series of important economic events" (CFIJ, p. 40). Indeed, Syria repaired and re-inaugurated the Aleppo-Mosul rail-tracks in about nine months. The reopening was crucial because, with train-tankers now moving oil to Aleppo, Syria was able to reopen an electricity plant it had there. The plant consumed nearly 30,000 barrels of Iraqi oil per day (CFIJ, p. 42). Iraq corresponded by repairing the pipeline that ran from Kirkuk, Northern Iraq, to Bania, a port at the Syrian Mediterranean coast. It motivated Syria to rapidly set aside $\$ 34$ million to repair and expand the port of Tartous. The Arabic News celebrated the announcement by reporting, on February 23, 2002, that "With the investment Iraq increases its imports through Syrian ports", but the Sunday Telegraphs editorialized on February $27^{\text {th }}$ that "It was another Saddam's set up of smuggling to beat sanctions".

Iraq opened another 4 border crossings, and Syria reciprocated by creating the National Trucking Company, which converted its trucking industry into small private fleets. It allocated $\$ 9$ million to build posts and repair roads along the Syrian-Iraqi border (CFIJ, p. 42). It also built new roads to connect seven free trade zones along their common borders. The Iraqi regime sent 25 diplomats to its Embassy in Damascus, and the Syrian government crated a new office at the Syrian Embassy in Bagdad. The office had a status of trade attaché, and it had 17 employees who participated in trade meetings with Iraqi delegates and companies (CFIJ, p. 42). Then, in 2000, Syria and Iraq consolidated their trade protocols and signed a trade agreement. The Duelfer Report 
stated that "The protocol was augmented to the category of Free Trade Agreement" (Duelfer Report, Syria-Iraq Protocol, p. 13). The agreements stated that Syria was to acquire oil at a discount. In return, Syria was to allow the use of its oil pipelines to ship oil out of Iraq to Lebanese ports, from where it would ship it to Turkey and then Europe. The Duelfer Report found that "From November 2000 until the fall of Saddam's Government, Iraq made an estimated - and these estimates differ- $\$ 2.8$ billion by smuggling oil through Syria. As much as 250,000 barrels per day flowed through Syria at cut-rate prices, allowing the Syrians to refine the oil for domestic use and sell reserves of their own oil on the world market" (Duelfer Report, Syria-Iraq Protocol, p. 13). For its part, GAO reported that “According to estimates from Iraq's State Oil Marketing Organization, known as SOMO, from June 2000 until July 2003, the Iraq-Syria Trade Protocol generated approximately $\$ 3.4$ billion from the sale of illicit Iraqi crude oil and Iraqi petroleum products" (GAO Report, p. 61).

Also, the Duelfer Report stated that "Syria acted as Iraq's banker, and some of its highest officials brokered military deals for Iraq and profited from these military deals" (Duelfer Report, Syria-Iraq Protocol, p. 9). American investigators from the Treasury Department detected some Iraqi accounts at Commercial Bank of Syria where "about $\$ 850$ million had been left behind by the Iraqi regime. The Syrian Government, without authentication or authorization from SOMO, had deposited an estimated $\$ 580$ million to pay out outstanding claims by Syrian and Iraqi companies, leaving \$266 million as Iraqi assets in the Commercial Bank in Syria" (Duelfer Report, Syria-Iraq Protocol, p. 14). Iraq consistently used the Syria-Iraqi Protocol to collect and make payments. Documents found at Iraq's ministry of trade revealed that Infobank, a Belarusian Bank, transferred 
\$114 million to an Iraqi bank account in Syria, from where it was transferred to Bagdad. The documents revealed a stream of payments from different sources, including Russian, French, and Chinese firms (Duelfer Report, Syria-Iraq Protocol, p. 14). In all, "Syria was Iraq's second largest market for smuggled oil, and the Syrian Protocol was Iraq's primary illicit income source from 2000 to 2003 when US and its allies invaded Iraq" (Duelfer Report, Syria-Iraq Protocol, p. 5). The Protocol included contracts for Syrian companies to buy goods on Iraq's behalf. Syria also became Iraq's main route for illegal trade with Iraq from 1999 to 2003. Just from October 2000 to April 2001, Syria transported \$2 billion worth of goods into Iraq, most of which was purchased in Bulgaria, Rumania, and Yugoslavia. Goods included machineries and spare parts for transportation and electrical grids (Duelfer Report, Finance and Procurement, p. 102). Chart 3.4 shows the distribution of goods imported into Iraq under the Syrian-Iraqi Protocol.

\section{Chart 3.4 - Iraq-Syria Trade Protocol}

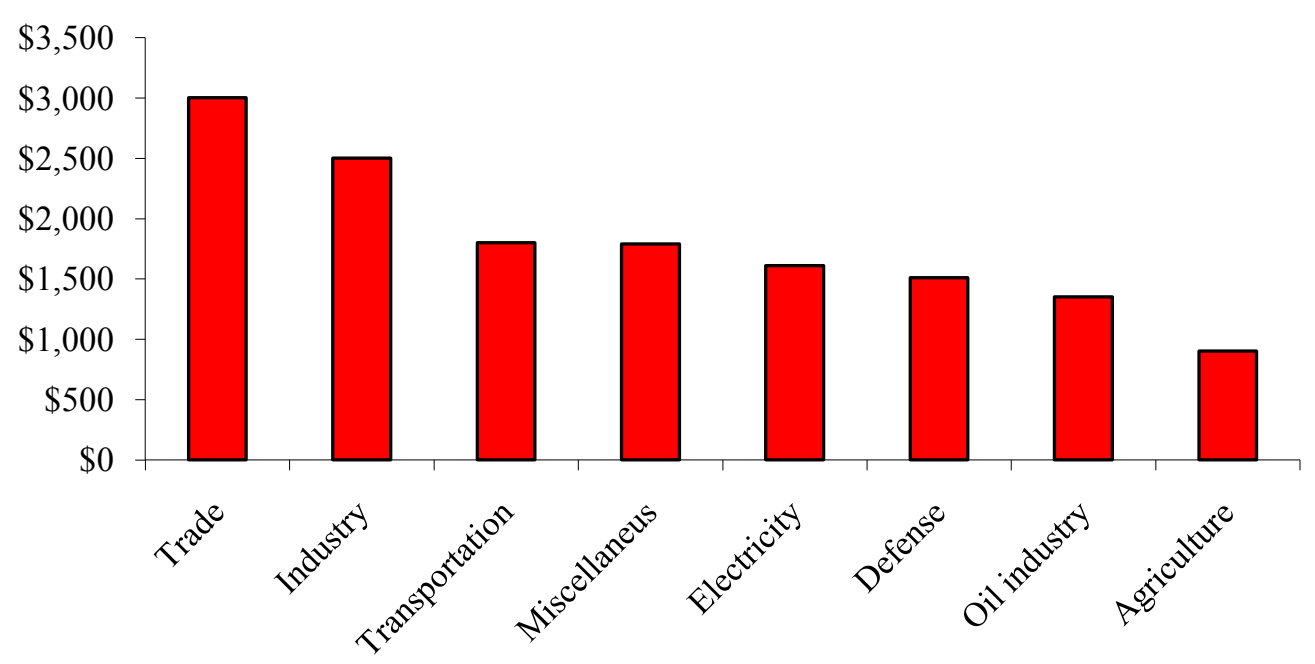

Source: Duelfer Report, IIC, CFIJ, Michigan Project 
Chart 3.4 reveals the overall scope of the Syrian-Iraqi trade protocol. For instance, it shows that industry ranked second in trade volumes even though Syria and Iraq are not industrial nations. But above all, it calls to my attention that defense trade reached $\$ 1,500$ million dollars, and that miscellaneous accounted for almost $\$ 1,700$ million. Note that the Iraqi regime usually tallied military hardware as miscellaneous charged it to a NGO. Therefore, here defense and miscellaneous mean the same thing: military hardware. But Graph 3.4 does not say it all. For example, it does not reveal the multiplicative effects trade had over Jordan and Lebanon.

\section{$\underline{\text { Lebanon }}$}

I study the case of Lebanon as part of the Syria-Iraq trade agreements because, as I stated earlier, this case illustrates how interdependent Syria and Lebanon are and how such interdependency affected the effectiveness of the UN sanction regime against Iraq.

Syria has for many years shown great geopolitical interests in Lebanon. Lebanon does not have oil in abundance. It depends on oil imports from Libya and Northern Iraq via Turkey. Lebanon consumes about 50,000 barrels of oil per day, and it imports close to $\$ 1$ billion worth of oil and its derivatives every year (CFIJ, p. 53). For its part, Syria has for long tried to control the flow of oil into Lebanon for political reasons and because it would add a billion dollars annually to its budget. Then, there is Iraq, which needed to export as much oil as it could, and to do so it had to circumvent UN inspectors. The Iraqi regime had at that point two standing routes. It had the Turkish-Kurd route and Iranian territorial waters, which I will discuss shortly. Nonetheless, the Iraqi regime reasoned that having a third route would increase its oil exports without saturating the other two routes. 
A Syria-Lebanon pipeline would do it. It was a good route to Europe too. Therefore, Iraq, Syria and Lebanon struck a deal to repair a pipeline that ran from Iraq to Syria and then to Lebanon. They agreed to do it within the marks of the Syria-Trade trade agreement. They also brought in Libya to: a) provide technical support; b) provide infrastructure; c) provide ship-tankers under Cypriots flag from Lebanon to North Africa and Southern Europe (CFIJ, p. 53). As for Lebanon, the deal brought million of dollars not only for using its territory for the pipeline but also all the commerce that Iraq smuggled back from Europe and northern Africa. The following table shows the volume of trade between Iraq, Syria and Lebanon from 1999 to 2002.

Table 3.6 - Trade Volume between Iraq, Syria and Lebanon from 1992 to 2002

\begin{tabular}{|l|l|l|l|l|}
\hline & 1999 & 2000 & 2001 & 2002 \\
\hline Iraq & \$110 millions & \$113 millions & \$119 millions & \$125 millions \\
\hline Syria & \$165 millions & \$172 millions & \$121 millions & \$129 millions \\
\hline Lebanon & \$121 millions & \$88 millions & \$91 millions & \$97 millions \\
\hline
\end{tabular}

Sources: The Duelfer Report, the CFIJ

Table 3.6 shows that trade between the three nations was voluminous. But the main point here is how trade and political relations between two nations can affect other nations within the same region. In this case, trade between Iraq and Syria benefitted Lebanon. Yet, trade between Iraq and Syria affected American politics toward Iraq, Syria and Lebanon. First, Iraq was capable of linking its economy to a market it did not have before: Syria. It translated into low costs, more commerce, and more revenues. Second, 
economic gains eventually translated into political gains. Iraq hoped that, as Syria's economic gains increased, Syria would become active against the sanctions regime. Moreover, the two economies would be so linked that Syria would have no choice but to violate the UN sanctions. Third, Iraq also expected that other neighboring nations would ultimately imitate Syria. In particular, the Syrian-Iraqi deal pushed Jordan to compete with Syria for Iraqi trade. Iraq hoped that such competition would force Jordan to relax its stand on smuggling.

It actually occurred. I explained earlier that, by the year 2000, Jordan's King was traveling to Bagdad and that Jordan was openly breaking with the UN sanctions regime.

$\underline{\text { Jordan }}$

Like the Syrian-Iraqi case, Jordanian-Iraqi trade has for long been based on tribal and family relations. Jordan usually exported agricultural products and foodstuffs to Iraq, controlling $45 \%$ of the Iraqi food market. In 1991, Iraq imported $70 \%$ of the food it consumed from Jordan. In exchange, Iraq exported oil to Jordan, meeting Jordan oil needs. Jordan depends on Iraq for about $85 \%$ of its oil consumption. To facilitate their trade, Jordan and Iraq never taxed their trade zones along their borders.

The UN sanctions regime disrupted the trade between the two nations. It affected Jordan so much that Jordan protested numerous times before the UN Security Council. Jordan based its claims on Article 50 of the UN Charter (CFIJ, p. 35). This Article states that a nation-state whose economy is affected by economic sanctions that the Security Council imposes on another nation "Shall have the right to consult the Security Council with regard to a solution of those problems" (CFIJ, p. 35). Jordan argued that the UN 
sanctions regime led to "Extreme economic hardships, including a direct financial loss of approximately $\$ 1.5$ billion dollars per year and even the total collapse of the Jordan economy" (CFIJ, p. 35). Jordan took its case to the 661 Committee. There it stated that "Finding a continuous and secure source of oil was almost impossible since Iraq was a regional supplier and Jordan's cheapest trade partner" (CFIJ, p. 35). Then, Jordan approached UN Security Council. It proposed that Iraq funded oil deliveries not with cash or credit but with the money Iraq owed to Jordan. Jordan promised to submit a monthly report that would account for quantities, value, schedules of deliveries and their costs.

The 661 Committee and the U.S. accepted it. The 661 Committee allowed Jordan to sign a first bilateral trade agreement with Iraq based on oil-for-debt-reduction. Jordan would get oil from Iraq in exchange for a reduction of Iraq's debt with Jordan. Once the debt was paid off, Jordan would exchange oil for foodstuffs. In addition, the U.S. granted to Jordan $\$ 2.4$ billion dollars in economic aid, the most favored nation status, and it even signed a bilateral trade protocol with Jordan (CFIJ, p. 36). Jordan utilized those benefits to trade with Iraq. With the American loans, Jordan purchased American products that it could then resell to Iraq. The U.S. knew about it but decided to ignore it for geopolitical reasons. Let us not forget that Jordan is a moderate nation in a volatile region, and it is one of the few allies the U.S. has in the Middle East. As Meyer and Califano state it: "Successive U.S. administrations acknowledged that U.S. - Jordan trade undermined the sanctions but cited its cooperation in other foreign policy objectives and annually invoked the national interest exception in Jordan's favor" (Meyer and Califano, 2006, p. 117). 
The new trade eventually led to a new trade agreement, which the two nations signed in late 1992 and renegotiated in 1996 (Duelfer Report, Regime Finance and Procurement, p. 144; CFIJ, p. 37). In reality, it did not alter the nature of their trade relations that much. Like always, Iraq exported oil and its derivatives to Jordan in exchange for foodstuffs and access to Jordan's oil pipelines. However, there was a new component to it: Iraq pumped oil to Jordan, which Jordan then channeled to Lebanon and Egypt. Lebanon and Egypt shipped the oil to the Balkans, Italy, Spain, France and other nations in the Mediterranean basin. It was during this period that the UN sanctions regime had its strongest effects on the Iraqi economy, so this oil sells through Jordan constituted a huge break for Iraq. The Duelfer Report stated that "Jordan ensured the Iraqi regime's financial survival until the UN OFF program began in December 1996" (Dulfer Report, Regime Finance and Procurement, p. 143). The Report also stated that “Iraq's earnings amounted to about $\$ 400$ million annually from 1992 through 1995. This estimate includes trade under US-Jordan Protocol averaging about \$200 million annually and Iraq's debt to Jordan increasing by $\$ 1$ billion, which accounts for additional Iraqi imports averaging another \$200 million a year" (Dulfer Report, Regime Finance and Procurement, p. 144.)

Iraq also smuggled about $\$ 2.4$ billion worth oil into Jordan during the same period. The IIC detailed the operation as follow: "Iraq trucked both crude oil and oil products—fuel oil, gas oil, LPG, base oil and gasoline—to Jordan under the agreement, according to SOMO records. Then Jordan trucked and piped the crude to ports in the Mediterranean. Lebanon and Egypt led the trade; Italy, Spain, Cyprus and the Balkans 
were their customers" (Duelfer Report, Regime Finance and Procurement, p. 148). Chart 3.5 summarizes Iraq-Jordan exports under the Protocol.

\section{Chart 3.5 - Iraq-Jordan Trade Protocol}

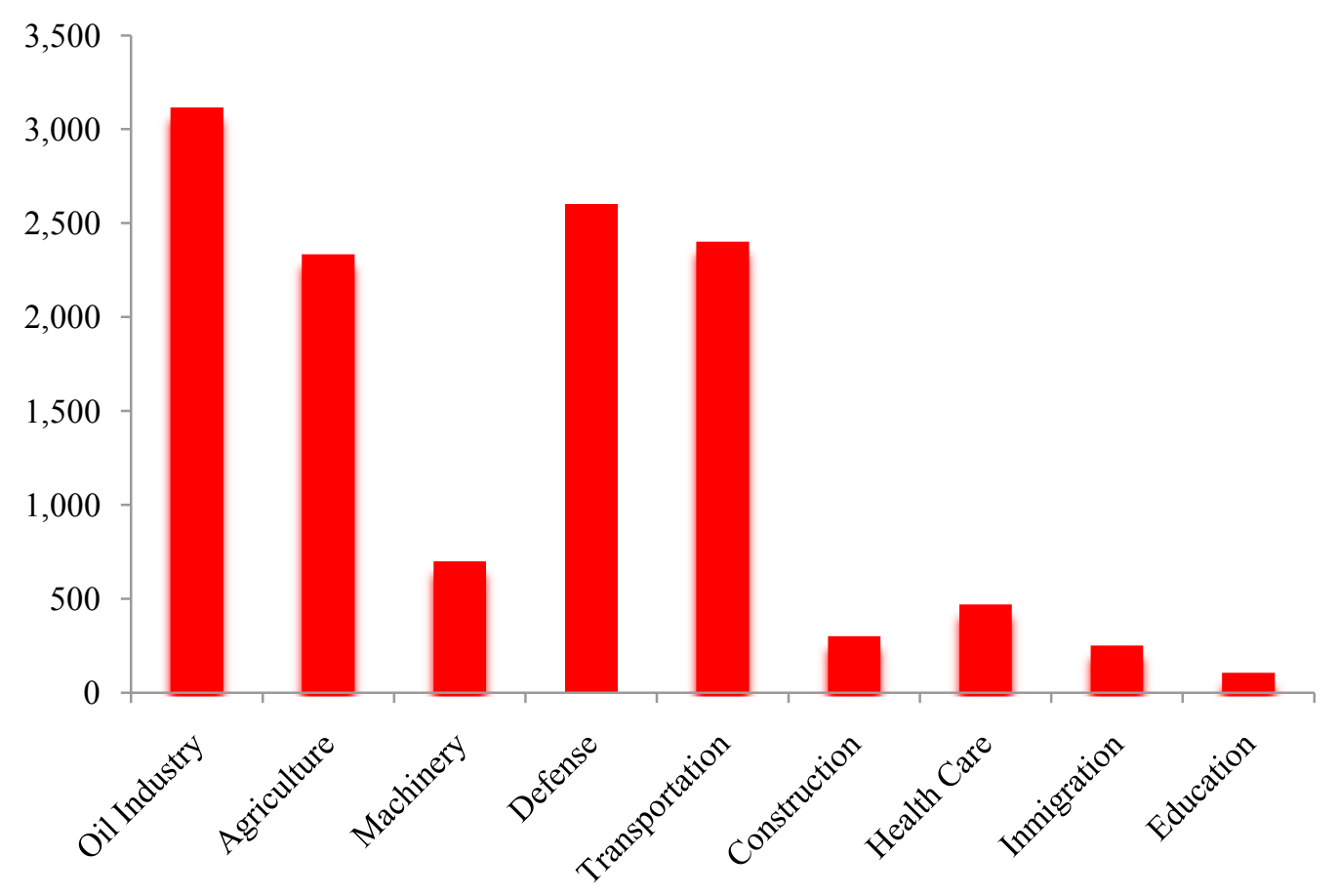

Sources: Duelfer Report, CFIJ, ICC, Michigan Project

We can see in the Chart that trade between Iraq and Jordan covered multiple industries, even immigration, which is understandable since they are neighbors of common tribal and religions heritage. We can also see that their trade was a multimillion dollar operation. Ironically, Jordan exported to Iraq about $\$ 2,300$ million in food, which was much more of what Jordan could actually produce, considering its agricultural 
capabilities. By 1995 , the volume increased by $\$ 300$ million annually, and Jordan's agriculture produces only about $\$ 200$ million per year. Also, note that defense scored high levels of trade as well. Of course, it does not mean that Jordan manufactured arms for Iraq because Jordan does not have an arm industry. Rather, it means that Jordanian intermediaries and Iraqi firms based in Jordan purchased components and spare parts for the Iraqi military industry, as I will explain more in Chapter VII. For now, observe that most of the Jordan-Iraqi trade was done by trucking. That explains the large amount of revenues in term of transportation. It is another evidence of the importance that the trucking industry had for commerce under the UN sanctions regime.

For its part, Iraqi oil deliveries were so voluminous that Iraq almost saturated the Jordanian market. As result, in 1997, Jordan and Iraq began to talk about renegotiating the trade agreement. They signed a final draft in 1998, and they amended it in November 1999 and December 2001 (Duelfer Report, Regime Finance and Procurement, p. 146; CFIJ, p. 37). They agreed to meet yearly to discuss trade volumes, prices, types of products, delivery schedules and other trade issues. According to Iraqi officials, the negotiations were rough and lasted long hours. Saddam questioned every aspect of the agreement and always demanded more. Jordan limited itself to accept Iraqi conditions for it needed Iraqi oil. For example, Jordan had to accept an increase in oil delivery from 65,000 barrels per day to 110,000 when Jordan only needed about 50,000 for its economy. About 300 trucks full of Iraqi oil per day entered Jordan (Duelfer Report, Regime Finance and Procurement, p. 146; CFIJ, p. 37). The Overland Transport Company managed the operation. Both Jordan and Iraq owned the company in a jointventure since 1980. Yet, Iraq managed to force Jordan to pay between $\$ 50$ and $\$ 80$ 
million per year for transportation (Duelfer Report, Regime Finance and Procurement, p. 148; CFIJ, p. 37). But perhaps the most important accord was the building of an oil pipeline from Iraq to Jordan and then to Lebanon. Work on the pipeline began in 2001, with a planned capacity for 350,000 barrels of oil per day, part of which was to be redirected to Palestine and Israel. In the end, construction was put on hold due to the USled invasion of Iraq in 2003 (Duelfer Report, Regime Finance and Procurement, p. 146; CFIJ, p. 37). Table 3.7 below shows trade volumes from 1995 to 2002.

$\underline{\text { Table } 3.7 \text { - Trade Volume between Iraq and Jordan }}$

\begin{tabular}{|l|r|r|r|r|r|r|r|r|}
\hline & $\mathbf{1 9 9 5}$ & $\mathbf{1 9 9 6}$ & $\mathbf{1 9 9 7}$ & $\mathbf{1 9 9 8}$ & $\mathbf{1 9 9 9}$ & $\mathbf{2 0 0 0}$ & $\mathbf{2 0 0 1}$ & $\mathbf{2 0 0 2}$ \\
\hline Protocol in bpd & 82000 & 84000 & 90000 & 96000 & 96000 & 96000 & 100000 & 110000 \\
\hline Actual bpd & 83000 & 88000 & 87000 & 94000 & 91000 & 94000 & 125000 & 135000 \\
\hline Imports in USD millons & $\$ 220.00$ & $\$ 220.00$ & $\$ 255.00$ & $\$ 200.00$ & $\$ 300.00$ & $\$ 450.00$ & $\$ 260.00$ & $\$ 310.00$ \\
\hline Iraq in USD millons & $\$ 317.00$ & $\$ 185.00$ & $\$ 249.00$ & $\$ 199.00$ & $\$ 162.00$ & $\$ 190.00$ & $\$ 430.00$ & $\$ 424.00$ \\
\hline Jordan in USD millions & $\$ 442.00$ & $\$ 502.00$ & $\$ 510.00$ & $\$ 330.00$ & $\$ 414.00$ & $\$ 677.00$ & $\$ 734.00$ & $\$ 646.00$ \\
\hline
\end{tabular}

Sources: Duelfer Report, CFIJ

This trade protocol was exuberant, excellent for Iraq, but it had two undesirable consequences for Jordan. First, Iraq was saturating Jordan oil market, and Jordan did not have storage capacity for so much oil. Second, Iraq was literally forcing Jordan to sell the surplus in the black market, something that Jordan wanted to avoid, so it could keep in good standing its political relations with the UN and the U.S. Nevertheless, some evidence shows that Jordan did sell oil in the black market. For example, the CFIJ found 
that "Jordan sold the excess at a discount, believed to be \$5-6 below market price. The value of which has ranged from $\$ 200$ million in the early 1990s to $\$ 450$ million in 2001 " (CFIJ, p. 38). But according to the Arab Oil and Gas Directory, "Jordan works hard to accommodate the money from oil surplus. Jordan deposits payment for the cut-rate oil into an Iraqi-controlled account at the Central Bank of Jordan. Iraq can use these funds to purchase Jordanian goods. It practice, these funds could be used to purchase anything, including items imported into Jordan that are otherwise banned by UN sanctions" (CFIJ, p. 38).

It is revealing the way Jordan and Iraq worked together to laundry the money that Jordan made though illicit oil sells. For instance, in reality Iraq never received any money from Jordan. I stated earlier that Iraq had a commercial attaché in its embassy in Jordan. This attaché would show up at a branch of the Central Bank of Jordan and hand in an invoice stamped by the Iraqi government. The Bank would then transfer the value of the invoice to the company or nation that purchased the goods on behalf of Iraq. The issue was that nations like Russia, Egypt and Jordan itself purchased goods on Iraq's behalf in the global market. The CFIJ explains that "The modus operandi is far from new: using the Central Bank of Jordan to provide funds, ostensibly to subsidize Jordanian-produced goods, but in fact to help powerful Jordanian firms move foreign goods to Iraq, was a technique employed by Bagdad to evade UN sanctions and obtain access to foreign commerce" (CFIJ p. 35).

The Iraq-Jordan trade protocol was profitable for both nations. The Jordan Times made the math and reported in November 1st, 2000 that "The $\$ 600$ million per year oil Protocol with Iraq weights in the Kingdom's economic balance sheet”. For Iraq, the 
Protocol represented about 2,000 million per year, but above it helped to the survival of the Iraqi regime.

Egypt

Iraq signed a trade protocol with Egypt. The CIA acknowledged that "We do not have access to documents outlining this agreement," (Duelfer Report, Regime Finance and Procurement, p. 162) for which little is known about the Protocol. Most of what is known was obtained after the American led invasion of Iraq in 2003, and it is not abundant. Nonetheless, I found that the protocol lasted about five years, from 1998 to 2003, and that Egypt was among a handful of nations that kept illegally trading with Iraq after September 11 (Duelfer Report, Regime Finance and Procurement, p. 168).

That is, as the U.S. began to make plans to invade Iraq, Iraq lost most of its customers and its oil sales fell dramatically. But Egypt seized the opportunity, stayed in and profited handsomely from Iraq's few customers, very low oil prices, and high oil supplies. I also found that the Egyptian-Iraqi protocol "Was 60-percent credit and 40percent cash. The credit account was under SOMO's name at the National Bank of Egypt and the cash proceeds were deposited in the Ahli Bank (Jordan National Bank) in Jordan” (Duelfer Report, Regime Finance and Procurement, p. 163). It involved the Iraqi Military Industrialization Commission (MIC), an Iraqi front company with subsidiaries in Jordan, Syria, Lebanon, Yemen and Egypt itself.

I also found that Iraq trucked its oil and delivered it to Aqaba, Jordan, then shipped it to Yemeni ports, and then to Egypt. The final destination was East Asia, in particular Taiwan and China. The smuggling included crude oil and its derivatives. Iraq 
charged $\$ 7$ dollars per barrel to Egypt, half less than the price of crude oil in the global market and much less than what UN allowed Iraq to charge, which was between $\$ 16$ and \$20 dollars per barrel (Duelfer Report, Regime Finance and Procurement, p. 165). The CIA estimated that oil sales under the Protocol amounted to $\$ 21$ billion dollars in three years (Duelfer Report, Regime Finance and Procurement, p. 165). In exchange, Egypt provided Iraq with steel, copper, aluminum, chemicals and electrical wiring. All those materials were strictly prohibited by the UN sanctions regime since they could be used for military purposes. Egypt also sold Iraq acid nitric. This chemical was specifically prohibited by the UN sanctions regime because it is widely used in the making of WMDs although it is a basic component for pesticides as well, useful in the agriculture in the Middle East.

In total, Egypt shipped back to Iraq about $\$ 150$ million dollars annually from 1993 to 1997 (Duelfer Report, Regime Finance and Procurement, p. 165). During the first half of 1999 , Egyptian exports to Iraq increased by $\$ 570$ million dollars, a 50\% higher than in 1998 (Duelfer Report, Regime Finance and Procurement, p. 165). In 2000, just one Egyptian company, Ginza, exported \$300 million dollars to Iraq (Duelfer Report, Regime Finance and Procurement, p. 167). It motivated the Egyptian Prime Minister to declare to AFP that "Egypt's exports to Iraq will reach three billion dollars by the end of 2002" (Duelfer Report, Regime Finance and Procurement, p. 168). Whether the Egyptian Prime Minister was exaggerating of not, the number gives us a rough idea of the volume of trade between Egypt and Iraq at the time. I would have expected that the sanctions regime should have brought that number down to much lower levels. 


\section{Chart 3.6 - Iraq-Egypt Trade Protocol}

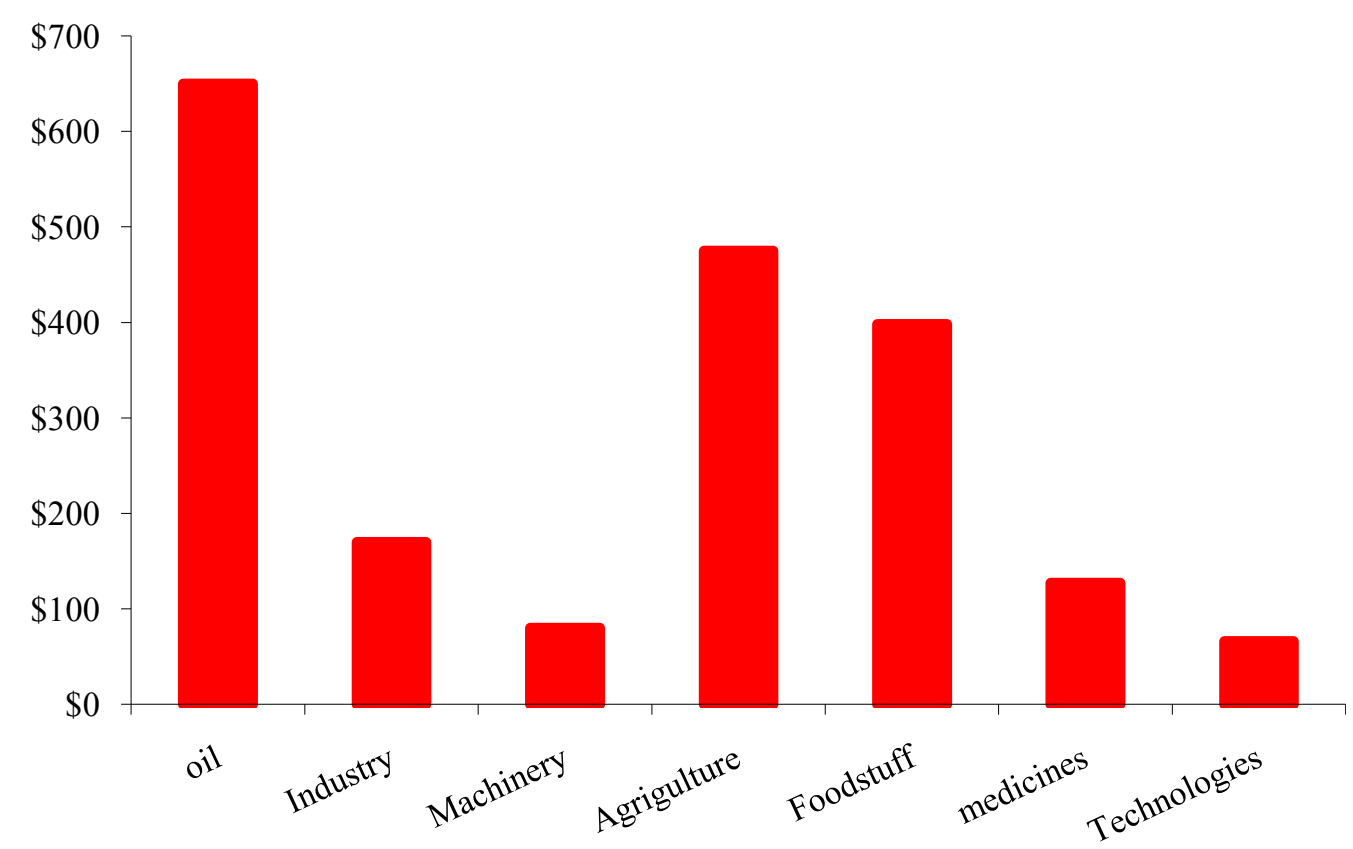

Source: the Duelfer Report

As a whole, the trade agreement provided Iraq with about $\$ 8$ billion dollars over 10 years. Additionally, it provided about $\$ 75$ million in fees, $\$ 28$ million from kickbacks, \$990 million from oil "cash sales" or smuggling; and \$230 million from other surcharge impositions (Duelfer Report, Regime Finance and Procurement, p. 165). Still, the most significant finding here is that Chart 3.6 omits revenues for transportation, unlike in the cases of Syria Jordan and Turkey and Iran. Of course, it means that there were no transportation revenues in the case of Egypt, but it also means that trade between Egypt and Iraq was so expensive that revenues were not significant. It explains why the overall trade between Iraq and Egypt was less voluminous than with Jordan, Syria, Turkey, and Iran. Iraq does not have border with Egypt. It does with Jordan, Syria, Turkey and Iran. 
This is exactly what I would expect to find based on Krugman's trade theory as applied to circumvention of the UN sanctions against Iraq.

The Iraqi-Egypt Protocol was not the most profitable for Iraq. It was not the most significant for the UN sanctions regime. Surely, it is not the most important for this dissertation. The most relevant case study is the Iraqi-Turkey trade agreement. We will next see why.

Turkey

The Turkey-Iraq trade protocol was vital for Iraq's survival because, as the Duelfer Report put it, "Turkey provided Iraq with significant revenue streams that permitted the Iraqi Regime to fund its illicit procurement activities" (Duelfer Report, Regime Finance and Procurement, p. 163). But the Turkey-Iraq trade protocol was the most interesting of all Iraqi protocols for one main reason: its multiplicative effect benefitted not only Turkey and Iraq but also Kurdistan, Cyprus, and even Iran. I will study those nations separately for they have unique features and political impact.

The first free trade zone opened for business in 1994, and it was an immediate success for Turkey, Kurdistan, and Iraq since legal trade amounted to $\$ 1$ billion dollars in the first 2 years (Duelfer Report, Regime Finance and Procurement, p. 165). The trade resembled what it had been for decades. Iraq sold crude oil to Turkish companies which then refined it and shipped a portion, in the form of diesel oil, to Europe and another portion back to Iraq and Iran (CFIJ, p. 27). Kurds from both sides of the border transported crude and diesel oil by truck (CFIJ, p. 27). Turkish small companies brought all sorts of goods from Europe, from clothing and food to industrial machinery, trucks, 
cars and spare parts (CFIJ, p. 28). They sold them throughout the Middle East. Since they crossed Iraqi territories, Iraq taxed their cargoes and even purchased portions for itself and for resale. Turk and Iraqi Kurds did not mind paying taxes to the Iraqis (CFIJ, p. 27). Trade was still good enough. Besides, they had no more opportunities for they were being discriminated against and deprived of almost all rights under the Saddam's regime.

Trade was booming. Turkish, Kurds and Iraqi intermediaries were smuggling about 70,000 barrels of oil per day. TUPRAS, the largest Turkish refinery, had so much oil to refine that it outsourced some to its clients (CFIJ, p. 28). TUPRAS was the second largest recipient of illegal Iraqi oil from 1992 to 1997, a period of intense contraband in the zone. In fact, trade was so booming and contraband was so rampant that by 1996 Turkey proposed a trade protocol to the Iraqi government (CFIJ, p. 28). They decided to cooperate because they both were losing money to contraband. UN sponsored the Protocol, and the U.S. served as an observer (CFIJ, p. 28).

According to the Protocol, Iraq was to reserve $21 \%$ of its market for Turkey's exports. In return, Iraq was to sell crude oil to just 4 Turkish private companies. They were: OZ Ortadobgu, Ram Dis, Tekfen and the state-owned company Turkish Petroleum International Company (TPIC). TUPRAS was to refine the crude and convert it into diesel. The Protocol also authorized "Turkey to pay roughly \$6 less than the authorized price for crude under the UN OFF Program; the low price served as an incentive for Turkey to participate in the scheme as a guarantor of the UN sanctions regime against Iraq” (Duelfer Report, Regime Finance and Procurement, p. 162). In addition, the deal stipulated that Iraq could increase oil sales in 3 million barrels per day to Turkish Petroleum International Company, a subsidiary of the state-owned Turkish National Oil 
Company (Duelfer Report, Regime Finance and Procurement, p. 163). It is worth noting that TPIC was also a subsidiary of Erdem, which traded oil on behalf of Mobil Corp, a parent company of Exxon-Mobil (CFIJ, p. 28). Both Mobil Corp and Exxon-Mobil are American companies. In Chapter V, I will explain how corporations utilized corporate models such as subsidiaries and parent companies to evade UN sanctions against Iraq. For now, let me state that the CIA and the CFIJ showed ample evidence of how the TPIC, Mobil Corp and Exxon-Mobil lobbied for Turkey-Iraq trade protocol (CFIJ, p. 28). It is yet another case of how private firms influenced bilateral and regional trade agreements. Suddenly "an army" of intermediaries emerged in Turkey. They rushed to Turkish-Iraqi border to grab a piece of the Iraqi market. They purchased cloths, foodstuffs, medicines, furniture, school and medical supplies, and spare parts for construction and the oil industry in European markets to sell them in Iraq. The CIA cited some captured documents to reveal that "Turkish intermediaries exported to Iraq 10,000 generators, Mitsubishi pickup trucks, cranes and assorted construction materials" (Duelfer Report, Regime Finance and Procurement, p. 106). The CFIJ argued that "Turkish merchants played a leading role in reactivating agriculture in Kurdish lands by selling tractors, equipments, seeds and pesticides to Kurdish farmers" (CFIJ, p. 31). Indeed, Turks purchased most of the Kurd's harvest at preferential price, which they then resold in European markets. In Chapter VII, I will explain how some of those intermediaries even sold military equipment and hardware to Iraq. At the request of Iraq, Turkish intermediaries purchased equipment in Europe and utensils to be used in research projects that the Iraqi government sponsored. Some projects had civilian ends, but some 
had both civilian and military use as they dealt with biochemical research. This evidence led the CIA and UN investigators to believe that Iraq was working on a WMD program.

Still, I would argue that the Turkish-Iraqi trade agreement was a political solution to a problem that the UN sanctions created along the Turkish-Iraqi border. For the CFIJ, "Trade agreement between Turkey and Iraq is a political deal. Although shortsighted, it will curb unexpected effects of UN sanctions in this strategic region. The arrangement involves first direct contacts between the Turkish and Iraqi governments, and second the KDP and Turkish Kurds acting as middlemen between Iraqi 'private sellers' and Turkish entrepreneurs. Turkey is going after the PKK and Saddam won't interfere" (CFIJ, p. 31).

Two factions de facto occupied the Iraqi-Turkish border. On one hand, there were the Iraqi-Kurds and their militia known as Peshmerga. With the support of the US, they established a stronghold on the Iraqi side of the Iraqi-Turkish border. On the other hand, there were the Turkish-Kurds and their KDP. They too had a stronghold along the Iraqi-Turkish border, but on the Turkish side. Both the Iraqi and Turkish-Kurds noted the business opportunities that the UN sanctions regime against Iraq had created for them. The sanctions automatically created a black market along the border. On top of it, coalition forces had bombed the pipelines that transported Iraqi oil from Iraq to Turkey (CFIJ, p. 32). It meant that transporting oil, and all cargoes, had to be by truck and truckers had to cross Kurdish lines. The Kurds realized that they could control trade in the zone, and they did so. They first imposed a sort of "tax" to pay for security in the zone. But soon they began to serve as intermediaries between Iraqis and Turks. They arranged contracts, financed operations, transported the cargo, collected fees, and even 
policed the region. The CFIJ stated that "The Kurds came to develop a modus Vivendi out of the UN sanctions regime" (CFIJ, p. 28).

For the KDP, it was a means to survival as an Iraqi minority under Saddam's regime. Iraqi-Kurds even set a mission for themselves by claiming that they were the intermediaries between Iraqis and Turks. As early as 1993, the KDP's representative in Ankara publicly stated that "The diesel trade is tying the economy of the KDP's territory close to that of Turkey. Almost all the goods that Kurdish businessmen purchase with their profits from the diesel trade come from Turkey. And Turkish entrepreneurs are beginning to take an interest in the KDP's market; so far, that has spawned several joint ventures in hotels and the opening of the first private supermarket in Dahuk" (CFIJ, p. 29). The KDP created a corporation named Asia to manage trade along the Iraqi-Turkish border on Turkish side. The Financial Officer of Asia was Massoud Barzani, the leader of the KDP. According to the CFIJ, the KDP was making \$1 million daily just for taxing oil that was crossing its territory from Iraq (CFIJ, p.28). As one official from the State Department noted, "The Kurds are getting a lot of money through the oil trade, and we like the Kurds. Two American presidents appear to have calculated that Baghdad's profits from the Turkish oil trade were a tolerable cost for the above mentioned benefits to other participants in that trade. The argument put forward has been that, as long as the Turks took care to inspect and interdict materials that would support Saddam's development of weapons of mass destruction, US policy was being implemented" (CFIJ, p. 29).

Turkey had no problem with that either. They actually wanted the Kurds to prosper, hoping that they would not turn against the Turkish government and engage in 
guerrilla warfare. A Turk-Kurd legislator, arguing in the Turkish parliament in favor of illicit trade, affirmed that "If people were not offered employment, they would have no alternative but to take their guns and go to the mountains" (CFIJ, p. 30) And Prime Minister Bulent Ecevit argued that he would "Increase, not curtail the illicit trade with Iraq" (CFIJ, p. 28). Two months later, he declared that the Turkish government intended to increase imports of crude oil to 80,000 barrels per day. The CFIJ suggested that "The United States and the UN Sanctions Committee have allowed trade to flourish with only nominal protestations. With the northern no-fly zone patrolled from Turkish airbases, the US and UN are not eager to press the Turkish authorities to shut down the smuggling. Moreover, Western governments see some advantage in allowing the trade to go on to benefit the Turks and Kurds" (CFIJ, p. 28).

There was a problem, though. By 1996, the Turkey began to suspect that the Kurds were channeling money to the PKK, the military arm of the Turkish-Kurds separatists that the Turkish government classified as terrorists. In 1997, Turkish oil traders handed a Report to the Turkish National Security Council with evidences of how the Kurds transferred money to the PKK. In the same year, the Turkey took over a contract that a suspected PKK-linked company had won in an open bid (CFIJ, p. 28). Turkey complained to the U.S. and UN, and the U.S. allowed Turkey to take control over trade along its border with Iraq. In 1998, Turkey passed several laws to regulate trade in its border with Iraq. The Turkish government defended the regulations in an editorial that it published in the Turkish Daily News, March 7, 1998. The editorial informed that "The government tightened border trade regulations to avoid tax losses" (CFIJ, p. 30). 
The new regulations centralized the oil trade with Iraq. The CFIJ argued that the measure "Effectively legalized the sanctions-busting trade in diesel with Iraq" (CFIJ, p. 30). It created a Turkish Petroleum International Corporation, a subsidiary of Turk Petrol, a corporation that the Turkish government owned, and as I will argue in Chapter VI, governments and corporations utilized corporate models like subsidiaries as means to circumvent the UN sanctions regime. Still, Turkish Petroleum created an oil deposit near the Turkish-Iraqi border where all crude and diesel traders had to dump their cargoes for auditing (CFIJ, p. 31). Trucks and truckers had to obtain a special license for a fee. They had to sell their loads to just 15 Turkish companies, previously designated by the Turkish government. In reality, those 15 companies were part of SILOPI A.S, an auditing firm that the Turkish government had created to manage trade with Iraq under the UN sanctions regime. The new system began to operate in 1998 (CFIJ, p.31).

The printed media reported the events as they developed. For example, the Turkish Daily News reported in July 28, 1998 that "Silopi A.S. established for Habur diesel trade". The Los Angeles Times reported in August 4, 1998 headlines: "Turkey Shrugs off UN blockade of Iraq commerce as it lets truck drivers openly import, sell diesel from Kurdish-controlled areas". For its part, Reuters revealed in September 3, 1998, that "Turk takes control of illicit Iraqi diesel". The New York Times denounced in March 30, that "At Iraq's backdoor, Turkey Flouts UN sanctions". The CFIJ concluded that "The involvement of the Turkish government has also further politicized the diesel trade: as the Turkish government now has a direct financial stake in each transaction, the Iraqi government enjoys new leverage” (CFIJ, p. 33). Ironically Iraq, an embargoed nation, donated 500,000 barrels of oil to Turkey (CFIJ, p. 33). It did not mind that Iraqi 
people were starved. Saddam wanted to show "solidarity" to the Turks in light of the earthquake that had hit Turkey two weeks earlier.

Turkey profited handsomely from the trade as it made $\$ 74$ million dollars during the first three months of the new Plan, just in taxes. It made $\$ 324$ million in the first year (CFIJ, p. 33). By then, bottlenecks had been forming along the Turkish-Iraqi border. Such a massive traffic could not go unnoticed. The UN calculated that, at some point, TurkishIraqi trade employed about 45,000 Turkish truckers, mechanics, retailers and other personnel along the Habur-Kirkuk route. This trend continued until right before the American led invasion of 2003 (CFIJ, p. 33).

The Kurds benefited as well from the Iraqi-Turkish trade. The CFIJ summed it up in this way: "For the Kurds, the Iraq-Turkey oil trade is a mixed blessing. The wholesale and retail trade in Iraqi Kurdistan of Turkish and European goods has flourished due to this arrangement, and estimates of revenues run as high as $\$ 3$ million a day; the trade in oil, diesel and other commodities is the most significant source of funds for the embargoed areas, amounting to \$11 million per day” (CFIJ, p. 33). Table 3.8 below shows Kurds' profits for moving oil out of Iraq and diesel back to Iraq and Iran.

Table 3.8 - Kurds' Profits for Moving Oil and Diesel

\begin{tabular}{|l|r|r|r|r|r|r|r|r|r|r|}
\hline & 1993 & 1994 & 1995 & 1996 & 1997 & 1998 & 1999 & 2000 & 2001 & 2002 \\
\hline Diesel & $\$ 27$ & $\$ 98$ & $\$ 121$ & $\$ 553$ & $\$ 830$ & $\$ 1,078$ & $\$ 2,005$ & $\$ 1,648$ & $\$ 1,170$ & $\$ 598$ \\
\hline Crude & $\$ 112$ & $\$ 117$ & $\$ 237$ & $\$ 648$ & $\$ 897$ & $\$ 1,210$ & $\$ 2,115$ & $\$ 1,781$ & $\$ 980$ & $\$ 321$ \\
\hline Diesel-Crude & $\$ 63$ & $\$ 67$ & $\$ 214$ & $\$ 596$ & $\$ 553$ & $\$ 830$ & $\$ 2,005$ & $\$ 2,126$ & $\$ 1,151$ & $\$ 1,006$ \\
\hline Total & $\$ 202$ & $\$ 282$ & $\$ 572$ & $\$ 1,797$ & $\$ 2,280$ & $\$ 3,118$ & $\$ 6,125$ & $\$ 5,555$ & $\$ 3,301$ & $\$ 1,925$ \\
\hline
\end{tabular}

Sources: The Duelfer Report, IIC, CFIJ 
The numbers explain three main points. First, they explain the intensity of Iraq's crude oil sales under the sanctions regime. The trade was so intense that UN inspectors estimated that, at some point, 5000 Kurd truckers were engaging in illegal oil trade along the Turkish-Iraqi border. The data account just for Iraq's sales to the Kurds. It does not include sales to Syria, Jordan, Lebanon, Egypt and Turkey. Second, the numbers also explain Iraq's consumption levels of diesel-crude. Iraq utilizes most of its oil to produce oil derivatives. Third, Iraq profited too. For example, note in Table 3.8 that most of the crude oil the Kurds moved out of Iraq came back to Iraq in the form of diesel. A portion of it was for Iraq's consumption, and another portion went to Iran. Eventually, Iraq found in diesel a steady source of income. The CIA, the Michigan Project, the IIC and other sources agreed that the portion of diesel meant for Iraq decreased over the years as Iraq repaired some of its refineries. Conversely, the portion that Iraq shipped to Iran increased steadily to satisfy Iran's demand for subsidized diesel.

Iraq also gained access to foreign goods that Turkish-Kurds brought with them when they came to dump the diesel and collect crude oil. Turkish-Kurds left a lot of money in Iraq for goods they purchased and services they consumed in Iraqi territories. The CFIJ cited CIA's findings to explain the nature of the Turkey-Iraqi trade. It noted that "The busting traffic is two-way, with truckers and traders bringing in many types of consumer goods for sale. The truckers often spend up to a week in Iraq and hence spend money in restaurants, hotels, and on vehicle maintenance. The Turkish-Kurd truckers thus provide spin-off economic benefits to those northern regions of Iraq under Baghdad's control, such as Mosul and Kirkurk" (CFIJ, p. 33). 
The CIA calculated that Iraq generated about $\$ 12$ billion from 1996 to 2000, just from its trade protocol with Turkey (Duelfer Report, Regime Finance and Procurement, p. 162). The CFIJ set the amount at $\$ 9$ billion in a six-year period (CFIJ, p. 29), and the IIC put it at \$14 billion from 1992 to 2003 (IIC, p. 89). The Duelfer Report found that "Some of these funds were transferred to interest bearing accounts. As of January 2004, SOMO held $\$ 157$ million in these accounts and had earned almost $\$ 7.7$ million in interest since October 2000" (Duelfer Report, Regime Finance and Procurement, p. 162). Chart 3.8 summarizes Iraqi revenues from its trade protocol with Turkey but by industry from 1995 to 2002.

\section{Chart 3.8 - Iraq-Turkey Trade Protocol}

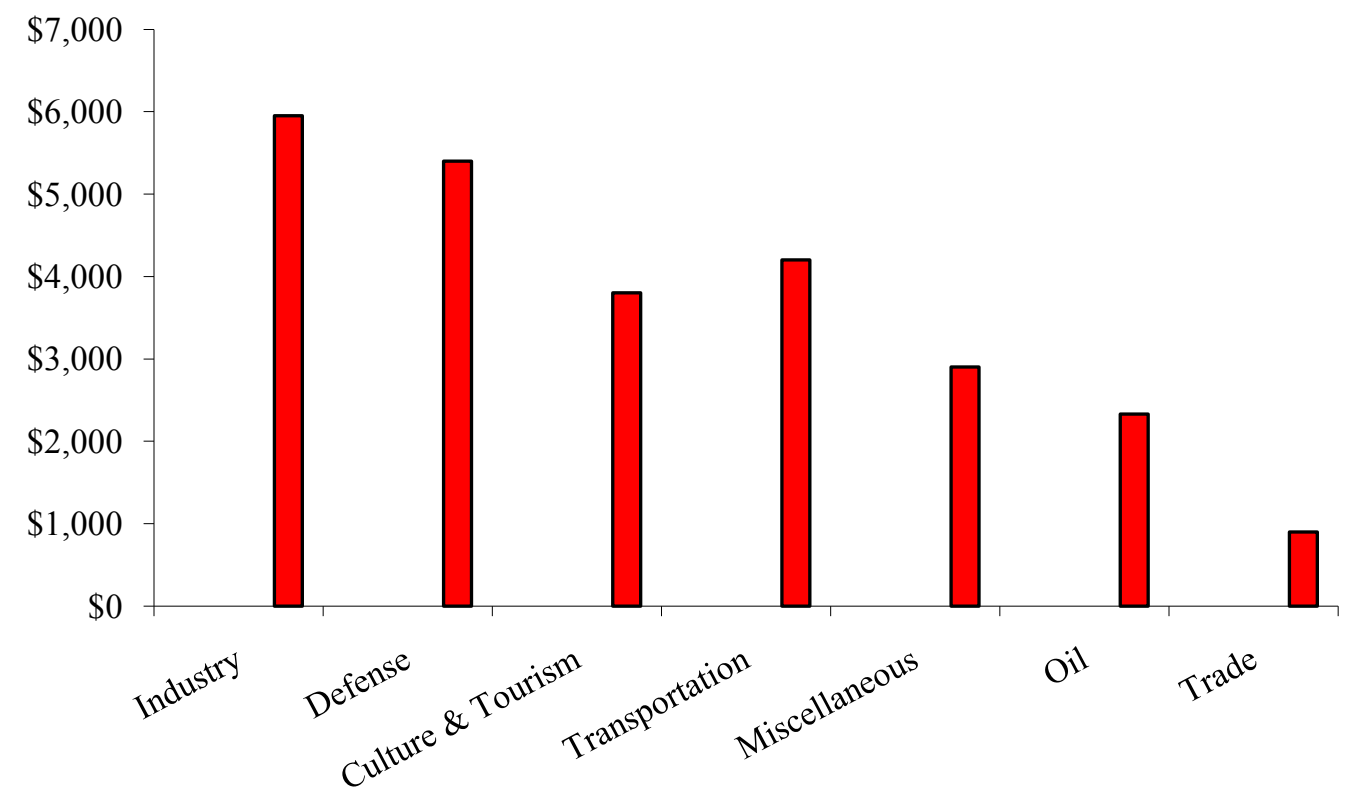

Source: The Duelfer Report, IIC, CFIJ 
Chart 3.8 shows an average of revenues per industry calculated from three main sources: The Duelfer Report, the IIC, and the CFIJ. First, the Chart shows the diversity of trade between Iraq and Turkey. Note that some industries were not included for two reasons: a) lack of dates; b) conflictive, not reliable sources. I did not include revenues from kickbacks, artificial fees, and illegal taxes. When I say illegal, I mean according to the UN sanctions. Iraq was a sovereign nation and as such it could impose any tax it considered pertinent. Second, defense was the second largest source of revenues. This is important because Turkey actually granted permission to the U.S. and UN to use Turkish territories to manage the UN sanctions regime from Turkey, not to mention that a large number of UN inspectors were stationed in Turkey to monitor Iraq's rearmament and WMD programs from there. Still, Iraq managed to import goods and services for its defense industry via the Iraqi-Turkish border. And I do not mean here that Turkey, as a nation-state, sold military equipment and hardware to Iraq. I did not find any evidence of it. What I am saying is that Turks, Kurds, and intermediaries from other nationalities sold military equipment to Iraq, and that Iraq utilized its trade agreement with Turkey and Turkey's territory for that purpose. In Chapter VI, I will explain the extent of such a trade. For now note that oil was not the largest source of revenue for Iraq. There was a reason for that. Most Iraqi oil exports to Jordan, Syria, Lebanon and other Iraqi neighbors were through oil pipelines. In the cases of Egypt, Libya, Tunisia and Morocco, Iraq shipped the oil by sea. However, in the case of Turkey, oil trade had to be by truck because, as I stated earlier, the American led Coalition Forces had bombed the two oil pipelines that connected Iraqi oil fields to Turkish refineries. In fact, that is the reason 
why the trucking industry flourished so much in Turkey, Iraq and Kurdistan. The Table below shows revenues drawn from oil trade under the Iraqi-Turkish trade protocol.

Table 3.9 - Iraqi Revenues Drawn from Iraq-Turkey Protocol

\begin{tabular}{|l|r|r|r|r|r|r|r|r|r|r|r|}
\hline & 1993 & 1994 & 1995 & 1996 & 1997 & 1998 & 1999 & 2000 & 2001 & 2002 & 2003 \\
\hline Iraqi Gov't & 17 & 19 & 24 & 27 & 27 & 46 & 92 & 68 & 75 & 27 & 11 \\
\hline Udai's Corp. & 21 & 27 & 22 & 72 & 55 & 55 & 247 & 243 & 73 & 38 & 14 \\
\hline Iraqi-Kurd Gor & 20 & 22 & 37 & 56 & 56 & 93 & 186 & 139 & 56 & 28 & 9 \\
\hline Iraqi-Kurd Cor & 22 & 22 & 61 & 108 & 82 & 82 & 370 & 365 & 109 & 57 & 14 \\
\hline Turkish Gov't & & & & & & & 74 & 185 & 74 & 37 & \\
\hline Turkish Corp & 57 & 81 & 119 & 333 & 333 & 555 & 1036 & 648 & 259 & 130 & 19 \\
\hline
\end{tabular}

Sources: Duelfer Report, CFIJ

Note that all parties, except Turkey, seem to have started oil smuggling in 1993, two years after the sanctions regime was implemented. The Turkish government started only in 1999. Second, Udai's Corp means front companies that belonged to Udai Hussein, Saddam's son. Udai's companies made more money than the Iraqi government every year except in 2001 when it beat Udai by just $\$ 2$ million. I could not determine whether or not Udai's money went to his personal savings or to the Iraqi government. I did find, though, that Udai had a fleet of 50 tankers for his oil trade. Evidence shows that he wanted to purchase 250 smaller, rapider tankers from Japan and South Korea. Finally, both the Iraqi-Kurdish government and Iraqi-Kurds consistently made money, only outperformed by Turkish corporations. It was a remarkable performance if we take into 
account that only as recently as 1991 Iraqi-Kurds had been gassed by the Iraqi government and only in 1992 won autonomy of their territories.

\section{Cyprus}

Cyprus too signed a trade agreement with Iraq. The uniqueness of this agreement derives from two main features: 1) Cyprus signed it on behalf of Turkey; 2) Turkey used the agreement to smuggle goods, cigarettes and liqueur in particular, into Iraq.

The Cyprus-Iraq trade agreement included agricultural, fishery, agro-industrial, and oil industries, but that is not new. Most Iraqi trade agreements included those same industries. Therefore, what is really new here is that Turkey made of Cyprus the operational center for the largest contraband ring of cigarettes that ever occurred in Europe. The CFIJ summed it up: "In reality the Cyprus-Iraq trade agreement was an effort by the Turkish to exploit Iraq's fascination with cigarettes" (CFIJ, p. 55). Indeed, Iraq is a lucrative market for cigarettes as Iraqis consume about 18 billion cigarettes annually, of which they imports 10 billion (CFIJ, p. 55). Iraq also imports about 2000 tons of tobacco leaves. For its part, Cyprus has an excellent cigarette industrial infrastructure for it produces about 26.5 billion of cigarettes per year while it consumes just about 3.5 billion (CFIJ, p. 55). Cyprus is famous for smuggling cigarettes to Europe. According to the EU, Cyprus also smuggled cigarettes into Iraq. It found that "Iraq became a prime market for cigarettes smuggled via Cyprus" (CFIJ, p. 56), and the EU was not happy about it. Note that taxing cigarettes constitutes a sound source of revenues for EU nations (CFIJ, p. 56). 
In effect, the EU had for many years been trying to dismantle cigarette smuggling via Cyprus. For example, the EU sued American firms in American Courts for using Cyprus as a platform for cigarette smuggling in Europe. The EU filed a lawsuit against RJ Reynolds and Phillip Morris in November 2001 for violating the RICO Laws (the Act of 1970), but U.S. Courts dismissed the charges and the contraband continued (CFIJ, p. 55). So it was kind of ironic that just two months later the U.S. asked the EU for help to crack down on cigarette smuggling in Iraq. The EU responded with an "I told you so" and passed on to the U.S. the evidences it had of how Cyprus, the PKK, Iran and Iraq engaged in cigarette smuggling. In addition, the British Foreign Office produced evidences of cigarette and alcohol smuggling to Iraq through Cyprus and Kurdistan. The Office argued that, "In the last 6 months, and these figures incidentally have been provided through the United Nations Security Council, Saddam Hussein has imported over 300 million packs of cigarettes, 38,000 bottles of whisky per month, 230,000 cans or 115,000 liters of beer per month, over 120,000 cans or 40,000 of vodka per months and almost 19,000 bottles of wine a month" (CFIJ, p.56). The British Foreign Office accused Cyprus of ignoring, as it put it, "an epidemic in Cypriot territory" (CFIJ, p. 55).

The results of the American investigation alarmed American officials. The contraband included cigarettes and liquor but also furniture, appliances, cars, motorcycles, cloths and even perfumes. Saddam distributed those products among high ranking officials, closest allies and soldiers who excelled in their duties and obligations. Yet, the U.S. could do no more than take the case to UN Security Council and propose a resolution to warn Cyprus. After all, Cyprus was acting on behalf of Turkey, a member of NATO and key ally of the U.S. 
$\underline{\text { Iran }}$

Iran was yet another beneficiary of both the UN sanctions regime against Iraq and the Turkish-Iraqi trade protocol. It was not unexpected because some common factors unite Iran and Iraq. On one hand, Iran and Iraq had a common enemy: the United States. An old geopolitical proverb goes: the enemy of my enemy is my friend, and sticking to the proverb, Iran and Iraq found in the U.S. a good motive for cooperation. On the other hand, Iran and Iraq have common borders by land and sea, and according to Krugman's theory, this is very advantageous for trade. For instance, for Iraq, one way of cooperating with Iran was by smuggling diesel into Iran by truck. Another way was to use Iranian waters to ship out crude oil. For its part, Iran itself has oil in abundance, but it does not have refining capacity to convert it into gasoline or diesel. Even today Iran imports 89\% of the gasoline and diesel it consumes (CFIJ, p.43). Iran reasoned that it could balance out its disadvantage by cooperating with Iraq in violating the UN sanctions regime. Iran could: a) get free gasoline from Iraq in exchange for allowing Iraq to ship crude oil through its waters; b) charge Iraq for using Iranian waters for smuggling; 3) charge all foreign ships for using Iranian waters to get cargoes into Iraq. This was especially true for ships navigating under Russian, Ukrainian, Belarusian and French flags (CFIJ, p. 43; Duelfer Report, Regime Finance and Procurement, p. 166). Those nations had good political and trade relations with Iraq and Iran.

Iran did all of the above. Conscious of the political and even military risks, Iran charged hefty fees to any foreign ship crossing its waters in route to Iraq (CFIJ, p .44; Duelfer Report, Regime Finance and Procurement, p. 167). Iraq did a lot of trade by trucking, especially though Syria, Turkey and Saudi Arabia. But it was slow, costly, and 
risky. To be fair with UN inspectors, plenty of evidences show that they did intercept thousands and thousands of trucks trying to get in and out of Iraqi territory full of goods CFIJ, p.45; Duelfer Report, Regime Finance and Procurement, p.166; IIC, p.114). Smuggling was so rampant that it was not really hard for UN inspectors to catch some violators of the sanctions. Even intercepted violators, once put back to the streets, would get back to smuggling for it was one of the most profitable jobs around at the time.

The point is that Iraq preferred smuggling by sea, mainly oil, and Iranian waters were the route to go through. For example, the CFIJ describes operations as follow: "Smaller tankers fill up at the Shatt al-Arab ports of al-Muftiya and Abu al-Flus, north and south of Basra respectively, cross to the Iranian side and then travel along the Iranian coast, all the way to the islands of Qesh or Qeshim. Along the way, naval patrols of the Iranian Revolutionary Guard, particularly from the Revolutionary Guard's maritime station just north of the mouths of the Shatt al-Arab, record, facilitate and charge for the transit. These vessels, each with carrying capacities in the range of 15,000-50,000 barrels, are often overloaded and listed. Iran furnishes its own pilots to navigate the shallow waters close to shore and to help prevent accidents and spill outs that could leave evidences of smuggling behind. At Qeshim, at the Strait of Hormuz, the smugglers may acquire Iranian certificates of origin for their cargo. For all these services the Iranians reportedly charge a fee of approximately $\$ 7$ a barrel. The oil is then either transferred into larger vessels or, bearing the new documentation; the barges proceed to Pakistan, India or cross the Strait of Hormuz to the port of Fujairah or Dubai where the oil enters the world market system and is reloaded for onward shipment. 
During the UN sanctions regime, 100,000 bpd transited this route almost daily" (CFIJ, p.45).

Foreign ships coming into Iraq took a riskier route in terms of exposure to UN inspectors as well as to patrols from U.S. and UK. First, they utilized Iranian waters, and then they moved into Kuwaiti, Bahraini and Qatari waters, down to the UAE (CFIJ, p. 44; Duelfer Report, Regime Finance and Procurement, p. 168). The risk consisted in that all those nations were allies of the U.S., and as such they allowed UN, American and British patrols all along their coasts to enforce the UN sanctions. For that reason, stopping in Iranian ports to later sail toward Iraq was the most common option for all parties. The ships got to their destinations. Iran collected its fees. And Iraq got their cargoes.

It worked. The Duelfer Report noted that the Iraqi Ministry of Industry, Mr. Hussein Kamel al-Majid, at first commanded the Iraqi-Iranian maritime route (Duelfer Report, Regime Finance and Procurement, p. 171). Mr. Kamel broke a deal with Russian tankers to operate under Bahamian and Honduran flags, which is a common practice in global trade and, as we saw in Chapter II, Iraq successfully employed it to circumvent UN inspectors. So through the Iraqi-Iranian route, Mr. Kamel exported about 60,000 bpd in 1993, just two years into the sanctions regime (Duelfer Report, Regime Finance and Procurement, p. 168). In 1994, Mr. Kamel exported 30,000 bpd to Pakistan. In return, Pakistan sold about $\$ 240$ million dollars worth of North Korean long-range missiles to Iraq, which Mr. Kamel shipped back to Iraq through Iranian waters. But Mr. Kamel did not last long in his post. Suddenly, the Iraqi government dismissed him, arguing that at 57 
he was too old for the job that demanded a lot of traveling and risky operations (Duelfer Report, Regime Finance and Procurement, p. 168).

The job went to Saddam's son Udai (Duelfer Report, Regime Finance and Procurement, p.168). It is said that Mr.Udain broke a deal with the Iranian President Rafsanjani's son to expand diesel trade to 70,000 bpd by truck and smaller and rapider boats. No one exactly knows how much diesel Udai trucked into Iran. Most sources set the volume at 100,000 bpd since mid 1995 to 1997 (Duelfer Report, Regime Finance and Procurement, p. 168; IIC, p. 171). The CFIJ argued that the volume increased drastically in 1998 when UN inspectors left Iraq and then decreased in 2000 when UN inspectors came back (CFIJ, p.46). In fact, when UN inspectors came back, they found a rail track connecting the port of Bash'ra in Southern Iraq with Khorramshar, an Iranian port also in the South (Duelfer Report, Regime Finance and Procurement, p. 168; CFIJ, p. 46). Table 3.10 shows some estimates of the Iraqi-Iranian oil trade under Udai's command.

Table 3.10 - Estimates of Iraq-Iran Oil Trade under Udai's Command

\begin{tabular}{|c|c|c|c|c|c|c|c|}
\hline & 1995 & 1996 & 1997 & 1998 & 1999 & 2000 & 2001 \\
\hline & 25,000 & 49,000 & 70,000 & 90,000 & 75,000 & 52,000 & 45,000 \\
\hline Iraq & \$ 117 & $\$ 222$ & \$ 314 & $\$ 402$ & $\$ 336$ & $\$ 235$ & $\$ \quad 205$ \\
\hline Iran & 53 & 97 & $\$ 135$ & \$ 172 & 144 & \$ 107 & $\$$ \\
\hline
\end{tabular}

Source: The Duelfer Report; the CFIJ 
Of course, the U.S. knew about the trading. The U.S. Navy actually intercepted numerous shipments. I can cite a couple of examples. In 2000, the U.S. Navy detained two Russian tankers on Iraq-Iranian waters (CFIJ, p. 44). The first tanker, Volgoneft-147, belonged to SovFinAmTrans (SFAT) a Russian firm in joint venture with Transcisco, an American company. The European Bank for Reconstruction and Development (EBRD) financed the operation. UN inspectors found that EBRD had loaned the money to Transpetro-Volga, a subsidiary of SFAT, but the cargo belonged to Primestar, an oil trading firm based in British Virgin Islands. The Volgoneft-147 had given 40 trips between Iraq and Iran by the time U.S. intercepted it (CFIJ, p. 44). The second tanker was Novorossisk Shipping. It was navigating under Russian flag, in route to Singapore. The cargo belonged to Royal Dutch/Shell, and UN fined Shell for $\$ 250,000$ dollars (CFIJ, p. 44). But then why would the U.S. allow Iran to engage in illegal trading with Iraq?

There was much speculation among observers in that regard (CFIJ, p. 46). However, the consensus is that the US wanted to improve relations with the Iranian President. This President, Khatami, was a moderate. He was sending 'signals' to the U.S. about his interests in improving U.S.-Iran relations. In fact, during this period, the U.S. eased unilaterally the U.S sanctions regime against Iran, so Iran could import some agricultural and industrial products (CFIJ, p. 46). Iran reciprocated by intercepting smuggling that was not meant for Iran. In April 2000, the Iranian Navy, in a surprising move, blockaded Iraqi waters and confiscated ships and cargos coming from Iraq (CFIJ, p. 46). However, two factions opposed President Kathami's actions. One faction was Russian and French lobbyists representing Russian and French corporations with large 
interests in both the Iraqi and Iranian economies. They approached the Iranian hard-liners and threatened to withdraw from the Iranian market if President Khatami did not lift the blockade (CFIJ, p.46). The second faction was Iranian hardliners. They argued that President Khatami was giving in to American pressure and affecting Iran's good economic relations with France and Russia. After all, the U.S. had a sanctions regime against Iran, and France and Russia were Iran's best trade partners. In the end, the hardliners prevailed. They went after the Iranian moderates, and President Khatami had no choice but to lift the blockade and allow the smuggling to go on (CFIJ, p.46).

\section{Trade Fairs}

Iraq promoted its trade agreements with trade fairs it held in Bagdad. These trade fairs were very important because they enabled Iraq to circumvent the UN sanctions regime. Specifically, the fairs allowed Iraq to: a) obtain immediate much needed revenues; b) obtain access to global markets; c) rally political support again the UN sanctions regime.

First of all, the international trade fairs enabled Iraq to immediately raise huge revenues. Each fair brought about $\$ 100$ million to Iraqi balance sheets (CFIJ, p. 50). For example, the Iraqi government charged $\$ 1000$ fee per person and per company just for participating in the Fair. It charged for processing passport, custom and other bureaucratic documents. Then, Iraq charged participants for everything they used and/or consumed, from water to food, telephones, fax machines, office supplies, etc. It certainly charged for air conditioning, electricity and even security. Estimated expenditures per person were about $\$ 3000$ dollars over a five days stay in Iraq (CFIJ, p. 50). Note that 
18,000 people attended the Annual Fair Trade of Bagdad of 1998, including merchants, journalists, diplomats and their bodyguards, members of NGOs, etc (CFIJ, p. 50). In 2001, 65,000 people attended the Bagdad trade fair (CFIJ, p. 50). Third, Iraq charged between $\$ 50$ and 100 dollars per square meter of floor space, depending on location, exposure, and visibility among other factors. Minimum allotment was $\$ 2000$ per exhibitor (CFIJ, p. 51). In 2001, Iraq rented out almost 28,000 square meters of indoor floor space and 18,000 square meters of outdoor space. Besides, construction and furnishing of cubicles was mandatory, and Iraq charged $\$ 30$ dollar per square meter (CFIJ, p. 51). Of course, all those fees increased over time as Iraq gained in experience, attracted more participants, and more companies and nations were willing to participate in the fairs. Consequently, if Iraq made about 4.5 million dollars in the first fair it held in Bagdad, by 2002 it was making $\$ 400$ million dollars per year (CFIJ, p. 51). Iraq could not have done better. After all, it was under a multilateral sanctions regime.

Second, international trade fairs enable Iraq to get access to global markets and attract trade partners from around the world. Iraq held its first fair in 1995, three years into the UN sanctions regime. Iraq called it Baghdad International Fair (CFIJ, p. 52). The use of the word international was intentional. Words have meaning, and here Iraq meant that the fair had an international character: 400 companies from 15 nations had accepted invitations to participate (CFIJ, p. 52). In fact, in the end 421 companies from 17 nations travelled to Iraq and showed their products to Iraqi companies, and Iraq signed about 900 contracts in that Fair (CFIJ, p. 52). It was such a success that Iraq decided to organize at least two fairs per year. It even created a state-owned company for that purchase. Iraq called it State Company for Iraqi Fairs. The Company hired the German 
firm IMAG for consulting and marketing, and it also opened a bank account at the Baghdad branch of Rafidain Bank-Al-mansour, which had branches in most Middle Eastern nations (CFIJ, p. 52). In 1996, Iraq celebrated three trade fairs. This company hired the German firm IMAG for consulting and marketing (CFIJ, p. 52).

Iraq celebrated its second international trade fair in 1997, attracting 800 companies and 20, 000 people from 31 nations (CFIJ, p. 52). In 1999, it attracted 1,210 companies and 29,000 people from 35 nations. The international trade fair celebrated in Bagdad in 2001 brought 1,650 companies and 65,000 people from 48 nations from almost all continents (CFIJ, p. 52. It was a true global event, although European, North African and Middle Eastern nations dominated it. Companies from Germany, Sweden, Denmark, Italy and Austria sent representatives. About 200 Russian and French companies sent delegates. And about 150 firms from Egypt and Turkey participated. Even Palestine produced 325 small companies to participate in the fair (CFIJ, p .52).

Absent from the fairs were always Kuwait, the US and UK. However, it does not mean that companies from those nations missed out business opportunities. They did obtain contracts but though intermediaries, subsidiaries, parent companies and other corporate models. Indeed, in Chapter VI, I will examine how companies utilized corporate models to obtain contracts and circumvent the UN sanctions regime upon Iraq. Here, it is worth noting that British companies complained to the British government. This time British companies argued that trade was rampant in Iraq anyway, and that they were missing out on great business opportunities. They reminded the British government that British firms had been absent from the Iraqi market since the 1970s, and that the 
sanctions regime was a good opportunity to return to it. A few months later, the Foreign Affairs Committee of the House of Commons concluded that "The "the Baghdad Trade Fair is not in itself a breach of sanctions. The UN Oil for Food humanitarian program, with revenues of about 14 billions, offers considerable opportunities for legitimate trade with Iraq. We are supporting British companies in their efforts to win a share of this trade" (CFIJ, p. 54; www.parliament.the-stationery-office.co.uk).

Third, perhaps the most important gain for Iraq was that it got access to the global market. Indeed, by year 2000, numerous nations were holding trade fairs to, as Saddam put it, "honor the Iraqi people" (CFIJ, p. 53). In 2000, Morocco, Syria, Lebanon, Algeria, the UAE and even the Philippines held trade fairs in which Iraq was the main honoree (CFIJ, p. 53). In 2001, Ukraine went so far as to sponsor a trade fair (CFIJ, p. 53). The main exhibitors were the Ukraine Ministry of Defense and Iraq's Military Industrial Commission, by then Iraq's most important military procurement agency. This is very relevant because in Chapter VII we will see that Ukraine played a pivotal role in procuring components, spare parts and machinery for Iraq's missile programs. But in November of the same year, during the Bagdad Trade Fair, Tunisia and Morocco announced that they were opening free trade zones where Iraqi companies could sell their product (CFIJ, p. 53). Two days after, Lebanon and Iraq were signing their $2^{\text {nd }}$ trade agreement in three years (Daily Star Beirut, Nov., 6, 2001.) Still, the following year was even better for Iraq. In May 4, 2002, the Iraqi News Agency announced with much fanfare that the French government had invited Iraq to participate in the Paris International Fair (Iraqi News Agency, May 4, 2002). In May 21 of the same year, the Agency announced that Germany too was inviting Iraq to the $4^{\text {th }}$ International 
Commercial Fair (Iraqi News Agency, May 21, 2002). In August 2001, Egypt invited Iraq to its international trade fair. This was important because Iraq had invested a lot of political and financial capital to improve political and trade relations with Egypt (RFE/RL, August 24, 2001, and October 12, 2001). Iraq sent 2000 representatives and, more important, two Ministries. Then, in August 2002, Turkey invited Iraq to participate in the Izmir International Fair (CFIJ, p. 50). Even Saudi Arabia invited Iraq to the trade fair that it celebrated in September 2002.

Finally, most analysts agreed that Iraq scored huge political gains from the trade fairs. It did it in two main ways: a) Iraq granted contracts to companies that publicly declared opposition to the UN sanctions regime; b) eventually, state actors began to personally participate in the trade fairs, which Iraq used for political advantage.

Indeed, the CIA acknowledged that "The Iraqis have become very effective at using the annual Trade Fairs for their wider purposes" (Duelfer Report, Regime Finance and Procurement, p. 171). The CIA was referring to how Iraq was utilizing trade fairs for political gains and propaganda as much as for commercial purposes. In a trade fair held in Bagdad n 1999, the Iraqi Vice-President Taha Yassin Ramadan publicly declared that "The sanctions are a terrorist weapon responsible for the deaths of over a million Iraqi children" (RFE/RL, Nov. 5, 1999). He then went on to "Grant the best prices and contracts to those who denounce the horrors of UN sanctions against the Iraqi people" (RFE/RL, Nov 5, 1999). Indeed, participants in the fairs soon learned that, as Dania Saadi from the Daily Star of Beirut put it, "Competitive prices without sound political stands will not tempt Iraqi authorities to strike business deals". Dania Saadi went on to warn that "Opposing sanctions will secure deals" (Daily Star, Nov 6, 2001). Eventually, 
governments joined companies in their public opposition to the UN sanctions regime. At the beginning, most governments published conciliatory statements. For example, the Saudi government defended a trade fair it held to honor Iraq by stating that "Your Majesty was honoring the warm relations between the peoples of Iraq and Saudi Arabia," and the government of Jordan stated that "We are helping our own families, for Iraqis are our blood" (CFIJ, p. 54). But other governments were more explicit and directly condemned UN sanctions. Such was the case of France, Russia, Egypt, and even Turkey. Still, by the year 2000, some governments not only spoke but also acted. They began to utilize the trade fairs to visit Iraq. As the CFIJ put it, "Fair attendees witnessed a parade of Prime Ministers, Vice-Ministers and foreign dignitaries flying into Baghdad airport; we should note that those flights in themselves were violations of the sanctions regime" (CFIJ, p. 54). They usually met with Iraq and made public condemnatory remarks against the sanctions regime, like in the Prime Minister of Lebanon. During the trade fair of Baghdad in 2002, he remarked that "Lebanon is here to help Iraqis break unjust sanctions" (Daily Star, Nov 6, 2001).

\section{$\underline{\text { Conclusion }}$}

This Chapter tests whether or not global trade allowed Iraq to circumvent the UN sanctions regime. Based on the evidence presented here, we conclude that the fragmented nature of global trade allowed Iraq to circumvent UN sanctions. Iraq accessed global trade through a number of trade agreements it signed with about 25 nations, particularly with Jordan, Egypt, Turkey and Syria. The trade agreements opened two-way trade routes: Iraq shipped its oil to global markets through Jordan, Egypt, Turkey and 
Syria. In turn, those nations attracted trade from all around the world, which Iraq accessed through its trade protocols.

Altogether, the protocols allowed Saddam to feed his people and postpone the fall of the regime for a few years. For the most part, and based on the evidence collected, we can conclude that: 1) the UN embargo was circumvented; 2) instruments of globalization such as front companies, intermediaries and the international banking system were utilized to circumvent the embargo 3) when it comes to Middle East nations, any relationship between GDP, exports and oil imports under the UN Oil for Food Program is illusive, unless we utilize it to argue that, more than GDP per nation, geography, history and traditional trade ties played an important role in the performance of Middle East nations in the UN Oil for Food Program and their consequent violations of the UN embargo. Those nations share the following characteristics: geographical proximity, long standing trade routes and markets, centuries of trade partnerships, common local trade costumes and business trends, a common language, a shared animosity toward the West, the United States in particular, and, consequently an opposition to the UN embargo against Iraq. As third world economies, they needed trade, jobs and money, and the UN embargo, just like all embargoes, offered sound economic opportunities, in particular to companies losing global competition, to companies from the developing world. That explains their performance in the $\mathrm{UN}$ sanctions regime against Iraq. 


\section{AGENTS AND MEANS OF GLOBALIZATION: GLOBAL CIVIL SOCIETY AND NON-STATE ACTORS}

"The first [era of Globalization] lasted from 1492....until around 1800. I would call this era Globalization 1.0. This era was about countries. In this era, countries and governments (often inspired by imperialism or a combination of both) led the way in breaking down walls and knitting the world together, driving global integration. The second great era [of] Globalization lasted roughly from 1800 to 2000. In globalization 2.0, the key agent of change, the dynamic force driving global integration, was multinational companies. These multinationals went global for markets and labor, spearheaded first by the expansion of the Dutch and English joint-stock companies and the Industrial revolution".

Thomas L. Friedman

“Arguably Christopher Columbus was a non-state actor, were Vasco da Gama and Martin Luther and Henry Hudson, a subcontractor for West Indian Company and discoverer of the Hudson River as were the East India Company, the Hudson Bay Company, the French revolutionaries, and nationalist movements of the nineteenth and twentieth centuries".

Fred Halliday

"The UN once dealt only with governments. By now we know that peace and prosperity cannot be achieved without partnerships involving governments, the business community and civil society".

Kofi Annan, UN Secretary-General

\section{$\underline{\text { Introduction }}$}

This chapter examines non-state actors (NSAs) in relation to a multilateral sanctions regime under globalization. I posit that NSAs undermine the overall effectiveness of sanctions regimes, and that globalization facilitates their activities. In the case of Iraq, I specifically argue that a large number of NSAs formed alliances among themselves and with nation-states for the sole purpose of circumventing the UN sanctions regime against Iraq. That is, individuals, NGOs, political and religious groups, banks and businesses of all sorts worked together, with state actors and members of Saddam's regime, to evade UN sanctions and conceal their profits.

To better illustrate my argument, I have divided this chapter into two sections. In the first section, I review the literature on NSAs. In the second section, I present and 
discuss evidences of how NSAs, as agents of globalization, facilitated the evasion of UN sanctions regime. I gathered the evidence from multiple sources, among which are the IIC Report, the Duelfer Report, a report from the CFIJ, the Michigan Project, and the Heritage Foundation. I also utilize reports from Western and Middle Eastern newspapers.

\section{$\underline{\text { NSAs and Global Politics }}$}

Most scholars of international politics accept as a fact the presence of NSAs in global politics, but some still hold mixed opinions about how NSAs affect it. As Josselin and Wallace put it, "The debate no longer focus on whether NSAs play a role in world politics, but rather on how they do so" (Josselin \& Wallace, 2001, p. 12). In this section, I discuss the nature of NSAs and their relations with states and world politics.

First, NSAs like to distance themselves from state actors. They may act as autonomous entities, but they are not completely autonomous. There are well defined relations between NSAs and states, and I mean here legal, administrative, procedural and financial practices and relations. Josselin and Wallace argue that "Defining non-state actors chiefly by their independence from states and state authority would be misleading for both in domestic and international politics the theoretical purity of these opposing ideal types -state and nonstates- is muddied by the complexities of praxis" (Josselin \& Wallace, 2001, p. 2). That is, NSAs and states are opposing categories interconnected through what Keohane and Nye (1971) define as governmental, national and transnational relations. NSAs grow so interconnected with respect to state actors that in time they lose autonomy, blurring political spaces between them. NSAs and states become interdependent, and according to Krasner (1983, 1995), as interdependence 
consolidates, it at some point leads to a new regime type, a sort of partnership among them. Josselin and Wallace (2001) call it triangular relationships, whereas NSAs stand somewhere between states, their agencies and agents. The question is, as Josselin and Wallace put it, "How far non-state actors, in their triangular relations with states, still operate within the constraints of national and international politics" (Josselin and Wallace, 2001, p. 7). In the case of Iraq, many NSAs went really far in their interactions with state officials. This was the case for NGOs like Qandil and Diakonia from Sweden, Peace Winds of Japan, and Handicapped International of Belgium (IIC, 2005, p. 78; CFIJ, 2002, p. 19). In an effort to carry out their duties, those NGOs maintained a close relationship with the Iraqi regime. They not only lobbied Saddam for a license to operate in Iraq but even paid a hefty annual "fee" that Saddam demanded for those licenses. But Saddam needed more than money. Saddam needed public solidarity and political support. So he asked NGOs to publicly denounce the hardships that UN sanctions inflicted upon Iraqi people (IIC, 2005, p. 18; CFIJ, 2002, p. 19). Saddam cautiously courted not only NGOs but also corporations, scientists, universities, European political parties and religious denominations for their political support (IIC, 2005, p. 18; CFIJ, 2002, p. 19).

Indeed, the Iraqi case illustrates some of the problems that NSAs must confront in order to exist and operate. NSAs must deal with financial, legal, political, climatic, religious and even cultural limitations. But according to Smith (2001), Josselin and Wallace (2001), above all there are two concepts that limit the actions and nature of NSAs. They are: raison d' eta and national security. Those two concepts are directly related to the very nature of nation-states. According to Smith, the two concepts became the motive of domestic politics as states emerged and struggled with NSAs to establish 
the best approach toward neighboring states and world politics (Smith, 2001, p. 51). For Smith, "The two concepts neither mean nor imply that NSAs are enemies of nation-states and that those NSAs necessarily oppose states' interests" (Smith, 2001, p. 51). Yet, I would state that raison d' eta and national security define, to this date, the nature of relations between states and NSAs. In the name of raison d' eta and national security, states try to keep NSAs away from national and global politics. Nation-states set legal jurisdictions to prevent NSAs from accessing states' information, which state actors conceal and manipulate, arguably to protect the interests of the state. Nation-states outlaw some of NSAs' activities which, according to state actors, could affect national security. Some nation-states outlaw and persecute religious groups, political parties and activists.

For instance, I explained in Chapter II how states used the concepts of securitization and sectorization to define which issues constituted a raison d' eta and of national security. Securitization and sectorization allow nation-states to overuse raison $d$ ' eta and stretch out the notion of national security as a means to limit the activities of NSAs. In the case of Iraq, NSAs had to navigate through a political scenario that included: a) politics among permanent members of UN Security Council; b) US and UK's foreign policies toward Iraq; c) Iraq's own notion of national security, given the fact that it was a nation isolated politically and economically, and threatened militarily. Opposition to NSAs such as political activists and NGOs mainly came from the US, UK, and Iraq itself (CFIJ, 2002, p. 19).

They blocked NSAs by: 1) harassing them politically and legally; 2) denying them visas to travel to Iraq; 3) revoking their operational licenses; 4) imposing on them 
unbearable taxes, fees and other financial obligations; 5) denying them access to financial resources and logistics (CFIJ, 2002, p. 19).

Again, by using national security as an excuse, Saddam banned many NSAs from ever entering Iraq. Saddam sectored the oil industry and declared it an issue of national security. But then he granted oil contracts to NSAs according to raison d' eta and national security interests. Especially, he granted contracts to NSAs that publicly denounced UN sanctions (IIC, 2005, pp. 78-87). For their part, both the US and UK favored NSAs that condemned the Iraqi regime. The US and UK publicly condemned, in some cases harassed, NSAs who opposed the sanctions against Iraq, like Mr. Oscar Wyatt, an oil tycoon from Texas and, for many years, the only American that Saddam trusted. Mr. Wyatt publicly opposed the UN sanctions against Iraq from the beginning. In 2001, the Bush administration opened an investigation against Mr. Wyatt and his oil corporations. In 2003, Mr. Waytt was indicted for conspiracy and racketeering under the RICO Act (New York Times and Wall Street Journal, July 20, 2006).

\section{Types of NSAs}

There are many types of NSAs. There world is so diverse that most scholars define them according to their interests, the nature of their work, and their political affiliation. But according to Colomonos (2000), Smith (2001), and Josselin and Wallace (2001), most NSAs are: 1) independent from states and/or state actors; 2) relatively autonomous; 3) domestic actors but their politics and operations seldom transcend transnational networks; 4) affect foreign policy agendas and relations among states. Based on those parameters, in this Chapter I focus on seven NSAs. They are: 
transnational corporations, political parties, NGOs, religious organizations, Diaspora, political activists, and empowered individuals. They all demonstrated a high level of engagement in the UN sanctions regime against Iraq

The first NSA I want to analyze is transnational corporations due to their active role in shaping globalization, circumventing a sanctions regime, and in international politics in general. I dedicate Chapter VI to examine the role of corporations in the circumvention of the UN sanctions regime against Iraq. However, for now let us define transnational corporations as NSAs. For Josselin and Wallace (2002), as for Colomonos (2000), transnational corporations are basically corporations that operate in more than one nation. Such corporations can be private or public, or a combination of both. They can also be state-controlled through partial or total ownership. Their main goal is to produce goods and services, but they also engage in domestic and transnational politics. As Halliday states, "You do not have to be a Marxist to write the history of international relations in terms of political activities by transnational corporations" (Halliday, 2000, p. 31). Transnationals are not isolated entities. They are part of a global civil society. Yes, they are rich and powerful. I would argue that they are the strongest and most influential of all NSAs, but they do not dominate global politics as they used to. Transnationals must share power and influence with other NSAs who have their own interests and goals. Global trade, traditionally the main concern of transnationals, no longer dominates the global agenda. First, transnational have gradually moved away from trade issues to focus more on obtaining investment privileges across nations. Second, many NSAs see global trade as just one among many issues, among which are the environment, human rights, 
nuclear proliferation, and terrorism. In fact, limiting the powers of transnational corporations is a key issue in global politics and a goal of many NSAs.

In order to cope with other NSAs and their initiatives, transnational corporations have adopted two main approaches. The first is to avoid global regulations by relocating their operations to nations where governments are weaker, laws are flexible and enforcement lousy or nonexistent. Some governments facilitate relocations and grant incentives as part of their quest for foreign investment, itself a policy that transnational corporations defend and lobby for. Stephen F. Cohen argues in "Failed Crusades" that the case of Russia is a good example because, on the one hand, transnational corporations almost took over the Russian state through the privatization process that occurred there in the 1990s. On the other hand, Russia became a critical destination for corporations seeking to evade UN sanctions against Iraq. In Chapter II, I showed that Russia, an oil producer itself, ranked second in oil purchases from Iraq under the UN sanctions regime. But in chapters V and VI we will see that Russia did not really consume that oil. Rather, transnational corporations hired nascent Russian corporations as intermediaries to circumvent the UN sanctions against Iraq.

The second approach that corporations use is to invest in trade regimes favorable to them. Transnationals lobby for and against regulations that affect their bottom lines. They influence norms and procedures embedded in the GATT, the WTO, and various bilateral, regional and global trade organizations. Not surprisingly, they invest against sanctions regimes. As Colomonos points out, "transnational corporations lobbied heavily against the promulgation of the Helms-Burton and Iran-Libya Sanctions (ILSA) Act. They fought the UN sanctions regime against Iraq and they have emerged at the 
forefront of protest against commercial embargoes imposed by their own country" (Colomonos, 2000, p. 85). In their quest against sanctions regimes, transnational corporations often seek support from NSAs that oppose sanctions regimes. Colonomos explains that "Corporations have contacted think-tanks specializing in international economics and sponsored studies highlighting the cost of American sanctions for US companies and the American economy" (Colomonos, 2000, p. 85). Referring to British transnationals, the CFIJ noted that "The British too appear to be eager for their piece of the action" (CFIJ, 2002, p. 24). In all, I find that in order to trade with Iraq under the UN sanctions regime, transnational corporations allied with NSAs like NGOs, political parties, activists, scientists and even universities to evade UN sanctions and inspectors.

The second group of NSAs related to this dissertation is NGOs. The beginning of NGOs dates back to the early 1900s. For instance, the Rotary International, known as the Rotary, was created in 1904. The Red Cross was created around the same time. By 1940, there were about 1,500 NGOs (www.un.org). But NGOs only became popular with the creation of UN which, in its Charter, Article 71, called for the creation of "Organizations that are neither governments nor member states" (www.un.org). A second definition drew from Resolution 288 of ECOSOC, the UN's Agency that regulates and attends NGOs' affairs. The Agency defined NGOs as "Any international organization that is not founded by an international treaty" (ECOSOC, www.un.org; Josselin and Wallace, 2001, p. 26). It was a broad definition. It was the early days of the Cold War, and UN members wanted to attract resources from all nations despite their ideology, religion, political affiliation and economic system. Later, the UN elaborated a more specific definition. It 
stated that an NGO was a "Legally established non-for profit organization with no relation to any government" (www.un.org; Josselin and Wallace, 2001, p. 27).

A few years after that, the UN once again amended it to invite more governments to cooperate in the promotion of NGOs. The Amendment limited governments to funding NGOs, which should remain self-sufficient and unbiased even if they received resources from nation-states. State actors should not participate in the daily operations, planning and decision-making of NGOs (ECOSOC, www.un.org). Now, it is very important to note that I utilize here the definition of NSAs as stated by UN statutes. There are three main reasons for it. First, based on such a definition, UN granted and denied licenses to NSAs that sought to operate in Iraq under the UN sanctions regime against Iraq. Second, based on UN's definition of NGOS, the U.S., UK, Germany, India, Australia, New Zealand and other nations reprimanded and in some cases prosecuted NSAs that violated the UN sanctions against Iraq (IIC Report, p. 181; CFIJ, 2002, p. 19). In sum, there are other, perhaps more scholarly, definitions of NSAs, but they lack the legal and institutional frameworks as to explain violations of a UN sanctions regime by NGOs. Violating UN sanctions is a legal matter, not a political one.

The numbers and significance of NGOs were limited throughout the Cold War. The politics of the bipolar system impeded their work as the two leading superpowers, the U.S. and the USRR, limited their free movement and access to needy people, particularly in third world nations where proxy wars provoked poverty, diseases, starvation and exodus. Americans and the Soviets wanted to show the superiority of their political, social and economic systems. As Josselin and Wallace (2001) argue, they both wanted to hide their systemic failures, so they accused each other of using NGOs for 
propaganda, proselytism, spying, and in some instances of breaching sovereignty. Right after the end of the Cold War, there seemed to be an ideological "consensus" about NGOs and their work. Most nations began to recognize that governments had limits on what they could do. Also, global crisis such the spread of HIV in poor nations, the war in Bosnia, and ethnic cleansing in Rwanda created a new spirit of cooperation among nations and NGOs. The intensification of globalization during the 1990s brought people together through greater transnational communication, traveling and global mass-media. People began to take note of what NGOs were doing to fight diseases, illiteracy, poverty, and other issues in poor nations. Today, NGOs are in all continents delivering social work under labels such as independent sector, civil society, grassroots organizations, transnational social movements, private voluntary organizations, self-help organizations and others. There are also the "mega" or "super" NGOs that emerged during the 1990s, owned and managed by philanthropists-entrepreneurs like Bill Gates, George Soros, Warren Buffet, Richard Branson, and other powerful individuals.

Most nations greet NGOs, but they are also suspicious about their intentions. Some nations accuse NGOs of corruption and proselytism. For many, NGOs have become a way of life, a source of influence and fame. In Afghanistan, the Afghan government has repeatedly accused some NGOs of driving luxury cars, living in fancy houses and partying too much (WSJ, June 17, 2007). In Latin America, some governments have accused NGOs of engaging in prostitution and drug trafficking, and there the Catholic Church keeps accusing some NGOs of promoting abortion and executing it illegally. (El Pais, September 7, 2007). Other governments find NGOs taking political positions, siding with opposition parties and leaders. In the 2009 political crisis 
in Honduras, ten NGOs publicly supported the removal by force of the Honduran President (El Pais, October 21, 2009). Some nations go as far as directly financing NGOs. The ten largest NGOs in Honduras are funded by the U.S. State Department to this day (WSJ, September 28, 2009). In the case of Iraq, I found concrete evidence of NGOs acting as intermediaries to Iraqi and non-Iraqi corporations. NGOs took contracts from the Iraqi regime and sold them to Russian, American, and Ukrainian corporations among others.

The forth NSA to argue is religious denominations. They have historically had a visible presence in global politics, mostly through the Catholic Church. As Ryall argues, they are "One of the oldest and largest transnational actors of all. [] ... and Jesuits can claim to be prototypes of globalization" (Ryall, 2001, p. 41)

At least in the West, the Church dominated global politics since the fall of the Roman Empire through the Middle Ages, the Renaissance, Reformation and Counterreformation up to the Peace of Westphalia (Cantor, 1994, p. 181). The rise of the Westphalia System represented a major loss of power to the Church for it brought two key assumptions: 1) the State was the supreme authority within a demarcated territory and over a people; 2) the State held a monopoly over the use of force (Ryall, 2001, p. 42). Thus, religious denominations became NSAs, often opposing the authority and actions of the State. As religious NSAs, they attempted to address questions related to the nature of the state and their monopoly over the use of force against civilians (Ryall, 2001, p. 42). In the case of the UN sanctions regime against Iraq, religious NSAs directly challenged not only the legitimacy of the sanctions but also the morality of imposing them (ICFJ, 2001, p. 20). Like corporations, NGOs and other NSAs, religious NSAs denounced the UN 
sanctions regime against Iraq. Unlike corporations, NGOs and other NSAs, religious NSAs were more prepared, in theory and praxis, to challenge the overall legitimacy of a sanctions regime as an instrument of force and foreign policy. For them, the question was: how moral and practical is it to starve millions of powerless women and children in the name of national security, regime change and international relations.

Religions NSAs are not powerless. As Ryall argues, they are as transnational and global as corporations (Ryall, 2001, p. 41). They own schools, universities, newspapers, radio and TV stations, think-tanks, interest groups, and NGOs around the world. They have the support of millions of believers around the world. In the case of Catholic organizations, they have the financial, legal and political support of the Vatican, a state in itself. This is very important for two reasons. First, we must be cautious when defining Catholic organizations as NSAs for their actions can respond to specific policies and interests of the Vatican. Second, numerous Catholic NSAs publicly opposed the UN sanctions regime against Iraq. Later in this chapter we will discuss the case of a Catholic priest who in connection with the Central Bank of the Vatican violated the UN sanctions regime against Iraq. We must not ignore that the Central Bank of the Vatican has on numerous occasions been accused of money laundering and racketeering.

The fifth NSA relevant here is Diasporas. The term Diaspora refers to the exile of Jews in Egypt in 70 AD. Today, it refers to " $A$ victimized exile group unable to return to their homeland for political reasons" (Ostergaard-Nielsen, 1999, p. 220) and to "Any group with a territorially discontinuous relationship with a group settled elsewhere" (Marientrans, 1989, p. 120). The term implies a legal status, a political stand and a social condition. Diasporas are voluntary or involuntary, but both hold some degrees of 
persecution to a large number of its members. A Diaspora usually settles in several nations. It is why Ostergaard-Nielsen argues that "Diasporas are transnational per definition" (Ostergaard-Nielsen, 1999, p. 220). They settle mostly in nations willing to welcome them as political refugees, a status with some sense of stability or "permanent" security. In this dissertation, Diaspora refers to Iraqis living in exile due to: 1) opposition to Hussein's regime; 2) born in exile; 3) self-imposed exile. Those three groups had many differences, mainly with respect to Saddam's regime and the UN sanctions against Iraq. But most of them played key roles in violating the sanctions regime.

Diasporas tend to remain in touch with their homeland emotionally and economically. Diasporas are exceptionally active politically. Ostergaard-Nielsen observes that "Their emotive, social, economic and not least political cross-border networks with their homeland - or with other segments of the diasporas- constitute one of their main resources for political influence" (Ostergaard-Nielsen, 1999, p. 220). They have two main goals. For one, they aspire to one day return safely to their homeland, for which they lobby parliaments, international institutions and whoever likes to hear their case. As Ostergaard-Nielsen points out, "A Diaspora has no government or state, it is the agenda devoted to obtaining one which mobilize the Diaspora" (Ostergaard-Nielsen, 1999, p. 220). Second, since they cannot guarantee their return to their homeland, they must work to secure a place to live and prosper. Diasporas tend to create a community for themselves in their adoptive nation. Such a situation is "Related to its (often troubled) relationship with its host country as well as its continued identification with is homeland" (Ostergaard-Nielsen, 1999, p. 220). It is that troubled identity deficit what makes Diasporas unique NSAs. Diasporas mobilize, raise funds, and lobby for foreign 
policies directly related to their motherland. For example, the Cuban-American Diaspora based in the U.S. is largely responsible for the 50 years of unilateral American sanctions against Cuba. For its part, the Iraqi Diaspora lobbied heavily against Saddam's regime in France, UK, the U.S and other nations (IIC, p. 324; ICFJ, 2001, p. 22). They asked the $\mathrm{UN}$, the EU and other international organizations for support. The American government employed members of the Iraqi Diaspora to "build" the case for the invasion to Iraq in 2003. Many Iraqis in exile engaged in violations of the UN sanctions against Iraq.

The final NSA to discuss is empowered individuals (Josselin and Wallace, 2001) since they played important roles in regard to the UN sanctions regime against Iraq. I mean here individuals with direct access to the means of power, namely politics, finances, and public opinion. As Josselin and Wallace state, "Globalization allows them to globalize their messages and expose themselves to global multitudes through means of globalization such as mass media" (Josselin and Wallace, 2001, p.19). Examples of empowered individuals are Bill Gates, George Soros and Bono. They attract global audiences. They shape public opinion through a global media interested in selling their public images and life styles. They are political assets for they have an audience. They use their political capital to lobby politicians, governments and international institutions. So George Soros is an investor who spends his money promoting civic societies around the world. Bono, a singer, is a recurrent participant in WTO meetings where he lobbies Presidents and Prime Ministers for fair trade. In Iraq, the politics around the UN sanctions attracted empowered individuals of diverse social, political and professional stratums. I present five models of how NSAs worked together to evade the UN sanction against Iraq. They are: a) empowered individuals - UN associates - corporations; b) 
individuals - religious organizations - corporations; c) individuals - political activismcorporations; d) individuals - civic organizations - corporations; e) individuals international organizations - corporations. Note that individuals and corporations are the common denominators. Figure 4.1 represents the relations among NSAs.

Figure 4.1 - Relations among NSAs

empowered

individuals

political, religious,

international

organizations

corporations

I infer from Chart 4.1 three main points. First of all, individuals are responsible for the actions of NSAs because, in the end, individuals manage and lead religious, political and international organizations and corporations. Individuals set and execute their agendas. They donate money and write grants in the name of numerous causes. In the Iraqi case, it was individuals who facilitated access to the Iraqi regime and its contracts. Second, corporations are the means to evade the UN sanctions against Iraq. Most NSAs relied on corporations to execute the contracts they obtained from Saddam's regime, and most corporations employed NGOs, religious groups, and empowered individuals to obtain contracts from Saddam's regime. Third, most individuals fallow almost the same modus operandi. They first seek access to Iraq's governmental agencies 
and agents. They then convert access into influence, paying special attention to agenda setting and policy-making. Lastly, they turn influence into marginal gains, then into power and finally into political leverage. The process requires funding, public relations, media coverage, and favorable public opinion among other capacities. In the next section, I show how NSAs worked together to evade the UN sanctions against Iraq.

Overview of NSA Activities during the UN Sanctions Regime

The IIC found that "Saddam Hussein, beyond favoring companies from Russia, China and France, also decided to furnish allocations of oil to friendly political figures and organizations had political positions favorable to Iraq" (IIC, p. 334). The CIA agreed. I draw Chart 4.1 with data from the CIA's Report on violations of UN sanctions.

\section{$\underline{\text { Chart } 4.1 \text { - Nationality of Individuals and Organizations }}$}

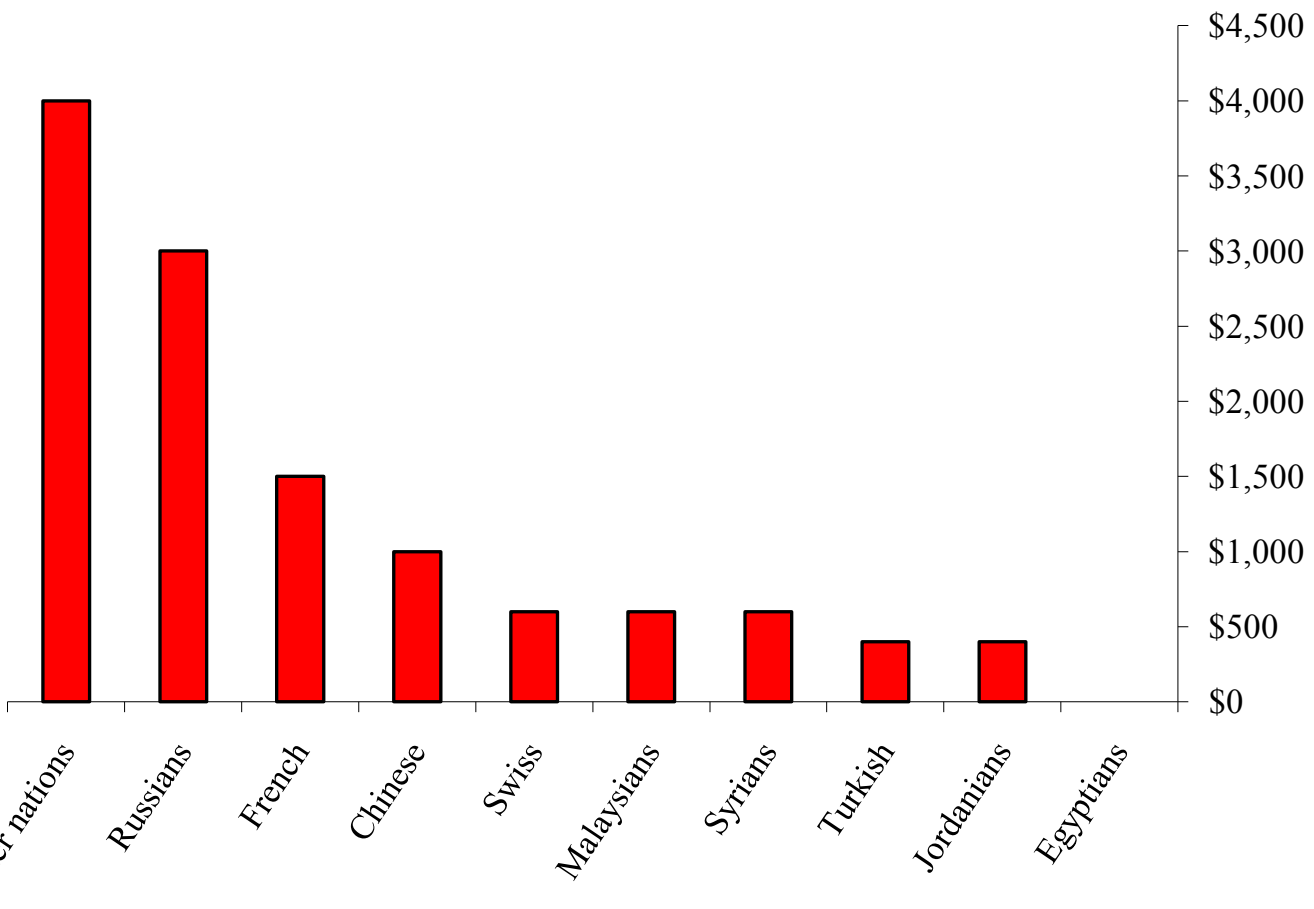


Source: The Duelfer Report (CIA)

The Chart shows individuals and organizations of different nationalities that illegally obtained about $\$ 18,000$ million worth of contracts from Iraq. NSAs had never engaged in trade operations of such a magnitude under a sanctions regime. In the graph, we can see that individuals and organizations from "other nations," about 41, accounted for $\$ 4,000$ million worth of contracts. Russia, French, Chinese and Swiss ranked second, third, and fourth respectively. They obtained about $\$ 6,000$ million worth of contracts. Syrians, Turks, Jordanians and Egyptians ranked seventh, eighth, ninth and tenth respectively, accounting for nearly $\$ 1,200$ million. Still, individuals and organizations did not have resources and expertise to execute their contracts. Also, Meyer and Califano argue that "Most political figures who received oil allocations from Iraq [...] had no desire to have their name appear on a contract with SOMO. For this reason, political beneficiaries often nominated companies to exercise their allocation rights, and these companies were named to sign formal contracts with SOMO to buy the oil" (Meyer and Califano, 2006, p. 75). In their investigations, the IIC and CIA defined as beneficiaries those individuals and organizations that sold their contracts to corporations (IIC, p. 334; Duelfer Report, p. 451). I will discuss individuals and organization separately to better examine their role in the circumvention of the UN sanctions regime against Iraq.

$\underline{\text { Individuals }}$ 
To better explain the role of individuals under the UN sanctions regime against Iraq, I present Table 4.1. The Table shows a sample of individuals and their beneficiaries under the UN sanctions regime as they appear n the IIC and CIA's Report.

$\underline{\text { Table } 4.1 \text { - Individuals-Violators of UN Sanctions Regime }}$ 


\begin{tabular}{|c|c|c|c|c|c|}
\hline Individual & $\begin{array}{l}\text { Proffesion/Type } \\
\text { of Non-state Actor }\end{array}$ & Nation & Beneficiary Company & Beneficiary & $\begin{array}{l}\text { Contracts } \\
\text { In USD }\end{array}$ \\
\hline Adel Al-Dzhilaui & Business \& political activist & Iraqi Exile & Pitkin Lmt. & Cyprus & $2,925,000$ \\
\hline Ali Ballout & Religious leader & Lebanon & Galaxy Management S.A. & Italy & $1,764,000$ \\
\hline Ali Ballout & Religious leader & Lebanon & Primacosa Enterprises Ltd. & Cyprus & $1,002,000$ \\
\hline Ali Ballout & Religious leader & Lebanon & Amosta S.L. & Spain & 995,000 \\
\hline Ahmed Saeed Al-Otaiba & Business \& political activist & UAE & Emirol Est. & UAE & $3,984,000$ \\
\hline Ahmed Saeed Al-Otaiba & Bussines \& political activist & $\mathrm{UAE}$ & Loyoil LLC & UAE & $2,441,000$ \\
\hline Ahmed Saeed Al-Otaiba & Business \& political activist & UAE & Benzoil & UAE & $2,004,000$ \\
\hline Benon Sevan & UN affiliate & France & Impexoil LLC & Russia & $3,913,000$ \\
\hline Benon Sevan & UN affiliate & France & African Middle East Petroleum & Panama & $7,291,000$ \\
\hline Burhan Al-Chalabi & Business \& political activist & Iraqi in Exile & Fortun Oil And Gas OY & Finland & $3,935,000$ \\
\hline Enrica Benniti & Political activist & Italy & Finasi SPA & Italy & $1,113,000$ \\
\hline Father Benjamin & Priest & Italy & Zyria Management Serv. Ltd & Switzerland & $2,055,000$ \\
\hline George Galloway & ex Member of UK Parliament & UK & Middle East Semiconductor & Jordan & $6,681,000$ \\
\hline Hamad Bin Ali Jabr & Political activist & Qatar & Emiroil Est. & UAE & $5,954,000$ \\
\hline Hamad Bin Ali Jabr & Political activist & Qatar & Int'nal Petroleum Services & Egypt & $2,927,000$ \\
\hline Jean Bernard Merimee & Retired Diplomatat & France & Fenar Petroleum Ltd & Lichtenstein & $2,027,000$ \\
\hline Khalifa Al-Nahyan & Political \& religious leader & UAE & Fenar Petroleum Ltd & Lichtenstein & $1,955,000$ \\
\hline Mohammad Helmi & Al-Sahwah newspaper & Egypt & Antemina International LLC & Jordan & $1,000,000$ \\
\hline Mohammed Al-Houni & Journalist & Libya & K.T.G. Kentford Globe Ltd. & Cyprus & $3,929,000$ \\
\hline Mohammed Al-Houni & Journalist & Libya & Gulf Erdolhandels GMBH & Austria & $5,407,000$ \\
\hline Mohammed Al-Houni & Journalist & Libya & Arcmed Energy Ltd & Cyprus & 998,000 \\
\hline Mr. Mousinikov & President of Ukraine Soc. Party & Ukraine & Inves Co. Ltd & Ukraine & 899,000 \\
\hline Mr. Persenkov & Chairman of Social Dem. Party & Ukraine & Commercial Council Deal & Ukraine & $3,392,000$ \\
\hline President Lahhoud' son & Son of President of Libanon & Lebanon & Fadi Oil International Sal & Lebanon & $2,280,000$ \\
\hline Riad El-Taher & Friendship without Borders & Iraqi in Exile & Perenco PLC & UK & 960,000 \\
\hline Russian Embassador's son & Son of Russian Embassador & Russia & RA0 Mes Int'nal Econ. Co. & Russia & $13,071,000$ \\
\hline Serge Boiedeevaix & Retired Diplomatat & France & Vitol S.A. & Switzerland & $29,525,000$ \\
\hline Sergei Rudassiev & Solidarity for Iraqi People & Russia & Hyperborey Company & Ukraine & $1,940,000$ \\
\hline Shaker Bin Zaid & Bussinessmen & Jordan & Aredio Petroleum S.A.R.L & France & $3,253,000$ \\
\hline Shakir Al-Khafaji & Assoc. Solidarity/Iraqi People & Iraqi in Exile & Omni Oil & S. Africa & $2,070,000$ \\
\hline Son of a President & President / Republic of Kalmykia & Russia & Kalmyk Oil \& Gas Company & Russia & $1,563,000$ \\
\hline Wafa Tawfiz Butrus & Professor and Political activist & Palestine & National Oil Well Maint. & Qatar & $2,050,000$ \\
\hline Wafa Tawfiz Butrus & Professor and Political activist & Palestine & B.C. International PVT Ltd. & Pakistan & $1,000,000$ \\
\hline Zia Ja'far & Religious leader & Iraqi in Exile & Cressent Petroleum Ltd & UAE & $1,389,000$ \\
\hline Ziad al-Hadi & Businessmen \& political activist & Iraqi in Exile & VTT Vulcan Petroleum SA & Switzerland & $1,766,000$ \\
\hline Total & & & & & $129,458,000$ \\
\hline
\end{tabular}

Source: The Duelfer Report; the IIC

The Table shows, in Column I, 35 names of participants, the largest recipients of 
oil and procurement contracts, in the UN sanctions regime against Iraq. Column II shows their professions or "type" of non-state actors as they appeared in Iraqi official documents. Column III reveals their nationalities. Since they sold their contracts to "beneficiaries," Column IV shows the names of beneficiaries, and Column V their nations of registration. Column VI includes the value of the contracts that individuals and their beneficiaries exchanged. The data show three main aspects: a) dominance of Arab and Russian NSAs; b) Middle Eastern individuals living in Europe; c) contributions of Russian and Ukrainian politicians, consistent with what Califano and Meyer found: "Among the most favored beneficiaries were politicians and political parties from Russia and Ukraine" (Meyer and Califano, 2006, p.76).

The participation of NSAs from the Middle East is understandable. In political terms, the UN sanctions regime against Iraq constituted an insult to most Muslims and Arabs. They considered it an aggression to Islam and the Arab world. I would argue that, for Muslims and Arabs, violating the UN sanctions was just a reaction to an aggression, a political statement, and an expression of solidarity with respect to the Iraqi people. Nonetheless, not all was about politics for, in economic terms, the UN sanction regime created good business opportunities for many Arabs and Muslims. After all, they had a comparative advantage in terms of geography, culture, customs, and historic trade relations. In Chapter III, I explained that the UN sanctions regime could not disrupt the historic trade relations that Iraq had with its neighbors, especially Syria, Turkey, Jordan, and even Iran, Iraq's historic enemy. On the contrary, the UN sanctions brought them together. I also argued in Chapter III that those nations in fact increased their trade through bilateral trade agreements as a means to maximizing their comparative 
advantages. It explains the participation of Arabs and Muslim NSAs in the circumvention of UN sanctions against Iraq. From corporations and banks to scientists and universities, churches and religious activists, politicians and political parties, they all profited from the business opportunities that UN sanctions created not only in Iraq but in the region. UN's inspectors could not prevent NSAs from engaging in the intense economic activity that UN sanctions created in Iraq and the region. UN and US' officials could not comprehend the magnitude of the issue. Yet, Western NSAs understood it so well that they hired Arab and Muslims NSAs to evade UN inspectors and access the Iraqi market. It explains: a) the low number of Western NSAs that violated the UN sanctions against Iraq; b) the high number of Arabs and Muslims that violated the UN sanctions.

A bit more complex is the participation of NSAs from ex-Soviet societies. Political and economic reforms that occurred in ex-Soviet republics after the collapse of the Soviet Union created opportunities for consolidating trade, commercial relationships that ex-Soviet republics had with Iraq. Cohen (2001) argues in his "Failed Crusades" that the reforms created a civic society composed by Russian and foreign NSAs that took advantage of the new economic opportunities in Russia. But some Ukrainian, Belarusian, and Russian NSAs, like the conglomerate Gasprom and the Russian National Party, took advantage of the traditional economic relations Iraq had with former Soviet Union. As previously noted, the Soviet Union had been Iraq's main business partner for almost 40 years. NSAs from ex-Soviet republics will be the focus of discussion all throughout this dissertation due to their presence in Iraq under the UN sanctions.

Second, according to the CIA, individuals declared 27 professions when they introduced themselves to Saddam's bureaucrats (IIC, Committee Tables, Table IV). They 
included doctors, politicians, businessmen, ex-legislators and ex- ambassadors, and even priests and professors. I can cite a few examples from Table 4.1. For example, according to the IIC, CIA and CFIJ, Father Benjamin was a priest who received about 21,000 barrels of oil from Saddam's regime, which he sold to Zyria Management Service Ltd., a Swiss corporation. Another example was Serge Bojedeevaix, a French ex-diplomat who obtained almost 30,000 barrels of oil, only to sell them to African Middle East Petroleum. Ironically, the Firm was based neither in Africa nor in the Middle East but in Panama. For his part, Benon Sevan, an ex French diplomat too and UN official for almost 20 years, received almost 12,000 barrels of oil. According to the IIC, CIA and CFIJ, he passed his vouchers on to Vitol S.A, a Swiss company, and to Impexoil, from Russia. Note that both Mr. Bojedeevaix and Mr. Sevan retired from their diplomatic posts early into the UN sanctions regime and rapidly began to travel to Iraq as private citizens.

Politicians were among the most visible violators of the UN sanctions. Table 4.1 shows 13 individuals who one way or another made a living out of politics. Table 4.1 shows that Arab and Middle Eastern politicians were the largest recipients of contracts. Russians and Ukrainians participated in larger numbers, but they received fewer contracts. Also, note that the data only include oil contracts. It does not include construction, industrial, educational and health contracts, over which, French, Russians and Ukrainians largely dominated. According to the IIC, Saddam's regime granted $\$ 6$ billion in contracts to Russian and Ukrainian individuals within a five-year period (IIC, Chapter III, p. 39). Some were executed, but some were not. Again, Saddam's regime granted contracts based on political criteria, and most of those individuals had no resources and expertise to execute those contracts. 
Iraq also granted contracts to sons, daughters and relatives of ambassadors, political leaders, prime ministers and heads of states. Table 4.1 above shows that Saddam's regime grated 2,280,000 barrels of oil to the son of the President of Lebanon, who then sold his oil to Said Oil International Sal, a Lebanese oil corporation. The Table indicates that the Iraqi regime granted 1,563,000 million barrels to the son of the President of Kalmykia, a small ex-Soviet Republic. He sold the contracts to Kalmyk Oil \& Gas Company, an oil company owned by the state of Kalmykia. The son of the Russian ambassador to Iraq received 13,071,000 barrels, which he sold to RAO Mes International Economic Company, of Russia. All told, Table 4.1 shows that 36 individuals obtained a total of $129,458,000$ barrels of oil. It accounted for $29 \%$ of all oil contracts granted to individuals under the sanctions regime (IIC, Chapter III, p. 39).

\section{$\underline{\text { Organizations }}$}

The UN issued 259 licenses to 172 NGOs, including political and religious organizations, from 1996 to 2002, so they could carry out humanitarian work in Iraq (IIC, Chapter III, p. 44). Some of those NGOs were very vocal when denouncing the impact that the UN sanctions had on Iraqis. Others focused on lobbying governmental agencies, politicians and UN officials to ease the sanctions or create "smart sanctions." But others

decided to profit from the sanctions regime. Like individuals did, they allied to oil traders, financiers and export-import firms to execute the contracts they obtained from Saddam's regime. The IIC reported 73 religious NGOs as violators of the UN sanctions (IIC, Chapter III, p. 79). The CIA reported 84. Table 4.2 shows a group of 29 violators 
selected according to the size of the business they accrued (CIA, Regime Finance and Procurement, p. 211). They obtained contracts for 1,000,000 million barrels of oil.

\section{Table 4.2 - Organizations-Violators of the UN Sanctions Regime}

\begin{tabular}{|c|c|c|c|c|}
\hline Organization & Nationality & Beneficiary Company & Nationality & Barrels Lifted \\
\hline Russia Communist Party & Russia & Monaco JSC & Russia & $110,618,000$ \\
\hline Russia Peace and Unity Party & Russia & Rossbulneft Ad & Russia & $87,281,000$ \\
\hline Russian Liberal Democratic Party & Russia & Sindanco & Russia & $62,068,000$ \\
\hline Mujahedeen Khalq Organization & Iraq & Century Marketing Associates & UK & $27,983,000$ \\
\hline Socialist and Radical Parties (50\%ea) & Yugoslavia & Eurol Int'l (based in Bermuda) & UK & $19,392,000$ \\
\hline Amities Franco-Irakiennes & France & Aredio Petroleum S.A.R.L. & France & $11,140,000$ \\
\hline Iraqi-Ukraine House & Ukraine & H.I.U. Ltd & Ukraine & $10,318,000$ \\
\hline Ukraine Communist Party & Ukraine & Hyperborey & Ukraine & $7,393,000$ \\
\hline Liberal Democratic Party & Belarus & Belmetalenergo, Inc & Belarus & $6,552,000$ \\
\hline Belarus Communist Party & Belarus & ACTEC & Russia & $6,435,000$ \\
\hline Yugoslavia Radical Party & Yugoslavia & Pitkin Ltd & Yugoslavia & $4,056,000$ \\
\hline Socialist Party of Yugoslavia & Yugoslavia & Emiroil EST & UAE & $3,984,000$ \\
\hline Palestine Economic Institute & Palestine & Petrolina Oil Ltd & Jordan & $3,688,000$ \\
\hline Russian Political Science Academy & Russia & Zerich GMBH & Russia & $3,635,000$ \\
\hline Gubkin University of Oil And Gas & Russia & Zarubezhneft & Russia & $3,337,000$ \\
\hline Bulgaria Socialist Party & Bulgaria & Vassilevy Brothers Ltd & Bulgaria & $3,023,000$ \\
\hline India-Congress Party & India & Masefield AG & Switzerland & $2,937,000$ \\
\hline Union of all Russian Officers & Russia & Tatneft & Russia & $2,708,000$ \\
\hline Romania Labor Party & Romania & Petroline FZC & UAE & $2,275,000$ \\
\hline Palestinian Liberation Front & Palestine & Awad Ammora Co. \& Partners & Syria & $2,051,000$ \\
\hline National Press Association of Algeria & Algeria & Zyria Management Services & Switzerland & $2,041,000$ \\
\hline Iraqi-Bulgaria Co. Ltd & Bulgaria & Vassilevi Brothers Ltd. & Bulgaria & $2,039,000$ \\
\hline Russia for Benefit of Government & Russia & Zarubezhneft & Russia & $2,016,000$ \\
\hline Yugoslavia Left Wing Party & Yugoslavia & Petroline FZC & UAE & $1,840,000$ \\
\hline Hungary-Welfare Party & Hungary & Rompetrol S.A. & Rumania & $1,101,000$ \\
\hline Romania Communist Party & Romania & Petroline FZC & UAE & $1,038,000$ \\
\hline Arab-Austrian Friendship Society & Austria & Al-Hoda Int'l Trading Co. & UAE & $1,023,000$ \\
\hline Ukraine Socialist Party & Ukraine & Zerich GMBH & Russia & $1,001,000$ \\
\hline Yugoslavia Kostunica Party & Yugoslavia & Gromig Export-Import & Yugoslavia & $1,000,000$ \\
\hline Total & & & & $393,973,000$ \\
\hline
\end{tabular}

\section{Source: Duelfer Report, IIC Report}

There are several findings here. First, see in Column I that political parties, 
universities, academies, unions and civic associations are among the NSAs that illegally approached Saddam's regime for contracts. Political organizations led the trend. Second, there is a notable presence of political parties from nations of the former communist bloc. Hungary, Romania, Bulgaria, Yugoslavia and ex-Soviet republics led this tendency. I argued earlier that the UN sanctions coincided with the disintegration of the communist bloc and the economic crisis that followed there. Also important is the sweeping political reforms that occurred in those nations. The reforms brought about a multiparty system with no financial support from the state. Political parties had to fund themselves. They had to raise money from their constituencies or other sources. Evidences suggest that the UN sanctions regime became a source of funding

Indeed, Table 4.2 reveals that twelve political parties obtained over a million barrels of oil. The three leading beneficiaries were Russian political organizations, and that the leading recipient was the Russian Communist Party. This may be the result of the long standing relations between the Russian Communist Party and the Iraqi regime, dating back to the days when the Soviet Union was among the main political and economic allies of the Iraqi regime. Now observe in the Column IV the number of Russian companies. There are nine in total, acting as beneficiaries. It was the result of the privatization process that took place in Russia during the 1990s, which only in the oil industry led to the creation of hundreds of oil companies. Russian political organizations and Russian oil firms worked together to circumvent the UN sanctions regime. In fact, later in this dissertation I explain that banks, companies and businesses of all sorts preferred Russian companies to execute their contracts. Among other things, it illustrates how rapidly Russian political parties and businesses transitioned from a closed society 
and market to the open global society and economy.

It is important to emphasize the role of two Palestinian organizations: the Palestinian Liberation Front (PLO) and the Palestine Economic Institute, in circumventing the sanctions regime. These organizations had no experience in the oil business. In fact, Palestine is not a state, and there are no oil firms and refineries in Palestinian territories. The Palestinian people actually meet $100 \%$ of its energy demands through Israel (Duelfer Report, Regime Finance and Procurement, p. 188). What then did Palestinian organizations do with those oil contracts? The answer is straightforward: they resold them to finance their political activities, just like most political organization did. As Table 4.2 shows, the PLO resold 2,016,000 million barrels to Awad Ammora Co. \& Partners, a Turkish Firm registered and based in Syria. The Palestine Economic Institute resold 3,688,000 million barrels to Petrolina Oil Ltd, an Italian petroleum conglomerate with numerous refineries in Jordan and other nations in the Middle East.

Overall, Table 4.2 shows that 29 organizations received a total of 421,022,000 barrels of oil within an average period of 3 years (IIC, Chapter III, p. 79). The IIC estimated that the contracts were worth about $\$ 550$ million dollars (IIC, Chapter III, p. 79). The CIA reported that, in total, Saddam's regime granted about $\$ 3$ billion dollars worth of oil to NGOs, political parties, religious organizations and other civic entities from all around the world (Duelfer Report, Regime Finance and Procurement, p. 190). In the next section, I discuss examples of how individuals and organizations worked with corporations and banks to evade the UN sanctions and to conceal their profits.

\section{$\underline{\text { Case Studies }}$}


In this section, I present eight case studies to explain how NSAs evaded or helped evade the UN sanctions in Iraq. The cases are: 1) Mr. Kojo Annan and Cotecna; 2) Mr. Benon Sevan and AMEP; 3) Mr. Jean Bernard Mérimée; 4) Father Benjamin; 5) Mr. George Galloway, Mariam Appeal, Fortum and Delta Services; 6) Mr. Vladimir Zhirinovsky, his son Mr. Igor Lebedev, the Liberal Democratic Party of Russia, and the three companies: Bayoil, Sidanco, and Plasco Shipping Co.; 7) the Communist Party of the Russian Federation, the Foundation for Friendship with Peoples of Arab States, the Council for Trade and Economic Cooperation with the Middle East and North African Countries, and Glencore International AG, a transnational corporation; 8) the African National Congress, the South Africa-Iraq Friendship Association, the Non-Aligned Movement (NAM) and two corporations: Montega Trading Ltd and Imvume Management Ltd. Again, corporations are the common denominator here. It is so because most NSAs confronted the same key issue: they did not possess the "know-how" to execute business contracts they obtained from Saddam's regime; therefore, they allied to corporations that did have the capabilities to execute the contracts. But above all, these case studies illustrate: a) how NSAs interact within the context of a global civic society; b) how vulnerable multilateral sanctions regimes are to a global civil society.

\section{$\underline{\text { Kojo Anan and Cotecna }}$}

The first case involves the model individual-UN associates-corporations. The model typifies how individuals lobbied UN associates on behalf of corporations interested in trading with the Iraqi regime under the UN sanctions regime. The case focuses on Kojo Annan, the son of Kofi Annan, UN's Secretary General at the time the 
UN conceived and enforced its sanctions regime against Iraq. Strong evidences suggest that Kojo Annan utilized his contacts at UN to win, among other contracts, perhaps the most important contract under the UN sanctions regime: the contract to inspect importexport operations in Iraqi. Kojo won the contract for Cotecna Inc.

Cotecna was a family-owned business, registered and based in Geneva, Switzerland (IIC, p. 480). The company belonged to Elie Massey, an Egyptian old friend of Boutros-Ghali, a former UN Secretary General (IIC, p. 480). The CIA and IIC assumed that thanks to the friendship, Cotecna obtained several contracts from UN during Ghali's tenure, to the point that Cotecna became a multimillion dollars business and UN's main subcontractor in Pakistan, India, Bangladesh, Kenya, Ghana, and Nigeria. But once Boutros-Ghali's Secretariat was over, Cotecna began to lose influence at UN and, as result, numerous contracts. Cotecna even faced a corruption scandal in Pakistan, which involved the Prime Minister Benazir Bhutto (Meyer and Califano, 2006, p. 48). It was during this period of crisis for Cotecna that Kojo Annan sought to work for the company. Kojo applied for a job there through his old friend Michael Wilson, Cotecna's Vice President for Marketing Operations in Africa. Cotecna hired Kojo as a consultant. Meyer and Califano affirmed that that "Cotecna decided to hire Kojo because of his connections and standing. Though not yet Secretary-General, Kofi Annan was already a prominent UN functionary serving under the Secretary-General and a strong candidate to substitute Boutros Ghali. The United States saw in Annan a reformer and supported his candidacy from the very beginning" (Meyer and Califano, 2006, p. 48).

Kojo became a consultant for Cotecna in 1995, and Cotecna became the sole inspection company of import-export operations in Iraq in 1996 (IIC, p. 481; Meyer and 
Califano, 2006, p. 48). The contract itself was not lucrative for it was worth just $\$ 6$ million per year, but Cotecna began to impose hidden fees and surcharges, accepted briberies, and paid kickbacks to Saddam's regime. Cotecna paid its way into Saddam's bureaucracy, which eventually translated into more lucrative contracts. Cotecna obtained 39 procurement contracts (IIC, p. 482; Meyer and Califano, 2006, p. 48). Through its auditing work, it absorbed contracts that included construction projects, transportation, and even in the health care sector. The CIA and IIC calculated that Cotecna made about $\$ 120$ million dollars per year through illegal deals and operations. Their activities had multiplier effects of about $\$ 800$ million dollars per year for the Iraqi economy (IIC, $\mathrm{p}$. 481; Meyer and Califano, 2006, p. 48).

Cotecna paid Kojo a salary of $\$ 2,500$ per month for seven days of work per week, and it also paid Kojo $\$ 500$ dollars per day in allowances and issued a credit card for him. Cotecna paid Kojo about a $\$ 3$ million dollars in "consulting fees" for a period of two years (IIC, p. 482; Meyer and Califano, 2006, p. 48). Cotecna's bank records revealed a trail of transactions from its accounts to Kojo's. For example, the IIC found that Cotecna paid $\$ 195,000$ dollars through Confiner and Meteor, two dormant companies owned by Mr. Massey, Kojo's friend and mentor. The trail of proof shifted toward Westexim by the year 2000. Westexim was a shell company registered in Switzerland but with P.O. Box in London. Cotecna issued seven money transfers of $\$ 118,000$ dollars through Westexim, but there were another two payments of $\$ 130,000$ to Kojo from an offshore account Cotecna had in Jersey Island (IIC, p. 483).

What is important here is that Kojo Anan utilized his influence as the son of UN's Secretary General to attain a lucrative UN contract for Cotecna, which was a 
private enterprise. Cotecna paid Kojo for his services, and it paid itself handsomely. Yet, it failed to inspect and detect violations of sanctions. Under Cotecna's watch, NGOs, individuals, political parties, banks, companies and Iraq profited hundreds of millions of dollars through kickbacks, overcharges, surcharges, money laundering, and other illegal operations. Thus, I would safely argue that Cotecna was largely responsible for the failures of the UN sanctions regime against Iraq.

\section{Benon Sevan}

The second case explains the model UN bureaucrats - corporations, namely how bureaucrats working for an international institution such as UN can affect a multilateral sanctions regime. The case study is about Mr. Benon Sevan, one of the most visible individuals in the UN sanctions regime against Iraq. Mr. Sevan was the Executive Director of OIP, the very office responsible for overseeing the UN sanctions regime. Mr. Sevan's actions contributed to violations of the UN sanctions.

Mr. Sevan began to work for UN in 1965 . He was promoted to Assistant Secretary General and Secretary-General's Personal Representative in Afghanistan and Pakistan from 1989 to 1997 (IIC, p. 213). He was then appointed Executive Director of the OIP in 1997, an office explicitly created to oversee the sanctions regime. It was a powerful post in bureaucratic and political terms. From his office, Mr. Sevan supervised daily operations of the sanctions regime during the period 1997-2003 (IIC, p. 213; Meyer and Califano, 2006, p. 182). The office established administrative rules and policies, set agendas, conducted periodic audits, gathered statistical and financial data, and prepared reports for the five permanent members of the UN Security Council. Sevan's office had 
an adjacent division responsible for overseeing the execution of contracts. It had hundreds of auditors monitoring compliance of contracts and sanctions. In addition, it had a third office, this one "on the ground," on Iraqi soil, to coordinate enforcement of sanctions throughout Iraq and its borders. In other words, under the right leadership, Mr. Sevan's office could have been an effective instrument of the UN sanctions regime. On the wrong hands, it could have led to mismanagement, corruption and nepotism. The latter prevailed.

Right after his appointment at the UN, Mr. Sevan started lobbying against the very sanctions regime he was supposed to enforce and oversee. He travelled 16 times in one year to Iraq, always as a UN representative; yet, while there, he spoke against the UN sanctions regime (IIC, p. 213; Meyer and Califano, 2006, p. 182). He traveled across the world to speak to prime ministers, politicians, religious leaders and human right groups. He spoke of relaxing the sanctions, rebuilding the Iraqi oil industry, and increasing sells of Iraqi oil. Meyer and Califano noted that "Mr. Sevan became the unofficial ambassador and voice of the Oil for Food Program” (Meyer and Califano, 2006, p. 183).

It is plausible that Mr. Sevan truly felt the need for relaxing the sanctions regime after witnessing the suffering of Iraqi people at first hand. However, evidences show that he illegally accepted oil vouchers from the Iraqi regime and sold them to AMEP, an oil trader registered in Panama (Meyer and Califano, 2006, p. 183). I showed in Table 4.1 that Mr. Sevan illegally obtained vouchers for 11 million barrels of oil. IIC's records indicated that Mr. Sevan sold the vouchers to AMEP, and Sevan's bank statements revealed "Regular deposits of thousands of dollars of cash-usually in the form of onehundred-dollar U.S. banknotes- to their New York bank accounts at the UN Federal 
Credit Union and Chase Manhattan Bank" (Meyer and Califano, 2006, p. 183). Chart I right below shows deposits in Sevan's personal bank accounts.

\section{Chart 4.2 - Benon Sevan's Personal Bank Account during the UN Sanctions Regime}

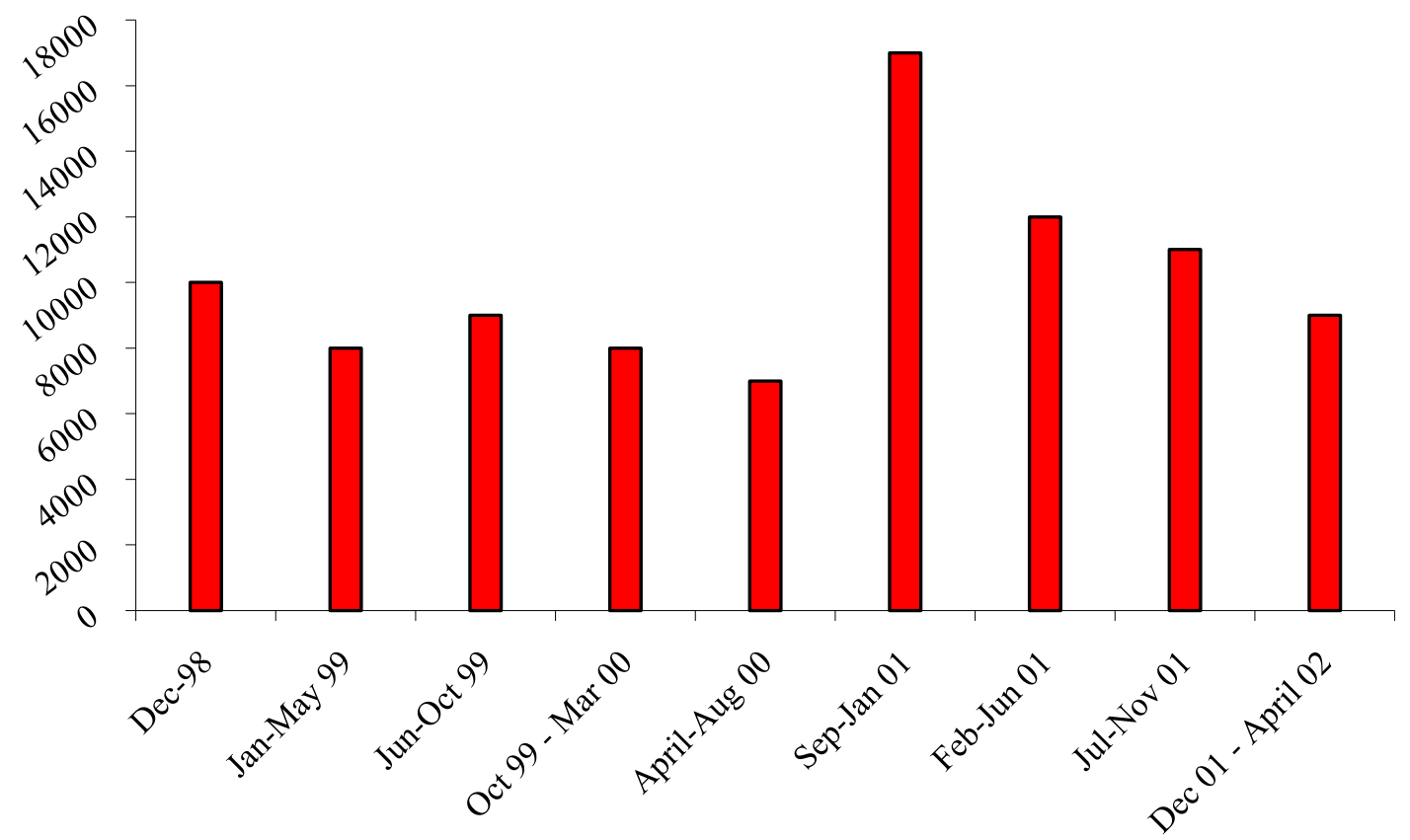

Source: IIC, Duelfer Report

Chart 4.2 shows deposits from $\$ 7,000$ to $\$ 18,000$ thousand from December 1998 to April 2002 even though Mr. Sevan had just one legal source of income: the salary he received from the UN. Curiously, "Bank records for accounts used by Sevan and his wife, Micheline Sevan, who was also a UN employee, showed that... their accounts went into overdraft status almost two hundred times. But after AMEP's first oil sale at the end of 1998, all of it changed as a mysterious chain of cash deposits emerged" (Meyer and 
Califano, 2006, p. 183). The IIC linked Mr. Sevan's bank deposits to AMEP's bank withdrawals. The deposits coincided with the first oil voucher the Iraqi regime assigned to Mr. Sevan, coinciding with AMEP's first oil sale under the UN sanctions regime. AMEP tallied its payments to Mr. Sevan "as commissions that ranged between 5 to 10 cents per oil barrel" (IIC, p. 215; Meyer and Califano, 2006, p. 183). Mr. Sevan and his wife made their last large deposit in April 2002. Coincidently, AMEP executed its last oil sale just a month earlier. I found evidences of Mr. Sevan and AMEP's illegal activities through records that Shell Corporation made public upon subpoena by the IIC. Shell's records revealed that AMEP resold Mr. Sevan's vouchers to Shell Corporation (IIC, p. 215; Meyer and Califano, 2006, p. 183).

\section{Jean Bernard Mérimée}

This third case also involves the model individuals - UN associates -corporations. The case is about Mr. Jean Bernard Mérimée. This case is significant because Mr. Mérimée was the French Ambassador to UN from 1991 to 1995, and as such he conceived and negotiated UN Resolution 986, which established the UN sanctions regime against Iraq. Let us not forget that France has veto power as one of the permanent members of the UN Security Council, which gave Mr. Mérimée authority and a lot of power with respect to the $\mathrm{UN}$ sanctions regime and in $\mathrm{UN}$ in general.

Mr. Mérimée began to oppose Resolution 986 soon after UN approved it. To be fair, he "Advocated for lifting the sanctions once Iraq satisfied its obligations concerning its weapons program pursuant to United Nations resolutions" (IIC, Chapter II, p. 49; Meyer and Califano, 2006, p. 77). He favored the "smart sanctions" initiative, which 
eventually became France's policy toward the Iraqi question. Yes, I would argue that it was France's policy and not Mérimée's. Yet, it all seems suspicious because Mérimée ended his ambassadorship to UN in 1995, and soon afterwards he became the Special Advisor to UN Secretary General on European Affairs, from where he voiced his support for "smart sanctions" as an alternative to the UN sanctions regime against Iraq (IIC, Chapter II, p. 49; Meyer and Califano, 2006, p. 77).

It turned out that Mr. Mérimée had forged a friendship with Tariq Azid, Iraq's Foreign Minister. "To show his pleasure for Mr. Mérimée's fair negotiations," Tariz Azid granted \$2 million barrels of oil and a dozen procurement contracts to Mr. Mérimée, who then sold them to Fenar Petroleum Ltd; a Firm based in Liechtenstein and subsidiary of Taurus Group, a Swiss oil trader (IIC, p. 49; Meyer and Califano, 2006, p. 77). Mr. Mérimée hired Mr. Elias Firzli to manage the operations. Mr. Firzli was an intermediary who "Often helped beneficiaries based in France to sell contracts received from Saddam's regime" (IIC, Chapter II p. 51; Meyer and Califano, 2006, p. 78). Mr. Mérimée, Mr. Firzli and Fenar utilized BMCE Bank of Morocco to conduct their financial transactions. The idea came from Mr. Mérimée himself. He declared to the IIC that "He was careful not to involve a French entity in the transactions" (IIC, p. 51; Meyer and Califano, 2006, p. 78). The obvious plan was to use Morocco's flexible banking system to avoid French and UN auditors. The IIC estimated that Mr. Mérimée pocketed about $\$ 2$ million dollars, the result of his illegal business deals under the UN sanctions regime against Iraq (IIC, Chapter II; p. 52; Meyer and Califano, 2006, p. 78). Father Benjamin 
The fourth case study involves the formula individual-religious activismcompanies. It is about Father Jean-Marie Benjamin, a priest who used humanitarian work and a private enterprise as a façade to evade sanctions.

Father Benjamin worked as Assistant to the Vatican Secretary of State from 1991 to 1994 (IIC, Chapter II, p. 99). Once his assignment ended, he began a public relations campaign against the sanctions regime. He produced the documentary "Iraq: The Birth of Time" (IIC, Chapter II, p. 99). It was his personal account of the negative effects that the sanctions had upon Iraqi population. The documentary was well-acclaimed in Europe, motivating a passionate debate about the morality of sanctions regimes as instruments of foreign policy, given their negative impact on civil population. Father Benjamin also created "Benjamin Committee for Iraq," a NGO to raise money, cloths, medicines, and school supplies for Iraqi children (IIC, Chapter II, p. 100). In April 2000, Faher Benjamin became the center of media frenzy as he, and another 200 activists, boarded an illegal flight to Baghdad in defiance of UN sanctions. In fact, he visited Iraq and met Saddam on various occasions. He even invited Tariq Aziz, a Christian, to pay a visit to Pope John Paul II at the Vatican (IIC, Chapter II, p.100; Meyer and Califano, 2006, p. 88).

It was during one of those meetings that Father Benjamin asked Tariq Aziz for oil vouchers and procurement contracts (IIC, Chapter II, p. 100; Meyer and Califano, 2006, p. 88). He argued that selling the contracts would have raised capital to fund his public relations campaign against the sanctions regime. Tariq Aziz accepted the proposal, and Father Benjamin proceeded to contact Alain Bionda, a Swiss oil trader, owner of Zyria Management Services (IIC, Chapter II, p. 100, Meyer and Califano, 2006, p. 88). Mr. Bionda had been seeking business opportunities in Iraq without success, so he rapidly 
accepted and proceeded to hire several companies to execute the contracts. The most notable was Taurus Group and its subsidiaries. Bank records show that Zyria and Taurus shared transactions for about \$25 million per year from 1997 to 2001 (IIC, Chapter II, p. 101; Meyer and Califano, 2006, p. 88). They transferred about $\$ 7$ million dollars in the form of bank notes to Father Benjamin's accounts at UBS Geneva and Vatican Bank, Istituto per le Opere di Religione. The companies described the transfers as "donations." The IIC calculated that Father Benjamin received vouchers for about 6 million barrels of oil and procurement contracts worth $\$ 20$ million dollars (IIC, Chapter II, p. 101; Meyer and Califano, 2006, p. 88).

\section{$\underline{\text { George Galloway }}$}

The case, like the fourth, illustrates how NSAs evaded the UN sanctions regime in the name of charitable work, only that this case involves a legislator using a NGO as a façade. The case fits the formula individuals- political activism - corporations. It entails Mr. George Galloway, his charity foundation Mariam Appeal, and corporations Fortum and Delta Services.

Mr. Galloway was a British MP well-known for his opposition to the UN sanctions regime. He reasoned that the sanctions affected the Iraqi people, not the Iraqi regime. To illustrate his argument, he visited Iraq on several occasions and documented the effects that the UN sanctions were having on Iraqi civilians. He even brought a four year old Iraqi girl to Great Britain for medical treatment. Her name was Mariam. In her honor, Mr. Galloway founded the charitable foundation Mariam Appeal, whose mission was to mobilize public opinion, lobby the UN and governments, and raise money to 
purchase medicines, food, and school supplies for Iraqi children. Mr. Galloway toured ten nations in a double-decker British bus, including Iraq. He voiced his message wherever he went. Below is a record of his visits to Iraq in violations of the UN sanctions.

Table 4.3 - George Galloway's Visits to Iraq during the UN Sanctions Regime

\begin{tabular}{|c|c|}
\hline & George Galloway's Visits to Iraq from 1993 to 2002 \\
\hline Date & Meeting \\
\hline Oct-02 & Deputy Prime Minister tariq Aziz \\
\hline Aug-02 & Saddam Hussein and T ariq Aziz \\
\hline May-02 & Tariq Aziz \\
\hline Jan-02 & Information Minister, Muhammad Said al-Sahhaf \\
\hline Nov-01 & T ariq Aziz \\
\hline Oct-01 & Agriculture Minister, Abd-al-Ilah Hamid Muhammad \\
\hline Feb-01 & T ariq Aziz \\
\hline Jan-0 1 & T ariq Aziz \\
\hline Nov-00 & T ariq Aziz \\
\hline Oct -00 & T ariq Aziz \\
\hline May-00 & Culture Minister, Humam Abd-al-Khaliq \\
\hline Mar-00 & T ariq Aziz \\
\hline Dec-99 & Vice Chairman, Revolution Command Council Izzat Ibrahim \\
\hline Nov-99 & Tariq Aziz and Foreign Minister Muhammad Said Al-Sahhaf \\
\hline Aug-99 & T ariq Aziz \\
\hline Jun-99 & Mariam Appeal Convoy \\
\hline Oct -98 & T ariq Aziz \\
\hline Apr-98 & T ariq Aziz \\
\hline Mar-98 & T ariq Aziz \\
\hline Jan-94 & Saddam Hussein and T ariq Aziz \\
\hline May-93 & Speaker of the National Assembly, Sadi Mahdi Salih \\
\hline
\end{tabular}

Source: IIC, Meyer and Califano

Mariam Appeal received many donations. Among others, it received $\$ 500,000$ from the UAE government, $\$ 150,000$ from the King of Saudi Arabia, $\$ 6,750$ from Fortum Oil and Gas, and \$375,000 from Fawaz Zureikat (IIC, Chapter II, p. 79; Meyer 
and Califano, 2006, p. 78). But Mr. Galloway was using Mariam Appeal as a façade to receive contracts from the Iraqi regime. Galloway adopted the pseudonym Abu Mariam. With it, he channeled to Mariam Appeal 39 contracts, worth $\$ 50$ million dollars, to export British foodstuffs and medicines to Iraq (IIC, Chapter II, p. 79; Meyer and Califano, 2006, p. 78). In addition, he channeled between 18-20 million barrels of oil for a value $\$ 80$ million in a three year period (IIC, Chapter II, p. 79; Meyer and Califano, 2006, p. 78). The scheme worked as follow: Mr. Galloway appointed Fawaz Zureikat as co-Chairman of Mariam Appeal and his liaison in Baghdad. Mr. Zureikat was a Jordanian businessman, owner of a dozen small companies throughout the Middle East. The Iraqi regime granted contracts to Mariam Appeal as "donations for Iraqi women and children." Mariam Appeal then passed the contracts on to Mr. Zureikat's various companies. Zureikat used his companies to provide business logistics, sell the oil in European markets, and channel payments to Mr. Galloway. In turn, both Galloway and Zureikat worked with Mr. Al-Chalabi, an Iraqi businessman living in Great Britain and owner of Fortum and Delta Services, two import-export Firms (IIC, Chapter II, p. 81; Meyer and Califano, 2006, p. 79). The role of Al-Chalabi was to move money from Mr. Zureikat to Mariam and then to Galloway's bank accounts at Citibank. Al-Chalabi referenced its transfers as "funding for medical supplies."

For example, the IIC revealed that Delta Services sold oil contract M/07/83 in January 2000 (IIC, Chapter II, p. 81; Meyer and Califano, 2006, p. 79). Soon after, it made a series of electronic transfers of $\$ 120,000$ thousand to Mr. Zureikat until totaling $\$ 472,228$, who then transferred the money to Mariam in the form of "donations for medical supplies" (IIC, Chapter II, p. 81; Meyer and Califano, 2006, p. 79). Ms. 
Galloway's bank records showed a series of deposits for $\$ 472,228$ thousand during the same period of time (IIC, Chapter II, p. 81; Meyer and Califano, 2006, p. 79). Fortum made a series of transfers of 70,000 thousand dollars to Mr. Zureikat as well (IIC, Chapter II, p. 82; Meyer and Califano, 2006, p. 78). Coincidently, Ms. Galloway’s bank records accounted for seven consecutive deposits of $\$ 70,000$ during seven consecutive weeks (IIC, Chapter II, p. 82; Meyer and Califano, 2006, p. 78).

\section{Vladimir Zhirinovsky and the Liberal Democratic Party}

The sixth case study follows the model individual-political parties-corporations. This case is involves a legislator, a state-actor, who employed his son, a NSA, to circumvent UN sanctions. Father and son used a political party as a means to access Saddam's regime and obtain contracts.

This case is about Vladimir Zhirinovsky, co-founder of the Liberal Democratic Party of the Soviet Union. Mr. Zhirinovsky consolidated his political career during the 1990s with the emergence of Russian nationalism. He founded the Liberal Democratic Party of the Russian Federation (LDPR), and almost overnight he became the most visible face of Russian nationalism and right-wing politics in Russia. Mr. Zhirinovsky ran for President in 1991, 1995 and 2000. He always lost although scoring large numbers of votes. For instance, he won $23 \%$ of votes during the Russian elections of 1993, ranking third among a large number of political candidates (IIC, Chapter II, p. 30). It was not enough to win the Russian Presidency, but it was large enough to legitimize his political persona and control 12\% of the Russian Duma. 
The rise of Zhirinovsky's political career coincided with the consolidation of the UN sanctions regime. Mr. Zhirinovsky visited Bagdad a dozen times, not as a legislator but as a leader of the LDPR. On one occasion, he led a delegation of 50 Russian political activists and businessmen to Baghdad where he "Called for the immediate end to UN sanctions against Iraq and the end of American occupation of Iraqi territories" (IIC, US Senate, Permanent Subcommittee on Investigations, p. 8). He also met "With Saddam Hussein, Deputy Prime Minister Tariq Aziz and Speaker of the National Assemble Saadi Mehdi Saleh" (IIC, US Senate, Permanent Subcommittee on Investigations, p. 8). They signed "An agreement of cooperation between the parliament of Iraq and the LDPR faction; in addition, he signed an agreement on "inter-party ties" between the Husseincontrolled Baath Party and the LDPR" (IIC, US Senate, Permanent Subcommittee on Investigations, p. 8). He promised Saddam that "He and the LDPR will stand firmly against the enforcement of the United Nations economic sanctions against Iraq... and that in order to balance the political situation in the world, the LDPR will use our influence on the Duma to adopt resolutions that will facilitate the economic cooperation between our countries" (IIC, US Senate, Permanent Subcommittee on Investigations, p. $8)$.

The Iraqi government rewarded Mr. Zhirinovsky for his services. The IIC and the US Senate estimated that the Iraqi government illegally granted 78.8 million barrels of oil to Mr. Zhirinovsky, and that he made about $\$ 9$ million in a two-year period (IIC, Chapter II, p. 31; Meyer and Califano, 2006, 2006, p. 76-77). The Iraqi government also granted 32 procurement contracts to Zhirinovsky, so he could export industrial parts and machinery to Iraq. The contracts were worth about $\$ 20$ million (IIC, Chapter II, p. 31; 
Meyer and Califano, 2006, p. 76-77). Mr. Zhirinovsky obtained a contract to repair three Iraqi oil refineries that had been damaged during the Persian Gulf War. The contract was worth $\$ 600$ million dollars, but he lost it (IIC, Chapter II, p. 31; Meyer and Califano, 2006, p. 76-77). He could not find a subcontractor, a company willing to execute the contract at the prices he had set forth.

The IIC and the U.S. Senate concluded that it was impossible to estimate exactly how much Zhirinovsky made through violations of the UN sanctions. The problem was that most Russian individuals, organizations and companies used cash, among other reasons, for lack of credit history. In fact, in the following chapters I will explain how the use of cash was a common practice to evade the sanctions, but for the moment I will cite the IIC, which stated that "Some surcharge payments were partially or fully satisfied through cash payments at the Iraqi Embassy in Moscow," and that "Diplomatic bags, which could hold up to $\$ 1.5$ million in $\$ 100$ bills, were used to transport the money" (IIC, US Senate, Permanent Subcommittee on Investigations, p. 8). Still, the IIC did trace some of the money back "to an account in the Bank of Cyprus with the reference in favor of Igor Lebedev" (IIC, Chapter II, p. 32; Meyer and Califano, 2006, p. 77).

Igor Lebedev was too a member of the LDPR, but he also was the son of Mr. Zhirinovsky. It turned out that the IIC and CIA linked Mr. Lebedev's account at Bank of Cyprus to accounts owned by Bayoil, Sidanco, and Plasco Shipping Co. Ltd (IIC, Chapter II, p. 32; Meyer and Califano, 2006, p. 77). It all suggests that Igor Lebedev was the intermediary between Zhirinovsky (his father) and those companies.

Bayoil was an oil trading company based in Bahamas and a parent company of Bayoil Inc., based in Houston, Texas. Bayoil Inc. was a financier of oil, coal and other 
forms of energy (IIC, Chapter II, p. 32; Meyer and Califano, 2006, p. 88-89). For its part, Sidanco was a Russian company specialized in the extraction and refining of oil, and Plasco was a Liberian company specialized in the transportation of oil and linked to Bayoil Inc. as a subcontractor (IIC, Chapter II, p. 32; Meyer and Califano, 2006, p. 8889). The three companies helped Mr. Zhirinovsky finance, lift and transport oil from Iraqi oil wells to world markets by using Igor Lebedev as their intermediary. Their operations went undetected for about seven years of multilateral sanctions, until Zhirinovsky defaulted in his "kickbacks" to the Iraqi government and Saddam banned him from doing business with Iraq.

\section{Communist Party of the Russian Federation}

This case is about the Communist Party of the Russian Federation (KPRF.) It shows how a political organization aligned to an $\mathrm{NGO}$ and a private corporation with the goal of evading a sanctions regime. They followed the model individuals - political activism-corporations.

The KPRF was founded in 1993 after the disintegration of the Soviet Union (IIC,

Chapter II, p. 27). The Party was largely recognized as the heir of the Communist Party of the USRR, which had solid ideological, political and commercial relations with Saddam and his regime. Their relations go back to the days when the Communist Party was the sole spiritual, ideological, political leader of former Soviet Union and its satellites.

In Chapters II and III, I showed evidences of how Saddam's regime was one of the most important commercial and military partners the Soviets had in the Middle East 
during the Cold War. The partnership continued after the end of the Cold War through the UN sanctions regime. The KPRF was powerless and penniless, and Saddam's regime was doomed to collapse. Thus, they needed each other. The KPRF needed money and international recognition in a time when most communist parties, and their ideology, were considered dead. Saddam, for his part, needed support against the UN sanctions regime and the multilateral coalition led by the U.S. and UK, which occupied half of the Iraqi territory. Saddam thought that the KPRF and Mr. Zyuganov could be a useful voice in the Russian Federation and around the world (IIC, US Senate, Permanent Subcommittee on Investigations, p. 22). From 1996 to 2000, Gennady Zyuganov came second in the Russian Presidential election, and the KPRF held an important number of seats in the Russian Duma (IIC, Chapter II, p. 27; IIC, US Senate, Permanent Subcommittee on Investigations, p. 22). Above all, consider that Russia was a permanent member of the UN Security Council.

For those reasons, the KPRF had no problem obtaining oil and procurement contracts from Saddam's regime. After all, it publicly opposed the sanctions and military actions against Iraq. It even submitted a public letter to the UN calling for lifting the inhuman embargo against Iraq. Its problem, however, was executing those contracts for, as a political organization, it had no business experience whatsoever. The KPRF found a solution in the global civil society.

First, the KPRF found a partner in the Foundation for Friendship with Peoples of Arab States (FFPAS), a relatively well-known political organization with offices in Paris, London, Amsterdam, Geneva and other European capitals (IIC, US Senate, Permanent Subcommittee on Investigations, p. 22-23). The KPRF was not to receive contracts 
directly from Iraq but rather through FFPAS. The obvious objective was to evade the UN sanctions regime. Second, the KPRF itself created a non-state actor and named it "The Council for Trade and Economic Cooperation with the Middle East and North African Countries" (ACTEC). In its Articles of Incorporation, ACTEC assures us that its main and sole objective was the promotion of Iraqi trade throughout the Middle East and North Africa. However, Meyer and Califano stated that "It was merely a nameplate company that temporarily leased an office space at a Russian foreign services training school in Moscow" (Meyer and Califano, 2006, p. 103) and the IIC affirmed that "The exact scope of ACTEC's business activity is unclear, but it appears to have been established specifically for Programme-related business projects" (IIC, Chapter II, p. 43-44). Nevertheless, ACTEC proceeded to hire Glencore International AG as a subcontractor. Glencore was a holding company specializing in commodity trading (IIC, Chapter II, p. 43-44). It was registered and based in Switzerland, owned by a partnership between its management and employees. The partnership presented a difficulty to Glencore's management though: it feared that employees would oppose engaging in business relations with ACTEC, a Russian NGO promoting business with Iraq, which was an embargoed nation.

Glencore reinvented itself to deal with that difficulty. It created Petrogaz Distribution S.A. and Glencore France S.A. in 1999, and it registered them in France (IIC, Chapter II, p. 43-44). Then, Glencore approached Al-Khaled Engineering Est., a Jordanian company specialized in logistics and transportation of crude oil. Next, Glencore created several layers of bank accounts dispersed at different banks throughout the global banking system. Bank records show that Glencore deposited $\$ 9.1$ billion in its 
accounts at Arab Bank Geneva, in Geneva, Deutsche Bank A.G., in Munich, and Commercial Bank International and Arab Bank Dubai, both in Dubai (IIC, Chapter II, p. 45, Meyer and Califano, 2006, p. 104). The IIC traced the money to accounts that Delta Petroleum Products Trading owned in Geneva, Switzerland. Delta was a dormant company Glencore created and registered in Switzerland in 1999. Through it, Glencore paid Scandinavian T. Ltd, which in turn paid ACTEC for its contracts. ACTEC ranked fourth among all Russian non-state actors, including companies, in oil and procurement contracts. It ranked eight among all participants in the UN sanctions regime against Iraq. The money was supposed to go to KPRF, but the CIA and the IIC could only account for approximately $\$ 2$ billion dollars in oil contracts and $\$ 2$ billion for its procurement contracts in a period of 3 years (IIC, Chapter II, p. 45; Meyer and Califano, 2006, p. 104).

\section{The ANC, the South Africa-Iraq Friendship, and the Non-Aligned Movement}

The last case involves the model individuals - international organizations corporations. This case is about an alliance that a political party, a NGO and an international institution forged to evade the UN sanctions regime against Iraq. This case shows one of those ironies in international politics for it involves the African National Congress (ANC). The ANC violated the UN sanctions regime upon Iraq after benefiting itself from one: the multinational embargo imposed upon South Africa to eradicate the apartheid regime. Moreover, one of the pillars of the multilateral embargo against South Africa was to free Nelson Mandela, the ANC's most prestigious leader and founder of Umkhonto we Sizwe, which was ANC's armed arm. This case study also involves the 
South Africa-Iraq Friendship Association (SAIFA) and the Non-Aligned Movement (NAM.)

This case is relevant for two main reasons: first, the ANC was governing South Africa when it conceived its scheme to circumvent the sanctions regime. Second, the ANC negotiated with Iraqi officials in the name of the South African government. Nevertheless, as soon as the IIC launched its investigation on violations of the UN sanctions regime, the South African government distanced itself from the ANC, and South African officials went out to publicly state that the government of South Africa had nothing to do with ANC's actions. The government of South Africa never investigated the allegations, which in the end were ignored and forgotten.

The problem was that the South African president, Thabo Mbeki, was also the Chair of NAM and the African Union. It appeared that some important members of the ANC took advantage of NAM to engage in business relations with the Iraqi government. For instance, in November 1999, members of the ANC organized a delegation to visit Iraq in the name of the NAM. The ANC did not hide its intentions. It announced that the objective of the visit was to "Expose South African businesses with already established interests in the so called oil for food Programme with Iraq to the processes involved in winning such UN-approved contracts" (IIC, Chapter II, p. 103). According to the IIC, the ANC pushed for establishing full diplomatic relations between South African and Iraq, and it even invited Tariq Azid, Iraq's Minister of Foreign Affairs, to visit South Africa. Then, the ANC joined the South Africa-Iraq Friendship Association (SAIFA) to welcome Tariq Azid to South Africa. It turned out that SAIFA had been serving as a business intermediary between Montega Trading Ltd (Montega), Imvume Management Ltd 
(Imvume), and the Iraqi government. The IIC pointed out that "South African businessmen formed the companies to take advantage of the oil contract available under the UN sanctions regime” (IIC, Chapter II, p. 104), and "Mr. Majali used Montega and Imvume as the contracting companies to purchase the oil" (IIC, Chapter II, p. 104). Sandi Majali was the Chairman of both SAIFA and SABCETT. A series of letters and actions showed that he was the ANC's strong man in Baghdad for the purpose of organizing ANC's operations in Iraq.

For example, in a letter to Tariq Azid, the ANC appointed Mr. Majali "As a recognized representative of the ANC" (IIC, Chapter II, p. 103). Iraqi officials accredited him as "Advisor of the ANC and to the President of South Africa" (IIC, Chapter II, p. 103). Second, Mr. Majali "Led a delegation to Iraq, which included officials from the South African Strategic Fuel Fund Association and South African Department of Minerals and Energy" (IIC, Chapter II, p. 104). The purpose of the trip was to hold "Discussions on strengthening ties between the ANC and the Iraq Friendship Association and Arab Ba'ath Socialist Party, as well as building better oil trade relations between the two countries" (IIC, Chapter II, p. 105). A letter from Mr. Montlanthe, Chairman of Iraq Friendship Association, stated that "Mr. Majali's position as Chairperson of SAIFA had the ANC's full approval and blessing” (IIC, Chapter II, p. 105). The letter confirmed “ANC's approval of Mr. Majali as a designated person to lead the implementation process arising out of our economic development programme” (IIC, Chapter II, p. 103).

For his part, Mr. Majali "Wrote two letters to Iraqi authorities in which he referred to a request for oil allocations that had been made to support South Africa's political activities in connection with Iraq" (IIC, Chapter II, p. 108). In another letter, 
this one addressed to the President of the Iraqi Friendship Association, Mr. Majali argued that " $A$ joint effort between the ANC and the Arab Baáth Party will add a lot of value towards achieving the common political objectives, which will result in an effective strategy geared toward campaigning for the lifting of sanctions" (IIC, Chapter II, p. 108). In the same letter, he requested 12 million barrels of oil "With particular attention to the competitive advantage pricing of this transaction for the benefit of both parties in order to build financial resources to support political programs [...] that the ANC and Ba'ath parties will be implementing and to run seminars, workshops in order to develop effective political development strategies" (IIC, Chapter II, p. 108). Still, in another letter Mr. Majali requested another 12 million barrels of oil. He argued that the oil was "Required by the South African government for its strategic reserves" (IIC, Chapter II, p. 109). He confirmed that the "ANC will be sending a high level delegation" to a colloquium the Iraqi government was organizing in Baghdad against the UN sanctions regime.

The correspondence between Mr. Majali and Iraqi officials was abundant. It went on for almost five years, proving that Mr. Majali did not act alone; rather, he always appeared as a representative of the African National Congress, the South African ruling party at the time. The IIC calculated that the ANC illegally made about $\$ 80$ million dollars through oil sales and another $\$ 120$ million through procurement contracts (IIC, Chapter II, p. 110). It is worth repeating that the ANC itself was a beneficiary of the multilateral sanctions regime imposed upon South Africa to end racism there. It clearly shows political and even ideological contradictions within the ranks of the ANC, but as important as it might be, it is not a determinant. What is primarily relevant here is: firstly, 
the conflicts of interests between states and global non-state actors; secondly, the diversity of global non-state actors relative to their economic, political, and ideological interests; thirdly, the complexities of multilateral sanctions regimes, and the difficulty of enforcing them.

\section{$\underline{\text { Conclusion }}$}

In this chapter, I found that NSAs do affect foreign policies such as multilateral sanction regimes. For instance, I found that a large number of NSAs allied with each other and a wide range of other actors for the sole purpose of circumventing the sanctions regime. Individuals, NGOs, political and religious groups, banks and businesses of all sorts worked together, and with Saddam's regime, to evade the sanctions and profit from them. Their actions undermined UN policy toward the Iraqi regime, affected politics in the Middle East, and relations among world superpowers. Here, one key finding is that political and civic activists, NGOs, religions organizations and political parties did not have the required expertise to finance and carry out the contracts they obtained from Saddam's regime. As result, they had to pass those contracts on to banks and companies, which were ultimately responsible for resuming the operations. This is particularly important because in the next Chapter I will discuss how banks and creditors, through the global banking industry, circumvented the UN sanctions regime against Iraq to finance import-export operations there. 


\section{AGENTS AND MEANS OF GLOBALIZATION: THE GLOBAL BANKING SYSTEM, BANKS, INVESTORS AND SPECULATORS}

"Someone has asked you to make a payment to a third party, and that third party happens to be a bank owned by a company that is incorporated out of the Cayman Islands, and that is the only thing you know about it. That seems suspicious".

Congressman Dana Rohrabaher

"Iraq manipulated its national banking structure to finance illicit trade... Iraq established international accounts to finance its illegal procurement network. Iraq's international accounts, mainly located in Jordan, Lebanon and Syria were instrumental in Iraq's ability to successfully transfer billions of dollars of its illicitly earned oil revenues from its various global accounts to international suppliers, front companies, domestic government and business entities".

The Duelfer Report

"Some movements of funds, such as large deposits followed quickly by similarly large withdrawals from the account, combined with other factors, including the identity of the recipient of the funds, are examples of possible money laundering behavior perpetrated by some of these lesser known companies, which went undetected by banks engaged in trade with Iraq".

The IIC Report

\section{Introduction}

Globalization is a system formed by subsystems, groups and units. In order to explain the system, we must study its various components, identify their characteristics and behaviors, and clarify how they interact and what makes them unique within the system. In this chapter, I examine a very unique subsystem of globalization, a means of globalization, a system in itself. I examine the global banking system and its various agents, namely banks, investors and speculators.

In this chapter, I argue that the current global banking system allows nation-states, banks, investors, speculators, corporations, and NSAs in general to operate and profit under a sanctions regime, even if it is multilateral. Specifically, I argue the UN sanctions regime in Iraq failed in large measure due to a global banking system that, directly and indirectly, intentionally or not, financed the circumvention of the sanctions. To illustrate 
my argument, I present evidences of how states and global NSAs utilized global banking to finance purchases of Iraqi oil and its derivatives, to finance procurement contracts and exports to Iraq, to laundry and conceal money, and evade UN inspectors.

I address three main points in this chapter. First, I study the Iraqi banking system and its surprising expansion under the UN sanctions regime. Second, I examine the role of BNP Paribas, the bank that the UN appointed to oversee Iraq's banking. Third, I discuss how banks, investors and speculators collaborated to finance the circumvention of the UN sanctions regime. I have collected most of the evidences from the Duelfer Report, the IIC Report, the Michigan Project, the Heritage Foundation, and media sources.

\section{Global Banking and Banks}

I cannot overemphasize the role that the global banking system plays in the global economy. For one, global banking guarantees the free exchange of money from banks to investors, speculators, corporations and nation-states throughout global markets and back to banks. The World Bank estimates that $\$ 1.5$ trillion dollars flows into the global economy every day to finance global trade (imports and exports), transportation, labor, production, investment and speculation (IIC, Chapter IV, p. 545). Second, most of that money circulates in the form of credit and electronic money. Most businesses operate on credit, and electronic money, not cash, is the predominant way money circulates through global markets. The collapse of the global banking system and the subsequent global credit crisis during the summer of 2008 illustrates a fact of globalization: global banking finances global trade and credit in the form of electronic money is its blood. 
To begin with, banks have existed for centuries. I can trace them back to the Greek city-states and Roman Empire where they financed commerce, construction, armies and wars (Cantor, 1993, p. 41). And Venetian bankers financed some of the most expensive projects of the Roman Church, including the Crusades (Cantor, 1993, p. 42). Venetian bankers sponsored the Renaissance too (Cantor, 1993, p. 44). And Dutch and British banks funded slavery and colonialism. They financed the textile, tobacco, cotton and other labor-intensive industries. They also invested heavily in the industrial revolution, which created large industrial outputs and facilitated the accumulation of capital, used in turn for reinvestment and for the consolidation of the capitalist system.

Banking was already an international industry by the 1920s, but its contemporary global characteristics came with the collapse of the Bretton Woods regime in 1971 (Burchill, 2001, p. 77; Smith, 2003, p. 57). The "regime" regulated the banking industry to prevent the speculative excesses of the 1920s that had led to the "crash" of the stock market in 1929 and the economic depression of the 1930s. Over time, inflation, slow economic growth, trade barriers and other economic factors caused the collapse of the American dollar, provoking in turn the collapse of the Bretton Woods Accords. Deregulation of capital in 1971 coincided with very important innovations like banking software and electronic money, which facilitated the flow of money throughout global markets at speeds never realized before. The new Regime linked markets and consolidated interrelations between banks, producers, consumers, and nation-states, but it kept in place a key feature of Bretton Woods Accords: it did not allow banks to invest in the import-export industry (Smith, 2003, p. 54). The rationale was that banks were in large measure responsible for the misfortunes of global trade during the 1910s, 1920s and 
1930s. But by 1982, the U.S. deregulated banking and the import-export industries, allowing banks to invest in import-exports if they invested through subsidiaries and affiliates (the Export Trading Company Act of 1982, the $97^{\text {th }}$ Congress). Soon, American banks such as Bank of America, Manufacturer of Hanover Trust, Chase Manhattan, City Bank and others created subsidiaries and affiliates for the sole purpose of investing in import-export firms. The new American law also mobilized foreign banks, which rushed themselves into American markets, at the time the largest importer-exporter of goods and services in the world (Barovic, 1985, p. 4). Today, banking is a true global system composed of investment and brokerage houses, insurance and security firms, and all sorts of "funds," from mutual to edge, to sovereign funds.

Next, data from World Bank indicate that banks currently finance $56 \%$ of the global trade, namely the export-import industry (IIC Report, Chapter IV, p. 545). Financing refers to pay for investing, insurance, legal advising, account management, currency exchange, cost and payment processing, and lending. Financing is for the most part made in the form of credit. There are three main types of credit in the global trade: consignment, open-account and payment in advance (Smith, 2003, p.13-14).

Trading on consignment means that exporters run with all costs and risks involved in trading (Smith, 2003, p. 15). Exporters ship their cargo with the required documentation. Once arrived, importers claim ownership of the cargo, but they pay for it only when the merchandise is sold out. With open-account, exporters absorb all shipping expenses, but importers pay for the cargo according to a contract previously agreed upon (Smith, 2003, p. 15). Payment in advance is a sort of insurance, a fee that exporters charge to importers for risks involved in shipping operations (Smith, 2003, p. 16). Such 
fees can be large, usually from 50 to 70 percent of the total amount owed. It depends on the importers' credit history and years in service. In all instances, the role of banks is to finance shipping operations for which they charge some fees. Banks finance global trade through two banking devices: trade bills and letters of credit.

Export-import firms utilize trade bills to curtail risks like damages and loss of goods, failure to pay on time and/or defaulting on loans (Smith, 2003, p. 17). That is why most banks operate through intermediaries or third parties. Exporters draft a trade bill for an intermediary, which is usually a carrier or shipping company. Intermediaries run with all shipping expenses in advance through a loan they receive from a bank. They issue a bill of landing to exporters as proof that the cargo was shipped (Smith, 2003, p. 17). Importers receive and pay intermediaries for the trade bill upon arrival of the cargo. Finally, intermediaries pay the loan back to the bank. If the cargo is lost, damaged or never delivered, the intermediary still has to pay for the loan unless it declares bankruptcy. If it does, the intermediary's insurance pays for the loan. The bank never loses its money. On the other hand, a letter of credit is the most common, efficient, secured mechanism for financing global trade (Slager, 2004, p. 44; Smith, 2003, p. 1314). There are two main types: commercial and standby (Smith, 2003, p. 18). A commercial letter of credit is the prime payment mechanism. Importers and exporters utilize it when they do not want -or cannot afford- to run with shipping risks and expenses. A commercial letter of credit is a contractual agreement between an advising bank (exporter's bank) and an opening or issuing bank (importer's bank) through which they assume all shipping costs and risks involved in the import-export operation (Slager, 2004, p. 47; Smith, 2003, p. 19). If an exporter does not deliver its cargo as stipulated in 
the contract, the advising bank pays for fees and fines. If the cargo is lost or damaged, the advising bank also pays for it. If an importer defaults or fails to receive the cargo as contracted, then its opening bank pays. On the other hand, a standby letter of credit serves as a secondary payment method to ensure that primary payment is delivered within the terms of the contract (Slager, 2004, p. 55; Smith, 2003, p. 13-14). The standby letter of credit is also a back up credit to strengthen the exporters and importers' credit worthiness. An opening bank issues a standby letter of credit with an expiration date attached to it. The exporter holds (or standby) the letters until terms of contracts are met. If they are, the importer pays the exporter for the cargo, and the advising bank disregards the letter and ends the contract. In general, commercial and standby letters of credit are backed up by other documents such as invoices, promissory notes, and insurance.

In all, letters of credits are valuable for banks, exporters and importers (Slager, 2004, p. 77). First, exporters and importers never use their money up front but just credit, or a promise to pay later in montly amounts. For their parts, banks do not use their credit but their customers'. Also, by financing trade through credit, exporters-importers do not need to move large sums of capital. Consider that global trade is expensive for it requires chartering planes, vessels and large trucks to transport cargoes. It incurs in costs such as freight, port and airport fees, warehousing, security, insurance, salaries among others.

Global trade also demands that money be moved from account to account and banks to banks in a rapid, secured and efficient manner. This has largely been accomplished through a sophisticated global banking infrastructure built on two pillars: electronic banking and electronic money (Slager, 2004, p. 62; Smith, 2003, p.102). 
Electronic banking refers to banking products and services executed through electronic channels (Slager, 2004, p. 63; Smith, 2003, p. 107). They include deposittaking, lending, account management, electronic bill payment and electronic money. Delivery of these products and services occurs through two electronic networks: closed and open (Slager, 2004, p. 65; Smith, 2003, p. 115). Closed networks restrict access to participants, meaning to financial institutions, merchants and, more important, third party service providers or intermediaries who conduct voluminous transactions of investments and liquidation of capital (Slager, 2004, p. 65; Smith, 2003, p. 115). Conversely, open networks have no membership requirements, and they are delivered through automatic tellers, telephones, computers, smart cards and other electronic devices (Slager, 2004, p. 65; Smith, 2003, p. 115). Electronic money refers to prepaid payment mechanisms executed through direct transfers, from digital debit to digital credit (Slager, 2004, p. 65; Smith, 2003, p. 115). Electronic money saves time and increases efficiency, but it has two important disadvantages: it is anonymous, so it lends itself to money laundering and evasion of regulatory regimes such as sanctions regimes. Collin Powell defined electronic money as the life-line of terrorism (Collin Powell, Testimony Before Banking Committee, Houser of Representatives, 2002). It is not a hyperbole. I stated earlier that about $\$ 1.5$ trillion dollars moves throughout global markets on a daily basis, making it too difficult for governments to trace it from account to account and bank to bank. Money is especially difficult to trace when it is stored in shell companies and offshore banking (Slanger, 2004, p. 209).

Shell companies have no real business activity. Also known as "aged" or "dormant" companies, they are not incorporated for three main reasons (Slanger, 2004, p. 
209). First, they carry an aura of corporate longevity. Since some nations require that a company be in existence for some time before ever obtaining a contract, a shell company represents a useful tool to overcome such a requirement (Slanger, 2007, p.209). Besides, longevity facilitates access to letters of credit, cheap credit, and fresh capital. That is why shell companies are often sold to a company seeking credit (Slanger, 2004, p. 209; Smith, 2003, p. 119). Finally, businesses and individuals use shell companies to avoid taxation and currency restrictions imposed in some countries. Though, shell companies are usually linked to financial crimes. Banking officials are often suspicious about large movement of capital through shell companies for they are usually related to bribery, tax evasion, money laundering, prostitution, and the finance of terrorism.

Like shell companies, offshore banking is seldom utilized for financial wrongdoings such as tax evasion, money laundering, and white collar crimes (Slanger, 2004, p. 209; Smith, 2003, p. 124). Yet, it offers some advantages to corporations, investment firms and individuals seeking flexibility and profitability. Offshore banking refers to a bank based in a jurisdiction beyond its original residence, meaning beyond the nation where it was originally created. Under this corporate structure, offshore accounts enjoy several advantages. First, offshore accounts guarantee great savings in terms of taxation. Second, they offer privacy and anonymity. Third, they provide easy access for deposit and withdrawal, facilitating movement of capital for investments or just emergencies, something so vital in today's volatile financial markets. Fourth, they offer asset protection and limited liability against domestic and international laws. And finally, when coupled with an escrow account, offshore accounts become important sources of 
liquidity and fresh, cheap, reliable credit, especially in the form of letters of credit, so important in global commerce (Slanger, 2004, p. 209; Smith, 2003, p. 124).

Economists believe that half of global capital, in terms of investments and savings, is moved to offshore accounts in offshore centers. For the IMF, offshore banking centers account for $26 \%$ of the global financial wealth, which is about $\$ 6$ trillion dollars (www.imf.org); yet, offshore centers account for just $1.2 \%$ of the world's population (www.un.org). The IMF and the World Bank estimate that, of that money, between $\$ 500$ and $\$ 2$ trillion can be traced back to money laundering, tax evasion, prostitution, illegal gambling, arms trafficking and terrorism (www.imf.org; www.wb.org). Money laundering amounts to $\$ 500$ billion dollars while tax evasion may reach a trillion. According to the American Federal Reserve, American corporations redirect 31\% of its profits toward offshore banking centers every year, and the GAO affirms that " 59 out of 100 largest publicly-traded federal contractors had established hundreds of subsidiaries in offshore-tax havens" (Sen. Dorgan, Hearing Before Finance Committee, 2007). Just recently, the U.S. government and the Swiss bank UBS settled a lawsuit to uncover about 4,450 accounts that American investors own there, and the accounts are worth about $\$ 18$ billion dollars (www.nyt.com, August 20, 2009). Lynnley Browning, from the New York Times, states that "The landmark settlement peels back layers of Swiss banking secrecy and expects to provide a road map for the authorities as they try to crack down on tax evasion by Americans who, through private banks and other Swiss-based financial intermediaries, use offshore accounts to go undeclared to the IRS" (www.nyt.com, August 20, 2009). They use offshore accounts for tax evasion, but the U.S. government is most concerned about terrorist groups using them for financing terrorist activities. 
Switzerland and Cayman Islands constitute the two most important offshore banking centers in the world, but The Bahamas, British Virgin Islands, Hong Kong, Cyprus, Panama, Liechtenstein, Monaco and Andorra are important as well. For example, the infamous Enron Corporation had 1,300 tax-havens around the world, 441 of which were located in Cayman Islands. Exxon-Mobil Corporation has 11 tax-haven subsidiaries in The Bahamas. Halliburton Corporation has 17, including 13 in Cayman Islands, Panama and Liechtenstein (Uncooperative tax Heavens, www.elpais.es, March 25, 2008). Recently the Organization for Economic Cooperation and Development, headquartered in Paris, labeled Liechtenstein, Monaco and Andorra as "uncooperative tax havens" (Uncooperative tax Heavens, www.elpais.es, March 25, 2008). In chapters II and III, I explained that The Bahamas, Cyprus, Panama, and Liechtenstein ranked among the most active importer-exporter nations under the UN sanctions in Iraq. In this chapter, I explain why. I argue that banks, companies, investors and other NSAs used banking centers in those nations to conceal profits made under the UN sanctions regime in Iraq. In fact, the UN was well aware of those issues, to the point that it mandated the use of an escrow account to collect proceeds from the UN sanctions regime in Iraq.

An escrow account is a trust account held on a borrower's name to pay obligations such as debts, taxes and insurance premiums (Slanger, 2004, p. 127; Smith, 2003, p. 194). Under a contract, a beneficiary deposits cash into an escrow account managed by a third party, an escrow agent acting as a trustee. Once the cash is deposited, the escrow agent delivers the payments as the contract mandates (Slanger, 2004, p. 127; Smith, 2003, p. 194). Escrow accounts are widely used for wire transfers and letters of credit. Note that both the UN Security Council and Saddam Hussein chose escrow 
accounts to store money, but they did it for two very different reasons. The UN Security Council sought transparency and reliable oversight while Saddam Hussein sought to circumvent the UN sanctions regime. An estimated $71 \%$ of all corporations that traded with Iraq chose offshore accounts (IIC, Chapter IV, p. 481), which can be an indication of their true intentions, that is concealing trade and profits from UN inspectors.

\section{$\underline{\text { Investors and Speculators }}$}

Investors and speculators play a crucial role in both the global banking system and global trade. They played a key role under the UN sanctions regime against Iraq.

Investors and speculators are financial intermediaries, individuals or entities acting as financial contacts between two parties, which could be two companies, two individuals, or a company and an individual (Slanger, 2004, p. 151; Smith, 2003, p. 89). The intermediation mainly consists in the transferring of funds from one account to another, and it could involve lending, borrowing, depositing, saving and investing of different forms (Slanger, 2004, p. 151; Smith, 2003, p. 89). This usually occurs through regular commercial banks. However, there are larger and more complex business operations like financing and insuring large volumes of goods and services for global trade. They involve large amounts of funds, logistics, risks and liabilities. In such cases, instead of using their own funds, names and licenses, businesses prefer to employ investors and speculators (Slanger, 2004, p. 151; Smith, 2003, p. 89). They are small, as in the case of day traders, but they are also large, often linked to brokerage firms, mutual funds, edge funds, insurers and others financial entities (Slanger, 2004, p. 151; Smith, 2003, p. 89). 
Investors and speculators are expensive due to the fees and interest rates they charge. Yet, importers and exporters seek their services for several reasons. First of all, investors and speculators have "easy" access to credit. Second, they assume all financial risks involved in trade. Third, they offer great solutions to the issue of liquidity. For instance, when there are losses, investors and speculators assume them all or a portion. They can even save companies from bankruptcy. Fourth, they contribute to business diversification and expansion. They help companies to participate in several businesses and markets at the same time. Finally, investors and speculators are sound substitutes for banks. They have taken $42 \%$ of world commerce from banks during the last twenty years (Slanger, 2004, p. 153; Smith, 2003, p. 94; www.fmi.org, 2007). They have done it through the creation of brokerage firms specializing in import-export operations. Some of them are publicly traded in stock exchanges in global markets. Some are small and private. Still others are part of mutual, edge and sovereign funds.

Investors and speculators have a lot of critics for some of their practices can create serious systemic problems. For instance, Slanger and Smith argue that investors and speculators are responsible for the volatility of global markets. They manipulate the "invisible hand", altering the "natural" course of supply and demand (Slanger, 2004, p. 153; Smith, 2003, p. 94). They drive prices up and down for no other reason that quick profits. In the specific case of global trade, investors and speculators impose high interest rates, commissions and fees for their services, which, according to Senator Lieberman, "Are divorced from market realities" (Hearing Before Senate Committee on Finance, Sep. 26, 2007). It all is reflected in the cost of transportation, labor, warehousing and other expenses, which drives inflation. 
In sum, the global banking system is a subsystem of globalization. Banks, investors and speculators are very important NSAs with unique roles in global trade. Global banking guarantees the free flow of money among banks, investors, speculators, corporations and nations in the global markets. Banks, investors and speculators are the main creditors to global trade. They issue credit to importers and exporters alike. Yet, these actors affect global politics as well. They create trade crises, market volatility, and affect macroeconomic indexes such as inflation. They lend themselves to tax evasion and money laundering. They finance illegal arms trade, terrorism, and even wars. Banks, investors and speculators can be so damaging to international peace that governments and international organizations like the UN have created international laws such as the OFAC, SDN's lists, and the NCS, among others to combat illegal banking practices.

\section{Global Banking and Iraq}

I discuss four findings in this section: 1) Iraq entered the UN sanctions regime with a solid centralized banking system; 2) Iraq used its banking system under the sanctions regime despite UN Security Resolution 986, which ordered Iraq to utilize an escrow account at BNP Paribas New York for all its businesses; 3) Iraq expanded its banking system by opening new banks and branches along with hundreds of new secret

accounts in banking centers throughout the Middle East; 4) Iraq used domestic and regional banking to reach the global banking system.

The government of Abd Al-Salam Árif nationalized the Iraqi banking system in 1965. The National Banking Law, as it was known, consolidated 65\% of all Iraqi banks into the Rafidian Ban, and it mandated the creation of the Central Bank of Iraq with three 
national jurisdictions: Bagdad, Mosul, and Bashra. The Bank was to "Issue and store currency of the government, protecting against counterfeit currency and disbursing funds based on directives from the Minister of Finance" (Duelfer Report, Regime Finance and Procurement, p. 45). In 1988, the CBI created another state-owned, the Rasheed Bank, to focus on investments, currency exchange, and trade. The CBI created 4 other banks: Agriculture Cooperative Bank, Real State Bank, and Social Bank. Chart 5.1 shows the state of the Iraq's banking net by 1991.

\section{Chart 5.1 - The State of Iraqi Banking System in 1991}

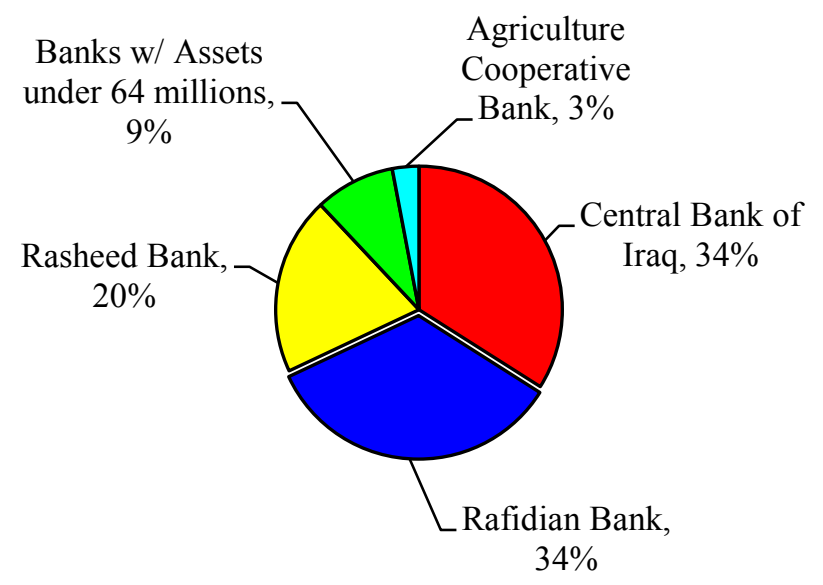

Source: the Duelfer Report (CIA)

The data were drawn from the Duelfer Report, Regime Finance and Procurement.

Observe that the state-run Central Bank controlled 34\% of the Iraqi banking industry, holding actives worth $\$ 770$ million. The Rafidian Bank controlled another 34\%, with 
actives of about $\$ 758$ million. Rafidian Bank allocated $60 \%$ of its funds to imports, indicative of Iraqi's reliance on foreign goods and services. Note that Iraq dedicated 3\% of its banking, just $\$ 65$ million dollars, to agriculture, which explains Iraq's reliance on imports of foodstuff from neighboring nations. One final factor is Iraq's private banking. In Chart 5.1, it appears as "banks with assets under 64 million". Iraq had 19 private banks in times of Saddam Hussein, accounting for $9 \%$ of the Iraqi banking system, worth $\$ 192.70$ million. Their share was minuscule, but their impact on the UN sanctions regime was considerable. Table 5.1 shows all Iraqi banks since 1935.

Table 5.1 - Iraqi Banks since 1935

\begin{tabular}{|l|r|r|r|}
\hline \multicolumn{1}{|c|}{ Bank's Name } & \multicolumn{2}{c|}{ Year } & \multicolumn{1}{c|}{ Active } \\
& Branches & Established & \multicolumn{1}{c|}{ Capital } \\
\hline Al-Baraka Bank for Investment & 4 & 2001 & 815 \\
Mosul Bank & 3 & 2001 & 667 \\
Al-Warka Bank for Investment & 3 & 2000 & 667 \\
Gulf Commercial Bank & 7 & 2000 & 880 \\
Babylon Bank & 6 & 1999 & 833 \\
Economic Investment Bank & 14 & 1999 & 267 \\
Summer Commercial Bank & 6 & 1999 & 533 \\
Credit Bank of Iraq & 10 & 1998 & 833 \\
Dar Al-Salam Bank Company of Investment & 14 & 1998 & 800 \\
United Bank for Investment & 5 & 1995 & 1,000 \\
Al-Ahli Al-Iraqi Bank & 4 & 1995 & 500 \\
Iraqi National Bank & 4 & 1995 & 500 \\
Iraqi Islamic Bank & 9 & 1993 & 365 \\
Iraqi Middle East Investment Bank & 11 & 1993 & 2,160 \\
Basrah Private Bank for Investment & 14 & 1993 & 667 \\
Investment Bank of Iraq & 17 & 1993 & 1,280 \\
Baghdad Investment Bank & 20 & 1992 & 1,167 \\
Commercial Bank of Iraq & 11 & 1992 & 1,665 \\
Social Bank & 4 & 1990 & 667 \\
Rasheed Bank & 170 & 1988 & 1,300 \\
Estate Bank & 16 & 1948 & 733 \\
Rafidian Bank & 5 & 1941 & 2,700 \\
Industrial Bank & 1935 & 300 \\
Agricultural Cooperative Bank & 1935 & 400 \\
\hline Total & & & 21,699 \\
\hline
\end{tabular}

Source: the Duelfer Report 
I collected the data for Table 5.1 from the Duelfer Report, Regime Finance and Procurement. The Table reveals three main points. First, Iraq had five large banks in 1991 when the UN enacted the sanctions regime. Though, observe that Iraq created 18 banks from 1992 to 2001 despite the UN sanctions. Second, note that Iraq created six banks from 1992 to 1995, coinciding, on one hand, with the most severe period of the UN sanctions, and on the other, with the establishment of trade protocols with Jordan, Syria, Turkey, Lebanon and Yemen. This is also the period when Iraq intensified trade relations with former Soviet Republics such as Belarus, Ukraine and Russia. Third, observe that Iraq established yet another 9 banks from 1996 to 2001, coinciding with implementation of the UN Oil for Food Program. This sudden expansion of the Iraqi banking industry suggests that commerce was intense, and that there was a new governmental policy toward investing, funding, and circulation of money. Iraq decentralized its banking system during this period.

Next, Iraq always enjoyed good relations with the global banking system until the Gulf War of 1991 and the passing of the UN sanctions regime thereafter. Yet, it does not mean that Iraq pulled out of the global banking system entirely. As the Dulfer Report stated, "Before the 1991 Gulf War the Regime had funds in accounts in the U.S., Europe, Turkey and Japan, but after 1991, the Regime shifted its assets into accounts in Jordan, Lebanon, Egypt and Syria" (Duelfer Report, Regime Finance and Procurement, p. 48). Iraq used Jordan, Lebanon, Egypt and Syria's banking systems to connect with European and American banks. In other words, Iraq used regional banking to reach global banking, corroborating two points that I stated in Chapter III. First, regional trade, more than a 
choice, is a means to reach global trade. Second, custom and traditional trade relations among neighboring nations help evade a sanctions regime.

After 1991, Iraq opened more than two hundred secret foreign accounts. Iraq opened a dozen of what the Duelfer Report called bridge accounts (Duelfer Report, Regime Finance and Procurement, p. 40). Also known as numbered accounts, banks use them to track the flow of money through various accounts, but Iraq used them "To conceal the fact that foreign companies were making payments to Iraq" (Duelfer Report, Regime Finance and Procurement, p. 46). Iraq had 5 of those accounts but individually named at Ahli Bank in Jordan. Three accounts were for oil proceeds and two were " $A$ Protocol trade account set up to receive payments related to the Iraq-Jordanian Protocol and was opened just a few months before 1996" (Duelfer Report, Regime Finance and Procurement, p. 40). Under the scheme, $60 \%$ of oil proceeds were transferred to "Protocol" accounts and another $40 \%$ went to at least seven accounts at Halk Bank's branches at Jordan, Syria, Lebanon, and the UAE where it gained almost $\$ 8$ million in interest rates in just one year (Duelfer Report, Regime Finance and Procurement, p. 42). Then, $40 \%$ of oil proceeds went to the Commercial Bank of Syria. The Duelfer Report stated that "The Bank was instructed to transfer all extra amounts to the Syrian-Lebanese Commercial Back account once the proceeds exceeded \$1 million dollars" (Duelfer Report, Regime Finance and Procurement, p. 42). In addition, Iraq had two bank accounts at the Queen Nor Branch of the Jordan National Bank, under the name of the Jordan Petroleum Refinery Co. Ltd, which had deposits of $\$ 7.4$ and $\$ 3.9$ million respectively (Duelfer Report, Regime Finance and Procurement, p. 44). 
The money came from "surcharges" and "service fees". Still, illegal proceeds delivered to Iraqi embassies in the Middle East were deposited in three individually named accounts at Ahli Bank (Duelfer Report, Regime Finance and Procurement, p. 44). But Iraqi proceeds resulting from oil "surcharges" were deposited in several accounts at Ahli Bank, Sardar Bank and Fransabank in Lebanon, Jordan, Syria, UEA and Turkey (Duelfer Report, Regime Finance and Procurement, p. 45). Iraq kept two accounts at Fransabank, one in Euros and another in American dollars, so it could convert it into Euros as needed. Lastly, Iraq had another 24 accounts in Lebanese banks, seven in Jordanian banks, and one in a Belarusian bank. Iraq used them to deposit cash from kickbacks, surcharges and other illicit practices (Duelfer Report, Regime Finance and Procurement, p. 45). By 1999, Rafidian Bank took over CBI's management section, mainly its Foreign Accounts Section, which really was a ring of hundreds of accounts that Iraq had in banks in the Middle East. By 2003, Iraq had brought most of its assets to a few banks in the Middle East. Table 5.2 shows Iraq's deposits as 2003.

Table 5.2 - Iraq's Deposits as 2003

\begin{tabular}{|l|l|l|r|r|}
\hline Bank & Nation & Account Type & Private Sector & State Sector \\
\hline Ahli Bank & Jordan & Cash & $329,155,944.56$ & $9,264,353.00$ \\
Fransabank & Lebanon & Cash & $48,000.00$ & $44,285,476.00$ \\
Jordan National Bank & Jordan & Cash & $47,026,041.80$ & - \\
National Bank of Egypt & Egypt & Trade Account & - & $19,710,881.00$ \\
Commercial Bank of Syria & Syria & Trade Account & - & $790,361,517.00$ \\
Commercial Bank of Lebanon & Lebanon & Cash & - & $251,949,039.00$ \\
Halk Bank & Turkey & Trade Account & - & $195,697,846.00$ \\
Sardar Bank & Lebanon & Trade Account & & $520,778.00$ \\
Total & & & $376,229,986.36$ & $1,311,789,890.00$ \\
\hline
\end{tabular}

Sources: Duelfer Report, IIC 
The data for Table 5.2 were collected from the Duelfer and the IIC Reports. In general, Iraq preferred to utilize Jordanian banks for its operations. Iraq created private accounts, managed by the Iraqi Trading Office in Amman and the Iraqi embassy in Jordan. Iraq avoided the use of electronic money for it feared that the U.S. would track its transactions. Instead, Iraq used cash, vouchers, and intermediaries who "laundered" the money through the HSBC in collaboration with the Jordanian Ministry of Industry and Trade and the Central Bank of Jordan. Still, Iraq utilized 16 Lebanese banks to conceal cash, pay for bribes and receive payments. This money was personally managed by the Ministers of Trade, Treasury and Commerce, and the governor of the CBI. Next, by 1999, when Iraqi-Jordanian relations came to a stalemate, Iraq moved its operations to Syrian, Turkish and Egyptian banks. Iraq transferred \$500 million to the Commercial Bank of Syria, \$700 million to Egypt, and \$200 million to Turkey (Duelfer Report, Regime Finance and Procurement, p. 62). Iraq used Turkey as a gateway to European financial institutions. Iraq agreed with Turkish Petroleum International Company (TIPC) to use Turkish oil pipelines to deliver oil to Europe in exchange for keeping a minimum of $70 \%$ of the proceeds at Turkish banks at preferential rates (Duelfer Report, Regime Finance and Procurement, p. 70; CFIJ, 2002, p. 33)

The two parties shared the profits. Finally, Iraq laundered money through gold purchases. In 2003, Iraq had four tons of gold reserves, purchased "In relatively small quantities on a frequent basis from Lebanese banks in which Iraq had large foreign currency deposits" (Duelfer Report, Regime Finance and Procurement, p. 51). For the operation, Iraq used its embassies in Beirut, Amman, and Damascus. How did Iraq and banks in the Middle East manage their operations amid the UN sanctions regime? 
For the CIA, the answer is the Arab money transfer system known as hawala. When the UN 661 Committee conceived the sanctions regime, it ignored, or did not take into account, the hawala system. Hawala is a credit and payment device used in the Arab world for centuries. In Arabic, the word hawala means "change" or transform, but in banking it means "transfer" or "wire". Today, there are three types of hawalas. First, bank hawala is money circulating throughout the banking system in the form of a note or electronic money. Second, there is a hawala for money exchange. This is a licensed and unlicensed investor who exchanges currencies according to "fluctuations" in the market. This is very common in the Middle East where there are so many currencies, economies are rather informal, based on cash and bartering. Finally, there are illegal hawalas too. The practice is based on an ancient informal banking used throughout South Asia and the Middle East to send money to distant places with no regard for bureaucratic limits. This hawala is based on religious norms, tribal values, prestige, and trust above all, which is, according to Francis Fukuyama, the basis of trade (Fukuyama, 2006, 17). In all, hawalas are speedy, flexible and cheap. They reduce paperwork and bureaucracy. With hawalas, there is no need for exchange and interest rates, which are banned by the Koran (Duelfer Report, Regime Finance and Procurement, p. 255).

Hawalas have historically presented serious problems to regulatory regimes in Arab nations. Since hawalas do not require recordkeeping, they lend themselves to illegal activities such as tax evasion, black-market operations, money launderings, and drug trafficking. Such illegal operations have become more sophisticated in today's global economy with the "Use of e-mail, faxes, and telephones, which have made these private 
cash transfers almost instantaneous and nearly impossible to trace or regulate" (Duelfer Report, Regime Finance and Procurement, p. 255).

In fact, Saddam Hussein banned the use of hawalas right after he took over power, but Iraqis continued to use them anyways in the black market to pay for illegal trade across the Syrian, Jordan, and Turkish and Iranian borders. The CIA found that "Illegal hawalas were often used by the average Iraqi individual or company to transfer funds from expatriate communities to the homeland" (Duelfer Report, Regime Finance and Procurement, p. 255). However, Saddam allowed hawalas -without formally legalizing them- right after the Gulf War of 1991 to fight inflation, stabilize prices, and keep liquidity in the Iraqi economy (Duelfer Report, Regime Finance and Procurement, p.255; CFIJ, 2002, p. 62). In the end, Saddam fully legalized hawalas in 1993 to link the Iraqi economy with the economies of the Middle East and evade UN sanctions regime. Rapidly, hawalas became a practice promoted by the Iraqi regime. The CIA addressed the role of hawala in the circumvention of the UN sanctions. It stated that "In order to import goods, a letter of credit was normally needed from a bank in Jordan. To get this, the Jordanian bank would need some cash. Because it was illegal to transfer cash out of Iraq through the normal banking system, the illegal hawala system was used to move the money” (Duelfer Report, Regime Finance and Procurement, p. 256).

\section{BNP Paribas and Other Banks}

When the UN sanctions regime against Iraq was approved, the UN SecretaryGeneral selected BNP New York to manage Iraq's money and financial resources in general. BNP is a transnational French bank, a subsidiary of Banque Nationale de Paris 
S.A, registered in Paris and licensed to operate in New York in 1993 (IIC, Chapter IV, p. 433). The UN Resolution 986 enacted the Banking Negotiated Contract Act, which mandated that BNP Paribas of New York had the right and obligation to: 1) establish and manage an escrow account to receive proceeds from the sales of Iraqi oil and to disburse funds so Iraq could purchase humanitarian goods and services; 2) confirm letters of credit issued from banks and retained by companies interested in buying oil from Iraq; 3) issue letters of credit to Iraqi companies so they could purchase humanitarian goods and services (IIC, Chapter IV, p. 433). Based on those mandates, BNP issued 2,234 letters of credits worth $\$ 9.7$ billion, of which it issued credit for $\$ 6.2$ billion to finance purchases of Iraqi oil (IIC Report, Chapter IV, p. 433). It also extended credit to Iraq for $\$ 3.5$ billion to purchase goods and services (IIC, Chapter IV, p. 433). Again, those letters of credit were legal, in tune with the contract signed between BNP and United Nations. Table 5.3 shows distribution of letters of credit through BNP's subsidiaries and affiliates.

Table 5.3 - Distribution of Letters of Credit through BNP

\begin{tabular}{|l|r|lr|}
\hline BNP Subsidiaries & Number of L/Cs & \multicolumn{2}{l|}{ Value of L/Cs } \\
\hline Geneva & 1,224 & $\$$ & $25,897,061,250$ \\
Paris & 495 & $\$$ & $9,716,040,616$ \\
London & 172 & $\$$ & $3,507,013,659$ \\
Milan & 60 & $\$$ & $856,101,638$ \\
Hong Kong & 52 & $\$$ & $1,157,795,138$ \\
Basel & 36 & $\$$ & $727,568,006$ \\
Others (13 Branches) & 195 & $\$$ & $3,905,122,639$ \\
Total BNP & 2,234 & $\$$ & $45,766,703,001$ \\
Total UN Program & 3,120 & $\$$ & $64,181,293,181$ \\
\% of BNP to Total UN Program & $71.6 \%$ & \\
\% of Other Banks \& Firms & $28.4 \%$ & \\
\hline
\end{tabular}

Source: IIC Report 
First, I must clarify that BNP acquired the Swiss bank United European Bank in 1998, becoming BNP in Geneva; then, it acquired Banque Paribas in 2000, and it became BNP Paribas S.A (IIC, Chapter IV, p. 433). The timing of the acquisitions was perfect. The French and Swiss banking systems offered independence and anonymity, two key desirable features in the banking industry. With the acquisition, BNP had the potential to control $80 \%$ of all Iraqi purchases (IIC, Chapter IV, p. 433). To capitalize on it, BNP allowed its subsidiaries and affiliates to issue letters of credit to intermediaries not authorized to trade with Iraq under the UN sanctions regime. The Bank did so in violation of Article 2 of the 661 Committee, which demanded from BNP that "The United Nations would be made aware of, and approve, the parties to whom Iraq sold its oil and purchased humanitarian goods and services" (IIC, Chapter IV, p. 440).

Resolution 661 further banned BNP from selling or transferring letters of credit to any third party. The goal was: first, prevent buyers from reselling and speculating with Iraqi oil; second, prevent Saddam Hussein from either selling oil at a loss or engaging in price gauging (Meyer and Califano, 2006, p. 31). BNP violated both resolutions. It accepted letters of credits from banks, investment firms, and financiers who then paid BNP "service fees" for not disclosing their names, clients and terms of contracts, which is rightly legal in global banking but no in the UN sanctions regime. The IIC stated, "The opportunity to issue a letter of credit in the first instance rather than simply to confirm a letter of credit issued by another bank meant that BNP acquired a second customer, and with it, the possibility for a conflict of interest with its primary customer, the United Nations" (IIC, Chapter IV, p. 433). It all meant that BNP was creating a conflict of interest for itself. As an escrow agent, BNP was getting involved in two contracts with 
two different conflicting clients at the same time: one was a contract with the U.N.; the other was letters of credits that BNP extended to private companies, namely violators of the UN sanctions regime. Still, BNP invested $\$ 91$ million in credit, which it channeled to its companies through its subsidiaries, mainly, in Switzerland and Hong Kong. It was a lucrative business. Table 5.2 below shows BNP earnings related to letters of credits under the UN sanctions regime from 1998 to 2003. Data are from the IIC Report, Chapter IV, Report on Manipulations, the Escrow Bank.

\section{Chart 5.2 - BNP Earnings under the UN Sanctions Regime}

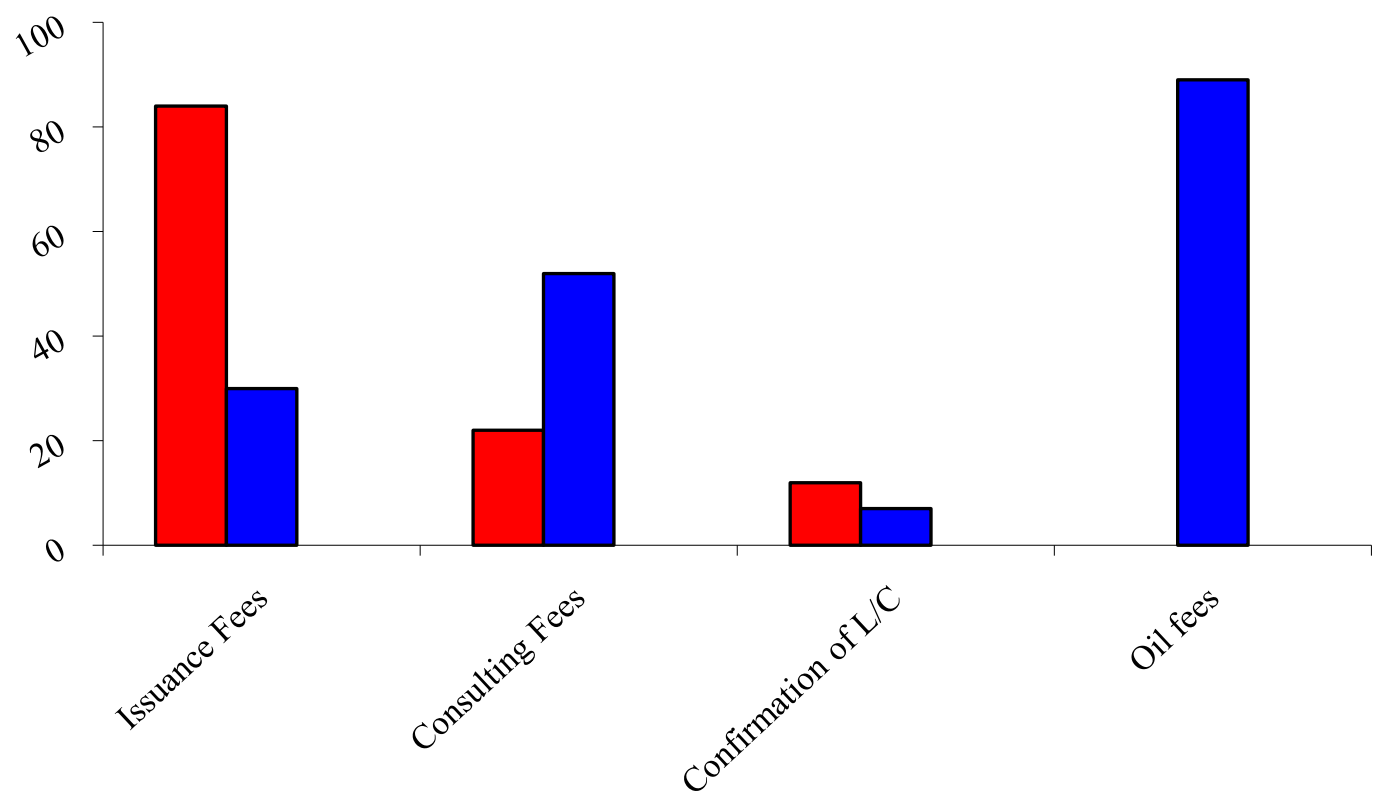

Source: IIC

The red bars represent fees that BNP imposed on companies that exported to Iraq. The blue bars account for fees that BNP charged to companies that purchased oil from 
Iraq. As we can see, BNP earned \$296 million, \$205 million above its initial investment of $\$ 91$ million. Yet, this only represents the legal side of the business. Based on the auditing that both the IIC and CIA conducted, they suspected that BNP engaged in money laundering or, at least, in illegal banking practices. For instance, the IIC found that BNP made 403 payments worth $\$ 1.5$ billion dollars to 30 non-financial institutions, violating Resolution 986 of the UN Security Council (Role of BNP-Paribas; Hearing before the Subcommittee on Oversight and Investigations, 2005, p. 55-81). Explicitly, the IIC examined 10 cases in which BNP engaged in illicit banking practices. They were: ACTEC, Glencore, Gulf-Drilling-Texaco, Belmetalenergo, East Star Trading, Al Douh Jordanian Establishment, Talfeet Trading Est., Inesfood Group, Telwar International Inc., Limpex Trading, and Zahrat Al Riyadh (Role of BNP-Paribas; Hearing before the Subcommittee on Oversight and Investigations, 2005, p. 55-81). Then, the IIC and the CIA found that only $70 \%$ of all companies participating in the sanctions regime financed their businesses through letters of credit issued by BNP (IIC, Chapter IV, p. 436). The other $30 \%$ obtained funding from other banks, third parties acting as financiers, and independent investors (IIC, Chapter IV, p. 441).

According to the IIC and the 661 Committee, the scheme worked as follow: companies created or hired a third party that would serve as an intermediary between the bank issuing the letter of credit and themselves. The contracting company extended a power of attorney to the intermediary, so it could execute contracts, request letters of credit from a bank, and acquire the right to operate as an independent commercial entity. The practice was so common that intermediaries consumed $75 \%$ of all letters of credit extended under the sanctions regime (IIC, Chapter IV, p. 441). 
There were three main reasons for utilizing intermediaries. First, most companies did not have technical support, experience and enough credit to engage in global trade, especially given the restrictions of the UN sanctions regime. Second, well-established companies did not want to see their names associated with the Iraqi regime. Such an association would affect their long-term business interests in nations opposed to the UN sanctions regime, in Middle Eastern nations in particular, for they regarded the UN sanctions as cruel and detrimental to their fellow Iraqi Muslims. Lastly, companies wanted to evade the sanctions and hide their wrongdoings. A front company or a thirdparty acting as an intermediary would work. One important finding is that $81 \%$ of banks other than BNP- that issued letters of credit were located in banking centers known as "offshore," as shown in Table 5.4.

Table 5.4-Most Used Banking Centers under the UN Sanctions Regime

\begin{tabular}{|l|r|l|l|l|l|}
\hline \multicolumn{3}{|c|}{ Bloc I } & \multicolumn{3}{c|}{ Bloc II } \\
\hline Banking Center & \# of & Balance & Banking Center & \# of & Balance \\
& Companies & US millions & & Companies & US million \\
\hline Switzerland & 178 & 1,756 & Switzerland & 178 & 1,756 \\
Cayman Islands & 142 & 1,527 & Cayman Islands & 142 & 1,527 \\
Bahamas & 140 & 942 & Cyprus & 65 & 1,373 \\
Liechtenstein & 137 & 1,272 & Liechtenstein & 137 & 1,272 \\
Monaco & 119 & 973 & Monaco & 119 & 973 \\
Hong Kong & 92 & 659 & Bahamas & 140 & 942 \\
British Virgin Islands & 78 & 863 & Panama & 29 & 877 \\
Cyprus & 65 & 1,373 & British Virgin Islands & 78 & 863 \\
Bermuda & 43 & 622 & Hong Kong & 92 & 659 \\
Panama & 29 & 877 & Bermuda & 43 & 622 \\
Total & 1,023 & 10,864 & Total & 1,023 & 10,864 \\
\hline
\end{tabular}

Source: The IIC Report 
The Table contains two blocs of data. Bloc I is sorted by \# of companies and bloc II by balance in USD millions. Column \# of companies means number of companies distributed per nation. Column balance in US million refers to the amount of money companies deposited in banks in those nations. These banking centers hosted 1,023 companies that traded with Iraq under the UN sanctions regime. Together, they deposited $\$ 10,864$ million dollars, representing $17.11 \%$ of all deposits. Also, note that Switzerland and Cayman Islands led both blocs as 320 companies chose Switzerland and Cayman Islands as their banking centers. Companies had, at some point, \$3,283 million dollars deposited in banks in offshore centers. Those nations are well known in the banking industry for promoting an international banking system that protects customers from regulatory regimes and governmental oversight. They played a crucial role in the UN sanctions regime as well. They concealed illicit payments, accounts and the identities of intermediaries and third parties. For instance, the 661 Committee stated the "The Committee has been unable to establish the percentage of letters of credit financed by third parties over the history of the Programmed" (IIC, Chapter IV, p. 441). The 661 Committee expressly referred to Swiss banks. They issued large numbers of letters of credit and refused to reveal their contents based on Swiss laws, which "Prohibited from disclosing client information to anyone other than its parent, including officials at other affiliates of the Bank" (IIC, Chapter IV, p. 447). Curiously, in 1997 Switzerland enacted the Money Laundering Act, obligating Swiss banks to comply with International AntiLaundering Law.

In addition, the IIC stated that banks failed to detect "Customers involved in a high risk business... and report them to the OFAC list or check if it was listed as a SDN" 
(IIC, Chapter IV, p. 545). Note that OFAC stands for Office of Foreign Asset Control, and SDN stands for Specially Designated Nationals. It all means that although BNP was doing business with foreign (non-American) customers, it did not report it as it was mandated by federal laws. The IIC particularly mentioned the case of "Augusto Giangradi of Italtech as a party involved in legal proceedings in South Florida in connection with an illegal sale of controlled American technology to Iraq as well as money laundering activity” (IIC, Chapter IV, p. 545). Also, the IIC was alarmed by the fact that banks did not report movements of large amounts of funds from account to account and bank to bank. Banks "Failed to scrutinize large unusual transactions or a series of large incoming deposits, followed shortly thereafter by large disbursements" (IIC, Chapter IV, p. 553) as mandated by International Anti-Money Laundering Laws. Explicitly, the IIC cited Alcon Petroleum, Fenar Petroleum, Taurus Group, Japal Petroleum and Petrocorp since, as it put it, "Their transactions were limited to large, often six-figure incoming wire transfers; these companies, in turn, disbursed similarly large sums" (IIC, Chapter IV, p. 545). The cases of Jabal Petroleum and Petrocorp were of more concern because "They were located in Lebanon, which at the time was listed as a Non-Cooperative Country or Territory (NCCT) in fighting Money Laundering... and associated with the Iraqi regime” (IIC, Chapter IV, p. 546).

The evidences presented so far attempt to explain how the current global banking facilitated the circumvention of the UN sanctions regime against Iraq. On one hand, I found that Iraq actually expanded its banking industry during the UN sanctions regime agasint Iraq, particularly throughout the Middle East. Iraq utilized regional banking to reach global banking. On the other hand, BNP failed to comply with the UN sanctions 
regime. BNP in fact extended credit to companies engaging in illicit practices. BNP helped companies to move money, conceal malpractice, and evade the UN sanctions.

\section{$\underline{\text { Investors and Speculators }}$}

In this section, I discuss investors and speculators, key NSAs in the global economy and under the UN sanctions regime. The goal is to explicate an essential feature of globalization, widely utilized to circumvent regulatory regimes like sanctions regimes.

First, the IIC defined investors and speculators as "Underlying financiers or established crude oil traders and companies that are involved in the purchase and resale of crude oil but do not generally process the oil in their own refineries; they often charter ships and expedite the logistics of getting oil to a refinery" (IIC, Oil Expert Report III, p. 4). The IIC also stated that "Most contract-holders currently fall under this category. They don't seem to add any value to the Programme and are just there to earn a risk-free commission at the expense of the United Nations-Iraq account; it is very difficult to find a justification for their participation in the Programme" (IIC, Oil Expert Report III, p. 4). In general, speculation here refers to how speculators usually move contracts throughout the global market, how contracts are sold and resold, passed on from a contractor to an investor, then to a company which in turn subcontracts another company, all in matter of days, even hours. Investors and speculators played a key role under the UN sanctions regime. They financed companies that had no money and no means to obtain it. They extended credit to companies created mainly to evade the UN sanctions. Table 5.5 below shows a list of investors and speculators, or underlying financiers. 


\section{Table 5.5 - Underlying Financiers}

\begin{tabular}{|c|c|c|c|}
\hline Underlying financiers & Nation of Registration & Barrels financed in USD & Barrels lifted \\
\hline Bayoil & Bahamas (USA) & $403,703,074$ & $7,349,738,302$ \\
\hline Taurus & Bahamas (USA) & $256,213,572$ & $4,970,216,904$ \\
\hline Vitol & Switzerland & $196,049,893$ & $4,034,320,347$ \\
\hline Glencore International AG & Switzerland & $149,247,723$ & $3,162,905,704$ \\
\hline Chevron Texaco & United States & $83,854,714$ & $1,778,799,188$ \\
\hline Betoil Ltd & & $44,023,908$ & $886,104,961$ \\
\hline Sinochem International Oil London & United Kingdom China & $29,633,836$ & $706,687,377$ \\
\hline Arcadia Petroleum Ltd & & $27,962,071$ & $596,389,267$ \\
\hline Gunvor Energy Ltd & & $20,877,957$ & $438,030,217$ \\
\hline Scandinavian T. Ltd & & $13,152,490$ & $309,882,592$ \\
\hline Galaxy Energy Intl. Ltd & & $11,708,415$ & $265,462,533$ \\
\hline Total International Ltd & France & $11,007,323$ & $293,399,846$ \\
\hline Marc Rich & & $10,179,086$ & $265,344,993$ \\
\hline Valero Energy Group & United States & $10,151,491$ & $186,137,767$ \\
\hline Sonatrach Petroleum Corp BVI & Algeria & $9,766,286$ & $223,444,361$ \\
\hline Petraco Oil Co Ltd & & $9,703,314$ & $229,868,316$ \\
\hline Shell International Trading & United Kingdom & $9,078,714$ & $251,375,169$ \\
\hline Mednafta Trading Co. Ltd & Swiss, Cyprus, USA & $8,140,763$ & $164,819,715$ \\
\hline Gunvor International Ltd & & $7,678,745$ & $146,200,291$ \\
\hline March Rich \& Co. Investment AG & & $6,915,565$ & $170,572,149$ \\
\hline Trafigura Beheer BV & Netherlands & $6,746,013$ & $141,683,838$ \\
\hline Crown Resources/ERC Trading & & $4,995,213$ & $120,987,228$ \\
\hline Mitsubishi & Japan & $4,875,597$ & $108,869,481$ \\
\hline ELF Trading SA & & $4,840,246$ & $120,036,022$ \\
\hline Totsa Total Oil Trading & & $3,249,753$ & $70,640,672$ \\
\hline NRG Oils SRL Geneva & Switzerland & $3,082,784$ & $78,485,902$ \\
\hline Wincor SA & & $3,007,534$ & $54,508,916$ \\
\hline OMV Supply \& Trading & Switzerland & $2,590,546$ & $68,595,607$ \\
\hline Sempra Oil Trading SARL & & $2,589,136$ & $68,666,097$ \\
\hline ERC Trading & & $2,085,074$ & $41,163,897$ \\
\hline Pedestal Enterprises SA & & $2,071,083$ & $38,580,826$ \\
\hline Naftex Oil Trading Ltd & & $1,986,991$ & $52,587,704$ \\
\hline Koch & & $1,917,957$ & $46,185,504$ \\
\hline Masfield & Switzerland & $1,909,909$ & $39,347,987$ \\
\hline Unipec & & $1,668,213$ & $39,293,089$ \\
\hline Repsol Petroleum SA - London & Spain & $1,602,374$ & $44,823,471$ \\
\hline Petroplus Ref. Intl BV & Netherlands & $1,529,381$ & $44,199,017$ \\
\hline Sovoil AG/Nafta Swiss AG & & $1,099,359$ & $29,765,331$ \\
\hline Arcadia/NRG & & $1,044,890$ & $19,340,583$ \\
\hline FADI Oil International S.A.L & Lebanon & $1,011,684$ & $18,326,976$ \\
\hline Petroserve Ltd S.A. & & $1,002,505$ & $18,788,766$ \\
\hline Inter INA Ltd & & 990,745 & $17,102,041$ \\
\hline Alexoil & Switzerland & 874,862 & $19,390,669$ \\
\hline Mediterranean Oil Supply \& Trading & Monaco & 620,431 & $14,726,263$ \\
\hline Addax BV, Rotterdam GE & Switzerland & 602,272 & $15,136,300$ \\
\hline Iplom International SA & Switzerland & 598,593 & $11,554,803$ \\
\hline Nafta Swiss AG & Switzerland & 594,788 & $11,667,956$ \\
\hline CO.GE.P. SRL Costieri & & 584,312 & $15,594,703$ \\
\hline Total & & $1,378,821,185$ & $27,799,749,648$ \\
\hline
\end{tabular}

\section{Source: IIC}


I collected the data for Table 5.5 from the IIC Report, Oil Expert Report III. The table has four columns. Columns one and two contain the names of underlying financiers and their nation of registration respectively. The third column represents oil barrels financed in USD million dollars. Column four accounts for number of oil barrels actually lifted. Values in column 4 will always be higher than values in column 3 . The data is sorted by "barrels financed." Above all, observe: 1) money invested versus the amount of oil purchased with it; 2) the role of underlying financiers in terms of funding; 3) since oil prices fluctuated, underlying financiers invested more money to lift the same or less amount of oil.

The data show that companies financed $\$ 27,799,749,648$ million of Iraqi crude, $43.3 \%$ of the oil lifted under the UN sanctions. Yet, there are key issues to discuss here. First, the data show that Chevron-Texaco and Valero were the only American underlying financiers, but that is incorrect. Bayoil and Taurus were American firms too, only that they were registered in The Bahamas. Bayoil belonged to a holding company based in Delaware, and Taurus was a subsidiary of Taurus Group, an oil trading firm based in Houston, Texas. Thus, when I add up all investments made by Chevron-Texaco, Valero, Bayoil and Taurus, I obtain that American underlying financiers financed 762,063,614 barrels of oil worth $\$ 14,449,711,876$ million dollars. Bayoil and Taurus ranked $1^{\text {st }}$ and $2^{\text {nd }}$ respectively while Chevron-Texaco ranked fifth. What those companies did is totally legal. It is indeed a common practice under globalization, but it was illegal under the UN sanctions. Firms from other nations engaged in the same practice. For instance, Sinochen was not British but a Chinese, and most Swiss underlying financiers were subsidiaries or parented to companies from other nations. They registered themselves in Switzerland to 
benefit from Swiss advantageous banking laws. As for American underlying financiers, the decision to operate in such a way is linked to Saddam's policy of banning American firms from getting Iraqi oil. As the IIC affirms, "None of these traders had been given the significant direct access to oil contracts that they sought under the Programme..., so they approached intermediary entities" (IIC, Chapter II, p. 12). A final point to make is that American underlying financiers ranked first, surpassing Russians, French and Chinese. This is essential for we saw in Chapter II that the U.S. ranked $27^{\text {th }}$ in oil purchases while Russia, France, and China ranked $1^{\text {st }}, 2^{\text {nd }}$ and $7^{\text {th }}$ respectively. It means that in terms of investing in oil purchases, American firms played a vital role, as Table 5.6 shows.

\section{$\underline{\text { Table 5.6 - American Investors Financing Non-American Firms }}$}

\begin{tabular}{|c|c|c|c|c|c|}
\hline Underlying & Contractual Company & \# of & Contractual & Barrels & Barrels Financed \\
\hline Financiers & & Contracts & Nation & Financed & in USD millions \\
\hline \multirow[t]{25}{*}{ Bayoil } & ACTEC & 8 & Russia & $12,027,284$ & $217,882,341$ \\
\hline & Alexoil S.A. & 4 & Switzerland & $3,936,639$ & $102,578,122$ \\
\hline & Alfa Eco & 49 & Russia & $76,709,258$ & $1,236,384,917$ \\
\hline & AL-Hoda International Trading Co & 7 & UAE & $12,171,851$ & $196,556,276$ \\
\hline & Asmos Ltd & 1 & Kenya & $1,000,000$ & $20,754,000$ \\
\hline & B.C. International Ltd & 3 & Pakistan & $1,426,475$ & $24,656,583$ \\
\hline & Bashneft & 1 & Russia & $1,237,445$ & $30,804,956$ \\
\hline & Bayoil & 3 & Bahamas & $5,673,263$ & $102,326,625$ \\
\hline & Belmetalenergo, Inc & 3 & Belarus & $5,356,326$ & $106,386,467$ \\
\hline & Benzol & 1 & UAE & $2,003,987$ & $48,636,764$ \\
\hline & CAMTECH Manufacturing LLC & 1 & UAE & 500,000 & $10,353,860$ \\
\hline & China National United Oil Corp & 3 & China & $5,021,626$ & $129,408,470$ \\
\hline & Consult \& Trade & 1 & Austria & $1,001,901$ & $16,403,944$ \\
\hline & Continental Oil Ltd & 1 & Cyprus & 500,000 & $12,944,026$ \\
\hline & Delt a Petroleum Products Trading Co & 1 & Turkey & $1,960,561$ & $38,110,819$ \\
\hline & Emercom Agency & 1 & Russia & $2,105,469$ & $32,946,142$ \\
\hline & Emiroil Est & 2 & UAE & $3,963,514$ & $84,131,603$ \\
\hline & Energy Resources People's Co & 2 & Ukraine & $2,928,233$ & $56,298,115$ \\
\hline & Erdem Holding (On behalf of Mobil Corp) & 1 & UAE & 457,000 & $8,897,207$ \\
\hline & Federally Torgoviy Dom Oil & 2 & Ukraine & $1,000,000$ & $18,529,772$ \\
\hline & Hiperborey Company & 1 & Ukraine & $1,940,324$ & $41,206,846$ \\
\hline & Impexoil LLC & 7 & Russia & $5,487,799$ & $117,949,145$ \\
\hline & Ives Co. Ltd & 1 & Ukraine & 510,401 & $13,213,287$ \\
\hline & Khrizolit & 1 & Russia & $1,979,539$ & $37,136,066$ \\
\hline & Lukoil & 12 & Russia & $18,000,747$ & $261,401,623$ \\
\hline
\end{tabular}




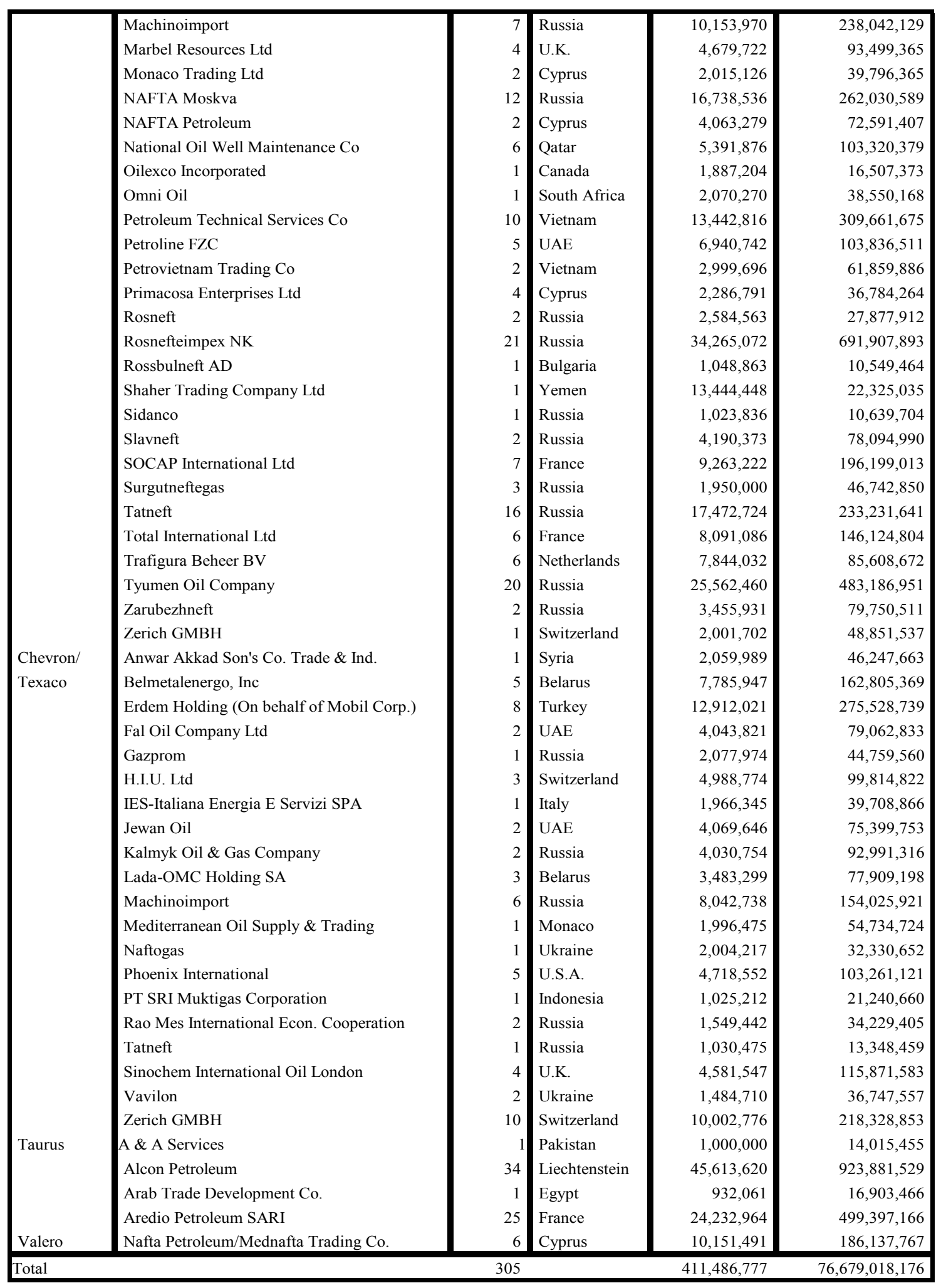

Source: IIC and Duelfer Report 
I collected the data from the IIC Report. Table 5.6 has six columns. The first column shows four American companies that acted as underlying financiers. The second column shows companies that received financing from underlying financiers. The third column shows the number of contracts financed. Column four shows nations of registration per company. Column five shows barrels financed and column six shows barrels financed in USD millions.

In total, four American companies acted as underlying financiers. They were Bayoil, Chevron-Texaco, Taurus and Valero. They financed 390 contracts for $539,552,832$ million barrels of oil, worth $\$ 9,922,151,501$ million dollars. Bayoil led the practice with 262 contracts, $373,767,982$ million barrels worth $\$ 6,503,469,064$ million dollars. Chevron-Texaco ranked second with 61 contracts, 83,854,714 million barrels and $\$ 1,778,347,054$ million dollars. Taurus came third with 61 contracts too but of $71,778,645$ million barrels worth $\$ 1,454,197,616$ million. Valero came forth with just 6 contracts, $10,151,491$ million barrels and $\$ 186,137,767$ million. The data illustrate the magnitude of American involvement in financing businesses under the sanctions regime. The involvement was not massive in terms of "company participation," but it was relevant in terms of amounts of money invested. Again, American companies could not purchase Iraqi oil because Saddam Hussein would not sell it to them. So they opted for financing purchases for other companies. What's more, observe in the third column the nationality of companies that American investors financed. It is diverse, but what is more revealing is how many Russian companies obtained financing from American financiers. The following table helps see this point. I collected the data for Table 5.7 from the IIC Report. 
Table 5.7-American Investors Financing Firms from Belarus, Russia and Ukraine

\begin{tabular}{|c|c|c|c|c|c|}
\hline $\begin{array}{l}\text { Underlying } \\
\text { Financiers }\end{array}$ & $\begin{array}{l}\text { Barrels } \\
\text { Lifted }\end{array}$ & $\begin{array}{c}\text { \# of } \\
\text { Contracts }\end{array}$ & $\begin{array}{l}\text { Noncotractual } \\
\text { Nation }\end{array}$ & $\begin{array}{l}\text { Barrels } \\
\text { Lifted }\end{array}$ & $\begin{array}{l}\text { Barrels Lifted } \\
\text { In USD }\end{array}$ \\
\hline Bayoil & $\begin{array}{l}\text { ACTEC } \\
\text { Alfa Eco } \\
\text { Bashneft } \\
\text { Emercom Agency } \\
\text { Impexoil LLC } \\
\text { Khrizolit } \\
\text { Lukoil } \\
\text { Machinoimport } \\
\text { NAFTA Moskva } \\
\text { Rosneft } \\
\text { Rosnefteimpex NK } \\
\text { Sidanco } \\
\text { Slavneft } \\
\text { Surgutneftegas } \\
\text { Tatneft } \\
\text { Tyumen Oil Company } \\
\text { Zarubezhneft }\end{array}$ & $\begin{array}{r}8 \\
49 \\
1 \\
1 \\
7 \\
1 \\
12 \\
7 \\
12 \\
2 \\
21 \\
1 \\
2 \\
3 \\
16 \\
20 \\
2 \\
165\end{array}$ & $\begin{array}{l}\text { Russia } \\
\text { Russia } \\
\text { Russia } \\
\text { Russia } \\
\text { Russia } \\
\text { Russia } \\
\text { Russia } \\
\text { Russia } \\
\text { Russia } \\
\text { Russia } \\
\text { Russia } \\
\text { Russia } \\
\text { Russia } \\
\text { Russia } \\
\text { Russia } \\
\text { Russia } \\
\text { Russia }\end{array}$ & $\begin{array}{r}12,027,284 \\
76,709,258 \\
1,237,445 \\
2,105,469 \\
5,487,799 \\
1,979,539 \\
18,000,747 \\
10,153,970 \\
16,738,536 \\
2,584,563 \\
34,265,072 \\
1,023,836 \\
4,190,373 \\
1,950,000 \\
17,472,724 \\
25,562,460 \\
3,455,931 \\
234,945,006\end{array}$ & $\begin{array}{lr}\$ & 217,882,341 \\
\$ & 1,236,384,917 \\
\$ & 30,804,956 \\
\$ & 32,946,142 \\
\$ & 117,949,145 \\
\$ & 37,136,066 \\
\$ & 261,401,623 \\
\$ & 238,042,129 \\
\$ & 262,030,589 \\
\$ & 27,877,912 \\
\$ & 691,907,893 \\
\$ & 10,639,704 \\
\$ & 78,094,990 \\
\$ & 46,742,850 \\
\$ & 233,231,641 \\
\$ & 483,186,951 \\
\$ & 79,750,511 \\
\$ & 4,086,010,360\end{array}$ \\
\hline Chevron /Texaco & $\begin{array}{l}\text { Gazprom } \\
\text { Kalmyk Oil \& Gas Company } \\
\text { Machinoimport } \\
\text { Rao Mes Intnl. Econ. Coop. } \\
\text { Tatneft }\end{array}$ & \begin{tabular}{r|}
1 \\
2 \\
6 \\
2 \\
1 \\
12 \\
\end{tabular} & $\begin{array}{l}\text { Russia } \\
\text { Russia } \\
\text { Russia } \\
\text { Russia } \\
\text { Russia }\end{array}$ & $\begin{array}{r}2,077,974 \\
4,030,754 \\
8,042,738 \\
1,549,442 \\
1,030,475 \\
16,731,383\end{array}$ & $\begin{array}{lr}\$ & 44,759,560 \\
\$ & 92,991,316 \\
\$ & 154,025,921 \\
\$ & 34,229,405 \\
\$ & 13,348,459 \\
\$ & 339,354,661 \\
\end{array}$ \\
\hline Grand Total & & 177 & & $251,676,389$ & $4,425,365,021$ \\
\hline
\end{tabular}

Source: IIC Report

In its final report, the IIC stated that "According to Iraqi Vice President Taha Yassin Ramadan... oil allocated to United States companies was given to Russian companies" (IIC, Chapter I, p. 2), but he failed to mention that, as we see in Table 5.7, American companies stayed in as financiers of Russian companies. Note that, at the time, Russia was going through an economic crisis and a privatization process. Russian companies needed credit and funding. We can see in Table 5.7 that American underlying 
financiers financed 177 Russian contracts, 251,676,389 million barrels worth $\$ 4,425,365,021$ million. It represents roughly $23 \%$ of all Russian oil purchased in the UN sanctions regime. Bayoil financed 165 Russian contracts, 234,945,006 million barrels worth \$4,086,010,360 million. Chevron-Texaco financed 12 Russian contracts, 16,731,383 million barrels worth $\$ 339,354,661$ million dollars.

The case of Mobil Refining illustrates one of the ironies of the corporate world and globalization. Mobil Corp did not finance oil purchases; rather, it obtained financing through its archrivals: Chevron-Texaco, Bayoil, Glencore and Shell. But Mobil Corp. did not do it directly. Instead, it hired a company called Erdem Holding Co., which them approached Chevron Texaco, Bayoil, Glencore and Shell for financing. Table 5.8 below shows Mobil Corporation refining purchases. I collected the data for Table 5.8 from the IIC Report, Oil Expert Report III.

$\underline{\text { Table 5.8 - Mobil Corporation Refining Oil Purchases }}$

\begin{tabular}{|l|l|r|r|r|r|}
\hline Financier & Contractual & \# of & No contractual & Barrels \\
& Purchaser & Contracts & Purchaser & Lifted & in USD \\
\hline Chevron Texaco & Erdem Holding Co. & 8 & On behalf of Mobil Refining & $12,912,921$ & $275,528,739$ \\
Bayoil & Erdem Holding Co. & 1 & On behalf of Mobil Refining & 457,000 & $8,897,207$ \\
Glencore & Erdem Holding Co. & 1 & On behalf of Mobil Refining & $2,002,942$ & $41,316,900$ \\
Shell & Erdem Holding Co. & 1 & On behalf of Mobil Refining & $1,037,812$ & $30,444,343$ \\
Total & & 11 & & $16,410,675$ & $356,187,189$ \\
\hline
\end{tabular}

Source: IIC Report

Knowing that Russia, Ukraine and Belarus are themselves important oil producers and hold large oil reserves, it is worth asking why companies from those nations purchased so much oil in violation of the UN sanctions regime. 
The answer is that they were oil speculators. They did not purchase oil for consumption but to resell it in world markets. Three factors helped them. Iraq stopped trading with British and American companies, "end-users" or refineries that convert oil into gasoline and other oil derivatives. Second, Iraq traded with small investors and trading houses, which did not own refineries and had no capacity to refine oil. As Meyer and Califano argued "Trade houses are very small in size and seem to have limited credit facilities...many of which had no equipment beyond a fax machine and a telephone" (Meyer and Califano, 2006, p. 144).

That is, they acted as front companies, as mere speculators. In fact, they were violating Resolution 986 of the UN Security Council, which stated that "It is expressly understood that Buyer will process crude oil sold under this contract in its own processing facilities" (Meyer and Califano, 2006, p. 144). Third, Iraq manipulated oil prices through discounts and wholesaling. Having so much oil, it could afford to sell it below the global market price. Iraq could have only done it through speculators, and Saddam controlled many of them. As Meyer and Califano stated "By controlling which obscure trading companies win the right to buy that oil, Iraq can direct the flow of these discounts; it explained why major western refiners have been bumped off the Iraqi buyer list and replaced by more and more unknown names" (Meyer and Califano, 2006, p. 140). According to Meyer and Califano, the scheme worked as follow: "Investors contacted a number of trading companies to which they proposed to sell oil if the companies in question agreed to their price (the official sales price plus the premium), issued them a letter of credit, chartered a ship and paid them" (Meyer and Califano, 2006, p. 145). Table 5.9 illustrates some of those investors. 
Table 5.9 - Independent Oil Investors and Speculators

\begin{tabular}{|c|c|c|c|c|c|}
\hline $\begin{array}{r}\text { Contractual party } \\
\text { Or Speculator }\end{array}$ & $\begin{array}{c}\text { Contractual } \\
\text { Nation }\end{array}$ & No contractual party & $\begin{array}{l}\text { No contractual } \\
\text { Nation }\end{array}$ & $\begin{array}{c}\text { \# of } \\
\text { Contracts }\end{array}$ & $\begin{array}{r}\text { Barrels } \\
\text { Lifted }\end{array}$ \\
\hline \multirow[t]{2}{*}{ Mr. Serge Boiedeevaix } & France & Vitol S.A. & Switzerland & 8 & $29,525,000$ \\
\hline & USA & Nafta Petroleum/Mednafta Trading Co. & Cyprus & 4 & $26,257,000$ \\
\hline \multirow[t]{2}{*}{ Mr. Zain Al-Abedeen Erdem } & Turkey & Erdem Holding Co. & Turkey & 11 & $25,754,000$ \\
\hline & Italy & Costieri Genovesi Petrolferi & Italy & 11 & $24,104,000$ \\
\hline Mohammad ABDE Al-Manan & Bangladesh & Lukoil Petroleum Ltd & Russia & 5 & $22,285,000$ \\
\hline \multirow[t]{2}{*}{ Mr. Vladimir Zhirinovsky } & Russia & Sindanco & Russia & 3 & $18,739,000$ \\
\hline & Russia & Soyuzneftegaz & Russia & 4 & $18,053,000$ \\
\hline \multirow[t]{2}{*}{ Mr. Mikhael Gutseriev } & Russia & Slavneft & Russia & 4 & $16,961,000$ \\
\hline & Russia & Nafta Moskva & Russia & 1 & $16,738,000$ \\
\hline Mr. Awad Ammora & Syria & Awad Ammora Co. \& Partner & Syria & 5 & $16,691,000$ \\
\hline Reliance Petroleum Ltd & India & Alcon Petroleum Ltd. & Liechtenstein & 3 & $15,780,000$ \\
\hline China North Industries Corp. & China & China Wanbao Engineering Corp & China & 6 & $14,462,000$ \\
\hline Mr. Bassim Qaqish & Jordan & Lubna Trading S.A. & Spain & 7 & $14,105,000$ \\
\hline \multirow[t]{2}{*}{ Mr. Salvatore Nicotra } & Italy & Industria Petrolifera Siciliana I.P.S. & Italy & 7 & $13,787,000$ \\
\hline & Russia & Tyumen Oil Company & Russia & 2 & $13,498,000$ \\
\hline Mr. Patrick Maugein & France & Trafigura Beheer B.V. & Netherlands & 2 & $13,201,000$ \\
\hline Mr. Talal Abu-Reyaleh & Jordan & Glencore International AG & Switzerland & 1 & $12,107,000$ \\
\hline Mr. Michel Grimard & France & Addax S.A.R.L. & Switzerland & 7 & $11,831,000$ \\
\hline Mr. Bashar Nouri & Syria & Nouri For Trading Co. & Syria & 5 & $11,156,000$ \\
\hline Amities Franco-Irakiennes & France & Aredio Petroleum S.A.R.L. & France & 8 & $11,140,000$ \\
\hline Mr. Charles Pasqua & France & Genmar Resources GMBH & Switzerland & 3 & $10,751,000$ \\
\hline Mr. Sokolov & Ukraine & H.I.U. Ltd & Ukraine & 4 & $10,318,000$ \\
\hline NIS Yugopetrol & Yugoslavia & Eurol International, reg. in Bermuda & UK & 2 & $10,219,000$ \\
\hline Mr. Lotfi Doughan & Turkey & Seta Insaat Petrol Ve Petrol Urunleri & Turkey & 8 & $10,202,000$ \\
\hline Thai Rice Trader & Thailand & Chayaporn Rice Co. Ltd & Thailand & 5 & $9,886,000$ \\
\hline Mr. Ghassan Shallah & Syria & Ghassan Shallah Co. & Syria & 4 & $9,664,000$ \\
\hline \multirow[t]{3}{*}{ Riad El-Taher (live in U.K.) } & Iraq & Bula Resources PLC & Ireland & 7 & $8,981,000$ \\
\hline & Jordan & Petrogaz Distribution SA & Switzerland & 1 & $8,626,000$ \\
\hline & Bangladesh & Jordan Grain Co.LTD & Jordan & 3 & $8,613,000$ \\
\hline Mr. Claude Kaspereit & France & E.O.T.C. & France & 4 & $8,538,000$ \\
\hline Mr. Abu Al-Abbass & Palestine & Awad Ammora Co. \& Partner & Syria & 4 & $8,375,000$ \\
\hline Mr. Mohamed Osman Said & Kenya & Asmos Ltd & Kenya & 6 & $8,017,000$ \\
\hline Mr. Leith Shbeilat & Jordan & Petrogaz Distribution SA & Switzerland & 3 & $7,648,000$ \\
\hline Mr. Emad El-Said El-Galada & Egypt & Alexoil S.A. & Switzerland & 3 & $7,625,000$ \\
\hline Mr. Benon Sevan & Cyprus & African Middle East Petroleum Co. & Panama & 5 & $7,291,000$ \\
\hline Mr. Abdallah Al-Sallawi & Morocco & Petrade & Morocco & 4 & $7,190,000$ \\
\hline \multirow[t]{2}{*}{ Mr. Muhammad Aslan } & Turkey & Emin Dis Ticaret Petrol Ve Petrol & Turkey & 4 & $7,030,000$ \\
\hline & Russia & Neftegazexport & Russia & 2 & $6,725,000$ \\
\hline Mr. George Galloway & UK & Middle East Advanced Semiconductor & Jordan & 3 & $6,681,000$ \\
\hline Mr. Agababov & Russia & Rosneftegazexport & Russia & 2 & $6,370,000$ \\
\hline \multirow[t]{2}{*}{ Zarubezhneft } & Russia & Zarnestservice Ltd & Russia & 1 & $6,203,000$ \\
\hline & Yemen & ZSA Services Ltd & Yemen & 3 & $6,129,000$ \\
\hline Mr. Ahmad Al-Bashir & Jordan & Al-Rasheed International Cooperation & Jordan & 3 & $6,100,000$ \\
\hline \multirow[t]{2}{*}{ Asia Public Trading Co. } & Iraq & Oil \& Gas Services Group Ltd & Pakistan & 3 & $6,084,000$ \\
\hline & & & & 380 & $874,767,000$ \\
\hline
\end{tabular}

Source: IIC and Duelfer Report 
I collected the data for Table 5.8 from the IIC Report. Table 5.8 has six columns. Column I consists in a list of contractual non-state actors, and Column II lists their nationalities. Column III lists no-contractual investors and/or speculator. Column IV shows their nationality while Column $\mathrm{V}$ shows the \# of contracts they purchased from contractual non-state actors. Column VI accounts for the amount of barrels they lifted.

First, according to the CIA and the IIC, there were a total of 121 contractual nonstate actors from 40 different nationalities that invested in oil and speculated with it under the UN sanctions regime against Iraq. However, I included in my analysis only those that speculated with contracts worth more than a million barrels of oil. Including those that contracted less than a million would have been redundant and confusing. Still, the high number of participants and their nationalities explains two points: first, the violation of the sanctions was massive and violators were diverse.

Second, whereas some contractual actors had more than one nationality, noncontractual actors had just one: their nation of registration. For instance, Serge Boiedeevaix appears as French and an American, but his real nationality is French. Mr. Zain Al-Abedeen Erdem is a Turkish national, but he appears as Turk and Italian. Also, Mr. Salvatore Nicotra was an Italian, and he signed contracts as a Russian. And Mr. Riad El-Taher was an Iraqi residing in the UK; yet, he accepted contracts as a citizen of Jordan and Bangladesh. I can mention another 22 cases, but the central point here is that contractual non-state actors altered their nationalities to evade UN inspectors. Then, noncontractual actors operated under a license issued by their country of registration, which most of the time differed from the nationality of whoever owned the license. That is, noncontractual actors like Glencore and Vitol had Swiss licenses to operate, but their owners 
were French nationals. There were 67 cases like it under the UN sanctions regime. It is a common practice under globalization, though.

Third, note that Column I includes individuals, NGOs, universities and other nonstate actors. Most of them appeared in Chapter III as NSAs, and their nations appeared in Chapters II and III as the largest money-makers under the sanctions regime. Meanwhile, Column III includes only companies because, as we saw in Chapter III, contractual NSAs accepted contracts only to sell them non-contractual actors. Contractual actors had no money and expertise to execute the contracts they took on. Precisely, their "mission" was to obtain contracts from the Iraqi government and sell them to non-contractual actors. Conversely, non-contractual actors had the money so that their "mission" was to finance contracts. They usually financed several contractual actors, and they did not limit themselves to finance oil contracts. They financed every sort of trade, from construction, tourism and agriculture to education, health and even public relations.

In fact, some non-contractual actors had never invested in the oil industry. The UN sanctions regime was their first time because it offered good business opportunities. Meyer and Califano found that speculators financed $25.68 \%$ of the oil traded under the sanctions (Meyer and Califano, 2006, p. 145). Finally, observe that selling contracts from contractual to non-contractual parties almost always involved a change of non-contractual nations. For example, Mr. Serge Boiedeevaix was a French national who also obtained contracts as an American. Here, France and the US were the contractual nations. But Mr. Boiedeevaix sold his contracts to companies registered in Switzerland and Cyprus; therefore, Switzerland and Cyprus were the non-contractual nations. Perhaps the most illustrative case involves six contractual actors from Iraq who sold their contracts to six 
non-contractual speculators. It all explains why some nations received more oil than others and the global nature of such operations.

In sum, based on their modus operandis, we can see why investors, speculators and investing are such important agents and means of globalizing. They are the drivers of speculation because they move contracts throughout the global market, from contractor to investors, to then a company, then a subcontractor, and so on. They play central unique roles in the circumvention of sanctions regimes as well. In the next section, I present 4 cases to illustrate how banks, investors, companies and even state actors concur in the market place to invest and speculate.

\section{Case Studies}

In this section, I further illustrate the hypothesis of this chapter: global banking undermines a multilateral sanctions regime; global banking, as a means of globalization, facilitated the circumvention of the UN sanctions regime against Iraq by providing financial instruments to the agents of globalizations, namely corporations, NGOs, political activists and other NSAs.

Circumvention of UN sanctions against Iraq occurred through three main categories: 1) state-owned banks; 2) private banks, 3) speculators. They all require participation of third parties or intermediaries, which mostly included state and/or nonstate actors such as speculators, politicians, and political organizations and businessmen. In order to execute their contracts, intermediaries then sold their contracts to companies. The Chart below illustrates the most common financing scheme under the UN sanctions regime. 
Figure 5.1 - Most Common Financing Schemes under the UN Sanctions Regime

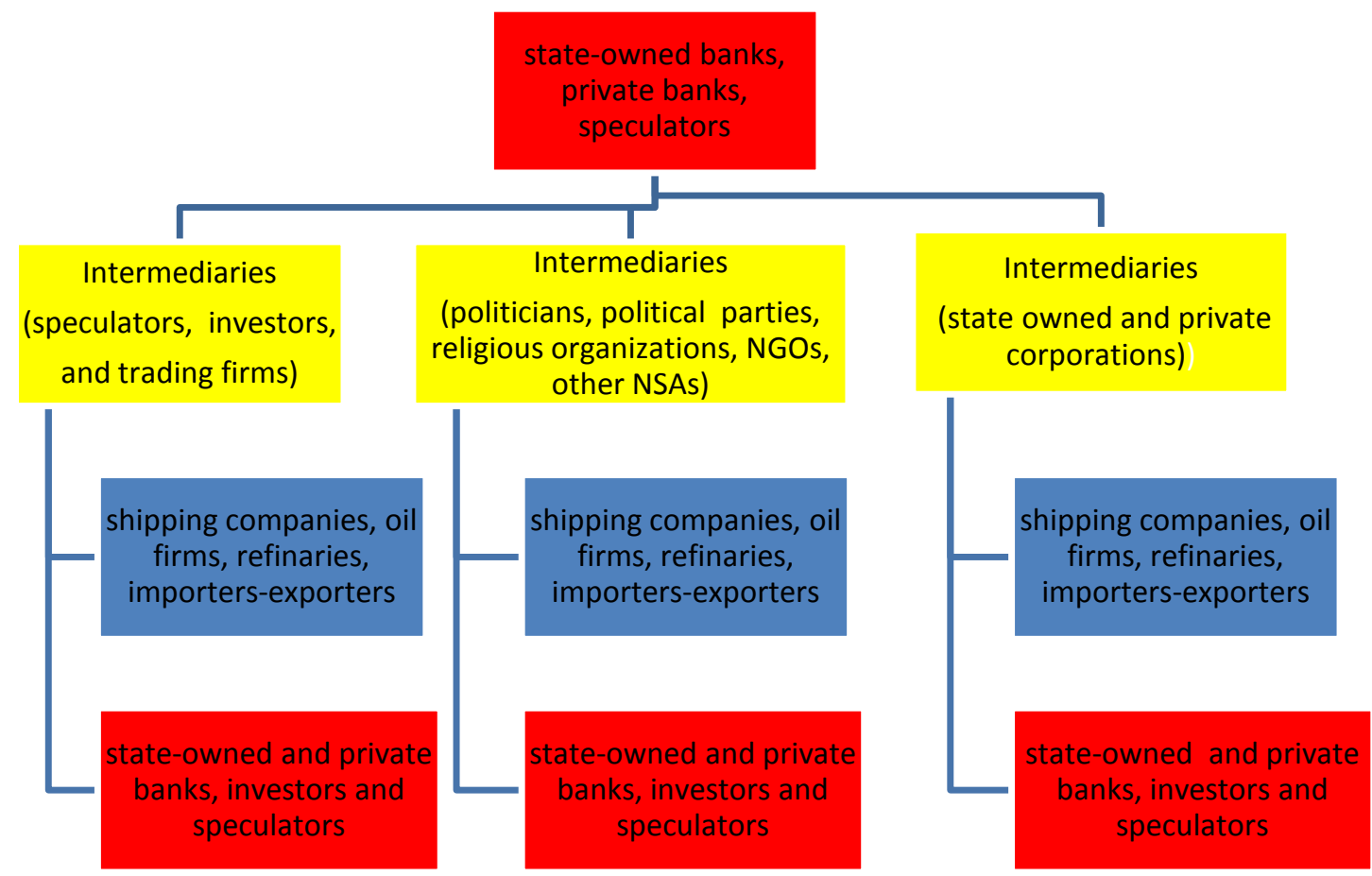

I present four case studies to explain my findings. The first case is InfobankBelmetalenergo, which involved a state-owned bank and a public company. The second case is about East Star Trading, Texaco Corp and BNP New York. Texaco speculated through East Star and BNP to conceal its wrongdoings. The third case is about Mr. Chalmers, a NSA empowered by his oil trade firm, Bayoil Inc. The fourth case is Trafigura Beheer B.V, Ibex Energy, and Multi-Prestation S.A.R.L. This case involves an oil and commodity trader and an oil service company. All cases present three common denominators: a) the use of multiple layers of offshore bank accounts, of which the IIC 
stated that "Were typical of the financial transactions under the sanction regime" (IIC, Chapter IV, p. 434); b) the use of wire transfers and cash; c) the use of intermediaries or third parties to ultimately execute the services.

$\underline{\text { Infobank-Belmetalenergo }}$

The first case involves a state-owned bank. It explains how nation-states and banks worked together to circumvent the UN sanctions regime. This case is about Infobank, Belarus and Iraq.

The Duelfer Report affirmed that "The critical financial element in the illicit trade process between Belarus and Iraq was Infobank" (Duelfer Report, Regime Finance and Procurement, p. 129). But the model was simple: "Belarus demanded to be paid 75 percent of any contract price in hard currency before delivery of any goods. In return, it would purchase goods in the world market for Iraq, including military goods. Infobank agreed to provide bridging funds, including the 75 percent up-front fee, to finance illicit deals between Belarus and Iraq for a fee of 15 percent of any contract" (Duelfer Report, Regime Finance and Procurement, p. 129)

Infobank was a result of privatization of Soviet Union's banking industry in 1994 (Duelfer Report, Regime Finance and Procurement, p. 129). Infobank became Belarus' largest bank, taking over 39\% of all investments the former Soviet Union had throughout the Middle East (Duelfer Report, Regime Finance and Procurement, p. 129). Infobank also acquired 10\% of Belmetalenergo, a firm registered in Belarus in 1993 (Duelfer Report, Regime Finance and Procurement, p. 129). Like Infobank, Belmetalenergo picked $67 \%$ of the businesses that the former Soviet Union had in the Middle East. 
Belmetalenergo even took over the office the Soviets had in Bagdad and used it as headquarter. Belmetalenergo's businesses consisted in the export of tractors, trucks, construction equipments, heavy machinery and spare parts, including military spare parts, all made in Belarus and/or Russia. When the UN sanctions regime was established, Infobank emerged as the main financier of Belmetalenergo's businesses in Iraq. The partnership soon became a trade engine between Belarus and Iraq. The importance of Infobank was confirmed in a letter from the Iraqi Ministry of Agriculture to Iraqi business nomenclature. The Minister stated that "Guarantees from Infobank are accepted by all Iraqi companies and ministries; we must be certain that cooperation with Infobank is never broken" (IIC, Chapter III, p. 337).

Infobank guaranteed Belmetalenergo's good image in European markets where it purchased goods to export to Iraq. At some point, most of Belmetalenergo's businesses responded to Iraqi needs. It became the 13th largest exporter to Iraq (IIC, Chapter III, p. 337). The IIC found that Belmetalenergo picked 71 contracts worth $\$ 349.3$ million dollars in just 2 years of sanctions, all of which was financed by Infobank through 129 letters of credits (IIC, Chapter III, p. 340). The CIA found another 20 contracts that UN auditors could not detect because Infobank did not keep records of Belmetalenrgo-Iraqi deals (IIC, Chapter III, p. 340). When the CIA asked why, Infobank's officials argued that "It was a practice to destroy all documentations once contracts were satisfied" (IIC, Chapter III, p. 340). The CIA did identify, however, around $\$ 69$ million dollars that Iraq illegally paid to Belmetalenergo through Jordan National Bank and then to Infobank (IIC, Chapter III, p. 340). Observe that Iraq was not supposed to pay its customers. UN Resolution 896 mandated that Iraq had to issue payments through BNP New York, the 
bank that guarded Iraq's escrow accounts. In 2003, Infobank still held \$7 million dollars that belonged to Iraq (IIC, Chapter III, p. 340).

Although Belmetalenergo was mainly an export oriented enterprise and Infobank a financier of its exports, they also engaged in oil trading under the sanctions regime. They purchased 21.6 million barrels worth $\$ 464.2$ million dollars (IIC, Chapter III, p. 337). Infobank and Belmetalenergo undertook another four oil contracts, which they insured through Bayoil and Chevron-Texaco, two American oil companies (IIC, Chapter III, p. 337). Chevron-Texaco kept the oil and paid \$1 million dollars to Belmetalenergo and \$2.9 million to Infobank (IIC, Chapter III, p. 337). To conceal its dealings, ChevronTexaco made its payments through an amalgam of front companies that included Balmorals Ventures, Hanner Tired Trading, Hi-Tech Technology Corp Ltd, and Rouden Co. LLC (IIC, Chapter III, p. 337). Those firms belonged to Belmoral International and Trustbank, a parent company of Infobank. Belmoral International and Trustbank were also funded and registered in Belarus. The linkage between Infobank and Trustbank was Mr. Victor Shevtsov, Chairman of the Board of Directors of both Infobank and Trustbank. Belarus' legislature appointed him, and he supervised Infobank's operations (IIC, Chapter III, p. 337).

\section{East Star Trading-BNP Paribas}

This second case involves two oil traders and a private bank. This case is illustrative of how oil traders and banks allied to finance Iraq's oil exports. The IIC and GAO cited a total of 14 major private banks as violators of the UN sanctions, among 
which were HSBC of Hong Kong, Chase Manhattan Bank of New York, and Barclays of London (IIC, Chapter III, p. 341; GAO, Audits, p. 11).

The IIC explicitly accused private banks of: 1) concealing the identities of violators of the UN sanctions; 2) paying intermediaries and third parties. Specially, BNP was the target of direct accusations. Congresswoman Rohrabacher accused BNP Paribas of paying East Star, Al-Douh, Glencore International AG, Belmetalenergo, Texaco Corp. and other intermediaries for services they did not render. She argued that "They were not authorized to receive payments as they were not the original party to the transaction, and this is a third party being paid for what someone else is doing" (The Role of BNP Paribas, Hearing before the Subcommittee on Oversight and Investigations, 2005, p. 7). UN Security Council Resolution 986 stated that "only financial institutions could have funds reassigned to them" (The Role of BNP Paribas, Hearing before the Subcommittee on Oversight and Investigations, 2005, p. 7). East Star, Al-Douh, Glencore International AG, Belmetalenergo and Texaco Corp were not financial institutions, yet, they had funds reassigned to them through BNP of Geneva, Credit Agricole Indosuez Singapore and HSBC Bank Middle East among other banks.

East Star Trading was incorporated in the Cayman Islands on February 27, 1990 as an affiliate to Pacific Inter-Link SDN BHD (www.pacificinterlink.comny, 2002). Both companies belonged to Commodities House Investment Ltd., which in turn was part of Hayel Saeed Anam Group, an Arab conglomerate formed by about 100 companies. Pacific Inter-Link was incorporated in Malaysia on June 22, 1988 as the "leader" of a group of subsidiaries and affiliates specialized in imports-exports. Seven of them traded 
with Iraq under the UN sanctions and made about \$270 million dollars (The Role of BNP Paribas, Hearing before the Subcommittee on Oversight and Investigations, 2005, p. 7-8). East Star was just one of them. East Star instructed Al-Riyadh International Flowers, one of its many affiliates, to establish trade relations with Iraq (The Role of BNP Paribas, Hearing before the Subcommittee on Oversight and Investigations, 2005, p. 8). Al-Riyadh began to finance exports to Iraq through letters of credit it obtained from Credit Agricole Indosuez Singapore. Al-Riyadh then reassigned its contracts to a subcontractor, Investment Trading Industry \& Medical Hygienic Services, which actually executed the exports; then, BNP New York paid Al-Riyadh with Iraqi funds and AlRiyadh repaid its loans to Credit Agricole Indosuez. Any money remaining was actually a profit for East Star (The Role of BNP Paribas, Hearing before the Subcommittee on Oversight and Investigations, 2005, p. 7). For its parts, Investment Trading Industry \& Medical Hygienic Services never got paid although it actually executed the contracts. Investment Trading was just a front company to East Star. Congresswoman Ms. Rohrabacher called East Star "a shadowy company" (The Role of BNP Paribas, Hearing before the Subcommittee on Oversight and Investigations, 2005, p. 7).

When Saddam Hussein refused to trade with American companies, some of those companies proceeded to hire intermediaries in the form of subcontractors. One of them was Texaco Corp, which in turn hired Bulf, a company registered in The Bahamas but based in Panama (www.pacificinterlink.com.ny, 2002). Bulf was a subsidiary of Midway Oil of Reston, a little known oil company based in Virginia. According to the partnership, Bulf was to obtain contracts from Iraq and execute them, and Texaco was to obtain letters of credit from BNP to finance Bulf's operations (The Role of BNP Paribas, Hearing 
before the Subcommittee on Oversight and Investigations, 2005, p. 11). Texaco's outstanding credit history guaranteed the lowest interest rates for Bulf. Texaco even lent its technologies, equipments and expertise to Bulf. Texaco asked BNP to conceal its identity and redirect payments to its numerous subsidiaries and affiliates, then to BNP Geneva, and from it to Chase Manhattan Bank. Texaco also asked BNP to channel the money in the form of "liquid securities," so it could convert it back into cash at anytime (The Role of BNP Paribas, Hearing before the Subcommittee on Oversight and Investigations, 2005, p. 11). Midway Oil of Reston too asked BNP not to reveal its association with Bulf and to channel payments through Bank of America to Panama Bank, in Panama. BNP agreed in violation of UN Security Council Resolution 986 (The Role of BNP Paribas, Hearing before the Subcommittee on Oversight and Investigations, 2005, p. 11).

Bulf obtained 14 contracts from Iraq in a period of two years. It lifted two million oil barrels per contract, which it later resold in European markets. Bulf profited a total of $\$ 97$ million. Iraq paid BNP New York, which then paid Texaco Corp. Yet, BNP claimed to have no record of Texaco's involvement in Bulf's operations (The Role of BNP Paribas, Hearing before the Subcommittee on Oversight and Investigations, 2005, p. 12). GAO and IIC learned about Texaco's scheme through Panama Bank and Bank of America.

In all, what is most relevant in this case is the participation of BNP New York in the scheme. BNP was the bank that $\mathrm{UN}$ chose to manage Iraqi finances under the UN sanctions regime. Congresswoman Rohrabacher harshly criticized BNP for its acts in a Hearing before the Subcommittee on Oversight and Investigations in the House of 
Representatives of the U.S. Congress. Congresswoman Rohrabacher told BNP's CEO that "You were not supposed to deliver these payments to third parties unless they were banks. But you went ahead and delivered it to that company, which was then owned by some other company in the Cayman Islands. Really, this smells; this stinks" (The Role of BNP Paribas, Hearing before the Subcommittee on Oversight and Investigations, 2005, p. 13). Congresswoman Rohrabacher suspected the obvious: that BNP laundered money for East Star, Al-Douh, Glencore and many other companies that traded with Iraq. In fact, auditors from GAO found that BNP issued a total of 572 payments to third parties (GAO Report, p. 9).

\section{David Chalmers and Bayoil}

The third case is relevant since it involved an empowered individual, the sort I explained in Chapter IV. This case is about Mr. David Chalmers and his Bayoil Inc, an oil trading firm based in Houston, Texas. Mr. Chalmers and Bayoil speculated with about $\$ 600$ million dollars worth of oil in about three years. As I stated earlier, oil traders financed $26 \%$ of all contracts under the UN sanctions regime. By 1999, just "Four traders financed and lifted over 60\% of the Iraqi oil under the Program" (IIC, Chapter II, p. 115). Bayoil was one of them.

Mr. Chalmers opposed the UN sanctions regime from day one, and he made his position known to President George Bush Sr. through several letters and personal meetings, hoping that the President, an oil trader himself, would eventually ease the American position toward Iraq (Meyer and Califano, 2006, p. 323). Mr. Chalmers also visited Bagdad and met with Saddam on several occasions. He asked Saddam to accept 
UN conditions for disarmament in exchange for easing UN sanctions against Iraq. Mr. Chalmers became one of the main negotiators involved in helping to set the terms of the UN sanctions regime in Iraq. He actively intermediated between the U.S., UN, Saddam and OPEC. He served as an expert in oil trading, frequently warning about instability in oil prices and markets. Meyer and Califano pointed out that "Mr. Chalmers let the parties know that Iraqi oil industry was to be untouched if the Coalition wanted stability in oil prices in OPEC" (Meyer and Califano, 2006, p. 323). Additionally, Mr. Chalmers collected money, medicines and school supplies for Iraqi children and women. He even used his own money to repair an Iraqi hospital and several schools damaged during the Coalition's bombing in 1991 (Meyer and Califano, 2006, p. 323).

For its part, the Bayoil was a conglomerate registered in Delaware but headquartered in Houston, Texas. Among its many subsidiaries and affiliates were Bayoil Technologies, Bayoil S.A., and Bayoil Supply and Trading Ltd. Bayoil registered and based them in Nassau, The Bahamas. Never mind the names of those companies. They were oil traders, mere speculators.

Bayoil did not engage itself in oil deals under the UN sanctions regime. I found that Bayoil violated UN sanctions through Italtech SRL, one of its many affiliates. Italtech was registered in Italy and had been "dormant" for some years. Bayoil revived it as a front company specialized in oil trading (IIC, Report on Oil Allocations, p. 36). Then, Bayoil approached several Russian firms and asked them to act as intermediaries between Italtech and the government of Iraq (IIC, Chapter II, p. 36). The Russian companies were: Alfa Eco (JSC), Tatneft (OAO), Lukoil, Tyumen Oil Company, Nafta Moskva (JSC), Zarubezhneft, and ACTEC. Bayoil chose Russian companies for two 
main reasons: 1) Russia was a close ally of Saddam who, in turn, was willing to grant any oil contract to any Russian company for political support at the UN; 2) during this period -1998 to 2002- most Russian companies were immersed in a deep financial crisis. They needed businesses to stay afloat.

Bayoil bridged money to Italtech in the form of letters of credit. Italtech utilized it to finance Russian companies that ultimately executed the contracts. For that purpose, Italtech opened a series of bank accounts in banks around the world, including: Merrill Lynch S.A. in Geneva, Switzerland; UEB in Abu Dhabi in Dubai; and BNP in France, Brussels, Luxemburg, Cyprus, Singapore and Bangladesh (IIC, Chapter II, p. 36). Right afterward, Italtech created United Management, an accounting firm to process billing, payments, and route profits back to Bayoil. Italtech registered and based United Management in Santiago de Chile (IIC, Chapter II, p. 36). Lastly, United Management opened bank accounts in Santiago de Chile, Paris, Geneva, and Luxemburg (IIC, Chapter II, p. 36).

Through that scheme Buyoil purchased and sold \$215 million barrels of Iraqi oil in just 10 months. For instance, in January $8^{\text {th }}, 1999$, SOMO confirmed the allocation of contract $\mathrm{M} / 5 / 50$ for $\$ 7$ million barrels divided in five shipments to J.S.C. and Nafta's parent companies in Singapore and Bangladesh (IIC, Chapter II, p. 37). In July 1999, SOMO amended contract $\mathrm{M} / 6 / 25$ to allocate $\$ 10$ million barrels to Lukoil, another Russian company, and Plasco Shipping, a subsidiary of Lukoil, delivered the contract in 6 shipments (IIC, Chapter II, p. 37). Italtech's records indicate that Plasco delivered a total of 7,843,376 million barrels, and that United Management routed about $\$ 1.4$ million dollars to Bayoil for the same contract (IIC, Chapter II, p. 37). In January $19^{\text {th }}, 2000$, 
SOMO granted contract M/7/90 for 6.5 million barrels of oil to a Russian front company called Tyumen Oil Co., also known as TNK (IIC, Chapter II, p. 37). The contract consisted in four deliveries worth $\$ 620,000, \$ 221,650$ and $\$ 128,650$ million respectively. Italtech bridged $\$ 4$ million dollars to a Russian financial entity with the name of Bayvan Consulting to pay for the shipments, and United Management collected $\$ 7$ million dollars for the sale of the contracts (IIC Report, Chapter II, p. 37). Soon after, SOMO granted contract M/8/40 to Crown Trade and Finance Ltd., a financial firm affiliated to Tyumen, a Russian oil company as well. Tyumen delivered the contract in September 2000. It contained 9 million barrels, and Italtech paid three cents per barrel to Tyumen through Crown Trade and Finance Ltd. It always did it on Bayoil's behalf. United Management collected $\$ 30$ million dollars (IIC, Chapter II, p. 37).

Later, in December $7^{\text {th }}, 2000$, SOMO assigned contract M/8/9/19 for 4 million barrels to Machinoimport, yet another Russian company (IIC, Chapter II, p. 38). Machinoimport delivered the contract in three shipments between July and August 14, 2001, but IIC and the 661 Committee did not find payments related to them. In August 2001, there was still a contract, M/10/19 for 6 million barrels. United Management's accounting ledgers revealed that it deposited $\$ 839,368.10$ at Cyprus Popular Bank Ltd. in favor of Machinoimport (IIC, Chapter II, p. 38). Finally, in August 26, 2001, Lukoil Asia Pacific PTE Ltd, a subsidiary of Lukoil, Inc executed contract M/10/67 for 4 million barrels which had been granted a couple of months before. Yet, United Management paid Plasco Shipping three cents a barrel for the shipments (IIC, Chapter II, p. 38). It did not pay Lukoil Asia Pacific Pte Ltd as it should have done according to the mandates of the UN sanctions regime against. 
On the other hand, the way Italtech paid the Iraqi government was as intricate. It went as follow: Bayoil deposited funds in Italtech's accounts at BNP Paris. Italtech, at its discretion, wire transferred the funds to United Management, Al-Hoda, or Al Wasel \& Babel's accounts at Abu Dhabi Commercial Bank or Jordan National Bank (IIC, Chapter II, p. 39; Duelfer Report, Regime Finance and Procurement, p. 117). They then paid SOMO. One case illustrates it. Early in 2001, Bayoil financed and delivered Iraqi oil for Petroleum Technical Services Co., also known as PTSC. Bayoil charged PTSC for the services and instructed it to wire transfer $\$ 812,386.20$ thousand dollars to Italtech's account at United European Bank, which in turn wire transferred it to Al Wasel \& Babel's account at Abu Dhabi Commercial Bank in Dubai (IIC, Chapter II, p. 40; Duelfer Report, Regime Finance and Procurement, p. 117). In total, between 2000 and 2001, Italtech paid \$11 million to Saddam Hussein through this intricate financial network o bank accounts and banks (IIC, Chapter II, p. 40).

In all, David Chalmers and Bayoil purchased $9 \%$ of all oil contracts sold under the UN sanctions regime against Iraq (WSJ, Oct $13^{\text {th }}$, 2004; American Journal of International Law, vol.99, p. 904-906). Their network involved 7 nations, 12 Russian intermediaries, 11 subsidiaries and affiliates, 9 banks, and an undetermined number of bank accounts. In the end, the government of the United States accused Mr. Chalmers and Bayoil of "Paying inflated commissions to brokers knowing that these commissions were earmarked for the kickback to the Hussein regime" (WSJ, Oct $\left.13^{\text {th }}, 2004\right)$. The accusations included "wire fraud, conducting financial transactions with a state sponsor of terrorism and breaking the economic embargo with Iraq" (WSJ, Oct $13^{\text {th }}, 2004$; American Journal of International Law, vol.99, p. 904-906). Mr. Chalmers and Bayoil 
were indicted in 2007 (WSJ, Oct 13 ${ }^{\text {th }}$, 2004; American Journal of International Law, vol.99, p. 904-906).

\section{$\underline{\text { Trafigura - Ibex }}$}

This last case reveals the intricacy of global trading. This case tells us: a) how banks, speculators and companies interact through multiple layers of bank accounts, letters of credits, wire transferring and electronic money; b) how speculators circumvented the Iraqi government; c) how speculators corrupted UN officials. This case involves Trafigura and Ibex, two well established global traders secretly associated through an amalgam of bank accounts and companies they owned around the world.

Trafigura Beheer B.V. was a British oil and commodity financier while Ibex Energy/Multi-Prestation S.A.R.L. was a French oil and commodity service corporation (IIC, Chapter II, p. 176). Basically, they both specialized in financing large operations of commodities. Trafigura Beheer B.V. purposely created Trafigura Ltd in May 1997 to participate in the UN sanctions regime. Yet, Trafigura created its own net of subsidiaries and affiliates, among which was Toro Energy S.A.M. Trafigura registered and based it in Monaco in October 1997 (IIC Report, Chapter II, p. 176). It made an initial wire transfer of \$51 million dollars to Toro's account at a branch of Barclays Bank in Monaco. Immediately, investors rolled in, and three months later Toro was worth $\$ 100$ million (IIC, Chapter II, p. 177). Trafigura employed Toro as a front company. Trafigura received $65 \%$ of all profits while Toro retained $35 \%$ in form of investment for future operations (IIC, Chapter II, p. 176). Toro purchased oil from Iraq and resold it in Europe. In return, it purchased commodities in Africa and Latin America and sold them to Iraq. In 
total, Toro traded 21 million barrels of Iraqi oil in 1998 for a net profit of $\$ 128$ million, and it sold Iraq \$29 million worth of rice, corn, salt and sugar to Iraq in two years (IIC Report, Chapter II, p. 176). Toro paid dividends to its investors and still retained $\$ 17$ million, a stocky amount for a 1 year-old company with just one customer: the Iraqi government (IIC, Chapter II, p. 176).

Trafigura expanded its operations in 1991. It began to purchase oil allocated to SOCO International, another speculative firm registered and based in London (IIC, Chapter II, p. 178). Under the deal, Trafigura subcontracted 44 million barrels of oil worth $\$ 240$ million dollars. But in that same year, Saddam Hussein banned American and British companies from purchasing Iraqi oil. The ban affected Trafigura and all its associates. Trafigura circumvented Iraqi authorities by allying itself to Ibex, which at the time was smuggling oil on behalf of the Iraqi government. Ibex was receiving $25 \%$ of the proceeds, so it decided to pay $12 \%$ to Trafigura Ltd for allocating the oil in refineries around the world and laundering the money (IIC, Chapter II, p. 178).

Trafigura and Ibex began cheating on the Iraqi government and the UN sanctions regime in March 2000. They bribed Iraqi and UN inspectors who repeatedly allowed the overloading of oil tankers (IIC, Chapter II, p. 182). The tankers belonged to Falcon Navigation Corp., another affiliate of Trafigura Beheer B.V. Trafigura financed its oil deals according to two schemes. First, it financed the top-off of the cargo portion with standby letters of credit issued to Roundhead Inc., an "off the shelf" Bahamian company that Trafigura Ltd had acquired in February 2000 (IIC, Chapter II, p. 182). Bank records showed that on June 14th, 2001, Trafigura wire transferred \$51 million from its account at Credit Agricole Indosuez to Ibex Service \& Equipment Ltd., a company registered and 
based in the British Virgin Islands. Part of the money, \$24 million, was to cancel Roundhead's standby letters of credit (IIC, Chapter II, p. 182). The remaining portion, \$27 million, Ibex Service \& Equipment Ltd. wired transferred it to Windmill Trade Ltd., also a shelf company registered and based in British Virgin Islands and parented to Trafigura Beheer B.V. (IIC Report, Chapter II, p. 182). Windmill received the money in its account at Banque Audi's branch in Beirut. Finally, Windmill wire transferred the money to a SOMO account at Fransabank in Beirut, Lebanon (IIC, Chapter II, p. 182).

A second scheme consisted in issuing letters of credit to Ibex. Trafigura issued credit and sold contracts to Koch Petroleum and Marathon Ashland, two American oil refineries. Koch Petroleum paid Trafigura $\$ 20.8$ million dollars in two installments wire transferred to Trafigura's accounts at BNP Paris (IIC, Chapter II, p. 182). For its part, Marathon Ashland paid Trafigura \$23.2 million in two installments wired transferred to Trafigura's accounts at the London branch of Credit Agricole Indosuez S.A. The IIC traced the two amounts to a branch of Barclays Bank in Cayman Island (IIC, Chapter II, p. 182). In one instance, Trafigura issued a letter of credit to finance an Ibex contract worth one million barrels of oil. Ibex overloaded the tanker with about 200,000 barrels. It then sold it to Koch Petroleum and Petromar S.A., based in Curazao and affiliated to Petróleos de Venezuela S.A., owned by the state of Venezuela (IIC, Chapter II, p. 182). Trafigura financed the extra 200,000 barrels through a stand-by letter of credit issued to Roundhead (IIC, Chapter II, p. 184). To honor the credit, it wired transferred \$6.4 million to Ibex Standard \& Equipment's account at Credit Agricole Indosuez, which transferred the money to Windmill's account at Banque Saradar in Beirut. Windmill paid SOMO's 
share by wire transferring $\$ 5.2$ million to SOMO’s account at Fransabank, in Beirut (IIC, Chapter II, p. 182).

Even though the 661 Committee could not determine exactly how much oil the two companies smuggled out of Iraq, it did estimate that they engaged in at least 75 overloading operations worth $\$ 900$ million dollars in a period of three years (IIC, Chapter II, p. 182). Trafigura and Ibex's operations involved three holdings, 7seven subsidiaries, four affiliates, three offshore companies, two shelf companies, five banks and a dozen bank accounts. To complicate it even more, they involved seven nations from five continents. It was so complicated that their smuggling went unnoticed with these operations until 2003. The U.S. discovered it only after it invaded Iraq and confiscated the archives of the Iraqi Ministry of Oil. Indeed, the case of Trafigura and Ibex is intricate and difficult to decipher precisely because Trafigura and Ibex wanted it that way, so they would not get caught. After all, that is nature of trade under globalization: intricate and difficult to decipher.

\section{$\underline{\text { Conclusion }}$}

In this chapter, I discussed how global banking, a means of globalization, and banks, investors and speculators, the agents of globalization, undermines a multilateral sanctions regime. I conclude that in effect, the current global banking system allowed nation-states, banks, investors, speculators, corporations, and NSAs in general to operate and profit under the UN sanctions regime. On one hand, I first found that the Iraqi banking system actually expanded throughout the Middle East under the UN sanctions regime. Secondly, Iraq utilized the domestic and regional banking to reach global 
banking. On the other hand, when the UN conceived and implemented the UN sanctions regime upon Iraq, it basically ignored the hawala, the credit system that Iraq and most Middle Eastern nations had been using for centuries but alien to Western banking standards. In addition, companies, traders, speculators and even nation-states such as Belarus and Russia utilized banks and global banking to conceal their wrongdoings and even to launder money. They did it through banking instruments such as letters of credit, wire transferring, offshore accounts, and multiple layers of bank accounts for their affiliates, subsidiaries, and parent companies. But what are affiliates, subsidiaries and parent companies anyway? They are corporate models, another means of globalization. In the next chapter, I analyze in more detail how companies employed global corporate models to circumvent a sanctions regime. 


\section{AGENTS AND MEANS OF GLOBALIZATION: CORPORATIONS AND CORPORATE MODELS}

"The second great era [of] Globalization lasted roughly from 1800 to 2000. In globalization 2.0, the key agent of change, the dynamic force driving global integration, was multinational companies. These multinationals went global for markets and labor, spearheaded first by the expansion of the Dutch and English joint-stock companies and the Industrial revolution”.

Thomas L. Friedman

"The company that then asked you to deliver its money that it was receiving for that overcharging to East Star, which then of course, as we can see now, was owned by Commodities House Investment. Who knows who owns Commodities House Investment?"

Congressman Mr. Rohrabacher

$\underline{\text { Introduction }}$

Corporate models were essential for the circumvention of the UN sanctions regime in Iraq. On the one hand, the government of Iraq employed corporate models to sell to and purchase from corporations and states. Iraq used corporate models to reach local, regional and global markets. On the other hand, there were non-Iraqi corporations that were interested in the Iraqi market. They too employed corporate models to evade UN sanctions and inspectors, conceal their wrongdoings, and laundry their profits. I use the first part of this chapter to analyze corporate models. I include an analysis of corporate governance and responsibility since they are part of the overall structure of corporate models. In the second part, I present specific examples of how corporations employed corporate models to circumvent the UN sanctions regime in Iraq.

\section{The Corporation: A Global Agent and Globalizing Force}

Corporations are among the main agents of globalization. I would argue that corporations created globalization. For example, let us look at the colonization of the 
Americas. The European Crowns could not manage their American colonies from their metropolis because they did not have the infrastructure. Bureaucracies were lousy, and global means of transportation and communication were still in their "primitive" stages. It took weeks to send a message from London to Philadelphia and months to send an envoy to India. The solution was decentralization and delegation of authority to corporations through charters.

A charter is probably the first global corporate model that ever existed. A charter is a legal document issued to acknowledge full authority over a piece of territory (Draakman, 2004, p. 37; Easterbrook and Fishel, 1991, p. 74). The charter grants certain prerogatives to a recipient, but those prerogatives do not include ownership, which remains as a right of the entity or legal person who holds it. This person can annul the charter at any time (Draakman, 2004, p. 39; Easterbrook and Fishel, 1991, p. 74). If it occurs, the recipient must restrain from claiming indemnity or relation to the property in question (Draakman, 2004, p. 39; Easterbrook and Fishel, 1991, p. 74). Based on those principles, for example, the English Crown issued a charter to the London Company, which in turn created the Charter of the Virginia Company of London with the sole purpose of establishing colonies in North America. The English Crown also issued a charter to the Plymouth Company to create the Virginia Company of Plymouth, also known as Virginia Bay Company.

The Dutch Crown took another approach. It hired corporations to manage colonization. It contracted the Dutch West Indian Company to open trade routes through the Caribbean Sea and areas of South America like Brazil, Suriname and Guyana (Draakman, 2004, p. 40; Easterbrook and Fishel, 1991, p. 82). It created mining centers 
in what are today Ghana, Angola, Congo and some parts of South Africa. The Dutch West Indian Company financed the expedition that led to the discovery of the Hudson River. It later subcontracted the Hudson River Company to build a port there, and the port soon became the most important trade center in what was then New Amsterdam, which covered most of New York, Connecticut, Delaware and New Jersey (Draakman, 2004, p. 41; Easterbrook and Fishel, 1991, p. 82). The Dutch also used the Dutch East Indian Company, a parent corporation of the Dutch West Indian, to open trade routes in Asia and establish markets there. For Draakman (2004), Easterbrook and Fishel (1991) and other historian of Corporate Law, the Dutch West Indian was the first multinational corporation and the first mega-corporation in the world. It was so powerful that it had the power to wage war, negotiate treaties, coin money and establish colonies (Draakman, 2004, p. 44; Easterbrook and Fishel, 1991, p. 87). The Dutch West Indian created what is today Indonesia.

In "The World is Flat", Thomas L. Friedman argues that companies consolidated themselves as a true globalizing agent during the 1800-2000 period. Friedman calls it "the second great era of globalization" (Friedman, 2008, p. 61) He explicates that, during this period, corporations became multinationals through corporate models, which they created for two main reasons: a) to control sources of raw materials worldwide; b) to open and control new markets where they could allocate their finished products. It is in that sense that corporations structured globalization. But William I. Robinson (2004) disagrees. In "A Theory of Global Capitalism", Robinson suggests that there is a key difference between multinational and transnational corporate models, and that such a difference has a structural character. The multinational model is built on three 
assumptions: a) there is a global economy; 2) there are national economies; 3) there are different models of production and accumulation of capital across global and national markets (Robinson, 2004, p. 10-11). In other words, each nation adopted an economic model based on, among other factors, economic needs, natural resources, market forces, political systems, and position within the context of regional and global economies. Corporations had no choice but to conceive and adopt corporative models according to national economic models. I have drawn Figure 6.1 to typify a transnational Firm operating under the multinational model.

Figure 6.1 - Transnational "XYZ Inc" Operating under the Multinational Model

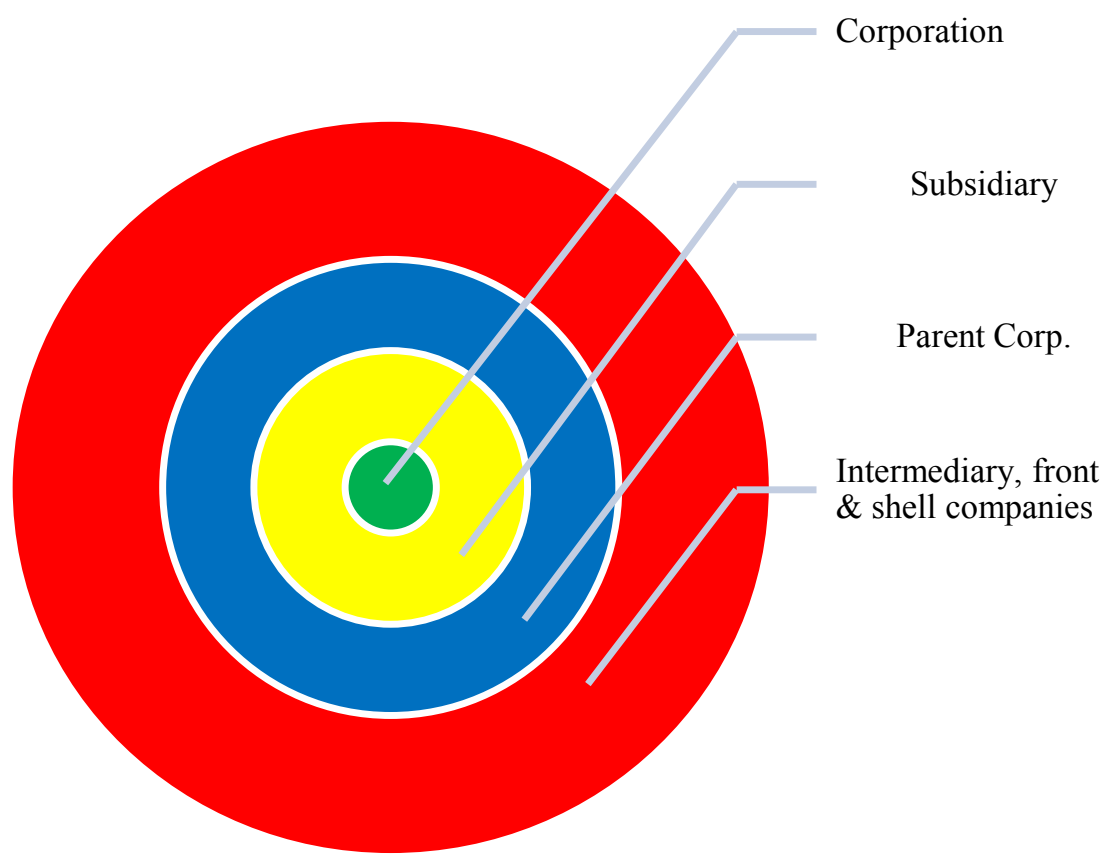


I have called this hypothetical transnational XYZ Inc. Now, in Figure 6.1 each color represents a unique corporate model, and each circle represents a different nation. XYZ Inc is based and licensed to operate in nation Green. But then, XYZ Inc creates a subsidiary to operate in nation Yellow. The subsidiary, known as ' $A$ Inc', decides to expand to operate in nation Blue, so it creates a parent company. It licenses and bases it in nation Blue under the name ' $B$ Inc'. Lastly, when $X Y Z$ Inc expands to operate in nation Red, it adopts three different corporate models. It becomes an intermediary, a shell, and a front company. The same occurs as the corporation moves to operate from local to bilateral, regional and global markets. That is, under the multinational model, a corporation adopts a different corporate model as it crosses national borders.

It all works differently under the transnational corporate model. This model, unlike the multinational, assumes that there is just a global economy, implying that there is uniformity across national markets. The end of the Cold War, according to Fukuyama (1992), presupposed the triumph of neoliberalism over planned-centralized and other economic models. According to Robison (2004), transnational capital expanded global models of production across states, in the process becoming a hegemonic political force in a large number of nations. Most nations have adopted, although with some variations, the same neoliberal economic structures, trade strategies, business legal codes, and even political systems. In fact, I can safely argue that the proliferation of bilateral and regional trade treaties during the last 20 years is an evidence of how little structural differences there are among national economies in most of Europe, Latin America and South East Asia. Moreover, the philosophical and practical concept behind the WTO is to induce uniformity across national and regional markets, so a true global economy can 
consolidate and flourish. GATT and WTO attempt to guarantee the existence of just one body of corporate and trade laws applicable to corporations regardless of their nation of origin, domicile, and jurisdiction. Some nations resist such attempts though. For instance, Russia and China have very different corporate and trade rules, and the European Union and the US have different regulatory structures. But in general, I find that under the transnational corporate model, this condition of uniformity across national economies is ideal for corporations because they do not have to adopt different corporate models as they cross markets boundaries. I drew Figure 6.2 below to exemplify how corporations operate under uniform transnational markets.

$\underline{\text { Figure 6.2 - Transnational "XYZ Inc" Operation under Uniform Transnational Markets }}$

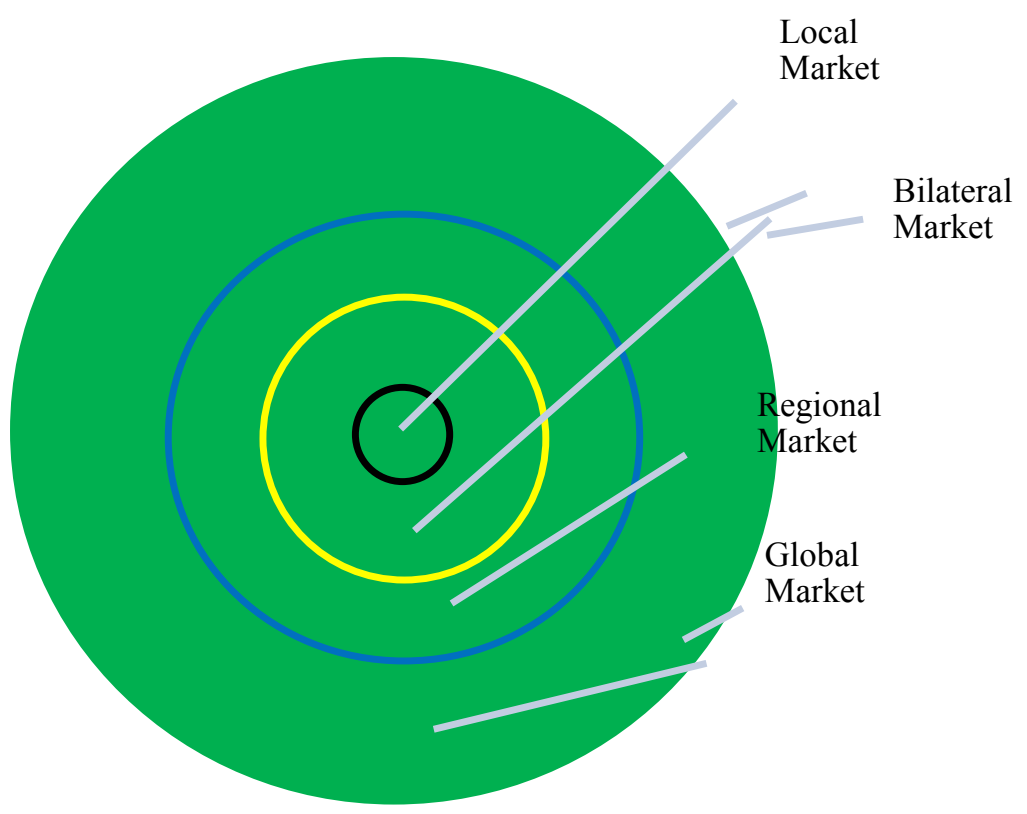


Let us assume that there is just one global regulatory regime. Let us assume that there is full globalization under a global capitalist system and all nations signed up on GATT, WTO and other international trade regimes. Under such assumptions, corporation XYZ Inc would operate under a condition of full uniformity across local, bilateral, regional and global markets, which in Figure 6.2 are delimited by black, yellow, and blue circles respectively. Observe that $X Y Z$ Inc remains green because it does not need to adopt different corporate models to operate across local, bilateral, regional and global boundaries.

For one, uniformity creates a sense of stability and positive expectations across transnational markets. It also facilitates production, transportation of raw materials and finished goods, and movement of capital from nation to nation, region to region, and globally. In addition, uniformity makes it easier for corporations to conceive and implement global business strategies. The underlying assumption is that if corporations did not need to adapt to different bodies of business laws and politics, then they would employ the same corporate models across nations and regions. Under such conditions, corporations can expand easily. They do not need to create new corporations. They just have to acquire existing ones. In fact, scholars like Bhagwati (2004) and Friedman (2008), and data from FMI (wwwfmi.org, 2008) indicate that merging and acquisition have been the most common means of corporate expansion and growth from 1800 s to 2000. I can cite many well known cases across different industrial sectors, from oil and pharmaceutical to computer and food industries. But let us just take three corporations in the automobile industry. For instance, although General Motors has consistently been losing market shares to its competitors over the years, it has grown steadily by purchasing 
several automakers around the world, among which were Opel and Volvo. The same occurred with Chrysler and Ford Motors. Chryslers, once in bankruptcy, purchased Daimler-Benz. Ford Motors grew spectacularly by purchasing Jaguar, Hyundai, and Land Rover. In all, General Motors, Chryslers and Ford are among the most globalizing agents in the global economy not only for the markets they control but also because they have suppliers, assembly plants and distributors in about 72 nations (Friedman, 2008, p. 119). In sum, corporations have historically been among the main agents of globalization. Their very nature demands expansion from their town of origin to the global market. But corporate expansion does not come easy. Corporations in fact often clash with politics, competition, litigation, geography and climate among other obstacles. Corporations have created an array of corporate models to circumvent those obstacles or at least minimize their effects.

\section{Global Corporate Models}

I can trace the concept of a corporation back to Roman times. The word itself derives from the Latin language to mean corpus or body (Corporate Law, Black Dictionary, 2007, Vol.3, p. 471). For the Romans, a businessperson was a legal "body," a corporation, and Roman courts treated it as such (Corporate Law, Black Dictionary, 2007, Vol.3, p. 475). The concept reemerged early during the industrial revolution with a new notion, of broader connotations. The "new" corporation was still a legal body but also a person. A corporation was an abstraction yet $a$ body in its own right (Corporate Law, Black Dictionary, 2007, Vol.3, p. 476). If in Roman times a corporation had slaves to do the work, the corporation of the industrial revolution had to hire free men for a 
salary. This new corporation could also raise capital, accumulate and use it as it pleased, according to its abilities (Corporate Law, Black Dictionary, 2007, Vol.3, p. 476). It is in that sense that capitalists utilized corporations as agents to create and manage wealth, and it was how corporations became the agents of capitalism. Even state-owned corporations have corporate rights and enjoy certain freedoms to act as a business enterprise. The Soviet Union, East Germany and other socialist states utilized corporations to manage their planned centralized economies. And there are corporations in North Korea and Cuba. They may be state-owned, but they are still corporations.

Indeed, the definition of a corporation varies according to each nation's legal framework (Corporate Law, Black Dictionary, 2007, Vol.3, p. 478), which suggests that different regulatory structures do exist. But as a whole, I would state that a corporation is an organizational instrument with legal obligations and privileges. There are several types of corporations, and each is formed according to business objectives and jurisdictions. Corporations are independent from the entity and/or body that incorporated it, and even ownership and profit sharing are limited by the legal rights of the corporation (Corporate Law, Black Dictionary, 2007, Vol.3, pp. 480-95). Yet, we must distinguish a corporation from a company. A corporation is a company that has been incorporated, meaning that a corporation is legally separated from the person or persons who creates and runs it (Corporate Law, Black Dictionary, 2007, Vol.3, pp. 480-495). A corporation exists and acts on its own. In other words, a corporation collects, accumulates and spends capital, sues and is sued, establishes structures and enacts statutes and procedures. A company, on the contrary, adopts the legal standing of the person who creates it (Corporate Law, Black Dictionary, 2007, Vol.3, pp. 511-521). A company does not act on its own right, 
and suing the owner is like suing the company, and vice- versa. For legal purposes, the money of the company is the money of the person who owns the company.

There are several types of corporations, but the most relevant for this analysis are: holding, parent, intermediary, offshore, front, and state-owned. In one way or another, all of them are: limited (Ltd) by shared capital, limited by guarantee, limited by guarantee and share capital, and unlimited by liability. Yet, they also have particularities.

A holding is a corporation that owns part, all, or a majority of other corporations (Corporate Law, Black Dictionary, 2007, Vol.8, p. 327-361). A holding does not produce any product or service per se; rather, its role is to hold or manage several corporations under one legal entity (Corporate Law, Black Dictionary, 2007, Vol.8, p. 327-361). A holding has two main objectives. The first is to maximize profits. It does it by gaining market shares through growth and expansion across different industries and economic sectors. The second objective is to minimize risks, chiefly legal risks. It does it by creating corporations according to sectors, markets shares, nations and even regions and sub-regions, which the holding usually defines as divisions and/or subdivisions (Corporate Law, Black Dictionary, 2007, Vol.8, p. 327-361). Such structuring guarantees flexibility while limiting liability. It means that the holding is only liable to the jurisdiction of its legal domicile or "general headquarter" and not to the jurisdictions of its numerous corporations (Corporate Law, Black Dictionary, 2007, Vol.8, p. 327-361). This way the holding can move funds throughout its numerous corporations; however, if a corporation in a particular sector, subdivision or region loses money or it is found guilty of a wrongdoing, only that corporation would be responsible. The other corporations of the holding, and the holding itself, are not accountable and can actually distance from it. 
Examples of holdings are American Investment Corporation, which owns numerous insurance groups around the world; UAL Corp., owner of United Airlines and its subsidiaries; and AMR Corp., that in turn owns American Airlines and its parent corporations.

Another model is the parent corporation. This is basically a holding that owns enough shares in another enterprise as to make decisions over operations and profits (Corporate Law, Black Dictionary, 2007, Vol.3, pp. 495-510). For example, Hewlett Packard is a parent company of Compaq. Since they manufacture computers, they compete against each other, seldom in the same market. One can go broke, found liable and even be dismantled but the other one would stay in business and even take over its failing "parent." A parent corporation usually owns two types of corporations: affiliate and subsidiary.

An affiliate, also known as an associate, owns small portions of shares while a subsidiary owns large portions (Corporate Law, Black Dictionary, 2007, Vol.3, pp. 495510). But also, an affiliate is a corporation that owns less than $50 \%$ of another corporation, either a subsidiary or a third party corporation (Corporate Law, Black Dictionary, 2007, Vol.3, pp. 495-510).

A parent corporation usually creates a subsidiary by acquiring or merging with an ailing company (Corporate Law, Black Dictionary, 2007, Vol.3, pp. 495-510). It may do it for two reasons. The first one is to get rid of the competition. A parent corporation buys out the competition, incorporates it as an affiliate and later dismantles it. It is a common practice among corporations that produce the same products and/or deliver the same service but are located in different markets. The second reason is to expand and grow. A 
parent corporation purchases an ailing company to retool and return it to profitability. An example is Nestlé, the Swiss producer and distributor of chocolate bars, among other products. During the 1990s, Nestlé purchased numerous companies in South America, including Donofrio, the largest candy and ice cream producer in Peru. Donofrio was an ailing family owned company. It operated with obsolete technologies in a poor market. It needed an infusion of cash to retool its plants and reduce costs, so it could make its products more affordable. Nestlé provided the investment but allowed Donofrio to keep its name, in part because it was a well-known brand, in part because of political reasons. Nestlé did not want Peruvians to resent the takeover. In time, Donofrio returned to profitability. Most Peruvians still ignore that their beloved Donofrio is actually owned by a Swiss multinational (El Comercio, Aug 20, 1998). We will see shortly that this was a common practice under the UN sanction regime in Iraq as corporations did not want their customers to know that they were trading with Saddam's regime.

Conversely, subsidiaries are mostly conceived to address issues related to taxation. There are two kinds of subsidiaries: operating and non-operating. An operating subsidiary refers to a corporation operating with its own identity, equipment, and within its market share (Corporate Law, Black Dictionary, 2007, Vol.3, pp. 495-510). A nonoperating subsidiary exists only on paper. It has been incorporated. It has a tax ID and domicile, but it operates under the article of incorporation of the corporation it is parented to (Corporate Law, Black Dictionary, 2007, Vol.3, pp. 495-510). It even uses its tax ID. Also note that a subsidiary can create its own subsidiaries, which in time can create their own as well. Berkshire Hathaway Inc. is a good example. Berkshire is a holding with many parent corporations, which in turn own about 60 subsidiaries among numerous 
industries across the world. Berkshire Hathaway Inc is a true global corporation; yet, most people have not heard of it. Indeed, anonymity is one of the main reasons for creating corporate models such as affiliate and subsidiary. Nevertheless, we should not confuse subsidiaries with divisions for the latter are legally binding and financially dependent on a parent company. A parent corporation does not have to be stronger or larger than its affiliates and/or subsidiaries. After all, they operate in different markets across different industries and industrial sectors.

In addition, parent corporations usually create front corporations to shield themselves from lawsuits, avoid accountability and still be able to collect profits on behalf of its parent corporation (Corporate Law, Black Dictionary, 2007, Vol.3, pp. 495510). A front corporation never acts independently, but its actions are difficult to trace back to the corporation it is parented to. The IIC defined a front corporation as " $A$ Company that the Government of Iraq secretly owned in part; the term does not connote that the company had no genuine business operations or that the full scope of its operations was carried in a fraudulent manner" (IIC, Chapter III, p. 249). Here, the irony is that the CIA invented this corporate model during the 1940s to conduct covert operations throughout the world, and now businessmen utilize it to "cover up" illegal operations and dubious sources of income (Draakman, 2004, p. 290; Easterbrook and Fishel, 1991, p. 221). For many years, Cuba has been using a dozens of front corporations to circumvent the U.S.'s unilateral sanctions regime against the island. But in 1989, the Cuban government accused and found guilty one of its front corporations, MC Inc., of drug-trafficking and money laundering (Cabello, 1998, p. 27). In fact, front corporations are seldom employed for gambling, money laundering, prostitution, and terrorism. 
A front corporation is not an intermediary, which is a corporation serving as point of contact between two or more corporations (Corporate Law, Black Dictionary, 2007, Vol.3, pp. 495-510). An intermediary does not produce any product. It is just a distributor of goods and services. For example, a supermarket is an intermediary for it does not produce anything. It purchases vegetables, meats and dairy products, which then advertises and sales to consumers at marginal price. Intermediaries dominate global trade due to: 1) new economic infrastructures in the developed world as it moves from an industrial-manufacturing oriented economy to one based on services; 2) improvement in transportation, communication, and storing technologies. The growing influence of intermediaries is reflected in the Dow Jones, Standard \& Poor and others financial indexes. For example, during the 1990s, the Dow Jones substituted old American manufacturing corporations for service-oriented intermediaries. In fact, 12 of its 30 members are intermediaries. The most notable are Home Depot and Wal-Mart.

Next, a conglomerate is a group of corporations of diverse, dissimilar enterprises across various industries (Corporate Law, Black Dictionary, 2007, Vol.3, pp. 495-510). A conglomerate can own a bank, an insurance company, an automobile plant, a construction company, a research lab, a university, and so on. Walt Disney Corp., for example, is one of the largest conglomerates in the world. It owns 15 corporations, each structured as a group, and each group owns numerous corporations as well. Walt Disney Corp owns movie and music studios, cable TV networks, newspapers and book publishers, radio stations, hotels, restaurants, resorts, cruise lines, and amusement parks. Other conglomerates are General Electric in the U.S., Vivendi in France, Televisa from Mexico, 
Sony from Japan, PRISA of Spain, Gruppo Editoriale L'Espresso of Italy, and Organizasoe O’Globo from Brazil.

Finally, another corporative model is the joint venture (Corporate Law, Black Dictionary, 2007, Vol.10, pp. 364-381). Here, two or more investors create a corporation to share legal responsibilities and operational expenses. This model aims at new markets, foreign in particular. For example, corporation "A" wants to enter market $\mathrm{X}$, in which corporation " $\mathrm{B}$ " is well positioned. So " $\mathrm{A}$ " joins " $\mathrm{B}$ " to create corporation "C." Corporation "A" provides fresh capital and technologies while "B" provides labor, required permits, licenses and market shares. The joint venture can take the form of a company, corporation, partnership or limited liability (Ltd). Usually, joint ventures operate for a limited period of time, after which inventors dismantle them. In a few instances, investors decide to expand their venture by either welcoming more investors or acquiring smaller corporations and/or Firms. Again, the underlying rationale is minimizing risks and accountability even at the expense of profitability. That is why joint ventures are considered one of the safest investments. Most governments utilize joint ventures as a means to investing.

Altogether, I find that a global corporation is a well defined organizational structure. The corporation is right at the center of the structure, from which emanates other corporations in different corporate models. The corporation utilizes corporate models to keep an active or dormant presence in global markets and move throughout the global economy. Figure 6.3 illustrates how transnational corporation $X Y Z$ Inc is structured to operate under globalization. 


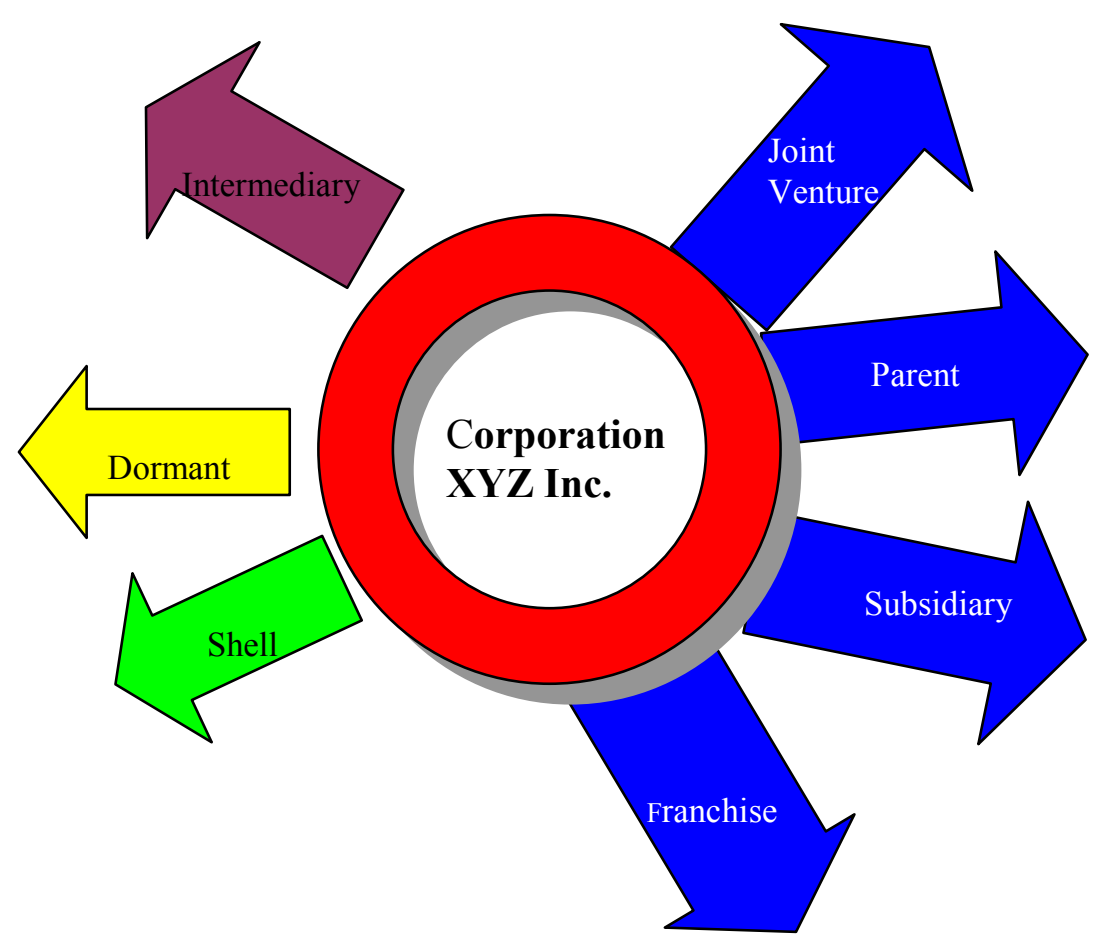

Note that XYZ Inc has become a holding, from which emanates several transnational corporations. Yet, not all corporations touch the holding, and not all of them keep the same distance from it. For instance, joint venture, subsidiary, parent and franchise - the blue arrows - touch the holding. They are under the "shadow" of the hurricane, and they spin at the same pace. But intermediary, dormant and shell do not. Intermediary and dormant do not touch the holding at all. And the shell barely does. It all means that, in the corporate world, some corporate models are closer to the corporation 
than others in terms of legal, financial, operational, and governmental standings. As we stated earlier, corporations adopt corporate models not only to enhance efficiency and high productivity but also to avoid accountability and circumvent regulatory regimes. The Graph shows how: a) the closer a corporate model to the corporation, the more accountable the corporation is; b) the closer the corporate model to the corporation, the harder it is for the corporation to evade regulatory regimes. That is why intermediary, dormant and shell corporations are so often utilized for the most risky businesses, in particular to avoid taxation, circumvent laws and regulations, and to conceal wrongdoings. They become more unaccountable when they are registered and based in "save heaven" centers such as The Bahamas, Cayman Island, Panama and Andorra among others. Indeed, we saw in Chapters II, III and V that a large number of corporations that violated the UN sanctions against Iraq had registration and domicile in those nations.

Some corporations adopt just one or two corporate models, but others implement three or four. It all depends on their business objectives, strategies, market conditions, and other factors (Draakman, 2004, p. 52; Easterbrook and Fishel, 1991, p. 102). But above all, Draakman (2004), Easterbrook and Fishel (1991) argue that corporations adopt corporate models depending on two main factors: institutional and geopolitical environments. On one hand, institutional environment here means civil and political institutions in a particular market. Institutions influence the way corporations choose a corporate model for that particular market. Institutions shape corporate culture, governance, and compliance with legal and social norms. Of course, corporations exercise great influence on civil and political institutions, their memberships and policies. They do not want to adapt to institutions. They prefer it the other way: institutions 
adapting to corporate models. Corporations lobby and invest heavily to reshape institutional environments, reframe institutional agendas, and bring institutional policies closer to corporate goals. Corporations lobby heavily to shape regulatory and trade regimes according to their interests.

Corporations fear geopolitics (Soskice, 1999, p.77). Geopolitics is bad for business, and corporations cannot shape and control it. To address it, corporations have conceived four market models: local, multi-local or semi-regional, regional, and global models (Soskice, 1999, p. 78). The local model targets local markets and focuses on local demand and consumption patterns (Soskice, 1999, p. 77). It targets cities of large populations such as New York, Los Angeles, Beijing, and Mexico City. Budgeting and marketing efforts are limited to a select clientele and competitors. The overall corporate strategy is coordinated and managed from the core of the corporation. Another model is the multi-local, which aims at several markets across a well-defined region (Soskice, 1999, p. 79). This is also a semi-regional model, and it can be national and multi-national for it often includes small regions of two or more nations. This model is particularly ideal for zones of high migrations, as it is the case of the U.S-Mexican and the VenezuelanColombian borders. According to Soskice (1999), some of those markets grow naturally as result of historic, cultural, and religious linkages, as occurred on the borders between Jordan, Syria and Iraq. A good example is the Kurdistan, which covers a good part of eastern Turkey and a chunk of Northern Iraq. For Soskice (1999), this is probably the most difficult model for it attempts to establish centralized corporate strategies while recognizing the existence of marketing differing patterns across the various localities it 
targets. Management is centralized, but it grants some autonomy to budgeting and decision-making.

As its name indicates, the regional model focuses on specific regional markets like NAFTA in North America, CARICOM in the Caribbean Basin and Mercosur in the south of South America (Soskice, 1999, p. 86). In the corporate world, regions are also known as divisions. For instance, General Motors has a North American division, a European Division, a South American division, and so on. That is so because the regional model recognizes that there are different market patterns within and across regions. Corporations cope with differing market patterns by: a) limiting the size of a market; b) creating market-blocs (Soskice, 1999, p. 87). In other words, corporations conceive regional models to induce uniformity and create a market of standardized features. The main goals are to predict and control market behavior. Lastly, there is the global model (Soskice, 1999, p. 98). The model is centralized and hierarchal. It is organized from top to bottom, and it has a nucleus from where decisions emanate. Around the nucleus spin several satellites, or regional and semi-regional trade centers. The model attempts to consolidate blocs, segments and categories into just one big unit while keeping some levels of differentiation. The goal is to demark assembling from distribution, supply from demand, short from long term investing, short from long term planning, etc (Soskice, 1999, p. 98).

In sum, corporations conceive, adopt and dismiss corporate models as part of their overall corporate strategies. Corporations expand, grow smaller, stagnate and even disappear due to market conditions and decisions they make to deal with market behavior. One of those decisions is to choose a corporate model to cope with regulatory 
regimes. I will explain here examples of corporations that adopted corporate models to circumvent the $\mathrm{UN}$ sanctions regime in Iraq.

\section{Corporate Governance}

Examining corporate governance here is important for two main reasons: a) the decision to circumvent a regulatory regime depends on corporate governance; b) the decision to choose a corporate model to cope with a regulatory regime is a result of corporate governance.

Corporate governance is a set of rules, processes, goals and interests inherent to a corporation (Aaronson and Reeves, 2002, p. 32; Aguilera and Jackson, 2003, p. 449). Corporate governance is built on goals and interests, which eventually lead to praxis. Corporate governance directly affects the way a corporation operates. Of course, corporate governance has both institutional and human faces. It is an institution because it behaves according to rules, structures and hierarchies, and it is human because human actors populate it and lead the decision-making process (Aaronson and Reeves, 2002, p. 32; Aguilera and Jackson, 2003, p. 449). Actors include: board of directors, investors, creditors, members of management, regulators and in some instances unions and employees. Scholars like Aaronson and Reeves (2002) do not consider unions, workers and even management as part of corporate governance. They argue that unions and employees have no saying whatsoever in the operations and decisions of a corporation, and that investors and boards of directors dominate the agenda and decision-making process. That is probably true. Yet, here the objective is to focus on diversity of interests, conflicts among investors and between the headquarters, its subsidiaries and parents 
firms. Specially, I examine how corporations decide to violate a sanctions regime and how they choose a corporate model to conceal the violations.

Global corporations seek two main goals: expansion and integration. Corporate models and corporate governance aim at expanding production, distribution, marketing, and accessing raw materials and financing, all at global levels. It is part of the operational side of the corporation. However, only corporate governance has the means to integrate the corporation according to global legal systems, political processes, culture, compliance, responsibility, and accountability (Aaronson and Reeves, 2002, p. 51; Aguilera and Jackson, 2003, p. 451). In other words, only corporate governance can create and manage a true global corporation

First, corporate governance focuses on politics as much as it does on business (Aguilera and Jackson, 2003, p. 454). Corporate governance integrates political and business decisions. Corporate governing boards are integrated to the politics of the markets in which they operate. Politics determine laws and policies friendly and unfriendly to corporations. Observe that nation-states establish regulatory regimes to which corporations must adapt or circumvent at their own risk. Also, corporate governing boards interact with multiple actors of diverse means, ends and idiosyncrasies (Aaronson and Reeves, 2002, p. 32; Aguilera and Jackson, 2003, p. 449). They must engage, negotiate, compromise and be willing to trade short-term gains for long-term goals and not consider it a loss. Besides, as Soskice (1999) points out, corporations seldom operate under complex market conditions like unfair competition, intense scrutiny, political instability, and even violence. It is the task of corporate governance to adopt strategies corporate models among them - that could successfully take the corporation though 
diverse market conditions. Additionally, corporate governance is restricted and protected by corporate laws, the result of over 300 years of corporate jurisprudence under capitalism (Soskice, 1999, p. 141; Aaronson and Reeves, 2002, p. 99; Aguilera and Jackson, 2003, p. 457).

Second, corporate governance is about accountability too, which includes efficiency and behavior (Aaronson and Reeves, 2002, p. 117; Aguilera and Jackson, 2003, p. 456). Efficiency here means profits. It aims at minimizing costs while maximizing production and quality control. To address efficiency, corporate governance relies on internal and external mechanisms (Aguilera and Jackson, 2003, p. 458). Internal mechanisms are boards of directors, internal auditors, and balance of power between directors, investors, management and employees. External mechanisms are competition, creditors, governmental regulations and regulators, the media and interest groups. Some corporations voluntarily invite and pay for external auditors whose task is to counterbalance internal auditors. On the other hand, accountability attempts to deal with behavior, both human and corporate behaviors. Individuals shape corporate structures, culture and behavior (Aaronson and Reeves, 2002, p. 117; Aguilera and Jackson, 2003, p. 456). They decide and act on behalf of the corporation. But individuals bring their own vices and habits in to the corporation as well. Corporate accountability attempts to tackle them before they become part of a corporate culture. It does it by establishing codes of conduct and corporate ethics.

It is common to find a corporation with multiple codes of conduct, one per market and region (Soskice, 1999, p. 147). For example, a corporation can have a code of conduct for its division in South America, another code for its parent corporations in 
Europe, and still another one for its subsidiaries in Asia. In effect, by doing so, the corporation acknowledges the existence of operational divides or "ways of doing things" across markets, namely subregional, regional and even local (Soskice, 1999, p. 148; Aaronson and Reeves, 2002, p. 125). The corporation can even acknowledge cultural divides. It just cannot treat cultural patterns equally, with the same code of conducts and corporate ethics. In fact, a corporation can have a code of conduct for its subsidiary in Japan and another code for its subsidiary in China. Here, the corporation may be addressing some cultural features inherent to Japanese market, but it may be coping with some political issues characteristics of the Chinese political system. The case of Cuba is illustrative. Corporations doing business there have created "especial" codes of conduct to deal with Cuba's unique economic and political systems. For example, Sol Meliá Corp, the Spanish hotel chain, operates several hotels in Cuba. Sol Meliá pays some of its Cuban employees in Cuban currency and some in American dollars. The objective is to stimulate efficiency, high productivity and quality, but the corporation also wants to create a corporate hierarchy to promote corporate mobility. That is, Sol Meliá retains and promotes its best employees by paying them in the highly appreciated, by Cubans, American dollars. Cubans seem to like it, but the practice may seem repugnant and unacceptable to workers in other nations.

As a whole, corporate governance addresses multiple issues, from market conditions, geography, scarce resources and local and regional politics to human behavior. Corporate governance is above all about making business decisions while restraining human impulses, balancing corporate with human interests (Soskice, 1999, p. 152; Aaronson and Reeves, 2002, p. 129). It involves multiple actors, interests, 
procedural maneuvering, bureaucratic encroachments and structural imbalances among other aspects. It is a very fragile process, one in which personal interests and greed can overshadow corporate goals and reputation. At times, corporate rules are bent, codes of conduct are twisted, and ethic is ignored, all for the sake of short-term goals. Then, the corporate mission gets lost and the corporation loses its way. Corporate governors place the corporation in a state of emergency and redefine their own responsibilities. Corporate responsibility becomes 'guaranteeing the survival of the corporation.' Indeed, corporate governance resembles a socio-political construct, but it also reflects the agency dilemma: a conflict of interests between the corporation and its own agents resulting from imbalances of powers. It usually leads to corporate scandals.

In the case of the UN sanctions regime against Iraq, violations of sanctions provoked a scandal of political dimensions. First, it affected the UN's reputation as the most important global political institution for it was responsible for enforcing and overseeing the sanctions regime. Second, it affected the U.S. as the most powerful global superpower and the main sponsor and advocate of the UN sanctions regime against Iraq. Yet, it could not control corporate behavior, not even of American corporations. Third, it illustrated the limits of sanctions regimes and their inability to deal with global corporations and their corporate models.

\section{Corporate Responsibility}

Should corporations do more than just business? We know that they do politics, but should they care about the environment, human rights and work conditions among 
other sociopolitical issues? Should they comply with sanctions regimes? What is the limit of corporate responsibility? What is corporate responsibility?

The concept of corporate responsibility emerged during the 1970s, after about 200 years of capitalism and corporate history. The concept grew out of the Watergate Scandal in the U.S. (Hall and Soskice, 1999, p.19; Federowicz, Aguilera 2003, p.11). The scandal reveled that corporations had channeled corporate money to political figures at the highest level of the American federal government. The decision had been made at the highest level of corporations. Some corporations had decided that it was a corporate interest -and as such they included it in the corporate agenda- to finance the reelection of the President Nixon even if they had to break some American laws. After Watergate, the concept of corporate responsibility became a key component of corporate models and an intrinsic part of the corporate world. Today, corporate responsibility has strong linkages with the structures of global production, branding, marketing, and profitability (Hall and Soskice, 1999, p.27; Federowicz, Aguilera 2003, p.41). Yes, corporate responsibility can boost profits when integrated into a well-coordinated public relation campaign. For instance, many corporations utilize patriotism and nationalism to justify their actions. Other corporations talk about corporate responsibility as a mean to eliminate poverty and create jobs when in fact they mean profits for themselves. Certainly, in the case of Iraq, many corporations claimed that they violated the sanctions regime to help the Iraqi people. Some corporations, from the beginning of the sanctions regime, publicly stated that they opposed the sanctions on moral grounds. Such a public stand, I would argue, legitimized their later violations of the UN sanctions. 
There are several definitions of corporate responsibility. Some focus on its legal side. Some are business driven. Others attach ethical and social components to it.

The legal definition addresses two key issues: jurisdiction and statutes. Jurisdictions shield corporations from accountability and lawsuits (Hall and Soskice, 1999, p.37; Federowicz, Aguilera 2003, p.42). They do it through procedural statutes like forum non-convenient and subject matter jurisdiction (Federowicz, Aguilera 2003, p.45). Most American laws utilize those two statues to block transnational litigations. That is why corporations based beyond American jurisdictions are not liable to American labor and environmental laws, among others. But scholars like Hall and Soskice (1999) depart from the assumption that corporations are legal entities bounded by articles of incorporation, namely rights and obligations. If statutes protect corporations from people, governments and other legal entities, then the same statues shall hold corporations liable for their acts with respect to others. Liability should include subsidiaries, parent companies and even the activities of subcontractors overseas. Hall and Soskice suggest that, "Corporations can be held vicariously liable for the torts of their overseas subsidiaries based on theories alter ego, of agent, and respondent superior, and identity. Note that European laws follow similar rules" (Hall and Soskice, 1999, p.62).

The theory alter ego argues that a corporation and its subsidiaries are equally responsible for their acts since they are linked through business and statutes (Hall and Soskice, 1999, p.79; Federowicz, Aguilera 2003, p.111). If they share profits, losses, and statutes, then they are just one corporation. The theory of agent states that the principal, or a corporation, has so much control over the agent, namely its subsidiaries, that the first is responsible for the acts of the latter. For its part, the theory respondent superior affirms 
that liability can be traced from the lowest to the highest corporate authority (Hall and Soskice, 1999, p.79; Federowicz, Aguilera 2003, p.111). Lastly, the identity theory argue that the interests and ownership of a parent and subsidiary companies overlap so much that the subsidiary could legally be considered to as if it does not exist (Hall and Soskice, 1999, p.79; Federowicz, Aguilera 2003, p.111).

There are other theories, but overall Soskice (1999) claims that "The issue of jurisdiction can be tackled through specific evidences of congressional intent to the contrary. For instance, U.S. corporations can be directly liable for some wrongful acts abroad which are illegal under U.S. laws such as violations of securities' and exchange commission rules and the Sherman Anti-trust laws" (Soskice, 1999, p.124). To which I add that the U.S. often employs tax, wire transferring and money laundry laws as well as the RICO Act to prosecute corporate wrongdoings. The U.S. used some of those laws to prosecute a group of corporations and individuals for violations of the UN sanctions regime in Iraq. For instance, we will see here in this Chapter that the U.S. charged Mr. Waytt and his corporation of money laundering and conspiracy, but the true crime was purchasing oil contracts from Saddam's regime (New York Times, www.nyt.com, Sep. $20^{\text {th }}, 2007$; New York Times, www.nyt.com, April $\left.15^{\text {th }}, 2005\right)$. According to New York's Court of Appeals, Mr. Waytt did it through a group of front companies and a complicated ring of offshore accounts that in the end belonged to his corporation. He was sent to prison for two years and fined for $\$ 9$ million dollars. His two corporations were put on probation for three years and ordered to pay restitution (New York Times, www.nyt.com, Sep. $20^{\text {th }}, 2007$; New York Times, www.nyt.com, April 15 $5^{\text {th }}, 2005$.). 
In all, Aronson (2002), Federowicz and Aguilera (2003) argue that ccorporate responsibility is about how corporations behave in the marketplace, produce goods and services, deal with competitors, overcome market demands and still have positive impact on the common good. The concept has evolved over the years. It has come from the pure laissez-faire of early capitalism to a "government intervention" in the economy during the twenty and twenty-first centuries. In the end, the debate on corporate responsibility revolves around the two classic schools of economics: neoliberalism and Keynesianism.

For Aronson (2002), businesses have only one responsibility: manage resources to create wealth. Aronson (2002), a neoliberal economist and corporate lawyer, argues that private expenditures on environmental and social ends are resources that can be distributed to employees, entrepreneurs, and stockholders in the form of salaries or investments. He assumes that, first, money is what motivates employees and entrepreneurs to produce efficiently; second, motivation based on self interest is necessary for an effective and well functioning market. The pursuit of social responsibility interferes with those two classic market assumptions. But Keynesians, economists like Krugman and Obstfeld (2003) state that corporate responsibility can lead to innovation, higher efficiency and productivity. Corporate responsibility should be seen as an investment: it hurts a corporation's bottom line in the short run, but it contributes to profits at the long run. In addition, corporate responsibility usually translates into sound public relations, which is very important in the era of global mass media. Yet, in the end both neoliberals and Keynesians share two common denominators. First, they coincide in that expenditures versus profits are at the center of the debate. That is corporations would not be socially responsible if it affects their bottom line, but they would become socially 
responsible if responsibility leads to profitability. Second, corporate actions impact public relations and trigger governmental policies, which then affect corporations and markets.

Next, scholars like Soskice (1999), Streeck (1997) and Hall (1997) attach social and cultural features to corporate responsibility. The underlying assumption is that corporations are not as autonomous as they claim. They are more than private entities protected by legal statutes. They are in fact social creations, and they show all the features of social entities. Moreover, they are an intrinsic part of human societies. They are highly dependent on human behavior, habits, and actions. As evidence, Soskice (1999), Streeck (1997) and Hall (1997) point to the fact that corporate features differ across societies. For instance, there is the French model, which is rather socialist, meaning that it emphasizes on redistribution of wealth as a means toward social justice and equality. There is also the Japanese and Asian model, known as Nippo-Rhenish model. It focuses on discipline, organization and loyalty to the corporation in exchange for secured long-term employment, decent salaries, stability, and pride. Thirdly, there is the Scandinavian, also known as the welfare model. This model is built on the assumption that corporations must care for the overall wellbeing the employees. That is, the success of the corporation depends on the wellbeing of its employees. Lastly, there is the Anglo-Saxon, built on laissez-fair and individualism. More recently, India has put forward its own model as it emerges as a world economic power. India incorporated in its constitution Gandhi's idea of trusteeship, which defines corporate responsibility as a moral duty and a matter of pride (Sosckice, 1999, p.227).

All those models have advantages and disadvantages. Yet, Soskice (1999) and other scholars propose that nation-states should renounce certain "cultural and ethnic" 
features in favor of a uniform global model that takes the Anglo-Saxon as the ideal type. But Streeck (1997), Hall (1997) and others repudiate such an idea, arguing that the Anglo-Saxon model jeopardizes accountability and lends itself to corruption since: a) it excludes employees from decision-making process; b) it focuses on short-term profits; c) its vertical hierarchy overshadows distinctions between personal and corporate interests. Still, others scholars find no differences whatsoever among those models. They contend that the capitalist system has eradicated most of those differences, and that globalization will eventually eliminate any vestige of contradiction between the models.

Finally, I would argue that corporations are today more conscious about corporate responsibility. Most corporations recognize the value of being responsive to the environment, human rights, women rights, child labor laws, and fair salaries among other issues. Corporations at least acknowledge that there is a global media and a global civic society watching them. Reckless corporate behavior can translate into bad publicity, which in turn may lead to the loss of customers and market shares. Yet, although there is public demand for corporate responsibility, it does not seem to include compliance with sanctions regimes. There are sharp disagreements about the issue. Eleven polls conducted around the world during 10 years of $\mathrm{UN}$ sanctions against Iraq showed that $52 \%$ of the people opposed the sanctions (CFIJ, 2002, p. 67). Opposition to the sanctions regime was so strong that it forced the UN to adopt what then became known as "smart-sanctions", those that targeted products and technologies that could be used for military purposes. But even if "smart sanctions" do not cause harm to civilians, I ask: Are sanctions regimes fair to corporations? Should corporations comply with a sanctions regime? 
This argument is twofold: one approach is economic, and the other is political. The economic approach argues that a sanctions regime is basically a political regime. It is a group of political measures that target trade to attain a political objective. So a sanctions regime is a political instrument that has particular effects on the behavior of economic actors. First, sanctions regimes go against two key premises of laissez-faire capitalism: open markets and free trade. Second, a sanctions regime is by default a sanctions regime on corporations attempting to operate in the sanctioned market, limiting, constraining and destroying the creation of wealth not only in that market but also at its adjacent. Third, there is yet another paradox: by reducing commerce to a minimum, a sanctions regime frees of competition an entire market, and corporations do not like competition. In fact, I argue that sanctions regimes create business opportunities, in particular for nascent small corporations not really capable of competing in regional and global markets. In the case of the sanctions regime in Iraq, I found that most violators of the sanctions were small, young corporations from developing nations, mainly from Russia, Ukraine, Belarus and the Middle East, which in the past, had enjoyed good trade relations with Iraq. Also, small young corporations acted as intermediaries since well-known corporations did not want to be associated with Saddam's regime but still wanted to do business with Iraq.

The political approach focuses on the feasibility of sanctions regimes as instruments of global politics. Enforcement of sanctions regimes is not feasible due to the fragmented structures of global trade and corporations. Sanctioned nations can go around the sanctions through the numerous agents and means of globalization. In fact, some of those who favor sanction regimes acknowledge that the true value of a sanctions regime is not economic but political. That is, economic sanctions do not really lead to economic 
collapse, but they are useful tools for diplomatic negotiations and political maneuvering, as in the cases of Libya and North Korea. Libya's economic and political system did not collapse, and nation-states like the U.S. and UK used their sanctions regime against Libya as a negotiated way out of their conflict with that nation. The same is true with North Korea. Its regime remains strong and defiant, and negotiations of the Five Parties Negotiations spin around lifting and/or imposing sanctions regime on North Korea.

Sanctions regimes are political instruments and corporations are often criticized for their involvement in politics. So, the question is, if corporations ought not to engage in politics at all, why would they endorse a sanctions regime? Why would they endorse a political policy that limits their very nature? There is another aspect here. The sanctions regime in Iraq originated in the UN, a political institution with no real legal power over corporations. The enforcement of the UN sanctions in Iraq relied solely on the will of nation-states and corporations. In fact, the U.S. was the only nation that prosecuted corporations and individuals for violating the sanctions, and the U.S. did it not for violating the UN sanctions but for breaking American tax laws and the RICO Act. In other words, if the sanctions regime was multilateral, its enforcement was unilateral.

All told, I conclude that it is around the contradictions between business interests, corporate governance and corporate responsibility that corporations try to come to terms with regulatory regimes, mainly political regimes such as sanctions regimes. Those are contradictions that corporate governance must sort out before establishing a corporate policy, one that could either strengthen or jeopardize the very existence of the corporation. In the next section I present evidence of how corporations circumvented the UN sanctions regime in Iraq through corporate models. 


\section{Corporate Models and the Evasion of the Sanctions Regime in Iraq}

GAO and the IIC estimated that during the period 1996-2002 corporations generated $\$ 67$ billion under the sanctions regime in Iraq (GAO Report, p. 22; IIC Report, Chapter I, p. 9). On top, the IIC estimated that Saddam Hussein generated \$10.1 billion in illegal revenues, $\$ 5.7$ billion from oil smuggling and $\$ 4.4$ billion in "surcharges" (IIC Report, Chapter I, p.10-11). According to GAO and IIC Reports, those are just estimates because no one really knows how much money he generated from illegal trade. But what is relevant here is how Saddam managed to circumvent UN sanctions. He could not have done it without a helping hand from the corporate world. In fact, the IIC cited 23 case studies to illustrate how front and middlemen companies contributed to the breakdown of the UN sanctions. Table 6.1 lists corporate models used under the UN sanctions regime.

\section{Table 6.1 - Distribution by Type of Company}

\begin{tabular}{|l|r|r|r|}
\hline Type of Company & \multicolumn{1}{|l|}{$\begin{array}{l}\text { Based in } \\
\text { Nation of Origin }\end{array}$} & $\begin{array}{l}\text { Based } \\
\text { Offshore }\end{array}$ & \multicolumn{1}{l|}{ Total } \\
\hline 1-Affiliate & 321 & 586 & 907 \\
2-Intermediary & 293 & 531 & 824 \\
3-Front Company & 236 & 482 & 718 \\
4-Subsidiary & 112 & 546 & 658 \\
5-Parent company & 158 & 263 & 421 \\
6-Shelf company & 67 & 161 & 228 \\
7-State owned company & 27 & 31 & 58 \\
8-Holding & 48 & - & 48 \\
9-Joint Ventures & & & \\
Total & 1,214 & 2,600 & 3,862 \\
\hline
\end{tabular}

Source: IIC Report

Table 6.1 reveals that 3,862 corporations traded with Iraq under the UN sanctions regime, and 1,213 operated from their nations of origins while 2,600 chose to operate 
from offshore. It also shows that corporations employed eight corporate models. The table shows that 907 companies operated as affiliates, a model that does not lend itself to corporate wrongdoings for it is too close to its parent corporation. But front company is the ideal corporate model for corporate wrongdoing. The IIC Report, Annex 1 (pages 5455) shows a list of front companies that evaded the UN sanctions against Iraq. Table 6.1 above shows 718 front companies operated under the UN sanctions regime, and that intermediaries were the second main corporate model under the sanctions regime. The IIC defines intermediary firms as "third-party purchaser" (IIC, Chapter I, p. 3). GAO calls them "middlemen companies" (GAO, p. 11). The IIC explains that "Companies with limited access to the Programme used intermediaries to maintain their access to the Iraqi market" (IIC, Chapter I, p. 3), to which I add that corporations hired intermediaries to circumvent UN inspectors, conceal their profits, and launder their money. Also, most intermediaries chose to register and obtain operational licenses in France, Russia, China, Germany, Jordan, and Syria. Since those nations were friendly to Iraq, Saddam rewarded them with "the most favored" status. It explains why there were so many French intermediaries violating UN sanctions. It prompted a French official to argue that "Contracts submitted to the French mission... were often formulated by economic entities that were not French and whose goods and merchandises were not produced in France and had not even transited through France" (Communiqué by the Embassy of France in the U.S., October 11, 2004). It means that corporations did not necessarily represent their nations of origin but where they registered to operate. France revealed a list of American corporations that operated through intermediaries registered in France. Table 6.2 reproduces a sample of the list. 
Table 6.2 - American Corporations Trading with Iraq from France

\begin{tabular}{|l|r|}
\hline \multicolumn{1}{|c|}{ Company } & Profits in USD millions \\
\hline Agco & $113,491,600.00$ \\
Baker & $10,611,624.00$ \\
Becton Dickinson & $4,611,828.00$ \\
Boston Scientific & $315,911.00$ \\
Cameron & $5,764,117.00$ \\
Case France & $32,418,805.00$ \\
Dosapro & $1,199,904.00$ \\
Dow Agroscience & $3,856,741.00$ \\
Dresser International / Dresser Rand & $16,136,532.00$ \\
Envirotech & $76,372,954.00$ \\
Fisher Rosemount & $9,846,413.00$ \\
Flowserve & $19,772,973.00$ \\
FMC Europe & $3,327,597.00$ \\
General Electric & $1,181,594.00$ \\
Grove & $9,556,000.00$ \\
Hexacorp & $5,072,602.00$ \\
Ibex & $32,595,435.00$ \\
Ingersonll & $62,105,914.00$ \\
Kema-Proser & $7,598,562.00$ \\
Luxor & $17,265,777.00$ \\
Marsoneilan & $40,480.00$ \\
Purolite / Baker & $357,833.00$ \\
Sanchez & $2,046,178.00$ \\
Siemens S.A.S. & $82,283,149.00$ \\
Toekheim & $829,229.00$ \\
Toekhein & $1,234,696.00$ \\
Tossco & $3,025,489.00$ \\
Trouvay \& Cauvin / Mandrel & $20,625,320.00$ \\
Wemco / Envirotech & $9,064,142.00$ \\
Wyeth / Lederle & $101,849.00$ \\
Total & \\
\hline & \\
& \\
\hline
\end{tabular}

Source: Embassy of France in the United States - October 11, 2004

Intermediaries worked between: 1) local and global corporations; 2) Iraqi and foreign corporations; 3) banks and corporations; 4) non-state actors and banks. The IIC and the CIA found that intermediaries smuggled nearly $\$ 1$ billion dollars per year through the free-trade zones along the Jordan-Iraqi and Syrian-Iraqi borders. 
Next, according to the IIC, nation-states and corporations operated 718 front corporations under the UN sanctions regime (IIC, Chapter I, and p. 17). Corporations had two reasons for doing so. The first one was for business reasons. The IIC stated that, " $A s$ the price of oil went higher, oil sales increasingly took the form of contracts with front companies, backed financially and technically by international trading companies" (IIC, Final Report, p. 4). The IIC here refers to corporations that lacked financial and logistical expertise to execute import-export contracts. Some of those corporations were really small businesses seeking their first opportunities. In fact, we saw in Chapter IV that individuals, NGOs, political parties and other NSAs operated through 327 front corporations.

The second reason was more about public relations than any other issue. The IIC explained that corporations "Concerned about public relations opted for hiring front companies to avoid being associated with Saddam's regime" (IIC, Final Report, p. 5). This issue -public relations- applied more to large global corporations preoccupied with political correctness, public opinion, and their overall global image. As examples, the IIC cited transnational corporations such as Shell Corp, Exxon-Mobil, Motorola, Volvo, Siemens and Mitsubishi. Note that some nations saw in front corporations a means to circumventing the UN sanctions regime against Iraq. These nations owned or co-owned front corporations, to which they provided financial, legal and political support. Some nations even utilized their embassies and diplomatic prerogatives to cover up their relations and activities with their front corporations. In total, 58 nations owned front corporations under $\mathrm{UN}$ sanctions regime. Table 6.3 below shows the top ten nations that sponsored front corporations. 


\section{Table 6.3 - Top Ten Nations Sponsoring Front Corporations}

\begin{tabular}{|l|r|}
\hline Countries & $\begin{array}{c}\text { \# of Front } \\
\text { Companies }\end{array}$ \\
\hline Russia & 41 \\
Ukraine & 37 \\
Belarus & 29 \\
Jordan & 29 \\
Syria & 26 \\
France & 17 \\
China & 14 \\
Iraq & 13 \\
Germany & 9 \\
Vietnam & 8 \\
Romania & 4 \\
Total & 227 \\
\hline
\end{tabular}

Source: IIC Report

The IIC found that Iraq created and operated two dozen front corporations right after the UN established the sanctions regime. The IIC defined Iraqi front corporations as "A Company the Government of Iraq secretly owned in part" (IIC, Chapter VI, p. 302). Here, "owned in part" means owned in partnership with another corporation, individual, nation or any other entity or third party, which seldom included a corporation owned by the state of Iraq. In fact, the CIA explained that Iraq had front partnership corporations with nations like Russia, Ukraine and Belarus. Some other front partnerships included 50$50 \%$ partnerships with private corporations from Egypt, Jordan, Syria, UAE, Lebanon and Qatar. The CIA set their overall market value at $\$ 4.6$ billion dollars and profits at \$9.3 billion during the 1996-2002 periods (Duelfer Report, Regime Finance and Procurement, p.179). The Table 6.4 right below lists 16 of those front partnership corporations. I gathered the data from the IIC and the Duelfer Report. 
Table 6.4 - Iraqi Front Firms in Partnership with Private Firms in the Middle East

\begin{tabular}{|l|l|l|l|}
\hline Company & \multicolumn{1}{|c|}{ Industry } & \multicolumn{1}{|c|}{$\begin{array}{c}\text { Nation of } \\
\text { Registration }\end{array}$} & \multicolumn{1}{c|}{$\begin{array}{c}\text { Based } \\
\text { in }\end{array}$} \\
\hline The Mudiaf Company & General Trade & Dubai, Egypt, Jordan, Lebanon, Qatar, Turkey & Jordan \\
Al-Wadi Al-Akhab & General Trade & Egypt, Jordan, Lebanon, Qatar & Jordan \\
Al-Mansurah Company & General Trade & Egypt, EUA, Jordan, Lebanon, Syria, Yemen & Jordan \\
Al-Awabi Company & General Trade & Egypt, EUA, Jordan, Lebanon, Syria, Yemen & Jordan \\
Al-Nid & General Trade & Dubai, Egypt, Jordan, Lebanon, Qatar, Syria & Jordan \\
Al-Wasel \& Babel & General Trade & Dubai, Egypt, EUA, Jordan, Lebanon, Qatar, Syria, Turkey & Jordan \\
Al-Hoda & General Trade & Dubai, Egypt, EUA, Jordan, Qatar & Jordan \\
Alia & General Trade & Dubai, Egypt, EUA, Jordan, Lebanon, Qatar, Syria, Turkey & Jordan \\
Al-Yarmuk & Travel & Dubai, Egypt, EUA, Jordan, Lebanon, Qatar, Syria, Turkey & Lebanon \\
Al-Dala & Travel & Dubai, Egypt, EUA, Jordan, Lebanon, Qatar, Syria, Turkey & Jordan \\
Al-Huda Religious Tourism & Travel & Dubai, Egypt, EUA, Jordan, Libya, Qatar, Syria, Yemen & Syria \\
Al-Zaytun & Restaurants & Jordan & Jordan \\
Al-Riyadh & Transportation & Jordan, Syria, Turkey & Jordan \\
Al-Riat & Unknown & Egypt, Jordan, Syria & Syria \\
Al-Manuria & Unknown & Egypt, Jordan, Syria & Syria \\
Al-Enbuah & Enknown & Egypt, Jordan, Syria & Syria \\
\hline
\end{tabular}

Source: The Duelfer Report (CIA Report)

Then, 658 subsidiaries traded with Iraq under the sanctions regime. The fact that 546 of them operated offshore tells us that they sought legal and financial protection outside their nations of origin. The most illustrative example is Halliburton, which France accused of using French subsidiaries to circumvent the UN sanctions regime. France's embassy in the Washington D.C. revealed that Halliburton's subsidiaries in France conducted business for almost $\$ 200$ million dollars under the sanctions regime (Communique by the Embassy of France in the US, Washington, October $11^{\text {th }}, 2004$ ). The case of Halliburton explains why subsidiaries are not the best means to evade a sanctions regime. They are just too "close" to their parent corporation, which could end up paying for the violations. For their part, 421 parent corporations participated in the sanctions regime, of which 263 were registered offshore from their nations of origin. 
Table 6.5 below shows that 531 of those companies were incorporated in offshore "paradises". I collected the data from the IIC Report.

\section{Table 6.5 - Top Ten Corporate Paradises}

\begin{tabular}{|l|r|}
\hline Nation & Companies \\
\hline Switzerland & 97 \\
Lichtenstein & 88 \\
Panama & 71 \\
Cayman Islands & 70 \\
The Bahamas & 56 \\
British Virgin Island & 41 \\
Qatar & 40 \\
Aruba & 36 \\
Dubai & 32 \\
Total & 531 \\
\hline
\end{tabular}

Source: IIC Report

Many parent entities were large global corporations such as General Electric, Siemens S.A., Boston Scientific, Hyundai, Volvo, Lukoil, Gazprom and The Arab Establishment (IIC, Chapter I, p. 34). But they did not seize the market for themselves. They were not the most profitable either. In fact, mid-size regional corporations controlled $61 \%$ of the Iraqi market (IIC, Chapter I, p. 37). Among them were Bayoil, Taurus, Glencore, and Vitol. These four corporations were the most profitable under the UN sanctions regime, accounting for $21 \%$ of all revenues (IIC, Chapter I, p. 37).

Finally, shelf corporations had a very active participation under the sanctions regime, but they served mostly for banking purposes, for issuing and collecting payments. Some of them were no more than empty offices with a p.o. box for mailing purposes. In total, 228 shelf corporations traded with Iraq under the sanctions regime, and 161 were offshore (IIC, Chapter I, p. 39). Likewise, most holding companies operated 
through their affiliates, subsidiaries, intermediaries, parent, and front companies. Their direct participation was minimal, rather unnoticed. For the most part, participation of holding and parent corporations in the sanctions regime was detected only after thorough investigations of front corporations.

All in all, I found that corporate models served several purposes. First, they helped corporations operate under a sanctions regime that was politically motivated. Second, they helped deal with Saddam's policy of granting contracts to nations friendly to his regime. Third, they helped conceal their true identities. In all instances, companies evaluated their positions and concluded that utilizing corporate models would minimize risks and maximize profits. I explain next through several case studies how corporate models really operated and helped corporations evade the UN sanctions regime in Iraq.

\section{$\underline{\text { Case Studies }}$}

In this section, I further discuss the hypothesis of this chapter. First, corporations are among the main agents of globalization. They are a globalizing force with a direct impact on global politics. Second, corporations employ corporate models to circumvent regulatory regimes, among which are sanctions regimes. To illustrate this hypothesis, I present seven cases that involve several corporate models. They are Alia, Vinafood and Vinamilk, Chinochem, Phoenix Investment International, Russian Engineering Company, El Paso Corporation, and Vitol International. Those corporations exemplify: a) corporate attitudes toward a sanctions regime; b) different facets of the corporate evasion of the sanctions regime; c) and more important, how corporations utilized corporate models to circumvent UN sanctions. In particular, I pay special attention to multiple layers and 
linkages among small corporations, and multiple parallel bank accounts across corporations of no apparent relationship. Most of those corporations created small corporations, usually with no more than a dozen employees. After two or four transactions, they would shut down operations and create new small corporations. Lastly, I pay close attention to periodic deposits and withdrawals of large amounts of money. Mayer and Califano argued that "Money took circuitous routes that included a chain of front companies, complicit or captive banks" (Meyer and Califano, 2006, p. XX). Figure 6.4 gives us an idea of how Iraq utilized corporate models to evade UN sanctions.

Figure 6.4 - Iraq's Corporate Modeling to Circumvent the UN Sanctions Regime

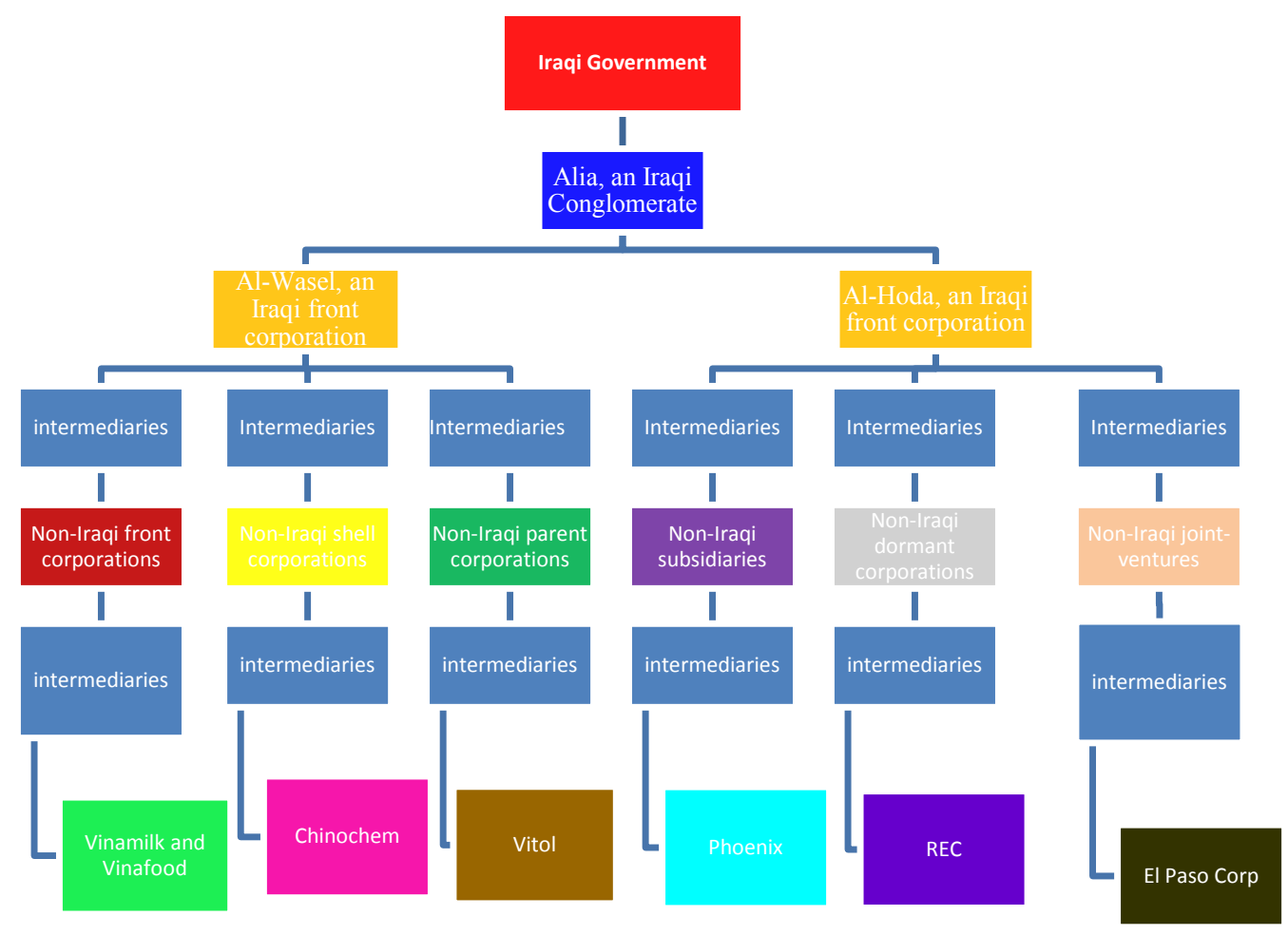


Figure 6.4 looks intricate and somehow overwhelming, but that is precisely the purpose of corporations. They structure their corporate models in such as a way as to overwhelm regulatory regimes and law enforcers. If the model in Figure 6.4 seems intricate, it is not due to their lack of imagination by corporations but to the nature of the business environment they want to circumvent. Indeed, models like the one in Figure 6.4 were very effective under the UN sanctions regime in Iraq.

\section{Iraqi Government's Front Corporations}

The first case study involves the Iraqi government. The UN sanctions regime constituted a matter of national security for Iraq. Therefore, dealing with it necessarily involved the Iraqi government. Iraq confronted the sanctions regime with a corporate model that involved an array of front corporations organized horizontally and through multiple layers. This case also involves Alia, the Iraqi conglomerate that led Iraq's offensive against the UN sanctions. Observe in Graph IV that the Iraqi government acted as an "umbrella" over Alia and its two front corporations. Business decisions came from top to bottom, but all corporations were out in the market to obtain as many businesses as possible. That is why some corporations overlapped, and at times their functions

duplicated. Also, observe in Figure 6.4 that Iraqi front companies did not deal directly with non-Iraqi corporations. Instead, they hired a large number of intermediaries usually owned by businessmen from the Middle East and loyal to Saddam's regime.

In effect, Alia for Transportation and General Trade, known as Alia, Alia controlled 39\% of Iraqi trade under the UN sanctions regime (IIC, Chapter I, p. 306). Alia was one big front corporation with several subsidiaries and intermediaries 
disseminated all throughout the Middle East. The most visible were Al-Hoda International Trading Co. and Al-Wasel \& Babel General Trading LLC.

The IIC found documents at Iraq's Ministry of Transportation confirming that the said Ministry purposely created Alia as a regional front corporation. The objective was to promote and manage Iraqi trade in the Middle East. The Ministry granted Alia the power to create other corporations, enter in contracts, finance trade with foreign corporations, collect payments and even establish its own bank. Alia's Articles of Incorporation showed that Alia entered in several 50-50 joint ventures with Iraqi private businessmen (IIC, Chapter I, p. 306). The first was with Husain Al-Khawam, an Iraqi living in Jordan, a close associate of Saddam Hussein. Mr. Al-Khawam registered Alia as a single Jordanian corporation in Amman, Jordan, in August 1994 (IIC, Chapter I, p. 306). Its first big project was to rebuild Iraq's naval fleet and ports. It also included recruiting and training a naval labor force and purchasing and shipping hardware, trucks, and construction equipment to Iraq (IIC, Chapter I, p. 303). Alia reorganized and trained a naval labor force in about three years. It also repaired a good portion of its cargo fleet and two ports in southern Iraq. That Iraq had a functioning naval cargo fleet and ports is a bit ironic. Cargo fleets and ports are means of trade, and the UN sanctions regime banned Iraq from foreign trading. In fact, Alia signed contracts with Siemens, Peugeot, and Volvo to import spare parts for Iraqi cargo vessels and trucking industry (IIC, Chapter I, p. 308). It also signed a contract with Kato Corp, a Japanese manufacturer of industrial cranes, and a three-year contract with Toyota to acquire $\$ 135.5$ million in spare parts for Iraq light trucks, the most popular means of cargo transportation in Iraq's domestic market (IIC, Chapter I, p. 308). 
Alia also operated as a "debt collector." The IIC found that "In 1999 the Iraqi Ministry of Transportation arranged with Alia to have it act as a...collection agent for foreign suppliers" (IIC, Chapter I, p. 303). It was another illegal operation because the 661 Committee expressly "Prohibited any third party from engaging in financial transactions with the government of Iraq except as permitted under Security Council resolutions" (IIC, Chapter I, p. 303). In Chapter V, I explicated that the 661 Committee designated the French bank BNP-New York as the sole payment collector under the sanctions regime. Yet, the Iraqi regime ignored the mandate and ordered Alia to open several bank accounts at Arab Land Bank, in Egypt, at Jordan National Bank and Rafidain Bank, both in Jordan, allowing Alia to collect about $\$ 788$ million in different currencies from 2000 to 2003 (IIC Report, Chapter I, p. 303). Alia converted the money into dollars and submitted it to the Iraqi Ministry of Transportation. The IIC concluded that the main source of the money was fees on smuggling through Iraqi ports and free trade zones along the Jordan-Iraqi and Syrian-Iraqi borders (IIC, Chapter I, p. 305).

Alia had several subsidiaries and intermediaries. Al-Hoda International Trading Co. was one of the most active, as a front company though. The Iraqi government appointed Hikmat Jergi, an Iraqi citizen living in Syria, as the sole proprietor of Al-Hoda. Mr. Jergi registered it in the United Arab Emirates "For the purpose of entering into contracts with foreign corporations" (IIC, Chapter I, p. 306). Al-Hoda acted as a subcontractor for Alia. On its behalf, it negotiated most of the contracts Iraq entered with Middle Eastern corporations under the UN sanctions regime. Al-Hoda specialized in long-term contracts with large discounts on medicines, foodstuffs, pesticides and agricultural machineries. Al-Hoda spent about $\$ 1,220.8$ million worth of foodstuffs, 
construction materials, water tanks, medicines and detergents in just one year (IIC, Chapter I, p. 307). Like Alia, Al-Hoda collected payments from importers and exporters, only that it collected cash. It deposited it in accounts that the Ministry of Transportation had at Arab Land Bank, in Egypt, and at Jordan National Bank and Rafidain Bank in Jordan. After that, the money was wire-transferred to the Iraqi State Oil Marketing Organization. SOMO's account receivables show that $\$ 92$ million dollars were received from Al-Hoda from 1999 to 2003, and another \$14 million in kickbacks and briberies were received from 2002 to 2003 (IIC, Chapter I, p. 308). Sometimes the money was carried in cash to Iraqi embassies in Moscow, Amman, El Cairo and Abu Dhabi.

Lastly, Al Wasel \& Babel General Trading LLC was the third most important Iraqi front corporation. It mainly acted as intermediaries between the Ministry of Oil, the Ministry of Transportation, and non-Iraqi corporations. Alia created it in a 50-50 joint venture with Ibrahim Lootah, a citizen of the United Arab Emirates with long business relations with Iraq, where he had a permanent office until the UN established the sanctions regime (IIC, Chapter I, p. 308).

The IIC found that Al Wasel operated from Abu Dhabi. It had several bank accounts at Abu Dhabi Commercial Bank and at Jordan National Bank, both in Abu Dhabi. Al Wasel instructed its customers to deposit their payments at Abu Dhabi Commercial Bank. Al Wasel then wire transferred the money to its account at Jordan National Bank, from where it would be transferred to SOMO and the Iraqi Ministry of Oil. The IIC and GAO reported that Al Wasel \& Babel transferred $\$ 800$ million to Iraqi coffers in just 2 years (IIC, Chapter I, p. 308). 
Overall, the Iraqi government took many business risks, but it was cautious in the way its corporations operated. Iraq worked hard to keep its front corporations in anonymity, to the point that it hired a group of intermediaries for both A-Hadal and AlWasel. One of them was the Belhasa Group, which was a trading conglomerate specialized in the distribution of diverse goods and services throughout the world (IIC, Chapter I, p. 308-334). It was administered through a holding registered and based in Dubai as Belhasa International Co. (IIC, Chapter I, p. 334). Belhasa had four major subsidiaries. The first was Belhasa Motors Co. LLC, known as Belhasa Motors, which distributed automotive and industrial spare parts. The second was Union Trading Co. LLC, better known as Union Trading. It distributed construction technologies, materials and combustibles. The third was Al-Rowa'a General Trading Co. LLC, known as AlRowa'a. The fourth was Safire Ltd., or Safire, which invested in real estate and tourism. But Belhasa itself did not want to trade directly with Iraqi front corporations. Belhasa's top representatives told the IIC that "Some of the most important Belhasa's customers in the Middle East were not in good terms with the Iraqi government since it had defaulted in some businesses" (IIC, Chapter I, p. 335). Therefore, Belhasa hired Ebstikar Investment Company LLC and the Hartha Group, both based in Jordan. The Belhasa Group became the largest Iraqi trade partner under the sanctions regime. It picked 129 contracts, worth $\$ 742.2$ million (IIC, Chapter I, p. 334).

Still, Al-Hoda and Al-Wasel played a key role as representatives of the Iraqi government in the trade protocol that Iraq signed with Vietnam. It takes us to the second case study. This case is relevant because it illustrates how governments can secretly create corporations to circumvent a sanctions regime. The governments of Vietnam and 
Iraq utilized front companies to execute a trade protocol that they had secretly conceived and signed (IIC, Chapter I, p. 329). The governments of Vietnam and Iraq created a Joint Committee to develop trade partnerships. The Committee was responsible for: a) establishing terms of trade and contracts; b) setting prices, volumes and terms of deliveries; c) meeting every six months to review compliance with contracts and discuss future business deals (IIC, Chapter I, p. 330). Vietnam's Minister of Trade headed the Vietnamese party while the Grain Board, also known as "the Board," led the Iraqi party. Vietnam created two state-owned front companies to engage the Iraqi party. They were Vietnam Northern Food Corp. and Vietnam Dairy Joint Stock Company. The Vietnamese government registered them in the UN Sanction Commission as Vinafood and Vinamilk (IIC, Chapter I, p. 330). For its part, the Iraqi government assigned the trade mission to Alia, which in turn delegate it to Al-Hoda, and Al-Wasel.

$\underline{\text { Vinafood and Vinamilk }}$

Vinafood was a Vietnamese agro-industrial company that specialized in processing, packing and exporting rice, beans, sugar, coffee, ground nuts and other commodities. Vinafood illegally sold $\$ 891$ million in agricultural products to Iraq from 1996 to 1998. It sold another $\$ 429$ million in medicines, cloths and school supplies from 1997 to 1998 (IIC, Chapter I, p. 331). In addition, UN investigators found that Vinafood engaged in oil trade. It turned out that Vinafood had created The Nghe An Petro Trading Services, a subsidiary through which it could purchase and import oil from Iraq. Vinafood paid in cash for the oil, and it used the Vietnamese embassy in Bagdad as collection center in plain violation of UN mandates and international law (IIC, Chapter I, 
p. 331). Records found at the Iraqi Ministry of Oil revealed that Iraq sold to Vinafood an average of $\$ 700$ million worth of oil per year. Iraq sold to Vinafood $\$ 1,100$ million worth of oil to Vietnam in 2001 when trade under the UN sanctions regime was at its highest (IIC, Chapter I, p. 331).

Like Vinafood, Vinamilk was a state-owned front corporation only that it specialized in processing and distributing dairy products. Vinamilk sold to Iraq $\$ 517$ million in baby foods from 2000 to 2003 (IIC, Chapter I, p. 332). Vinamilk received its payments from Alia through bank accounts at Jordan National Bank in Amman, Jordan. The IIC estimated that Vinamilk paid about $\$ 23.5$ million in bribes and kickbacks to businessmen in Jordan and Syria (IIC, Chapter I, p. 332). Those businessmen helped Vinamilk smuggled its goods into Iraq through the Jordanian and Syrian borders. The IIC could not estimate how much Vinamilk exactly paid for inland transportation, but it put it at $\$ 32$ million in two years. Surprisingly, Vinamilk dared to make a delivery under the Coalition Provisional Authority led by the U.S. after the fall of Saddam Hussein in 2003 (IIC, Chapter I, p. 332). It was its last. Vinamilk sent payments to a bank account belonging to State Company for Foodstuffs at Jordan National Bank, but the Coalition Provisional Authority seized and reported it to the 661 Committee. The IIC noticed that the payment to be $10 \%$ above the total value of the contract. It concluded that the extra $10 \%$ was to cover fees that the Iraqi regime imposed on foreign corporations for transporting goods in Iraqi territory. The IIC also found $\$ 11$ million in a second bank account at Jordan National Bank in Amman. Vinamilk had deposited the money on Alia's behalf. Vietnam claimed it for itself (IIC, Chapter I, p. 332). 
In all, the IIC found that Vinafood and Vinamilk together made near $\$ 1.2$ billion dollars from 1998 to 2001. Iraq made close to $\$ 4$ billion through its front corporations Alia, Al-Hoda and Al Wazel. The Iraqi-Vietnamese trade protocol resulted in a $\$ 1.2$ billion yearly trade operation, from 1997 to 2003 (IIC, Chapter I, p. 333).

\section{$\underline{\text { REC and Its Subcontractors }}$}

The third case involves Russian Engineering Corporation (REC) and its subcontractors. I include them here for three main reasons: a) its corporate models; b) the way that corporations from the former Soviet Republics utilized their long trade relations between the Soviet Union and Iraq to profit from the sanctions regime; c) how quickly nascent ex-Soviet corporations learned their ways into the global economy. Indeed, the UN sanctions regime in Iraq was a blessing for ex-Soviet corporations. They purchased $\$ 19.4$ billion worth of Iraqi oil, and in return they exported about $\$ 7.1$ billion in goods and services to Iraq at a time when ex-Soviet republics were going through a severe economic crisis (IIC, Chapter I, p. 349).

REC was registered in Moscow in 1994 and operated from there. REC inherited several military contracts with Iraq from the Soviet era. It did not engineer or manufacture anything. It was just an exporter of Russian spare parts to the Middle East, and Iraq represented almost $40 \%$ of its revenues. Thus, the Iraqi market was crucial for its survival, and circumventing the UN embargo became a corporate goal. The IIC explained that REC "Always maintained an office in Bagdad with Iraqi personnel, and REC Staff members, including Sergei Issakov, Chairman of the Board of Directors, frequently traveled to Iraq during the sanctions regime and reportedly met with high- 
level Iraqi officials, including Tariq Aziz and Saddam Hussein" (IIC, Interview to Andrei Okhotking on May $\left.5^{\text {th }}, 2004\right)$. For his part, Sergei Issakov confessed to the IIC that "Since 1997 on he traveled to Iraq four or five times a year" (IIC, Interview to Sergei Issakov, May $\left.28^{\text {th }}, 2005\right)$. REC relied on three front corporations and one intermediary to trade with Iraq. In fact, REC does not appear in any document of the Iraqi government. The data that I gathered from IIC and Duelfer Report, and the Report from the Coalition for International Justice show that Rosnefteimpex, Breton Ventures, North Refineries Co., and Bukkehave A/S. REC registered Rosnefteimpex and Breton Ventures in Ukraine in 1997. It registered North Refineries Co. in Baiji, in 1996. For its part, Bukkehave A/S was a Danish corporation (IIC, Chapter I, p. 349-359).

Through them, REC secured 40 contracts worth about \$210 million. It also struck 22 "side" deals worth $\$ 90$ million (IIC, Chapter I, p. 349). REC supplied Iraq with foodstuffs, cars and truck, construction materials and industrial equipments, most of them manufactured in Germany, Japan, Italy and Russia. The IIC calculated that REC paid Iraq about $\$ 9$ million in kickbacks just for obtaining those contracts. In addition, REC obtained contracts to purchase and resell Iraqi oil. According to the data, REC purchased 24.5 million barrels of oil, worth $\$ 517$ million (IIC, Chapter I, p. 350). The money was deposited in four different bank accounts owned by Iraq at BNP Genève in Switzerland, Arab Land Bank in Egypt, and Rafidain Bank in Lebanon. In addition, REC paid the Iraqi government $\$ 2.5$ million for the right to resell that oil (IIC, Chapter I, p. 350). According to the IIC, an Iraqi official testified that "Payments were done in cash and delivered by Mr. Issakov in person to the Iraqi embassy in Moscow between February and August 2002" (IIC, Chapter 1, p. 352). The IIC itself was able to obtain receipts with footnotes 
confirming that "Payments were also made through the Iraqi embassy in Moscow between October and December 2001; receipts for some of these payments reflect that Mr. Issakov personally brought the payment money to the embassy" (IIC, Chapter I, p. 352). The receipt in question is tallied as No.7. It refers to contract $M / 09 / 25$, dated April 28, 2001, and signed by Iraqi ambassador in Moscow, Dr. Mazhar No'man Al-Douri (IIC, Chapter I, p. 353).

IIC's records show that REC entered in partnership with Bukkehave through Breton Ventures (IIC, Chapter I, p. 349). The Iraqi regime was shopping around for spare parts for its transportation industry, but it had to be non-Soviet technologies. So it granted a contract to Breton Venture, which in turn turned to Bukkehave $\mathrm{A} / \mathrm{S}$, the Danish distributor of spare parts for buses, trucks, and automobiles. It was not a random pick. Bukkehave' best clients were global giants such as Kenworth, Renault, Mercedes Benz, Toyota and Isuzu. Bukkehave had a net of affiliates in the United States, France, Germany, Sweden, Brazil, Japan, Mexico and China, but not in the Middle East. Bukkehave declared to the IIC that it contracted with Breton Ventures believing that the contract was not about Iraq but the Middle Eastern market as a whole (IIC, Chapter I, p. 349). It was a good deal. Breton Venture obtained 11 contracts worth $\$ 731$ million during four years. Bukkehave financed and supplied all of them. It had a net profit of nearly \$300 million (IIC, Chapter I, p. 350). Bukkehave also entered "on the side" contracts with Iraq. It eventually became an intermediary for Iraq's front companies. As such, it appointed Mr. Peter Post as its regional sales export-import person, and opened offices in Amman, Jordan. Mr. Post hired Mr. Riad Marei, a Jordan sales export agent, to act as an intermediary between Iraqi front companies and himself. When questioned about the 
need for an intermediary, Mr. Post argued that Bukkehave was new in the market and that it did not have a permanent dealer in the region (IIC, Chapter I, p. 351). Nevertheless, the IIC summarized Bukkehave's modus operandi as follow: Bukkehave opened credit lines for Iraqi State Company for Oil Projects, a front corporation of Iraqi Ministry of Oil. In turn, Iraq paid Bukkehave through Mr. Marei's account at Rafidain Bank. Mr. Marei channeled the money to bank accounts that Bukkehave had in Rafidain Bank (IIC, Chapter I, p. 352).

\section{$\underline{\text { El Paso Corporation, Coastal Petroleum Company and Mr. Oscar Wyatt }}$}

The fourth case is exceptional in that it brings together the four agents of globalization discussed in this dissertation. They are: 1) nations-states; 2) global non-state actors such as empowered individuals; 3) global banks; 4) global corporations. This case is about El Paso, a corporation that circumvented the sanctions regime through merger and acquisitions, a key means of globalization and a recurrent practice in the global economy during the 1990s. Court records in the State of New York show that El Paso acquired Coastal Petroleum Company and by doing so it inherited Coastal's customers

and, more importantly, access to Iraqi oil (the New York Times, Sep. 20 ${ }^{\text {th }}, 2007$ ). El Paso took over Coastal's secret operations and expanded them. When it was caught, it simply blamed it all on Coastal, arguing that it was not aware of Coastal's previous business deals (the New York Times, Sep.10 ${ }^{\text {th }}, 2007$ ).

Coastal Petroleum, a Texan firm, had been a key Iraqi customer since Iraq nationalized its oil industry early in the 1970s (IIC, Chapter I, p. 191). The owner of Coastal was Mr. Oscar Wyatt. By all means, he was one of those empowered individuals 
described in Chapter IV. The IIC and the New York Times revealed a good deal of Mr. Wyatt's activities related to the UN sanctions regime against Iraq. First, Mr. Wyatt lobbied intensely the U.S. government against the American led invasion of Iraq in 1990, an act that Saddam Hussein appreciated and did not forget. Second, Saddam invited Mr. Wyatt to mediate between Iraq and the UN Security Council. Mr. Wyatt was among the main negotiators of the UN sanctions regime in Iraq. Third, Mr. Wyatt had full access to the Iraqi political nomenclature and oil industry. Fourth, Coastal Petroleum was the only American corporation that Saddam Hussein granted oil contracts under the UN sanctions regime (IIC, Chapter I, p. 171; the New York Times, Sep.10 ${ }^{\text {th }}$, 2007).

Court Records published by the New York Times on Sept $10^{\text {th }}, 2007$, show that early in the 1990s Coastal Petroleum hired an Argentine company and made it its "front company" to purchase oil from Iraq. According to the Times, the Court does not mention the name of the Argentinean Corporation, but it does state that it acquired about $\$ 550$ million dollars worth of Iraqi oil. Coastal's success did not go unnoticed to El Paso, a Texan gas trader. El Paso acquired Coastal Petroleum in 1998. Michael J. Garcia, the U.S. Attorney for Southern District of New York argued that "The acquisition of Coastal seems to have been motivated to avoid successor liability in the context of mergers and acquisitions. The timing of the merging itself seems suspicious as it stem from Coastal's illegal activities, of which El Paso was aware" (the New York Times, Sep.10 ${ }^{\text {th }}, 2007$ ).

Again, citing court records, the New York Times reported that, in the year 2000, and following instructions from El Paso, Coastal created Nafta Petroleum and Mednafta Trading Co. Nafta Petroleum was incorporated in January 2001 and Mednafta Trading Co. in March 2001. Both opened bank accounts at BNP Suisse with the pseudonyms 
"Cyprus" and "America" respectively. Curiously, when the Court followed Coastal's money, it found a company called NuCoastal, founded, registered and based in Houston, Texas. NuCoastal had active deposits worth $\$ 40$ million, which had been wire-transferred from El Paso to Coastal Petroleum, to Nafta Petroleum and Mednafta Trading Co., and

then to NuCoastal. The money was to pay for one shipment of Iraqi oil. Nafta and Mednafta were the beneficiaries. In total, after two years of investigating, the Southern District Court of New York found 47 deposits totaling $\$ 1.2$ billion dollars, all traced back to El Paso Corporation (the New York Times, Sep.10 ${ }^{\text {th }}, 2007$ ).

\section{Vitol Group and Vitol France}

The fifth case is different. First, the corporation in question executed and financed contracts. To protect itself, it created a corporate model that involved two rings of corporations. One ring covered up execution of contracts while the other concealed the flow of money. The rings included a conglomerate, two regional subsidiaries, two shell firms, a dormant company, two partnerships and a dozen of intermediaries for shipping purposes. Second, this case explains a common practice in the global economy, widely used to evade sanctions regimes: faking corporate identity and nation of registration. This case is about Vitol France, of which the IIC Report stated that "No company called Vitol France ever existed" (IIC, Chapter I, p. 158). Vitol was a Swiss company that "Used the name to give it a French angle" (IIC, Chapter I, p. 158) since Saddam Hussein favored french companies in appreciation for France's friendly approach to Saddam's regime.

Vitol France was in fact Vitol S.A. Geneva, a corporation registered and based in Switzerland, a regional subsidiary of Vitol Group, a Swiss conglomerate with 27 
affiliates and subsidiaries operating in several European nations (IIC, Chapter I, p. 159). Vitol Group authorized Vitol S.A. Geneva to provisionally change its name to Vitol France, so it could obtain contracts from Saddam Hussein. To masquerade even more the scheme, Vitol France created two rings of subsidiaries, intermediaries, front, dormant and shelf corporations. It also hired Mr. Serge Boidevaix, a French diplomat, to act as a liaison between itself and the Iraqi government (IIC, Chapter I, p.67 and p. 158).

Vitol France was officially registered as an oil trader, but it executed and financed contracts under the sanctions regime. Vitol France organized a ring of intermediaries around itself to which it channeled money and contracts. Some of them were Bayoil, Sidanco, Awad Ammora \& Co., and about a dozen Russian corporations such as Rosneftegazexport, purposely created to ship oil out of Iraq (IIC, Chapter I, p. 160). Vitol's operations went unnoticed for a few years. The IIC traced about $\$ 670$ million back to Vitol France (IIC, Chapter I, p. 160). According to the IIC, it was just half of what Vitol France actually invested in the sanctions regime. However, by 1998, Vitol France saw itself involved in a dispute over fees, surcharges and revenues with Peakville Limited, its financial trustee. Peakville Limited was the financial entity that Vitol France hired to channel payments to SOMO. In practice, if there was any linkage between Vitol France and the Iraqi government, it was Peakville. But payments and deliveries were usually late, for which Vitol France had to pay penalties. Vitol France put the blame on its ring of intermediaries, ultimately responsible for executing the contracts. They had been confronting issues when chartering vessels to transport their cargoes. In the end, Vitol France and Peakville Ltd agreed to pay the Iraqi government, hoping that it would 
grant some other contracts, but that was not the case. The Iraqi regime collected its money and banned both corporations from Iraq (IIC, Chapter I, p. 161).

After that, Vitol SA Geneva replaced Vitol France with Vitol Asia, another of its regional subsidiaries. Vitol Asia operated from Singapore. It approached a corporation called Mastek Sdn Bhd and asked it to act as its front corporation. Mastek was a dormant Malaysian corporation (IIC, Chapter I, p. 163). Three Malaysian businessmen "revived" it in an attempt to access the Iraqi regime for contracts, but they were unsuccessful. So they accepted the proposal from Vitol Asia. Mastek soon obtained its first contract. Its role was to hire the shipping companies that would execute the contracts. It was also to pay the surcharges that the Iraqi government demanded for using Iraqi roads and ports (IIC, Chapter I, p. 161). The partnership worked well for a while. Mastek executed $\$ 89$ million in imports-exports and paid about $\$ 10$ million in surcharges to the Iraqi government, $\$ 30$ million to Vitol Asia, and it kept \$20 million for itself (IIC, Chapter I, p. 162). But by 2001, Mastek was facing illiquidity. Mastek claimed that Vitol Asia was not paying enough surcharges and bribes, which the Iraqi government kept raising. The Iraqi government considered that there were just too many corporations violating the sanctions regime, and UN could find out at any time. Raising the surcharges was a way of reducing participants. Even so, Mastek threatened Vitol Asia with going public with its secret operations. In February 26, 2002, Vitol Asia paid Mastek an undisclosed sum and abandoned the partnership for good (IIC, Chapter I, p. 162).

In the end, it all seemed like if Vitol Asia and Mastek never had direct business contacts. Vitol Asia had placed two layers of corporations between Mastek and itself. First, it placed two shell Malaysian corporations: Cosmos Capital Group Ltd and Keppel 
Oil. Cosmos was to intermediate between Vitol Asia and Mastek. For its part, Keppel Oil was the link between Vitol and SOMO. Second, Vitol Asia hired a corporation called Bahrain E.C. to deal with financial transactions involving SOMO and other Iraqi institutions. The IIC discovered some transactions linking Bahrain E.C. to Vitol Asia and then to Vitol SA Geneva. They were letters of credit that Vitol S.A. Geneva extended to corporations trading with Iraq. The common denominator was that they had business accounts at JP Morgan-Chase London, in the UK. They led IIC's investigators to bank accounts at Jordan National Bank Amman, where SOMO too had accounts.

\section{Taurus Group}

The last case to discuss is Taurus Group. It is unique for it shows how American corporations evaded Saddam's ban American companies. Yet, Taurus bought $\$ 256$ million of Iraqi oil. It did through a dozen small Russian front corporations (IIC, Chapter I, p. 125). For its ingenuity, Taurus is one of the most illustrative cases of corporate modeling to deal with a sanctions regime and regulatory regimes in general.

Mr. Bem Pollmer founded Taurus Group in 1993 after resigning to its high executive post at Bayoil Corporation. The decision could not be more opportune. Both Taurus and Bayoil began to trade with Iraq very early into the sanctions regime. They both were among the most influential corporations lobbying against the sanctions and circumventing them. Taurus and Bayoil are examples of a dysfunctional corporate culture and governance. They both were found guilty of corporate wrongdoing in a New York Court (the New York Times, Sep. $20^{\text {th }}, 2007$ ). According to court records published by the New York Times, Taurus consisted of two main affiliates. One was Taurus Petroleum 
Ltd, based in Nassau, Bahamas. The second was Taurus Petroleum Nevis, incorporated as a shared ownership between Mr. Pollmer's sons, who also owned a holding company registered in Delaware. Both corporations had bank accounts at UEB Geneva and ING Bank Geneva, both banks based in Switzerland. In February 1995, Taurus Group formed a French-based company called Aredio Petroleum. In turn, Aredio hired a Liechtensteinbased financial service firm called ReviTrust to process the creation of two other corporations: Fenar Petroleum Ltd. and Alcon Petroleum Ltd. Soon afterwards, Fenan and Alcon opened bank accounts at BNP Geneva but not with their names. They used Petrocorp AVV and Jabal Petroleum SAL respectively. Iraqi officials working for SOMO confessed to the IIC that "They understood Taurus was using Fenar and Alcon as front companies to purchase Iraqi crude oil" (IIC, Chapter I, p. 126).

Fenar purchased oil in its own name, but Alcon hired Reliance Petroleum, a small Indian company, to do the purchases. Taurus, in order to conceal even more of its operation, ceded the ownership of Fenar Petroleum Ltd to Mr. Musbah Ladki. The corporate maneuvering allowed Taurus to extended 92 contracts to 17 small Russian front companies such as Sidanco, Machinoimport, Neftegazexport, Rosnefteimpex, Zangas, Zarnestservice, and Zarubezhneft. Taurus used some of those companies for just one contract. It used others to conceal money or move it from account to account, bank to bank. Most of those Russian companies dissolved right after UN ended the UN sanctions regime in Iraq. Again, after researching court records, as well as data from the IIC, the Duelfer Reports and the CFIJ, I was able to reconstruct Taurus's operational model under the UN sanctions against Iraq. Figure 6.5 exemplifies the intricacy of Taurus's corporate scheme. 
Figure 6.5 - Taurus's Intricate Corporate Scheme

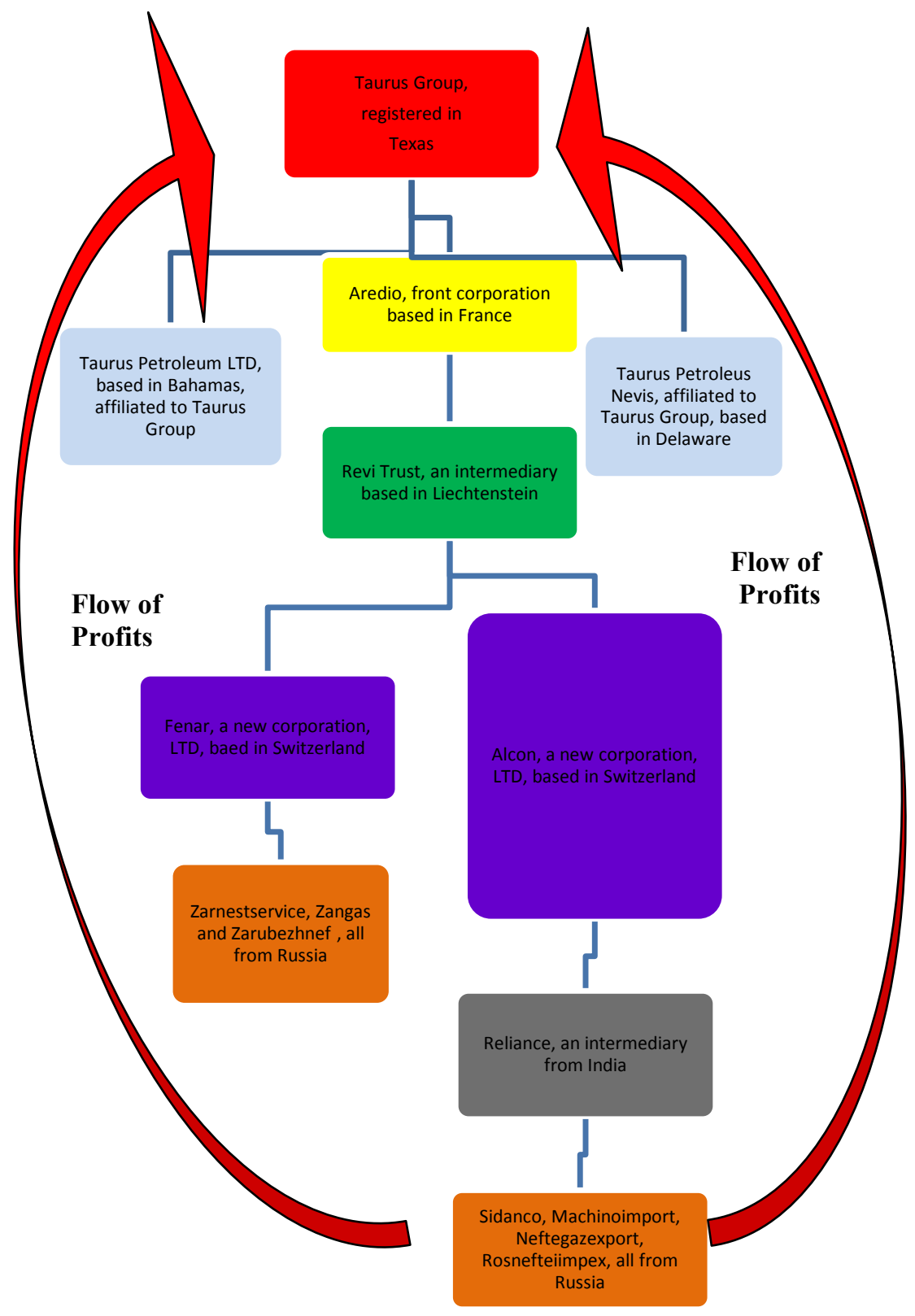

Observe in Figure 6.5 the flow of profits, represented in red arrows, from intermediaries at the bottom and back to Taurus Group. The flow was not as straightforward though. Taurus used a ring of bank accounts and financial institutions as 
intricate as its corporate models to evade UN auditors. The ring resembled a spider, linking about 50 bank accounts in nine different banks such as Credit Suisse, Banque Bruxelles, Lambert S.A., and UEB/BNP (IIC, Chapter I, p. 129). Most of the money circulated through wire transfers from two accounts under the names of Petrocorp and Jabal at First National Bank in Lebanon. Bank records showed that just between 1999 and 2000, Petrocorp and Jabal wired \$27.6 million from their accounts at First National Bank to Mr. Musbah Ladki's accounts at Cairo Amman Bank (IIC, Chapter I, p. 130). The money ended up at UEB, in Geneva, after circulating through seven bank accounts to Cairo Amman Bank, in Cairo. For its part, Taurus Nevis wired $\$ 9.2$ million from its accounts at UEB/BNP to Banque Bruxelles in 7 months (IIC, Chapter I, p. 130). And it later transferred the funds from Banque Bruxelles to Lambert and Credit Suisse. The IIC traced the money to Petrocorp's accounts at First National Bank, then to Cairo Amman Bank, and lastly to SOMO's accounts in Jordan National Bank. The money was to pay for execution of contracts. During the same period, Taurus Nevis wire transferred another $\$ 4$ million dollars to Jabal's account at First National Bank (IIC, Chapter I, p. 130). The money stayed there for two weeks, after which it was transferred to Cairo Amman Bank. It ended it up at SOMO's account at Jordan National Bank.

From August 1, 2001, to December 31, 2002, the flow of money from Taurus took two new itineraries. One began in an account at Credit Agricole Indosuez, in Genova. The account belonged to Taurus London, a small affiliate of Taurus Nervis. Taurus London moved \$6 million to Alcon's account at UEB/BNP, which then moved the funds to Jabal's account at First National Bank, and from there to Cairo Amman Bank and SOMO's Jordan National Bank (IIC, Chapter I, p. 130). A second itinerary began at 
Taurus Nevis in Paris and Geneva. From August 2001 to December 2002, Taurus Nevis moved \$14.3 million to Fenar's account at UEB, which then wired the money to Petrocorp, and from there to Cairo Amman Bank and to Jordan National Bank (IIC, Chapter I, p. 130).

In all, the operation worked well for a long time. The Taurus Group executed 14\% of all Iraqi contracts under the sanctions regime (IIC, Chapter I, p. 132). The operation involved complex wire transferring and corporate models. Taurus's operations came to illustrate, like no other case, the use of corporate modeling to evade not only a sanctions regime but any regulatory regime.

\section{$\underline{\text { Conclusion }}$}

This chapter is about key agents and means of globalization: corporations and their various corporate models. The argument is twofold. First, I argue that corporations are a key agent of globalization, one with enormous influence over regulatory regimes. Second, corporations use corporate models to attain efficiency, high productivity and expansion, but above all they use corporate models to circumvent regulatory regimes. Corporate models were essential for the circumvention of the UN sanctions regime in Iraq. On the one hand, the government of Iraq employed corporate models to sell to and purchase from corporations and nations. Iraq used corporate models to reach local, regional and global markets. On the other hand, foreign corporations interested in the Iraqi market employed corporate models to evade UN sanctions and inspectors, conceal their wrongdoings, and laundry their profits. I used the first part of this chapter to analyze corporate models. I included an analysis of corporate governance and responsibility since 
they are part of the overall structure of corporate models. In the second part, I present specific examples of how corporations employed corporate models to circumvent the UN sanctions regime upon Iraq.

In this chapter we showed how corporations circumvented the UN sanctions regime in Iraq though corporate models. In general, the method seems repetitious, but the examples illustrate how corporations can deal with not only a sanctions regime but also regulatory regimes in general. It is not simple. Corporations do a whole set of corporate models and maneuvering mechanisms to avoid regulations, responsibility and accountability. 


\section{AGENTS AND MEANS OF GLOBALIZATION: THE GLOBAL ASSEMBLY LINE, CONTRACT MANUFACTURERS AND VALUE NETWORKS}

"So this is our conference room, probably the largest screen in Asia - this is forty digital screens put together- [...] Infosys can hold a virtual meeting of the key players from its entire global supply chain for any project at any time on that supersize screen. So their American designers could be on the screen speaking with their Indian software writers and their Asian manufacturers all at once. We could be sitting here, somebody from New York, London, Boston, San Francisco, all live. And maybe the implementation is in Singapore, so the Singapore person could also be live here... That's globalization".

Thomas L. Friedman

"Iraqi chemical industry appears to have evolved into a nation-wide, pan-industry, pan-academia merit based competition for project ideas and project implementation into an operation of regional proportions".

The ISG Report

"By God, spare us your evil. Pick up your goods and leave. We do not need an atomic bomb. We have the dual chemical. Let them take note of this. We have the dual chemical. It exists in Iraq".

Saddam Hussein

\section{$\underline{\text { Introduction }}$}

I examined in previous chapters how Iraq utilized agents and means of globalization to circumvent the UN sanctions regime, reach global markets, and engage in trade with corporations, banks, financiers, NGOs, political parties and powerful individuals. Now I want to address a key question of this Dissertation: whether or not globalization allowed Iraq to rebuild its military infrastructure. I argue that Iraq attempted to rebuild its military capabilities in three main ways. First, Iraq designed and implemented a vast, ambitious procurement program to obtain components and parts for its military industry. Second, Iraq rebuilt part of its military industry. Third, Iraq outsourced an important portion of its military industry. In working toward these goals, Iraq's plan for rearmament consisted of purchasing technologies, industrial machinery, and component parts; rebuilding a grid of assembly lines that were domestic and regional in scope; and assembling, researching, testing and storing missiles and WMDs. 
I have divided this chapter into two parts. First, I discuss how globalization trends of the 1990s brought about a radical transformation of the global economy, precisely at the time the UN was enforcing a multilateral sanctions regime against Iraq. Specifically, I examine the changes that globalization brought about to productive processes and manufacturing models. I then discuss the transition from an international to a transnational economy and from the local to the global assembly line. I explain in the second part how Iraq took advantage of the new global manufacturing model to rebuild its military-industrial complex.

\section{From International to Transnational Production}

The UN sanctions regime did not allow Iraq to purchase weapons and to rebuild its military industry, especially industries linked to missiles and WMDs. Therefore, Iraq opted for manufacturing its own weapons. The problem for Iraq then became how to rebuild its military industrial complex and organize an efficient and secret production process. Basically, Iraq had two main choices. First, Iraq could manufacture its weapons in the traditional way: a domestic manufacturing operation based on Fordism or centralized assembly line. But such a choice was not feasible because UN inspectors could detect and stall the operation. Second, Iraq could do what most big transnational manufacturing corporations were already doing at the time: decentralize production processes and outsource the assembly line to foreign nations. Iraq opted for this choice. Iraq decentralized what was left of its military industrial production, dismantled portions of its assembly lines, and outsourced them to nations such as Egypt, Jordan, and Syria. 
Iraq accomplished this thanks to some important structural changes that occurred in the global economy during the 1990s.

The globalization process of the 1990s brought about radical structural changes to productive processes. The changes applied to almost all economic sectors and industries, from agriculture and agroindustrial, to services and manufacturing. Globalization converted a) international productive processes into transnational productive processes; b) centralized manufacturing into contract manufacturing $(\mathrm{CMs})$; c) lineal assembly lines into fragmented ensemble lines; d) local and regional distribution centers into global value networks.

International production process was the dominant manufacturing model for most of the 20th century. International production was "A simple extension of economic activities across national boundaries and is essentially a quantitative process" (Robinson, 2004, p.14). It accounted for just a few nations within well-defined small regional patterns. International production was in essence local, and bilateral in a handful of cases. It was rarely regional. But international production brought regional suppliers and importers to local production centers. In other words, regional economies were integrated into local industries as providers of raw materials and importers of finished products. Again, it was so for most of the 20th century. Before the 1950s, there were not regional economies at all (Dickens, 1998, p.74). There were no regional economic infrastructures, no regional integration, no regional markets and no regional trade treaties. Most nations were mainly suppliers of raw materials to the manufacturing centers in the U.S., Great Britain, Germany, France and two or three more European nations. With the exceptions of Mexico, Brazil and Argentina, Latin American nations only embraced large 
scale manufacturing by mid $1950 \mathrm{~s}$. They did it not as a means to integration but to substitute importation of industrial products for domestic industrial manufactures (Skidmore and Smith, 2008, p. 29). The model, above all, aimed at transforming trade relations that Latin American nations had with respect to the U.S. and European nations. For its part, most of Asia did not develop a manufacturing industry until 1960s. And even today it cannot be said that Africa is manufacturing center. Only South Africa could claim to have a manufacturing industry. Latin America, Asia and Africa were the largest importers and consumers of American and European manufactures. As a whole, it was only during the last 40 years of the $20^{\text {th }}$ century that manufacturing became a transnational trend.

According to Palloix (1975) and Robinson (2004), transnational production processes are radically different from international production processes. Transnational production is based on four pillars: a) decentralization of production; b) fragmentation of assembly line and distribution centers; c) integration of management and supply chains; d) specialization through creation of segments of productions.

First of all, transnational production is decentralized, fragmented and spatially dispersed throughout the global economy, but the fragments remain linked through integrated management and a chain of production (Robinson, 2004, p.16). Both are global in scope. Transnational production takes local manufacturing centers and imbeds them in regional clusters integrated into a global production process. Yet, integration does not mean asymmetrical relations between manufacturers on one hand, and suppliers of raw materials and importers of finished products on the other, for that was the case of the internationalization model. Rather, integration here refers to the production process itself, 
to the assembly line in particular. Transnational production breaks up the assembly line into phases and segments which are then outsourced to independent manufacturers. It means that a large number of small companies, namely sweat shops, disseminated throughout the globe, participate in the manufacture of just one product. Each shop manufactures a piece of the final product. It does not matter which part or piece of the final product they produce; all shops are important to the quality and overall cost of the final product. Under this model, national borders matter, for the most part, in terms of cost differentials due to national economic policies which affect the global structure of production. Regional boundaries act as organizational mechanisms, as a means of grouping, integration, cost saving, and efficiency. Every segment of the production process counts when it comes to minimizing costs and increasing productivity. The entire process aims at reconsidering and reconstructing the notion of comparative advantage, a process that Krugman (1991) explains in his trade theory.

The result is decentralization and fragmentation on a large scale. Yet, note that, as Robinson does, that "Worldwide decentralization and fragmentation of the production process has taken place together with the centralization of command and control of the global economy" (Robinson, 2004, p. 17). Indeed, there is a global chain of production and a global chain of command also, one that is highly coordinated even when the commanding center, as Friedman (2008) argues, is far away from the production centers. For one, no corporation leads the production process even thought there is an inherent hierarchy in the form of a pyramid. Brand-name corporations are at the top, followed by retail corporations, suppliers and the assembliers. Lately, retail corporations and suppliers have been merging as to increase their size, market shares and bargaining power with 
respect to brand-name corporations and contract manufacturers. In general, brand-name corporations, suppliers, retailers and contract manufacturers must be seen as a very cohesive structure of independent elements. If one of them fails, the entire operation collapses. Note that corporations like to keep little or no inventory at all, so they can save money in terms of warehousing, utilities and waste. It means that supply and demand must be highly synchronized, to the point that production occurs as actual orders for more products come in to the assembly line. The process is known as just in time production. The result is a fragmented production process, highly specialized but structurally strong and interconnected. Global production allows fragmented global production to work as a unit in different latitudes but in real time.

The intensification of globalization during the 1990s triggered technological innovations which facilitated further fragmentation and decentralization of assembly lines and the emergence and proliferation of contract manufactures (CMs) and global value networks (Arndt and Kierzkowski, 2001, p. 15), or as what Castell (2000) calls network societies, namely a new form of capitalist economic organization and association.

First of all, arguing that globalization transformed the international assembly line into a transnational operation actually means that globalization replaced Fordism with CMs and value networks (Robinson, 2006, p. 14; Castell, 2000, p. 37). Fordism was one of the most important innovations of the 20th century. It was the basis of the internationalization of the production process. It took manufacturing from a small scale regional operation to a large scale local one. As Berger and Doran argue, "Ford itself was a regional corporation before it was a local operation" (Berger and Doran, 1996, p. 74). Fordism centralized the entire production process. It put all phases of production 
together, one after the other, uninterrupted, in a lineal sequence, under just one roof. Henry Ford called it the assembly line, consisting of a step by step process in which workers performed a specific, repetitious task. The process sought the specialization of an uneducated, unskilled labor force. The idea was to create large outputs at the lowest cost and at the fastest pace possible. Fordism was about mass production and speed. It demanded large volumes of raw materials for its operations and large markets to allocate its large outputs. Yet, corporations could not utilize Fordism equally in all nations. They had to introduce some structural modifications in the model to adapt it to the specific conditions of some nations. For example, Berger and Doran (1996), as well as Robinson (2004), argue that Fordism did not work well in small markets where mass production often led to high inventories and waste. Fordism even had problems in Japan, a large and rich market. Fordism created outputs so large there that it saturated the Japanese market, to the point that manufacturers had to sale their products at a loss (Berger and Doran, 1996, p. 119). It led to massive layoffs and recessions. The transition from Fordism was a product of increased global competition for markets that original Fordist firms once dominated, and "An effort by these same corporations to lower costs and reverse declining rates of profit (from 1965-1985) that had characterized the leading Fortune 500 companies on the downside of the Fordist production system" (Berger and Doran, 1996, p. 127; Berger and Lester, 1997, p. 202).

The assembly line went through a series of transformations as new technologies emerged. The main was the restructuring of the production process dependant on parameters such as proximity to raw materials, market shares, access to cheap but qualified labor force, and geopolitical stability. Also, manufacturing corporations were 
very cautions when expanding their operations to other nations. They invested in nations with stable macroeconomic indexes and political systems, but they also sought weak labor laws since Fordism required intense labor. Thus, the assembly line did not really change for many years. Corporations retooled and improved it, but they did it within the scope of Fordism. Along the way, corporations created a comparative advantage for themselves. Corporations with the most efficient assembly lines reduced more costs and saved more money. Logically, corporations with local and regional advantages were better positioned to adapt to the changes that came during the 1990s (Castell, 2000, 9. 64; Arndt \& Kierzkowski, 2001, p. 20).

Globalization brought about drastic changes to the corporate world during the 1990s. This time, it targeted the production processes, the assembly line in particular. In Chapter VI, I explicated that corporations decentralized themselves through corporate models such as holdings, subsidiaries, and parent and front companies among others. But then globalization took corporations a step further toward decentralization. Globalization allowed holdings, subsidiaries, and parent companies to decentralize their production processes and to dismantle their local assembly lines and take them to regional zones. They replaced Fordism, the once vertically highly integrated assembly line, with CMs and value networks strategically located across regional centers of productions (Robinson, 2004, p. 17; Castell, 2000, p. 36; Luthje, 1997, p. 81).

Indeed, first note that consolidation of regional centers of production came after the creation of regional trade treaties such as Mercosur and NAFTA, just to mention two. It must not be ignored that: 1) manufacturers lobbied strongly for the treaties; 2) it is not a coincidence that firms began to move their manufacturing operations to regions like the 
Mexican-American and Argentinean-Uruguayan borders. Second, fragmentation of assembly lines and creation of regional production centers cannot be done without transnational flow and accumulation of capital essential, as Robinson (2004) argues, to finance production processes. Third, it all underlines Bhagwati's image of a global economy: "The global economy is not just one gigantic unit. It is a group of production and trade blocs dispersed across regional lines" (Bhagwati, 2004, p. 47).

Arndt and H. Kierzkowski (2001) explain that, under the new paradigm, brandname corporations broke up their assembly lines into phases and segments and outsourced them to CMs. A cautious study would reveal that CMs are just subassemblies, subcontractors, intermediaries, partnerships, and independent suppliers located around the world but linked through a contract to a brand-name corporation. As Sturgeon argues, "CMs are independent units interconnected by a common denominator: a finished product" (Sturgeon, 1997, p.20). CMs are usually under cheap contracts, meaning that their values and profits are marginal, but they still provide large outputs at very low cost. Some CMs provide logistics, repair services, and distributions at very competitive costs. They divide the production chain into multiple segments linked through assembling sequences. This idea is based on the theory of value added (Arndt and H. Kierzkowski, 2001, p. 25; Sturgeon, 1997, p. 22), meaning that each segment of the assembly process adds an $X$ value to the product being produced. In the case of Iraq, CMs and value added were not to increase sale values but to create trade linkages with Iraq's neighbors and conceal production from UN inspectors. This was particularly vital for Iraq's military industry, for its missile and WMD programs in specific. 
For Robinson (2004), Arndt and Kierzkowski (2001), and Castell (2000), CMs are at the core of the just-in-time-production process. Paradoxically, CMs are not brands. They do not stick their names and logos to the finished product they help to produce, which explains why they remain unknown to most people even though they are everywhere. In fact, as Arndt and Kierzkovski affirm, "An essential feature of transnational production process is the relationship between CMs and brand-name corporations, which structures the hierarchal relationships that still exist within the market" (Arndt and Kierzkowski, 2001, p. 17). Brand-name firms are now at the top of the value chain. That is, technologies allow brand-name firms to focus on bureaucratic functions like management, marketing and investment while delegating to CMs the operational portions of the production process. Brand-name firms do not manufacture any product. CMs do. Table 7.1 shows some of the most important CMs in the global assembly line in terms of specialization and/or division of labor across industries.

Table 7.1 - Some of the Most Important CMs in the Global Assembly Line

\begin{tabular}{|l|l|}
\hline $\begin{array}{l}\text { Fabless company - minimal final } \\
\text { ensemble and testing }\end{array}$ & $\begin{array}{l}\text { Full scale manufacturing and supply- } \\
\text { chain (engineering \& logistics }\end{array}$ \\
\hline $\begin{array}{l}\text { Full scale outsourcing of ensemble lines } \\
\text { and/or plants }\end{array}$ & $\begin{array}{l}\text { Full scale manufacturing and supply } \\
\text { chain management }\end{array}$ \\
\hline $\begin{array}{l}\text { Large scale final ensemble with high } \\
\text { volume outsourcing of key components }\end{array}$ & Mass production of key components \\
\hline $\begin{array}{l}\text { Customized final ensemble in key } \\
\text { markets }\end{array}$ & $\begin{array}{l}\text { Final ensemble (box-build) including } \\
\text { local CM partners }\end{array}$ \\
\hline
\end{tabular}

Source: IMF, World Bank 
The new business relationship between brand corporations and CMs emerged for the first time during the 1960s although in small scale. In 1981, IBM contracted a "noname" small corporation to take over a segment of IBM's keyboard manufacturing process (Berger and Lester, 1997, p. 51). It was a great financial success, so soon other brand-name firms began to execute the same model. By the 1990s, new technologies and regional trade treaties facilitated the expansion of fragmentation of the assembly line, which in turn led to the proliferation and consolidation of CMs. Erickson, the mobile phone manufacturer, led the wave of fragmentation, decentralization and outsourcing of the 1990s, but Siemens mastered it to levels difficult to outperform (Berger and Lester, 1997, p. 53). Siemens, a technological innovator itself, invested billions to create technologies that facilitated further fragmentation and outsourcing of assembly lines. Siemens in turn made billions selling its innovations to brand-name corporations and CMs (Berger and Lester, 1997, p. 52). Two cases illustrate how it all works.

The first example is Coda Automotive, a small car manufacturer headquartered in Santa Monica, California. Coda's owner himself, Kevin Czinger, revealed Coda's production line to the New York Times. Coda only does accounting and marketing, and it employs a Chinese assembly line to manufacture its cars. The Chinese assembling firm purchases the chassis from Mitsubishi Corporation and the hood, bumpers and lights from Porsche. Delphi Corp. provides the power steering and BorgWarner Corp the transaxle. Coda makes electric cars that use lithium batteries, so it buys the batteries from Tianjin Lishen Battery, a Taiwanese subcontractor to Motorola and Samsung. Coda does not have a dealer network. It does not need it for it sells its cars over the internet. 
The second example is more telling since most people ignore that computer brands like Dell and Hewlett-Packard (HP) do not really produce a thing. Pearson and Raymond (2006) explain in their reportage about Dell and HP that the two computer giants are just brands, or trademarks. They purchase components, meaning hard and software, from a number of suppliers around the world. They pay a shipping corporation for delivering the components to an assembly line owned by another corporation. Once the assembly manufactures the PCs, Dell and HP sell them in the global marketplace. Dell sells its products over the internet, so it does not need a net of stores and showrooms. HP does it through a global network of retail stores. Table 7.2 shows the largest CMs of hard and software in the global PC industry.

Table 7.2 - The Largest CMs of Hard and Software in Global Computer Industry

\begin{tabular}{|l|lr|}
\hline Company & $\begin{array}{l}\text { Revenues in US } \\
\text { Millions per year }\end{array}$ \\
\hline Solectron & $\$$ & 16,149 \\
\hline Flextronics Int.'1 & $\$$ & 12,923 \\
\hline Sammina SCI & $\$$ & 10,830 \\
\hline Celestica & $\$$ & 10,004 \\
\hline jabil Circuit & $\$$ & 4,086 \\
\hline Hon Hai Precission & $\$$ & 3,562 \\
\hline Elcoteq Network & $\$$ & 1,667 \\
\hline Symex & $\$$ & 1,620 \\
\hline Manufacturers' Services & $\$$ & 1,522 \\
\hline Benchmark Electronics & $\$$ & 1,277 \\
\hline
\end{tabular}

Sources: IFM, World Bank 
It catches my attention that those corporations in Table 7.2 are not really recognizable. They never make the headlines. They are almost anonymous to the public at large. We ignore their jurisdiction and nations of origin. We do not know if they are publicly owned, if they are partnerships or private enterprises. We really know very little about them. However, their contractors, Apple, Dell and HP among others, enjoy public recognition as computer manufacturers. This is very important to understand how vulnerable a sanctions regime is to this new global assembly line. Later in this chapter, I will site more examples, but for now I want to mention the case of Huawei Technologies, a Chinese firm that started out as a CM but is today among the most recognizable Chinese brands. Huawei was a sub-assemblier for Motorola. It manufactured fiber optic equipment for radio communication, a technology that Motorola owned. It turned out that Huawei sold some of this equipment to Iraq, which then used them for its missile system. Huawei is today one of the largest assemblier of smart phones in the world. Its most known product is the Android, Google's smart-phone.

In general, CMs guarantee: a) anonymity and dispersed accountability; b) mass production at high speed and very low cost; and c) linkage of the production process from national to regional and global assembly lines. CMs are by nature transnational network builders. The computer industry calls it the Silicon Valley System, but scholars knowledgeable of the assembly industry call it the value network paradigm

For Pearson and Raymond (2006), and Berger and Lester (1997), there are three types of value networks. First, there is the captive value network. It is a CM that depends on a brand-name corporation for it survival. CMs are mainly suppliers and intermediaries highly reliant on one or two customers. They are so dependent that if they lose a contract, 
they could go out of business. They are not treated equally; yet, they have no choice but to stay captive of their customers. Second, there is the relational value network, in which a CM builds a close, long-term business relationship with a brand-name corporation. The relationship can be contractual, but cost is not the base of the contract. Instead, trust, reciprocity and commitment to efficiency and productivity are the basis for their relationship. Relational value networks promote positive corporate culture and norms, as well as responsive corporate governance. Thirdly, there is the turn-key value network. These are short and/or long- term relations between highly qualified CMs specializing in manufacturing different pieces of the same product. Their relations consist in a pledge to cooperate and get the job done. Turn-keys networks are intrinsic parts of all productive sectors, from banking to infrastructures, chemical and high-tech industries. Saddam utilized turn-key networks for two main goals: 1) jump start trade with its neighbors, meaning regional trade; 2) obtain political support from contractors and subcontractors, any firm that had business relation with Iraq. I mentioned in Chapters II and III that Iraq granted contracts to firms and nations that publicly opposed the UN sanctions regime.

In addition, Pearson and Raymond (2006), as well as Berger and Lester (1997), explicate that corporations often employ turn-key networks to circumvent regulatory regimes. On one hand, Pearson and Raymond (2006) argue that turn-key networks are all over the global economy. They tend to operate around regional manufacturing centers, but they have very low entry-exit requirements, which allow them to move in and out of markets with no difficulty. Brand-name corporations often use turn-key value networks to enter and exit emergent markets, depending on the macroeconomic conditions of a 
particular market. Some corporations use turn-key value networks in the developing world to take advantage of weak laws and enforcement mechanisms there.

Berger and Lester (1997), on the other hand, find that turn-key networks over time develop solid relations with large numbers of corporations specializing in crosscutting operations, which refers to dual use components required to manufacture a specific product used in dissimilar industries. That is the case, for example, of certain chemicals manufactured for the pharmaceutical and semi-conductor industries, but they can also be used to manufacture some electronic components needed to assembly a longrange missile system. In fact, the U.S. Congress strictly regulates technologies that can have a use in military manufacturing industries. The most notable is the nuclear technology conceived for civilian purposes but that can be utilized for military ends. Though there are others not so notable. For instance, Iraq purchased large quantities of spare parts presumably for its trucking industry. The parts ended up in the Iraqi army, for its trucks and even tanks. As a whole, value networks take specialization and division of labor to levels never attained in the history of assembling and even industrialization. Pearson and Raymond (2006), Berger and Lester (1997), Sturgeon (1997) and other scholars call it dual fragmentation, or fragmentation of fragmentation, in which a corporation outsources some operations to CMs, but then some of those CMs retain a portion of their contracts and outsource the other portion to other CMs, and so on. This is particularly feasible when cargo transportation is cheap due to low operational costs and proximity between production, distribution and consumption centers.

The model works well for nations linked by bilateral and regional trade. As I stated earlier, intensification of globalization during the 1990s coincided with the creation 
of regional trade blocs and, as result, CMs and value-networks. The intensification of globalization led to the emergence of new manufacturing centers, this time aligned to regional trade blocs like NAFTA, ASEAN, EU, and MERCOSUR. Thus, as Berger and Lester (1997) explain, now Mexico is the manufacturing center in North America; Malaysia is the manufacturing hub for Asia and Brazil is for South America. Hungary, Poland, the Czech Republic became the manufacturing centers of Europe as soon as they entered the European Union. Hungary alone had 8 manufacturing centers in 2001. And of course, the obvious exception is China, which has become the manufacturing basket of the world. Figure 7.1 below shows some of the largest CMs in the information technology industry in the world. The Figure gives us an idea about percentages of market shares per nation of manufacturing centers across regions.

\section{Figure 7.1 - Market Shares of CMs per Nation across Regions}

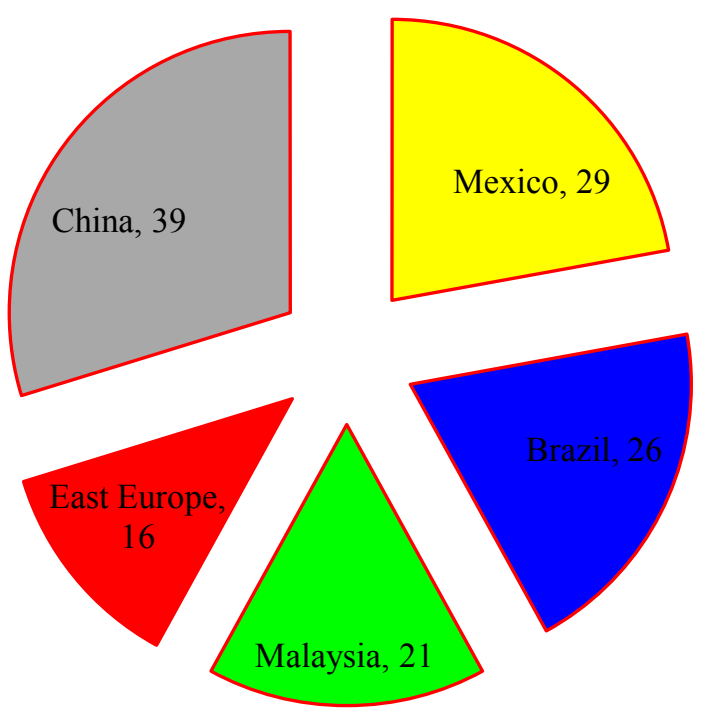

Sources: IMF, the World Bank 
Although wages are not the only factors influencing the proliferation and consolidation of $\mathrm{CM}$ centers, note that the largest $\mathrm{CM}$ centers are aligned to the lowest labor costs across regions and/or regional trade agreements. For instance, as for 2008, IMF and World Bank's data show that Mexico has the lowest salaries in North America and NAFTA. Mexico has the largest CM centers in North America and NAFTA as well. In the European Union, Eastern Europe has the lowest salaries and the largest number of CM sites. And we can say the same of China in Asia and Brazil in MERCOSUR.

One notable point here is that the new global manufacturing model does not seem to create problems for corporations in terms of cultural, social and political adaptation. American corporations work well in Mexico; Argentinean firms do well in Brazil, and the same is for British firms in Hungary. Corporations make profits and workers do not seem to mind. Of course, such a "stable relations" do not come naturally. In fact, global relations require a great deal of lobbying, bargaining and political maneuvering with institutions and governments to secure "peaceful" outsourcing. For example, in the case of China, the Chinese state works closely with corporations in a political process designed to facilitate their relocation and adaptation to China's political, social and cultural environments.

In all, the new model has brought about the relocation of economic activities and the realignment of productive forces. Productive structures and components have come together regardless of political systems, economic patterns and geography. Political relations still matter, but for the most part the highly centralized micro-managed Chinese capitalism has no problem doing business with the highly unregulated decentralized US economic system. The German and Japanese coordinated production models work well 
with the East Asian NICs. They all converge through global linkages, including economic and political ties.

\section{Transnational Production and Regulatory Regimes}

Corporations first decentralized corporate operations through corporate models such as holdings, subsidiaries, parent companies and others. But as Robinson (2004) and Henderson (2005) argue, with CMs and value-networks, they took decentralization and fragmentation of production processes to levels never seen before in the corporate world. Both decentralization and fragmentation of production processes aimed at minimizing costs while maximizing profits, but they also attempt to minimize accountability and responsibility at both corporative and national levels. In the Iraqi case, Iraqi corporations and Iraq itself were capable of circumventing the UN sanctions regime by adopting production processes within the context of bilateral trade agreements and regional trading schemes. On one hand, Iraq utilized subsidiaries, intermediaries, and parent and front companies to access the global markets, so it could acquire technologies, machineries and components for its military industry. On the other hand, Iraq utilized CMs and valuenetworks within the context of bilateral trade agreements with neighboring nations to rebuild an assembly line for its military industry. The formula seemed perfect for the overall objectives of the Iraqi government, which was the circumvention of UN sanctions with a minimum of accountability and responsibility.

Indeed, I find that transnational production presents a direct challenge to regulatory regimes precisely due to its level of fragmentation, dispersion and specialization, which in turn guarantees a high percentage of anonymity. The problem is 
that, as Henderson (2005) explains, by default, outsourcing manufacturing contracts means outsourcing both legal responsibility and corporate accountability to a third party. In fact, it means outsourcing to multiple parties because, as we stated earlier, under the new manufacturing scheme outsourcing is about breaking up the entire assembly line and selling its pieces to multiple contractors which, in turn, outsource some portions of their contracts to subcontractors.

Under this manufacturing network, corporate accountability is no longer relative to internal corporate structures but to external forces and actors. The result is a partition of contracts, the dissemination of duties and obligations through an amalgam of obscure parties. It all represents a true challenge to international institutions and nation-states in terms of supervision, enforcement and litigation. First, tracing evidence and assigning responsibilities becomes a true legal challenge for institutions that too often lack legal authority to take on transnational corporations. Even the follow the money method becomes somehow unfeasible because, as Robinson (2004) argues, transnational production liberates transnational money from institutional constrains. Even national governments lose control over the movement of money throughout regional and global markets. Second, enforcing accountability becomes a gargantuan task. It is so for nations with not enough financial resources to enforce their own laws. Poor nations are too vulnerable to powerful corporations. In addition, some nations are not really interested in holding corporations responsible for wrongdoings. They depend on corporations to create jobs, increase exports, and balance their national budgets. In fact, enforcing accountability is even difficult for rich nations like U.S., France, U.K, Germany and 
others. They are often trying to reconcile complicated geopolitical and economic dilemmas with rules and legal regimes they have set for themselves.

\section{The Iraqi Case}

In previous chapters I found that agents of globalization such as corporations, NGOs, individuals and nation-states, including Iraq, successfully and consistently circumvented the UN sanctions regime. They did it through means of globalization such as global trade, global banking, and global corporative models. In this section, I present findings that respond to the central questions of this dissertation: Did globalization allow Iraq to circumvent the UN sanctions regime and rebuild its missile and WMD programs?

There is a key point to observe here. UN inspectors and American troops did not find WMDs in Iraq after the invasion of 2003. That is, they did not find the final product, and by that I mean no missile, bomb or any kind of ammunition armed, ready to be launched, with chemical and bacteriological agents. But the objective of this dissertation is not to argue whether or not Iraq had such a final product. Rather, the central question here is if globalization facilitates the circumvention of a multilateral sanctions regime and if circumvention could in turn lead to rearmament. I find that yes: a) Iraq circumvented the UN sanctions regime; b) Iraq utilized the means and agents of globalization to circumvent the UN sanctions regime; c) Iraq rebuilt a good portion of its military manufacturing infrastructure; d) Iraq organized a regional and global procurement program to design, manufacture, and test missiles and WMDs.

To present and discuss the evidence, I divide this section into two parts. In the first part, I look at Iraq's procurement effort as a whole. I present a brief history and some 
accounts about reforms Iraq undertook to adapt to the demands of the UN sanctions regime. In the second part, I present two case studies: the Missile Program and the Chemical-Bacteriological Program.

\section{$\underline{\text { Iraq's Procurement Effort }}$}

The CIA, the ISG, the IIC, the CFIJ, and other sources coincide in that Coalition Forces destroyed most of Iraq's military infrastructure in 1991. It included about three thousand short, medium and long range missiles, and most of its WMD stockpiles. They also acknowledged that Iraq never fully recovered its military levels after the American led invasion of 1991. Particularly, Iraq did not really manage to replenish the military arsenals it had before 1991. But that does not mean that Saddam sat and waited for

miracles. He was not a religious person after all. After 1991, Saddam worked arduously to rebuild Iraq's military capabilities. He conceived and implemented a plan to circumvent the UN sanctions regime.

Indeed, I revealed in Chapter II how Iraq managed to sell oil by manipulating oil prices, imposing arbitrary fees, and bribing nation-states, corporations, individuals and NGOs. I explained in Chapter III that Iraq entered trade protocols with Middle Eastern nations. In Chapter V, I showed how Saddam reformed Iraq's banking industry, and that he created a network of banks all around the Middle East. In Chapter VI, I provided examples of how Saddam created hundreds of corporations throughout the Middle East. It was all part of a sound plan to circumvent the UN sanctions regime and rearm Iraq. Saddam personally managed the rearmament effort through the Military Industrial Commission (MIC), an institution of his own creation (Duelfer Report, 2004, Regime 
Strategic Intent, p. 8). The effort was top secret and enjoyed priority over any other governmental plan or activity. The Iraqi government did not hesitate in assigning resources to it. Saddam even put Iraq's intelligence services to work for MIC and the procurement effort.

According to the Duelfer Report, MIC became a solid institution after numerous restructurings. It emerged during the 1980s as SOTI, but it then evolved into MIO, after which it became the Ministry of Industry and Military Industrialization (MIMI). It became MIC in 1991, responsible for planning, financing, and managing Iraq's military industries, including those engaged in the missile, chemical-biological, and nuclear programs. MIC managed $95 \%$ of all purchases for the Ministry of Defense (Duelfer Report, 2004, Regime Strategic Intent, p. 18). But by 1997, after the failure of several projects, Saddam introduced several modifications. He made MIC a division of the Ministry of Defense, responsible for acquiring components, equipment and technologies for the military worth millions of dollars. MIC was basically the procurement arm for the Ministry of Defense. Its budget grew from $\$ 7.8$ million in 1993 to $\$ 2.7$ billion in 2002 (Duelfer Report, 2004, Regime Strategic Intent, p. 19). The organization obtained about $\$ 300$ million per year as result of its oil sales through the trade protocols with Syria, Jordan, Egypt, and Turkey. A second source of revenues was ARADET, an Iraqi front company with plants in most Middle Eastern nations. ARADET produced and sold oil derivatives all around the world, with annual revenues of nearly \$112.2 million (Duelfer Report, 2004, Regime Finance and Procurement, p. 37). ARADET also had an investment arm to purchase small failing factories in Egypt, Syria, Turkey and Lebanon. 
In reality, MIC consisted of hundreds of mid-side military front companies, manufacturing plants, and research and training centers dispersed throughout the Middle East (Duelfer Report, 2004, Regime Finance and Procurement, p. 53). I call them military because they only traded products and technologies that had military applications. We should not confuse them with civilian front companies studied in Chapter V and VI, which traded products for civilian purposes. More importantly, civilian front companies did not enjoy the support that military front companies had from IIS and ISS. Civilian front companies, moreover, did not enjoy the personal support of Saddam Hussein. Military front companies did. Saddam appointed CEOs for military front companies. He met with and briefed them weekly, in some instances daily. Saddam even set up intelligence offices throughout the Middle East to protect and oversee "his" military front companies.

Military front companies acted with relative independence. Unlike civilian front companies, they could create and dismantle subsidiaries, intermediaries and parent companies. They were autonomous, meaning that they sought their own funding. Yet, they could not move their money around so easily for they had to report directly to Saddam. The number of Iraqi military front companies grew rapidly from 1996 to 2002 . Their budgets grew as well, reaching $\$ 8$ billion dollars yearly, a considerable amount for an embargoed nation (Duelfer Report, 2004, Regime Finance and Procurement, p. 53-54). The ISG calculated that the workforce for military front companies amounted to approximately 63,000 in 2002 (Duelfer Report, 2004, Regime Finance and Procurement, p. 54). And as for research front companies, they usually worked closely with universities to camouflage their work. They researched mostly missile and bio-chemical technologies. 
Military research projects grew from 40 in 1994 to about 3,200 in 2002 (See Annex K).

Below is a list of the most important military companies (Duelfer Report, 2004, Regime Finance and Procurement, p. 54-55).

$\underline{\text { Table } 7.3 \text { - Most Important Military Companies in Iraq }}$

\begin{tabular}{|c|c|}
\hline Research & Companies \\
\hline Al Milad General Company & Al Quds General Company \\
\hline Al Battani General Company & Al Khawarizmi General Co. \\
\hline Ibn-Sina' General Company & Al Raya General Company \\
\hline Al Kindi General Company & al Basil General Company \\
\hline Al Fat'h General Company & Al Razi General Company \\
\hline Manufacturing & Companies \\
\hline Jabir Bin-Hayyan General Company & Al Hadir General Company \\
\hline Salah-al-Din General Company & Al Zahf Al Kabir General Co. \\
\hline al Karamah General Company & Al 'Izz General Company \\
\hline Ibn-Firnas General Company & Al Salam General Company \\
\hline Al Mansur General Company & Al Nida' General Company \\
\hline Al Nu'man General Company & Sab'a Nissan General Company \\
\hline Al Yarmuk General Company & Al Samud General Company \\
\hline al Majid General Company & Al Faw General Company \\
\hline Al Walid General Company & Al Radwan General Company \\
\hline Al 'Ubur General Company & Tariq General Company \\
\hline Saddam General Company & al Shahid General Company \\
\hline Hittin General Company & Umm-al-Ma'arik General Company \\
\hline Al Rashid General Company & Al Qa'qa General Company \\
\hline Badr General Company & Sinharib General Company \\
\hline Ibn-Rushd General Company & Sa'd General Company \\
\hline \multirow[t]{3}{*}{ Ibn-Majid General Company } & Tabuk General Company \\
\hline & Al Nasr Al'Azim General Company \\
\hline & Al Harith General company \\
\hline Front & Companies \\
\hline Al Bashair & Al Mufakhir \\
\hline Armos & \\
\hline
\end{tabular}

Source: ISG and the Duelfer Report 
I took the data from the ISG Report and the Duelfer Report. The data reflect the ranks of Iraqi military companies according to the size of their operational budgets. The Reports did not publish the actual numbers, and I could not find them in any other source. But digging into Iraqi (ISS and IIS) records, I found that, for example, Al Milad and Al Quds had the two largest Iraqi research front companies (ISS, p.116). Al Milad focused its research on missile systems while Al Quds focused on WMDs (IIS, p. 71) By the same token, among military manufacturing companies, Jabir Bin-Hayyan and Al Hair had the largest budgets (ISS, p.35; IIS, p. 78). Jabir Bin-Hayyan was the largest assemblier of components and equipment for Iraqi missiles. Al Hadir had the largest laboratories to process and test chemical and bacteriological substances in Iraq. For their part, Al Bash'ir, Al Mufakhir and ARMOS were procurement companies (ISS, p.42; IIS, p. 66). They had the largest procurement budgets among all Iraqi corporations. They procured components, equipment and technologies for both the Iraqi missile and WMD programs, while Mufakhir procured materials for the short-lived Iraqi nuclear program. Al Bash'ir and ARMOS emerged as the two largest, most important Iraqi front companies under the UN sanctions regime (Duelfer Report, 2004, Regime Finance and Procurement, p. 56). They contracted and subcontracted with hundreds of small companies throughout the Middle East to design, manufacture, refurbish, test and transport components for missile and WMD programs. These contractors had no direct relationship with the Iraqi government. They worked separately most of the time without knowing that, in the end, they produced for the Iraqi military.

MIC created Al-Basha'ir in 1991 (Duelfer Report, 2004, Regime Finance and Procurement, p. 56-57). Its CEO was Munir Mamduh Awad al-Kubaysi, a former 15-year 
employee of IIS. The company specialized in assembling. It had nine assembly plants dispersed throughout Iraq, some of them camouflaged in bunkers. It had another 19 assembly plants in Jordan, Syria, Turkey, Egypt, the four nations with which Iraq had Trade Protocol agreements (Duelfer Report, 2004, Regime Finance and Procurement, p. 56-67). Al-Basha'ir had one problem and one virtue. Its problem was that it was short of funding compared to its large, ambitious projects. Its virtue was that it was a great innovator in a nation so centralized that it left too little room for innovations. A careful research revealed that Al-Bashra'ir's main innovation was outsourcing. Through subcontractors, Al-Bashra'ir exported oil and, with the proceeds, purchased and imported military equipment and technologies, which it then channeled to its contracted manufacturers (Duelfer Report, 2004, Regime Finance and Procurement, p. 56-67).

According to the Duelfer Report, Mr. Munir, the CEO, established the Syrian Division through his friend Dr. Asif Shalish and his family. This Syrian family owned SES International, a procurement corporation with a dozen small companies in Syria (Duelfer Report, 2004, Regime Finance and Procurement, p. 74). Munir wanted SES to open more companies, not only in Syria but also throughout the Middle East and even in Europe if possible. For that end, Munir granted $89 \%$ of all Iraq's military procurement contracts to SES. Al-Basha'ir became the largest investor to SES, and Syria became the center of illicit procurement to Iraq's military industry. The company's name was found in hundreds of contracts to purchase technologies, weapons, "dual-use" materials as well as legitimate goods and supplies. SES smuggled the merchandise through the Syrian-Iraqi border with the complicity of Iraq's intelligence and secret services. This in part explains why it went undetected by UN inspectors (Duelfer Report, 2004, Regime Finance and 
Procurement, p. 74). Also, Al Basha'ir was the first Iraqi company to use humanitarian missions to smuggle military equipment into Iraq. Al-Basha'ir used a Bulgarian NGO known as JEFF Company to obtain spare parts for T-72 tank, artillery, and trucks. The NGO shipped the cargoes by air via Syria, Jordan and Turkey. Al-Basha'ir tallied those shipments as "Spare parts for air conditioning for hospitals" (Duelfer Report, 2004, Regime Finance and Procurement, p. 74-75; Albright and Khidhir, 1997, p. 59).

Fort its part, ARMOS was a front company that Al-Baha'ir created in 1998 in a joint-venture with Russia. ARMOS accounted for about 15 to $20 \%$ of Al-Baha'ir procurement contracts (Duelfer Report, 2004, Regime Finance and Procurement, p. 74). The Company's mission was to account for all military contracts with Russia. This included vital procurements for the Iraqi air force, helicopters, and missile defense systems. ARMOS purchased from Russia planes and helicopter engines in pieces to assembly them in Iraq (Duelfer Report, 2004, Regime Finance and Procurement, p. 116). ARMOS contracted an NGO to purchase components for the Iraqi missile project. The NGO was "The Russian Nuclear Disaster Victims Fund Institution" from Russia (Duelfer Report, 2004, Regime Finance and Procurement, p. 116). By 2003, ARMOS had spent $\$ 3$ billion dollars in Russian military products for Iraq's numerous military programs (Duelfer Report, 2004, Regime Finance and Procurement, p. 116; Albright and Khidhir, 1997, p. 60). ARMOS even expanded to markets like Bulgaria, Romania and Ukraine. There it spent about $\$ 700$ million in parts and components. ARMOS purchased from Poland 250 engines for Volga missiles (Duelfer Report, 2004, Regime Finance and Procurement, p. 121-123). In 2002, ARMOS paid \$70 million to a Cypriot firm to acquire and ship to Iraq a Bulgarian made electro-chemical lab. Other purchases, through the 
Cypriot intermediary, included about 65 types of substances for "fertilizers" and the petro-chemical industry (Duelfer Report, 2004, Regime Finance and Procurement, p. 139; Albright and Khidhir, 1997, p. 59).

According to the IIC, the Duelfer Report, and the CFIJ, Iraq used four main routes for its procurement programs. First, Iraq utilized Iranian territorial waters. Ironically, it did it with the consent of its archenemy: the Iranian government. Iranian coastguards even escorted the ships all throughout the zone. Second, Iraq utilized the Iraqi-Jordanian border. To camouflage this military operation, Iraq contracted the Land Transport Company, a front company Iraq created to carry out the terms of the Jordanian-Iraqi trade agreement of 1998 (Duelfer Report, 2004, Regime Finance and Procurement, p. 137142). Third, Iraq utilized the Iraqi-Syrian border. Again, Iraq assigned the operations to a civilian company created under the Syrian-Iraqi trade agreements. I should point out that there was a sharp increase of smuggling though this route when in 2001 Syria and Iraq reopened the rail tracks between Mosul in Northern Iraq and Aleppo in Syria. In June 10, 2002, the Times of London reported in headlines that Baghdad was using new rail tracks in Syria to smuggle military hardware. According to the article, the cargoes included old Bulgarian tanks, Czech-made Scud missile guidance systems, and surface-to-air missiles (Duelfer Report, Delivery System, p. 198; Albright and Khidhir, 1997, p. 59).

In all, Al-Basha'ir created hundreds of front companies to evade the UN sanctions and inspectors. The ISG accounted for nearly 230 such companies. Most of them closed operations after conducting just one or two transactions. Iraqi front companies were instrumental in procuring the materials necessary for the three primary military programs established by Saddam Hussein: the missile, chemical and biological programs. 


\section{Two Case Studies on Iraq's Rearmament: Missile and Chemical Programs}

Iraq's rearmament included conventional and non-conventional weapons, but my research focuses on non-conventional. Specifically, in this section I look at the missile and chemical programs. I examine how Iraq utilized agents and means of globalization to circumvent the UN sanctions regime and procure materials for its missile and chemical programs. I selected these two programs for four main reasons. First, the two programs complemented each other, meaning that Saddam wanted missiles armed with chemical agents. Second, by Saddam's own accounts, both programs were key parts of Iraqi deterrence policy toward Iran and Israel. The irony is that it did not deter the United States. Third, the programs required significant logistical, technical, and financial commitments from Iraq. Iraq's missile and chemical programs demonstrated that Iraq was capable of evading UN sanctions and inspectors. Fourth, they were the most scrutinized of all Iraqi rearmament efforts. They were scrutinized by the media, UN inspectors on the ground, intelligence services from the U.S. and Israel in particular, and two no-fly zones over Iraq enforced by American and British air forces.

\section{The Missile Program}

Iraq's missile program was the result of a 30 -year effort by the Iraqi regime. It was a secret that everyone knew. The UN knew about the program. The CIA and Israeli secret agencies knew about it. In fact, Iraq itself made it known as a means to deter Iran, Saddam‘s main security concern. Iraq began to build missiles in 1972 when it signed contracts with the Soviet Union. Iraq first focused on short-range missile systems, spending about $\$ 8$ billion from 1974 to 1988. Iraq also signed contracts with Yugoslavia, 
North Korea, Brazil and Argentina during 1980s (Duelfer Report, 2004, Delivery Systems, p. 3; Albright and Khidhir, 1997, p. 42). It was the "war of the cities" between Bagdad and Teheran that convinced Saddam of the need for long-range missiles and missiles armed with WMDs. This second aspect is important because, according to the CIA and ISG, at the time Iraq already had WMDs. Yet, all attempts to transport and drop them over Iranian territories had failed miserably. But the Independent IIC, after the IraqIran War Iraq had serious difficulties replenishing its missile stockpiles. The effort was too costly, mainly when oil prices were so low, and oil was Iraq's main source of revenue. Thus, Iraq chose to design and assembly its own missiles. The CIA and the ISG assure us that, by 1988, Iraq had its own assembly line ready to start production (Duelfer Report, Delivery Systems, p. 3-4). Iraq purchased enough components to assembly 1000 Scud-B missiles, most of them acquired from the Soviet Union, North Korea, Yugoslavia, and France (ISG, p. 229). Iraq bought components from the Soviet Union to assembly 400 Scud-B missiles and ground support equipment in two years. By 1991, Iraq had the technological capabilities to arm the Scuds with WMDs. The American led invasion of 1991 destroyed most of them (Duelfer Report, Delivery Systems, p.3-4; Albright and Khidhir, 1997, p. 53). The UN sanctions forced Iraq to rethink its rearmament.

UN Security Council Resolution 687 ordered Iraq to dismantle its long-range missile programs, but Resolution 687 allowed Iraq to develop and possess some types of missiles provided that they did not exceed the $150 \mathrm{~km}$ range (Duelfer Report, Delivery Systems, p. 17). The proposal came from Russia. China and France backed it up. The U.S. and United Kingdom agreed in an effort to get Russia, France and China to vote for the UN sanctions regime against Iraq. The U.S. imposed as condition that Iraq deploys its 
missiles along the Iraq-Iran border, pointing at Iran at all times. It was a great opportunity for Iraq because now it could legally work on missile projects it had put on hold for some years. Once the UN passed the new resolution, Iraq set itself two goals, which included rebuilding plants to manufacture missiles and establishing a procurement operation to acquire technologies, components and machinery. This takes us back to the central question of this dissertation: how would Iraq establish and implement its procurement program? Would globalization help? To answer this question, I examine the case of the Al Samud II missile.

The ISG always suspected that Iraq was secretly rebuilding its missile capabilities beyond $150 \mathrm{~km}$. It confirmed it when Husayn Kamil deserted the Iraqi regime in 1995. Kamil was Saddan's son-in law and, more importantly, Chairman of the MIC. He was in charge of the missile and WMD programs. Kamil confirmed that Iraq had already rebuilt 9 plants, which employed about 3,000 technicians and engineers working on eight assembly lines for three different missile models. Kamil also stated that Iraq had outsourced portions of the assembly lines to Syria and Egypt, and that Iraq was buying parts and machinery from Ukraine, Russia, Belarus, China and North Korea, Bulgaria, Yugoslavia and even American corporations (ISG, Annual Report, 1997, p. 91). Of course, UN inspectors and American intelligence services did not confirm everything Kamil said. They assumed that Kamil would inflate his information to obtain some benefits from it. UN inspectors investigated the allegation that American corporations were selling equipment and technologies to Iraq. This led to a paper trail followed up and published by the New York Time on September $16^{\text {th }}, 2002$. The trail connected the Iraqi regime to Huawei, a Chinese contract-manufacturer $(\mathrm{CM})$ that operated with technologies 
licensed by American corporations such as IBM, Digital Equipment Corp, Sun Microsystems, Qualcomm, and Motorola, among others. The Clinton Administration had granted permission to American firms to sell their technologies to Chinese entities, and Huawei was one of the beneficiaries. Another Chinese corporation, stated-owned, purchased some of Huawei's products and sold them to Iraq. Some of the products were microelectronics, transmission lines, fiber optics, receptors and respondent devices. They all are used in the missile industry.

$\mathrm{UN}$ inspectors later found that the Iraqi missile program had begun as early as 1993 when Saddam Hussein asked his most important scientists and engineers to work on a missile system capable of striking beyond $150 \mathrm{~km}$ (Duelfer Report, Delivery System, p. 17; Cordesman, 1998, p. 14). Saddam's project was both politically and financially risky; politically because it was a violation of UN Security Council Resolution 687 and financially because it was going to be expensive due to the costs of circumventing the sanctions regime. Saddam did not mind. He secretly brought in engineers and technicians from nations such as Russia, Ukraine, Belarus, Bulgaria, Yugoslavia, Romania, North Korea, China, France, Argentina, South Africa, and India (Duelfer Report, Delivery System, p. 79; New York Times, Sep. 16 ${ }^{\text {th }}$, 2002; Cordesman, 1998, p. 21; Albright and Khidhir, 1997, p. 61). Those technicians and engineers, along with Iraqi engineers, immediately began to work on a first project directly assigned by Saddam Hussein. The project consisted in a 400-1,000 km range solid propellant missile. Saddam Hussein called it Al Samud II. To procure the project, Saddam created the front company Al Karamah State Establishment, also known as Al Karamah General Company. The company included 16 plants in Iraq and dozens of contractors and subcontractors in 
Syria, Egypt and Lebanon. At some point, Al Karamah employed about 2,500 workers, including Iraqis and non-Iraqis (Duelfer Report, Delivery System, p. 166; Cordesman, 1998, p. 22; Albright and Khidhir, 1997, p. 61). Table 7.4 rights below represents the organizational assembly lines for the Iraqi missile Al Samud II. For the Table, I reproduced obtained from both the ISG and the Duelfer Report.

Table 7.4 - Organizational Assembly Line of an Al Samud II Missile

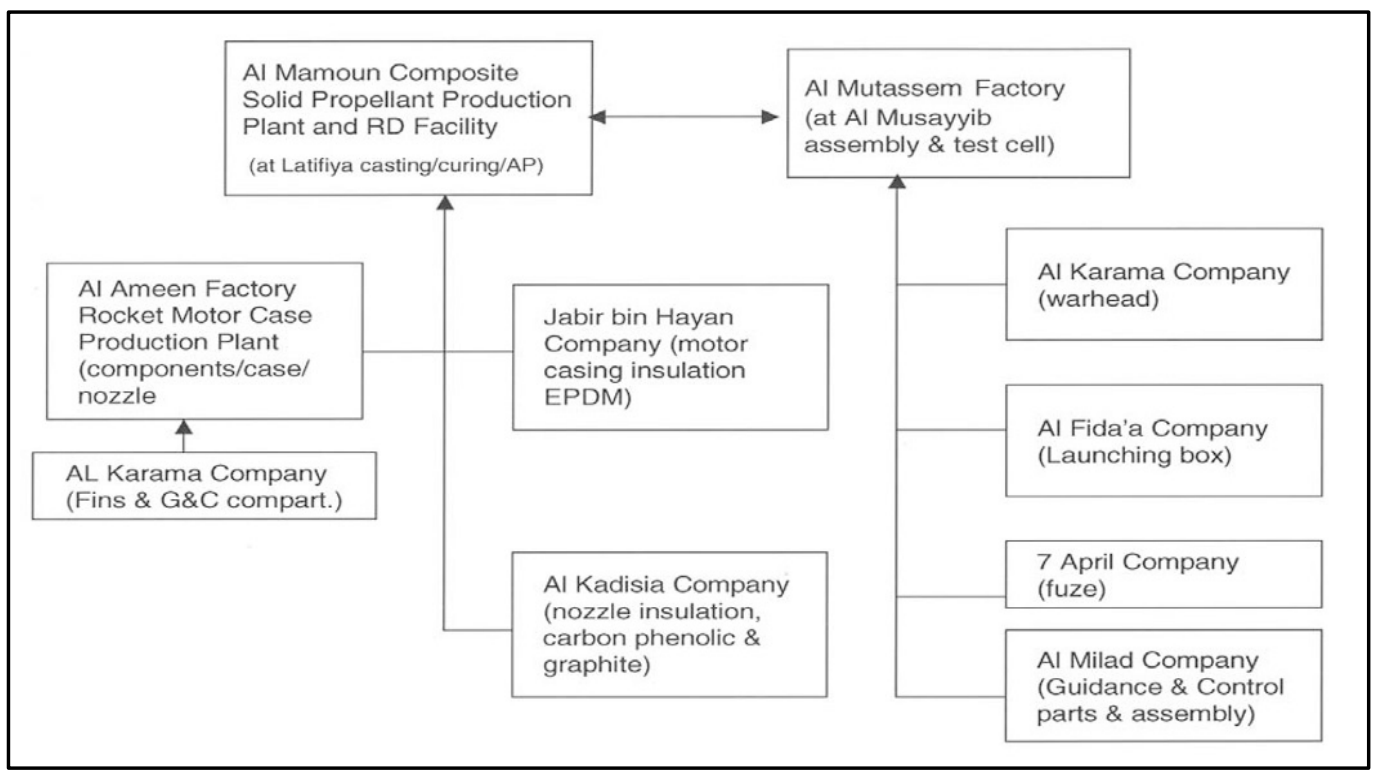

Source: ISG, the Duelfer Report,

The Table reveals that three factories and seven companies participated in assembling Al Samud II missiles, but in reality there were many more factories involved. The chart does not include them for two main reasons. First, a company can own several factories or plants. Second, and more importantly, Iraqi companies outsourced operations to private contractors or $\mathrm{CMs}$ to minimize costs and mislead $\mathrm{UN}$ inspectors and 
American intelligence services. The plants operated independently, and management and operators did not know each other. The plants were rather small with an average of 10-20 employees who were not aware of final product they produced (Cordesman, 1998, p. 79; Albright and Khidhir, 1997, p. 71). And the plants were located throughout Iraq, Syria, and Egypt. For example, data collected from the Duelfer Report and the Iraqi Survey Group (ISG) show that Al Ma'mun was located in Iraq, but its owner was a Christian Syrian émigré, living in Iraq for over 30 years. Al Ma'mun was the center of the manufacturing process, from research to manufacture and testing. But Al Ameen and Al Fida'a were based in Syria while Al Mutassem was based Egypt. They had Syrian and Egyptians employees, but the management was Iraqi, members of the Iraqi Intelligence Services (IIS). Still, note that each company specialized in assembling a piece of the missile, and only one plant would see the missile completely manufactured. This plant was Al Mutassern Factory at Al Mussayyib. It was responsible for putting together the final pieces of the missile and testing it (Duelfer Report, Delivery System, p. 172).

It is central to mention the role that former Federal Republic of Yugoslavia played in the Al Samud II project. The Duelfer Report and the ISG found data confirming that the government of Yugoslavia owned Yugoimport, a corporation that repaired and managed 32 small plants or shops to assembly portions of Al Samud II missiles. The government of Yugoslavia financed the operations (Duelfer Report, Delivery System, p. 181; ISG, p. 271; Cordesman, 1998, p. 29; Albright and Khidhir, 1997, p. 61).

Data collected from the Duelfer Report and ISG indicate that delegations from Yugoslavia and Iraq met from February $25^{\text {th }}$ to March $2^{\text {nd }}$ of 1999 in Bagdad. The Iraqi Minister of Defense headed the Iraqi delegation, and Major General Jovan Cekovic, 
Director General of Yugoimport, headed the Yugoslav party. The delegates signed a trade protocol. According to the Protocol, Yugoimport was to repair at least 21 Iraqi plants to assembly portions of Al Samud II missiles, for which Yugoimport would provide equipments and tools. For their part, the Iraqis had two proposals for the Yugoslavs. First, they wanted to manage the Protocol through the Iraqi-Syrian and Iraqi-Jordanian Protocols. Second, they wanted to pay not with currency but with crude oil and some of its derivatives. The Yugoslavian government agreed. They financed the operation through loans obtained from Infobank, the Belarusian state-owned bank. The Bank, in turn, issued bonds that the Yugoslavian government backed up. Yugoimport appointed Colonel Krista Grujovic as its representative in Bagdad. Colonel Grujovic traveled to Amman, Jordan, in 1998, where he opened several bank accounts for Yugoimport FDSP. He later named the accounts to MIKA, and later to MEGA, both Lebanese companies registered in Amman. In all, the operation lasted for about three years, during which the Iraqis manufactured and tested 70 missiles in cooperation with engineers and technicians from Yugoslavia (Duelfer Report, Delivery System, p. 166; ISG, p. 274; ISG, p, 129).

Next, I examine the second part of the missile program: the procurement operation. The operation was based on three pillars: purchase scrapped parts, target parts and products of dual use and, through the Iraqi Intelligence Services (IIS), recruit businessmen, military men, engineers and any individuals willing to go around the world buying components and technologies for Iraqi missile programs. As the Michigan Project commented in June 2002, "Saddam went in a shopping spree for his missile program."

Indeed, following the advice of his top engineers, Saddam authorized the purchase of scrap parts. My research shows that Saddam set up a procurement operation 
that targeted 271 corporations, businessmen, universities and NGOs from 31 nations (Duelfer Report, Regime Finance and Procurement, p. 154; Cordesman, 1998, p. 47; Albright and Khidhir, 1997, p. 65). I present here specific cases in which individuals, corporations, banks, NGOs, and nations worked together to circumvent UN sanctions and inspectors. These examples seem repetitious and similar at times, but it is okay: repetition and uniformity guarantee low costs, rapidness and efficiency in the global economy. I collected the data from multiple and diverse sources such as the CIA (Duelfer Report), the IIC, the ISG, CFIJ, the Brooking Institute, and Arms Control Today (ACT).

I start with Mr. Wiham Garbiyah, a Palestinian businessman. The particularity of this case consists in that Mr. Garbiyah was one among dozens of businessmen that the IIS recruited to help Iraq evade UN sanctions and inspectors. The IIS recruited Mr. Garbiyah for his 20 years experience as an importer of electronic devices and components from Asian nations like Taiwan, Japan, Singapore and South Korea. The ISG in fact found that "Illicit trade between South Korean companies and Mr. Garbiyah was largely limited to contracts signed for high technologies, such as military computer equipments, sophisticated communication and radar systems" (Duelfer Report, Vol.1, p. 47). The ISG also stated that "There is no evidence to suggest that the South Korean Government was complicit in illegal trade between Mr. Garbiyah and South Korean companies" (Duelfer Report, Vol. 1, p. 47).

Mr. Garbiyah began to work for Iraq in 1998 when he traveled to South Korea as the head of a group of engineers working for Al-Basha'ir Company, an Iraqi front firm. He closed a deal to purchase components to assembly communications systems for the $\mathrm{Al}$ Samud II missile. The deal was worth $\$ 51$ million dollars. The assembly plant was in 
Syria (Duelfer Report, Vol. 1, p. 47). In 2000, Mr. Garbiyah returned to South Korea. He struck a deal worth $\$ 44.4$ million dollars in which Techmec, a South Korean corporation, was to design for the Iraqis a computer to test missile launches and flights (Duelfer Report, Vol. 1, p. 47-48). The contract included building a $\$ 22$ million dollars facility in Bagdad to assembly circuit boards, integrated circuits and other microelectronic components. Also in 2000, Mr. Garbiyah mediated between the South Koreans and United Commodities, a front company from India. United Commodities purchased, on Iraq's behalf, components from South Koreans to assembly radios, radars, transponders and receivers. United Commodities also trained Iraqi engineers working for Salah-Al-Din General Company, a small Iraqi contract manufacturer (CM) to do the assemblage. In 2001, Mr. Garbiyah negotiated with LG Innotec, a South Korean corporation, a contract to purchase optical fibers, digital exchanges and CPU systems. The contract was worth \$22 million. Slah-al-Din General Company, an Iraqi shipping company operating under Lebanese flag, transported the cargo into Iraq (Duelfer Report, Vol. 1, p. 47). In 2002, Mr. Garbiyah met with representatives from Shinsung, Armitel, and Unimo, all South Korean companies. He negotiated several deals for Iraq's missile programs.

I could go on listing Mr. Garbiyah's business deals with South Korean corporations. In all, the ISG concluded that Mr. Garbiyah negotiated about $\$ 300$ million dollars with South Korean companies in a period of four years (Duelfer Report, Vol. 1, p. 50). The Michigan Project set the amount at $\$ 316$ million dollars (the Michigan Project, p. 132). But those amounts do not include what Mr. Garbiyah made through business deals with Russian corporations. 
I have explained throughout this dissertation that Russia played a distinctive role in Iraq's economic survival under the UN sanctions regime against Iraq. Russia was among Iraq's most important trading partners under the UN sanctions regime. Russia's outstanding trade relations with Iraq are linked to the former Soviet Union, which had been Iraq's second trade partner since the 1970s. The Soviet Union was the premier supplier of weapons to Iraq during the 1980 s, accounting for $50 \%$ of all Iraqi military purchases from 1981 to 1991. Since Russia was the economic and military engine of the former Soviet Union, it inherited the long-standing trade relations, including military relations that the Soviets had with Iraq. Consequently, Iraq became dependent on Russia's ability to supply spare parts, equipment and technologies. But Russia suddenly fell into an economic crisis during most of the 1990s, which affected its ability to supply spare parts to Iraq. Russian's military industrial output fell to almost zero. Russia was so short of money that it began to rely on the U.S. to safeguard its nuclear arsenals. To raise money, Russia began to sell its vast inventories of conventional weapons and technologies. Russian's decision coincided with Saddam's decision to purchase scrap parts for his missile programs. The ISG and the CIA calculated that Iraq purchased from Russia about $\$ 900$ million dollars worth of inventories and scrap parts from 1993 to 2003, and it was just for missile projects. Purchases included parts for anti-tank guided missiles, electronic jamming equipment, communication and guiding systems, start rotors, engines, launchers and radars (Duelfer Report, Vol. 1, p. 102). And Mr. Wiham Garbiyah was the mastermind of the negotiations.

Indeed, in September of 1994, Mr. Garbiyah visited Zagorsk, a city near Moscow and house of Mars Rotor, a Russian military conglomerates with long experience with 
guidance equipments (Duelfer Report, Vol. 1, p. 107). Mars Rotor was famous for having designed and manufactured the short mid-range missile SS-N-18. Iraqi technicians determined that they could use some of the SS-18 components for their Scuds and Al Hussein missiles. At the time, Mars Rotor was selling its inventories, particularly scrapped parts. So Garbiyah closed the deal with representatives of Mars Rotor. UN records show that on July 15, 1995, Garbiyah made his first shipment to Amman, Jordan (Duelfer Report, Vol. 1, p. 108). UN inspectors detected and intercepted it. But after that, Mr. Garbiyah successfully smuggled into Iraq 28 fiber-optic gyroscopes, 40 ring laser gyroscopes, 100 Volga rotors, 100 Volga starters, and 380 missile thermal batteries (Duelfer Report, Vol. 1, p. 102). Mr. Garbiyah kept making deals with the Russians throughout the 1990s, until 2001 when the Russian government banned him from entering Russia. The Russian decision was a reprisal to Iraq's ban on Mr. Vladimir Zhirinovsky, the nationalist Russian legislator and head of the Russian National Party but who had failed to pay Saddam millions of dollars for oil purchases.

Iraq also had Yuri Orshansky, a three-star Ukrainian general now purchasing scrapped parts from Ukraine, Belarus, Bulgaria, Romania, Czech Republic and Poland. UN inspectors found out about it in details in the year 2000 when they returned to Iraq to resume inspections of Iraq's military capabilities. UN inspectors found about 300 files concealed, apparently, in an abandoned office of a military manufacturing plant at $\mathrm{Al}$ Kawthar. One file revealed that the IIS recruited Yuri Orshansky to "Gain access to Ukraine's significant military production facilities, including plants in Ukrainian soil but that belonged to former Soviet space and rocket industries" (Duelfer Report, Vol. 1, p. 
119). For 5 years, Gen. Orshansky served as an intermediary between the IIS and various military corporations from ex-Soviet Republics and nations in Eastern Europe.

General Orshansky secured a deal with Aviation Trading House, a Russian small corporation specialized in export-import of military industrial equipments and machineries. For the enterprise, Gen. Orshansky created a small firm named Montelect, and he registered it as an industrial auditor. Livinvest, the financial arm of Ukrainian Air Force, financed the operations. The Lebanese shipping company Amsar Trading Co transported the cargo into Iraq. The deal accounted for six shipments of scrapped parts for short and long range missiles, totaling \$21 million each in 15 months. The shipment included \$7 million dollars worth of equipments for a small chemical plant that was going to manufacture tiethylamine (TEA) and other ingredients required to produce combustible for missiles (Duelfer Report, Vol. 1, p. 119). The plant in question was being rebuilt at a cost of $\$ 26$ million dollars. Iraq obtained the funds from Financial and Investment Bank of Jordan and the Central Bank of Syria.

Gen. Orshansky also helped the Iraqis obtain access to military corporations in Belarus and Bulgaria. Gen. Orshansky had been stationed in Belarus and Bulgaria as military attache during the 1990s. He had many friends there. And he knew well the political terrain of those two nations. So he visited Belarus in July of 1995 with a delegation from Badr State Establishment, an Iraqi front company (Duelfer Report, Vol. 1, p. 122). The objective of the visit was to negotiate the purchase of high precision machineries to refurbish scrapped parts. Badr was the Iraqi manufacturer of some components utilized for the Iraqi Al Hussein missiles, launched against Tel Aviv during the invasion of 1991. Badr's delegates paid special interest to Belstroyimpex and Visoky 
Vacuum Co., two Belarusian small firms that produced diamond-cutting tools, powder metallurgy, and highly sensitive plasma sprays to protect missiles from corrosion and heat. Badr and Belstroyimpex signed seven contracts with Iraq. Trading Company, a Syrian financial firm, loaned $\$ 70$ million dollars to finance the operations in exchange for a 10-12\% margin profit. The Belarusian Infobank kept an escrow account for the transactions. Also, Al Zarka Trading Co, a Syrian shipping firm, transported the cargoes from Belarus to Iraq via the free-trade zones of Aqaba, in Jordan (Duelfer Report, Vol. 1, p. 122-123).

Later in 1998, Gen. Orshansky and Badr's delegates traveled to Sofia, Bulgaria, where he introduced Iraqi delegates to JEFF, a Bulgarian corporation. According to the Duelfer Report, Mr. Orshansky's trip was private, and he claimed that he did not represent the Ukrainian Ministry of Defense. However, Iraqi records showed that the Ministry did cover the expenses of the trip and that the Iraqis later reimbursed the Ministry.

Bulgarians and Iraqis met for two days. They agreed that a delegation from JEFF was going to travel to Bagdad to "Evaluate the situation on the ground" (Duelfer Report, Vol. 1, p. 123-126). JEFF's personnel traveled to Bagdad two months later. They met with delegates of Basha'ir Corp, a leading Iraqi military corporation. Basha'ir proposed the used Iraq-Syrian trade Protocol as an umbrella for the deal. Basha'ir purchased from JEFF tandem warheads, launcher units, thermal imagers, testing and simulators software. SES International, a Syrian financier, paid for purchasing and operational costs. JEFF sold to Basha'ir $\$ 80$ million dollars worth of dual use machines (Duelfer Report, Vol. 1, p. 1123-126). The next Table shows some of them. 
$\underline{\text { Table } 7.5 \text { - Dual Use Machines and Technologies }}$

\begin{tabular}{|c|c|c|}
\hline Machine Type & Model & Quantity \\
\hline $\begin{array}{l}\text { Rotating double step compressor } \\
\text { Atlas-Copko }\end{array}$ & Type-Zr5-52 & 2 \\
\hline Bullet-Shear 1600 -Ton & Type SCK 1600 & 1 \\
\hline $\begin{array}{l}\text { Heavy duty vertical milling machine } \\
\text { with cross table }\end{array}$ & Stanko 65 A6 OF-11 & 1 \\
\hline Single column jig/grinder & SKOE-630 X 1000/PS2 & 1 \\
\hline Thread grinding machine & MIC GSU315-1X1000 & 1 \\
\hline Centerless grinding & Type 3E-184B & 1 \\
\hline Centerless grinding & Type 3E-183 & 1 \\
\hline Universal optical profile grinding & Dobeli UPFS $150 / 195 \mathrm{CNC}$ & 1 \\
\hline $\mathrm{CNC}$ vertical machine center & RV 501 & 2 \\
\hline Column drilling $\mathrm{M} / \mathrm{C}$ & $\begin{array}{l}\text { PM -28 } \\
\text { PMP-40 } \\
\text { PMC-40 }\end{array}$ & $\begin{array}{l}5 \\
5 \\
5 \\
\end{array}$ \\
\hline Double action press & $\begin{array}{l}\text { KG 5530-100t } \\
\text { KG 5532-160t } \\
\text { KG 5535-315t }\end{array}$ & $\begin{array}{l}1 \\
1 \\
1 \\
\end{array}$ \\
\hline Six spindle automatic machine & Type ASH-160 & 2 \\
\hline Universal cutting $\mathrm{M} / \mathrm{C}$ & Type FUW-250V & 1 \\
\hline Radial drilling $\mathrm{M} / \mathrm{C}$ & $\begin{array}{l}\text { Type } 553 \\
\text { Type } 554\end{array}$ & $\begin{array}{l}1 \\
1\end{array}$ \\
\hline Round M/C & & 1 \\
\hline Column drilling $\mathrm{M} / \mathrm{C}$ & PK 031 & 1 \\
\hline Eccentric press 25 Ton & PE $25 \mathrm{~A}$ & 1 \\
\hline Eccentric press 63 Ton & PE $63 \mathrm{~A}$ & 1 \\
\hline Eccentric press 100 Ton & PE $100 \mathrm{~A}$ & 1 \\
\hline Six spindle automatic $\mathrm{M} / \mathrm{C}$ & AS-32 & 1 \\
\hline Hydro copy lathe & Stanko IE 713 & 2 \\
\hline Centerless grinding $\mathrm{M} / \mathrm{C}$ & $\begin{array}{l}3 \mathrm{M} 182 \\
3 \mathrm{~A} 184 \\
\end{array}$ & $\begin{array}{l}1 \\
1 \\
\end{array}$ \\
\hline Six spindle automatic $\mathrm{M} / \mathrm{C}$ & Ash-160 & 2 \\
\hline Universal cutting machine & FSS-400V-2PS & 1 \\
\hline $\begin{array}{l}\text { Single action, single crank stamping } \\
\text { press } 160 \text { ton }\end{array}$ & Stanko Type K 18-232-02 & 1 \\
\hline Hydraulic press 100 ton & PHM-160A & 1 \\
\hline $\begin{array}{l}\text { Planner type double column milling } \\
\text { and boring }\end{array}$ & 6M6 10FI & 1 \\
\hline $\begin{array}{l}\text { Double column vertical boring } \\
\text { machine }\end{array}$ & 1525 & 1 \\
\hline Cutting planning $\mathrm{M} / \mathrm{C}$ & FLP1000 & 1 \\
\hline Die casting & Raper Werk ND 14-10-500 & 1 \\
\hline
\end{tabular}

Source: Iraqi Survey Group (ISG)

The UN created a list of codes for all goods allowed to export to Iraq under the UN sanctions regime. The name of the list was the Goods Review List (GRL). UN 
inspectors audited and approved each good upon arrival to Iraqi soil. But the goods in the chart had a use in both civilian and military industries. For example, the machines in the chart have a use in the oil industry, but the Iraqis found a use for them in the missile industry. They utilized some of those precision machineries to reshape metals and polytetrafluorethylene (PTEE), which is a special type of plastic used for rocket motor cases and propellant tanks. Machineries like CNC served to mold special patterns on metals. The Iraqis utilized them to reproduce and, particularly, refurbish scrapped parts for old discontinued missiles they were purchasing from the Russians, Ukrainians, Belarusians and others (Duelfer Report, Vol. 1, p. 127).

Gen. Orshansky also worked with Polish corporations. One of those corporations was Evax Corp, from which Gen. Orshansky purchased components for 380 engines for the Al-Rawa missile model (Duelfer Report, Vol. 1, p. 123-126). The shipments were to arrive through the port of Tartus, in Syria; yet, at an Iraqi port UN inspectors detected a shipment of 32 Volga rocket engines and 750 different types of components that included water and air pressure valves, radars, radio transmitters, and tow trucks to transport missiles (Duelfer Report, Vol. 1, p. 123-126). Additionally, Gen. Orshansky and Evax acted as intermediaries between two Australian corporations and Rabban Safina, an Iraqi front company. On Gen. Orshansky's behalf, Evax purchased from the Australians American-made 100 WAE-342 engines, 29 servomechanisms, 70 mechanical gyroscopes, and 20 MP2000 and 3200 VG autopilot systems. Evax sold them to Rabban Safina (Duelfer Report, Vol. 1, p.123-126). In another deal, Gen. Orshansky purchased military components and weapons systems on Iraq's behalf from Metropol Ltd, a Czech corporation. In a letter to Metropol, dated October 2001, the General expressed his 
interests -Iraq's interests- for industrial parts. Metropol responded that it had access to "Old Russian missiles and other equipments" (Duelfer Report, Vol. 1, p. 123-126). The Czech government wanted to get rid of its missiles because it could not maintain and did not need them. The Duelfer Report quoted an Iraqi official as saying that "After all the Czechs would not need the obsolete Russian arsenals for it'll soon be a member of NATO” (Duelfer Report, Vol. 1, p. 129). Gen. Orshansky purchased from Metropol 60 portable GPS jamming systems, radios and radars for cruise missiles (Duelfer Report, Vol. 1, p. 128).

Next, one the 300 files found at Al Kawthar revealed in detail how Iraqi engineers envisioned yet another approach to circumventing the UN sanctions regime and procuring components for Iraq's missile programs (Duelfer Report, Regime Finance and Procurement, p. 57). The approach consisted of purchasing parts of dual use in the global market from well-established global corporations. Note first that the UN sanctions regime defined "dual use" as "items that might be of use to the military, but were not specially or originally designed or modified for military use; the term dual-use can be contrasted with military goods that were specially or originally designed for use by the military" (Duelfer Report, Comprehensive Report on Chemical Welfare, p. 18). This included equipments, chemicals, raw materials, spare parts, technologies and software.

Here too the Iraqi Intelligence Services (IIS) were involved. The IIS recruited businessmen and supervised procurement operations. For example, according to the files, two Iraqi engineers recruited by the IIS needed a high precision electronic switch to create "controlled" electrical pulses to activate missile warheads once in the air. After searching through numerous catalogs, they found the switchers in a lithotripter, a 
machine designed to disintegrate kidney stones. They could care less about kidneys and stones. They needed about 3000 switchers, six per warhead. So they contacted Siemens, the German transnational. Siemens and Iraq had had a long trade relationship, so it was not hard for them to work out a deal. They did it under humanitarian licenses granted by the UN and sponsored by French-Arab Friendship, a French NGO. Siemens sold the 1200 switchers to the NGO. Siemens never confirmed nor denied the transactions, but the most important issue here is the novelty of the approach to procurement via goods of dual use (Duelfer Report, Regime Finance and Procurement, p. 61). Purchases like the one just described became a common practice for Iraqis. Every time they needed a component, they searched for products of civilian ends. They would contact the manufacturer and purchase a large quantity of the product. That was in effect the reason for the UN to boost the sanctions to goods of dual-use, which Iraq evaded anyway.

For example, the IIS recruited Mr. Xu Govan, a member of the Chinese High Committee for Electronic Warfare and a Professor in a Chinese university. $\mathrm{Xu}$ was an expert in electro-optics. The IIS recruited $\mathrm{Xu}$ in May $17^{\text {th }}, 2001$ for a monthly salary of $\$ 7,500$ and a bonus of $\$ 500$ per month (Duelfer Report, Vol.1, p. 428). The IIS filmed the recruitment. Xu's boss was Abd - Al Wahab, the head of the IIS at the Iraqi embassy in Beijing and director of the Iraqi procurement effort in China. Initially, Xu's job consisted in collecting information on products of dual use but related to missile technologies, communication in particular. Xu located infrared cameras, so Iraqi engineers could watch mid-range missiles while flying at long distances. He also located electronic equipment in Taiwan to test communication and guidance systems for Iraqi missiles. But in 2002, the IIS created a front company for $\mathrm{Xu}$, so he could purchase parts and technologies for 
Iraq's missile programs. They named the company CIEC Corp. Through it, Xu purchased laser tracking systems and infra-red cameras for radars for "civilian" aviation. He labeled the equipment as children's computer software (Duelfer Report, Comprehensive Report on WMDs, p. 428).

All in all, I would safely conclude that the Iraqi procurement operations allowed Saddam to begin assembling missiles around December 2001. Saddam's goal was to produce 10 missiles per month, an ambitious quantity for an embargoed nation. The files found at Al Karamah also showed that an Iraqi subcontractor had assemblied 20 Al Samud II missiles during the first two quarters of 2002 (Duelfer Report, Report on Delivery Systems, p. 439). Testing showed that it could reach $183 \mathrm{~km}$, a technical success for an embargoed nation.

In addition, during the period 1998-2002, Iraqi technicians worded on the Al 'Ubur SAM missile project. The missile carried an Al Fat'h rocket engine. With a singlestage ballistic launcher, it could exceed the $200 \mathrm{~km}$ range, $50 \mathrm{~km}$ more that what UN allowed under the sanction regime. Saddam Hussein ordered the design of a new missile that could range from 650 to $725 \mathrm{~km}$. Saddam wanted the missile ready in about one year. The project was terminated in 1999 due to poor technical feasibility, but it was resuscitated in 2001 with the $\mathrm{Sa}$ 'd, a project to develop a missile of $250-400 \mathrm{~km}$ range (Duelfer Report, Comprehensive Report on WMDs, p. 439). Iraqi scientists and technicians worked on the project until 2002 when, under pressure from the international community, Saddam Hussein accepted UN Security Council Resolution 1441 and allowed UN inspectors to return to Iraq. The table below represents some of the missile components that $\mathrm{UN}$ inspectors found when they finally came back to Iraq. 
Table 7.6 - Parts of Iraqi Missiles Accounted by ISG, CIA, and IIC

\begin{tabular}{|l|r|r|r|r|r|r|r|r|r|r|}
\hline & 1995 & 1996 & 1997 & 1998 & 1999 & 2000 & 2001 & 2002 & 2003 & Total \\
\hline Warheads & 18 & 24 & 61 & 79 & 86 & 102 & 127 & 127 & 109 & 733 \\
\hline Motors & 7 & 28 & 57 & 92 & 106 & 110 & 119 & 121 & 122 & 640 \\
\hline Airframes & 13 & 1 & 66 & 78 & 100 & 109 & 120 & 141 & 149 & 777 \\
\hline Sent to QC inspections & 0 & 9 & 24 & 53 & 60 & 88 & 82 & 90 & 72 & 478 \\
\hline
\end{tabular}

Source: ISG, the Duelfer Report, IIC, the Michigan Project

I draw three main conclusions from the data above. First, Iraq began recording this data in 1995. It is very unusual for a regime that, like most dictatorships, regarded record-keeping a means to survive political plots and purges. Since no data were recorded before 1995, I assume that, as the ISG and the Duelfer Report argued, Iraq did not purchase components for missile projects before 1995. After all, 1992-1995 was a period of deep financial and economic crisis for Iraq. Therefore, perhaps Iraq did not even have an ongoing missile project before 1995. If it did, it was in small in scope and used scrapped parts from missiles that Coalition Forces destroyed in 1991. Secondly, purchases show not only that Iraq had money but also that it managed to circumvent the sanctions regime. Third, observe that procurement consistently increased from 1998 on, precisely the year that Saddam Hussein expelled UN weapon inspectors from Iraqi soil. Also, note that despite the large purchases, Iraq sent 478 missiles to quality control (QC) for testing. Those are just too many missiles for a nation under a multilateral sanctions regime. Still, I assume that many missiles failed the testing process, after which they did not become operational and were not accounted for in the chart above. The next chart shows the number of missiles that the IIS, CIA, and Michigan Project accounted for as "operational" after the fall the Saddam in 2003. 
Table 7.7 - Iraqi Missiles Accounted as Operational by IIS, CIA and Michigan Project

\begin{tabular}{|l|r|r|r|}
\hline Missiles available & 260 & 256 & 259 \\
Missiles fired & 12 & 16 & 16 \\
\hline Missiles damaged/destroyed & 74 & 77 & 72 \\
Missiles captured & 159 & 147 & 143 \\
\hline Unaccounted for & 167 & 187 & 191 \\
\hline
\end{tabular}

Source: ISG, the Duelfer Report, IIC, the Michigan Project

First, note that the data do not vary significantly from source to source. There are three main reasons. On one hand, UN inspectors never had full access to Iraq's military arsenal because Saddam kept fooling them until he finally decided to expel them from Iraq. Saddam considered UN inspectors American and British spies. On the other hand, the American army seized most of Iraq's records and archives after the invasion of 2003. The CIA and other American intelligence services had full access to Iraqi archives while investigators from the ISG, IIC, Michigan Project and others worked with second hand, "contaminated" information, which they often shared. Nonetheless, what is notable here is that the Iraqi army had had between 256 and 260 missiles at its disposal in 2003. That is a number a bit high for a nation under a 12 year-old multilateral sanctions regime. More importantly, Iraq manufactured its missiles through a net of civilian contractors and subcontractors closely watched by Iraq Intelligence Services (IIS).

In sum, the evidence suggests that Iraq did rebuild a good portion of its missile defense after 1991. The ISG and the CIA concluded that Iraq had rebuilt one-third of the capacity that existed in 1991. The Michigan Project assures us that, by 2003, Iraq's missile capabilities were $25 \%$ short of what it had been in 1991 . But here I am not 
concerned about Iraq's operational missiles, although settling on a final number of missiles could constitute a good measure of Iraq's ability to circumvent the UN sanctions regime and the scrutiny of U.S. intelligence services. That is, manufacturing 200 missiles under a multinational sanctions regime is a big deal. It could us enough about how efficient and useful the sanctions regime might be. It could tell $\mathrm{s}$ us enough about the utility of conceiving and enforcing a sanctions regime in a global economy. Nevertheless, the key question here is how Iraq managed to acquire whatever amount of missiles it had from 1991 to 2003. In fact, the question is: how Iraq circumvented UN inspectors and American intelligence services? Evidences cited here suggest that Iraq relied on the agents and means of globalization to evade UN sanctions. Iraq utilized a network of secret agents, NGOs, banks and bank accounts, businessmen, corporations and corporate models, and even universities and scientists to circumvent the UN sanctions regime. Through them, Iraq purchased technologies, parts and machinery for its missile programs. In the next section I examine how Iraq attempted to rebuild its WMD program.

\section{Chemical and Biological Programs}

There are contrasting findings with respect to Iraq's possessions of WMDs during the UN sanctions regime. For example, the ISG found "No credible indications that Baghdad resumed production of chemical munitions thereafter the 1991 Persian Gulf, a policy ISG attributes to Baghdad's desire to see sanctions lifted, or rendered ineffectual, or its fear of force against it should WMD be discovered in Iraqi soil" (Duelfer Report, Vol. 3, p. 1). However, the ISG acknowledged that "Based on available chemicals, infrastructures, and scientist debriefings, Iraq probably had a capability to produce large 
quantities of WMDs", and that the Iraqi Intelligence Service (IIS) "Maintained throughout 1991 to 2003 a set of undeclared covert laboratories to research and test various chemicals and poisons" (Duelfer Report, Vol. 3, p. 3). UN inspectors confirmed that "Baghdad's declarations vastly understated the production of biological agents and we estimate that Iraq actually produced two-to-four times the amount of agents that it acknowledged producing" (Duelfer Report, Vol. 3, p. 3-4). For its part, the CIA recognized that "ISG did not discover chemicals or production units configured to produce key precursors or CW and BW agents" (Duelfer Report, Vol. 3, p. 3-4). The CIA cited ISG's own findings to affirm that "Site visits debriefs revealed that Iraq maintained its ability for reconfiguring and 'making-do' with available equipments as substitutes for sanctioned items" (Duelfer Report, Vol. 3, p. 4).

Note that in this report (Report on WMDs) the CIA's language is rather moderate, somehow opened for future findings and conclusions. In fact, later in the Duelfer Report the CIA reported that "Although Iraq's WMD was crippled by the Gulf war, its chemical industry began to recover in the mid 1990s. Subsequent changes in the management of key military and civilian organizations, followed by an influx of funding and resources, provided Iraq with the ability to reinvigorate its industrial base, its military in particular" (Duelfer Report, Vol. 3, p. 14).

My findings coincide with ISG's and CIA findings. Coalition Forces did destroy most of Iraq's WMD stockpiles during the Persian Gulf War of 1991, and thereafter UN inspectors kept Iraq in check, limiting for the most part Iraq's ability to complete any project related to WMDs. I also found that Iraqi claims of having destroyed WMDs unilaterally were true only in part. Iraq kept some of its infrastructure in conditions 
suitable enough to allow Iraqi engineers to return to WMD projects some time later. Yes, I found that from 1991 to 2003, Iraq neither possessed nor fully developed WMDs of any kind. But I emphasize the word fully because although Iraq did not succeed, it did attempt to develop WMDs. Yet, Iraq's WMD program after 1991 was not as vast as some "experts" predicted. Iraq itself was largely responsible for such failed predictions and the perception that the world had about its possession of WMDs even though evidences suggest that the Bush administration exaggerated Iraq's WMD capabilities to legitimize its invasion to Iraq. After all, most Iraqi officials, under interrogation, declared that Saddam too exaggerated the scope of Iraq's WMD programs to fool Iran and Israel (Duelfer Report, Vol. 3, p. 11).

There were still enough factual reasons to believe Saddam though. For example, the ISG calculated that Iraq invested about $\$ 3.5$ billion dollars from 1991 to 2003 to rebuild factories, purchase parts and equipments, and recruit scientists to produce WMDs (Duelfer Report, Vol. 3, p. 16). At some point, Iraq had about 2,000 engineers and technicians working on activities related to WMDs. Iraq spent nearly $\$ 400$ million dollars in research and development of chemical and bacteriological agents (Duelfer Report, Vol. 3, p. 22). Yes, $\$ 3.5$ billion dollars is not really enough considering that WMDs are expensive. It is actually a luxury of few rich nations such as the U.S., Great Britain, and France, which in fact develop and possess WMDs. But $\$ 3.5$ billion dollars is indeed a considerable amount of money for Iraq if we take into account that it was a nation under a multinational sanctions regime, apparently, heavily enforced and scrutinized.

Iraq's WMD Programs had three main phases: 1) the Edict of 1993 and the centralization of research in universities and labs; 2) the Edict of 1997 and the 
centralization of petrochemical, fertilizing and pharmaceutical industries; 3) the establishment of a procurement program.

\section{First Phase: The Edict of 1993}

The first phase officially began with the Edict of 1993, through which Saddam Hussein forced all Iraqi universities to conduct research for WMD Programs. The Edict consolidated all universities under an office of the Iraqi Intelligence Services (IIS). It also asked universities to search for funding in the private sector, although the Ministry of Defense and Saddam himself provided enough resources as to keep them busy. The Edict, as a result, triggered a nationwide competition among companies, universities, institutions and scientists for funding. As the ISG put it, "With the Edict of 1993, the IIC's Program for the Indigenous Production of Chemicals appears to have evolved into a nation-wide, pan-industry, pan-academia merit-base competition for projects, ideas and project implementation" (Duelfer Report, Vol. 3, p. 12-13).

Two universities in particular took over WMD research: the University of Baghdad and Saddam University. The University of Baghdad was the center of research for Variola (smallpox), Newcastle virus, chicken eggs vaccines and other pathogenic viruses. For its part, Saddam University was particularly relevant because Saddam personally funded and directed it. He would show up regularly without previous notice. He would ask questions, demand results, and punish those who failed.

The Edict of 1993 forced hundreds of Iraqi engineers and technicians to work in the WMD programs. Iraqi scientists and technicians had strong incentives to join the programs. First, the Iraqi government paid well. Second, Iraqi scientists did not really 
have a choice: they either worked for the government or Saddam would kill them. The ISG and the Michigan Project coincided in that "The issue of retaining scientists in Iraq was a Regime policy. Given the nature of the Iraqi economy, which offered limited possibilities for work at private chemical companies, it is not surprising that most key personnel from the former $C W$ program remained employed in the government chemical sector" (Duelfer Report, Vol. 3, p. 12-13). Nonetheless, the Edict financed the recruitment of hundreds of scientists and technicians from other nations, especially from former Soviet Republics and Egypt. I have previously mentioned that, at the time, most former Soviet Republics were going through a severe economic crisis, which affected all economic sectors, including universities and research institutions. Saddam paid well, so many former Soviet scientists were happy to join Saddam's laboratories and universities. Second, Saddam for many years relied on Soviet technologies and scientists. In fact, the three top Iraqi scientists, in charge of Iraq's WMD programs, obtained their PhDs at the Chemical Warfare Academy in Moscow, former Soviet Union. They were: Dr. Imad Husayn 'Abdallah Al 'Ami, Chair of Research and Development; Dr. Salah-al-DimAbdallah, Chair of Weapons Design and Toxicity Research; Dr. Hammad Shakir, Chair of Weapons Preparation and Planning.

Conversely, Egyptian and Iraqi scientists had worked together before. They worked to develop various WMD projects during the 1980s. For example, in 1983, they modified the $122 \mathrm{~mm}$ multiple launch rocket system to arm it with chemical agents. In 1984, Egypt sold Iraq rockets of the Grad model, capable of carrying chemical agents. In 1987, Iraq brought in Egyptian scientists to oversee research of Sarin and CW agents. Nationals and foreign technicians worked side by side in Iraq's WMD programs. 
Second Phase: The Edict of 1997

The second phase of Iraq's WMD program began in 1997 when Saddam issued yet another Edict to create the National Project for Pharmaceuticals and Pesticides (Duelfer Report, Comprehensive Report on Chemical Warfare, p. 24). Through NPPP, Saddam centralized all Iraqi industries that utilized chemicals in any way. The main objective was to guarantee what Saddam Hussein called the breakout capability (Duelfer Report, Comprehensive Report on Chemical Warfare, p. 24), namely the ability of Iraq's chemical industrial sector to produce and test CWs as needed. He argued that all industries, not only the chemical, had to be able to move rapidly from civilian to military production and back to civilian. NPPP supposedly focused on drugs and pesticides, but in reality NPPP's plants and procurements had dual purposes, meaning civilian and military. Iraq's industrial investments ensured such a duality, but, basically, Iraq halted chemical production for civilian purposes, and Iraqi engineers were told to "cannibalize" chemical plants to ensure production capabilities for military ends. As the ISG stated, "By cannibalizing production and equipments from civilian chemical facilities, it was possible for Iraq to ensemble production plants for chemical weapons (CW). Alternatively, equipments that were less suitable were reconfigured at an existing site and used for short-term limited production of civilian use" (Duelfer Report, Comprehensive Report on Chemical Warfare, p. 26). I found evidences suggesting that, in effect, Iraq was on its way to accomplishing its breakout capability policy.

One example is the case of Al-Dawrah, a small plant built during the 1980s to produce a vaccine for foot-mouth disease. American war planes bombed it in 1991. In 1996, Saddam asked the UN for permission to repair it, so it could produce a vaccine to 
fight a sudden outbreak of "foot and mouth" virus in some Iraqi rural areas. The UN objected, arguing that the organization could sell the vaccine to Iraq at a preferential price. But Saddam insisted and UN granted permission. One year later, UN inspectors found BW agents in the plant (Duelfer Report, Comprehensive Report on Chemical Warfare, p. 29). Other examples include the Amiriyah Serum and Vaccine Institute and the Fallujah III Castor Oil Production, which did produce several types of engine oil. But UN inspectors were always suspicious about the plant for two reasons (Duelfer Report, Comprehensive Report on Chemical Warfare, p. 45-50). First, it was situated next to an industrial park well-known as a center for research, testing and production of CW agents. Second, Iraq had in the past created resin-toxin, a key ingredient for BW and CW agents, from engine oil residuals. In 1997, UN inspectors found residuals of psychomimetic, mustard and nerve agents in the plants. And in 1998, UN inspectors found that work conducted on a biopesticide (Bacillus thuringiensis) and single protein (SCP) at Al Hakam was in fact a cover up for a research on dry anthrax spores (Bacillus anthracis) (Duelfer Report, Comprehensive Report on Chemical Warfare, p.45-50).

Those findings were so important that they eventually led to serious tensions between UN inspectors, the Clinton Administration, and the Iraqi government. The tension escalated in 1998 when UN inspectors discovered and unveiled the infamous Air Force Document, an Iraqi report that revealed extensive evidence of numerous Iraqi plants engaging in research, testing and production of chemical vectors and biochemical agents (Duelfer Report, Comprehensive Report on Chemicals Welfare, p. 13). The Michigan project argues that "The discoveries of 1998 and Saddam's subsequent 
demonstration of anger contributed to Saddam's decisions to suspend cooperation with UNSCOM and IAEA and expel UN inspectors from Iraq" (The Michigan Project, p. 74).

In effect, UN inspectors left Iraq in 1998. When they left, NPPP had just 4 companies, which in turn controlled about 9 small plants and a dozen very small laboratories. When they came back in 2001, they found that Iraq's chemical and petrochemical industries were booming, literally. When they came back, they found that NPPP had grown into a huge conglomerate of 70 companies and hundreds of small plants, laboratories, contractors and subcontractors. The Complex, as Saddam liked to call it, had a Board of Directors known as Research and Development Directorate (R\&DD). The ISG concluded that "Iraq was successful in procuring, constructing, and commissioning complete state-of-the-art chemical facilities, notably from 1998 to 2003 as its economy grew and UN inspectors left Iraq" (Duelfer Report, Comprehensive Report on Chemical Warfare, p. 11). NPPP was a true big enterprise with operations even outside of Iraq. So, the questions to ask are: how did Iraq do it? Where did it get the money? How did it acquire equipment, machineries, raw materials, entire plants? How did it smuggle into Iraq? I found evidences suggesting that Iraq did it by exploiting the means and agents of globalization. Indeed, in previous chapters, I showed evidences of how and why the Iraqi economy began to improve in 1997 as result factors such as: 1) the Oil for Food Program; 2) the emergence of domestic and regional black markets; 3) smuggling; 4) Iraq's ability to make allies willing to trade with Iraq; 5) Iraq's own ability to circumvent UN inspectors; and 6) Iraq's ability to manage scarce resources.

In 1998, NPPP led a major effort to rebuild Iraq's chemical and petrochemical industries. It began by creating Al-Furat State Company for Chemical Industries and the 
State Enterprise for Petrochemical Industries. These were two major complexes of small plants, labs and warehouses to produce fertilizers, pharmaceuticals, plastics, and other products. Consequently, Iraq's capacity to produce nitric acid tripled between 1998 and 2003, plastic production increased by $12 \%$ in 2000 , and PVC production increased by $105 \%$, just to mention a few examples (Duelfer Report, Comprehensive Report on Chemical Warfare, p. 30-36). Also in 1998, Iraq repaired and rebuilt: 1) Al Tariz, two plant at Fallujah to produce chlorine, benzyl alcohol, acetyl chloride, and phenols; 2) a plant to produce sulfuric acid and corrosion resistant metals at Al Qa-Qa'a ; 3) a plant for nitric acid, another one for sodium hydroxide, aluminum hydroxide, calcine, orthochloroanaline, ferrous chloride, and phosphorous in Karbala, 4) and another, known as Samara Drug Industries, for animal oils and mono-chloro-acetic acids at Samarra (Duelfer Report, Comprehensive Report on Chemical Warfare, p. 32-36).

Iraq could not do it alone. The Duelfer Report stated that Iraq built seven chemical plants and repaired another 9, in some instances with foreign collaboration (Duelfer Report, Comprehensive Report on Chemical Warfare, p. 40. For instance, Iraq rebuilt the Al Tariq complex with French collaboration. This plant processed about 60 different substances for the pharmaceutical and agricultural industries. UN inspectors visited the plants on several occasions. They found that the company imported concentrated pesticides used to produce nerve agents, and that (Duelfer Report, Comprehensive Report on Chemical Warfare, p. 32-36). Iraq purposely produced pesticides that carried substances similar to nerve agents. In addition, the Iraqi company Al Majid rebuilt a chemical plant in collaboration with the Germans to process multipurpose controllers of chemical mixes. The plant complied with the UN sanctions 
regime, but the production process enabled Iraq to divert resources and substances to labs and smaller plants working on WMD projects (Duelfer Report, Comprehensive Report on Chemical Warfare, p. 45-54). For example, the plant converted phosphate rock and white phosphate into a nerve agent precursor. The Germans helped Iraq to rebuild a second plant, known as Hutin Munitions Production and Storage Facility, where UN inspectors found about 30 gallons of phosphorus like the one used to produce phosphorus illumination rounds (Duelfer Report, Comprehensive Report on Chemical Warfare, p. 4554). In 1999, Iraq hired the Indian company NEC Engineers Private to rebuild a chlorine production line. A group of Iraqi technicians traveled to India to train on how to operate the plant. The plant became operational by 2000 , although I found no evidence of the plant being used to produce $\mathrm{CW}$ and BW agents. Finally, the Italians helped Iraq rebuild the Al-Qaim Superphosphate Plant. The plant converted phosphate into phosphoric acid and phosphorus compounds for highly reactive agents. Iraqi paid $\$ 41$ million for the repair (Duelfer Report, Comprehensive Report, Chemical Warfare, p. 45-54).

\section{Third Phase: Procurement Program}

The third phase of Iraq's WMD program included a procurement operation. Through it, Iraq managed to purchase a significant amount of chemicals to produce BW agents to arm its short, mid and long-range missiles called the Al Husayan Missile Project. During this period, Iraq was busy working on other projects as well, such as the Fahad-300, Fahad-500, Al Rohma (Javwelin) SAM, the G-1 and SA-1. They all were redesigned to carry biological agents. But the Al Husayan was without doubt the most important because it eventually became the core of Iraq's deterrence policy toward Iran 
and Israel. Ironically, the plan to arm the Al Husayan missile with biological agents did not deter the United States. Instead, the United States used it as the main reason for invading Iraq in 2003. The procurement program targeted 1,000 substances which Iraqi engineers considered vital to produce $\mathrm{CW}$ and BW (Duelfer Report, Comprehensive Report on Chemical Warfare, p.12). The list of substances were labeled according to order of importance, or as Saddam called it, order of emergency. So there was a "first," "second", and "third" order emergency. Below is the list of "first order emergency."

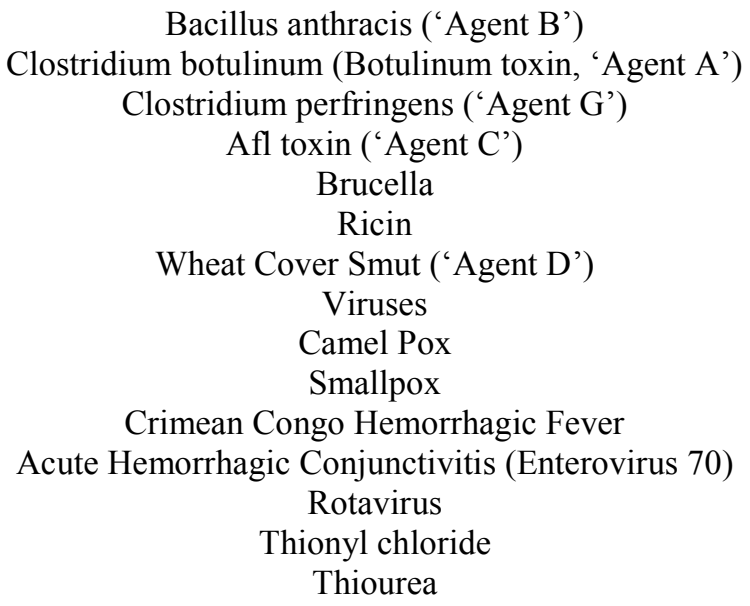

Source: ISG, the Duelfer Report, the Michigan Project

Here, it is central to note that all those substances are of dual use, and as the British Intelligence Services asserted, "Almost all components and supplies used in WMDs and ballistic missile programs are of dual-use. For example, any major petrochemical or biotech industry, as well as public health organization will have legitimate need for most materials and equipments required to manufacture chemical and biological weapon" (British Assessment on Iraq, Report on WMD Program, p. 27). The 
CFIJ argued that Iraq's WMD production is difficult to trace for "All key components are dual use items and can be used for peaceful medical purposes, food processing, and include everything from bio-medical equipment and micro-encapsulation equipment and food storage equipments" (CFIJ, Sources of Saddam's Money, p.7 7). Further, the Michigan Project found that "Iraqi research and production efforts can be widely dispersed and can be concealed in relatively small buildings, particularly if the government is willing to take moderate risks of the kind widely taken by the Soviet Union during the Cold War" (Michigan Project, Report on WMD, p. 167). Here, I should mention that the Iraqi WMD Program resembled very much the Soviet's in terms of design, components and scope. Iraq actually purchased must of equipment and chemical agents from the former Soviet republics. I have stated earlier, the most prominent Iraqi scientists working for Iraq's WMD program went to Soviet universities to train there.

\section{Combustible Materials for Missiles}

A central part of the Iraqi missile project was to procure combustible, or propellant, materials for missiles. Propellant was difficult and expensive to acquire, so Iraq decided to manufacture it. Since manufacturing required dozens of chemical compounds, the Iraqi regime assigned it to the WMD program under the supervision of IIS. Based on my research, I conclude that the project was multinational in scope, and that global commerce facilitated the use of a multinational procurement network where Iraq could acquire most of what it needed to manufacture propellants.

Iraq used two types of propellants: solid and liquid. I focus on liquid propellant because it seems to have been the most important for Iraq in terms of money invested and 
type of missile projected for manufacturing. Iraq invested $\$ 70$ million in two plants and one research lab for liquid propellant (Duelfer Report, Report on Delivery Systems, p. 68). The figure below shows Iraqi plants and labs engaged on research, production and testing of liquid propellant.

$\underline{\text { Figure } 7.2 \text { - Iraqi Plants and Labs for Liquid Propellant }}$

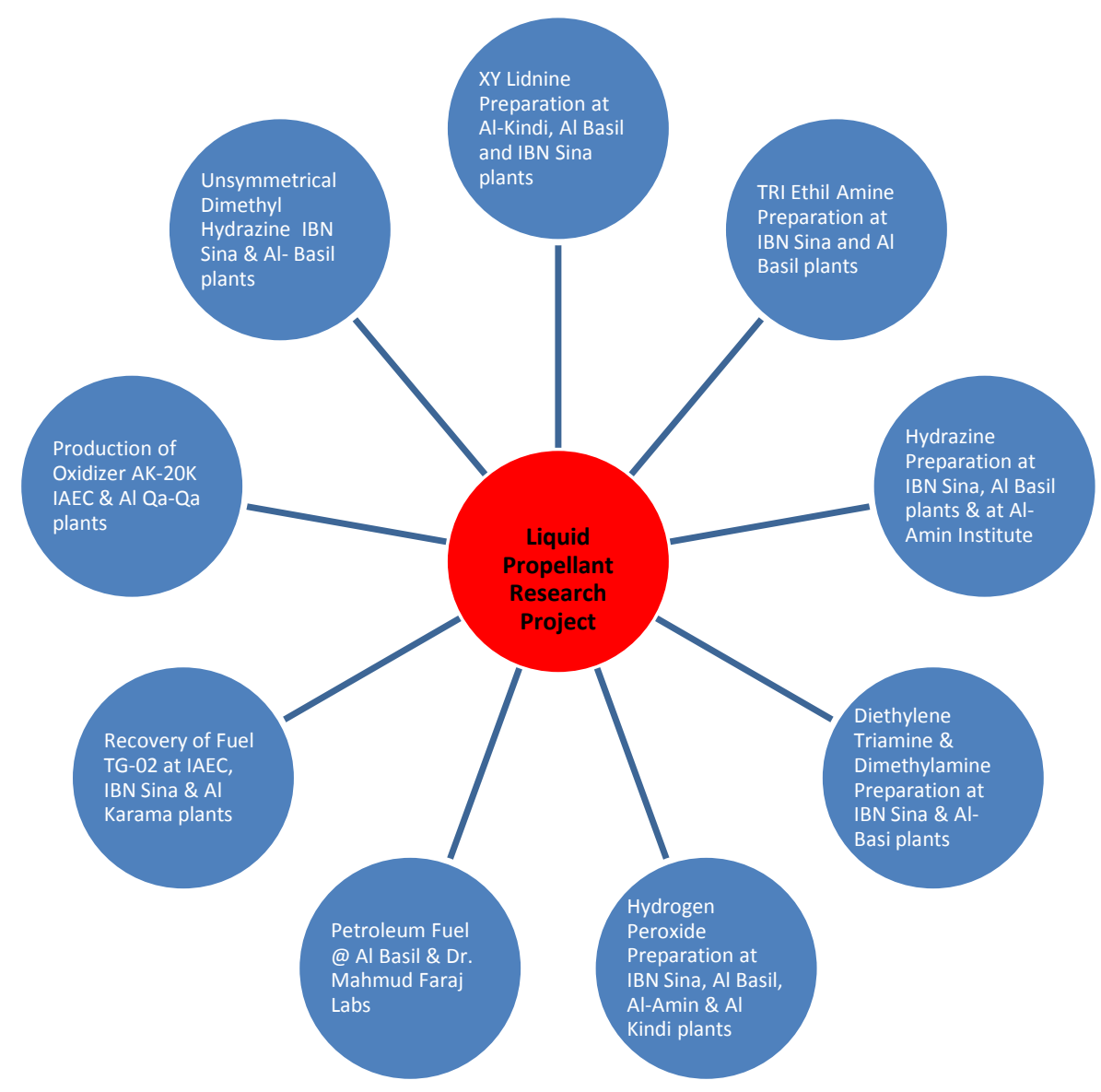

Source: ISG, the Duelfer Report, the Michigan Project 
Eight plants participated in the project. Three were located in Iraq, three in Syria, and two in Egypt. The plants had German technology. Iraq purchased them from Karl Kolb, a German firm. The ISG described the plants as "General multi-purpose pilot plants, which provided Iraq with plausible deniability regarding the plants and distancing Karl Kolb from being implicated in contributing to WMD programs" (Duelfer Report, Report on Delivery Systems, p. 69). In effect, the plants had been designed to process chemicals for fertilizers, pharmaceuticals, and petrochemicals, but now utilized parts of their facilities to manufacture liquid propellant.

I observed two points here. First, unlike before 1991, most of the new plants were rather small, employing from seven to ten employees. Small plants guaranteed discretion and flexibility, the ability to conceal illegal operations and to move from military to civilian production quickly in preparation for unexpected, unannounced visits by UN inspectors. Second, the products they produced were just a part or portion of a larger product, so employees would not know the true purpose of the products they produced. One individual, Dr. Mahmud Faraj, managed the entire project through a small Syrian corporation subcontracted by Al-Basil (Duelfer Report, Report on Delivery Systems, p. 66-74). Here too the process was decentralized, secretive and compartmented.

Iraq had to cope with the problem of procuring ingredients to produce the propellant. Once again, Iraq returned to the agents and means of globalization. For example, several contracts show that Iraq turned to Inaya Trading Company, a Chinese corporation, to acquire Diethylenetriamine (DETA), Hydrazine, Hydrogen, Xylidene and Triethlanmine, the main ingredients to produce liquid propellant for the mid-range missile AZ-11 (Duelfer Report, Report on Delivery Systems, p. 66-74). On the other 
hand, Iraq hired NEC, an Indian corporation, to act as intermediary. NEC established an office in Bagdad, in the same building as the Iraqi corporation Al Qa'qaa General Co. had an office. Al Qa'qaa was the Iraqi front company created to deal with NEC exclusively. NEC purchased 20 tons of methyl aziridinyl phosphate oxide (MAPO) from China to then sell them to Iraq through Al Qa'qaa. NEC purchased from France 200 tons of perchlorate (AP) and 120 tons of aluminum powder that were then sold to Iraq. NEC also acquired chloride, nitric acid, and unsymmetrical Dimethylhydrazine (UDMH) from a state-owned plant in India that was then sold to Iraq (Duelfer Report, Report on Delivery Systems, p. 64-74).

Below is a list of chemicals, part of a shipment belonging to NEC that UN inspectors intercepted and confiscated near the Iraqi-Syrian border.

\author{
Ammonium Perchlorate (AP) \\ Ammonium Perchlorate (AP) \\ Aluminum Powder \\ Hydroxyl Terminated Poly Butadiene (HTPB) \\ Dioctyl Azelate (DOZ) - or - Dioctyl Adepate (DOA) \\ Ferric Oxide \\ Toluene Disocyanate (TDI) \\ TriMethyl Aziridiny or Phosphine Oxide (MAPO)
}

Source: ISG, the Duelfer Report, the Michigan Project

After this incident, NEC proposed a new plan. NEC wanted Iraq to bring back production of those products to an Iraqi plant that had been bombed during the US-led invasion in 1991. NEC offered itself to repair the plant. Iraq granted permission to the NEC, along with a $\$ 52$ million loan drawn from an Iraqi account in Jordan National Bank (Duelfer Report, Report on Delivery Systems, p. 69). By 2000, the plant was already 
producing small quantities of substances like ferric oxide, dioctyl, chlorine and caustic soda. However, they could not use them because they did not meet quality standards. Then Iraqi engineers turned to Aerofina, a military firm based in Romania specialized in the production of liquid-propellant. Experts from the Iraqi firms Ibn Al Haytham and Al Karama signed contracts with Aerofina to purchase 25 tons of some of the substances (Duelfer Report, Report on Delivery Systems, p. 69-71). As part of the deal, Romania's Industrial Group of the Army agreed to purchase, if needed, more of those substances from Russia. Romtechnica and Turbomechanica, parent companies of Romania's Industrial Group, executed the freight-forwarding and shipping to Lebanon, where GIARA, an intermediary, smuggled it into Iraq (Duelfer Report, Report on Delivery Systems, p. 68).

For their part, Iraqi front companies purchased directly from French, Italian, and Brazilian corporations. For example, the ISG found that Iraqi front companies Al Sharquivah, Al Maghib and Al 'Ayan, all of them established in Syria, purchased 126 tons of aluminum powder from France. The Iraqi front company Al Sharquiyah, based in Jordan, purchased 40 tons of hydroxyl-polybutadience (HTPB) from an Italian petrochemical. Al Sharquiyan also purchased 60 tons of dioctylazelate (DOZ from a Japanese intermediary and 10 tons of resin-phenol from South Africa (Duelfer Report, Report on Delivery Systems, p. 57-67). This last purchased caught the attention of UN inspectors, members of ISG, because Iraq actually had a plant north of Baghdad that produced resin-phenol. It seemed that Iraq preferred to import the product than to manufacture it itself. Nevertheless, Iraq also paid $\$ 80$ million to a Brazilian corporation for carbon fiber filaments (Duelfer Report, Report on Delivery Systems, p. 69). This 
material is a key ingredient for missile construction. It has unique material properties like weight, flexibility, and durability. It stands well the heat of the dessert. This is important because carbon fiber filaments are used, among other things, to ignite engines and warheads. Eventually, Iraq built a plant with Russian and French technologies to produce carbon fiber. The plant began production in August 2002 (Duelfer Report, Report on Delivery Systems, p. 69).

\section{The Unmanned Aerial Vehicle Project and WMDs}

Another key part of the missile and WMD programs was a project for an unmanned aerial vehicle (UAV) armed with chemical and/or bacteriological agents. The CSIS said of this Program that " $U A V$ and slow flying civilian aircraft make excellent delivery systems of WMDs. They do not produce major indications of testing and development, and are inherently difficult to detect and track to a given source and location" (Duelfer Report, Report on Delivery Systems, p. 42).

The UAV was a very ambitious and challenging project for a nation under a multilateral sanctions regime. Even the U.S., the richest nation in the world, had not yet fully developed an unmanned aerial vehicle, today known as "drones". In fact, at the time, Israel was working on a UAV, which later proved useful to the U.S. in designing its own UAV. But for Iraq, a UAV constituted a technological puzzle, a procurement nightmare at a huge financial risk, none of which it could afford. The UAV project was a caprice of a dictator.

Iraq did not mind. I found that Iraq had first tried to develop a UAV before 1991 as part of its overall military strategy toward Iran. Iraqi engineers experimented with the 
Russian fighter jet MIG-21. They promptly abandoned it due to technical difficulties that they could not reconcile. The jet was too heavy to lift up when armed with liquid chemicals, and it was too fast to drop them on time to hit its target. According to SIPRI, Iraqi engineers tried for a while with the French Exocet missile technology and Mirage jets, but they gave it up as well. Then, after 1991, and despite the UN sanctions regime, Saddam Hussein kept funding the program. This time they tried with an L-29, a plane that the Russians used to train pilots. It was a success. Even the CIA stated that "Given the time, most likely (Iraq) would have produced some UAVs even with greater payload capabilities” (Duelfer Report, Report on Delivery Systems, p. 42).

Evidences show that Russian technicians gave a big boost to the Iraq's UAV program. But after long discussions, Iraqi technicians opted for the advice of Dr. Olga Vladimirovna, from Ukraine. She reasoned that, given the unstable economic and political situation in Russia, Iraq should not rely solely on Russian procurements. Russia in fact was having problems complying with the several procurement contracts that it had with Iraq at that very moment. Dr. Vladimirovna further recommended that Iraq should design a UAV capable of using components from different sources, particularly from China, North Korea, and France (Duelfer Report, Report on Delivery Systems, p.4 2).

The Duelfer Report and SIPRI found, in separate researches and reports, that Iraq never really managed to assembly more than two UAVs, but it did purchase most of the parts and components needed to build 12. It purchased them from 14 nations. For instance, the Iraqi UAV model Al Musayara-20, posted by the Duelfer Report in its website, was really a Russian L-29 with British WAE-342 piston engines, French MP2000 and 3200VG Micropilots, German embedded GPS cards, Chinese guidance 
software, Taiwanese radios, and Argentinean radars. The launching ramps were North Korean, Russian and Ukrainian. The testing equipment was Brazilian made, and the simulators were from Belarus (Duelfer Report, Report on Delivery Systems, p. 42-54). The entire project could not be more multinational.

Yugoslavia played a key role in procuring materials for the UAV project. The Duelfer Report reported in 2000, a group of American soldiers found 60 computer hard drives while searching a military base at Bijeljin, Bosnia-Herzegovina. Among other things, the hard drives revealed discussions between Yugoslavian and Iraqi officials related to procurement for Iraq's UAV project. Just to mention three examples, the two delegations discussed the sale to Iraq of 20 R13-300 and R25-300 overhauled jet engines. ORAO Aviation Company from Yugoslavia made the sale, worth $\$ 70$ million dollars (Duelfer Report, Report on Delivery Systems, p. 57-58). Yugoimport, another Yugoslavian company, sold to Iraq parts and equipments to test the jet engines. The deal was worth $\$ 18.5$ million dollars. The Iraqi company Al-Basha'ir paid a Lebanese shipping firm to transport the cargo from Bosnia to Turkey and then to Iraq. Al-Basha'ir paid \$300,000 for transportation (Duelfer Report, Report on Delivery Systems, p. 58-59). The hard drives also revealed financial records related to the operations, and that the President of Yugoslavia had a bank account in the Bank of Jordan which did not have a specific name. All it said was "the President of Yugoslavia." The Iraqi front company AlBasha'ir made 12 consecutive deposits of $\$ 2$ million dollars on that account, from where it was directed to an account that belonged to the Yugoslavian embassy in Amman, Jordan (Duelfer Report, Report on Delivery Systems, p. 57-58). 
In all, I found that Iraq did not really go beyond planning and trying to recreate the WMD program it had before 1991. Iraq had a WMD program in the form of a procurement program to acquire materials and equipment necessary to rebuild its chemical industry, which in turn would allow the production of WMD agents. However, Iraq never came near producing the final product, meaning a $\mathrm{CW}$ and/or BW readied to kill. Such a contradiction is reasonable: Iraq had a WMD plan to deter its archenemy Iran; but it never implemented it to avoid provoking the U.S.

\section{$\underline{\text { Conclusion }}$}

In this chapter, I examined a key question of this dissertation: whether or not the agents and means of globalization allowed Iraq to rebuild its missile defenses and acquire WMDs. With respect to the missile program, the Duelfer Report stated that "After the flight of Husayn Kamil in 1995, Iraq admitted that it had hidden Scud-variant missiles and components to aid future reconstitution of missile defenses" (Duelfer Report, Delivery Systems, p. 1). The ISG argued that "Between 1991 and 1998, Iraq had declared development programs underway for liquid and solid propellant ballistic missiles and unnamed aerial vehicles (UAVS)" (Duelfer Report, Delivery Systems, p. 74). I found that Iraq utilized agents and means of globalization to rebuild both its missile and WMD program. In this chapter I showed an array of cases in which Iraq and companies, banks, NGOs, secret services, universities, businessmen, scientists and others actively participated in violations of the UN sanctions regime. In particular, I found that Iraq utilized globalization, meaning the agents and means of globalization, to purchase 
technologies, industrial machineries, components and spare parts. Iraq also utilized globalization to decentralize its domestic military manufacturing industry and instead build regional networks of ensemble lines.

With respect to the WMD Program, the ISG found that "Given the circumstances “Iraq's WMD program grew tremendously during the 1996-2003. Iraq was able to conceive a procurement network, regroup skilled scientists and technicians, and work on projects financially and technically challenging for an embargoed nation" (Duelfer Report, Comprehensive Report on WMDs, p. 18). For my part, our findings pretty much coincide with that assessment. Iraq did attempt to rebuild its WMD programs. I showed in this chapter evidence of how Iraq employed its IIS, universities, companies, businessmen, scientists and even other nations to acquire equipment, labs, and chemicals to attempt to produce WMDs. Note that I emphasize "attempt." I do it because I did not find any evidence that Iraq produced, obtained, and stored WMDs. No one found WMDs in Iraq after the U.S. invasion of 2003. 


\section{CONCLUSION}

In this dissertation, I examine the limits of multilateral sanctions regimes as instruments of foreign policy. I argue that the political economy of contemporary globalization jeopardizes the overall efficacy of multilateral sanctions regimes. In particular, I hypothesize that six key features of globalization undermine the effectiveness of a sanctions regime. They are: 1) intense global competition among nation-states for strategic raw materials; 2) the nature of global trade fragmented by bilateral and regional trade agreements; 3) proliferation of global non-state actors such as NGOs, religious organizations, banks and corporations equipped with global instruments such as transportation, communication and mass media; 4) the nature of an international banking system built on transnational credit, electronic moneys, offshore accounts, and other means of moving capital throughout global markets; 5) proliferation of global corporate models such as subsidiaries, dormant, shell, and parent companies; 6) the global production process, reconfigured around a global assembly line linked to contract manufactures and regional manufacturing centers. Those six aspects form two specific blocs of features: agents and means of globalization. Agents of globalization are: corporations, NGOs, political parties, empowered individuals and others. Means of globalization are: global trade, the global banking system, corporate models, and the global manufacturing process or the global assembly line. To test my hypothesis, I utilize as case study the multilateral sanctions regime that the UN imposed on Iraq. I ask two central questions: 1) whether or not globalization allowed Iraq to circumvent the sanctions regime; 2) Did globalization allow Iraq to rearm and acquire or manufacture WMDs? 
My findings support the hypothesis of this Dissertation. On the first question, I find that globalization does undermine the efficacy of a sanctions regime. Globalization allowed Iraq to circumvent UN sanctions and inspectors. On the second question, I find that globalization allowed Iraq to access regional and global markets where it purchased technologies and components for its rearmament programs, including its missile and WMD programs.

For example, my findings in Chapter I show that a global demand for oil constituted a central motive for nation-states to violate the UN sanctions against Iraq and purchase Iraqi oil. In particular, geopolitics among permanent members of the UN Security Council, namely their interests in securing access to Iraqi oil wells, weakened the scope of the sanctions and the efficacy of enforcing them. Also, national interests contradicted corporate interests. For instance, whereas the British and U.S.'s governments were the leading voices behind the UN sanctions regime, British and American corporations were among the leading profiteers despite the sanctions. Then, I find in Chapter III that the fragmented nature of global trade allowed Iraq to circumvent UN sanctions. Iraq accessed global trade through a number of trade agreements it signed with about 25 nations, particularly with Jordan, Egypt, Turkey and Syria. Those Agreements opened two-way trade routes: Iraq shipped its oil to global markets through Jordan, Egypt, Turkey and Syria. In turn, those nations attracted trade from all around the world, which Iraq accessed through its trade protocols. Here, geography, history, a common language and traditional trade ties facilitated the circumvention of sanctions. Iraq also utilized geopolitical conflicts in the Middle East to attract support against the UN sanctions regime. 
Next, in Chapter IV I find that NSAs contributed to violations of the sanctions regime against Iraq. Individuals, NGOs, political and religious groups, banks and businesses of all sorts worked together, and in many cases with Saddam's regime, to evade the sanctions and profit from them. Here, one key finding is that political and civic activists, NGOs, religions organizations and political parties did not have the required expertise to finance and carry out the contracts they obtained from Saddam's regime. They passed their contracts on to banks and corporations. They ultimately executed the operations, which I discuss in Chapters V and VI. For instance, in Chapter V I examine the global banking system and how it financed trade under the UN sanctions regime against Iraq. I conclude that the current global banking system allowed nation-states, banks, investors, speculators, corporations, and nonstate actors in general to operate and profit under the UN sanctions regime. On one hand, I show evidences of how the Iraqi banking system actually expanded throughout the Middle East under the UN sanctions regime. Iraq utilized domestic and regional banking to reach global banking. It is worth noting that when the UN conceived and implemented its sanctions against Iraq, it basically ignored the hawala, the credit system that Iraq and most Middle Eastern nations had been using for centuries. The hawala system was essential to finance small businesses that sought to trade under the UN sanctions regime. On the other hand, I conclude that corporations, traders, speculators and even nation-states such as Belarus, Ukraine, Russia, Bulgaria, and Vietnam utilized banks and the global banking system to conceal their wrongdoings and launder money. They did it through banking instruments such as letters of credit, wire transferring, offshore accounts, and multiple layers of bank accounts for their affiliates, subsidiaries, and parent companies. 
For its part, Chapter VI is about corporations and their various corporate models. Corporations, including Iraqi's, utilized corporate models to circumvent the UN sanctions regime in Iraq. On the one hand, the government of Iraq employed corporate models to operate in local, regional and global markets. On the other hand, foreign corporations employed corporate models to evade UN sanctions and inspectors and reach the Iraqi market. Both the Iraqi government and corporations utilized corporate models to conceal their wrongdoings and laundry their profits. That is precisely why corporations intricate corporate models and their modus operandi. They aim at outmaneuvering governments, regulatory institutions and regulators. They want to avoid responsibility and accountability. In fact, one thing that UN and the US can learn from corporate the UN sanctions regime against Iraq is how corporations operate under globalization and global regulatory regimes such as WTO, GATT and sanctions regimes as instruments of foreign policy. Knowing how corporations operate the modus operandi, policy makers can target specific trends and models. Law enforcers would know where to look at and how to trace and gather evidences.

Finally, in Chapter VII I examined a key question of this dissertation: whether or not the agents and means of globalization allowed Iraq to rebuild its missile defenses and acquire WMDs. I conclude that globalization, namely the agents and means of globalization, allowed Iraq to access the global market, purchase technologies, industrial machineries, components and spare parts, and hire technicians and engineers from around the world. Globalization also allowed Iraq to decentralize its military manufacturing industry and disseminate it's a regional network of ensemble lines to ensemble, research and test its missiles. With respect to the WMD Program, my findings show that Iraq did 
attempt to rebuild its WMD programs. I showed evidences of how Iraq employed its IIS, universities, companies, businessmen, scientists and even other nations to acquire equipment, labs, and chemicals to attempt to produce WMDs. Note that I emphasize "attempt." I do it because I did not find any evidence that Iraq produced, obtained, and stored WMDs. No one found WMDs in Iraq after the U.S. invasion of 2003. But the objective of this Dissertation is not to find WMDs in Iraq. Rather, the main goal was to find evidences of whether or not globalization undermines the effectiveness of a sanctions regime and, in the case of Iraq, how globalization could have helped Iraq circumvent UN sanctions and inspectors to rebuild its WMD programs. According to my findings, the answer is positive. Globalization undermined UN sanctions against Iraq, and thanks to globalization Iraq acquired enough technologies, components and technicians to rebuild the infrastructures of its missile and WMD programs to levels unacceptable to UN resolutions on the issue and US's policy toward Iraq and the Middle East.

Overall, my findings have direct relevance with respect to the current U.S. policy of economic sanctions as a means to force Iran to give up its nuclear program. The policy could face setbacks in terms of diplomacy. That is, like in the Iraqi case, the U.S is confronting serious difficulties when trying to obtain support for a multilateral sanctions regime against Iran. For example, the U.S has not found support in the UN Security Council, where France, China, and Russia adamantly oppose such a regime against Iran, a nation in which they hold of economic interests. Also, the U.S has not found support from Middle Eastern nations against Iran. In addition, like in the Iraqi case as well, Iran can circumvent sanctions regime through neighboring nations such as Iraq, Afghanistan, and the ex former Soviet states in the north. 
In fact, the US has been confronting serious obstacles when enforcing a sanctions regime against Iran. Diplomatic dispatches recently leaked to the public by Wikileak confirmed what the Wall Street Journal, New York Times, Financial Times and Fox News have been reporting for quite some time: China, Russia, France and North Korea have been selling to Iran technologies and components for Iran's nuclear industry. The problem is that they can also be used for military nuclear purposes. For example, in 2010, the Wall Street Journal reported that Iran purchased hardware to enrich uranium from a Chinese company. Note that the Chinese company complicated its transaction just like many corporations did under the UN sanctions regime against Iraq. That is, the Chinese company bought the hardware from a French firm, which in turn had purchased it from a subsidiary of Tyco International, a U.S. industrial conglomerate. Another Wikileak's cable revealed that in 2009, US diplomats blocked a deal between a Russian and Chinese corporations that wanted to sell to Iran 66,000 pounds of tungsten copper. The mineral is a central element for missile-guidance systems. Wikileak also reported that "China brushed off several U.S. requests to stop Iran-bound shipments of technology and materials that could be used in ballistic-missile and chemical-weapons programs" (Cablegate, www.wikileaks.com). Another cable confirmed that "China declined to act on multiple U.S. requests that it stop shipments of ballistic-missile components from North Korea to Iran on commercial flights via the Beijing airport in 2007" (Cablegate, www.wikileaks.com). Still a third cable described how Secretary of State Mrs. Clinton asked China to prevent Chinese corporations from selling to Iran gyroscopes and carbon fiber for Iran's ballistic missiles. What it is more striking is that the Chinese government, in its reply to Mrs. Clinton, argued that "China, just like the US and other nations, cannot 
control its exports and enforce its exports laws under globalizations" (Cablegate, www.wikileak.com). 


\section{BIBLIOGRAPHY}

-Aaronson, S; Reeves, J. (2002) Corporate Responsibility in the Global Village: The Role of Public Policy, National Policy Association, Washington DC.

- Aguilera, R. and G. Jackson (2003) "The Cross-National Diversity of Corporate Governance: Dimensions and Determinants", Academy of Management Review, 28(3), $447-465$.

- Albert, Michel. (1991) Capitalisme Contre Capitalisme, Paris, Seuil.

-Albright, David and Mark Hibbs, "Iraq's Nuclear Hide and Seek", Bulletin of Atomic Scientist, Vol. 47, No. 7, September 1991

-Albright, David and Mark Hibbs, "Iraq's Shop-Till You Drop Nuclear Program", Bulleting of the Atomic Scientists, Vol. 48, No. 3, April 1992

-Albright and Khidhir Hanza, "Iraq's Reconstitution of its Nuclear Weapons Program", Arms Control Today, Vol. 28, No.7, October 1998

-Andrews, David M., "Capital Mobility and State Autonomy: Toward a Structural Theory of International Monetary Relations", International Studies Quarterly, Vol. 38, No. 2 (Jun., 1994), pp. 193-218,

-Anheier, Helmut (2001) Global Civil Society 2001, Oxford: Oxford University Press.

-Arndt, S.W. (1997) "Globalization and the Open Economy", North American Journal of Economics and Finance, 8(1), pp 71-79

-Arquilla J. and D. Ronfeldt (1996) the Advent of Netwar, Santa Monica: RAND,

-Axelrod, Robert (1981) the Emergence of Cooperation among Egoists, American Political Science Review 25, 306-318.

-Baldwin, R. (1997) “The Causes of Regionalism," The World Economy, Vol.20, pp.247281.

-Baker, Raymond, "Money Laundering and Flight Capital: The Impact on Private Banking," Senate Committee on Governmental Affairs, Permanent Subcommittee on Investigation, November 10, 1999

-Barovick, Richard (1985) "Banks are Rushing to Set Up Export Trading Companies", US Government Printing Office, Library of Congress, Washington DC. 
-Beehner, Lionel (2005) U.S. Military Bases in Central Asia, Council on Foreign Relations, July 26, 2005.

-Benjamin, Cohen J. (2006) the Future of Money, Paperback, Penguin, London

-Berger, Suzanne and Dore, Ronald (1996) National Diversity and Global Capitalism, Ithaca NY, Cornell University Press.

-Berger, Suzanne and Lester, Richard K. eds. (1997) Made By Hong Kong, Oxford University Press

-Bhagwati, J. (1993) "Regionalism and Multilateralism: An Overview," in Melo and Panagariya Ed; New Dimensions in Regional Integration, Cambridge: Cambridge University Press.

-Bhagwati, J. and A. Krueger (1995) The Dangerous Drift to Preferential Trade Agreements, American Enterprise Institute, Washington.

-Bhagwati, J., Krishna, P. \& Panagariya, A. eds. (1999) Trading Blocs: Alternative Approaches to Analyzing Preferential Trade Agreement, Cambridge: MIT Press.

- Bhagwati J. (2004) In Defense of Globalization, Cambridge: MIT Press

-Bonancich, E. (1994) Global Production: The Apparel Industry in the Pacific Rim, Philadelphia: Temple University Press

-Boyer, Robert and Daniel Drache (1996) States against Markets, New York, Rutledge.

- Braungart, M. and W. McDonough (2002) Cradle to Cradle, New York: North Point Press

-Buzan, Ole Weaver \& Jap de Wilde (1998) Security: a New Framework for Analysis, London: Lynne Rienner.

-Buzan, Barry, Charles Jones and Richard Little (1993) the Logic of Anarchy: Neorealism to Structural Realism, New York: Columbia University Press.

-Brzezinski, Zbigniew (1997) the Grand Chessboard, New York: Basic Books.

-Cabello, Robert R. (1998) "MC SA y la Causa Cero", Fondo de Cultura Económica, Ciudad México.

-Cantor, Norman (1994) the Civilization of the Middle Ages, New York: Harper Perennial. 
-Cardoso, Fernando Henrique (2003) "Civil Society and Global Governance," High Level Panel on UN Civil Society, retrieved January 18, 2006, from http://www.un.org/reform/pdfs/cardosopaper13june.htm.

-Carr, E. H. (1939) the Twenty Years' Crisis 1919-1930: An Introduction to the Study of International Relations, London and Basingstoke: Macmillan.

-Carter, Barry E., Chayes, Antonia, Damrosch, Lori (1997) "Sanctions US Sanctions Policy: Balancing Principles and Interests," Report of the Thirty-Eighth Strategy for Peace, US Foreign Policy Conference, in Warrenton, Virginia.

-Castells, Manuel (2000) the Rise of the Network Society, Oxford, Blackwell.

-Chomsky, Noam (2005) Ambiciones Imperiales: El Mundo Después del S-11, Barcelona: Océano Peninsular, Ediciones Península.

- Clark, Robert (1986) Corporate Law, Cornell University

-Clifford, Bob (2005) the Marketing of Rebellion: Insurgents, Media, and International Activism, Cambridge: Cambridge University Press.

-Cohen, Stephen F. (2001) Failed Crusades, New York and London: W.W Norton Company.

-Cohen, R. (1997) Global Diasporas: An Introduction, London: UCL Press.

-Cohen, Ariel (2007) Europe's Strategic Dependence on Russian Energy, The Heritage Foundation.

-Cohen, Benjamin J. (2001) "Electronic money: new day or false dawn?", Review of International Political Economy, Volume 8, Issue 2, June 2001 , pages 197 - 225

-Colomonos, Ariel (2000) "Non-State Actors as Moral Entrepreneur: a Transnational Perspective on Ethnics Networks", in World Politics: a Framework by Dphme Josselin and William Wallace, Palgrave Publishers Ltd, New York

-Cooley, Alexander and James Ron (2002) "The NGO Scramble: Organizational Insecurity and the Political Economy of Transnational Action," International Security, 27 (1) 5-39

-Cordesman, Anthony H. "Iraqi's Past and Future Biological Weapons Capabilities", Center for Strategic And international Studies (CSIS), www.csis.org, February, 1998

-Cortright, David and George A. Lopez (2000) the Sanctions Decade: Assessing UN Strategies in the 1990s, Boulder, CO: Lynne Rienner 
-Cox, Robert W. (1987) Power, Production and World Order, New York: Columbia University Press.

-Das, Dilip (2001) Regional Trading Agreements and the Global Economy: An AsiaPacific Perspective, Asian Development Bank, March 2001.

-Deardorff, A. V. (2001) "Fragmentation Across Cones", in Fragmentation: New Production Patterns in the World Economy, by S.W. Arndt and H. Kierzkowski, New York: Oxford University Press

-Dorgan, Byron (2007) "Testimony of U.S. Senator Byron Dorgan before the Senate Committee on Finance”, Hearing on Offshore Tax Issues, September 26, 2007

-Dphné Josselin and William Wallace (2001) Non-state Actors in World Politics: a Framework, Palgrave Publishers Ltd, New York

-Draakman, Reinier (2004) the Anatomy of Corporate Law: A Comparative and Functional Approach, Legal Information Institute at Cornell University School of Law, Cornell University.

- Easterbrook, Frank and Daniel Fishel, (1991) the Economic Structure of Corporate Law, Cornell University School of Law

-Ekeus, Rolf, Leaving Behind the UNSCOM Legacy in Iraq", Interview in Arms Control Today, Vo. 27, No. 4, June/July 1997

-Ethier, Wilfred J. (1998) "Regionalism in a Multilateral World," Journal of Political Economy 106(6): 1214-45

-Evans, Peter, D. Rueschemeyer and Theda Skocpol (eds.) (1985), Bringing the State Back In, Cambridge: Cambridge University Press.

- Federowicz, M. and R. Aguilera (2003) Corporate Governance in a Changing and Political Environment: Trajectories of Institutional Change on the Europe Continent, London: Palgrave Macmillan.

-Fine, Charles (1998) Clock speed - Winning Industry Control in the Age of Temporary Advantage, New York: Perseus Books.

-Frankel, J. (1997) Regional Trading Blocs in the World Economic System, Washington DC, Institute for International Economics.

-Frankel, J., Stein, E. and Wei, S. (1995) "Trading Blocs and the Americas: The Natural, the Unnatural and the Supernatural," Journal of Development Economics 47, 61-96. 
- Freeman, Richard B., and Kimberly Ann Elliott (2003) Can Labor Standards Improve under Globalization? Institute for International Economics, Washington DC.

-Friedman, Thomas L. (2008) The World is Flat, Picador, New York.

-Fukuyama, Francis (2006) La Confianza, Planeta, Barcelona

-Fukujama, Francis (1992) “The End of History and the Last Man”, Free Press, A Division of Simon \& Schuster, New York

-Gabriel Almond, (1988) the Return of the State, American Political Science Review 82 (3): 853-74.

-Gardiner, Nile (2006) Statement of Dr. Nile Gardiner, a Fellow in Anglo-American Security Policy, the Heritage Foundation, before the House Committee on International Relations: Subcommittee on International Oversight and Investigations.

-Gereffi, Gary (1994) “The Organization of Buyer-Driven Global Commodity Chains: How U.S. Retailers Shape Overseas Production Networks", in Gereffi, G. and Korzeniewicz, M. (eds.) Commodity Chains and Global Capitalism, Westport, CT, Praeger Publishers, p. 95-122

-Garrett, Geoffrey. (1998) “Global Markets and National Politics: Collision Course or Virtuous Circle?” International Organization 52(4 (Autumn-1998)), 787-824

-Garrett, Geoffrey. (1998) Partisan Politics in the Global Economy, New York, Cambridge University Press

-Gerson, Joseph (2007) Enduring U.S. Bases in Iraq: Monopolizing the Middle East Prize, Common Dreams Newscenter, www.commondreams.org, March 19.

-Gill, Stephen \& David Law (1989) Global Hegemony and the Structural Power of Capitalism, International Studies Quarterly 33 (4): 475-99.

-Gilpin, Robert (1981) War and Change in World Politics, New York: Cambridge University Press.

-Gilpin, Robert (1987) the Political Economy of International Relations, Princeton, NJ: Princeton University Press.

-Gilpin, Robert (1975) U.S. Power and the Multinational Corporation: The Political Economy of Direct Foreign Investment, Basic Books, New York. 
-Goodman, John B. and Louis W. Pauly, "The Obsolescence of Capital Controls? Economic Management in an Age of Global Markets", World Politics, Vol. 46, No. 1 (Oct., 1993), pp. 50-82

-Gourevitch, Peter, Bohn, R.E. and McKendrick, D. (1996) "Who is us? the Nationality Problem in Globalization of Production", the Data Storage Industry Globalization Project, 1996 (2), 96-01.

-Gowan, Peter (1999) Global Gamble: Washington's Faustian Bid for World Dominance, London: Verso.

-Grossman, Zoltan (2002) New US Military Bases: Side Effects or Causes of War, in Counterpunch, a Newsletter of Bounds Magazine, Feb. 2002.

-Guoxing, Ji (2005) “Asia-Pacific's Dependence on Middle East for Oil”, $\underline{\text { Shanghai's }}$ Institute of International Strategy Studies, Shanghai.

-Hall, Peter (1986) Governing the Economy: The Politics of State Intervention in Britain and France, Oxford University Press.

- Hall, Peter A. and D. Soskice (2001) Varieties of Capitalism: The Institutional Foundations of Comparative Advantage, Oxford University Press, Oxford.

- Hall, Peter A. (1997) "The Political Economy of Adjustment in Germany”, Oekonomische Leistungsfaehigkeit und Institutionelle Innovation., Berlin, 1997, 293315.

-Haas, Ernst B. (1997) Knowledge, Power and International Policy Coordination, University of California Press, Berkeley, California.

-Haas, Ernst B. (1989) Multilateralism, Knowledge, and Power: Three Modes of Change in International Relations, University of South Carolina Press, Columbia.

-Halliday, Fred (2000k by Dphme Josselin and William Wallace, Palgrave Publishers Ltd, New York) "The Romance of Non-State Actors", in Non-State Actors in World Politics: a Framework

-Hardt, Michel \& Antonio Negri (2000) Empire, Cambridge: Harvard University Press.

-Henderson, Jeffrey (2005) “Global Production Networks, Competition, Regulation and Poverty of Reduction: Policy Implications", Centre for Regulation and Competition, University of Manchester

-Hertel, Shareen (2006) Unexpected Power: Conflict and Change among Transnational Activists, Ithaca: Cornell University Press. 
-Hirst, Paul and Thompson Grahame. (1996) Globalization in Question, Cambridge MA, Blackwell

-Huntington, Samuel P. (1973) “Transnational Organizations in World Politics,” World Politics, 25 (2): 333-368.

-Huntington, Samuel (1993) the Clash of Civilizations, in Foreign Affair, Summer 1991.

-Huntington, Samuel (1996) the Clash of Civilizations and the Remaking of the World Order, Simon \& Schuster, New York.

-Ikemberry, G. John, David Lake, and Michael Mastanduno (1988) the State and American Foreign Economic Policy, Special Issue of International Organization, 42-1.

-Ikemberry, G. John (2000) After Victory, Princeton University Press.

-Ikemberry, John G. (2006) Liberal Order \& Imperial Ambition: Essays on American Power and World Politics, Cambridge: Polity Press.

-Jepperson, Ronald, Alexander Wendt and Peter J. Katzenstein (2006) "Norms, Identity and Culture in National Security," in Katzenstein, Peter, J. The Culture of National Security: Norms and Identity in World Politics, New York: Columbia University Press.

-Jervis, Robert (1976) Perception and Misperception in International Politics, Princeton: Princeton University Press.

-Joel S. Migdal (1998) Strong Societies and Weak States. State-Society Relations and State Capabilities in the Third World, Princeton: Princeton University Press, 1988

-Johnson, Chalmers (2003) Iraqi Wars, www.Antiwar.com, January 10.

-Johnson, Chalmers (2003) The Sorrows of Empire: How the Americans Lost Their Country, Metropolitan Books, 2003.

- Johnson, Chalmers (2006) Cold Warrior in a Strange Land: on Our Military Empire, www.tomdispatch.com, March 21.

-Juergens, Ulrich, Malsch, T. and Dohse, K. (1993) Breaking from Taylorism: Changing Forms of Work in the Automobile Industry, Cambridge: Cambridge University Press

-Katzenstein, Peter J. (1985) Small States in World Markets, Ithaca: Cornell University Press. 
-Katzenstein, P. (ed.) (1989) Industry and Politics in West Germany, Ithaca: Cornell University Press

-Katzenstein, Peter, J. (2006) the Culture of National Security: Norms and Identity in World Politics, New York: Columbia University Press.

-Keohane, Robert O. \& Joseph S. Nye (2001) Power and Interdependence, Third Edition, New York: Person Longman.

-Keohane, Robert O. (1989) International Institutions and State Power: Essays in International Relations Theory, Boulder, CO: Westview

-Keohane, Robert O. (1988) International Institutions: Two Approaches, International Studies

-Keohane, Robert O. (1984) After Hegemony: Cooperation and Discord in the World Political Economy, Princeton: Princeton University Press.

-Kissinger, Henry (1975) A New National Partnership, speech by Secretary of State Henry Kissinger at Los Angeles, January 24, News Release, Office of Media Services, Bureau of Public Affair, Department of State.

-Kissinger, Henry (1957) A World Restored: From Castlereagh, Metternich and the Restoration of Peace, 1812- 1822, Boston: Houghton Mifflin.

-Kissinger, Henry (2007) "Misreading the Iran Report: Why Spying and Policymaking don't Mix," The Washington Post, December 12.

-Klare, Michael T. (2004) Blood and Oil: the Dangers and Consequences of America's Growing Dependency on Imported Petroleum, New York: Metropolitan Books; Owl Books.

-Klare, Michael T. (2006) Resource War: The Landscape of Global Conflict, New York: Owl Books

-Kochan, Nick (2005) the Washing Machine: How Money Laundering and Terrorist Financing Soils US, (Hardcover - May 24, 2005)

-Kobrin, Stephen J. (1997) "Electronic Cash and the End of National Markets", Foreign Policy, No. 107 (summer, 1997), pp. 65-77

-Krasner, Stephen D. (1983) International Regimes, Cornell University Press, Ithaca, New York.

-Krasner, Stephen D. (1982) Structural Causes and Regime Consequences: Regimes as 
Intervening Variables, International Organization, 36, 1982, 185-206

-Kramer, Andre E. (2007) Iraq, With U.S. Support, Voids a Russian Oil Contract, the New York Times in Nov. 4, 2007.

-Krugman, P (1993) "Regionalism versus Multilateralism: Analytical Notes, in New Dimensions in Regional Integration, eds. J. de Melo and A. Panagariya, Cambridge: CUP.

-Krugman, P. (1991) “Is Bilateralism Bad?” In E. Helpman and A. Razin (eds.), International Trade and Trade Policy, Cambridge: MIT Press.

-Krugman, P. and M. Obstfeld (1994) International Economics: Theory and Policy (3rd edition), New York: HarperCollins.

-Krugman, Paul R. and Maurice Obstfeld (2003) International Economics: Theory and Policy, Sixth Edition, Addison Wesley, Ch. 9: 233-241.

-Krugman, Paul (1991) "Increasing Returns and Economic Geography", the Journal of Political Economy, Vol. 99, No. 3. pp. 483-499.

-Landes, Davis S. (1999) the Wealth and Poverty of Nations, W.W. Norton \& Company

-Lawrence, Robert Z (1996) Regionalism, Multilateralism, and Deeper Integration, Brookings Institution. Washington D.C.

- Leaver, Erik (2005) Building Permanent U.S. Bases in Iraq Sends Wrong Signal, the Seattle Post - Intelligencer, May 15, 2005

-Lenin, V. I., Imperialism: The Highest Stage of Capitalism, $7^{\text {th }}$ Edition, London: Penguin.

-Levy, D. and Dunning, J. (1993) "International Production and Sourcing", Organization for Economic Co-operation and Development, STI Review, Paris, December, 13-59

-Lipschutz, Ronnie D. (1992) "Reconstructing World Politics: The Emergence of Global Civil Society," Millennium, 21 (3): 389-411

-Lorenz, E. (1992) "The Search for Flexibility: Subcontracting Networks in British and French Engineering, in Storper, M. and Scott, A. (eds.), Pathways to Industrialization and Regional Development", London and New York: Rutledge, 122-132

-Luthje, B. (1997) Industrial Restructuring, Production Networks, and Labor Relations in the Silicon Valley Electronics Industry, University of Frankfurt, Germany 
-Maingot, Anthony P. (1995) "Offshore Secrecy Centers and the Necessary Role of States: Bucking the Trend", Journal of Inter-American Studies and World Affairs, Vol. 37, No. 4 (winter, 1995), pp. 1-24

-Marienstras J. 1989) "On the Notion of Diaspora," in Minority Peoples in the Age of Nation-States by G. Chaliand, London: Pluto Press.

-Mearsheimer, John J. (1995) the False Promise of International Institutions, International Security, 19 (3), pp. 5-9.

-Meyer, Jeffrey A. \& Mark Califano (2006) Good Intentions Corrupted: The Oil for Food Scandal and the Threat to the U.N., Public Affairs Report, Perseus Book Group; Cambridge

-Mearsheimer J. and Stephen Walt (2007) the Israel Lobby and U.S. Foreign Policy, New York: Farrar, Strauss and Giroux.

-Migdal, Joel S. (1988) Strong Societies and Weak States. State-Society Relations and State Capabilities in the Third World, Princeton: Princeton University Press, 1988.

-Milhollin, Gary and Kelly Motz, "Why Iraq Will Defeat Arms Inspectors", the New York Times, www.nwt.com, September 16 ${ }^{\text {th }}, 2002$.

-Morgenthau, Hans J. (1978) Politics among Nations: The Struggle for Power and Peace, 3rd Ed. New York: Knopf

-Nye Jr., Joseph S. (2002) The Paradox of American Power: Why the World's Only Superpower Can't Go It Alone, Oxford University Press.

-Ohmae, Kenichi. (1990) the Borderless World, New York, Harper Collins

-Orloy, Vladimir and William C. Potter, "The Mystery of the Sunken Gyros", Bulletin of the Atomic Scientist, Vol. 54, No. 6, November/December 1998

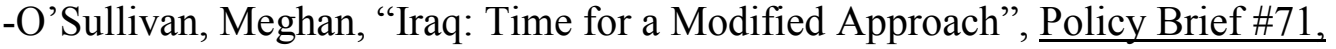
Brookings Institution, February 2001

-Ostergaard-Nielsen, Eva (1999) "Diasporas in World Politics", in Dphme Josselin and William Wallace, Palgrave Publishers Ltd.

- Palan, Ronen (2006) the Offshore World: Sovereign Markets, Virtual Places, and Nomad Millionaires, Paperback, Penguin, London

-Palan, Ronan, (2003) the Off-Shore World, Cornell Press University, New York 
-Palloix, Christian (1975) "The Internationalization of Capital and the Circuits of Social Capital", in International Firms and Modern Imperialism, ed. H. Radice, 67-92.

Harmondsworth: Penguin.

- Palmer, K, Oates, W; Portney, P. (1995) “Tightening Environmental Standards: The Benefit-Cost or the No-Cost Paradigm?" Journal of Economic Perspectives 9 (4) pp 3457

-Paul, James A. (2002) “Iraq: the Struggle for Oil”, Global Policy Forum, August 2002.

-Paul, James A. (2002) "Great Power Conflict over Iraqi Oil: the World War I Era," Global Policy Forum, October 2002.

-Pearl Daniel and Steve Stecklow, "Taliban Banned TV but Collected Profits on Smuggled Sony TVs", Wall Street Journal, www.wsj.com, January 9, 2002

-Pollack, Kenneth (2003) “Securing the Gulf”, Foreign Affairs 82, July 2003

-Pollack, Kenneth M. "Inspections in Iraq, Opening Statement”, Council of Foreign Relations, May 2, 2002.

-Rietz, Michael, "Dual-Use Exports, or a Twilight Business Versus Systemic Failures of Export Controls", delivered at a Luncheon sponsored by the Institute for Science and International Security, Washington, DC. December $10^{\text {th }}, 1999$.

-Robinson, William I. (2004) A Theory of Global Capitalism: Production, Class, and State in a Transnational World, Baltimore and London: Johns Hopkins University Press.

-Rosenau, James n. (1980) The Study of Global Interdependence: Essays on the Transnationalisation of World Affair, New York: Nichols.

-Rosenau, J. (1990) Turbulence in World Politics, Princeton: Princeton University Press.

-Rosenau, J. (1997) Along the Domestic-Foreign Frontier, Cambridge: Cambridge University Press.

-Rosett, Claudia (2006) “The Oil for Food Scandal Yields Its First Conviction," The Wall Street Journal, July 20.

-Ruggie, John G. (1993) Multilateralism: the Anatomy of an Institution, in Multilateralism matters: The Theory and Practice of an Evolutionary Form Ed. John Gerard Ruggie, Columbia University Press.

-Ryall, David (2001) "The Catholic Church as a Transnational Actor", in World Politics: a Framework by Daphme Josselin and William Wallace, Palgrave Publishers Ltd. 
-Safran, W. (1991) "Diasporas in Modern Societies: Myth of Homeland and Return," in Diaspora: a Journal of Transnational Studies, 1/1, pp. 83-99

-Samuelson, Paul (1947, 1983) Foundations of Economic Analysis, Harvard University Press

-Saxenian, A (1991) "The Origins and Dynamics of Production Networks in Silicon Valley", Research Policy 20: 423-437

-Scott, Burchill (2001) Theories of International Relations, Palgrave, New York, Third Edition

-Shane, Scott (2009) Documents show Iraqi Dictator's Fears, The New York Times, July $3^{\text {rd }}, 2009$

-Slager, Alfred (2004) the Internationalization of Banks, Penguin, London.

-Skidmore, Thomas E. and Peter H. Smith (2007) Modern Latin America, Fifth Edition, Oxford University Press, New York, Oxford.

-Skocpol, Theda (1979) States and Social Revolutions: A Comparative Analysis of France, Russia, and China

Cambridge University Press, Cambridge.

-Skocpol, Theda (1989) Wallerstein's World Capitalist System: A Theoretical and Historical Critique, American Journal of Sociology, 82, 5 (March 1989: 75-90.

-Smith, Walther (2003) Global Banking, Oxford University Press, Second Edition

-Smith, Julie (2001) "Political Parties in a Global Age," in Non-state Actors in World Politics by Daphné Josselin and William Wallace, Palgrave Publishers Ltd

-Soskice, David (1991) “The Institutional Infrastructure for International Competitiveness: A Comparative Analysis of the UK and Germany", in Atkinson, AB and Brunetta, T., eds., the Economics of the New Europe, London, Macmillan.

- Soskice, David. (1999) "Divergent Production Regimes: Coordinated and Uncoordinated Market Economies in the 1980s and 1990s", in Kitschelt, H., Continuity and Changes in Contemporary Capitalism, Cambridge, Cambridge University Press.

- Streeck, Wolfgang (1992) Social Institutions and Economic Performance, Beverly Hills, Sage. 
- Streeck, Wolfgang. (1997) “German Capitalism: does it exist? Can it Survive?” in Crouch, C. and Streeck, W., eds., Modern Capitalism or Modern Capitalisms?, London, Sage, 33-54.

-Strikwerda, Carl (1993) "The Troubled Origins of European Economic Integration: International Iron and Steel and Labor Migration in the Era of World War I", American Historical Review 98(4): 1106-1142

-Sturgeon, Timothy (1997) Turn-key Production Networks: A New American Model of Industrial Organization? University of California at Berkeley; Berkeley Roundtable on the International Economy

-Summers, L. (1991) Regionalism and the World Trading System: Policy Implications of Trade and Currency Zones, Wyoming: Federal Reserve Bank of Kansas City

-Synovitz, Ron (2007) “Iraq: U.S. Building Military Base Near Iranian Border,” Radio Free

-Thomas, Daniel (2001) the Helsinki Effect: International Norms, Human Rights, and the Demise of Communism, Princeton: Princeton University Press. Europe/Radio Liberty, September 28.

-Tyson, Ann Scott (2004) “Gates, US General Back Long Iraq Stay,” The Washington Post," June 1, 2007.

-Van Fossen, Anthony B. (2003) "Money Laundering, Global Financial Instability, and Tax Havens in the Pacific Islands", the Contemporary Pacific - Volume 15, Number 2, fall 2003, pp. 237-275

-Venables, A. (1999) "Regional Integration Agreements: A Force for Convergence and Divergence?" Paper prepared for the Annual World Bank Conference on Development Economics; Paris, June, Working Paper No. 2260, Washington, D.C., World Bank. Available from http://www.worldbank.org/research/trade/archive.html (Also published as "Winners and Losers from Regional Integration Agreements," CEPR Discussion Paper No. 2528).

-Vinton G. Cerf, (1998) "The Internet Society -Electronic Money: A Challenge to the Sovereign State?” by Eric Helleiner; Journal of International Affairs, Vol. 51, 1998

-Viotti, Paul R. \& Mark V. Kauppi (1999) International Relations Theory: Realism, Pluralism, Globalism, and Beyond, New York: Allyn \& Bacon.

-Von Clausewitz, Carl (1982) On War, New York: Penguin Books Ltd. 
-Wade, Robert. (1996) "Globalization and Its Limits: Reports of the Death of the National Economy are Greatly Exaggerated", in Berger, S. and Dore, R., eds., National Diversity and Global Capitalism, Ithaca, Cornell University Press, 60-88.

-Wallenstein, Immanuel (1979) the Capitalist World Economy, Cambridge: Cambridge University Press.

-Wallenstein, Immanuel (1974) the Modern World System I: Capitalist Agriculture and the Origins of the European World-Economy in the Sixteenth Century, Academic Press, New York.

-Waltz, Kenneth (1964) the Stability of a Bipolar World, Daedalus, 93: 881-909.

-Waltz, Kenneth (1993) The Emerging Structure of International Politics, International Security 17 (Fall 1993): 33-79.

-Waltz, Kenneth (1993) the New World Order, Millennium 22: 187-95.

-Ware, A. (1996) Political Parties and Party System, Oxford: Oxford University Press

-Weiner, Myron (2004) Security, Stability and Migrations in Conflict After the Cold War: Arguments on Causes of War and Peace, edited by Richard K. Betts, Second Edition, Pearson Longman, New York, New York.

-Wendt, Alexander E. (1987) the Agent-Structure Problem in International Relations Theory, International Organization 41, 3, summer, 335-70.

-Willetts, P. (1997) the Globalization of World Politics, Oxford: Oxford University Press.

-Willetts, P. (1982) Pressure Groups in the Global System, London: Pinter.

-Younes, Paul R. (2005) Follow the Money: Using Computer Network Attack to Enforce Economic Sanctions, Naval War Collection, Newport, Rhode Island, 2005

-Zysman, John, Doherty, E. and Schwartz, A. (1996) "Tales from the 'Global' Economy: Cross-National Production Networks and the Re-organization of the European Economy" San Francisco, BRIE.

\section{Other Sources}

-“\$34 Million for Tartous Port”, Syria Live, February 23, 2002.

-“Annual Report on WMD”, Iraq Survey Group, 1997 
-"Assembling the Electric Car, interview with Kevin Czinger", the New York Times, www.nyt.com, March 18, 2007.

-"Baghdad to Hold Trade Fair in Cairo", RFE/RL, August 24, 2001.

-"Baghdad Radio Broadcasts Remarks by George Galloway, Meeting with Saddam", BBC Summary of World Broadcasts; www.bbc.com, January 21, 1994.

-"Belarus Co-operates with Iraq in Strict Compliance with International Norms, Belarus Foreign Ministry declared to Reuters", www.reuters.com, September 24, 2002.

- "Benefits of Trade: Trade Agreements Work for America", Office of the United States Trade Representative, www.ustr.gov;

-Centre for Global Research on Globalization, www.globalresearch.ca

-“Comprehensive Report on UN Sanctions Regime against Iraq", also known as the Duelfer Report, sponsored and published by Central Intelligence Agency (CIA), 2006

-"Comprehensive Report of the Special Advisor to the DCI on Iraq's WMD", Iraq Survey Group, Sept. 30, 2004.

-“Corporate Law Black Dictionary", Legal Information Institute at Cornell University School of Law, 2007, $4^{\text {th }}$ Edition

- "Corruption Rampant in the Catholic Church, Latin America", El País, www.elpais.es., September 7, 2007,

-“Donofrio ya es rentable", El Comercio, August 20th, 1998.

-"Economic Sanctions: Too Much of a Bad Thing", by Richard N. Haass, Ways and Means Committee, Subcommittee on Trade, May $27^{\text {th }}, 1999$

-"Editorial: France Bolsters Military Ties with Gulf", the New York Times, 03/06/2008,

-“Egyptian Minister to Visit Baghdad in November", RFE/RL, October 12, 2001

-"Exxon, Chevron and El Paso are named in CIA Report on Hussein Era Program", Wall

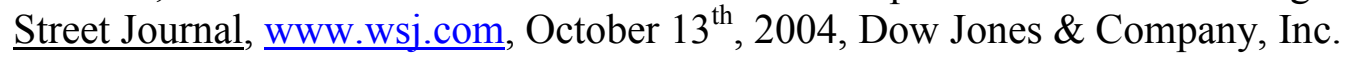

-"Federal Authorities Indicted a Texas Oil Executive, a South Korean Businessman and Two Others Thursday as Part of a U.S. Probe of the UN Sanctions Against Iraq", the New York Times, www.nyt.com, CNN, Thursday, July 20, 2006, (Phil Hirschkom, Chris Huntington, Richard Roth and Liz Neisloss contributed to the report) 
- "First Freedom Fries, Now Oil-for-Food Lies: Give France a Break", a Communiqué by the Embassy of France in the United States, Washington, April 7, 2004

-Foreign Affairs Committee of the House of Commons, the Foreign Office, www.parliament.the-stationery-office.co.uk/

-"Further U.S. Reactions to Abuses in UN Sanctions Regime against Iraq, Criminal Charges against UN Officials", The American Journal of International Law, Vol. 99, No. 4,Oct., 2005, pp. 904-906

-“George Galloway, Interviewed by Abu Dhabi TV”, BBC Worldwide monitoring; www.bbc.com, March 29, 2003.

-“George Galloway MP, Testimony before the Senate Permanent Subcommittee on Investigations”, May 17, 2005, at http://www.timesonline.co.uk/article/0,3$\underline{1616578,00 . h t m l}$

-"George Galloway and the Oil For Food Scandal: Time for U.S. and British Inquires", by Nile Gardiner, Ph.D., (Nile Gardiner, Ph.D., is Bernard and Barbara Lomas Fellow in the Margaret Thatcher Center for Freedom in the Shelby and Kathryn Cullom Davis, Institute for International Studies at The Heritage Foundation.

- "Hearing on The Role of BNP-Paribas SA in The United Nations Oil For Food Program, Committee on Foreign Affairs, the U.S. House of Representative, Washington DC, April 28, 2005

-"Independent Inquire Committee Report", also known as the Volker Report, sponsored by U.S. Congress (2004).

-International Monetary Fund, www.imf.org

- "Interview to Sergei Issakov in May 28 ${ }^{\text {th }}, 2005$ ", the IIC Report, Chapter I, p.359

-“Interviews to Mr. Ahmed Habboush on May $2^{\text {nd }}$ and $4^{\text {th }}, 2005$ ", IIC Report, Chapter I, p. 471.

- "Interview to Mr. Dawood Mohamme on May $2^{\text {nd }}$ and $4^{\text {th }}, 2005$ ", IIC Report, Chapter I, p.474

-“Interview to Mr. Rumman on May $2^{\text {nd }}$ and $4^{\text {th }}, 2005$ ", IIC Report, Chapter I, p.479

-“Interview to Mr. Andrei Okhotking on May 5 ${ }^{\text {th }}, 2005$, IIC Report, Chapter I, p.498

-"Interview with Dr. Kenneth Pollack", conducted by David Denny, the Brooking Institution, Washington File, October 2002 
- Iraq Survey Group (2004) Comprehensive Report of the Special Advisor to the DCI on Iraq's WMD, Sept. 30, 2004.

-"Iraqi-American Pleads Guilty in U.N. Sanctions Probe Samir Vincent a Former Olympic Athlete", by Terry Friedn and Phil Hirschkom, CNN, www.cnn.com, July 27, 2006

-"Iraq, Tunisia, Morocco to Boost Trade Relation, Algeria and Iraq Set UP Free Trade Zone, Lebanon and Iraq to Sign Free Trade Agreement”, RFE/RL, November 9, 2001

-“I was Right to Blame Blair, Says Galloway,” BBC News Online, July 8 2005, at http://news.bbc.co.uk/2/hi/uk_news/politics/4664343.stm

-"Law Profile Texas Oilman Draws Spotlight for Iraqi Deals", by Simon Romero, the New York Times, www.nyt.com; April 15, 2005

-"Many Helped Iraq Evade U.N. Sanctions on Weapons", by Craig Whitlock and Glenn Frankel, Washington Post Foreign Service, Friday, October 8, 2004

- "Methodology for Estimate of Total Illicit Iraqi Income during UN Sanctions (19912003)", United States Senate Permanent Subcommittee on Investigations \& Committee on Governmental Affairs, Nov. 15, 2004.

-"NGOs, the New Elite in Afghanistan", Wall Street Journal, June 17, 2007, a Dow Jones Company Inc

-NGOs Side with New Gov. in Honduras: the US Pays the Bill”, Wall Street Journal, September 28, 2009, Dow Jones Company Inc.

-"Of Many Characters mentioned at OFFP Trial, the most Prominent is Dead," by Alan Feuer, the New York Times, September 20, 2007

-"Quoted by Tim Butcher, Galloway Pours Petrol on the Flames," The Daily Telegraph, August 5, 2005.

-"Remarks by Tang Jiaxuan, Chinese Foreign Minister", the Wall Street Journal, June 3, 2001

-"Report Concerning the Testimony of George Galloway before the Permanent Subcommittee on Investigations", United States Senate Permanent Subcommittee on Investigations, Committee on Homeland Security and Governmental Affairs, October 25, 2005

-“Report on Iraq's WMD Program”, Stockholm International Peace Research Institute (SIPRI, May 2004 
-"Report On Iraq: Systemic Failures of UN Sanctions Regime", the Heritage Foundation (2005),

-"Saddam went in a shopping spree for his missile program", The Michigan Project, www.themichiganproject.org, June 2002.

-"Sanctions, Congress and the National Interest", by Congressman Lee Hamilton at Nixon Center Perspectives, Volume 3, Number 3, July 20 $0^{\text {th }}, 1998$

- "Silopi A.S. Established for Habur Diesel Trade", Turkish Daily News July 28, 1998.

-"Sources of Revenue for Saddam \& Sons, the Financial Underpinnings of the Regime n Baghdad", Coalition for International Justice, September 2002.

-"Spokesperson on the US Newspaper Report that Chinese Companies are in Iraq Helping the Latter Improve its Air Defense System", Chinese Foreign Minister in the Wall Street Journal, www.wsj.com, February 22 $2^{\text {nd }}, 2001$.

-"Spokesperson on the US Newspaper Report that Chinese Companies are in Iraq Helping the Latter Improve its Air Defense System", Chinese Foreign Minister in the Wall Street Journal, www.wsj.com, August 17th, 2001.

-“Statement on the Alleged Shipment of Cargo to Iraq", Belarus Ministry of Foreign Affairs to Reuters, www.reuters.com, January 15, 2003

- Statistical Review of World Energy, United States Department of Energy, www.energy.gov, 2007.

-Sunday Telegraph, Saddam Sets up New Oil Smuggling Deal to Beat Sanctions, by Con Coughlin, February, 2, 2002.

-"Syria's Rail Tracks; the New Smuggling Route in and Out Bagdad", the Times of London, June 10th, 2002

-"Syrian Rehabilitation is in the Pipeline", by Brian Whitaker, The Guardian, March 26, 2001.

- "Testimony before the Committee on Energy and Commerce, Subcommittee on Energy and Air Quality, House of Representatives", Report on the UN Sanctions Regime against Iraq, United States General Accounting Office, 2005.

-“The UN Sanctions Regime Yields Its First Conviction”, the New York Times, Thursday, July 20, 2006 
- "Turkey Shrugs off UN blockade of Iraq", The Los Angeles Times, August 4, 1998.

- "Ukrainian Firms Stage Trade Exhibit in Baghdad", Iraqi Press Agency, Editorial: May 14,2001

- "United Nations Observations on the Oil for Food Program and Iraq's Food Security", United States General Accountability Office, Jun 16, 2004.

-"US Sanctions Policy: Balancing Principles and Interests", Report of the Thirty-Eighth Strategy for Peace, US Foreign Policy Conference, sponsored by the Stanley Foundation, Virginia, October 23-25, 1997.

-United States Department of Energy, Statistical Review of World Energy, 2007; www.energy.gov

-"Use and Effect of Unilateral Trade Sanctions", House Ways and Means Committee, Subcommittee on Trade, May 28, 2000

-United Nations, www.un.org

- Weapons of Mass Destruction: U.N. Confronts Significant Challenges in Implementing Sanctions against Iraq, United States General Accountability Office (GAO), May 2002, 2004.

-Wikileak, www.wikileaks.com 
VITA

MANUEL DE LEON

January 1, 1964

2001

2005

2010
Born in Havana, Cuba

B.A. Political Science and International Relations Florida International University Miami, Florida

M.A. Political Science Florida International University Miami, Florida

Adjunct Faculty of Political Science Florida Keys Community College Key West, Florida 